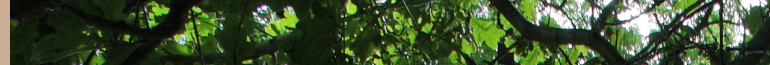

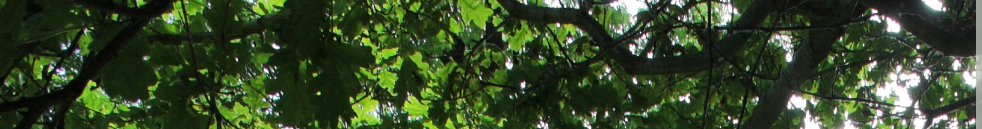

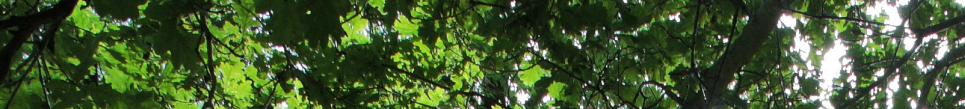

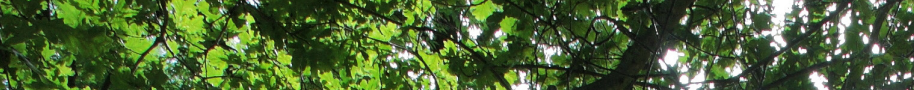

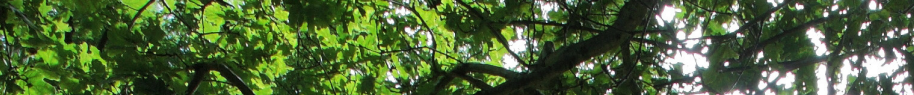

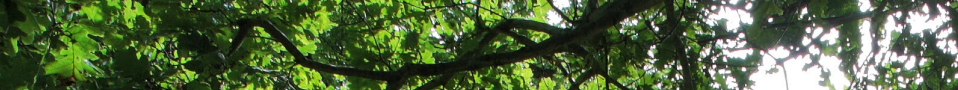
3. $1.3 \times(2)$

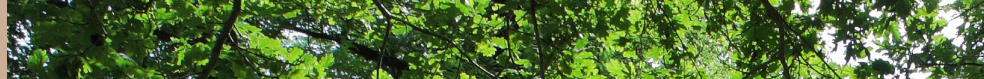

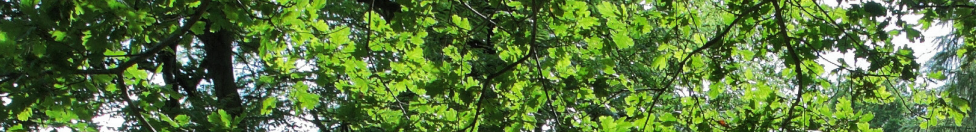

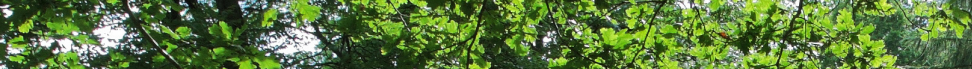

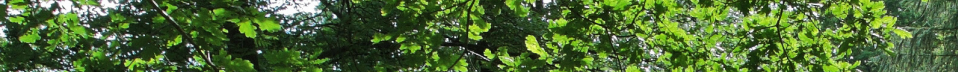

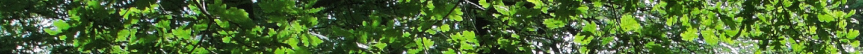

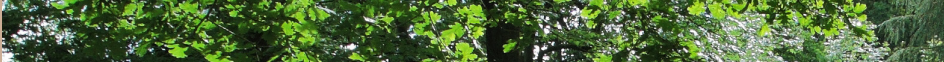

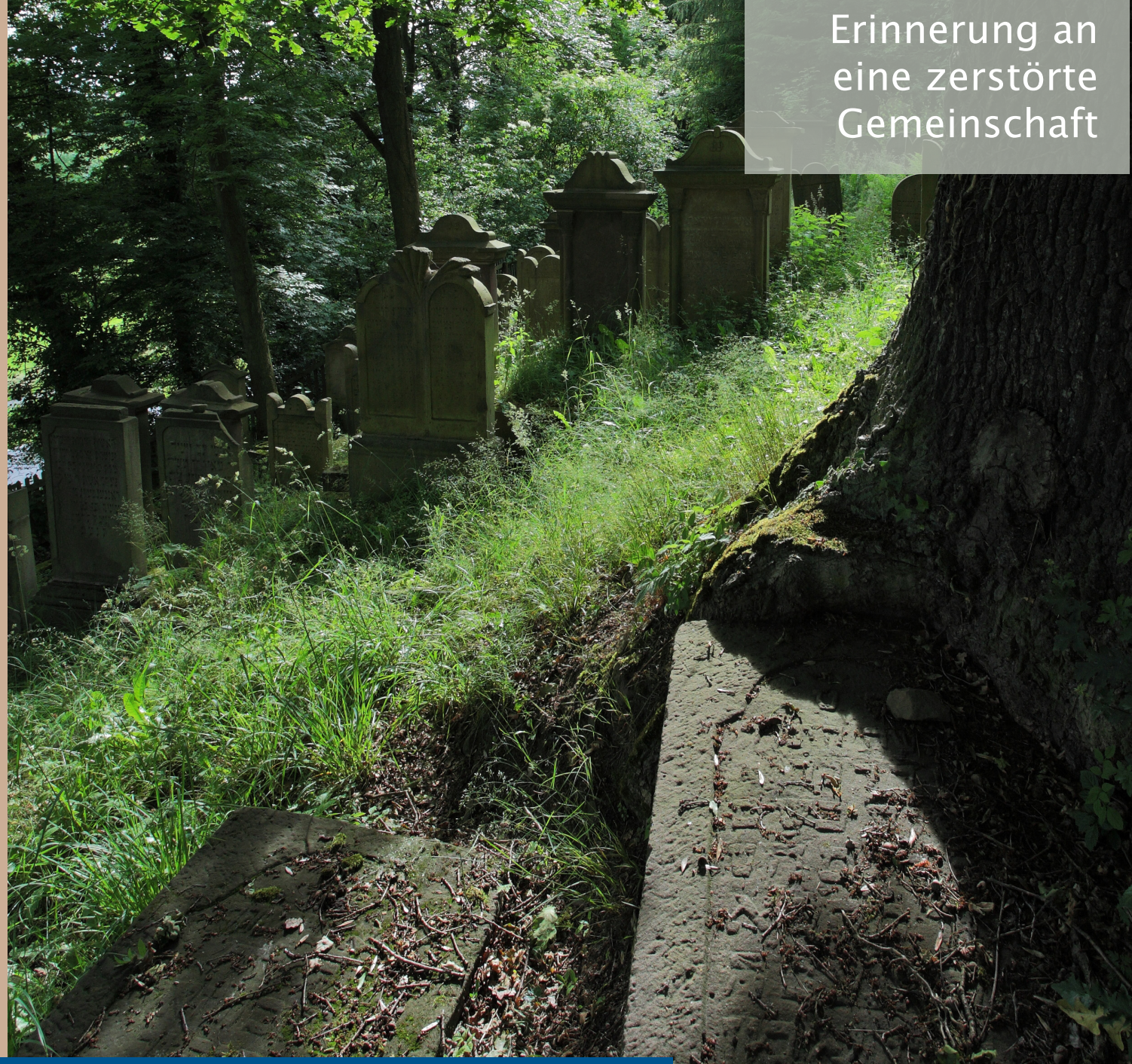

GÃ Universitätsverlag Göttingen

Berndt Schaller 1 und Eike Dietert

Der jüdische Friedhof zu Adelebsen
Erinnerung an eine zerstorte Gemeinschaft 

Berndt Schaller und Eike Dietert

Im Steilhang

This work is licensed under the Creative Commons License 3.0 "by-nd", allowing you to download, distribute and print the document in a few copies for private or educational use, given that the document stays unchanged and the creator is mentioned. You are not allowed to sell copies of the free version.

SOREERIGHIS RESERED 
erschienen im Universitätsverlag Göttingen 2010 
Berndt Schaller und Eike Dietert

\section{Im Steilhang}

Der jüdische Friedhof zu Adelebsen

Erinnerung an eine zerstörte

Gemeinschaft

unterstützt durch Adelheid Kramer und Jens Behnsen (Texterstellung)

Ralf König (Fotoarbeiten)

Thomas Kollatz (Textgestaltung)

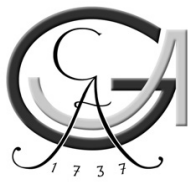

Universitätsverlag Göttingen 2010 


\section{Bibliographische Information der Deutschen Nationalbibliothek}

Die Deutsche Nationalbibliothek verzeichnet diese Publikation in der Deutschen Nationalbibliographie; detaillierte bibliographische Daten sind im Internet über $<$ http://dnb.ddb.de $>$ abrufbar.

Dieses Buch ist auch als freie Onlineversion über die Homepage des Verlags sowie über den OPAC der Niedersächsischen Staats- und Universitätsbibliothek (http://www.sub.uni-goettingen.de) erreichbar und darf gelesen, heruntergeladen sowie als Privatkopie ausgedruckt werden. Es gelten die Lizenzbestimmungen der Onlineversion. Es ist nicht gestattet, Kopien oder gedruckte Fassungen der freien Onlineversion zu veräußern.

Satz und Layout: Thomas Kollatz mit den TUSTEP Satzprogrammen Umschlaggestaltung: Margo Bargheer Titelabbildung: Frontcover: Ralf König Backcover: Christoph Berner

(C) 2010 Universitätsverlag Göttingen http://univerlag.uni-goettingen.de ISBN: 978-3-941875-14-2 


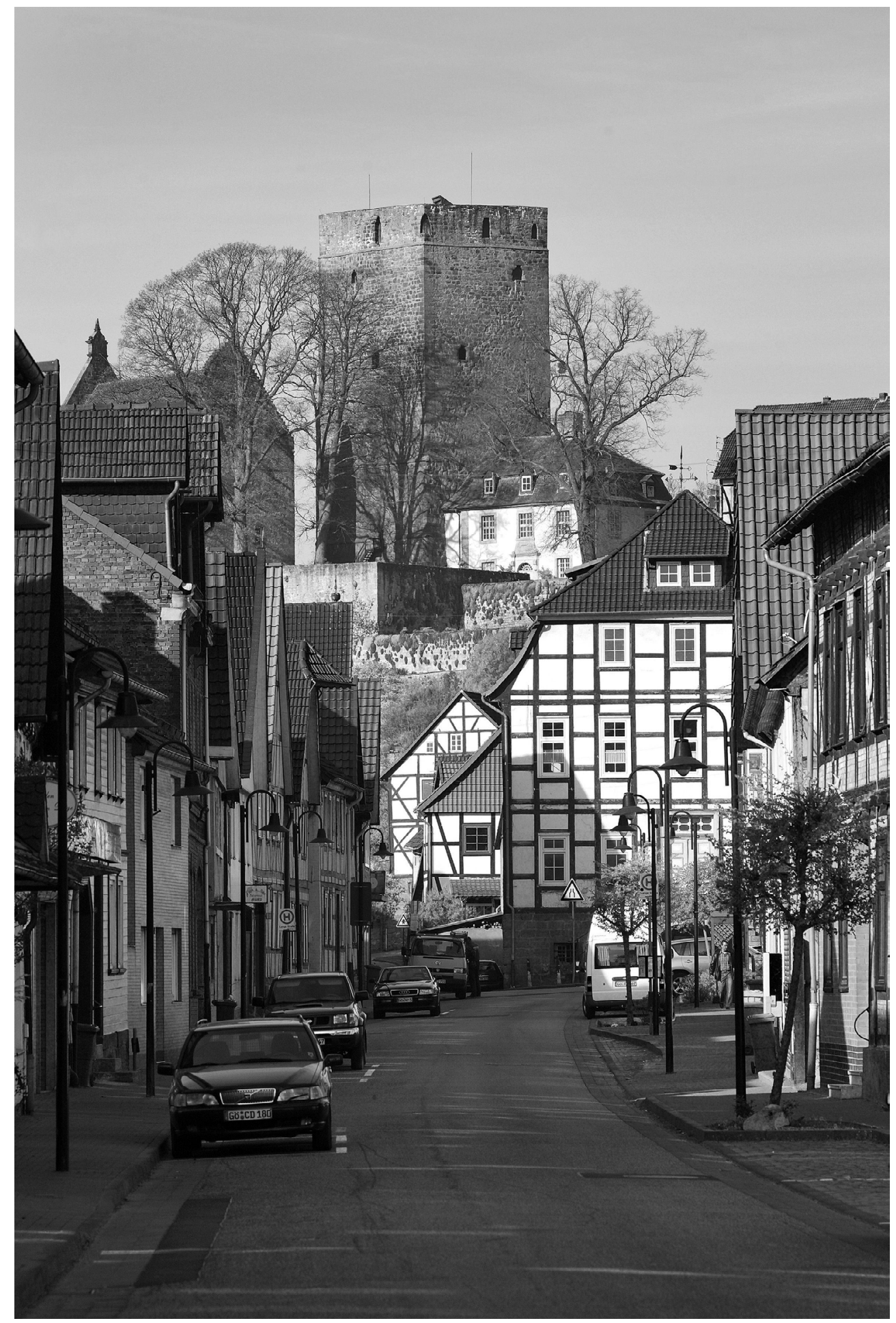





\section{Inhalt}

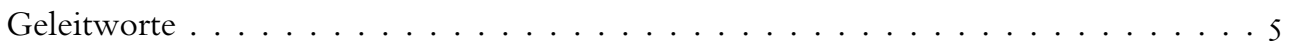

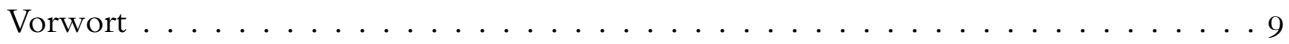

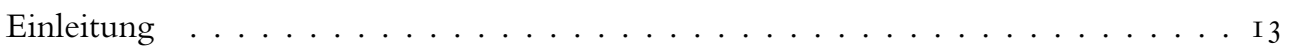

I. Jüdisches Leben im Flecken und Gericht Adelebsen . . . . . . . . . . . . I3

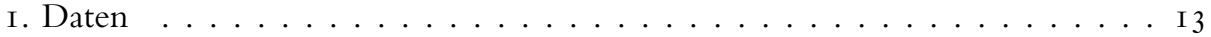

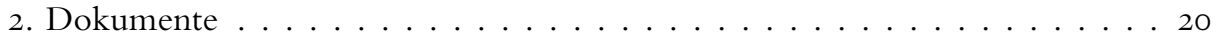

II. Der jüdische Friedhof zu Adelebsen . . . . . . . . . . . . . . . . . 39

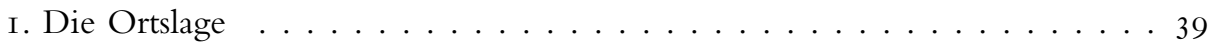

2. Umfang und Geschichte ....................... 40

3. Grabstellen und Grabsteine . . . . . . . . . . . . . . . 43

3.I Ausrichtung und Anordnung . . . . . . . . . . . . . . . 43

3.2 Material und Erhaltungszustand . . . . . . . . . . . . 44

3.3 Formgebung und Gestaltung . . . . . . . . . . . . . . 44

3.4 Symbole und Ornamente . . . . . . . . . . . . . . . 46

4. Die Inschriften . . . . . . . . . . . . . . . . . . . 48

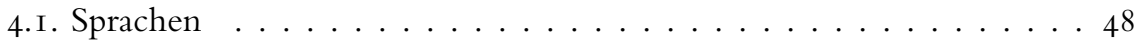

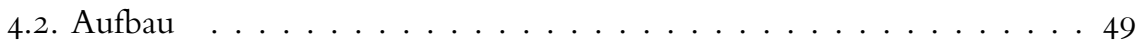

4.3 Zeitangaben und Zeitrechnung ............. 5I

4.4 Stilmittel . . . . . . . . . . . . . . . . . . 52

4.5 Gesellschaftliche und religiöse Profile . . . . . . . . . . . . 52

Dokumentation der Grabstätten . . . . . . . . . . . . . . 55

Technische Hinweise . . . . . . . . . . . . . . . . 56

Memorbuch für die Opfer der Schoa . . . . . . . . . . . . . 303

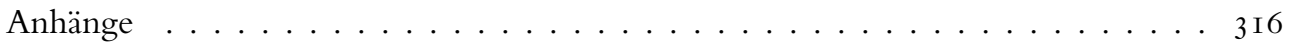

I. Register der Namen und Grabstellen . . . . . . . . . . . 3 I6

II. Literatur . . . . . . . . . . . . . . . . 326

III. Anspielungen und Zitate . . . . . . . . . . . . . . . 327

IV. Jüdischer Kalender . . . . . . . . . . . . . . . 328

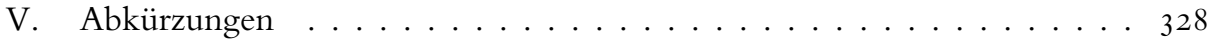

VI. Erklärung von Fachbegriffen . . . . . . . . . . . . . . . 329

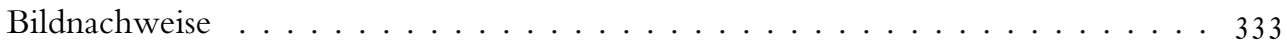





\section{Geleitwort}

Die über Iooo-jährige Geschichte Adelebsens ist seit Ende des I7. Jahrhunderts in vielfältiger Weise durch jüdisches Leben bereichert und mitgeprägt worden. Im Volksmund nannte man Adelebsen sogar „Klein Jerusalem“, weil die jüdischen Einwohner damals mehr als ein Zehntel der Bevölkerung ausmachten und das kulturelle, gesellschaftliche, wirtschaftliche, politische und religiöse Leben mitgestaltet haben.

Die Gewaltherrschaft des Nationalsozialismus in den Jahren I933 - I945 hat auch in Adelebsen Wirkung gezeigt und dazu geführt, dass die jüdischen Bürger vertrieben, manche sogar umgebracht wurden und an das einstige jüdische Leben abgesehen von der Gedenktafel am Standort der ehemaligen Synagoge kaum mehr etwas erinnert.

Allein der außerhalb der Ortschaft Adelebsen im Steilhang gelegene jüdische Friedhof erschließt sich in seiner Gesamtheit bis heute dem Betrachter als Ort der Erinnerung. Er gehört mit seiner Flächengröße und der Zahl der vorhandenen Grabmale zu den größten und bedeutsamsten jüdischen Friedhöfen im südniedersächsischen Raum und zeugt bis heute vom einstigen Leben jüdischer Mitbürgerinnen und Mitbürger.

Der vorhandene Bestand an teils stehenden, teils liegenden Grabsteine wurde mit Fördermitteln, namentlich der Deutschen Stiftung Denkmalschutz, in den Jahren I9992004 durch die Fa. Schmalstieg aus Großburgwedel aufwendig renoviert und restauriert. Für die notwendige Pflege kommt seither der Flecken Adelebsen mit seinem Bauhof auf. Das Erscheinungsbild des Friedhofes rückt inzwischen immer mehr in den Blickwinkel der Betrachter, zu denen vermehrt Schulklassen, sonst interessierte Gruppen oder auch einzelne Besucher zählen, die dieses Kleinod beim Vorbeifahren auf der Landesstraße erspähen und einige Zeit auf dem Friedhof zum Innehalten und Verweilen verbringen.

Bedingt durch die überwiegend Hebräisch und nur teilweise auch Deutsch abgefassten Grabsteininschriften blieb den interessierten Besuchern bislang versagt, den Friedhof genauer auch als Zeugnis jüdischen Lebens wahr zu nehmen.

Es ist der Initiative von Prof. Dr. Berndt Schaller vom Institut für Judaistik an der Theologischen Fakultät der Georg-August-Universität Göttingen zu verdanken, dass die Restaurierungs- und Sanierungsarbeiten durch eine Dokumentation der Inschriften ergänzt werden, die Historikern und anderen Wissenschaftlern sowie allgemein Interessierten den Zugang zu diesem herausragenden Dokument jüdischer Kultur eröffnen.

Für die Finanzierung des von vielen Seiten begrüßten Vorhabens konnten seitens des Flecken Adelebsen eine ganze Reihe von Sponsoren gewonnen werden. Der Abschluss des Projektes wäre ohne ihre Hilfe nicht zustande gekommen. Mein ganz besonderer Dank gilt diesen Sponsoren:

Deutsche Stiftung Denkmalschutz Bonn

Evangelisch-lutherische Kirchengemeinden Adelebsen,

Barterode-Eberhausen-Güntersen und Erbsen-Lödingsen-Wibbecke

Katholische Kirchengemeinde St. Hedwig und Adelheid Adelebsen

Firma Klausner Holz Niedersachsen Adelebsen

Landesverband der Jüdischen Gemeinden von Niedersachsen, Hannover

Landkreis Göttingen

Firma Schmalstieg Großburgwedel

Sparkasse Göttingen

Stiftung Burg Adelebsen

Volksbank Adelebsen

Firma Wegener Adelebsen 
Des Weiteren danke ich Berndt Schaller und Eike Dietert als Herausgeber sowie ihren Helfern und Beratern für den Einsatz bei der Abfassung dieser umfassenden und ausführlichen Dokumentation.

Mit ihr ist allen Besuchern des Friedhofs ein Werk in die Hand gegeben, das als eine Art „Leitfaden“ benutzt werden kann, der dazu verhilft, die Erinnerung an das zerstörte jüdische Leben wach zu halten und lebendige Einblicke in jüdische Gedächtniskultur zu vermitteln.

Ich hoffe, dass diese Dokumentation dazu beiträgt, Geschichtsbewusstsein zu fördern und Geschichtsvergessenheit ab zu bauen, und wünsche mir, dass allen, die in der Gegenwart und in der Zukunft Verantwortung für unsere Gemeinde tragen, die Erhaltung und Wahrung des jüdischen Friedhofes als mahnendes Geschichts- und Kulturerbe stets am Herzen liegt.

\author{
Dinah Stollwerck-Bauer \\ Bürgermeisterin Flecken Adelebsen
}




\section{Geleitwort}

„Eine heilige Pflicht haben unsere Rabbiner den Kindern Israels auferlegt, eigene Friedhöfe zu haben, deren Grund und Boden ihnen gehört, und selbst kleine Gemeinden haben [versucht] dem nachzukommen, um ihre Toten nicht in eine andere Stadt schicken zu müssen."

Dieser im Schulchan Aruch (Ajn Jitzchak Jore Dea \$34) verankerte Grundsatz fasst zusammen, was für uns Juden seit alters im Blick auf die Bestattung der Toten als Gebot gilt: Es ist unsere Pflicht, die Toten würdig zu bestatten und hierbei jede Anstrengung zu unternehmen, dies auf einem eignen Friedhof zu tun. So haben auch viele kleine Landgemeinden wie die Gemeinde in Adelebsen sich bemüht, eigenen Grund und Boden für einen Friedhof zu erwerben, was in der Regel nie leicht und immer mit großen finanziellen Mühen verbunden war.

Da die Toten gemäß der Halacha ein ewiges Ruherecht besitzen, obliegt die Pflege und Instandhaltung der Friedhöfe - auch der alten und belegten - der jeweiligen Gemeinde. Selbst ein unbelegter Friedhofsplatz darf nicht ohne weiteres verkauft werden, auch wenn hierdurch die Mauer um den restlichen Friedhof bezahlt werden könnte.

Die Aufgabe, sich um die Friedhöfe der in der Schoa zerstörten niedersächsischen Gemeinden zu kümmern, hat seit Anfang der 5oer Jahre der Landesverband der Jüdischen Gemeinden von Niedersachsen übernommen. Er trägt Sorge für 230 geschlossene Friedhöfe, zu denen sogar hin und wieder „,neu“ entdeckte alte Friedhöfe hinzukommen.

Diese geschlossenen Friedhöfe sind Orte der Mahnung und Erinnerung an die vernichteten, untergegangenen Gemeinden in Niedersachsen, häufig die einzigen Reste, die von ihrer Existenz Kunde geben. Von den 230 bekannten geschlossenen Friedhöfen sind inzwischen der größere Teil dokumentiert, eine ganze Reihe harren aber noch ihrer Erforschung. In Anbetracht der Tatsache, dass die Erosion viele Grabsteine so schädigt, dass ihre Innschriften sich kaum oder nicht mehr rekonstruieren lassen, bleibt nicht mehr viel Zeit diese Friedhöfe zu dokumentieren.

Aus diesem Grund sind wir Herrn Prof. Dr. Berndt Schaller sowie Herrn Eike Dietert und ihren Mitarbeitern für die geleistet beeindruckende Arbeit dankbar. Sie haben nicht nur den Friedhof dokumentiert, sondern gleichzeitig den Opfern der Schoah ein Memorbuch geschaffen, und so den Verstorbenen und den Ermordeten der Jüdischen Gemeinde Adelebsen ihren „Schem“, ihren Namen, wiedergegeben.

Michael Fürst

Vorsitzender des Landesverbands

der Jüdischen Gemeinden von

Niedersachsen K.d.ö.R.
Jonah Sievers

Landesrabbiner von Niedersachsen 



\section{Vorwort}

Der Flecken Adelebsen - am Südrand des Solling im Verlauf der von Göttingen nach Westen führenden Handelsstraße gelegen - kann auf eine nahezu 300 jährige Geschichte jüdischen Lebens zurück blicken. Ähnlich wie in einigen anderen benachbarten Ortschaften haben auch in ihm seit Ende des I7. Jahrhunderts jüdische Familien die Erlaubnis erhalten, sich als Anwohner nieder zu lassen. Ihre Zahl ist vom i 8. Jahrhundert an stetig gestiegen. In der Mitte des I9. Jahrhunderts hat ihr Anteil an der Gesamtbevölkerung sogar über I2 Prozent erreicht - was so ungewöhnlich war, dass im Volksmund für Adelebsen die Bezeichnung „Klein Jerusalem“ aufkam. Im Lauf der Zeit nahmen die Juden im Ort zunehmend Anteil am wirtschaftlichen, am gesellschaftlichen und auch am politischen Leben und wurden trotz mancherlei Vorbehalte und gelegentlicher Widerstände ein weithin anerkannter Teil der Bürgergemeinde.

Heutzutage ist dies vergangene, abgebrochene, zerstörte Geschichte. Wie in den meisten Dörfern und Städten unseres Landes haben auch in Adelebsen die christlichen Bürger es zugelassen, ja z.T. sich daran beteiligt, dass zwischen I933 und 1945 die überwiegend bereits seit Generationen hinweg ansässigen jüdischen Mitbürger in ihren Lebensmöglichkeiten beschränkt und bedrängt wurden und die meisten von ihnen, soweit sie nicht fliehen konnten, den staatlich organisierten Vernichtungsaktionen anheim fielen. Seither gehört jüdisches Leben in Adelebsen und den umliegenden Dörfern nur noch zur geschichtlichen Vergangenheit.

Was geblieben ist, sind museale, überwiegend papierne, textile oder steinerne Reste, die die Erinnerung festhalten. Überwiegend handelt es sich um Dokumente, die in öffentlichen und privaten Archiven in Adelebsen selbst, ferner in Göttingen und in Hannover aufbewahrt sind. Dazu kommen im Städtischen Museum Göttingen erhaltene Gegenstände, die aus der Einrichtung der Synagoge und aus dem Besitz jüdischer Familien stammen. Im Adelebser Ortsbild selbst sind es - abgesehen von der kleinen Hinweistafel, die 1989 an dem Haus Lange Straße is angebracht wurde (s. S. 37), in dessen dahinter liegenden Gelände das am ıo. November I 938 geschändete, angezündete und dann sofort abgerissene Gebäude der Synagoge stand, - nur einige metallene Buchstabenpaare, die als Schmuckelemente die Giebel der Häuser Lange Straße i 8 und 22 verzieren und sich auf die Namen ihrer jüdischen Erbauer beziehen - was heutzutage aber nur noch ganz wenigen bekannt ist. Dazu kommen im Hinterhaus Lange Straße 27 verborgen eine in Stein gehauene deutsche Inschrift, die neben der Jahreszahl i825 den Namen des jüdischen Eigentümers enthält sowie - erst jüngst im dortigen Keller entdeckt - möglicherweise Reste einer Mikwe, eines rituellen Tauchbads (s. S. 24).

Das einzige für die allgemeine Öffentlichkeit wahrnehmbar verbliebene Stück jüdischer Lebensgeschichte ist der außerhalb der Ortschaft gelegene Friedhof. Dieses „Haus des Lebens“, dieses „Haus der Ewigkeit“, dieser ,gute Ort“, wie frommer jüdischer Brauch die Totenfelder nennt, hat den Untergang der jüdischen Gemeinde ,überlebt“. Ungeachtet dessen ist er bislang aber in seiner Bedeutung als Dokument der jüdischen und der allgemeinen Orts- und Regionalgeschichte sowie darüber hinaus auch als herausragendes Zeugnis jüdischer Grabkultur im südlichen Niedersachsen kaum wahrgenommen worden.

Die hier vorgelegte Arbeit ist darum bemüht, die dazu erforderliche Grundlage zu liefern. Sie dokumentiert den gesamten Bestand der noch erhaltenen Gräber, stellt die vorhandenen Inschriften in Gestalt eigens für diesen Zweck aufgenommener Fotografien vor, bietet die entzifferten Originaltexte - soweit hebräisch verfasst mit der dazu gehörigen Übersetzung -, und liefert zu jeder bestatteten Person die aus den vorhandenen 
standesamtlichen und weiteren archivierten Unterlagen ermittelten biografischen Grunddaten. Vorangestellt ist eine Auswahl von Daten und Dokumenten, in denen sich Entwicklung und Eigenart jüdischer Gegenwart am Ort spiegeln, sowie daran anschließend eine Beschreibung des Friedhofs selbst, seiner Entstehung, Anlage und Gestaltung, letzteres verbunden mit dem Versuch, ansatzweise daraus Profile der örtlichen Gemeinde zu erschließen. Die Dokumentation des Gräberbefunds wird ergänzt durch eine Art Memorbuch, eine Liste der in Adelebsen geborenen bzw. länger wohnhaften jüdischen Kinder, Frauen und Männer, die zwischen I94I und I945 als Opfer der Schoa umgekommen, ohne Ort und Stein geblieben sind.

Das ganze ist das Ergebnis langjähriger, auf vielen Schultern ruhenden Vorarbeiten. Die ersten grundlegenden Schritte zur Entzifferung der Inschriften wurden bereits zwischen I983 und I985 vorgenommen im Rahmen von Tagesexkursionen überwiegend mit Studenten und Studentinnen der Theologischen Fakultät der Georg-August-Universität Göttingen. Die Teilnehmer - Jens Behnsen, Harald Böhm, Eike Dietert, Christoph Dühr, Jutta Ehlers, Nicola Feller, Peter Frost, Susanne Hartmann, Thomas Kaufmann, AnnaRuth Löwenbrück, Burkhard Menking, Iris Möllhoff, Torsten Nowak, Fritz Pinne, Axel Posmik, Rebecca Rottmann, Dr. Renate Rosenthal-Heginbottom, Rahel Schaller, Jochen Voigt, Hans-Günther Waubke, Kai Wessels - haben mit Lernbegier, Augenmaß und Geduld sich daran beteiligt, die oft nur noch schwer lesbaren, textlich auch nicht immer einfachen Inschriften zu erfassen und aufzunehmen. Die dabei erfahrene Arbeits- und Lerngemeinschaft bleibt in guter Erinnerung.

Für die Aufgabe, das zusammengetragene Textmaterial zu sichten, eine erste Rohübersetzung der hebräischen Inschriften anzufertigen und die Datierungen abzuklären, konnte Adelheid Markus (inzwischen Kramer), gewonnen werden. Jens Behnsen hat seine in langjähriger Praxis gewonnene sachliche und technische Kompetenz eingesetzt, um den ermittelten Textbestand $\mathrm{zu}$ überprüfen, den biblischen und rabbinischen Zitaten und Anspielungen nachzugehen und die bis dahin handschriftlich bearbeiteten Befunde auf ein elektronisches Medium zu übertragen. Während der Abschlussarbeiten, die erst nach meinem eigenen Eintritt in den „Ruhestand“ zustande gekommen sind, hat Eike Dietert die von ihm in umfangreichen Archivrecherchen ermittelten Personendaten eingebracht und damit die der Dokumentation beigefügten Erläuterungen bereichert sowie darüber hinaus die Herausgabe des gesamten Bandes entscheidend mitgefördert.

Der Band ist daraufhin angelegt, die Grabsteine und -inschriften so vorzustellen, dass sie auch für judaistisch nicht ausgebildete Interessenten zugänglich und auswertbar sind. Bedingt durch den z.T. stark verwitterten, vielfach auch mutwillig beschädigten Zustand der Steine, konnten in manchen Fällen die jeweiligen Inschriften nur stückweise ermittelt werden. Soweit möglich, wurden Fehlstellen auf Grund von bekannten Parallelen oder sonst vorhandenen Unterlagen rekonstruiert.

Bei der Übersetzung der hebräischen Texte ins Deutsche ist eine möglichst genaue, zugleich aber auch lesbare Wiedergabe angestrebt. Vereinzelt gibt es Lücken. Bisweilen sind auch die eigenen philologischen Kenntnisse an ihre Grenzen gestoßen. Vielfach haben Dan Bondy und Nathanja Hüttenmeister (Duisburg) als epigraphische Spezialisten mit ihrem Wissen auf die Sprünge geholfen und vor allem letztere mit ihrem Spürsinn Fehllesungen ausgeräumt. Die Verantwortung für alle verbliebenen Mängel liegt aber in jedem Fall bei mir.

Die fotografischen Aufnahmen der Grabsteine und der Gesamtanlage des Friedhofs sind überwiegend nach der 2000-2004, erfolgten Restaurierung aufgenommen worden. Sie stammen zumeist - aus Kostengründen - aus eigener Hand und reichen hoffentlich aus, 
um die Texte - soweit überhaupt möglich - lesbar zu machen. Bei einer Reihe von Steinen mit schlecht erhaltenen Inschriften hat Ralf König (Güntersen) mit seinen Fähigkeiten und Fertigkeiten als Fotograf ausgeholfen. Ihm ist auch das die Lage des Friedhofs „im Steilhang“ ins Bilde setzende Umschlagsfoto zu verdanken. Einige Bilder, die einen Eindruck von dem älteren Zustand des Friedhofs vermitteln, haben Gottfried Wehr (Göttingen) und Christoph Berner (Göttingen) zur Verfügung gestellt. Bei der Digitalisierung alter Fotos und Textseiten hat Martin Liebetruth (Göttingen) geholfen.

Die Herstellung des Bandes selbst wäre kaum gelungen, wenn nicht Thomas Kollatz (Krefeld), der die vom Salomon Ludwig-Steinheim Institut für Deutsch-Jüdische Geschichte, Duisburg herausgegebenen Dokumentationen jüdischer Friedhöfe betreut, seine Fach- und Sachkenntnis bereitwillig eingebracht hätte, um eine druckfertige Vorlage zu erstellen. Sein Einsatz und sein Einfallsreichtum haben das Erscheinungsbild und ebenso den Gehalt des Bandes nachhaltig gefördert.

Für das Zustandekommen der Dokumentation ist weiter Dank zu sagen: der Stiftung Niedersachsen, die in den Anfängen die Erkundung der jüdischen Friedhöfe in Südniedersachen gefördert hat, sowie der Stiftung Deutscher Denkmalsschutz, die am Ende die noch nötigen Vorarbeiten zur Drucklegung bezuschusst hat; ferner dem Rat und den Amtsträgern sowie den Bediensteten des Flecken Adelebsen, die das ganze langwierige Unternehmen ideell und materiell unterstützt haben - erwähnt seien insbesondere Birgit Krull-Nörtemann und Lothar Querfurth als die für das Standesamt bzw. die Bauabteilung Zuständigen; den Leitern des Städtischen Museums Göttingen, Dr. Jens-Uwe Brinkmann und Dr. Ernst Böhme, und ihren Mitarbeitern sowie dem Leiter des Museums und Stadtarchivs Uslar, Dr. Wolfgang Schäfer, die unkompliziert den Zugang zu den mit Adelebsen verbundenen Schätzen gestatteten; dem historisch versierten Göttinger Kollegen Dr. Peter Aufgebauer für fachliche Beratung und ferner Margo Bargheer und Jutta Pabst vom Göttinger Universitätsverlag sowie den Mitarbeitern der Druckerei Hubert \& Co., die am Ende entscheidend die Veröffentlichung befördert haben.

Ein besonderer Dank gilt schließlich Avri Gershon (Kibbutz Mazzubah) und David Blank (Jerusalem) - der eine selbst in Adelebsen aufgewachsen, der andere Enkel einer in Adelebsen lange ansässigen Familie -, die beide bereitwillig mit ihren Erinnerungen bzw. Kenntnissen ausgeholfen haben.

Dieser Band erscheint 68 Jahre, nachdem am 26. März und 2 I. Juli I942 die letzten I2 der noch in Adelebsen verbliebenen jüdischer Bürger über Hannover-Ahlen in das Ghetto Theresienstadt ,überstellt" wurden, wo sie von einer Ausnahme abgesehen entweder umkamen oder von wo sie weiter in eines der anderen Todeslager ,verbracht“ wurden. Ihrem Andenken sei er gewidmet. 



\section{Einleitung}

\section{Jüdisches Leben im Flecken und Gericht Adelebsen}

Eine Gesamtdarstellung der Geschichte der jüdischen Gemeinde im Flecken und Gericht Adelebsen muss noch geschrieben werden. Der folgende Beitrag bietet dafür keinen Ersatz. Er beschränkt sich auf eine Auswahl von Daten und Dokumenten, in denen sich allgemeine Konstellationen und spezifische Stationen jüdischen Lebens am Ort spiegeln.

\section{Daten}

seit 1670 Der Anteil jüdischer Bevölkerung im Herzogtum Braunschweig-Lüneburg nimmt in den ländlichen Gebieten durch Zuwanderung merklich zu. ${ }^{1}$

I675-I689 Die Kopfsteuerverzeichnisse I675 $\left(\rightarrow\right.$ Dokument Nr. I $\left.{ }^{\star}\right)$, I678, ${ }^{3}$ I686, ${ }^{4}$ I $689^{5}$ erwähnen für Adelebsen erstmals jüdische Einwohner: Hertz Naphthali [I675]; verheiratet, 3 Kinder (Gytele, Eva, Jakob), Besitzer eines Hauses (Kötner) mit 8 Morgen Land, handelt mit Kleinwaren (Klipkramer), teilweise auch mit Vieh.- Itzig /Isaak David [I689]; verheiratet, verfügt nur über „sehr geringe Nahrung “. 6

I687 Die Regierung in Hannover bekräftigt das alleinige Recht zur Ausstellung von Schutzbriefen für Juden durch den Landesherrn

I7I9 Anstelle der früheren jüdischen Einwohner werden neu vermerkt für Adelebsen: Meyer Levi, Meyer Nathan, Jakob Nathan, Jakob Salomon und Moses Jakob; für Barterode: Isaak Arend (Aaron); ${ }^{7}$ z.T. die Ahnherren von noch im 20. Jahrhundert ansässigen Familien.

I723 Die Erwerbstätigkeiten von Juden werden durch eine landesherrliche Verordnung auf den Handel mit Gebrauchtwaren, im bescheidenen Umfang auch mit Textilien und sonstigen Manufakturwaren festgelegt. „Offene Boutiquen" sind nicht erlaubt; für den Handel mit Vieh und sonstigen landwirtschaftlichen Produkten wie Wolle und Felle ist eine besondere Konzession erforderlich; statthaft ist die Schlachtung von Vieh für Eigenbedarf sowie der Verkauf von dabei anfallenden, nach jüdischen Vorschriften nicht verwertbaren Teilen.

I737 Die Justizkanzlei in Hannover fordert den Adelebser Gerichtsherrn auf, die von ihm aufgenommenen, aber nicht mit landesherrlichen Schutzbriefen versehenen (,,unvergleiteten“) Juden vor Ort (Jacob Nathan, Meyer Levin, Itzig Meyer, Abraham Meyer, Simon Meyer, Levin David, Hertz Isaac, Meyer Nathan, Itzig Ahrend, Jacob Speyer, Hertz Isaac, Michael) auszuweisen und in Zukunft weitere eigenmächtige Aufnahmen zu unterlassen. $\left(\rightarrow\right.$ Dokument Nr. $\left.2^{\star}\right)$

1 Dietert, Ansiedlung, 20-27.

2 HStAH, Cal. Br. I9 Nr. I032; vgl. Alphei, Geschichte, 83 u. A.264.

3 HStAH, Cal. Br. I9 Nr. I04I

4 HStAH, Cal. Br. I9 Nr. Io56.

5 HStAH, Cal. Br. I9 Nr. I074 zitiert nach: Die
Kopfsteuerbeschreibung der Fürstentümer Calenberg-Göttingen und Grubenhagen von I689 (bearb. v. Herbert Mundhenke), Teil 8, Hildesheim I965, I 3 I.

6 Ebd., (s. Alphei, Geschichte, 87 u. A. 27I).

7 Stadtarchiv Göttingen, AA Juden Nr. I I. 
Der darüber geführte Prozess endet mit einem Urteil des Oberappellationsgerichts in Celle, in dem der Landesherrschaft das ausschließliche Recht zur Aufnahme von Juden bestätigt wird. Die angeordnete Ausweisung wird dennoch nicht vollzogen. Die betroffenen Juden erhalten die landesherrlichen Schutzbriefe, für die sie neben dem an den Gerichtsherrn zu zahlenden „Beiwohnungsgeld“ nun auch das „Schutzgeld“ zu entrichten haben. ${ }^{8}$

1752

I 766

I 807

Als jüdische Haushaltsvorstände werden verzeichnet für Adelebsen: Simon Meyer, Joseph Meyer, Leifmann Jacob, Isaac Meÿer, Moses Jlten, Abraham Meyers Witwe, Moses Katzenstein, Philip Jacob; Nathan Meyer, David. Hertz Jsaac; für die Nachbardörfer Barterode: Joseph Jsaac, Arend Jsaac; Güntersen: Calmann Hammerschlag, Michael Levi; Lödingsen: Joseph Meyer. ${ }^{9}$

Jüdische Einwohner: 34 | Gesamtbevölkerung: 73 I

Simon Meyer, die Witwe Isaak Meyer, Nathan Meyer und die Witwe Moses Ilten verfügen über eigenen Hausbesitz ${ }^{10}$ ungeachtet des I7I 8 für Juden ergangenen Verbots, Grundbesitz zu erwerben bzw. zu vererben.

Aus ehemals preussischen, hannoverschen, braunschweigischen und hessischen Gebieten wird das Königreich Westphalen gebildet mit Napoléon Bonapartes Bruder Jérôme als König und Kassel als Hauptstadt. Im Zuge der dabei neu eingeführten, dem Code Napoléon zugeordneten, vom Grundsatz der Gleichheit aller Bürger unabhängig von Konfession/Religion bestimmten Verfassung erhalten die jüdischen Einwohner die volle politische und wirtschaftliche Gleichberechtigung. Alle sie bisher betreffenden Sonderregelungen wie „Schutzerteilung “, Beschränkung der Niederlassung und der Berufswahl entfallen. Neben die kirchlich geführten Register für Taufen, Trauungen und Beerdigungen Sterbefälle treten kommunale Zivilstandsregister für Geburten, Eheschließungen und Sterbefälle. Alle Bürger werden zur Annahme von Familiennamen verpflichtet. Die in Adelebsen und den benachbarten Dörfern gewählten Namen beziehen sich z.T. auf die Topographie der näheren (Gräfenberg und Stehberg, Dannenberg und Eichenberg, Backstein) Umgebung; daneben werden verbreitetem Brauch folgend insbesondere jüdische Vornamen mit deutschen Wortelementen verbunden (Meir $\rightarrow$ Meyersberg, Meyerstein, Meyenberg; Aaron $\rightarrow$ Arensberg; Levi/Leib/Löw $\rightarrow$ Löwenstern, Löwenthal). Z.T. legen sich Angehörige der selben Familie unterschiedliche Namen zu: die Familien Rosenberg, Stehberg, Eichenberg, Meyenberg und Dannenberg stammen sämtlich von Meyer Levi (Grab I 4) und dessen Sohn Simon Meyer ab, die Familie Gräfenberg von Meyer Nathan, die Familien Rosenbaum und Oppenheim von Moses Meyer Ilten (Grab I 9), ferner vermutlich die Familien Rothschild und Löwenthal von Levi David (Grab I I3) sowie die Familien Freudenstein, Rosenstein und Löwenstern von Jacob Nathan (Grab I 7). 
I 8 IO

I 8 I 3

I $82 \mathrm{I}$

I 825

I 832

I 835

I 836

I $84 \mathrm{I}$

Jüdische Einwohner: I07 | Gesamtbevölkerung: I I49

Nach dem Zusammenbruch des Königreichs Westphalen werden die alten Herrschaftsverhältnisse wieder hergestellt (Restauration). Im neu formierten Königreich Hannover sind die den jüdischen Einwohnern 1807 zugestandenen bürgerlichen Rechte sämtlich aufgehoben.

Jüdische Einwohner I27 | Gesamtbevölkerung: I240

Die ersten Gemeinde-Statuten zur Ordnung des Gottesdienstes, des Finanz- und Armenwesen sowie des Lehrer- und Schächteramts werden erlassen. $^{11}$

Das Grundstück Lange Straße I3 wird als Besitz der jüdischen Gemeinde vermerkt. ${ }^{12}$ Das darauf stehende Gebäude dient vermutlich für gottesdienstliche (Betstube bzw. Synagoge) und schulische Zwecke. Belege dafür fehlen allerdings, ebenso für die Anlage eines Ritualbads (Mikwe).

Lukas Stehberg erbaut das Hinterhaus Lange Straße 27, möglicherweise mit einer privaten Mikwe im Keller. ( $\rightarrow$ Dokument Nr. $5^{\star}$ )

Die jüdischen Gemeinden im hannoverschen "Land-Rabbiner-Bezirk" werden durch den amtierenden Landrabbiner Dr. Nathan Adler verpflichtet, ein eigenes Synagogenbuch mit dem Verzeichnis der zu ihnen gehörenden Familien anzulegen und Listen zur Registrierung der Geburten, Eheschließungen und Sterbefälle zu führen. $\left(\rightarrow\right.$ Dokument Nr. $\left.6^{\star}\right)$

Für die jüdischen Gemeinden erlässt der Landrabbiner eine allgemeine Synagogenordnung.

Die jüdische Gemeinde ersucht die Landdrostei Hildesheim um die Genehmigung zum Erwerb eines Hauses für die Einrichtung einer Synagoge, da das jetzige, dafür ,,angemiethete Local“" voller Mängel und ,für die sich vermehrende Judenschaft zu klein ist". ${ }^{13}$

Die jüdische Gemeinde erwirbt das Grundstück Langestr. I $5{ }^{14}$ Das Vorderhaus wird als Schulhaus für Unterricht und Lehrerwohnung verwendet und im dahinter liegenden Gelände die Synagoge auf einem eigens dafür angelegten und ummauerten, über eine I2 stufige Treppenanlage zugänglichen Areal errichtet. $\left(\rightarrow\right.$ Dokumente Nr. $9^{\star}$. I0 $\left.{ }^{\star}\right)$

Bürgermeister und Vorstand des Flecken Adelebsen übermitteln der Ständeversammlung des Königreichs Hannover eine gegen die hiesigen Juden und ihre wirtschaftliche Betätigung gerichtete Petition: Die große Zahl von 34 jüdischen Familien sei für den Ort wirtschaftlich schädlich, weitere Niederlassungs- und Gewerbefreiheiten würden dazu führen, „daß im Flecken Adelebsen die Christen von den Juden nach und nach gänzlich verdrängt werden und daß dann am hiesigen Orte und in der Umgebung Alles und hauptsächlich das Grundeigenthum der Handelsspekulation und dem Wucher anheimfällt." ${ }^{15}$

11 HStAH, Hann. 74 Uslar Nr. 2037.

12 Fleckenarchiv Adelebsen Nr. 205.

13 HStAH, Hann. 74 Uslar Nr. 2066.
14 Ebd.

15 HStAH, Hann. Io8 H Nr. 4888 Bd. I (Nr. I3/I4). 
Mit dem Erlass eines neuen Gesetzes über die Rechtsverhältnisse der Juden im Königreich Hannover bahnen sich erste Veränderungen in der rechtlichen Lage der jüdischen Bevölkerung an: die „Schutzverhältnisse“ werden aufgehoben (die damit verbundenen Abgaben aber erst 1847 abgeschafft), die Gewerbefreiheit wird (mit Einschränkungen) verkündet, im übrigen aber fest gehalten: „Die Juden sind von der Ausübung politischer Rechte, sowohl in Beziehung auf den Staat, als auf die Gemeinde, ausgeschlossen."

I 845

I 848

I 854

I 855

I 859

I 86 I

I 86 I-I9IO

Jüdische Einwohner: I85 | Gesamtbevölkerung: I508

Durch Änderung des Landesverfassungsgesetzes werden im Königreich Hannover die Juden erstmals den übrigen Untertanen in vollem Umfang gleich gestellt: „Jeder Landeseinwohner genießt völlige Glaubens- und Gewissensfreiheit und ist zu Religionsübungen mit den Seinen in seinem Haus berechtigt. Die Ausübung der politischen und bürgerlichen Rechte ist von dem Glaubensbekenntnis unabhängig. "

Jüdische Einwohner: I92 | Gesamtbevölkerung: I470

Dr. Heinemann Rosenstein aus Einbeck, in Adelebsen als Arzt niedergelassen, kandidiert als Wahlmann für die Deutsche Nationalversammlung in Frankfurt, ohne Erfolg.

Ein I853 entworfenes und beschlossenes neues Regulativs für die Gemeinde tritt in Kraft. In ihm wird erstmals u.a. ein eigener jüdischer Wohltätigkeitsverein erwähnt.

Der Landrabbiner fordert die Gemeinde auf, eine Mikwe anzulegen oder dafür zu sorgen, dass alle Gemeindeglieder Zugang zu einer der bestehenden privaten Einrichtungen bekommen. ${ }^{16}$ Nach längeren innergemeindlichen Auseinandersetzungen wird letzteres durchgesetzt.

Das erst $\rightarrow$ I 854 eingeführten Regulativ wird durch eine erneut veränderte Gemeindeordnung abgelöst, die in 40 Paragraphen ${ }^{17}$ die Angelegenheiten der Gemeinde regelt: I) Zusammensetzung, Pflichten und Rechte der Gemeindeversammlung, 2) Wahl und Befugnisse des aus Synagogenvorsteher, Rechungsführer und 5 weiteren Mitgliedern bestehenden Gemeinderats, 3) Aufgabenverteilung des geschäftsführenden Gemeindevorstands, dem die Verwaltung und Vertretung der Gemeinde obliegt und dem neben dem Synagogenvorsteher 2 für das Schul- bzw. das Armenwesen bestellte Vorsteher angehören; 4) ferner - besonders ausführlich das Gemeindevermögen und die Gemeindelasten, u.a. Synagoge, Schule, Friedhof und Armenpflege betreffend, sowie 5) das Rechnungswesen.

Jüdische Einwohner: I52 | Gesamtbevölkerung: I259

Sally Blumenfeld aus Momberg, Hessen, wirkt fast 50 Jahre in der jüdischen Gemeinde als Lehrer, Vorsänger und Schächter. Er war eine der die Gemeinde prägenden Gestalten: u.a. Vorsteher der Beerdigungsbruderschaft und des Israelitischen Lesevereins, darüber hinaus führend tätig im Verein der jüdischen Lehrer der Provinz Hannover sowie im Verband der jüdischen Lehrervereine im Deutschen Reich. ${ }^{18}$ 
I883-I895 Meyer Levi Eichenberg ist Mitglied im Bürgervorstehercollegium des Fleckens Adelebsen

I 889-I 893 Salomon Gräfenberg ist Mitglied im Bürgervorstehercollegium des Fleckens Adelebsen

I895 Jüdische Einwohner: 69| Gesamtbevölkerung: I048

I905 Jüdische Einwohner: 65 | Gesamtbevölkerung: I300

I9I4-I9I8 1. Weltkrieg Aus der jüdischen Gemeinde eingezogen und an der Front eingesetzt sind: Benedikt Höxter, Israel Jakobi (schwer verwundet), Leopold Nathan, Herbert Stehberg, Hugo Stehberg, Ludwig Stehberg (gefallen, Erinnerungsgrabstein IV 3 I $\rightarrow$ Dokument Nr. I3 $\left.{ }^{\star}\right)$.

I9I5 Die in ihren Anfängen ins I8. Jahrhundert reichende jüdische Schule wird nach Einberufung des Lehrers endgültig geschlossen.

I923 Aufbau einer NSDAP-Ortsgruppe in Uslar mit Mitgliedern aus Adelebsen ${ }^{19}$

I925 Jüdische Einwohner: 46 | Gesamtbevölkerung: I484

I929 April: Gräber des Friedhofs werden geschändet $\left(\rightarrow\right.$ Dokument Nr. I4 $\left.{ }^{\star}\right)$

I930 Gründung einer NSDAP-Ortsgruppe in Wibbecke, 1932 Verlegung nach Adelebsen. ${ }^{20}$

I932 Wahlen zum Reichtag. Die NSDAP wird stärkste Partei auch in Adelebsen

Jüdische Einwohner: 32 | Gesamtbevölkerung: I664

1933

30. Januar: Bildung der Reichsregierung unter Führung der NSDAP

I. April: Amtlich verordneter, reichsweit durchgeführter Boykott der jüdischen Geschäfte. Auch in den in Adelebsen verbreiteten Sollinger Nachrichten wird dazu aufgerufen $\left(\rightarrow\right.$ Dokument Nr. I $\left.5^{\star}\right)$ : mit welchem Erfolg ist nicht ermittelt.

I935 Erlass der „Nürnberger Gesetze“: Juden werden die seit 1848 für Hannover und seit 1871 für das gesamte Deutsche Reich geltenden vollen politischen Rechte aberkannt; Eheschließungen und sonstige Beziehungen zwischen Juden und „Staatsangehörigen deutschen bzw. artverwandten Blutes" sind verboten.

Der letzte jüdische Schüler, Arno Gerson verlässt die öffentliche Schule in Adelebsen wegen zunehmender Drangsalierung durch Mitschüler. Er findet zunächst Unterkunft in einer jüdischen Internatsschule in Dinslaken und kann noch I939 nach Palästina auswandern.

I936 Das Geschäft des Textilhändlers Noa Rothschild wird aus dem Handelsregister ${ }^{21}$ gestrichen, nachdem er durch fort dauernde Boykottmaßnahmen bedingt nicht mehr über hinreichende Einnahmen verfügt.

18 HStAH, Hann. 74 Uslar Nr. 2059 [Anstellung]/Israelitisches Familienblatt vom 7.IO.I9IO [Eintritt in den Ruhestand].

19 Hermann Weinreis, Uslar unter dem Hakenkreuz.
Verführung und Verführbarkeit einer kleinstädtischen Gesellschaft, Uslar o.D., 20.

20 Alphei, Geschichte, I 50.

21 Ebd., I 56. 

digen Teile der Inneneinrichtung. Im April I938 werden sie vom Schöffengericht Göttingen deswegen zu einer Gefängnisstrafe von 5 Monaten verurteilt, die sie aber nicht absitzen müssen. ${ }^{22}$

23. Juli: Allen jüdischen Einwohnern wird durch eine Verfügung des Innenministeriums auferlegt, eine besondere Kennkarte - mit einem großen eingestempelten "J"versehen - zu beantragen, aus der ihre "Eigenschaft als Jude" hervorgeht; bei jeglichem Umgang mit öffentlichen Dienststellen und Behörden haben sie künftig unaufgefordert auf ihre Eigenschaft als Jude" hinzuweisen.

I7. August: Eine Verordnung bestimmt, dass ab dem 1. Januar 1939 alle männlichen Juden den zusätzliche Vornamen „Israel“, alle weiblichen den zusätzlichen Vornamen „Sara“ zu führen haben.

I2. September: Der Farbengrosshandel von Julius Polak geht durch Notverkauf in den Besitz von Friedrich A. Bank über. ${ }^{23}$

9./ Io. November: Die oberste NS-Führung nimmt den Tod des durch ein Attentat des deutsch-polnischen Juden Herschel Grynspan verletzten Legationssekretärs Ernst vom Rath zum Vorwand, um durch Angehörige der SA, SS und NSDAP reichsweit ein Progrom gegen die jüdische Bevölkerung und jüdische Einrichtungen anzuzetteln.

Die Adelebser Synagoge wird in den Morgenstunden des Io. November durch ein aus Göttingen angerücktes SS-Kommando unter Mithilfe von Mitgliedern der örtlichen SS und SA in Brand gesetzt und vollständig zerstört; jüdische Einwohner werden in ihren Häusern überfallen, die Erwachsenen verhaftet, im Keller des Rathauses eingeschlossen $(\rightarrow$ Dokumente Nr. I7a-e`), dabei z.T. misshandelt; die Männer in „Schutzhaft“ genommen, zunächst nach Northeim und von dort nach Hildesheim ins Gerichtsgefängnis verbracht, nach 8 Tagen entlassen; die Warenbestände der jüdischen Geschäfte ,,beschlagnahmt“; 24 der „,Friedhofsacker“ wird ,stark beschädigt, ... Grabsteine zerschlagen und umgeworfen““. 25

I939 Jüdische Einwohner: 20 - (nach Emigration der Familien Polak in die Niederlande): I 2 | Gesamtbevölkerung: I699

Im Sommer bestehen letztmals Möglichkeiten, legal auszuwandern; mit Wirkung vom 1. Oktober wird die weitere Auswanderung von Juden aus Deutschland untersagt.

Am 20 Januar wird auf der sogenannten ,Wannsee-Konferenz" vor Vertretern der wichtigsten Reichsministerien und obersten SS-Dienststellen der Beschluss zur „Endlösung der Judenfrage" bekannt gegeben und in seinen Ausführungen erörtert. Im Anschluss daran werden die bereits 1941 begonnenen Deportationen der jüdischen Bevölkerung aus Deutschland reichsweit organisiert.

22 Sollinger Nachrichten 25.4.1938.

23 Alphei, Geschichte, I 58

24 Ebd., I $56 f$.

25 So der Bericht in dem vom Allgemeinen Organisations-Ausschuß, Celle am 21.2.I952 erlassenen
Beschluss, in dem die Eigentumsrechte an dem Besitz ehemaliger jüdischer Gemeinden der Jewish Trust Corporation übertragen wurden; s. Grundakten zum Grundbuch Adelebsen I2/505 Blatt 46. 
26. März: Alfred und Kurt Jakobi sowie Gustav und Toni Schaumberg mit ihrem 3 jährigen Sohn Hans werden nach Ahlem/Hannover und von dort ins Warschauer Ghetto deportiert.

2 I. Juli: Carl und Paula Dannenberg, Israel und Frieda Jakobi, Noa und Rosa Rothschild sowie Olga Eichenberg, die letzten noch in Adelebsen verbliebenen Mitglieder der jüdischen Gemeinde, werden nach Ahlem/Hannover und von dort ins KZ Theresienstadt deportiert.

I945

27. Januar: Befreiung des KZ Auschwitz durch die Rote Armee

8. Mai: Befreiung des KZ Theresienstadt durch die Rote Armee

9. Mai: Ende des 2. Weltkriegs und der NS-Herrschaft

Juli: Noa Rothschild kehrt aus als einziger Überlebender aus dem KZ Theresienstadt zurück.

24948 Mai: Noa Rothschild stirbt und wird als letzter Angehöriger der jüdischen Gemeinde auf dem Friedhof begraben (Grab V 5) ${ }^{26}$

26 Neben Noa Rothschild hat I946 für kurze Zeit eine Gruppe von 39 weiteren Überlebenden der Schoa deutscher, österreichischer, polnischer und ukrainischer Herkunft sich in Adelebsen aufgehalten, ferner ist der zwischen August I95 I und Januar I956 als Vorsitzender der Göttinger jüdischen Gemeinde amtierende Ernst Engwicht bis I956 hier wohnhaft gewesen. Dazu vgl. Cordula Tollmien, Juden in Göttingen, in: Ernst Böhme u.a. (hg.), Göttingen. Geschichte einer Universitätsstadt, Bd. 3: Von der preuBischen Mittelstadt zur südniedersächischen Großstadt I866-I989, Göttingen I999, 744-753. 


\section{Dokumente}

Nr. I* Ältester Beleg für jüdische Einwohner in Adelebsen, I675

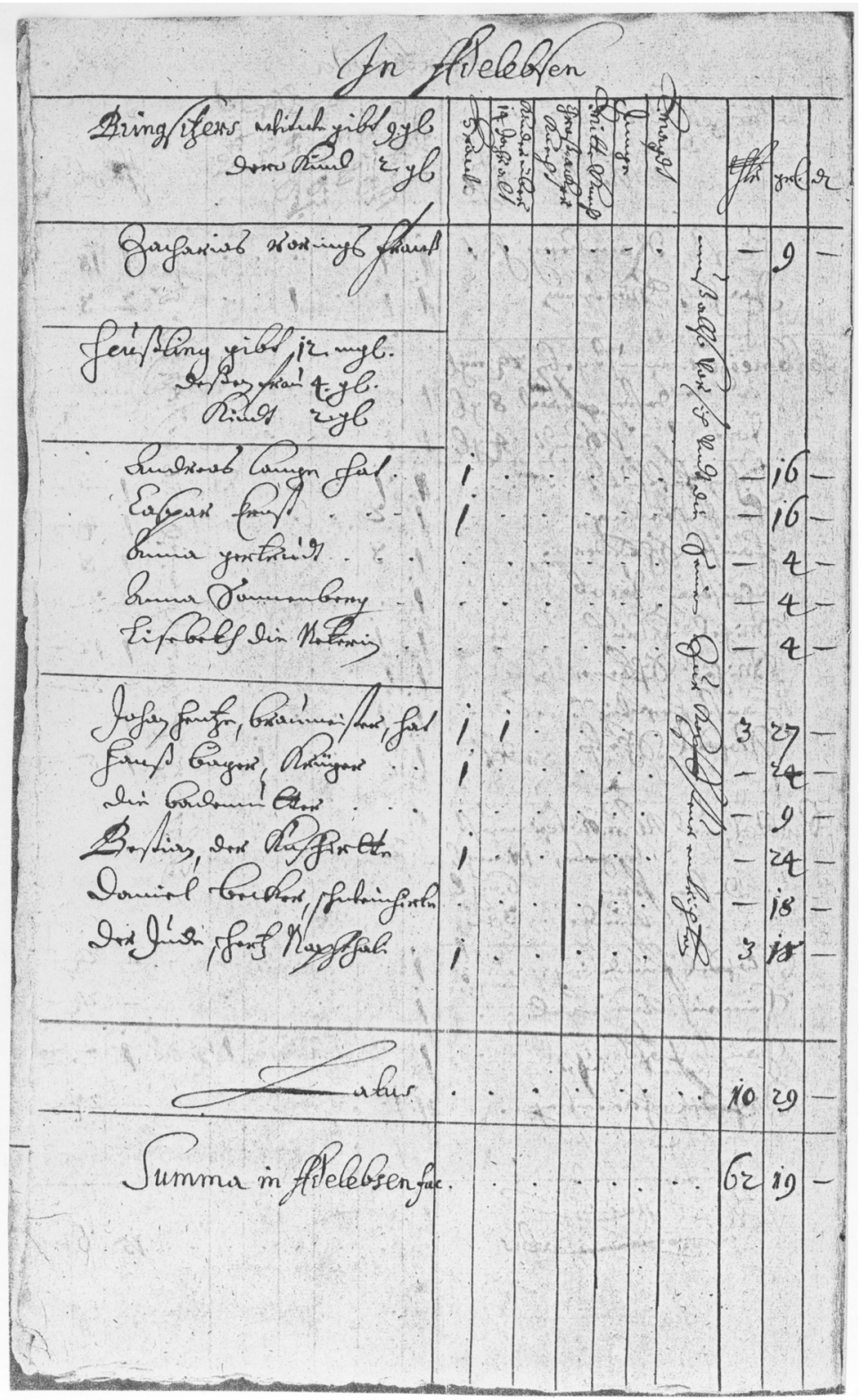

In der Kopfsteuerbeschreibung der Adelebser Einwohner des Jahres 1675 ist an letzter Stelle zu lesen: Der Jude, Hertz Naphthali. Dazu ist vermerkt, dass er eine Frau hatte und mit 3 Thalern I 8 Groschen zur Steuer veranschlagt wurde (nachträglich auf 2 Thaler herab gesetzt). (HStAH, Cal. Br. I9 Nr. I032) 
Nr. 2` Mandat der Justizkanzlei in Hannover an das Adlige Gericht Adelebsen, wegen der Aufnahme von „ohnvergleiteten“ Juden, I737

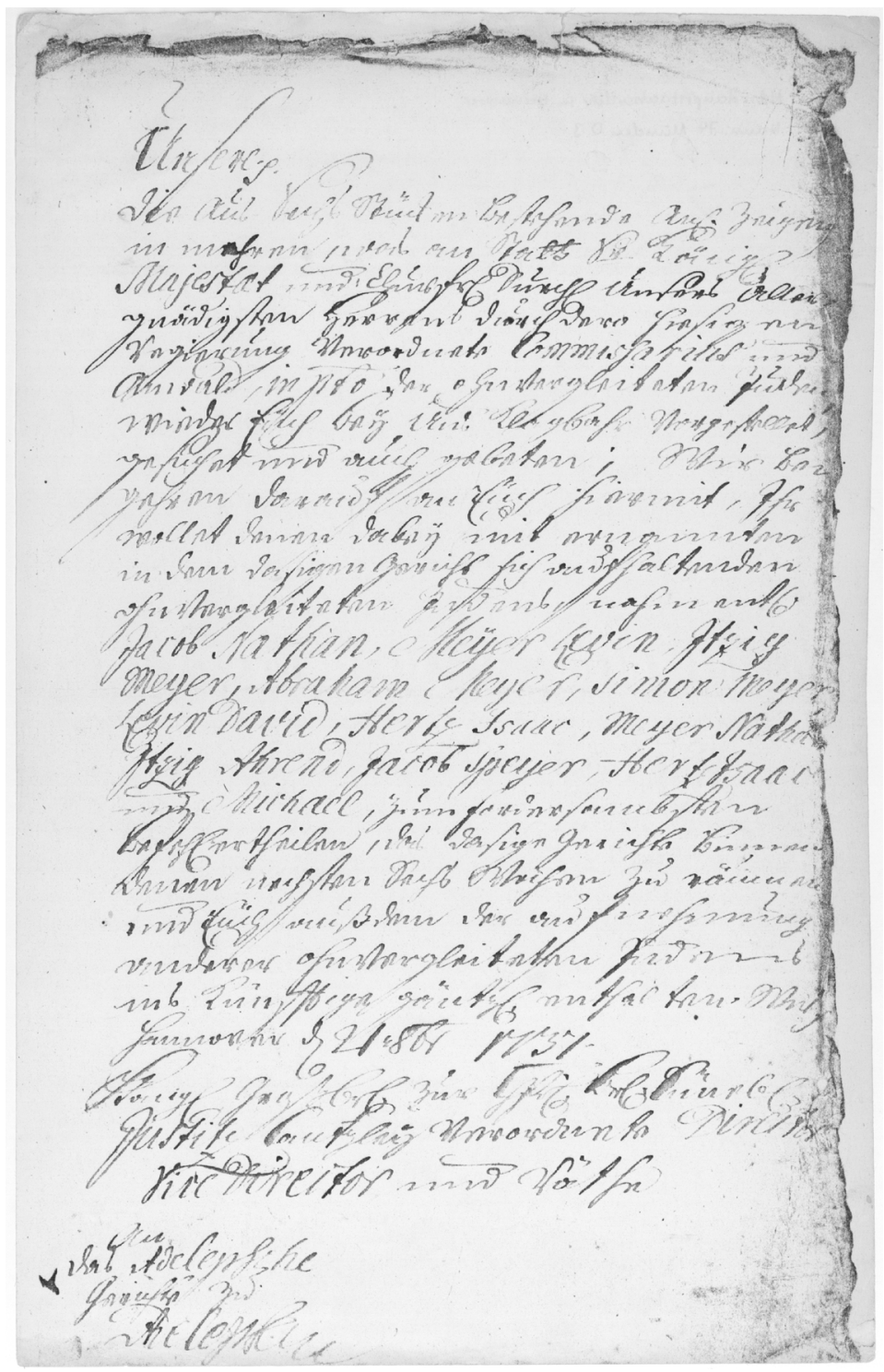

Nach der Verhaftung eines Juden aus dem Gericht Adelebsen beim Hausieren in Dörfern des Amtes Münden ließen die Landesbehörden genauere Ermittlungen anstellen. Im Anschluss daran wurde das Adlige Gericht Adelebsen 1737 angewiesen, I2 namentlich benannte »ohnvergleitete« (d. h. nicht mit einem landesherrlichen Schutzbrief versehene) Juden innerhalb von 6 Wochen auszuweisen und nicht weiterhin Juden ohne landesherrlichen Schutz aufzunehmen. (HStAH, Hann. 74 Münden Nr. 84I7) 
Nr. $3^{\star}$ Mappa von Meier Levi Eichenberg, I824

Das Städtische Museum Göttingen besitzt 27 Mappot. I 8 (oder 20 ?) von ihnen wurden von dem letzten jüdischen Lehrer in Adelebsen angekauft. Die meisten können auf Grund von Namens- und Datumsentsprechungen bekannten Personen aus Adelebsen bzw. den umliegenden Dörfern zugeordnet werden.
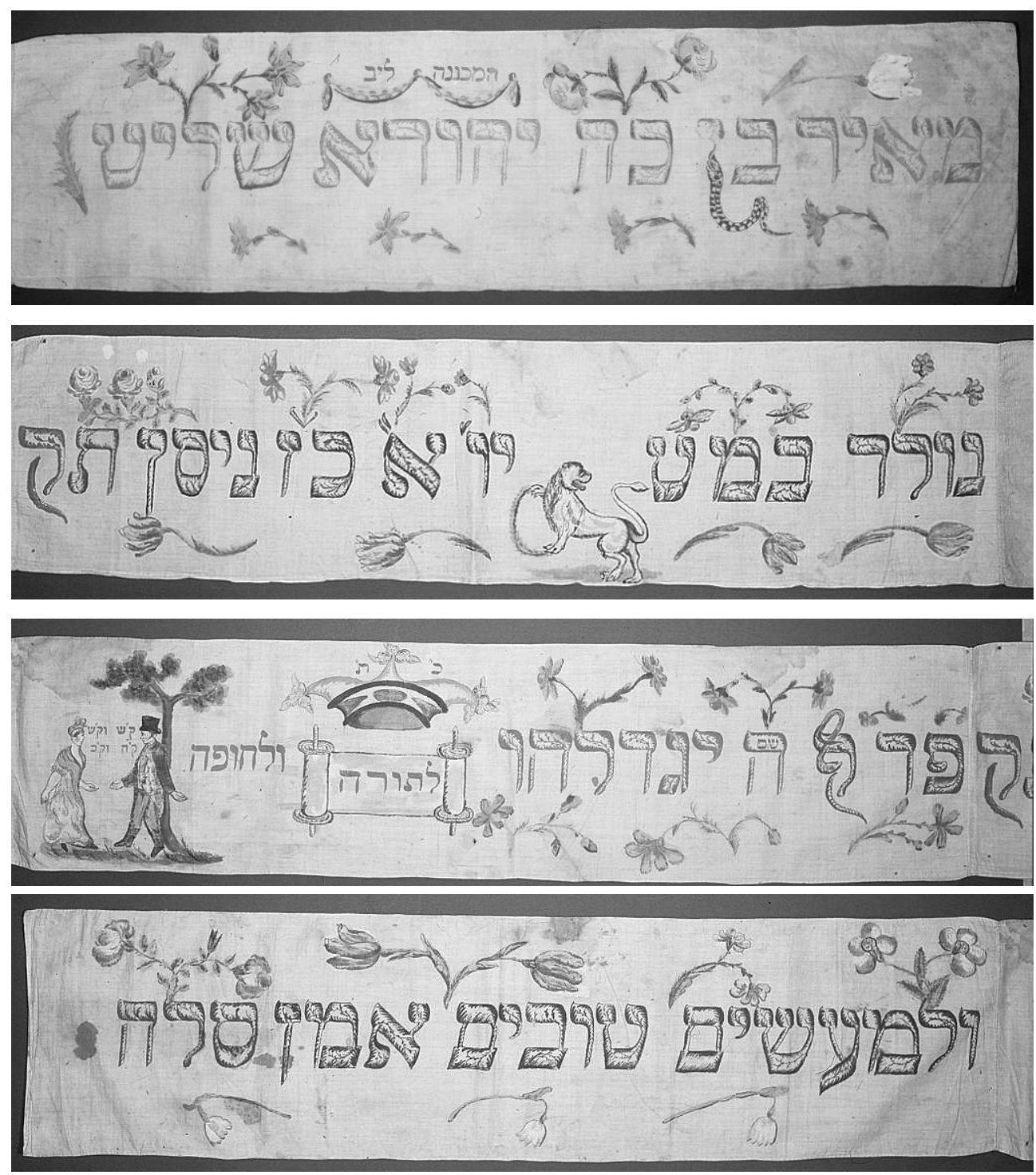


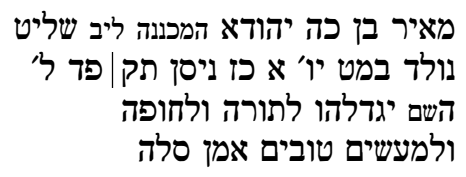

Meir, Sohn des e(hrbaren) H(errn) Jehuda, genannt Leib, Schalit, geboren in g(utem) St(ern) (am)Tag 1, 27. Nisan $5 \mid 84$ n.(kl.Z.)

Der Name lasse ihn groß werden zur Tora und zur Chuppa

und zu guten Taten. Amen. Sela.

\section{Erläuterungen:}

- "Schalit« ist die Abkürzung für ,,er möge die Fülle guter Tage erleben“.

- 27. Nisan (5) $584=25$. April I 824 .

- „Der Name“ (שם steht im Kopf des Buchstabens ה) ist Ersatzbezeichnung für den unaussprechbaren Gottesnamen.

- „,... groß werden zur Tora“, d. h. Heranwachsen zum Studium der Tora und zur Verlesung der Tora im Gottesdienst. Das Wort „Tora“ steht in der geöffneten Torarolle, darüber eine Krone und in Abkürzung „Krone der Tora“.

- „,... und zur Chuppa“, d. h. um unter den Heiratsbaldachin zu kommen. Auf letzteres spielt die bildliche Darstellung an; eigentümlicherweise wird die Trauung dabei aber nicht unter einer von Stangen gehaltenen Chuppa vollzogen, sondern unter einem Baum - eine in der Zeit des Biedermeier öfter anzutreffende Darstellungsform. Als Inschrift zur Trauszene ist in Kurzform ein biblischer Sinnspruch beigefügt: „Stimme der Wonne und Stimme der Freude, Stimme des Bräutigams und Stimme der Braut (Jer. 33, I I).

- Zu Meier Levi Eichenberg vgl. IV 38.

(Städtisches Museum Göttingen, Inventar-Nummer I9I7/335 J 24) 
Nr. $4^{\star}$ Bauinschrift, Hinterhaus Lange Straße 27, I825

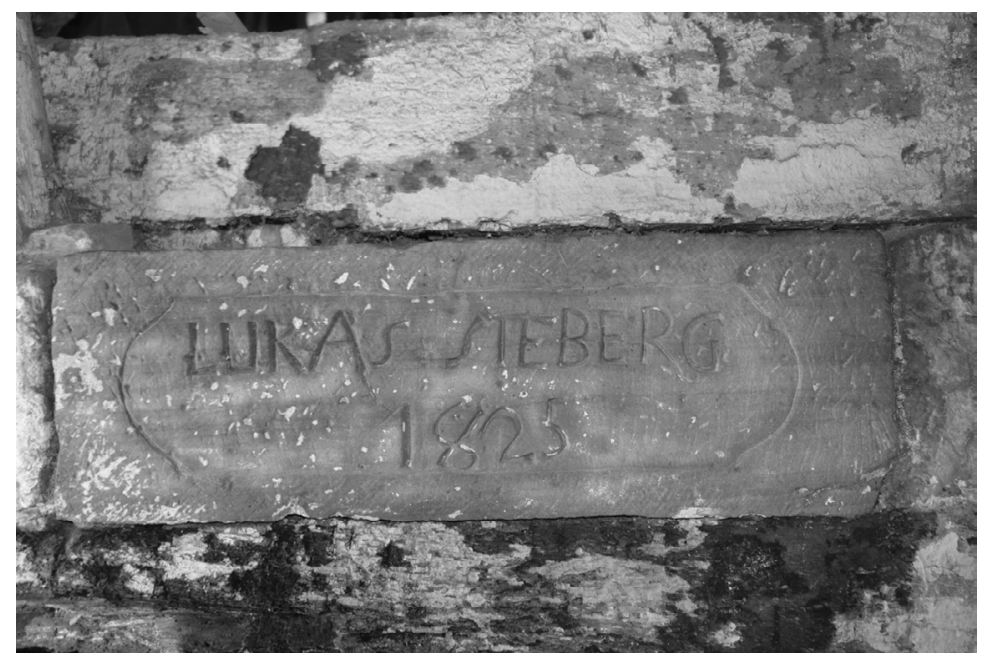

Angebracht nicht wie sonst üblich über dem Hauseingang selbst, sondern im Türsturz über dem Eingang zum Kellergewölbe (dazu s. Nr. $5^{\star}$ ). Zum Bauherrn Lukas Ste(h)berg vgl. III 77

Nr. 5 Kellergewölbe des Hauses Lange Straße 27

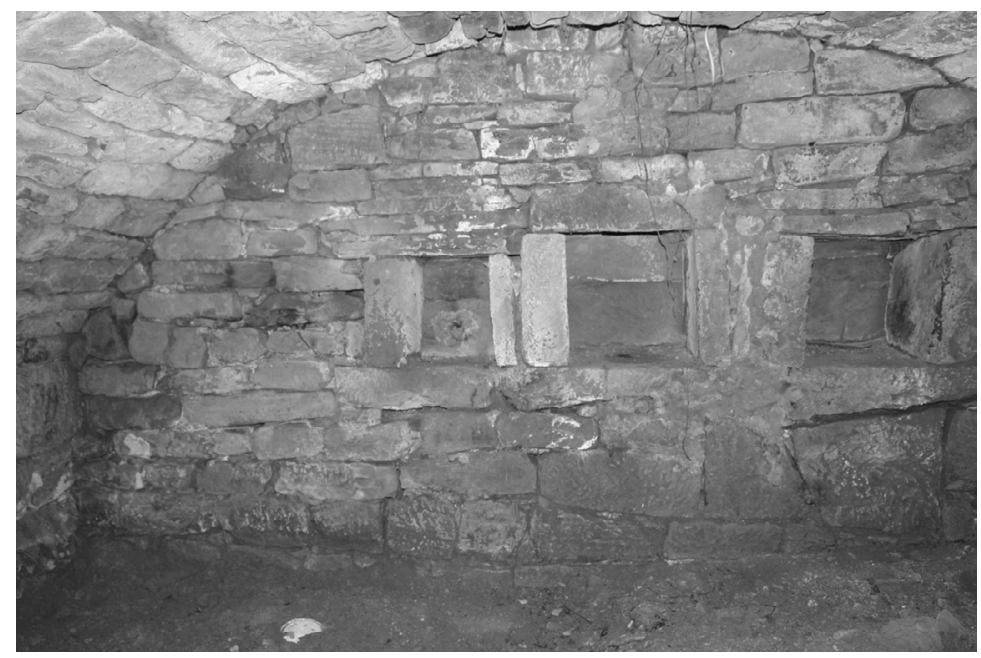

Der Zugang führt durch die mit „Lukas Steberg“ markierte Tür (s. Nr.` 4). Der Raum selbst war, wie Reste zeigen, an Wand und Decke verputzt und ist an der Rückwand mit 3 unregelmäßig großen Nischen versehen. Das alles ist für einen normalen Keller ungewöhnlich und könnte auf die Anlage einer Mikwe hinweisen; s.o. zu I855 
Nr. $6^{\star}$ Titelseite des Synagogenbuchs, I 832

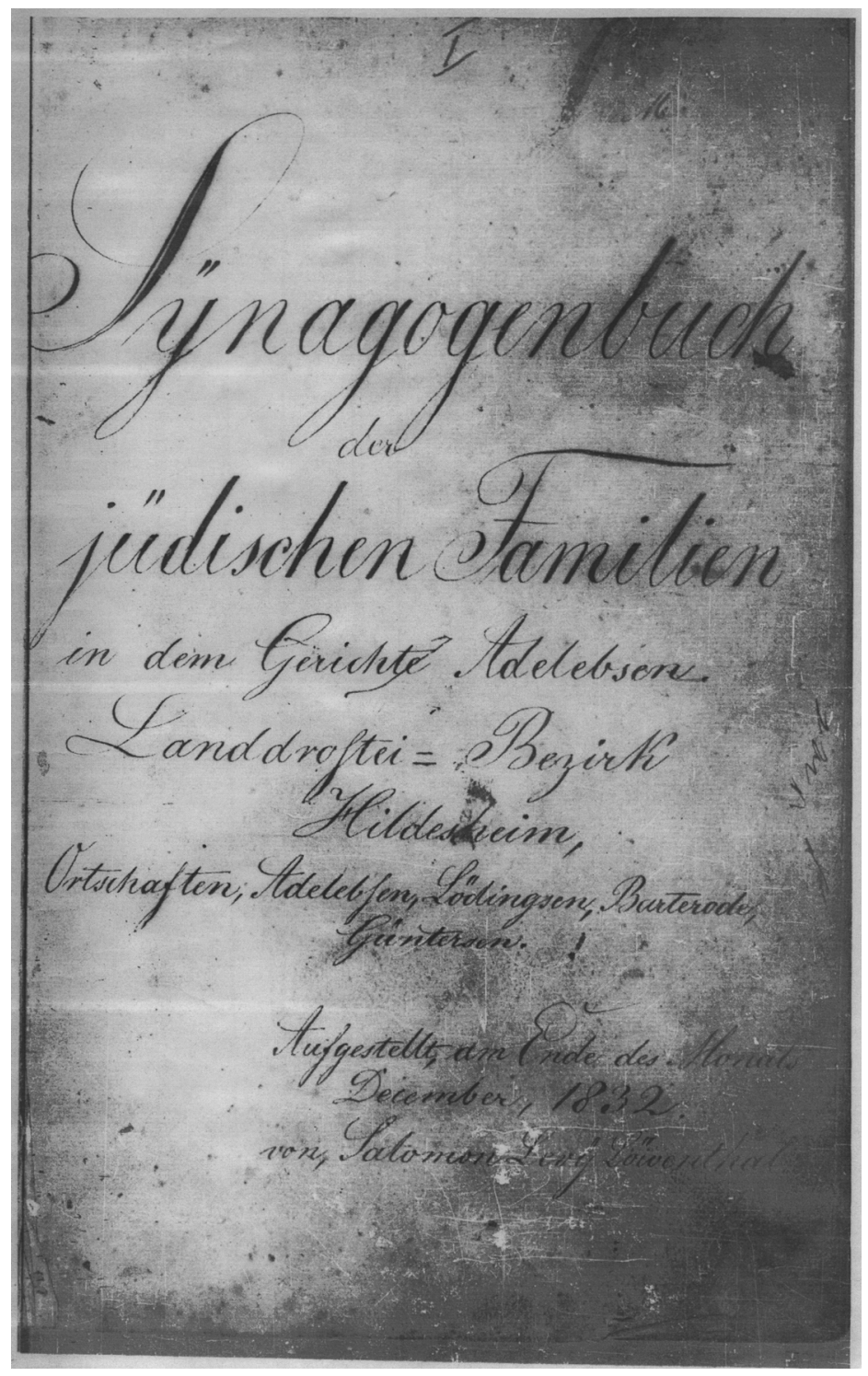

Auf Anweisung des Landrabbiners wurden I83I/32 alle in den jüdischen Gemeinden vorhandenen Familien in einem Familien- bzw. „Synagogenbuch“ verzeichnet. Für Adelebsen und die benachbarten Dörfer ist dies die älteste vollständige und detaillierte Erfassung der jüdischen Einwohner mit den bis in die Mitte des I8. Jhs. zurück reichenden Geburtsdaten und ggf. Herkunftsorten. (HStAH, Foto I Nr. 97) 


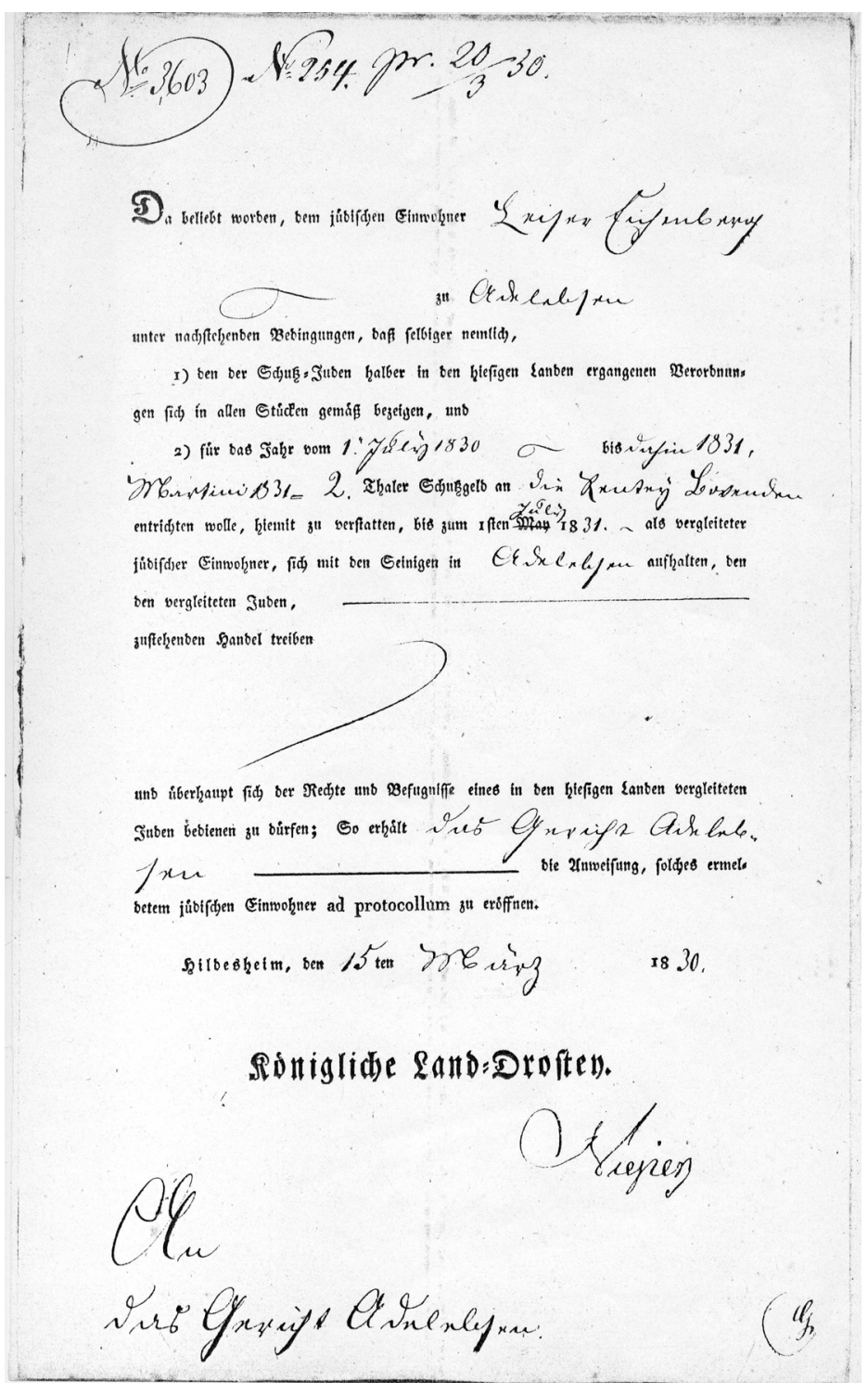

Bis zum Jahre I 842 mussten Juden für ihre Niederlassung bzw. die Gründung eines eigenen Haushalts die Schutzerteilung durch die Landesregierung erlangen und in bestimmten Abständen immer wieder erneuern lassen. Mit dieser befristeten Aufenthaltsgenehmigung war zugleich eine genau festgelegte Beschränkung der beruflichen Tätigkeit verbunden. (HStAH, Hann. 74 Uslar Nr. 2065) 
Nr. 8^ Erklärung der Jüdischen Gemeinde zur Schutzerteilung für Samuel Löwenstern, I 834

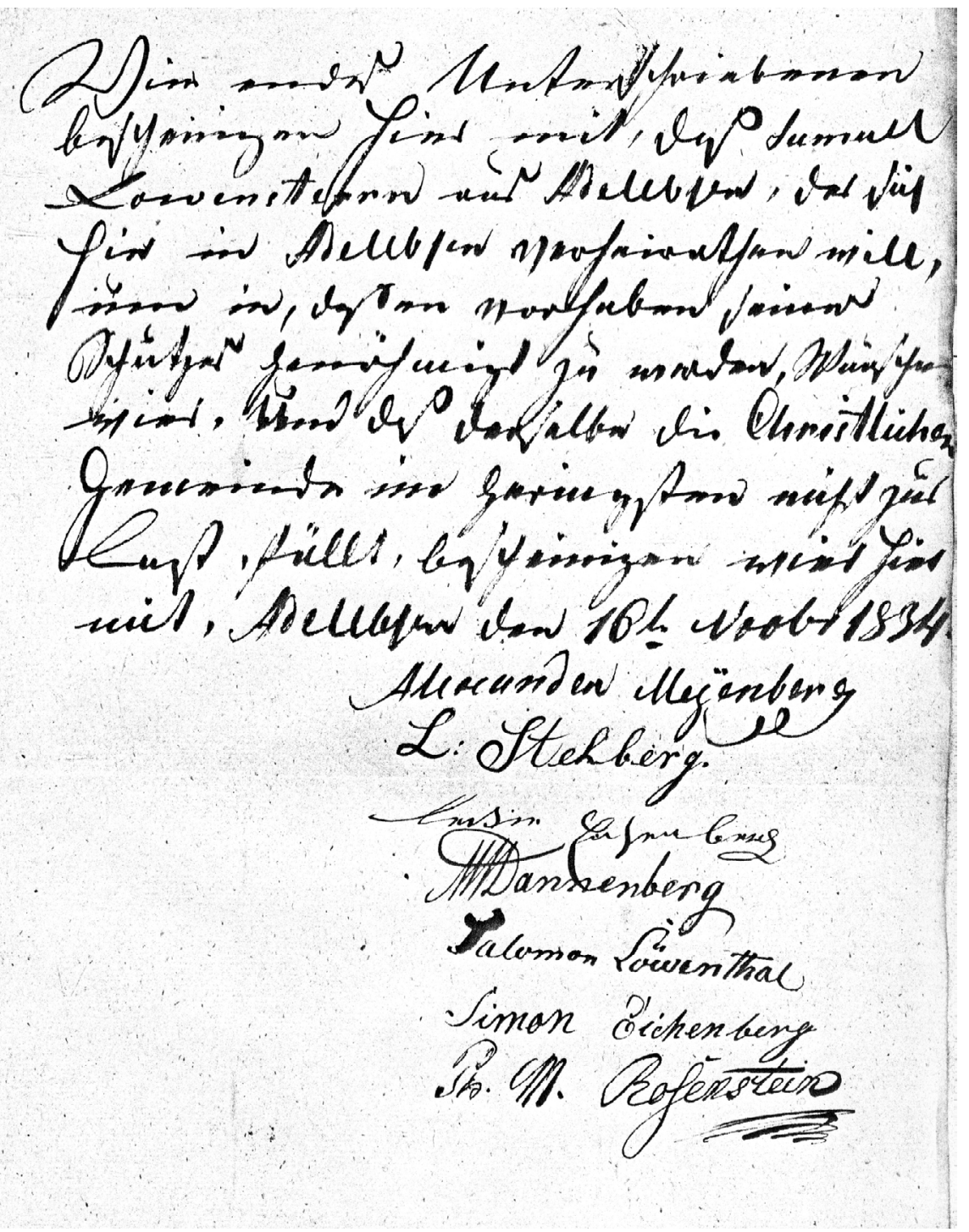

Gegen die Erteilung von Schutzbriefen wurden von Seiten des Fleckensvorstandes öfters Bedenken geltend gemacht, die betreffenden Juden könnten der Armenkasse des Ortes zur Last fallen. Deshalb musste die jüdische Gemeinde sich verbindlich machen, in einem solchen Falle für den Unterhalt einzustehen:

Wier endes Unterschriebenen bescheinigen hier mit, daß Samuel Löwenstern aus Adelebsen, der sich hier in Adelebsen verheirathen will, um in, dessen vorhaben seines Schutzes genähmigt zu werden, Wünschen wier. Und daß derselbe die Christliche Gemeinde im geringsten nicht zur Last fällt, bescheinigen wier hier mit. ... (HStAH, Hann. 74 Uslar Nr. 2065) 
Nr. 9^ Eingangsfront der Adelebser Synagoge, gezeichnet von Gabriele Ziegler (Göttingen) nach Angaben von Avri Gershon

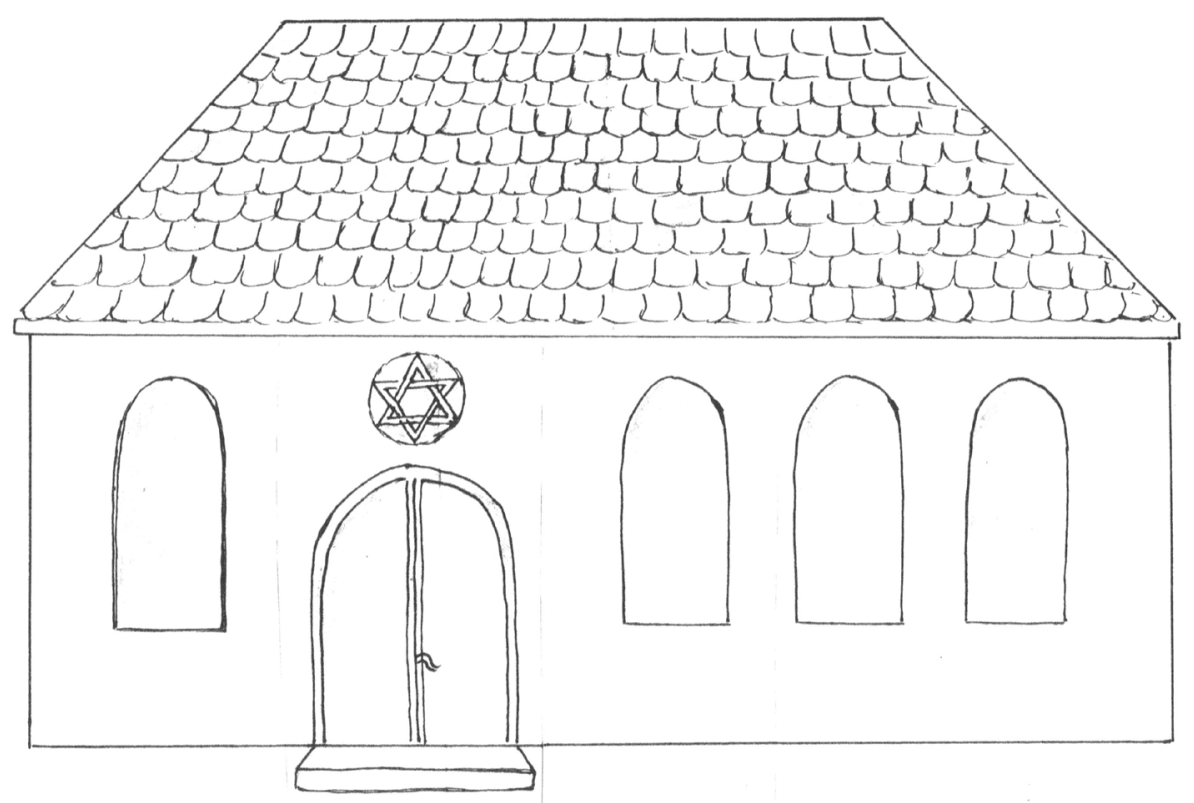

Die I836 erbaute und I938 zerstörte Synagoge der Adelebser jüdischen Gemeinde hat kaum Spuren hinterlassen. Weder Pläne noch Fotos sind erhalten, auch sonst gibt es keine genauen Beschreibungen. Ebenso wenig haben die bislang bei einer Grabung gefundenen Reste auswertbare Ergebnisse über die genaue Lage und Größe zutage gefördert. Die vorliegende Skizze der Eingangseite ist ebenso wie weitere Angaben Avri Gershon zu verdanken:

Das Gebäude war auf einem hinter dem Vorderhaus Lange Straße I 5 gelegenen, durch eine Mauer umgebenen, plateauförmigen Gelände errichtet, zu dem man über die heute noch vorhandene 12 stufige Treppe (s. Nr. Io*) gelangte. Es bestand aus einem nach Osten ausgerichteten Fachwerkbau, der an der Süd- und Nordfront mit Fenstern versehen war. Der Eingang befand sich nicht wie sonst meist üblich an der West-, sondern an der Südseite und zwar nach links versetzt, nicht in der Mitte. Über ihm war ein Rundfenster angebracht, in dem ein Davidsstern (Magen David) abgebildet war. Durch ihn gelangte man in einen Vorraum, von dem aus links eine Treppe zur Frauenempore führte und rechts ein abgeschlossener, für Sitzungen oder auch Festlichkeiten benutzter „Saal“ lag. Den für die Männer reservierten Hauptraum betrat man durch eine weitere, in der Flucht des Haupteingangs befindliche Tür. Wie üblich war er durch zwei Grundelemente bestimmt: Ungefähr in der Mitte war das Bima aufgestellt, eine Art Bühne mit Pult, auf dem für die wöchentliche Schriftlesung die Torarolle ausgebreitet wurde. Einige Schritte davon entfernt stand an der Ostwand, gleichfalls erhöht, der Toraschrein, ein mit einem kunstvoll gestalteten Vorhang, dem Parochet, verhüllter Schrank, in dem die Torarollen (zuletzt 5) aufbewahrt waren. Rechts davon befand sich der Stuhl für den Vorbeter. Der übrige 
Raum war mit zweisitzigen Bänken ausgestattet. Für die Beleuchtung diente ein großer Kronleuchter, der über dem Bima von der gewölbten, bläulich gefärbten Decke herab hing, sowie einige an den Wänden angebrachte kleine Lampen, die, wie auch bei der Grabung gefundene Reste bestätigen, zuletzt mit elektrischem Strom betrieben wurden. Alles in allem ein schlichter Bau, der laut Inventarverzeichnis in Gemeinderechnungen des I9. Jhs. ungefähr je 50 Männern und Frauen Platz bot.

Nr. Io` Der Treppenaufgang zur Synagoge (s. Nr. 9*)

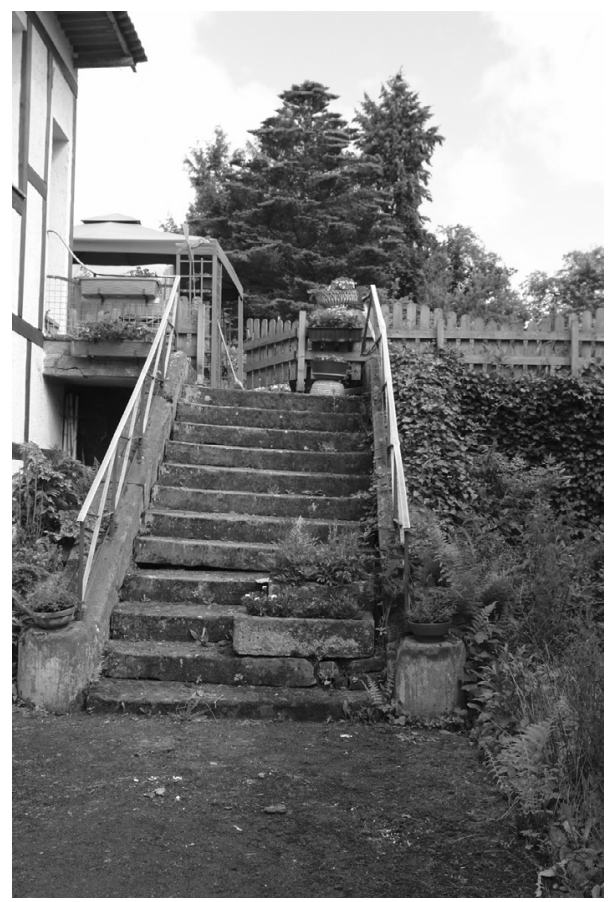

Die mit einem Eisengeländer versehene Treppe überwindet eine Höhe von 2,35 m. Sie besteht aus 12 Granitsteinstufen, die abgesehen von der untersten mit runden Seitenwangen versehenen - in den Maßen weithin übereinstimmen: B: I,75 $\mathrm{m}$; $\mathrm{H}$ : o, I5-20 m; T: 0,30-40 m (oberes Podest: I, $25 \mathrm{~m})$ 
Nr. I I ${ }^{\star}$ Gebetstafel aus der Synagoge in Barterode, I839

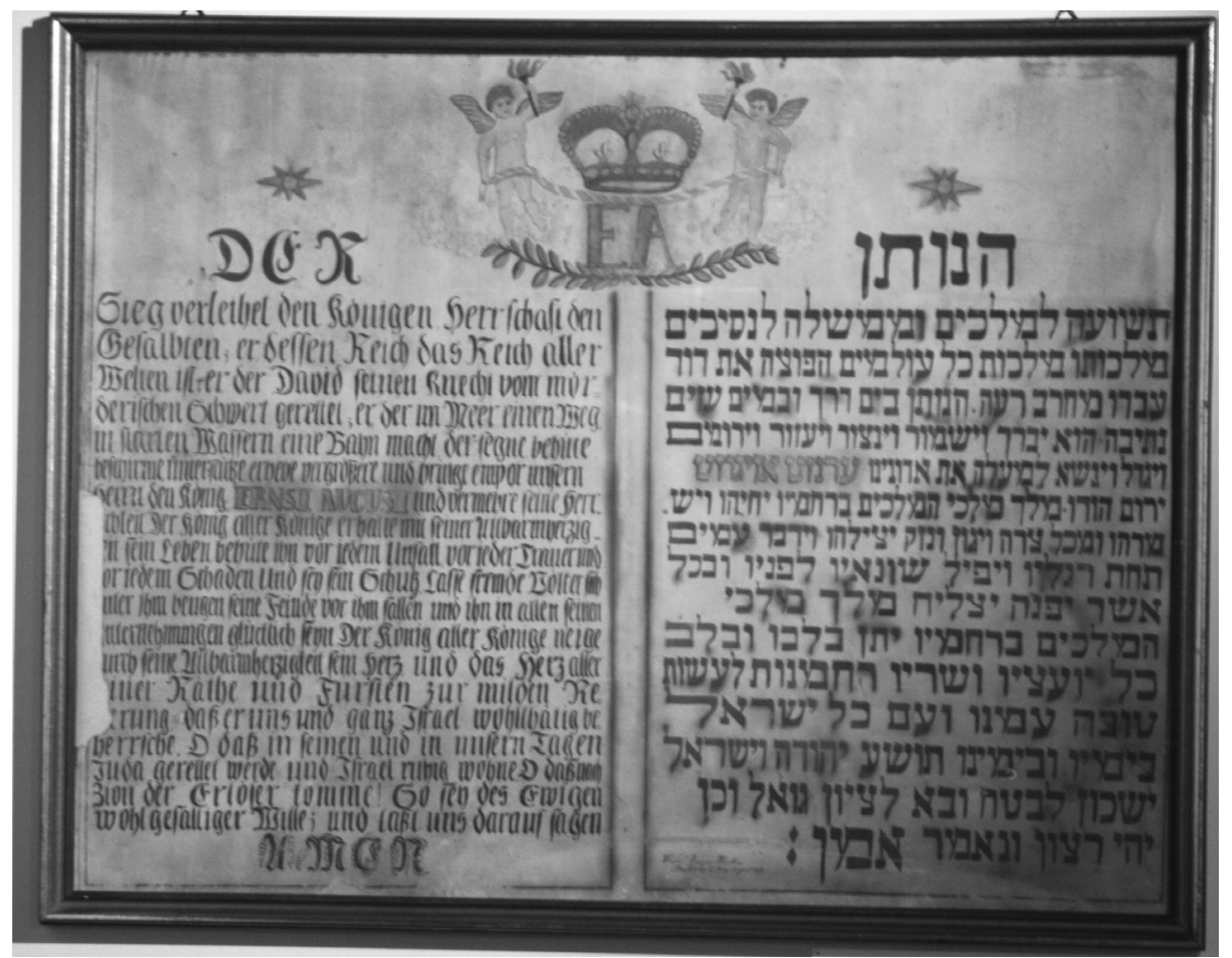

In der ersten Hälfte des 19. Jhs. bildeten die in Barterode und Güntersen wohnhaften Juden eine eigene Synagogengemeinde - der genaue Zeitpunkt der Entstehung und der Anlass sind unbekannt. I 838/39 wurde ein in Barterode angemietetes Gebäude als Synagoge neu eingerichtet. $\mathrm{Zu}$ ihrer Ausstattung gehörte die abgebildete Gebetstafel mit einem Fürbittgebet für den Landesherrn, das auch im Gottesdienst gesprochen wurde.

Diese Gemeinde konnte sich aber in ihrer Eigenständigkeit auf Dauer nicht halten. Häufige Streitigkeiten zwischen den Barteröder und den Günterser Familien über die Gestaltung und Finanzierung des Gemeindelebens führten dazu, dass die Günterser sich der Synagogengemeinde Dransfeld zuwandten und die Barteröder sich wieder nach Adelebsen halten mussten - ein Zustand, der von der Obrigkeit I 846 vorläufig gebilligt und I86I förmlich verfügt wurde. (Städtisches Museum Göttingen, Inventar-Nummer I9OI/544) 
Nr. I2* Notenbuch des Männergesangvereins »Hadassa«, Ende I9. Jh.
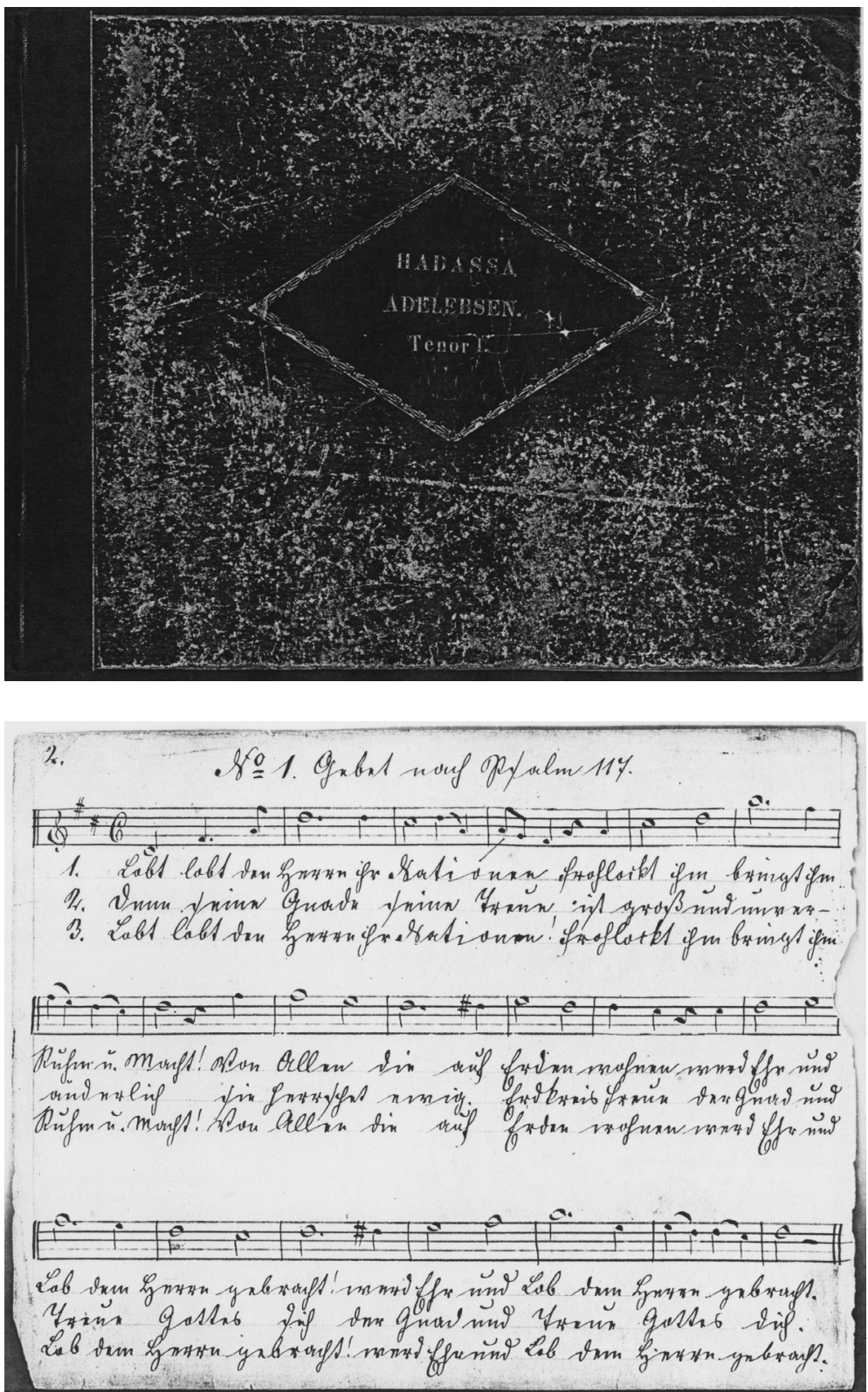

Schon I 866 - noch bevor es in Adelebsen einen Kirchenchor gab! - wird erwähnt, dass die Gottesdienste in der Synagoge von einem Chor mitgestaltet wurden (HStAH, Hann. 74 Uslar Nr. 2046). Dieser Chor dürfte mit dem Männergesangverein »Hadassa« (= Myrtenstrauch), dessen Existenz allein durch das abgebildete Notenbuch belegt ist, identisch oder aber dessen Ursprung sein. (Privatbesitz) 
Nr. I3* Kirchenfenster zur Erinnerung an die Gefallenen des I. Weltkriegs

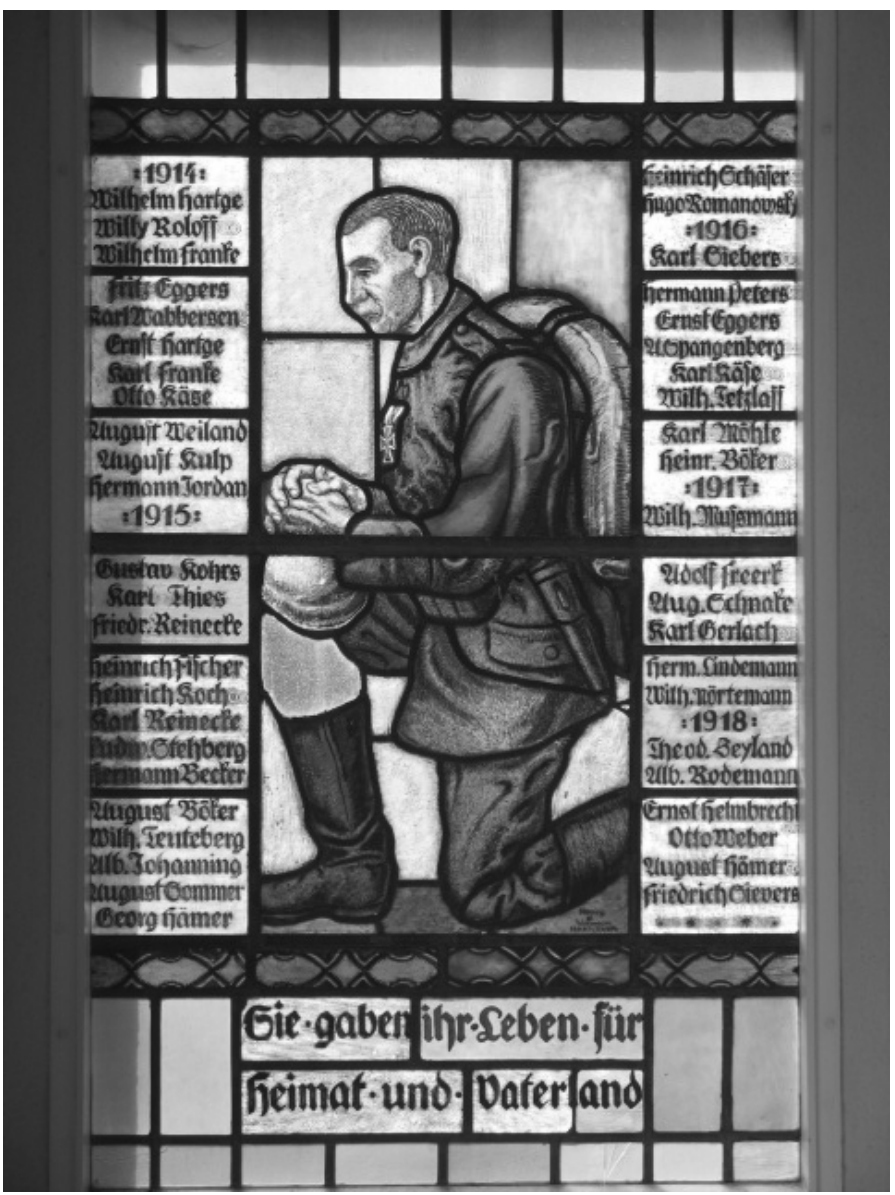

Auf der linken Seite im 5. Feld ist der Name von Ludwig Stehberg (s. IV 3I), verzeichnet, desgleichen auch auf dem neben der Kirche errichteten Ehrenmahl. 
Nr. I4 ${ }^{\star}$ Bericht über eine Schändung des Friedhofs im April I929

\section{(1) Irbetebjett. Sin Der Jeit bom 9. bis junt 12. 21pril}

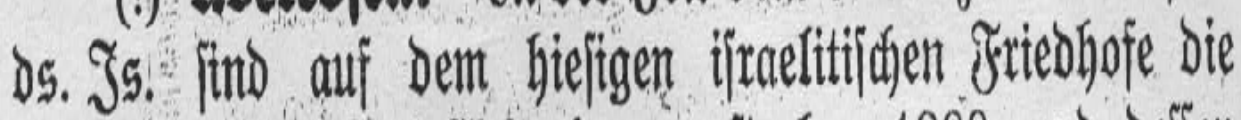
Grabiteine von Seot Citfertberg, gétorben 1889, uno defien.

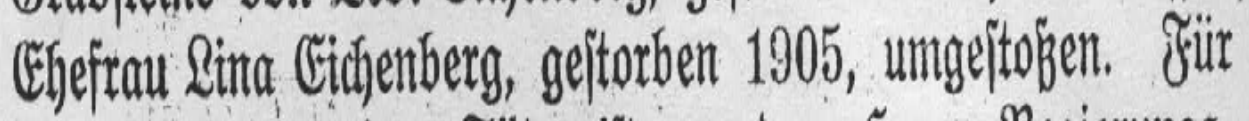
Die Cermittlung der Täter itt non Dem Sertn Regierungs: Bräpibenten in Sitbesheim eine. Belognung oon 100 Mart

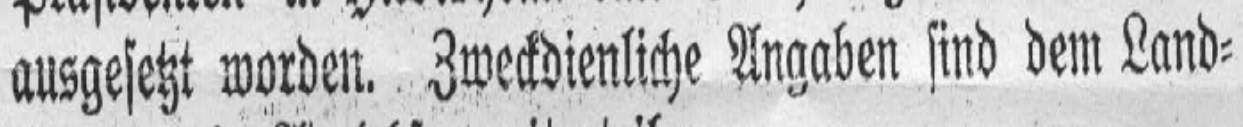
jügertant in SIDeiebjent mitzuteitlen.

Der ausschließlich in Sollinger Nachrichten vom 4. 5. 1929 veröffentlichte Vorfall war kein Einzelfall (dazu s. S. 4I A. I3). Die angestellten Ermittlungen blieben wie meist ohne Ergebnis. 
Nr. I $5^{\star}$ Aufruf der NSDAP-Kreisleitung Northeim-Uslar zum Boykott der jüdischen Geschäfte, I933

\section{Mationaliojililiten! Deutifide Bollts= genofinmen und Bollsgenofien!}

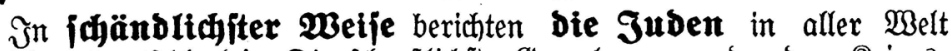
über Seutichland! Die fheußlichfte Breuelpropaganoa ber Friegs= zeit - unjeligen Ângedenfens - mirb von Juba heute noch übertroffen. Es ijt ber $\mathfrak{S a b}$ aller $\mathfrak{J u b e n}$ gegen ein freies, glïcklides Deutjaland.

Suben mibgandeln im Susland anjere bentiditen Brïber!

(5) ift an ber Beit, Das überbebliche Jubentum in jeine Sctaranten zurücţzumeijen.

Der beutjhe Menja tritt in Wabrung feiner beiligiten Lebenss

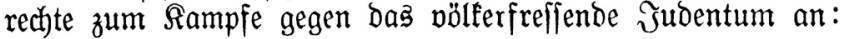

\section{Rettet Deutichland!}

Da bes Juben Bott - Der Mammon - das Bsold ijt, greifen rwir ifn bier an feiner empfindlichjten Stelle an.

Wir rufen baher bas beutide Bolk auf: "Raufe niemals meht bei cinem Juben, meibe jiibijaje Warenhäujer, büte Did vor jübijaben Aerzten unb Redjtsanwälten! Wer Dagegen veritößt, ftellt fic kewüt außerhalb Der beutiaen Lebensgemeinicaft. Er Darf fid nicht wun: bern, wenn ihn bie gleib) Strafe trifft, wie feine jiibifigen Freunde!

Wir erflären ben Boyfott über bas Sutbentunt!

Deutinland zwinge $\mathfrak{G u b a}$ auf bie Rnie!

Wer vom Şuben frip̉, ftirbt baran:

\section{MG DUP. Sireisleitum Mortheimullsiar.}

Sollinger Nachrichten (Uslar), 30.3.1933

Dieser Aufruf zu dem für den I. April I933 amtlich verordneten Boykott (dazu s. S. I7). wurde als Anzeige in den Sollinger Nachrichten vom 30.3.I933 veröffentlicht. 
Nr. I6* Der Novemberprogrom im Spiegel der Sollinger Nachrichten, IO.II.I938

\section{Gegen Das jübijhe Gejindel.}

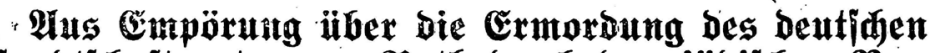
Gejandtidajtsrats vom Rath Durd ben jiibijaen $\mathfrak{B e r}=$

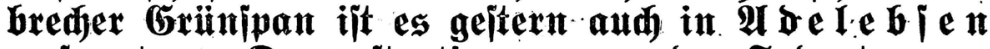
zu ipontanen Demonitrationen gegen Das Jubentum ge: fommen. Die in Mbelebjen wohnenden Juben wurben in Sdjubhaft gettontmen.

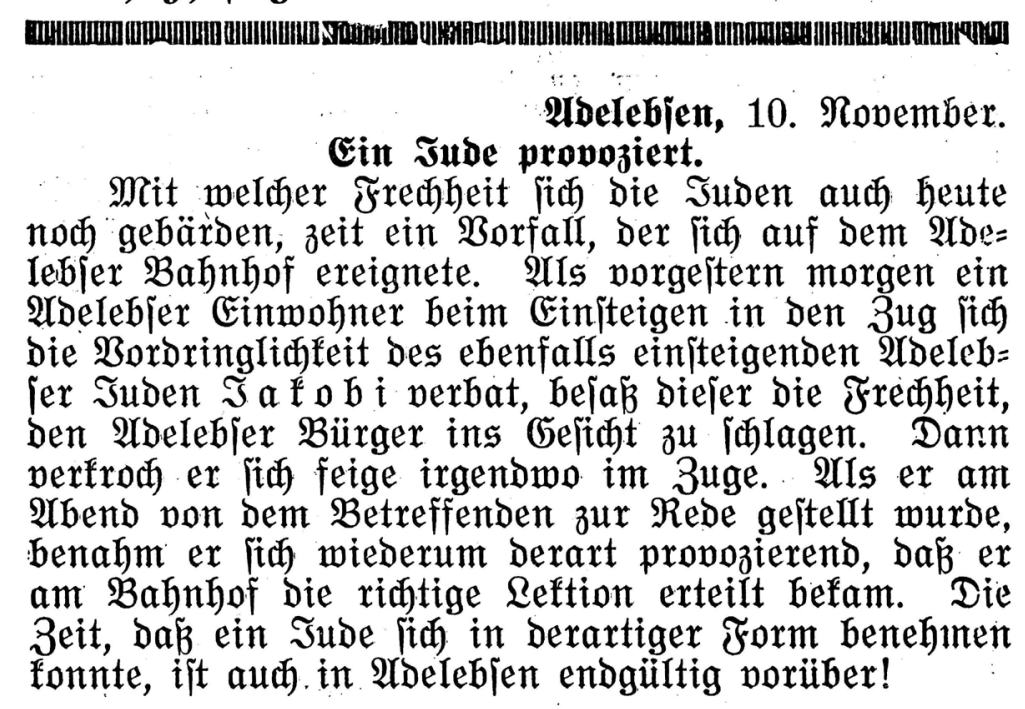

Sollinger Nachrichten (Uslar), 10.11.1938

Über die Ereignisse der vorhergehenden Nacht wird in einer 5 Zeilen Notiz verharmlosend berichtet, danach in einem längeren Artikel ein zurück liegender Fall ,jüdischer Unverschämtheit" propagantistisch ausgebreitet. 
Nr. I7 ${ }^{\star}$ Bilder von der Verhaftung jüdischer Bürger am IO.I I.I938
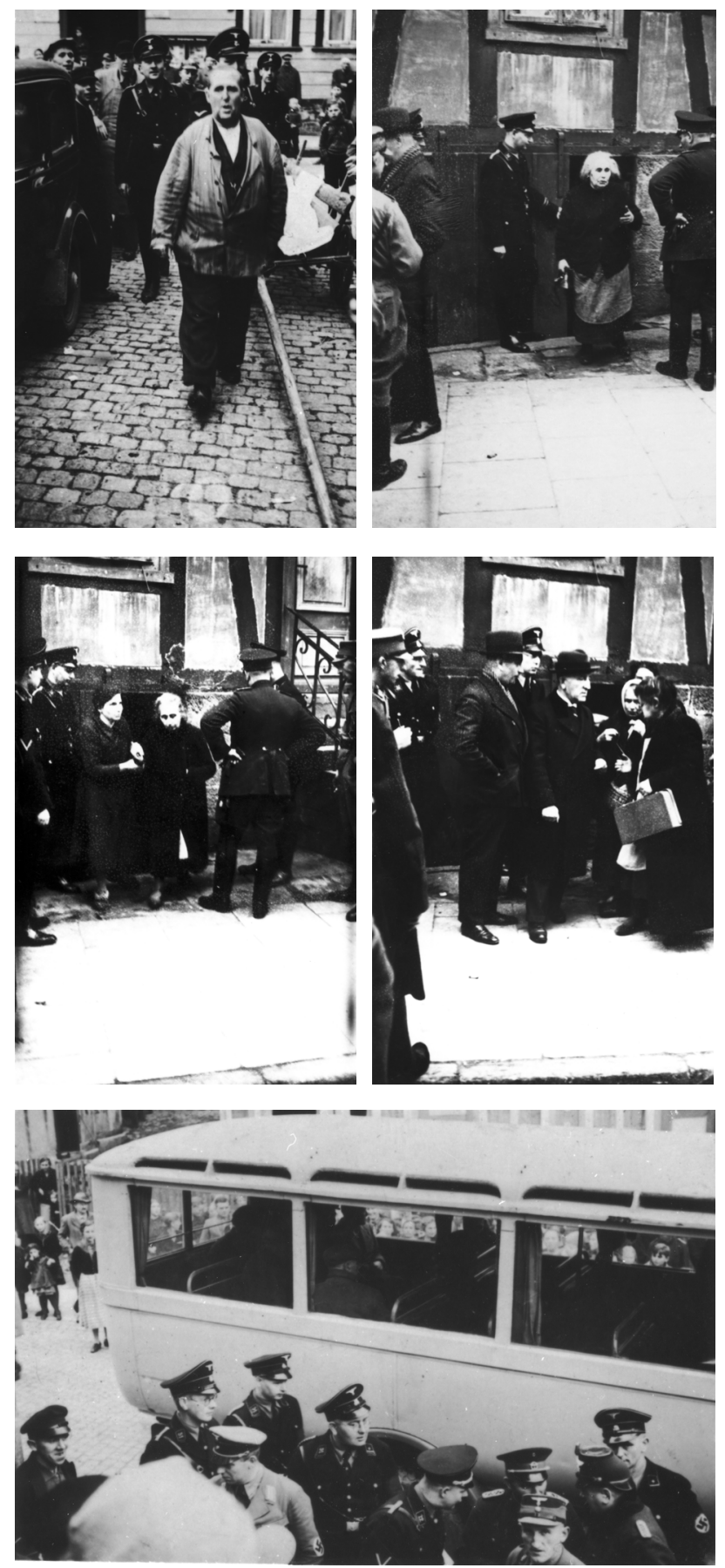

Israel Jakobi wird von seinem Haus (nach Verzeichnung seiner Warenbestände) zurück geführt in den Rathauskeller.

Frieda Jakobi verlässt den Rathauskeller.

Toni Schaumberg hilft ihrer Mutter Paula Dannenberg beim Verlassen des Rathauskellers.

Noa Rothschild steht mit anderen Verhafteten umringt von einigen SS- und SAMännern vor dem Ausgang des Ratshauskellers.

Ein Omnibus steht beim Rathaus bereit zum Abtransport der Männer nach Northeim, davor SS- und SA-Männer sowie der NSDAP-Ortsgruppenleiter (?), auf der anderen Straßenseite Kinder als $\mathrm{Zu}-$ schauer.

Die vorliegenden Bilder sind Teil einer Serie, die ein Adelebser Bürger auf Anordnung eines SS-Offiziers angefertigt hat. I948 wurden sie bei einer Hausdurchsuchung kurz vor der Hauptverhandlung vor dem Landgericht Göttingen gegen die am Pogrom Beteiligten entdeckt. Als Dokumente der Ereignisse des Novemberpogroms in Adelebsen (dazu s. S. I 8 ) sind sie von einzigartigem Wert. Ähnliche personenbezogene Fotos sind selten. (HStAH, Nds. 72 I Göttingen Acc. 93/79 Nr. 57) 
Nr. I8` Gedenktafel zur Erinnerung an die beim Novemberpogrom zerstörte Synagoge

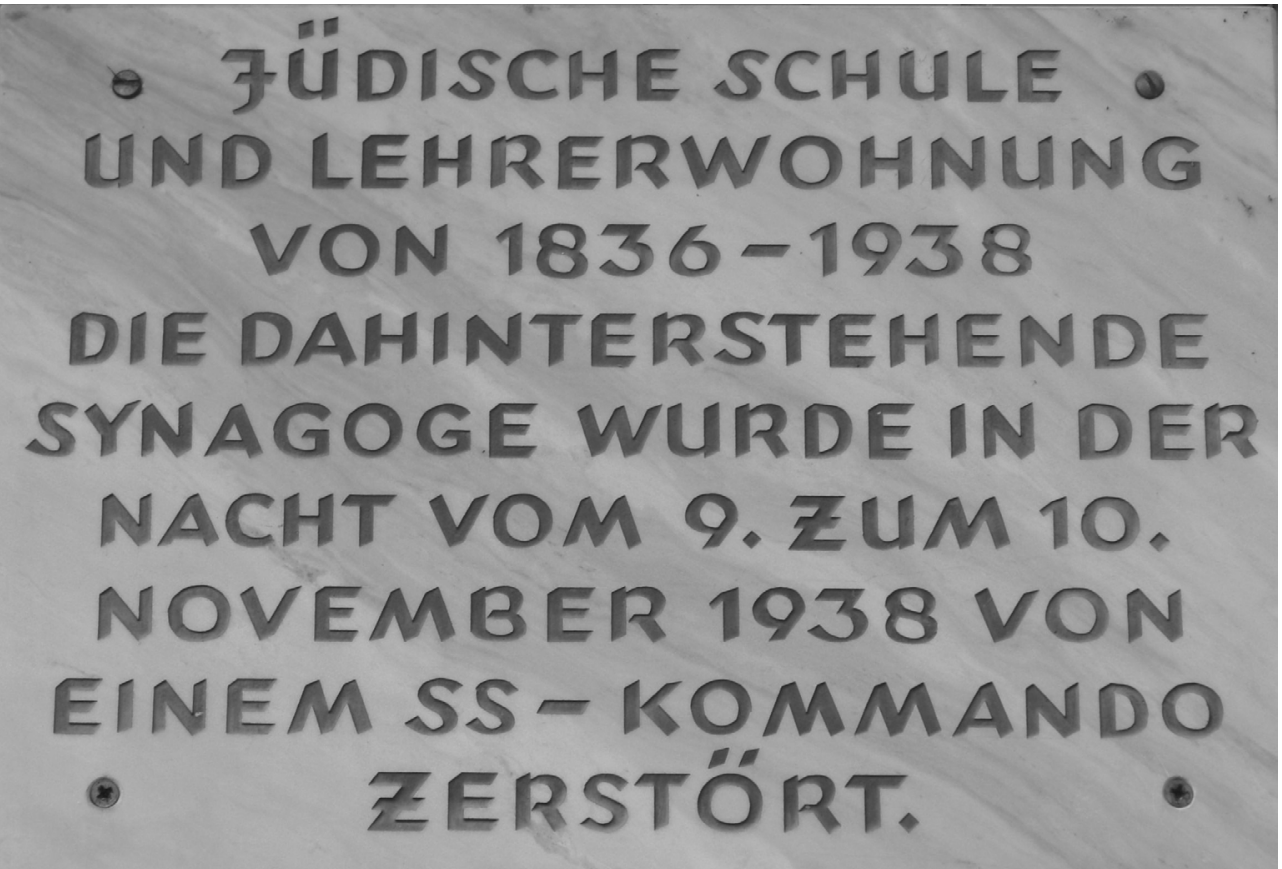

Diese Tafel wurde zum Volkstrauertag I989 am Eingang des ehemaligen jüdischen Schulhauses, Lange Straße I 5 , enthüllt. 


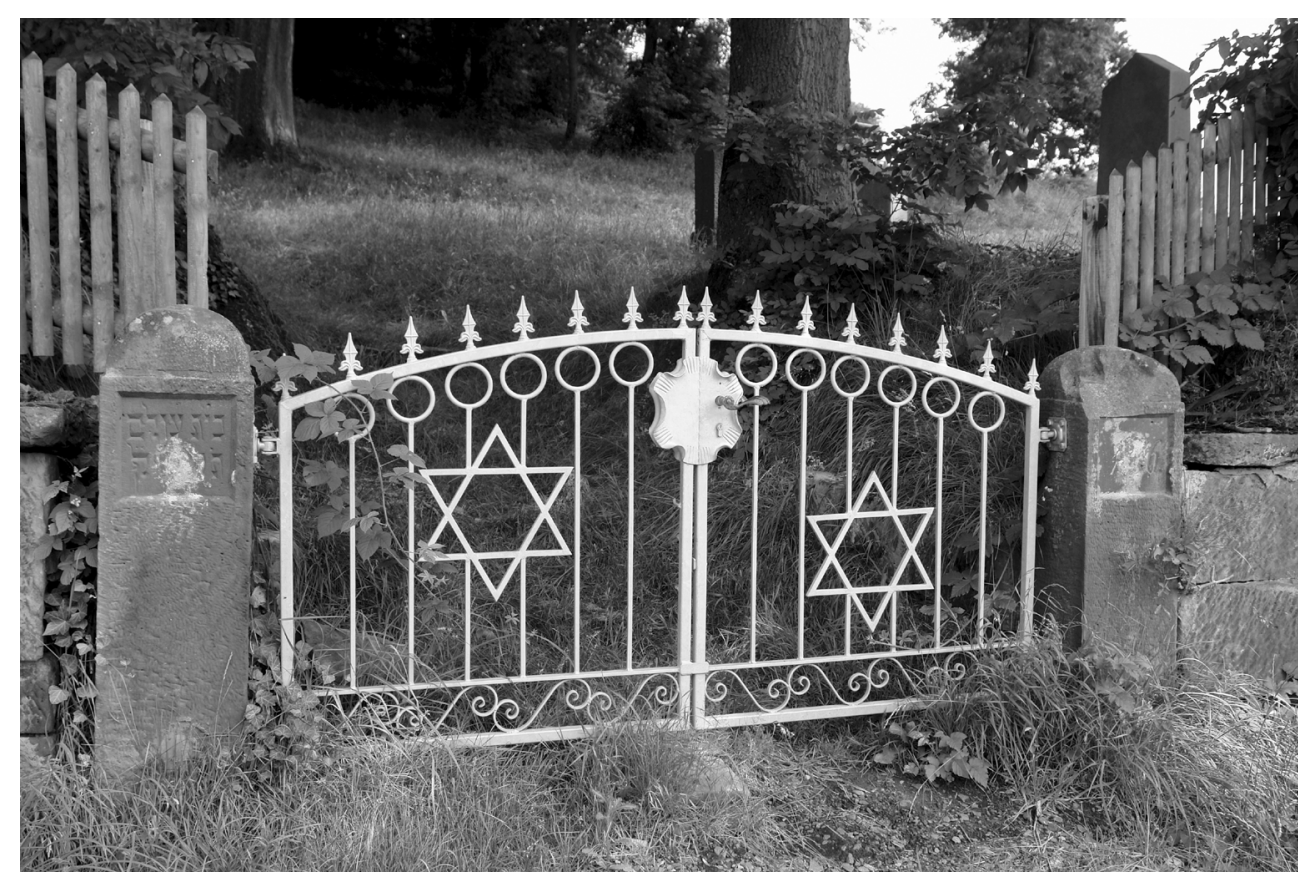




\section{Der jüdische Friedhof zu Adelebsen}

\section{Die Ortslage}

Der Friedhof für die seit Ende des I8. Jahrhunderts in Adelebsen und den umliegenden Dörfern ansässigen jüdischen Familien wurde weit außerhalb des besiedelten Wohngebiets angelegt. Er befindet sich an der nach Westen führenden Offenser Landstrasse in einem rechter Hand steil ansteigenden Hanggelände, das im Katasterverzeichnis als Flurstücke 6I und 62/I ausgewiesen ist und mit einigen Nachbargrundstücken unter der Bezeichnung „Judenberg“" läuft.

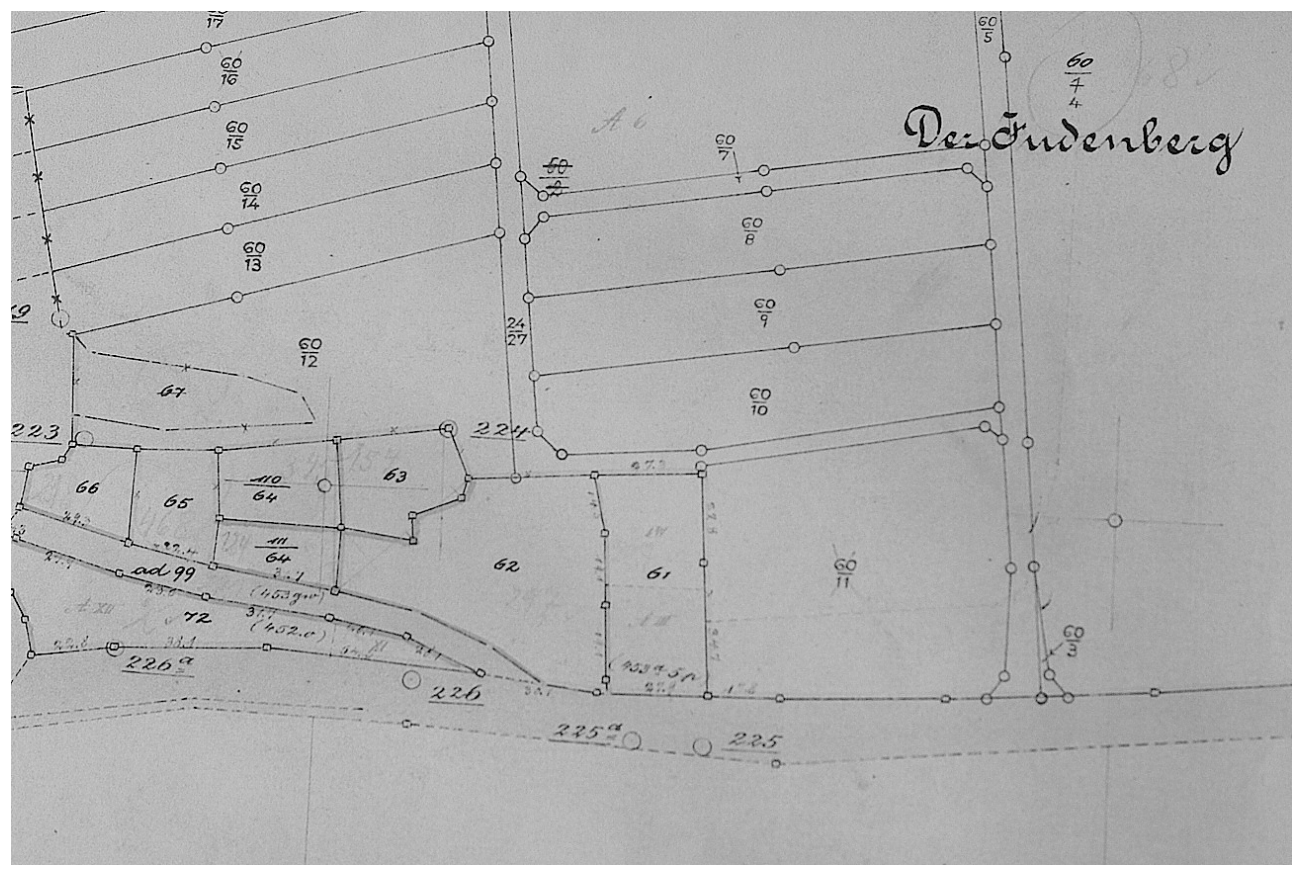

Ausschnitt Gemarkungskarte Kreis Uslar, Gemarkung Adelebsen i Blatt I6, I885/i 896

Die Lage außerhalb des Ortes entspricht religionsgesetzlich vorgeschriebenem jüdischem Brauchtum $^{1}$, die Anlage in einen für Begräbnisse schwer zugänglichen, höchst ungeeigneten Steilhang ist aber schwerlich selbst gewählt. Sie wurde aufgenötigt. In ihr spiegelt sich - wie auch in vielen anderen ähnlich gearteten Ortslagen jüdischer Friedhöfe ${ }^{2}-$ die soziale Ab- und Ausgrenzung wider, der die jüdische Bevölkerung seit dem Mittelalter in der christlichen Mehrheitsgesellschaft ausgesetzt war.

Bereits Mischna Baba Bathra II,9

2 So z.B. in der näheren Umgebung die Friedhöfe
Dankelshausen, Dransfeld, Bovenden, Göttingen, Nörten-Hardenberg, Mohringen. 


\section{Umfang und Geschichte}

Das Gesamtareal umfasst, ungleichmäßig geschnitten, insgesamt 39I $8 \mathrm{~m}^{2}$. Mit Grabstellen belegt ist indes nur der vom heutigen Eingang aus überwiegend links gelegene Teil mit $2483 \mathrm{~m}^{2}(=$ Flurstück 62/I). Dieser besteht aus 5 unterschiedlich großen Parzellen, in denen sich 5 Phasen der historischen Belegung widerspiegeln.

Der Ursprungskern, Parzelle I, liegt im oberen, noch etwas abgeflachten Abschnitt der Hanglage, der vermutlich über ein oberhalb gelegenes Wegstück zugänglich war. Über den Zeitpunkt und die Bedingungen (Kosten und Rechtsform) des Erwerbs ist nichts bekannt. ${ }^{3}$ Die Ursprünge reichen in jedem Fall ins frühe I8. Jahrhundert. Auch der Umfang der Belegung lässt sich nicht mehr genau ermitteln. Wie zahlreiche Lücken erkennen lassen, war er größer als der heute erhaltene Bestand von 25 massiven, in Form liegender Grabplatten ${ }^{4}$ gestalteten Steinen, von denen der älteste auf $1733^{5}$, der jüngste auf I 808 datieren.

Eine erste Erweiterung, Parzelle II, für die es gleichfalls keine urkundlichen Belege gibt, hat das im Hang darunter liegende, zur Landstraße abschüssige Gelände einbezogen. Ein Teil der massiven Mauer, die heute den Friedhof zum Talboden hin abschließt, dürfte damals bereits angelegt und, wie eine in ihr offenkundig nachträglich zugemauerte Maueröffnung anzeigt, mit einem eigenen, von unten her erreichbaren Eingang versehen worden sein. Die zum größeren Teil noch erhaltene Belegung stammt ausweislich der vorhandenen 47, weiterhin als Platten gestalteten Grabsteine aus der Zeit zwischen I809 und I848. Später sind an verschiedenen Stellen noch 3 weitere Gräber dazu gesetzt worden. ${ }^{6}$

Die danach erfolgenden Begräbnisse wurden auf einem westlich davon gelegenen, gleichfalls Hang abwärts gerichteten Grundstück vorgenommen: Parzelle III. Für diese wurde wiederum ein eigener, dies Mal über einen schmalen Seitenweg führender Zugang eingerichtet, dessen Reste noch heute schwach erkennbar sind.

Die Genehmigung zum Erwerb wurde schon I 834 erteilt $^{7}$, der Kauf scheint aber erst nach I 845 erfolgt zu sein. ${ }^{8}$ Dieses Gräberfeld hebt sich von den beiden älteren markant in der Gestaltung der Grabsteine ab. Das bisher übliche Plattengelege wird abgelöst durch aufrecht stehende Stelen. Die ersten Begräbnisse haben hier I849 statt gefunden, die letzten I 888 - von 6 Ausnahmefällen abgesehen. ${ }^{9}$ Mit Ioo Grabstellen sind vom ursprünglichen Bestand bis heute die meisten noch vorhanden.

Ein bereits I $865 \mathrm{im}$ Blick auf die weiter ansteigende Zahl der Gemeindeglieder vorausschauend erworbenes ${ }^{10}$, östlich der Parzelle II gelegenes Grundstück hat ab I 886 den Platz

3 Vermutlich gehörte das Gelände ursprünglich zum Landbesitz der Herren von Adelebsen. Wie weit es in dem leider nur schwer zugänglichen Familienarchiv dazu noch Unterlagen gibt, bedürfte einer genaueren Untersuchung.

4 Dazu s.u. S. 44

5 Ein noch älteres Datum weist die Inschrift des Grabes I 23 auf: I692. Diese Angabe beruht jedoch offenkundig auf einem Schreibfehler, s. den Kommentar dazu.

6 Gräber II 4I [I85I: Kinderdoppelgrab].39 [I 853 ].48 [I885]. - Der Grabstein II/A gehört ursprünglich nicht in das Areal. Er ist eine Dublette zu IV 39 und wurde bei der Restaurierung versehentlich als eigenständiges Grabmal aufgestellt.
7 Schreiben der Landdrostei Hildesheim vom 24.9.I 834 (HStAH, Hann. 74 Uslar Nr. 2066) an die Judenschaft zu Adelebsen gestattet, ein Stück Garten für 30 rth. zur Vergrößerung ihres Begräbnisplatzes $\mathrm{zu}$ erwerben.

8 Noch I7.I2.I845 konnten die damaligen Vorsteher der Gemeinde nur berichten: ,... jetzt steht uns wieder die kostspielige Acquisition eines Todtenackers bevor" (HStAH, Hann. I80 Hildesheim Nr. 3983: Schulakten). Diese Notiz kann sich schwerlich auf einen weiteren zweiten Zukauf beziehen. Die ersten Begräbnisse des Gesamtareals erfolgten erst I 849 .

9 Gräber von Ehepartnern: III 9 [I 893].2 I [I 894].34 [I923].47 [I898].82 [I906]. 84 [I900]. 
für die inzwischen notwendig gewordene 3. Erweiterung geliefert. Im Zusammenhang damit wurde auch die vorhandene untere Stützmauer erweitert und mit einem neuen großen Eingangstor versehen (s. S. 38). Diese bis I929 belegte Parzelle IV weist 50 Grabstellen auf, die wie in Parzelle III durchgängig mit stehenden Grabsteinen bestückt sind.

Einen Anhang dazu bildet - durch einen vom Haupteingang her hinauf führenden Weg getrennt - die Parzelle V. Auf diesem letzten, mit Gräbern belegten Geländestreifen des Friedhofs, an den sich die heute wiesenbedeckte Fläche des Flurstücks 6I (= I435 $\left.\mathrm{m}^{2}\right)$ anschließt, sind drei zwischen I935 und I938 verstorbene Gemeindeglieder bestattet sowie der einzige Adelebser jüdische Bürger, der die Deportation in das KZ Theresienstadt überlebt hat, nach der Befreiung I945 zurückkehrte und I948 verstarb.

Seither ist der Friedhof geschlossen. Über lange Zeit wurde er wenig beachtet. Er geriet zwar nicht völlig in Vergessenheit. Klassen der örtlichen Schulen haben ihn immer wieder besucht und bei der Suche nach ,jüdischen Spuren in unserer Region“11 im Unterricht behandelt. Gelegentlich wurde auch versucht, sich seiner Pflege anzunehmen. Aber auf ganze gesehen blieben das Ausnahmen. Die Anlage verwilderte allmählich und drohte zu verfallen. Zu den während der NS-Zeit an verschiedenen Stellen begangenen Verwüstungen der Grabstellen und Zerstörungen der Grabsteine ${ }^{12}$, denen bereits in der Weimarer Zeit im April 1929 die Schändung zweier Grabstätten vorausging ${ }^{13}$, kam es nach 1945 witterungsbedingt vermehrt zu Schäden, namentlich an den aus weichem Sandstein errichteten Grabmälern; daneben haben aber auch Unwetter dazu geführt, dass durch umstürzende Bäume ganze Grabreihen erfasst und zahlreiche Grabsteine umgeworfen und zerbrochen wurden.

Dass davon gegenwärtig nur noch Spuren erkennbar vorhanden sind, der Friedhof sich wieder in einem ansehnlichen Zustand darbietet, ist einer vom Landesverband der jüdischen Gemeinden in Niedersachsen als Rechtsnachfolger der örtlichen Gemeinde ${ }^{14} \mathrm{zu}-$ sammen mit dem Rat des Flecken Adelebsen angeregten und namentlich durch die Deutsche Stiftung Denkmalschutz finanziell geförderten Sanierung des gesamten Areals zu verdanken. Die von der dafür ausgewiesenen Firma Schmalstieg, Burgdorf, zwischen 2000

10 Dem bereits erfolgten Erwerb stimmt der Gemeindeversammlung am 3I.I2.I865 zu [HStAH, Hann. 74 Uslar Nr. 2043]. Das Grundstück ist als Gartengelände in der Inventarliste der Gemeinde seit I 867 entsprechend ausgewiesen (s. HStAH, Hann. 74 Uslar Nr. 206I).

11 Mit einer dabei entstandenen, unter dieser Überschrift eingereichten Projektarbeit nahm die Klasse R 9 der Haupt- und Realschule begleitet durch ihre Lehrerin Frau L.A. Busse I996 an dem von der Bundeszentrale für politische Bildung unter der Schirmherrschaft des Bundespräsidenten veranstalteten Schülerwettbewerb für politische Bildung teil und wurde dafür mit einem der Hauptpreise ausgezeichnet; s. den Bericht im Göttinger Tagblatt 6.3.I997.

12 Zerstörungen haben namentlich im Zusammenhang mit dem November-Pogrom I938 statt gefunden (s.o. S. I 8 A. 25), daneben erfolgten vorher bereits Beschädigungen bei einer I937/38 durchgeführten Beseitigung von Bäumen (Bericht von Fritz Möhle, Adelebsen, 4.IO.2007) sowie später vermutlich auch bei der Entfernung von Grabeinfriedigun- gen im Rahmen der „Metallspende des deutschen Volkes" I940.

13 S. o. S. 33 Dokument $\mathrm{I}^{\star}$. - Der Vorgang ist ausschließlich in den lokalen Sollinger Nachrichten vom 4.5.I929 vermeldet worden und auch dort nur in Form einer kurzen Notiz. Alle weiteren regionalen Blätter und ebenso die überregionale Presse haben ihn übergangen. Entsprechend ist er auch in der vom Centralverein Deutscher Staatsbürger Jüdischen Glaubens zusammengestellten Liste der „Friedhofsschändungen in Deutschland I923-I932" (5. Auflage I932) nicht erfasst.

14 Als Rechtsträger für die Besitztümer der vernichteten jüdischen Gemeinden war nach I945 auf Grund eines im Mai I949 von der britischen Militärregierung erlassenen Gesetzes (Nr. 59) zunächst die von internationalen jüdischen Hilfsorganisationen gegründete ,Jewish Trust Corporation for Germany“ eingesetzt worden. I959/60 wurde der Besitztitel dem Landesverband der jüdischen Gemeinden in Niedersachsen übertragen. 

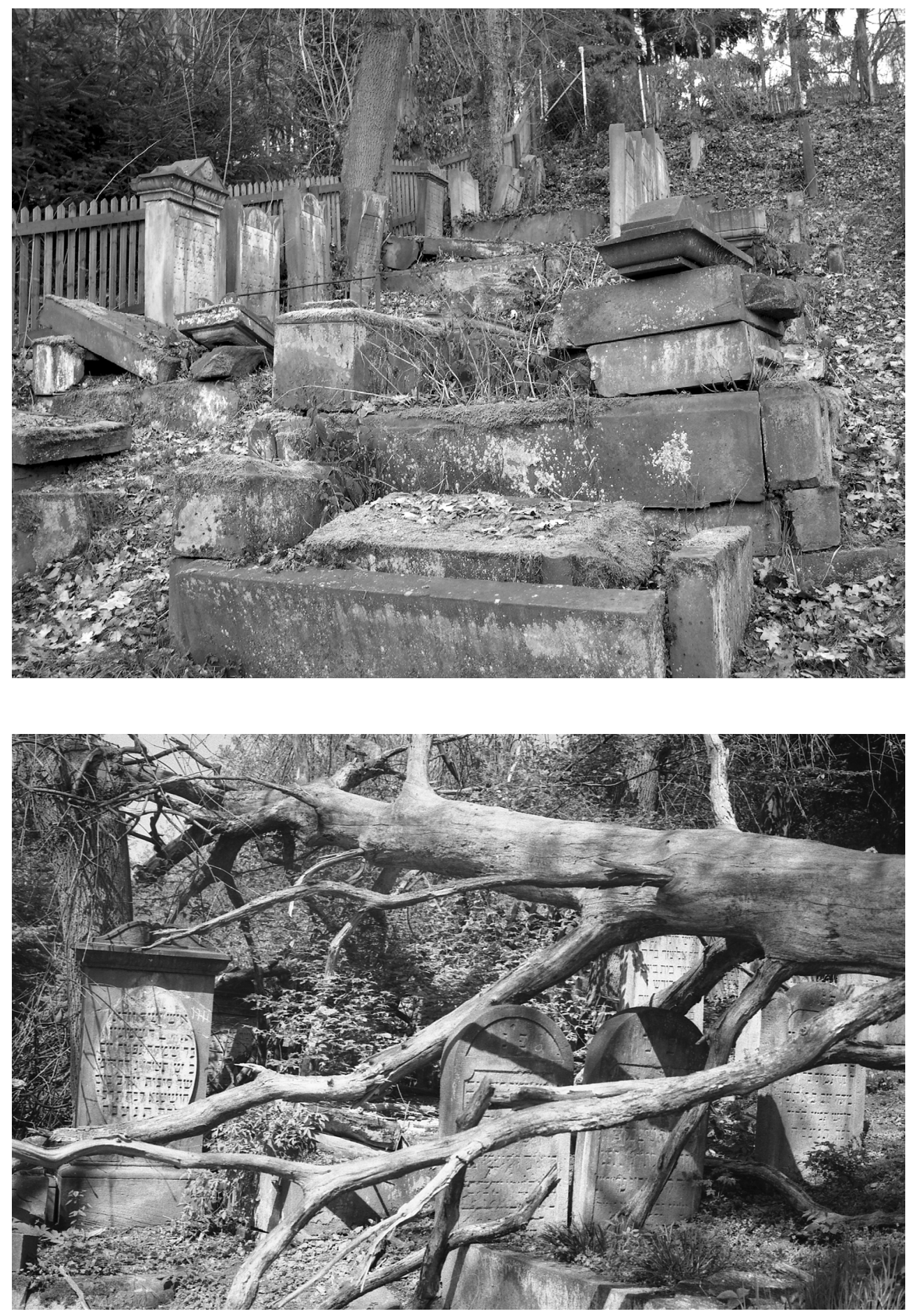

und 2004 durchgeführten Arbeiten haben behutsam sich darum bemüht, den alten Bestand möglichst genau wiederherzustellen, waren zugleich aber auch darauf bedacht, 
bestehende Schäden und Lücken weiter erkennbar zu belassen. Sie haben auf diese Weise dafür gesorgt, dass diesem ,guten Ort“ erneut die Aufmerksamkeit zuteil wird, die seiner Bedeutung als herausragendem Geschichts- und Kulturdenkmal zukommt. Ob zukünftige Generationen dies zu würdigen wissen, bleibt abzuwarten. Dass der Flecken Adelebsen sich in einer Vereinbarung mit dem Landesverband der jüdischen Gemeinden verpflichtet hat, für die nötige äußere Pflege Sorge zu tragen, ist ein verheißungsvolles Zeichen.

\section{Grabstellen und Grabsteine}

\section{I Ausrichtung und Anordnung}

Die auf dem Adelebser Friedhof erhaltenen 236 Grabstellen mit insgesamt $229^{15}$ Grabsteinen sind ungeachtet des Wechsels der Steine als Platten oder Stelen durchgehend einheitlich ausgerichtet. Sie liegen mit ganz leichten Verschiebungen allesamt in einer West-Ost-Achse. Das entspricht zwar nicht der althergebrachten Vorschrift, die Friedhöfe entsprechend der Gebetsrichtung ${ }^{16}$ mit Blick auf die - von Deutschland aus gesehen im Südosten gelegene - heilige Stadt Jerusalem anzulegen, war aber bereits im Mittelalter Brauch und ist in der Neuzeit weithin üblich geworden. ${ }^{17}$

In der Anordnung folgen die Gräber hingegen keiner einheitlichen Richtschnur. Die vielfach sonst übliche chronologischen Bestattungsordnung spiegelt sich in der Belegung nur begrenzt wider. Namentlich in den beiden ältesten Friedhofsparzellen (I und II) finden sich Gräber aus derselben Zeit an ganz verschiedenen, z. T. weit voneinander entfernten Stellen. Möglicherweise haben hier familiäre Beziehungen oder andere Gruppenzusammenhänge eine Rolle gespielt. Aber das bleibt unklar. Erst auf den späteren Parzellen (III-V) sind die Bestattungen überwiegend - auf den Parzellen IV in den meisten Fällen - der zeitlichen Abfolge entsprechend vorgenommen worden. Aber auch hier kommen immer wieder Ausnahmen vor und zwar - erstmals I 849 belegt - in der Anlage von Doppelgräbern für Ehepaare ${ }^{18}$ sowie ferner für Geschwisterpaare. ${ }^{19}$ In welchem Umfang der sonst verbreitete Brauch, Kinder eigens bei einander zu bestatten, befolgt worden ist, muss offen bleiben, da für die meisten in den Sterbelisten verzeichneten Kinder sich mangels Grabsteinen keine Grabstellen nachweisen lassen. ${ }^{20}$ Ansätze

15 Nicht gerechnet die Grabsteine II A und B, die beide erst bei der Restaurierung aufgestellt wurden, B ohne erkennbare Inschrift, A Dublette zu IV 39 (s. oben Anm. 6). - Die unterschiedliche Zahl der Grabstellen und Grabsteine beruht darauf, dass für 5 Kinderpaare (II 40a/b. 37a/b. 59a/b; IV 3a/b.4a/b) und 2 Erwachsenenpaare (III 6; IV 7) je ein gemeinsamer Grabstein errichtet wurde.

16 S. Schulchan Aruch, Orech chajjim $\ 94$.

17 Gleiches gilt für die Ausrichtung der Synagogen. Auch sie sind bereits im Mittelalter z.T. geostet worden. Vorbild war in beiden Fällen vermutlich das christliche Brauchtum der Ostung von Kirchen und Grabanlagen.Wie der fast zeitgleich eröffnete Altteil des Göttinger jüdischen Friedhofs zeigt, ist dies aber nicht durchgehend geschehen. Die auf ihm befindlichen Gräber sind noch alle nach Südosten hin angelegt.

18 Grabsteine: III 3[I849] - 3a[I864]. 67[I857] 69[I858]. 77[I858] - 76[I862]. 75[I858] -74[I868]. $79[\mathrm{I} 859]-78$ [I 873]. 90[I 860] - 89[I873]. 88[I860]
-87[I879]. 83[I865]-84[I900]. 97[I 866] - 96[I877]. $99[\mathrm{I} 868]-98[\mathrm{I} 882$ ]. I6[I876] - I7[I 888]. 48[I877] $47[\mathrm{I} 898$ ]. $8[\mathrm{I} 882]-7[\mathrm{I} 888]$. I9[I 882$]-20$ [I 885 ]. IO[I884] - 9[I893]. IV I6 [I886] - I5[I897]. I4[I889] - I3[I905]. 9[I892] - 8[I903]. 6[I893] - 5 [i 896].

19 Grabsteine II 4I; III 37 59; IV 34.

20 Auf dem ganzen Friedhof finden sich heute Gräber von insgesamt 36 Kindern (im Alter bis I 5 Jahren): 2 in der Parzelle I (I 2 I), 7 in der Parzelle II (8 I 32 I 3040 4Ia/b); 2 I in der Parzelle III (I4 202526 2829303 I 32 37a/b 59a/b 607285869 I 929495 ) und 6 in der Parzelle IV (I $23 \mathrm{a} / \mathrm{b} 4 \mathrm{a} / \mathrm{b}$ ). Das ist nur ein Bruchteil der bestatteten Kinder. In der Sterbeliste der Synagogengemeinde Adelebsen sind allein für den Zeitraum zwischen I 832 und I 874 insgesamt 65 Kinder unter ro Jahren verzeichnet. Von ihnen lassen sich auf dem Friedhof heute nur noch I 7 nachweisen. I Kind ist als auswärtig bestattet vermerkt; von den restlichen 47 fehlt jede Spur. 
dazu finden sich an 2 Stellen $^{21}$; in beiden Fällen handelt es sich allerdings um Gräber, die auch zeitlich nahe beieinander liegen und sich vom sonstigen Gräberbestand nicht merklich abheben.

\subsection{Material und Erhaltungszustand}

Die Grabsteine sind überwiegend - die des i 8. und frühen I9. Jahrhunderts alle - aus Buntsandstein hergestellt. In erster Linie handelt es sich um Bestände lokaler Herkunft, die meist wohl von ortsansässigen christlichen Steinmetzen bearbeitet wurden. ${ }^{22}$ Andere Steinarten wie weißer Sandstein, Gabbro oder Kunststein haben erst nach I900 in ganz wenigen Fällen Verwendung gefunden. ${ }^{23}$

Der heutige Zustand schwankt erheblich. Ein Teil der Steine - darunter auch viele ältere - ist noch recht gut erhalten. Daneben gibt es eine ganze Reihe mit beträchtlichen Beschädigungen, verursacht teils durch wetterbedingte Auswaschungen, teils durch flechtenbedingte Verkrustungen, mehrfach auch durch mechanische, gewaltsame Zerstörungen.

Die Lesbarkeit der Inschriften fällt entsprechend unterschiedlich aus. Überwiegend lässt sich der Textbestand ohne größere Schwierigkeiten vollständig entziffern. In manchen Fällen machen einzelne Textabschnitte zu schaffen, bisweilen sind aber nur noch geringe oder gar keine Reste an Buchstaben vorhanden, so dass die Inschrift sich nur partiell oder gar nicht mehr rekonstruieren lässt.

\subsection{Formgebung und Gestaltung}

In der Formgebung und Gestaltung der Grabsteine zeichnen sich zwei grundlegend unterschiedene Phasen der Entwicklung ab. Bis in die Mitte des I9. Jahrhunderts bietet der Friedhof in den Parzellen I und II ein in sich geschlossenes Bild. Die Gräber sind - bis auf eine Ausnahme ${ }^{24}$ - allesamt mit rechteckig geformten Steinplatten bedeckt. In den Maßen - Länge, Breite Tiefe - stimmen sie zwar selten genau überein, in ihrer Gesamtheit vermitteln sie aber weithin einen einheitlichen Eindruck. Die Oberfläche ist durch die quadratische Textstruktur der hebräischen Inschriften bestimmt. Mehrfach werden diese durch einfache Randleisten eingefasst, bisweilen durch ornamentale Gestaltung der Buchstaben erweitert. Vereinzelt finden sich Ansätze zu weiterer barocker Ausschmückung, teils in abstrakt, teils in konkret bildhafter Gestalt, was sich indes erst bei näherer Betrachtung abzeichnet. ${ }^{25}$ Das Ensemble wirkt wie in Stein gehauene Zeichen der Zusammengehörigkeit und Gemeinschaft.

Dies ist auf den danach eingerichteten Parzellen III-V zunehmend so nicht mehr durchgehend der Fall. Das Bild, in dem der Friedhof sich hier darbietet, weist schon

21 In Parzelle III bei den Gräbern I4[I 852 ]. 20[I 852 ]. $25[\mathrm{I} 852$ ]. 26[I 854 ]. 28[I 852 ]. 29[I 852 ]. 30[I 852$]$. 3 I [I852]. 32[I859] und in Parzelle IV bei den Gräbern I[I906]. 2[I892]. 3a/b[I89I]. 4a/b[I89I]. In beiden Fällen handelt es sich allerdings um Gräber, die auch zeitlich nahe beieinander liegen und sich vom sonstigen Gräberbestand nicht merklich abheben.

22 Nach Bericht von Fritz Möhle hat der in Adelebsen ansässige Steinmetz Philipp Franke (gest. I 897) einen Teil der Grabsteine auf der Parzellen III ange- fertigt. Genauer lässt sich das aber nicht mehr ermitteln, da sich auf jüdischen Grabsteinen keine Namen oder Steinmetz zeichen befinden.

23 Weißer Sandstein: IV 37[I904].38[I904]; Gabbro: IV 2I[I903].I9.[I904].I8[I9I4].20[I924]; V 4[I948]; Kunststein: V 2[1936]; Beton: Grab V 3[I938]. - Für fachkundige Auskünfte ist Prof. Dr. Karl Hans Wedepohl, Göttingen, zu danken.

24 Grab II 25 ist mit einem rundbogigen Abschluss versehen.

25 S.u. S. $46 f$. 
bedingt durch den Wechsel von liegenden Platten zu stehenden Stelen ein völlig anderes Gepräge auf. Mit diesem Wechsel, der sich auch auf anderen jüdischen Friedhöfen der näheren Umgebung findet ${ }^{26}$, ist eine grundlegende Veränderung der Grabsteingestaltung verbunden. Zunächst - im älteren Bereich - bestimmen die beiden für aschkenazische Friedhöfe weithin typischen Grundformen das Bild: I. Steine, die in einem klassischen
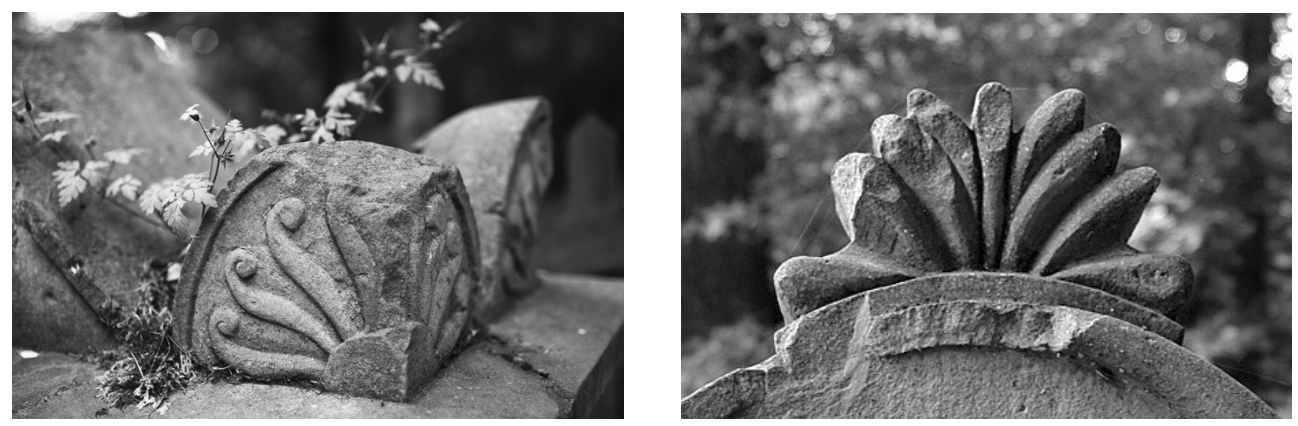

Rundbogen auslaufen, und 2. Steine, die oben mit zwei Seitenhörnern und einen dazwischen eingezogenen runden oder ovalen Bogen versehen sind. In den neueren Bereichen werden diese abgelöst, teils durch leicht sie variierende Formgebungen - neben Steinen mit abgeflachten Rundbogen finden sich solche mit spitzgiebligen Abschlüssen in der Mitte und Seitenhörner am Rand -, teils in steigender Zahl durch einen ganz neuen Grabmaltyp, der ähnlich wie auf christlichen Friedhöfen der Zeit aus drei Steinblöcken (Sockel-, Haupt- und Aufsatzstein) zusammen gesetzt ist. Mit diesem neuen Typ verbindet sich eine zunehmende Vielfalt der Grabsteingestaltung, sowohl, was die unterschiedlich ausgefallenen Größenmaße angeht, wie vor allem auch, was die künstlerische Gestaltung betrifft. Verziert sind insbesondere die Giebelfelder ${ }^{27}$, z.T. aber auch die Schrifttafeln selbst. Zur Anwendung kommen hauptsächlich in der Gründerzeit modische, spätklassizistische Stilelementen wie Akrotieren ${ }^{28}$, Palmetten ${ }^{29}$ und Halbsäulen. ${ }^{30}$

Der Gedanke der Zusammengehörigkeit als Glieder der jüdischen Gemeinschaft, als Volk Israel, am Jisrael, der in den beiden älteren Parzellen das Bild des Friedhofs prägte, ist offenkundig nicht allein mehr bestimmend. Statt dessen nutzt man den Friedhof, um den gesellschaftlichen, sozialen Status der Verstorbenen bzw. ihrer Familien über den Tod hinaus zu dokumentieren, und geht dazu über, durch gleiche oder ähnliche Gestaltung der Grabmäler familiäre Bindungen zum Ausdruck zu bringen. Im Vergleich mit den Befunden auf anderen zeitgenössischen Friedhöfen fallen die Unterschiede allerdings nicht besonders krass aus. Nach wie vor herrscht in der Form der Grabmalgestaltung eine gewisse Einheitlichkeit, dennoch ist nicht zu übersehen, dass der mit der rechtlichen Emanzipation einhergehende Trend zur Assimilation und Akkulturation an die christliche Umwelt auch in der eher konservativ ausgerichteten, ländlich-jüdischen Gemeinde wie der zu Adelebsen Fuß gefasst hat.

26 So die Friedhöfe in Bovenden, Dankelshausen, Dransfeld, Göttingen, Hedemünden, Hebenshausen, Imbshausen, Mackensen, Nörten. - Gleiches trifft auch für das südlich Wolffenbüttel gelegene Hornburg zu, s. Historischens Handbuch 2, 2005, 886. Der Gebrauch von liegenden und stehenden Grabsteinen gilt gemeinhin als Hinweis auf unterschiedliche sefardische bzw. aschkenazische Traditionszusammenhänge der jeweiligen Gemeinden bzw. Fa- milien. Im vorliegenden Fall kann das nicht zutreffen. Es gibt $\mathrm{m}$.W. keinerlei Belege, dass sich im südniedersächsischen Raum jüdische Familien mit einem sefardischen Hintergrund angesiedelt haben.

27 Grabsteine IV IO I I I6 $2328 \quad 3738$.

28 Grabsteine III 3697.

29 Grabsteine III 6; IV 27.

30 Grabsteine III I6 I7. 


\subsection{Symbole und Ornamente}

Ähnliches zeichnet sich in den auf den Grabsteinen angebrachten Symbolen und Ornamenten ab. Mit der auf jüdischen Friedhöfen sonst zu beobachtenden Fülle und Vielfalt an Schmuckmotiven kann der Adelebser Friedhof nicht aufwarten. Nur vereinzelt finden sich Grabsteine, die Elemente kunstfertiger Gestaltung aufweisen. Die meisten davon befinden sich auf Gräbern des späten I9. und frühen 20. Jahrhunderts in den Parzellen III und IV. ${ }^{31}$ Herausragende Beispiele liefern aber auch einige der ältesten Steine in Parzelle I. ${ }^{32}$

Von den genuin jüdischen Symbolzeichen hat nur ein einziges Verwendung gefunden und das auch nur in 4 Fällen: die Darstellung eines gespreizten Händepaars, die jeweils über der Inschrift angebracht ist. ${ }^{33}$

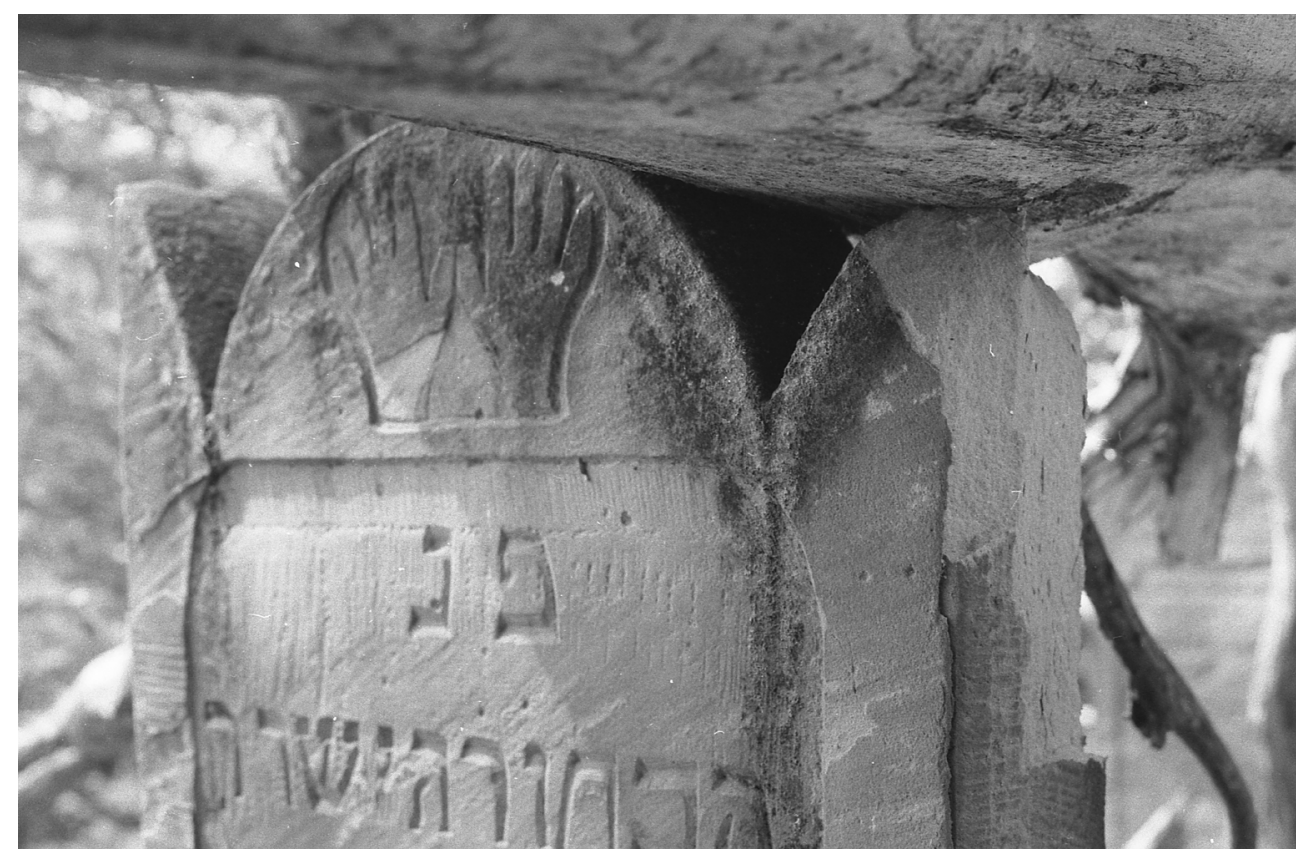

Dahinter verbirgt sich das Standessymbol priesterlicher Familien, das auf den am Jerusalemer Tempel von den Priestern als Söhnen Arons mit erhobenen Händen erteilten Segen, die Birkat ha-kohanim, Bezug nimmt und den Verstorbenen in seiner religiös besonderen Würde als einen ihrer Nachkommen, als kohen, herausstellt. Alle anderen spezifisch jüdischen Bildelemente fehlen: so die mit einem Henkel versehene und meist auf einer flach gewölbten Schale stehende Kanne als Hinweis auf die familiäre Zugehörigkeit zu der neben den Priestern einst am Tempelkult beteiligten Gruppe der Leviten, ebenso das Messer als Amts-/Berufszeichen des Beschneiders (mohel), ferner das an den Hohen Feiertagen geblasenen Widderhorn sowie auch die (oft von einem Löwenpaar flankierten) Krone des Lebens. Besonders auffällig ist das Fehlen der Levitenkanne, lassen sich doch für Adelebsen eine Reihe von Familien mit levitischem Hintergrund nachweisen, deren Angehörige auf dem Friedhof bestattet sind. ${ }^{34}$ Vergeblich sucht man auch

31 Grabsteine III 6 I6 I7 3 I 37 7I 838486 ; IV 27 Iо

II IS I6 232425283738 .

32 Grabsteine I 569 .

33 Grabsteine III 539 54; IV 39 - Das Symbol fehlt auf dem Grabstein III 89 für Julius Katzenstein.
34 Gräbersteine I 4 I 3 I 8 25; II 67242829303839 4I 46 49; III I4 $22232536424445464750 \quad 5668$ 7I 747684878895 ; IV 284849 . 
den siebenarmigen Leuchter, der ursprünglich zum Inventar des Jerusalemer Heiligtums gehört hat und schon in antiken Grabanlagen Verwendung fand, sowie vor allem den Magen David, der Davidsstern, der Ende des I9. Jahrhunderts - wohl unter dem Einfluss der zionistischen Bewegung - zu dem Zeichen jüdischer Konfession und Nation schlechthin geworden ist und entsprechend heutzutage das Wappen des 1948 neu gegründeten Staates Israel schmückt. ${ }^{35}$
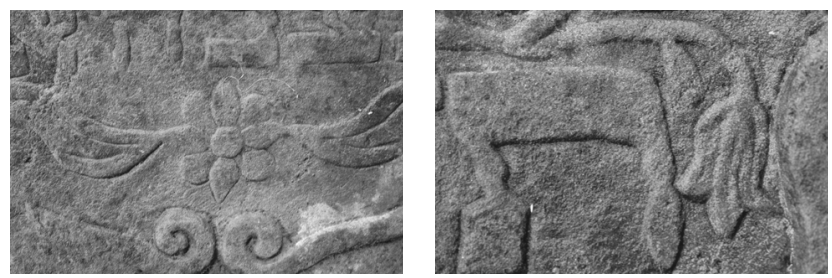

Häufiger kommen Symbole und Ornamente, allgemeiner, nicht spezifisch jüdische Art vor, doch auch sie sind auf ganze betrachtet Ausnahmen. In den meisten Fällen handelt es sich um reine Schmuckelemente, die teils in dekorativ-abstrakter, teils in floraler Form dargeboten werden: in Gestalt von Rosetten ${ }^{36}$; Blütenkelchen $^{37}$ bzw. Blütenglocken ${ }^{38}$, Eichenblätter ${ }^{39}$, u.a. mit Eicheln als Kranz zusammengebunden ${ }^{40}$ oder einem schlichten Kranzgebilde. ${ }^{41}$
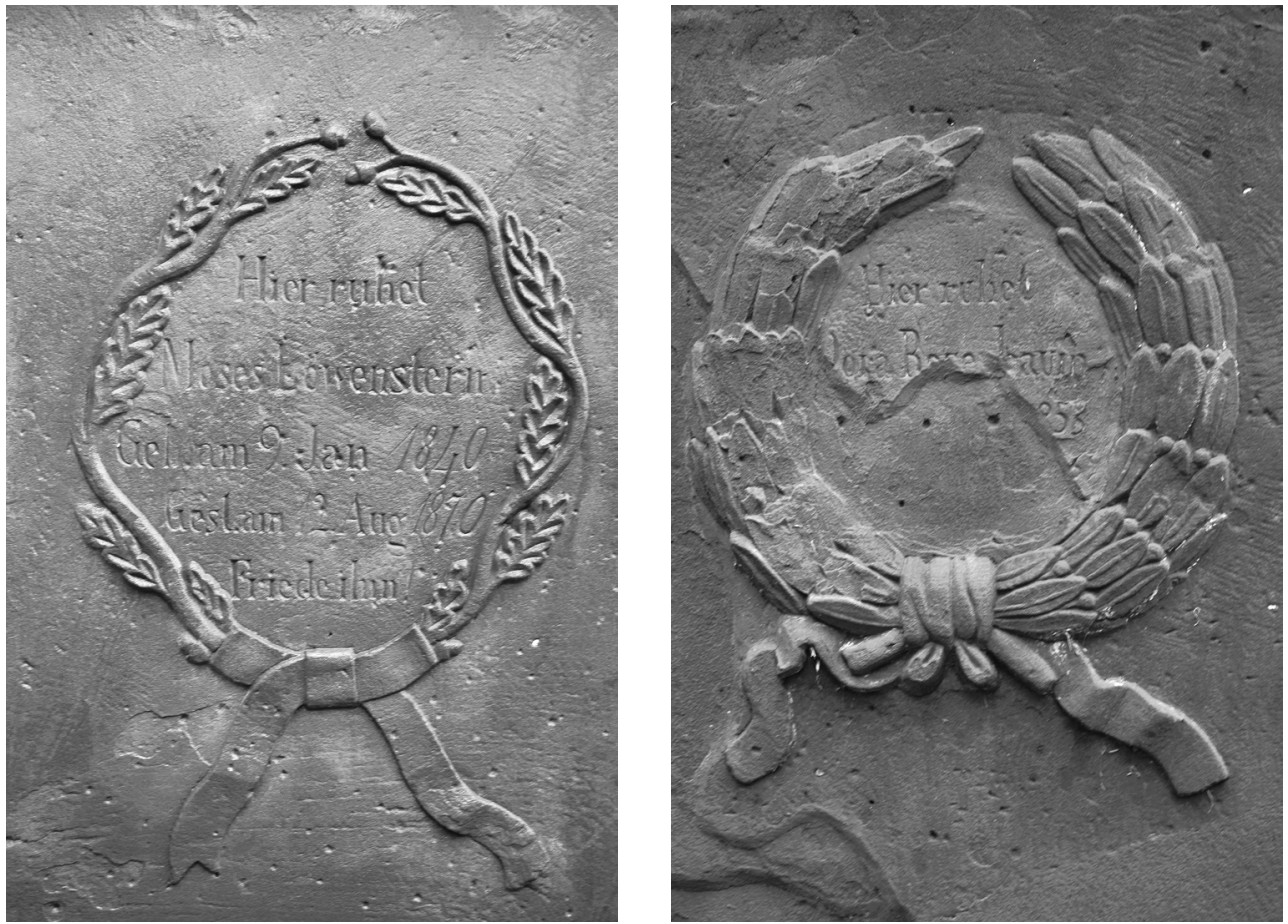

Symbolhaft ausgerichtete Bilder begegnen noch seltener: An einer Stelle kündet eine knospende Blume ${ }^{42}$ vom Tod eines Mädchens in der Blüte ihres Lebens. Auf zwei

35 Nach Bericht von Avri Gershon, Kibbutz Mazzubah, war ein Magen David über dem Haupteingang der Synagoge angebracht (s.o. S. 28).

36 Grabsteine I 6 (Medallionabschluß) II 49 (oberen Ecken), III 86 (Aufsatz).

37 Grabsteine I 5 I 2.
38 Grabstein I 6 (mehrfach im abschließenden Teil der Inschrift).

39 Grabsteine IV 40 4I.

40 Grabstein III 7I (Rückseite).

41 Grabstein III 86 (Rückseite).

42 Grabstein III 3 I (Rückseite). 
Grabsteinen zeigt die auf den Kopf gestellten Fackel ${ }^{43}$ das Erlöschen des Lebens an. Und in

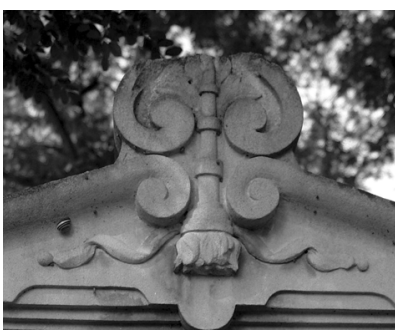
einem weiteren Fall dient ein stilisiert dargestellter Schmetterling dazu, den Gedanken der Unsterblichkeit der Seele $\mathrm{zu}$ versinnbildlichen. ${ }^{44}$ In all diesen Fällen sind die Anleihen bei nichtjüdischen Vorbildern offenkundig. Das trifft namentlich für Darstellung der ausgebrannten Fackel und das Bild des Schmetterlings zu. Beides sind aus der griechisch-römischen Antike stammende Motive, die im I8. wie I9. Jahrhundert neoklassizistischem Geschmack folgend auf Grabmälern christlicher, namentlich protestantischer Friedhöfe oft Verwendung fanden ${ }^{45}$ und dann auch

Eingang in jüdische Friedhöfe erhielten. Schwer deutbar ist ein mehrfach im Giebel des Aufsatzes angebrachtes graphisches Emblem, das in seinen Umrissen die Form eines
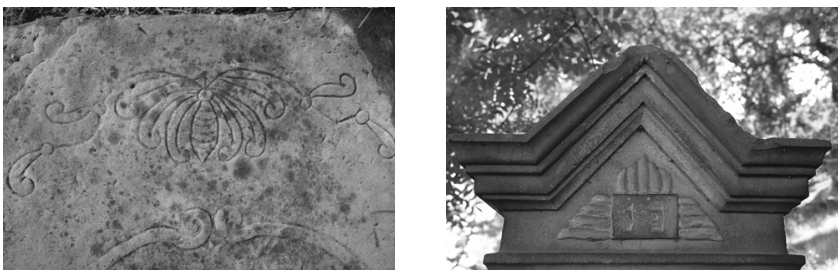

Dreiecks aufweist, dessen Fläche, - im unteren Teil mit quer- und im oberen Teil mit hoch laufenden Rillen versehen - dazu dient, die einleitenden hebräischen Buchstaben der Inschrift (I פ) aufzunehmen. ${ }^{46}$ Es könnte sich um eine Abwandlung des auf Grabsteinen christlicher Friedhöfe lange Zeit gebräuchlichen trinitarischen Dreiecks handeln, das gelegentlich - freilich in anderer Form - auch sonst jüdischerseits übernommen wurde. ${ }^{47}$ Aber das bleibt unsicher.

\section{Die Inschriften}

\section{I. Sprachen}

Stärker als der Schmuck der Symbole und Ornamente bestimmen die Inschriften das äußere Bild der Grabsteine. In erster Linie geschieht dies durch die Textur der klassisch hebräischen Quadratschrift, die meist in den Stein eingehauen ist, bei den liegenden Platten aber vielfach auch erhaben herausgearbeitet wurde. Bis in die Mitte des I9. Jahrhunderts sind alle Texte ausschließlich hebräisch abgefasst. Erst danach gesellen sich zunehmend deutschsprachige Textteile dazu, teils auf der Rückseite des Steins angebracht (erstmals I 852/I 854), ${ }^{48}$ teils unter dem hebräischen Textteil (erstmals I $855^{49}$ ), gelegentlich

43 Grabsteine IV I7 I8.

44 Grabstein I 6.

45 Die neuzeitliche Verwendung beider Symbole ist vermutlich durch Lessings ,Wie die Alten den Tod gebildet“ (I769) angeregt worden; auch literarisch hat man sie vielfach verarbeitet, s. Ludwig Uhlig, Der Todesgenius in der deutschen Literatur von Winckelmann bis Thomas Mann Untersuchungen zur deutschen Literaturgeschichte, Tübingen I979; Hermann Pongs, Das Bild in der Dichtung, I, Marburg I960, I3-I6/ I967, I4ff.. - Im Unterschied zum Schmetterlingsbild begegnet das Symbol der erloschenen
Fackel m.W. auf jüdischen Friedhöfen freilich nur selten und durchweg beschränkt auf die Darstellung der umgekehrten Fackel ohne die originär dazu gehörige Gestalt des Todesengels.

46 Grabsteine IV I5 I6 23.

47 Beispiele aus der näheren Umgebung finden sich Göttingen, Grab Nr. 238, und Dransfeld, Grab Nr. 84 .

48 Grabsteine III 29 (ausschließlich Namen). 50 (Namen mit Geburts- und Sterbedatum n. chr. Z.)

49 Grabstein II 48 (Namen mit Geburts- und Sterbedatum n. chr. Z.) 
auch dazwischen ${ }^{50}$ Aber auch in diesen Fällen bleibt der hebräische Text bestimmend. Die in der 2. Hälfte des I9. Jahrhunderts im Zuge der fortschreitenden Assimilation auf den jüdischen Friedhöfen sonst um sich greifende Neigung, das Hebräischen auf die Rückseite zu verdrängen, ist auf dem Adelebser Friedhof an keiner Stelle zum Zuge gekommen. Es überrascht daher auch nicht, dass ausschließlich deutschsprachige Inschriften höchst selten anzutreffen sind, überwiegend erst im jüngsten Grabfeld der Parzelle V. ${ }^{51}$ Vorher ist das nur auf einem Grabstein der Parzelle III von I $878^{52}$ und auf drei Grabsteinen der Parzelle IV von I $890 /$ I $_{892}{ }^{53}$ geschehen. Die sich hier abzeichnende, konstant gebliebene Dominanz des Hebräischen ist gemessen an den Befunden auf den meisten anderen zeitgenössischen jüdischen Friedhöfen ungewöhnlich. In ihr spiegelt sich offenkundig die Konstanz der religiös traditionsbewusst orientierten Prägung der örtlichen Gemeinde wider.
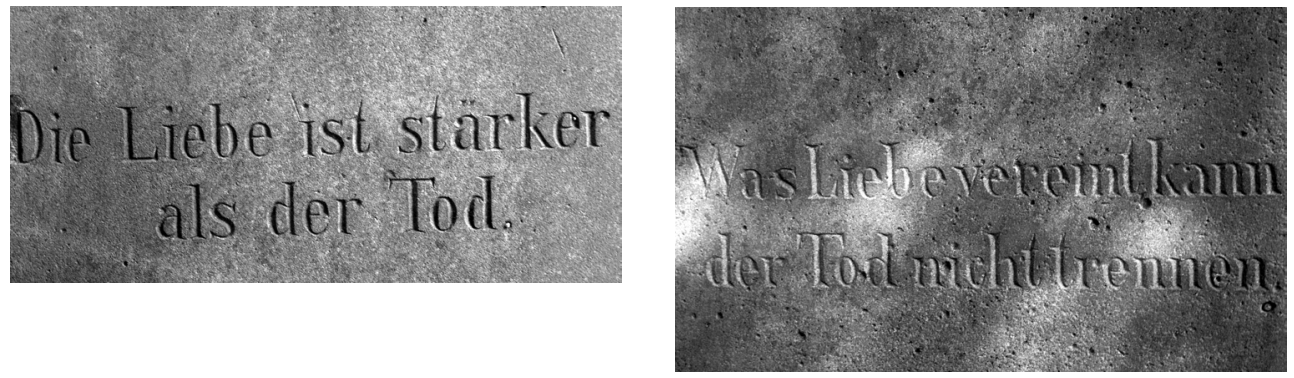

Die deutschen Textteile der Inschriften beschränken sich in den meisten Fällen darauf, die Namen sowie die Geburts- und Sterbedaten zu nennen. Dazu finden sich häufig ein formelhafter Friedenswunsch ${ }^{54}$ sowie vereinzelt, stets auf der Rückseite angebracht, einige Sinnsprüche aus dem Repertoire bürgerlicher Frömmigkeit. ${ }^{55}$

\subsection{Aufbau}

Der formale Aufbau folgt von wenigen Ausnahmen abgesehen einem im mittel- und osteuropäischen Judentum seit langem verbreiteten Grundmuster, das aus fünf Teilen besteht:

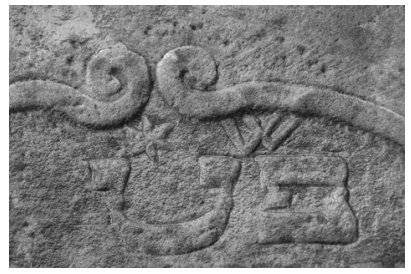

Den Anfang (I) bildet gewöhnlich eine Wendung, die der von christlichen Grabsteinen bekannten Formel »Hic requiescat «/»Hier ruht" entspricht und in verschiedenen Abwandlungen auftritt: פה נקבר/נקברת (poh nikbar/nikberet): "Hier ist begraben", פה נטמן/נטמנת (טמנת (poh nitman/nitmenet): "Hier ist geborgen", פה טמון/טמו/נממנה (poh tamun/temunah) "Hier wurde geborgen". In der vollen Form ist dieser Satz nur selten verwendet ${ }^{56}$, meist begnügt man sich mit den bei den Anfangsbuchstaben: ט $(p n / p t)$.

50 Grabsteine III 485759 9I 95.

51 Grabsteine V I[I935] 3[I938] 4[I948]. Anders noch der Grabstein V 2[1936], der neben dem deutschen auch einen hebräischen Text aufweist, diesen allerdings im Unterschied zu allen anderen doppelsprachig abgefassten Inschriften nicht an erster Stelle bietet.

52 Grabstein III 49.

53 Grabsteine IV IO I I 3 I.
54 Meist in Gestalt von „Friede ihm/ihr“ (Grabsteine [Vorderseite]: II 48; III I I I6 I7 I 8202 I 46587078 87899697 Ioo; [Rückseite]: III 6789 I9 353638 42 7I 84 86; IV 5679 Is I6 242526273 I 42) bzw. „Friede seiner/ihrer Seele (III 33 83), nie in der sonst durchaus gängigen, assimilatorisch geprägten Formulierung „Friede seiner/ ihrer Asche“".

55 Grabsteine IV 32353940 4I.

56 Grabsteine I I 8; II 26. 
Daran anschließend (2) wird vermerkt, ob es sich um einen Mann, eine Frau, ein junges oder herangewachsenes Kind handelt; unmittelbar damit verbunden folgt gewöhnlich eine Eulogie, ein Lobpreis des bzw. der Verstorbenen, vielfach aus biblischen, gelegentlich auch aus talmudischen Redewendungen zusammengesetzt. Dann erst kommen die Angaben zur Person und zur Chronologie.

Die Angaben zur Person (3) verzeichnen stets an erster Stelle den Rufnamen sowie üblicherweise den Namen des Vaters, bei verheirateten Frauen oft zusätzlich oder teilweise auch an Stelle dessen den Namen des Ehemannes. Darüber hinaus werden bei Männern in Form von Abkürzungen gern Ehrentitel wie "unser/der ehrenwerte Herr und Meister ${ }^{57}$ oder "unser Meister ${ }^{58}$ eingetragen sowie - soweit angebracht - Funktionen in der Gemeinde und vor allem die priesterliche oder levitische Abkunft angeführt. Bisweilen finden sich auch Hinweise, die Auskunft über den Ort der Herkunft geben. ${ }^{59}$ Familiennamen fehlen zunächst. Jüdischerseits lange nahezu ungebräuchlich, sind sie allgemein erst im Rahmen der staatlichen Maßnahmen zur rechtlichen Gleichstellung eingeführt worden. In Adelebsen tauchen sie erstmals auf Grabinschriften aus der Mitte des I9. Jahrhunderts auf (dazu s.u. 3 I 7 ff.).

Die chronologischen Angaben (4) folgen einem seit dem I2. Jahrhundert gebräuchlichen eigenjüdischen Kalenderwesen (s. u. 328). Überwiegend beschränken sie sich auf die Sterbedaten. Diese festzuhalten, ist besonders wichtig, da die Hinterbliebenen verpflichtet waren, alljährlich am Jahrzeittag das Kaddisch-Gebet zum Lob Gottes und zum Gedenken an den Verstorbenen zu sprechen. Gewöhnlich wird der Todestag angeführt, vielfach wenn die Bestattung nicht schon am gleichen Tag vorgenommen werden konnte zusätzlich auch der Tag des Begräbnisses. Die seit Ende des I 8. Jahrhunderts einsetzenden staatlichen Maßnahmen gegen den religionsgesetzlich vorgeschriebenen jüdischen Brauch $^{60}$, die Verstorbenen möglichst noch am selben Tag oder am darauf folgenden zu bestatten, und die damit verbundenen Forderung eines Abstandes von wenigstens 48 Stunden zwischen Ableben und Begräbnis, sind auch in Adelebsen lange Zeit nicht strikt befolgt worden. Noch I 844 hat ein Begräbnis bereits am Sterbetag statt gefunden. ${ }^{61}-$ Geburtsdaten werden im Unterschied zu den Sterbedaten auf den hebräischen Inschriften nicht vermerkt. Sie finden sich ausschließlich in den deutsch abgefassten Inschriftenteilen.

Den Abschluss der Grabinschrift bildet gewöhnlich ${ }^{62}$ eine Eulogie (5), die den Segensתהי נפשו/ה צרורה : משר (thi naphscho/ah zerurah bizror ha-chajjim): "Seine/ihre Seele sei eingebunden in das Bündel des Lebens. «63 In den meisten Fällen wird diese Formel ähnlich wie die תנצבה :Einleitungsformel abgekürzt geboten, in Gestalt der fünf Anfangsbuchstaben $(T N Z B H)$, gelegentlich findet sich der Text aber auch voll ausgeschrieben. ${ }^{64}$ Bisweilen wird die Reihenfolge der ersten bei den Wörter vertauscht ${ }^{65}$ bzw. ein oder der andere

57 Grabsteine I I 5; II 7; III I 523.

58 Grabstein II 38.

59 Grabsteine I I; III 4570 IOO; IV 34.

60 Dazu s. Daniel Krochmalnik, Scheintod und Emanzipation. Der Beerdigungsstreit in seinem historischen Kontext, Trumah. Zeitschrift der Hochschule für jüdische Studien 6, I998, I07-I47.

61 Grabstein II 34.

62 Es handelt sich um einen uralten Brauch; die ältesten Belege stammen bereits aus dem 2./3. Jh. chr.Z., s. Otto Eissfeldt, Der Beutel der Lebendigen. Berlin I960, $32 \mathrm{ff}$.
63 Statt mit „Bündel des Lebens“ kann der hebräische Text auch mit „Bündel/Beutel der Lebendigen“ wieder gegeben werden; vgl. Eissfeldt (A.62), 22 A. I. Verfehlt ist die in vielen Veröffentlichungen verbreitete Übersetzung „Bund des Leben“, die vermutlich durch die Bibelübersetzung von Leopold Zunz beeinflusst ist. Mit ihr wird der bildhafte Sinngehalt durch eine im Text nicht angelegte theologische Metapher überlagert.

64 Grabstein I 3.

65 Grabstein II 50. 


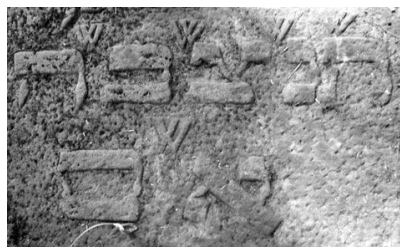

Buchstabe ausgelassen, mehrfach gibt es weitere formelhafte Erweiterungen: „Amen“66, „Amen Sela“67, „im Garten Eden, Amen, (Sela) “68, „,mit den (übrigen) Gerechten/gerechten Männern und Frommen/Frauen im Garten Eden. Amen, (Sela) “. ${ }^{69}$ Vereinzelt wird die Segensformel durch andere Segenswünsche ersetzt. ${ }^{70}$ Gelegentlich wird sie sogar ganz ausgelassen, so dass der Text der Inschrift mit den chronologischen Angaben schließt. ${ }^{71}$

\subsection{Zeitangaben und Zeitrechnung}

In den chronologischen Angaben folgen die hebräischen Inschriften dem eigenjüdischen Kalender, der seit dem frühen Mittelalter in nahezu allen hebräisch bzw. aramäisch verfassten öffentlichen und privaten Dokumenten Verwendung fand und erst im Verlauf des I9. Jahrhundert im Zuge der Assimilation auf den deutschsprachigen Inschriften zugunsten der christlichen Zeitrechung weithin abhanden gekommen ist.

Dieses eigenjüdische Kalenderwesen stimmt mit dem christlichen nur an einer Stelle überein: in der Einteilung der Woche in den Rhythmus von sieben Tagen, beginnend mit dem Sonntag als I. Tag der Woche. ${ }^{72}$ Im übrigen folgt es einem grundlegend anderen System der Zeitrechnung und zwar sowohl bei der Berechnung des Tages wie vor allem bei der Einteilung und Zählung der Jahre.

Tagesanfang und Tagesende sind nicht durch die chronographisch feststehende Mitternacht festgelegt, sondern durch den von Tag zu Tag wechselnden Stand der Sonne: Der Tag beginnt mit Eintritt der Nacht und er endet vor ihrem Untergang. Dieser Unterschied muss jeweils bedacht werden, wenn die auf der Grabinschrift vermerkte Tagesangabe auf die "zivile" Zeit umgerechnet wird. Im Durchschnitt beträgt die Abweichung sechs Stunden.

Die Einteilung des Jahres erfolgt nach einem luni-solaren Mischsystem. Mond- und Sonnenkalender sind miteinander verbunden. Grundmaß liefert der Umlauf des Mondes um die Erde mit seinem Rhythmus von ungefähr 29 Tagen und I2 Stunden. Das Jahr wird entsprechend in I2 Monate mit je 29 bzw. 30 Tagen eingeteilt. Daraus ergibt sich bei einer Gesamtzahl von 354 Tagen und nahezu 9 Stunden gegenüber dem Sonnenjahr (mit 365 Tagen) eine Verkürzung von jeweils fast I I Tagen. Um dies auszugleichen, wird in einem Zyklus von i9 Jahren siebenmal (am Ende jeden 3., 6., 8., I I., I4., I7. und I9. Jahres) je ein I3. Monat eingeschaltet, der auf den Monat Adar folgt (gewöhnlich die Märzzeit) und daher auch als 2. Adar bezeichnet wird. Die sonst zwangsläufig eintretende jahreszeitliche Verschiebung der Festtage, wie sie auf Grund eines reinen Mondkalenders z. B. in der muslimischen Welt zustande kommt, wird auf diese Weise vermieden.

Der Neujahrstermin des jüdischen Kalenders liegt im Herbst (September/Oktober) und beginnt mit dem Monat Tischri (zu den weiteren Namen s. die Übersicht im Anhang). Grunddatum für die Zählung der Jahre ist die Erschaffung der Welt. Es gibt kein Epochensystem eines "vor» und "nach». Die Weltgeschichte, Leben und Tod, wird auf das

66 Grabsteine I 9; III I6; IV 4I.

67 Grabsteine I 8 IO II I2 I3 I4 I6 I7 II 8 I9 20 2I

222324 .

68 Grabsteine I 25; II 3 IO I 5273 I 3248 .

69 Grabsteine I 7; II I 28 I $7222633 \quad 34$ 4I 45 5I.

70 Grabstein II 7.
71 Grabsteine I I 2; IV 48.

72 Dass in dem heute weltweit amtlich gängigen Kalendern die Woche mit dem Montag als I. Tag beginnt und der Sonntag als letzter Wochentag gehandelt wird, ist erst 1976 eingeführt worden, ein kommerziell bedingter, säkularer Gewaltstreich. 
Werk des Schöpfers bezogen. Nach rabbinischen Berechnungen, die den chronologischen Angaben im Kanon der biblischen Schriften folgen, wurde die Welt am I. Tischri des Jahres erschaffen, das 376I/60 Jahre vor dem Beginn der christlichen Zeitrechnung liegt. Das Jahr 5000 j. Z. fällt entsprechend auf I239/40 chr. Z., das Jahr 5770 j. Z. auf 2009/IO chr. Z.

Da im Hebräischen alle Zahlen durch die 22 Buchstaben des Alphabets wiedergegeben werden, die bis zum Zahlenwert 400 (ת) reichen, werden die Tausender gewöhnlich nicht vermerkt. Angeführt werden nur die weiteren, niedrigeren Zahlen und als Zusatz der Hinweis "nach kleiner Zählung« (לפרט קטן lifrat katan) angebracht, gewöhnlich durch לפר לפו (lfk, mitunter zu einem Buchstaben verschmolzen) - oder 'ל (l') abgekürzt.

\subsection{Stilmittel}

Die Inschriften des Adelebser Friedhofs sind durch die Bank kurz und schlicht gehalten. Soweit sie deutsch verfasst wurden, beschränken sie sich in der Regel auf die Angaben von Namen und Daten. Ausführlicher sind die hebräischen Inschriften, aber auch ihre Texte zeichnen sich weder durch Eloquenz noch durch Eleganz aus und sind gemessen an den Befunden auf anderen benachbarten Friedhöfen überwiegend knapp gehalten. Meist bestehen sie aus formelhaften, standardisierten, z. T. durch biblische oder talmudische Vorbilder geprägte Wendungen, die in zahlreichen Variationen dargeboten werden. Wert auf stilistisch kunstvolle Gestaltung wurde dabei freilich nicht gelegt. Es kommen weder Endreimbildungen vor noch begegnet die Form des Akrostich, des Leistengedichts, bei dem die Anfangsbuchstaben der Zeilen zusammen den Namen des Verstorbenen ergeben. Ansätze literarischer Finessen finden sich auffälligerweise nur auf 2 zum ältesten Bestand des Friedhofs gehörigen Grabinschriften, in denen die Daten des Sterbetags und -jahrs in Gestalt eines Chronogramms verschlüsselt dargeboten werden. Literarische Besonderheiten begegnen nur ansatzweise in 2 zum ältesten Bestand des Friedhofs gehörigen Grabinschriften in den Angaben zum Sterbedatum. Teils erfolgt dies unter Aufnahme einer biblischen Wendung, ${ }^{73}$ teils in Gestalt lautschriftlicher Wiedergabe der betreffenden Zahlbuchstaben. ${ }^{74}$

Diese Kargheit der Stilmittel entspricht den Befunden, wie sie auch sonst auf den Friedhöfen dörflicher und kleinstädtischer jüdischer Gemeinden anzutreffen sind. Sie ist Ausdruck einfacher Lebensverhältnisse und damit zusammenhängend bescheidener Bildung. ${ }^{75}$

\subsection{Gesellschaftliche und religiöse Profile}

Der Friedhof birgt die steinernen Relikte einer über 300 Jahre währenden Geschichte jüdischen Lebens in und um Adelebsen. Was diese mit ihren Inschriften zur Sprache bringen, bezieht sich nahezu ausschließlich auf die Lebensgeschichten einzelner Personen. Dennoch sind sie nicht nur familiengeschichtlich von Belang. In ihnen spiegelt sich durchaus auch die Eigenart der Lebens- und Glaubenswelt der jüdischen Gemeinde selbst wider. Freilich geschieht dies höchst bruchstückhaft und nur in groben Linien.

73 Grabstein I I3.

74 Grabstein I 2.I3.

75 Letzteres zeigt sich auch im bisweilen fehlerhaften
Hebräisch der Inschriften, z.B. im Gebrauch weiblicher Verbformen für Männer (s. Grabsteine III I6 48; IV I7). 
Über Stand und Beruf ist auf den älteren Grabsteinen gar nichts und auf den späteren auch nur ganz vereinzelt ${ }^{76}$ etwas zu erfahren. Ebenso kommen familiäre Beziehungen kaum zur Sprache. Durchgehend werden nur die Väter genannt, die Mütter nicht. Bei Ehefrauen ist es Brauch, den Mann mit Namen zu erwähnen, umgekehrt geschieht dies jedoch nie. Hinweise auf Kinder fehlen durchgehend. Gelegentlich werden Herkunftsorte $^{77}$ erwähnt. Genauere Rückschlüsse auf innerjüdische Wanderbewegungen lassen sich daraus aber kaum ziehen. Auch die in der 2. Hälfte des I9. Jahrhunderts einsetzende Vielfalt in der Gestaltung der Grabsteine ist nur begrenzt geeignet, um die Entwicklung und Ausdifferenzierung der wirtschaftlich-sozialen Verhältnisse unter den Mitgliedern der jüdischen Gemeinde zu belegen. Die in der Form und der Größe vorhandenen Abweichungen sind aufs Ganze gesehen gering und spiegeln eher Unterschiede des Geschmacks und weniger des Standes wider.

Deutlicher zeichnen sich auf den Inschriften Profile religiöser und sonstiger Bildung ab. Das gilt insbesondere für den Altbestand des Friedhofs; aber auch unter den neuzeitlichen Grabsteinen gibt es manche, deren Inschriften sich entsprechend auswerten lassen.

Man wird zwar nicht übersehen dürfen, dass die Texte überwiegend aus standardisierten, recht allgemein gehaltenen Wendungen bestehen, und man wird auch zu berücksichtigen haben, dass bei ihrer Abfassung fremde Hilfe in Anspruch genommen wurde, bei zuständigen Rabbinern oder an Hand spezieller Handbücher, die Beispieltexte für Grabinschriften lieferten. ${ }^{78}$ Dennoch sind dabei getroffene Auswahl der Motive und die damit verbundenen konkreten Bezüge durchaus geeignet, um ansatzweise ein Bild von der in der Gemeinde herrschenden religiösen Prägung und Stimmungslage zu vermitteln.

Die Wertschätzung religiöser Observanz und Bildung kommt in den Eingangseulogien dort zur Sprache, wo auf gemeindliche Funktionen der Verstorbenen abgehoben wird: Vorsteher der Gemeinde ${ }^{79}$, Lehrer ${ }^{80}$, Schächter und Fleischbeschauer ${ }^{81}$, Beschneider (Mohel ${ }^{82}$ Mitglied der Begräbnisgenossenschaft ${ }^{83}$; sie macht sich ferner besonders dort bemerkbar, wo Eigenheiten der Frömmigkeitspraxis hervorgekehrt werden: z.B. regelmäBiges Einhalten der Zeiten für Gebet ${ }^{84}$, das Studium der Tora ${ }^{85}$ sowie praktische Wohltätigkeit. ${ }^{86}$ In eine ähnliche Richtung weisen die Verwendung der Ehrenbezeichnung „gerechter Lehrer"87, die dem Namen beigefügt ist, sowie die Benutzung biblischer und talmudischer Zitate bzw. Anspielungen. ${ }^{88}$ Das alles sind zwar im traditionellen Arsenal religiöser Bildung vorgegebene Motive, dass man sich ihrer - gewiss nicht durchgehend, aber doch immer wieder neu - bedient hat, deutet darauf hin, dass derartige Kenntnisse in der Gemeinde Zeit zum bleibenden religiösen Wertekanon zählten. Und nicht nur das, man ist diesem Wertekanon offenkundig durchaus auch in der Praxis gefolgt. Auf den Grabinschriften zeichnet sich das namentlich ab in den Angaben zum Sterbedatum, bei denen ausdrücklich vermerkt wird, dass es sich um einen Feiertag gehandelt hat. Erwähnt

76 Tierarzt (IV Io); Lehrer (III 5; IV 39).

77 Aus der Nachbarschaftss Barterode (III 45), Güntersen (III 69 70), Lödingsen (III 30), sonst: Altona (III IOo) und Esens (IV 34).

$78 \mathrm{Zu}$ nennen sind hier insbesondere der von Simon Frankfurter herausgegebene Sefer ha-Chajjim, erstmals I703 gedruckt, danach überarbeitet durch dessen Sohn Mose Frankfurter in mehreren Auflagen erschienen, Grundlage für spätere gleichartige Kompendien, z.B. B.C. Rehfuß, Vollständiges Andachtsund Ritualbuch zum Gebrauch bei Krankheitsfällen, im Sterbezimmer, auf dem Friedhof, frei ins Deutsche übersetzt, Frankfurt I 834; S. Blogg, Israelitisches
Andachtsbuch bei Krankheitsfällen, in einem Sterbehause und bei Besuch der Gräber, Hannover I 856 . 79 Grabstein II I8.

80 Grabstein III 5 .

81 Grabstein III 5.

82 Grabstein I 2 (?) III 74.

83 Grabsteine III I2 23.

84 Grabstein II 7.

85 Grabsteine II 7; III 567.

86 Grabsteine II 3 6; III 33382 .

87 Grabsteine III 5; IV 39.

88 S. u. S. 327 
werden mehrfach Pessach ${ }^{89}$, Rosch ha-schana (Neujahr) ${ }^{90}$, Sukkot ${ }^{91}$, Simchat Tora ${ }^{92}$, Channuka $^{93}$ ferner speziell der 33. Tag der Omerzeit ${ }^{94}$ und der ,große Schabbat ${ }^{495}$ sowie Purim. ${ }^{96}$ Eine gewichtige Rolle spielen die Hinweise auf den Schabbat bzw. den Vorabend das Schabbat. In den jüdischen Gemeinden gilt es seit Alters als ein Zeichen besonderen Segens, während der festlichen Ruhe des Sabbat bzw. an seinem Ein- bzw. Ausgang zu sterben. Man hat dies gleichsam als eine Art Vorwegnahme der endzeitlichen Sabbatruhe gewertet und deswegen mit Bedacht notiert. Auch in der Adelebser Gemeinde ist man diesem Brauch meist gefolgt. ${ }^{97}$ Ausnahmen bilden bis auf einen Sonderfall ${ }^{98}$ jüngere Grabstellen. ${ }^{99}$ Dass man diese Konventionen frommer Praxis derart beachtet hat, spricht für religiöses Selbstbewusstsein und spiegelt Kernstücke religiöser Bildung. Gerade an dieser Stelle sind die stummen Grabsteine durchaus beredt. Daneben machen sich gelegentlich freilich auch Anzeichen säkularer Einflüsse bemerkbar, so namentlich in der zunehmenden inhaltlichen Kargheit auch der hebräischen Texte, ferner in der Aufnahme nichtjüdischer Sinnsprüche und Embleme. Die Adelebser Gemeinde war nach allem, was die vorhandenen Urkunden und Nachrichten zu erkennen geben, kein Ort ausgeprägt rabbinischer Gelehrsamkeit. Sie war aber, wie nicht zuletzt die Inschriften in ihrer Sprache und in ihren Inhalten anzeigen, über lange Zeit hinweg durchaus traditionstreu und traditionsbewusst.

89 Grabsteine I 9; IV 330.

90 Grabsteine III I I 5 I.

91 Grabsteine III 6884 .

92 Grabsteine I I 8; III 6294.

93 Grabsteine II 42 ; III 8.

94 Grabstein I 3.
95 Grabstein IV 3.

96 Grabstein III 56.

97 Grabsteine I I3; II 37; III, 4079.

98 Grabstein III I 5 .

99 Grabsteine IV 2937. 
Dokumentation der Grabstätten

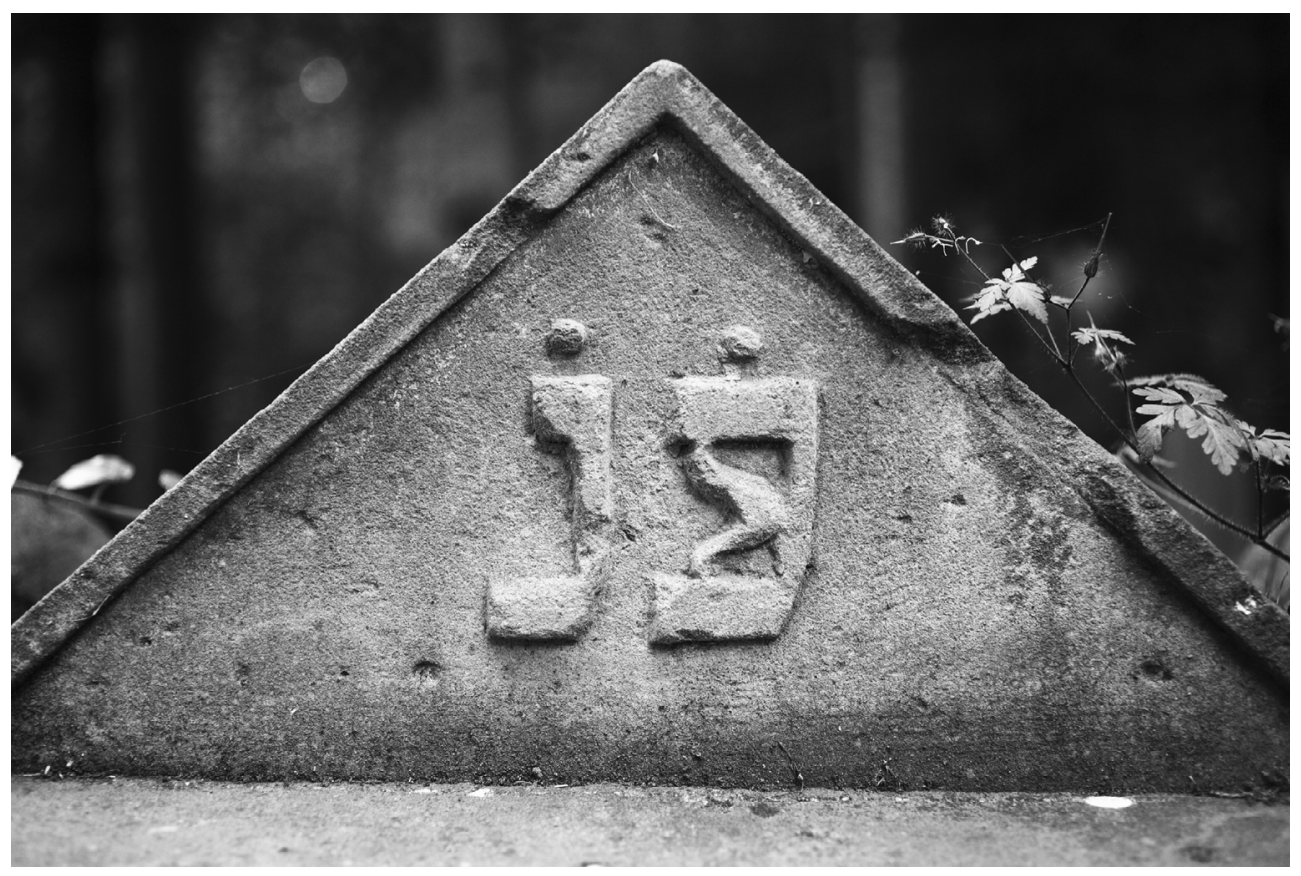




\section{Technische Hinweise}

Die Dokumentation umfasst den erhaltenen Bestand an Grab- und Gedenksteinen, darüber hinaus sind weitere Grabstellen erfasst, die sich auf Grund der vorhandenen Steinsetzungen noch ermitteln lassen.

\section{Anordnung, Nummerierung, Befundangaben}

Die Anordnung geschieht chronologisch, beginnend I733 und endend I948. Um das Auffinden vor Ort zu gewährleisten, ist jedes Grab mit einer eigenen Ziffernkombination versehen bestehend aus römischen Buchstaben (I-V) für die jeweilige Parzelle und aus einer innerhalb derselben vorgenommenen durchgehenden Nummerierung in arabischen Zahlen. Beides ist die auf dem beigegebenen Friedhofsplan eingetragen. Sofern in den weiteren Ausführungen, insbesondere bei Hinweisen auf familiäre Beziehungen, auf Gräber verwiesen wird, geschieht dies in derselben Form.

Die Nummerierung wird ergänzt durch Angaben zur Größe der Grabsteine und Hinweise auf Besonderheiten der Gestaltung und des Erhaltungszustands.

\section{Namen}

In den Überschriften werden die Vor- und Familiennamen, soweit bekannt, in der deutschen Fassung geboten. Die Wiedergabe der hebräischen Namensformen folgt nicht konventionellen, durch die deutschen Bibelübersetzungen standardisierten Fassungen, sondern ist bemüht, in lautlicher Umschrift die hebräische Klangfarbe zu wahren. Nicht berücksichtigt wurde dabei die den Verfassern der Inschriften vertraute aschkenazische Aussprache, sondern der heute verbreitete sefardische Sprachduktus.

\section{Abbildungen}

Die fotografischen Aufnahmen sind darauf abgestellt, die Inschriften so wieder zu geben, dass die vorgenommene Entzifferung nachvollzogen werden kann. Das ist indes nicht durchgehend gelungen. Manche Steine waren zu stark verwittert oder gar zerstört, manche weisen nur noch verblasste oder von Schlieren überdeckte Inschriften auf. Gelegentlich waren auch die Lichtverhältnisse höchst ungünstig.

Die Grabsteine werden teils vollständig, teils nur mit dem Inschriftenfeld wiedergegeben. Ein Vergleich der Größen ist an Hand der Abbildungen nicht ohne weiteres möglich. Steine mit kurzen Texten können auf dem Foto unverhältnismäßig größer wirken als Steine, die mit umfangreichen Textmengen versehen sind. Die Maßangaben sind stets zu berücksichtigen.

\section{Entzifferung und Abschrift}

Die Entzifferung der Inschriften beruht in allen Fällen auf einem Abgleich der Fotografien mit den Originalen vor Ort. Nur so konnten kaum mehr lesbare Textpassagen noch "zum Sprechen« gebracht werden.

Die Abschrift des jeweiligen hebräischen Textes ist bemüht, die Vorlage möglichst genau wiederzugeben. Nicht vermerkt ist, wenn Buchstaben miteinander verknüpft sind 
(Ligaturen). Auch Satz- und Abkürzungszeichen sind vereinfacht dargeboten. Ergänzungen werden durch eckige Klammem ([ ] angezeigt, fehlende oder unklare Textstellen durch runde Klammern mit eingefuigten Punkten; beides findet sich entsprechend auch in der Übersetzung des hebräischen Textteils ins Deutsche.

\section{Übersetzung}

Die Übersetzung ist um Genauigkeit, zugleich aber auch um Lesbarkeit bemüht. Sie folgt - soweit wie möglich - bis in die Wortfolge dem Duktus des hebräischen Grundtexts; die einzelnen Zeilen sind entsprechend auch optisch genau aufeinander abgestimmt

Die in den hebräischen Inschriften gern und viel verwendeten Abkürzungen wurde überwiegend aufgelöst. Ausnahmen bilden ständig gebrauchte, stereotype Wendungen. Sie werden in abgekürzter Form beibehalten, so dass der durch sie bestimmte optische Eindruck der hebräischen Inschrift wenigstens ansatzweise auch in der deutschen Fassung sichtbar wird. Dem mit der Materie nicht vertrauten Leser sei empfohlen, sich die im Abkürzungsverzeichnis vermerkte Entschlüsselung einzuprägen und jeweils dann laut zu lesen oder still mitzudenken.

Bei Bibeltexten richtet sich die Übersetzung nicht nach einer bestimmten Vorgabe. Neben der von Leopold Zunz herausgegebenen, inzwischen klassischen jüdischen Übersetzung wurden auch andere Übersetzungen herangezogen, je nachdem wie dies sachlich und sprachlich im Rahmen der Inschrift am ehesten zu passen schien.

\section{Anmerkungen und Erläuterungen}

Auf einen ausführlichen Kommentar wurde verzichtet, nicht zuletzt aus Raumgründen. Die den Inschriften beigegebenen Erläuterungen beschränken sich vornehmlich darauf, in aller Kürze Hinweise auf biographische Zusammenhänge zu geben. Darüber finden sich zu einzelnen Textstücken Informationen, die grundlegende Sachverhalte wie Namen von Orten, historische und religiöse Zusammenhänge, biblische und talmudische Zitate und Anspielungen betreffen. 


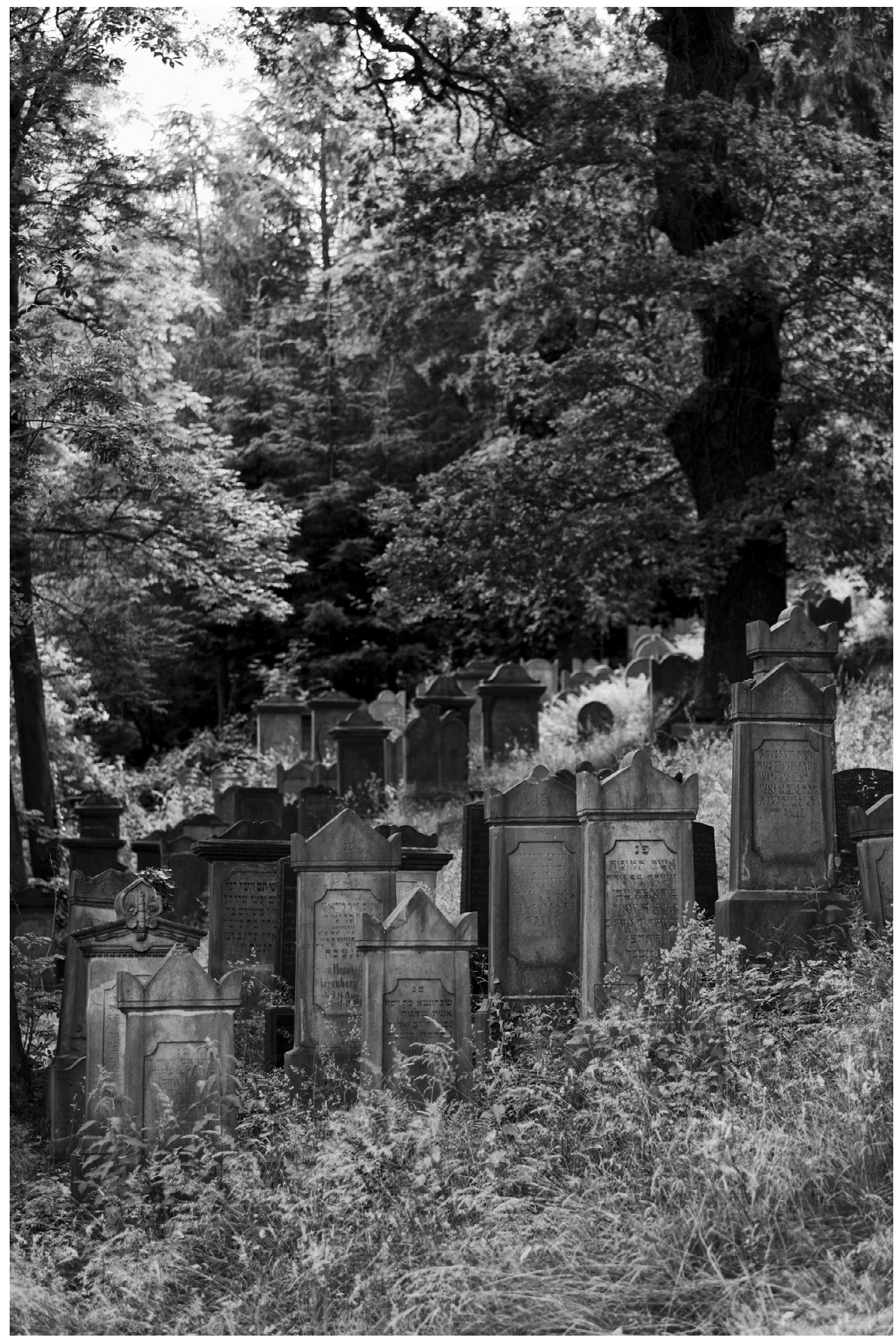




\section{Fromet}

\section{$3 \cdot 5 \cdot 1733$}

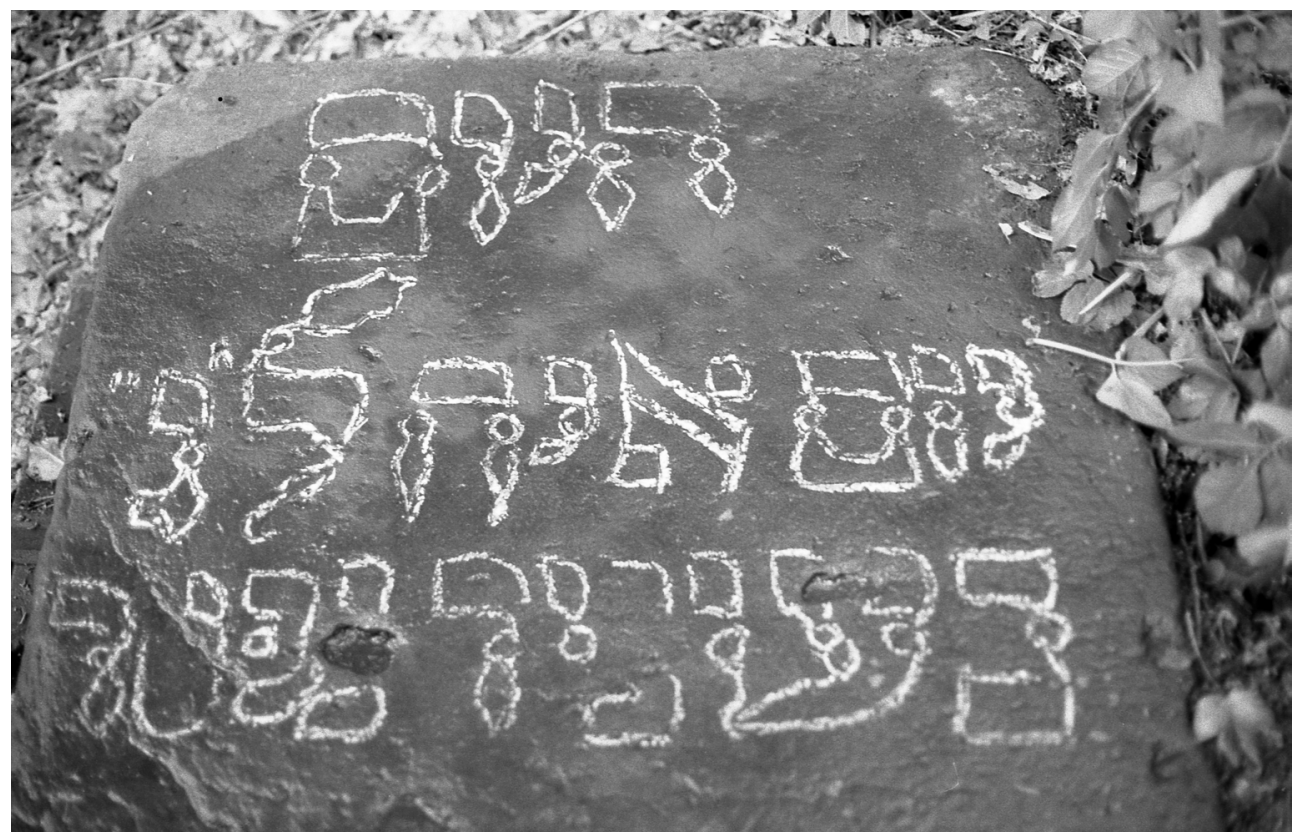

H $179 \cdot \mathrm{B} 90 \cdot \mathrm{T}$ I 8

Buchstaben in Umrissschrift, nur noch schwer lesbar

\begin{tabular}{|c|c|}
\hline 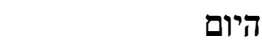 & Heute \\
\hline ום א י"ח ל'ג' & am Tag 1, 18.[Ijjar] dem 33.Tag \\
\hline צומר נפטר' & der Omer-Zeit verschie(d) \\
\hline ונקבר' האשה & und wurde begrab(en) die Frau, \\
\hline 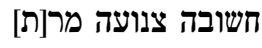 & 5 die angesehene, züchtige, Fra [u] \\
\hline פרומט ש'ת'צ'ג & Fromet (im) J(ahr) 493. \\
\hline ונשמתה תהא & Und ihre Seele sei \\
\hline בצרור החי & im Bündel des Lebens \\
\hline 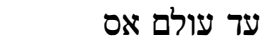 & vigkeit. $A$ (men) $S$ (ela) \\
\hline
\end{tabular}

2f. Omer-Zeit: Tage zwischen Pessach und Schavuot/Pfingsten. Der 33. Tag, Lag baOmer genannt (nach der hebräischen Zahlenangabe ל ל / lag), fällt auf den i8. Ijjar und zeichnet sich dadurch aus, dass an ihm die für die übrigen Tage üblichen Trauerriten ausgesetzt werden und Festlichkeiten (Hochzeiten u.ä) erlaubt sind. · 6 Auffällig: keine Angaben über die Familienverhältnisse. Auch der Versuch, aus der Jahreszahl שית'צ' den Familienname zu entnehmen, führt zu keinem Ergebnis. 
Gitel bat Naphtali ha-Kohen

20.9.1735

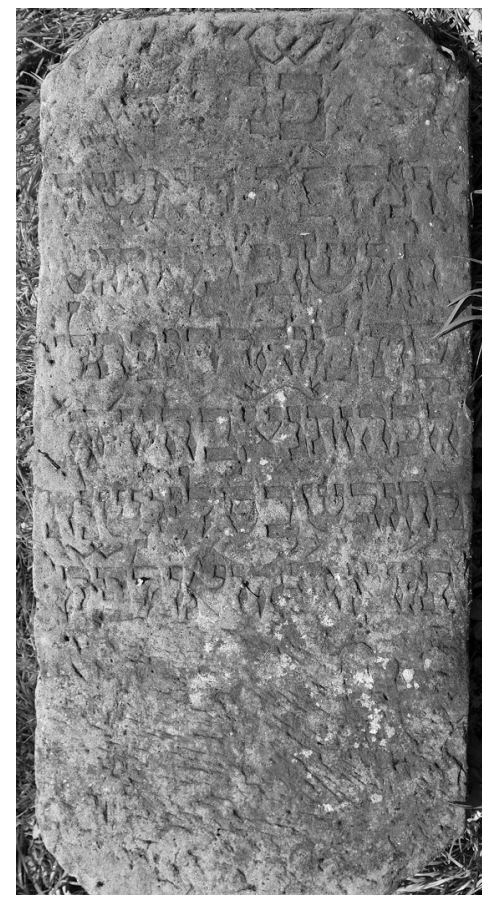

$\mathrm{H} \mathrm{I75} \cdot \mathrm{B} 84 \cdot \mathrm{T}$ I 7

\begin{tabular}{|c|c|}
\hline & \\
\hline קבר' האשה & \\
\hline החשוב' מרת גיטל & die angesehene, Frau Gitel, \\
\hline בת מוהל ר' נפתלי & Tochter des Beschneiders H. Naphtali \\
\hline 5 בחודש כסליו שנת' יו' ה' & $\begin{array}{l}\text { ha-Kohen S.S.E.B.L. am Ta }[g] 5 \\
\text { im Monat Kislew des Jahres }\end{array}$ \\
\hline תיו צדיה ואו לפק' & 496 n.kl.Z. \\
\hline
\end{tabular}

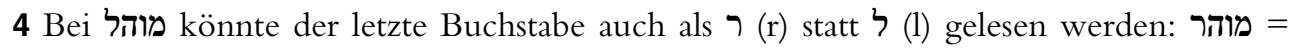
Abk. für מורנו הרב (morenu ha-rav) »unser Lehrer, der Herr». · 5 Ein zur Gruppe der Kohanim (s.u. S. 330) gehöriger Naphtali ist für Adelebsen urkundlich nicht belegt; gleiches gilt für den vielleicht mit ihm identischen Herz Kaz (s. I I) · 7 Zur Angabe des

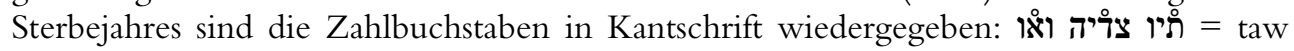
(400) [tiw (so Kimchi)]- zade (90) - waw $(6)=496-5$. Kislew $5496=20.9$. I 735 


\section{Meyer Levi}

$$
\text { 25.6. I } 737
$$

Meyer Levi(n), erstmals I7I9 erwähnt als "Meyer Iude«, scheint aber bereits um I700 in Adelebsen ansässig gewesen zu sein, vgl. die Angaben über Alter und Geburtsort seiner Kinder (L I 762). Dass er als "Meyer Levin" noch in einem Schreiben der hannoverschen Justizkanzlei vom 2I.IO.I737 (s. S. 2I Dokument $2^{\star}$ ) genannt wird, dürfte auf bereits zurückliegenden Ermittlungen beruhen. · Ehefrau (?): Freidche I 6 - Kinder: Abraham I I I; Simon (I702); Herz (I703); Joseph (I706); Gelle (I707); Isaac (?); Esther I 24

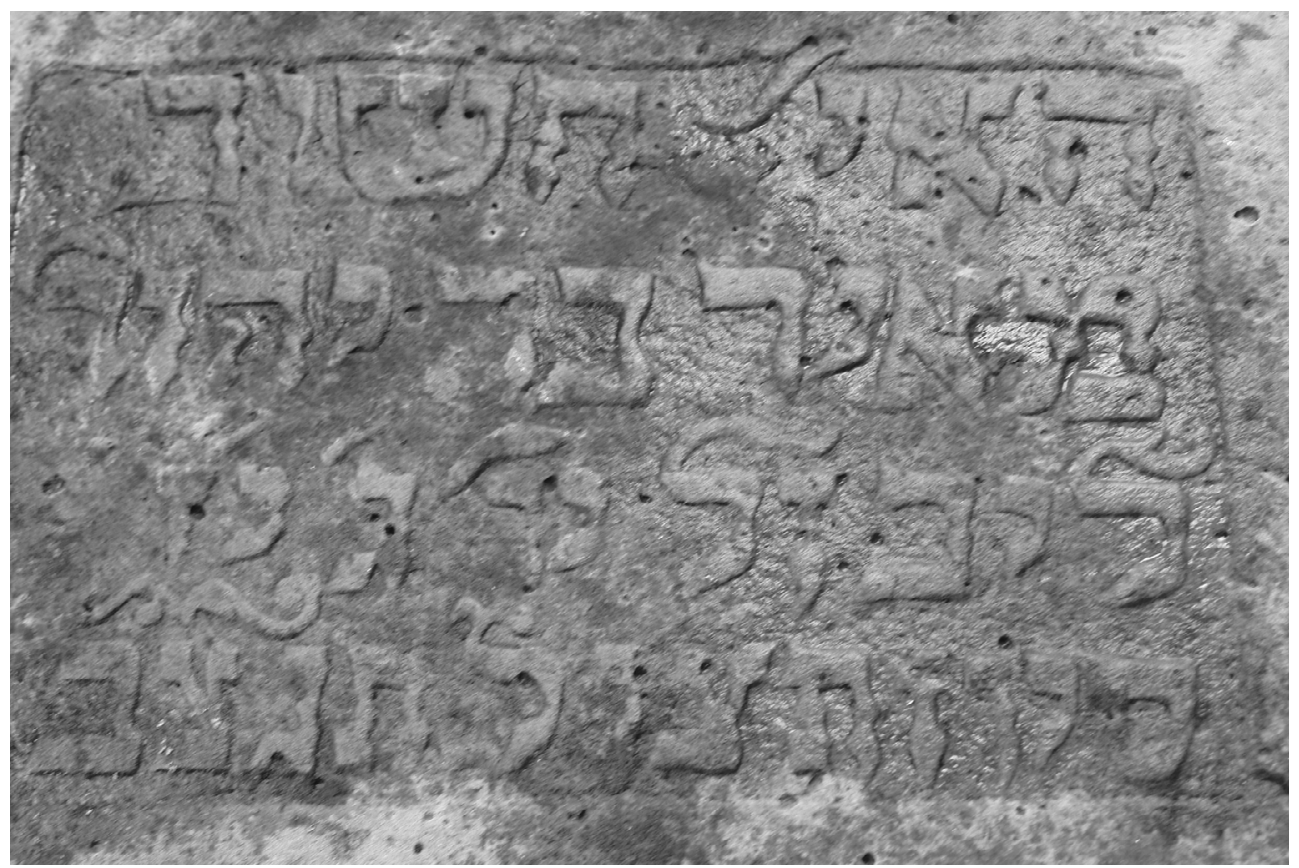

H I79 $\cdot$ B $89 \cdot$ T I4 - Inschrifttafel: $\mathrm{H}_{44} \cdot \mathrm{B} 70$

האיר Der Man[n]

מאיר בר יהוד' Meir, Sohn des Jehud(a)

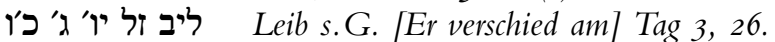

Siwan 497 n.kl.Z. S.S.E.B.(L.) 
Peier eschet Avraham

$$
\text { I 4.6. I } 74 \mathrm{I}
$$

Ehemann: (Möglichkeiten): a) Abraham Selig (I72 I erwähnt) b) Abraham Isaak (I740 erwähnt); c) Abraham Levi (I740 erwähnt).

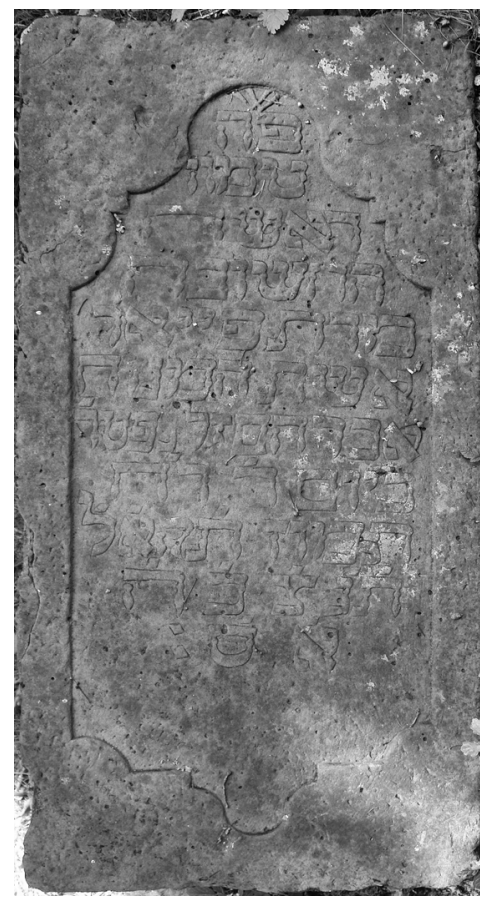

$\mathrm{H} \mathrm{I66} \cdot \mathrm{B} 78 \cdot \mathrm{T} 20$

Barocke Rahmung

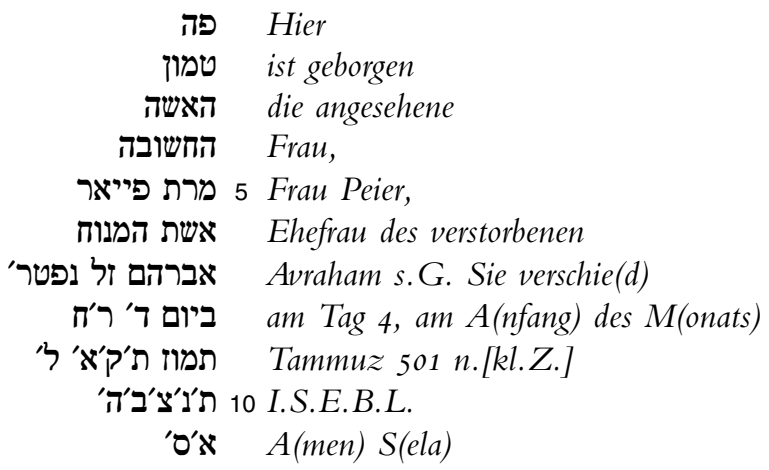

5 פייאר / Peier ist als Vorname (Herkunft?) auch auf dem Friedhof Hamburg Königstrasse 7 Mal belegt, s. EPIDAT - Steinheim-Institut. - 8 Der I. Tammuz (5)5o I beginnt Mittwochabend, I4.6.I74I 
Jacob Nathan

$3 \cdot 7 \cdot 1742$

I7I9 und I737 in Adelebsen erwähnt · Ehefrau (?): Elkele I 5 · Tochter: s. ebd.

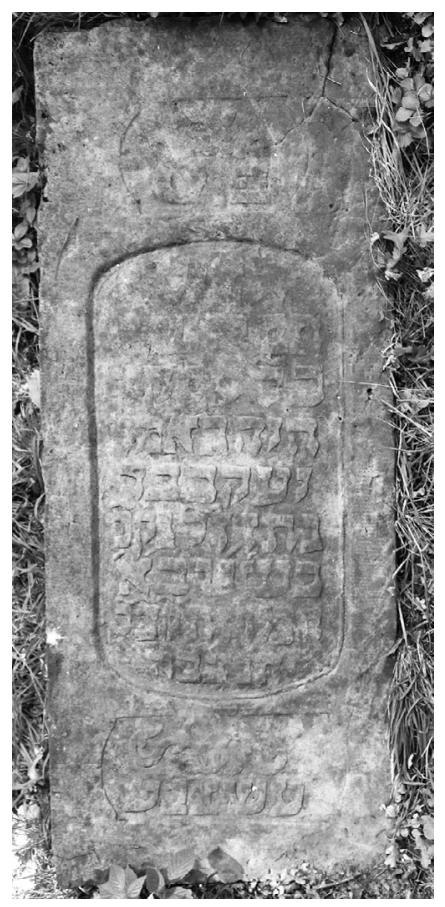

H I77 - B $72 \cdot$ T I 8

Inschrift in kunstvoller Rahmung

$$
\begin{aligned}
& \text { פ'ט Hier ist geborgen } \\
& \text { האיש der Mann, } \\
& \text { תם וישר } \text { כedlich und aufrecht (war er), } \\
& \text { כל עסקיו } \\
& 5 \text { geschahen in Tre(ue), } \\
& \text { יעקב בר Jaakov, Sohn des } \\
& \text { נתן ז'ל' נקב' Nathan s.G. Er wurde begra(ben) } \\
& \text { בש'ט' ב'א' } \\
& \text { Tammuz } 502 \text { n.kl.Z. } \\
& 10 \text { S.S.E.B.L. } \\
& \text { עשצבע (it) den ü(brigen) G(erechten) im (Garten) E(den) }
\end{aligned}
$$




\section{Esther bat Herz Kaz}

$\mathrm{I} 743 / 44$

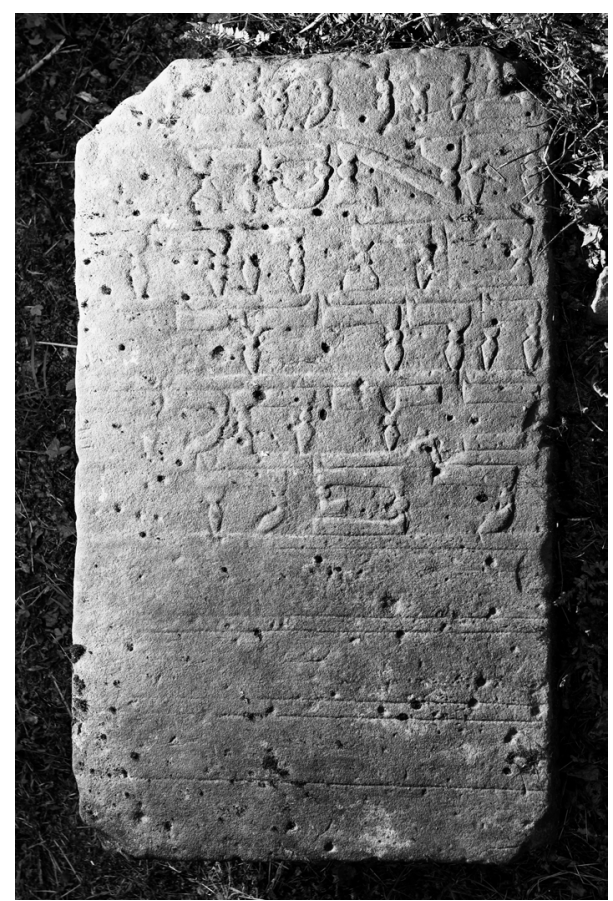

$\mathrm{H} \mathrm{IO} 2 \cdot \mathrm{B} 57 \cdot \mathrm{T}$ I5

In der Form ungewöhnlich, kurze Inschrift: benennt neben den Namen der Verstorbenen und ihres Vaters nur das Todesjahr, nicht den Sterbetag. Auch die gängige Schlußeulogie fehlt.

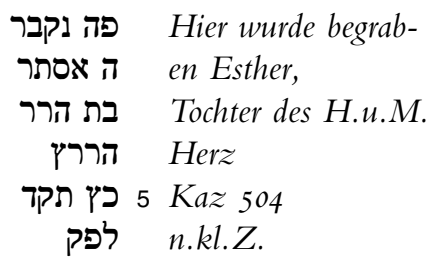

4 Die unübliche Schreibung des Namens mir רר (rr) beruht entweder auf einer Buch-

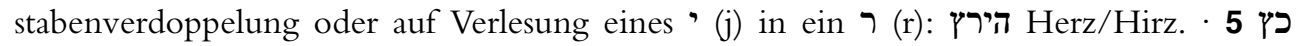
(Kaz), Abk. für kohen zedek "gerechter Priester». - Eine Person Herz mit priesterlicher Abkunft ist auch bei II 2 belegt. Möglicherweise handelt es sich um dieselbe Person (s. die Bezeichnung des biblischen Naphtali Gen 49,2 I als Hirsch). Das bleibt aber unsicher, da die Kürze der Inschrift eher auf ein Kindergrab hinweist. 


\section{Abraham Meyer}

$$
\text { 9.3. } 1749
$$

Handelsmann · I727 und I729-I73 I als Besucher der Leipziger Messe, I737-I740 mehrfach mit Aufenthalten in Göttingen erwähnt. - Eltern (?): Meyer Levi I 4 und Freidche I 6 • Ehefrau: NN (I752 als Witwe genannt)

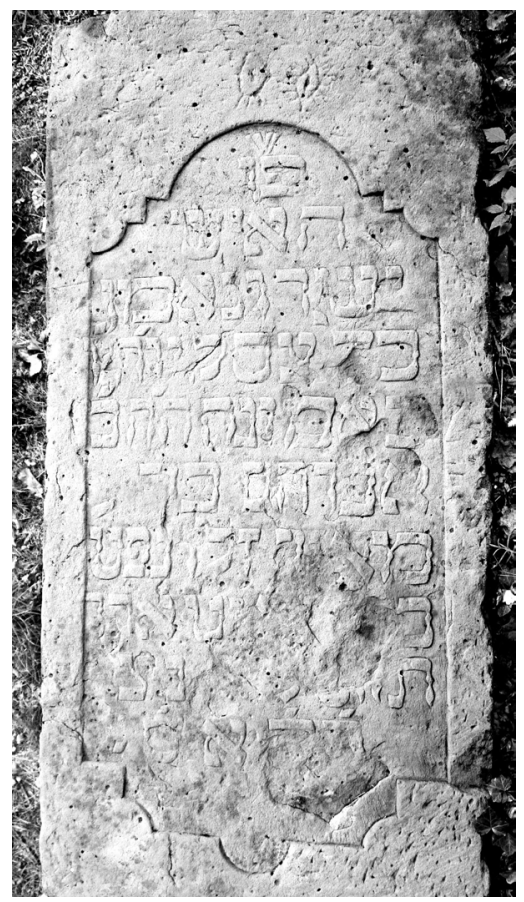

H I7I $\cdot$ B $82 \cdot$ T IO

$$
\begin{aligned}
& \text { פצ"ג Hier ist geborgen } \\
& \text { האיש פer Mann, } \\
& \text { ישר ונאמן aufrecht und getreu (war er), } \\
& \text { all seine Taten geschahen } \\
& \text { ' } 5 \text { in Treue. Dies ist der e. } \\
& \text { Avraham, Sohn des }
\end{aligned}
$$

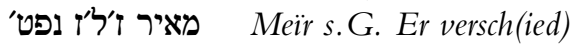

$$
\begin{aligned}
& \text { a[m Tag 1], 19. Adar } \\
& 509 \text { n.[kl.Z.] S.S.E. } \\
& 10 \text { B.L. A(men) S(ela) }
\end{aligned}
$$


Elkele eschet Jaakov

I3. IO. I 749

Ehemann (?): Jacob Nathan I 7 · Tochter (?): Merle I I 4

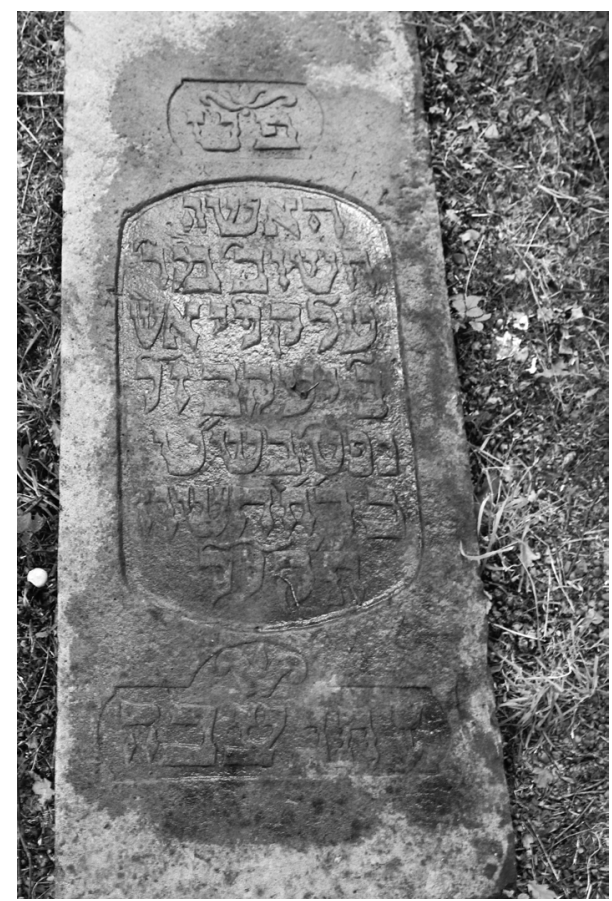

$\mathrm{H} \mathrm{I73} \cdot \mathrm{B} 7 \mathrm{I} \cdot \mathrm{T} 23$

Inschrift in kunstvoller Rahmung

פ'ט Hier ist geborgen

האשה פיט die Frau

חשוב' מר' die angesehen(e), Fr(au)

Elkele, Ehefr(au)

5 des e. Jaakov s.G.

Sie versch(ied) in g(utem) N(amen)

בר'ח חשון am A(nfang) des M(onats) Cheschwan

510 n.kl.Z.

I.S.E.B.L. 


\section{Moses Meyer Ilten}

$$
25 \cdot 4 \cdot 1753
$$

Seit 1742 Schutzjude in Adelebsen - Ehefrau: Gelle Meyer (Tochter von Meyer Levi I 4); I762 als Witwe nebst Kindern erwähnt, I766 als Hausbesitzerin, zuletzt I776/77 ' Kinder: Levi I 25; Schmeiche/Schemaja I I9; Selig Oppenheim II 26; Abraham Edelstein II 22; Schafte II I6; Rahel II I i; Meyer (I748/I752-um i8 I5)

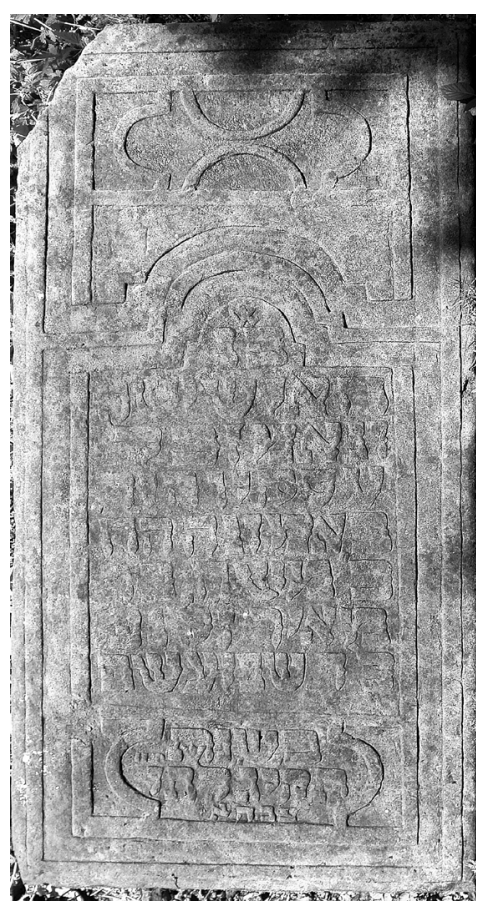

$\mathrm{H} \mathrm{I70} \cdot \mathrm{B} 80 \cdot \mathrm{T}$ I 3

פעינ Hier ist geborgen

der Mann, aufrecht

ונאמן כל ומיו

seine Taten geschahen

5 in Treue, dies ist der

e. Mosche, Sohn

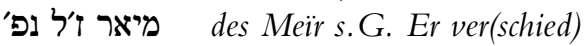

ב'ד שבוע שפ' am 4Tag] der Woche von P(essach)

im Jahr

'צ' 10513 n.kl.Z. S.S.

צ'B.L. A(men). 
Freidche eschet Meir

$$
5.5 .1755
$$

Ehemann (?): Meyer Levi I 4 · Kinder (?): s. ebd.

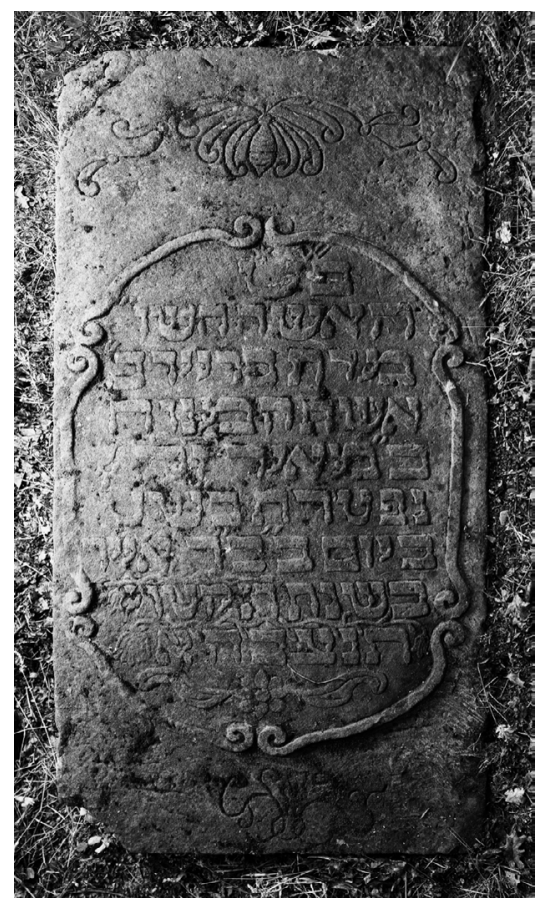

H I85 - B $87^{\cdot}$ T I7

Inschrift in barocker Rahmung mit Schmetterlingssymbol

\begin{tabular}{|c|c|}
\hline 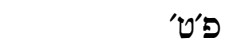 & Hier ist geborgen \\
\hline האשה חשן’ & die geach(tete) Frau, \\
\hline מרת פריידכ' & Frau Freidch(e), \\
\hline אשת המנוח & Ehefrau des verstorbenen \\
\hline נפ' מאיר ז'שי & $\begin{array}{l}\text { e. Meir s. G. } \\
\text { Sie verschied in g(utem) N(amen) }\end{array}$ \\
\hline ביום ב' כ'ד אייר & am $\operatorname{Tag} 2$, 24. Ijjar \\
\hline בשנת תקטו' לפק' & im Jahr 515 n.kl.Z. \\
\hline תנצבה' א[מן] & I.S.E.B.L. A[men] \\
\hline
\end{tabular}


Levi David

$$
\text { I0.4.1756 }
$$

I737, I740, I752 in Adelebsen erwähnt · Sohn: Joël Levi, Stammvater der Familien Rothschild und Löwenthal

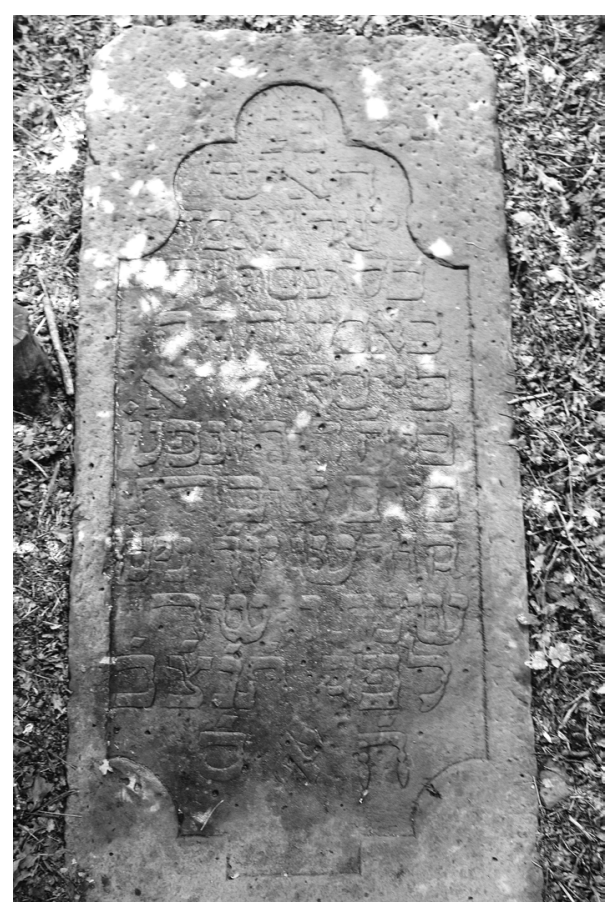

$\mathrm{H} \mathrm{I65} \cdot \mathrm{B} 76 \cdot \mathrm{T} 2 \mathrm{I}$

\begin{tabular}{|c|c|}
\hline & \\
\hline 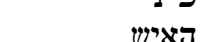 & \\
\hline 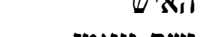 & der Mann, \\
\hline ישר ונאמן & aufrecht und getreu (war er, \\
\hline כל עסקיו היו & all seine Taten geschahen \\
\hline 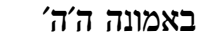 & in Treue. Dies ist der \\
\hline כ' יוספ יהודא & e. Joseph Jehuda, \\
\hline בן ה' דוד ונפט' & Sohn des H. David. Und er verschie(d) \\
\hline ביום שבת & am Tag des heiligen \\
\hline קודש יו'ד' ניסן & Schabbat, 10. Nisan \\
\hline שנת וישר & (im) Jahr 516 \\
\hline לפק ת'נ'צ'ב' & n.kl.Z. S.S.E.B. \\
\hline 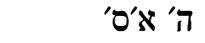 & L. $A($ men) $S$ (ela) \\
\hline
\end{tabular}

8.10 Tages- und Jahresdatum sind kunstvoll gestaltet. Das Tagesdatum besteht aus dem

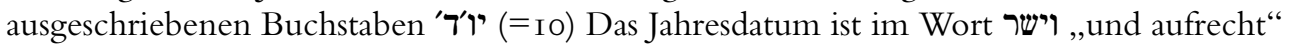
(s. Z. 3; vgl. ferner Hiob I, I) enthalten und ergibt zusammengesetzt aus I (6) ' (I0) ש (300) ᄀ (200) den Zahlenwert 5 I6. 
Rieke eschet Masus

$$
\text { I 4. I I. I } 756
$$

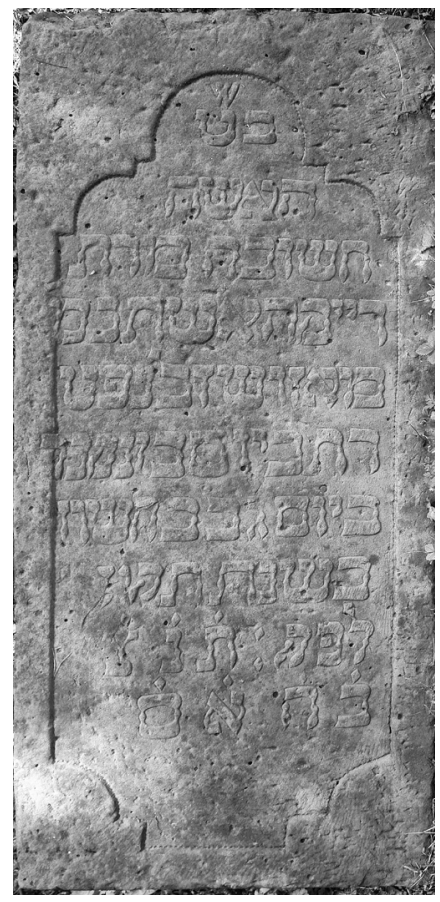

H I55 - B $69 \cdot \mathrm{T}$ I9

$$
\begin{aligned}
& \text { פ' Hier ist geborgen } \\
& \text { האשה פל die Frau, } \\
& \text { die angesehene, Frau } \\
& \text { Rieke, Ehefrau unseres e. Lehrers } \\
& 5 \text { Masus s.G. Sie ver- } \\
& \text { schied am Tag } 2 \text { und wurde begrab(en) } \\
& \text { am Tag 3, 22. Cheschwan } \\
& \text { im Jahr } 517 \\
& \text { n.kl.Z. I.S.E. } \\
& 10 \text { B.L. A(men) S(ela). }
\end{aligned}
$$

4 Oder »Reike« 5 Ein Jude namens Masus bzw. Masos oder seine Witwe ist in den Akten nicht belegt. Möglicherweise handelt es sich um den Vornamen von Moses Katzenstein, der im Jahre 1752 als Schutzjude in Adelebsen erwähnt ist. 


\section{Joseph Meier}

$$
\text { IO.5. } 1758
$$

Seit I 742 Schutzjude in Lödingsen • Ehefrau: Güdel Jacobs ("aus dem Hessischen « L I 762) - Kinder: Röschen (I745/46); Hanna (I747/48); Meyer (I748/49); Jacob (I749/50); Ruben (I752/53)

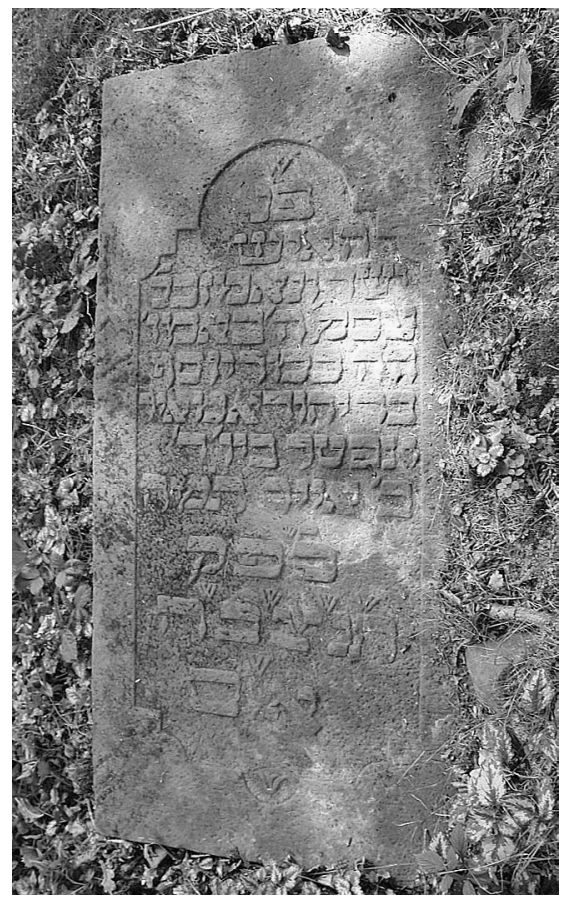

$\mathrm{H} \mathrm{I} 72 \cdot \mathrm{B} 85 \cdot \mathrm{T} 2 \mathrm{O}$

\begin{tabular}{|c|c|}
\hline פ״"נ & Hier ist geborgen \\
\hline 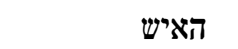 & der Mann, \\
\hline ישר ונאמן כל & aufrecht und getreu (war er), all \\
\hline עסק' ה' באמו' & (seine) Tate(n) gesch(ahen) in Treu(e). \\
\hline 5 ה'ה' כ מר יוסף & Dies ist der e. Herr Joseph, \\
\hline בר יהודא מאיר & Sohn des Jehuda Meir. \\
\hline ונפטר ביו' ד' & Und er verschied am Tag 4, \\
\hline בַ' אייר ת'ק׳יחח & 2. Ijjar 508 \\
\hline רפוּ' ת'ג'צ'ה' & $\begin{array}{l}\text { n.kl.Z. } \\
\text { S.S.E.B.L. }\end{array}$ \\
\hline 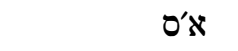 & $A($ men $) S($ ela $)$ \\
\hline
\end{tabular}




\section{Herz Mendel}

$$
\text { 3.IO.I } 760
$$

I738 und I748 in Barterode erwähnt · Kinder: Mendel II 49; Levi (Vater von Philipp, III 44)

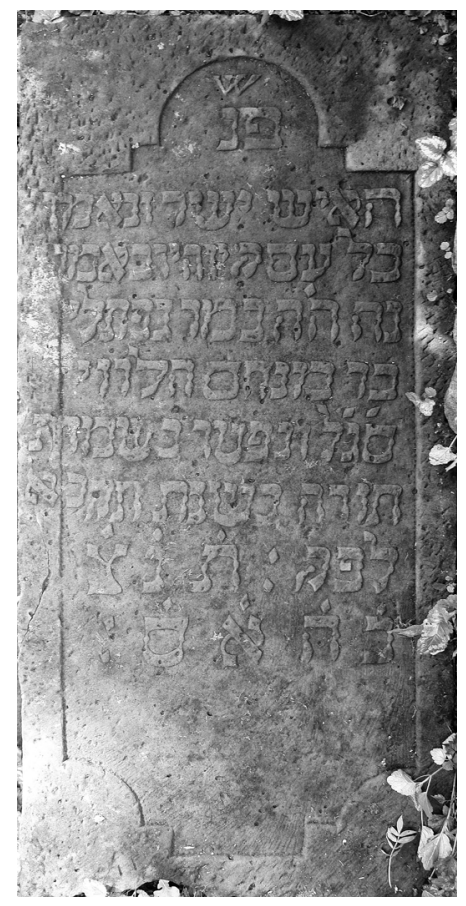

$\mathrm{H} \mathrm{I} 60 \cdot \mathrm{B} 77 \cdot \mathrm{T} \mathrm{I} 3$

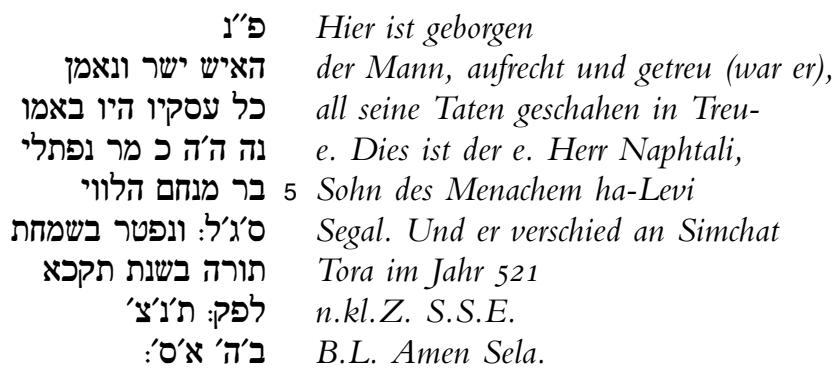

5 הלווי (sic!) · 6 zu Segal s. II 5I · 6/7 Am Fest Simchat Tora (Freude der Tora) wird die Tora als Gottes Gabe gefeiert. Das Fest beendet auch den jährlichen Zyklus der Toralesung und feiert den Beginn des neuen Zyklus. 


$$
\begin{gathered}
\text { Joseph Itzig } \\
\text { 28. I. I76I }
\end{gathered}
$$

Seit I742 Schutzjude in Barterode - Vater: Itzig Arend - Ehefrau: Esther Meyer I 24 . Kinder: Herz (I733/34); Jüdel (I737/38); Arend (I739/40); David (I743/44); Salomon (I745/46); Itzig (I749/50)

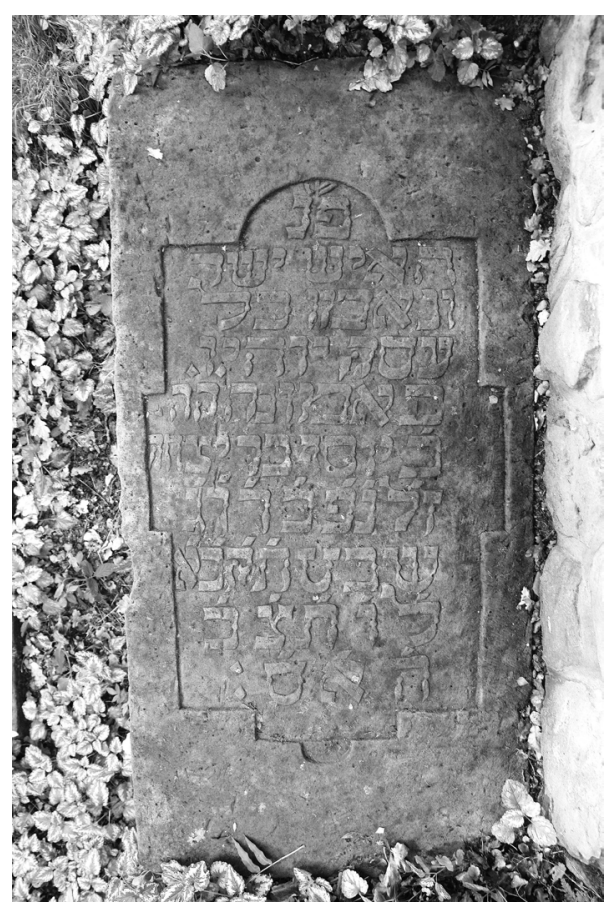

H $170 \cdot$ B $88 \cdot$ T I9

$$
\begin{aligned}
& \text { פ"נ Hier ist geborgen } \\
& \text { der Mann, aufrecht } \\
& \text { und getreu (war er), all } \\
& \text { עסקיו היו seine Taten geschahen } \\
& 5 \text { in Treue. Dies ist der } \\
& \text { e. Joseph, Sohn des Jizchak }
\end{aligned}
$$

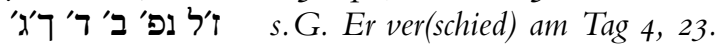

$$
\begin{aligned}
& \text { Schevat } 521 \\
& \text { n.(kl.Z.) S.S.E.B. } \\
& \text {. } 10 \text { L. A(men) S(ela). }
\end{aligned}
$$


Breine bat Meïr

I $3 \cdot 3 \cdot I 770$

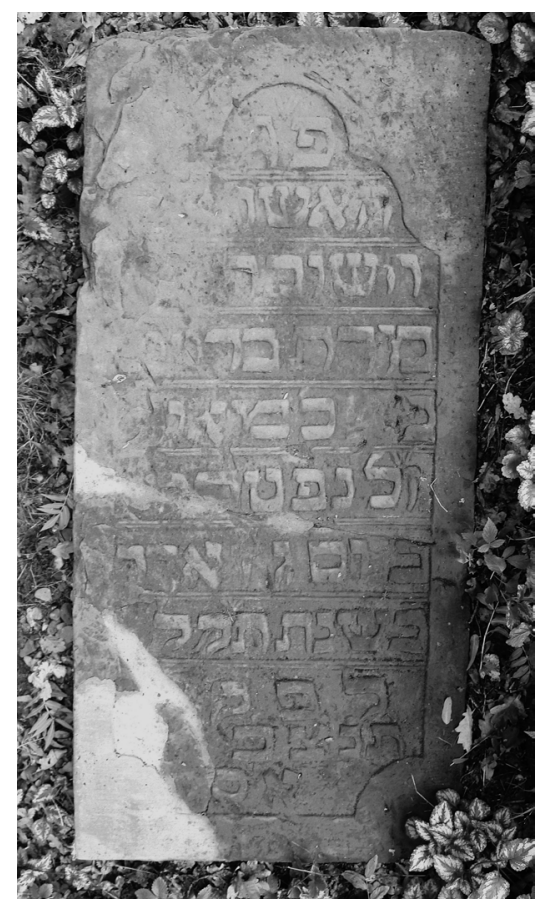

H I56 - B $75^{\cdot}$ T I 7

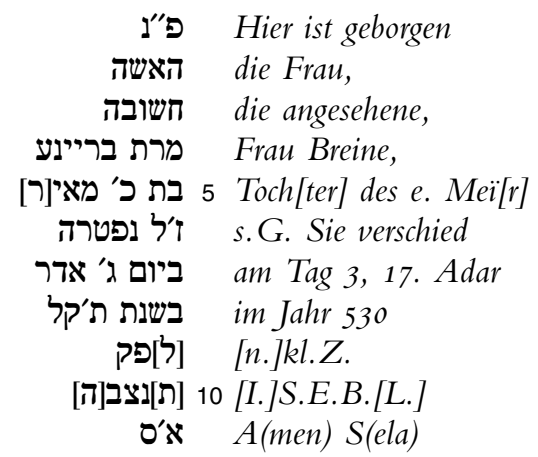

7 Ungewöhnliche Angabe der Zahl I7: ' über dem i angebracht. · Quelle: L I762 (Geburtsjahr nach Altersangabe) 


\section{Beila bat Benjamin}

$$
\text { 29. I.I } 773
$$

In den Archivunterlagen des I 8. Jh.s ist eine Person mit dem Namen Benjamin (bzw. dem Parallelnamen Wolf) für Adelebsen nicht belegt.

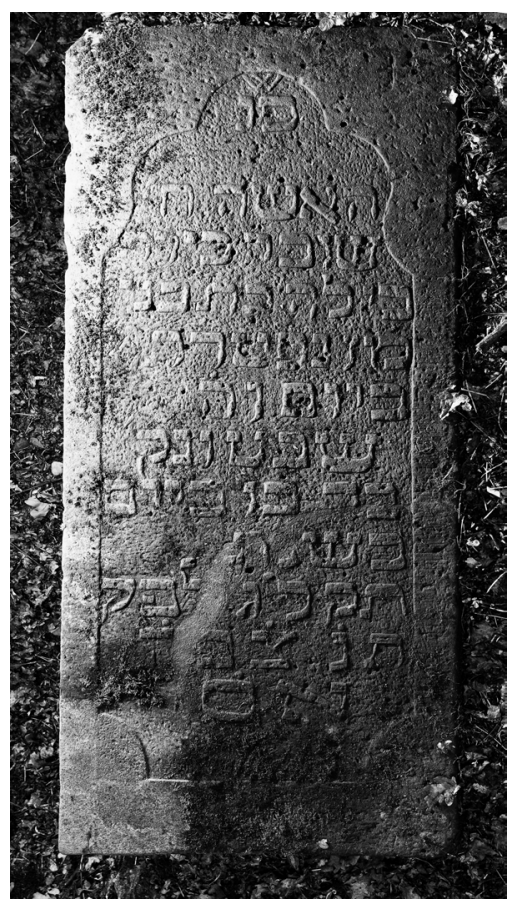

$\mathrm{H} \mathrm{I} 65 \cdot \mathrm{B} 70 \cdot \mathrm{T}$ I4

פ"ג Hier ist geborgen

האשה ח פ"נ die Frau, die an-

gesehene, Frau,

Beila, Tochter des Benja-

5 min. Sie verschied

am $\operatorname{Tag} 6,5$.

Schevat, und wurde begra-

ברון'[ בו ביום

im Jahr

תקלג לפק 10533 n.kl.Z.

I.S.E.B.L.

א' A(men) S(ela) 


\section{David Arend}

$$
\text { 23.2.1 } 773
$$

I752 Schutzerteilung für Adelebsen abgelehnt, I766 als Häusling (mit Frau und zwei Kindern) in Barterode erwähnt. · Vater: Arend Isaac

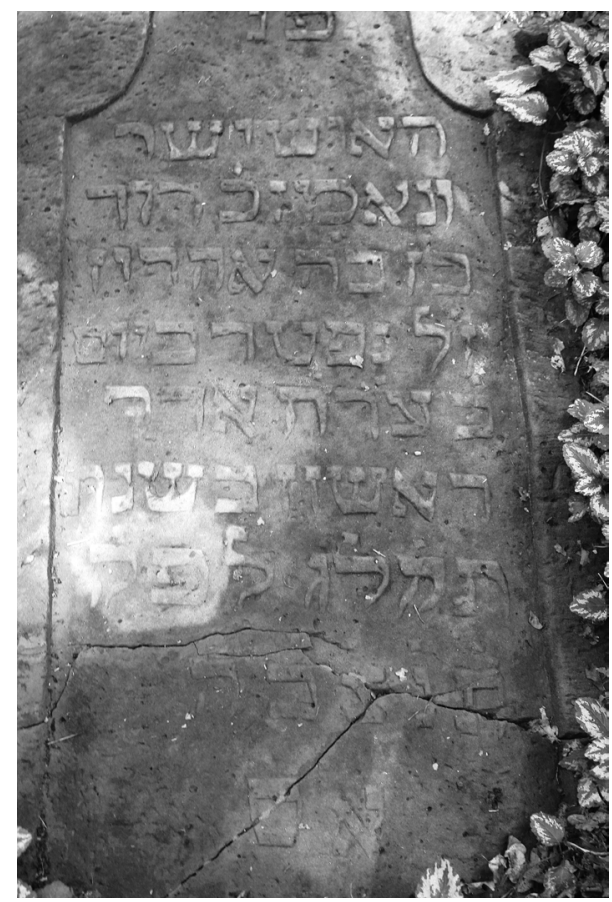

$\mathrm{H} \mathrm{I}_{1} 3 \cdot \mathrm{B} 74 \cdot \mathrm{T}$ I 3

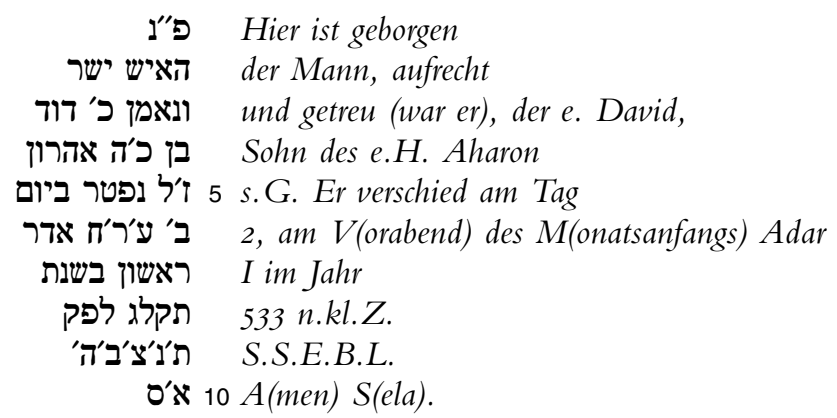

6 vgl. III $66 \cdot 7 \mathrm{zu}$ Adar I s. S. 5I 
Zerle bat Schlomo

8.3. 1773

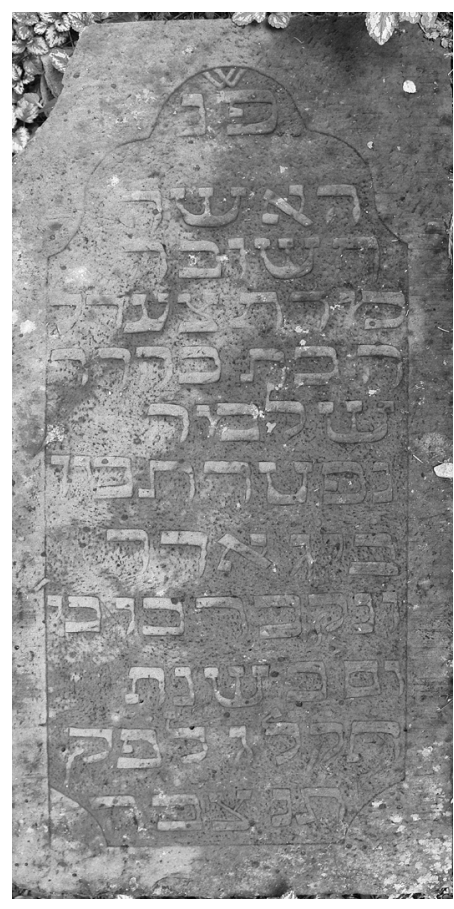

$\mathrm{H} \mathrm{I60} \cdot \mathrm{B} 7 \mathrm{I} \cdot \mathrm{T}$ I5

$$
\begin{aligned}
& \text { פצ'נ Hier ist geborgen } \\
& \text { האשה die Frau, } \\
& \text { משובה die angesehene, } \\
& \text { Frau Zerle, } \\
& \text { שלמה } 5 \text { Tochter des e.H.u.M. } \\
& \text { שלמה Schlomo. } \\
& \text { Sie verschied am Tag } \\
& \text { 2, 13. Adar, } \\
& \text { ונקבר]'[ בו בי' ניר } \\
& \text { Tag } 2 \text { (im) Jahr } \\
& 533 \text { n.kl.Z. } \\
& \text { ת'ת'נ'צ'ב'י'ה' I.S.E.B.L. }
\end{aligned}
$$

6 Ein Salomon, der als Vater dieser Frau in Frage kommen könnte, ist in den Akten nicht belegt. 
Merle bat Jaakov

I 2.5.I 775

Eltern (?): Jacob Nathan I 7 - Elkele I 5

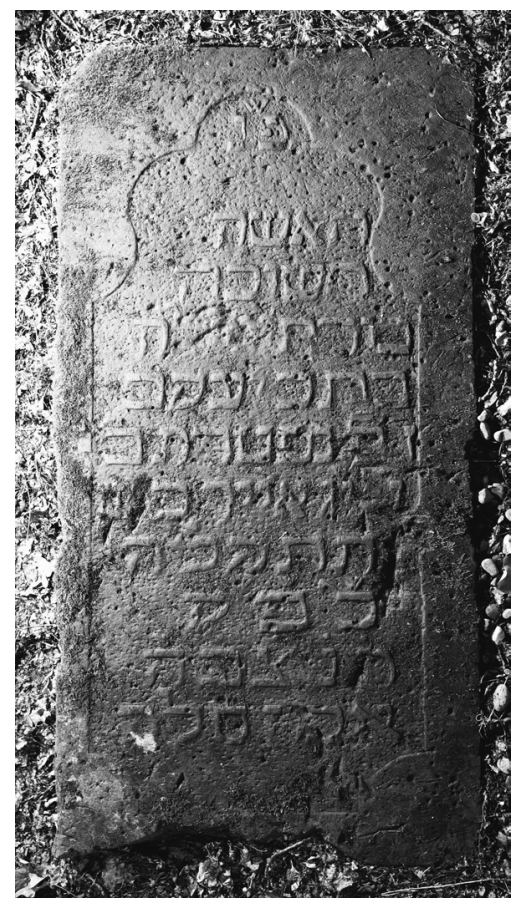

H I59 $\cdot$ B $74 \cdot$ T I3

פַּ Hier ist geborgen

האשה die Frau,

חשובה die angesehene,

Frau Mer[l]e,

5 Tochter des e. Jaakov

s.G. Sie verschied am [Tag]

6, 13. Ijjar im Ja-

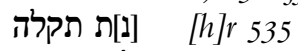

n.kl.Z. I.S.E.B.L.

10 Amen Sela. 
Moses Ilten

I 7.IO.I $775-29.3 .1778$

Vater (?): Levi Moses Ilten I 25

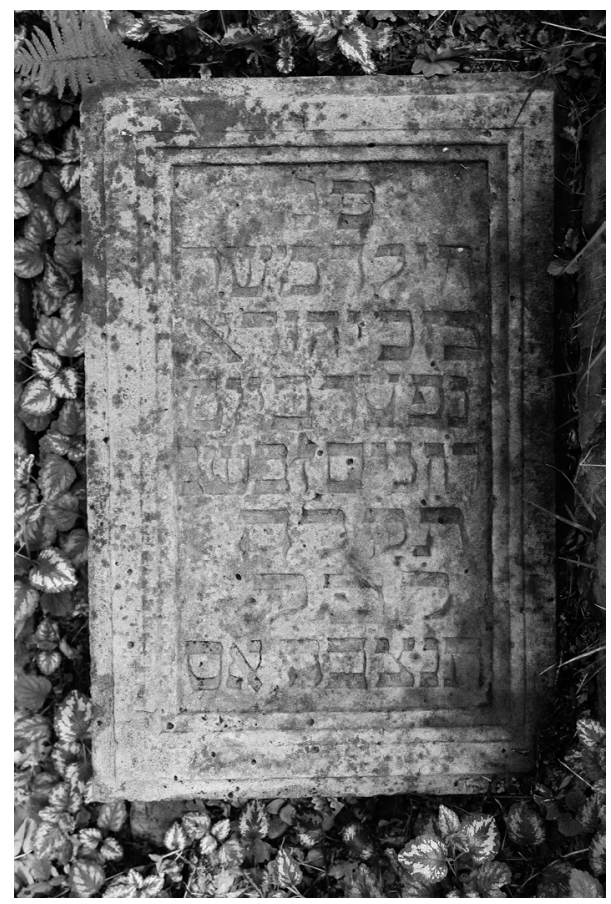

$\mathrm{H} 83 \cdot \mathrm{B} 58 \cdot \mathrm{T}$ I 5

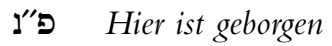

הילד משה פ"der Knabe Mosche,

בן כ' יהודא משר Sohn des e. Jehuda.

Er verschied am

5 Tag des Monatsanfangs Nisan im Ja(hr)

538

לפק' n.kl.Z.

S.S.E.B.L A(men) S(ela).

Quelle: Mappa Nr. I5 (Geburtstag) 
Schmeiche Moses

I $739 / 40-$ I6.7.I 785

I777 Antrag auf Schutzerteilung - Eltern: Moses Meyer Ilten I 9 - Gelle Meyer - Sohn: Samuel Simon Oppenheim[er] III I2

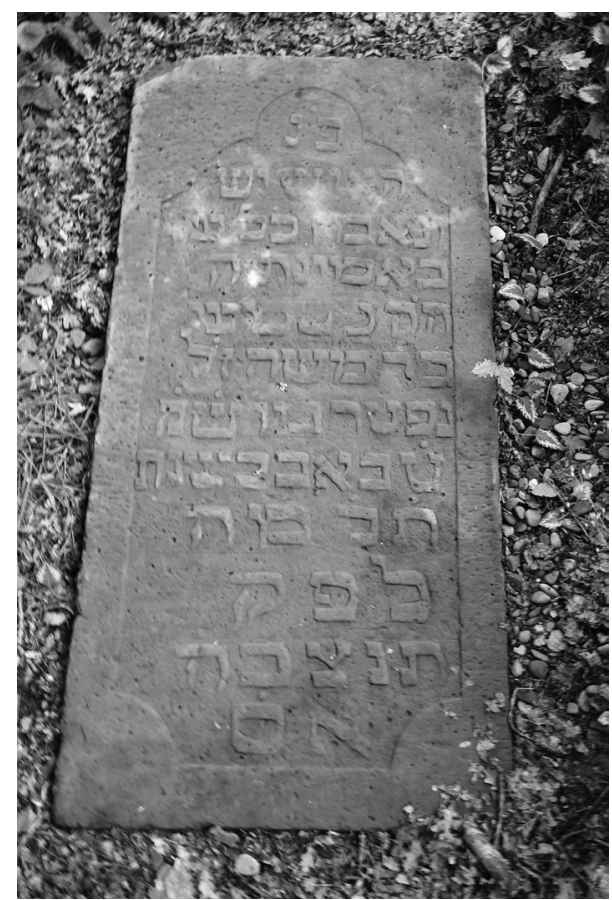

$\mathrm{H} \mathrm{I59} \cdot \mathrm{B} 77 \cdot \mathrm{T}$ I4

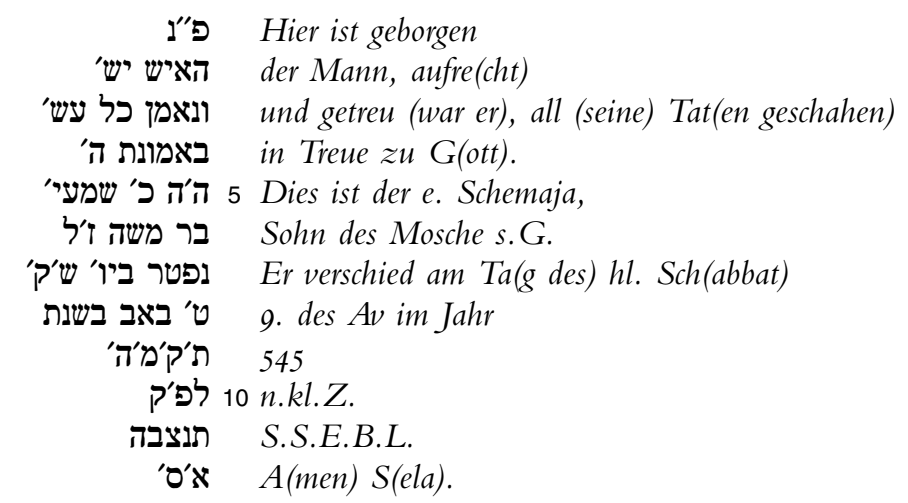

8 zum 9. Av (Tischa b’Av) s. IV $35 \cdot$ Quelle: L I762 (Geburtsjahr nach Altersangabe) 


\section{Esther bat Meïr}

$$
\text { 28.6.I79I }
$$

Eltern (?): Meyer Levi I 4 - Freidche I 6 - Ehemann (?): Joseph Itzig I I7

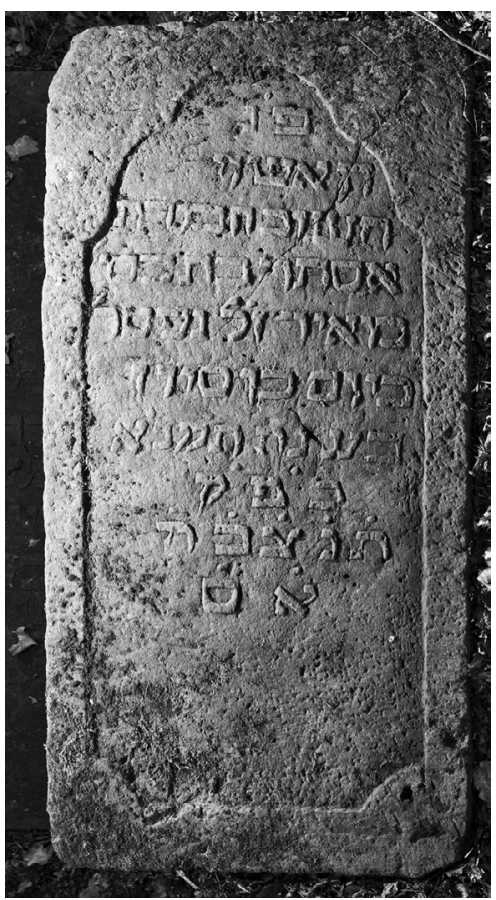

$\mathrm{H}$ I $58 \cdot \mathrm{B} 68 \cdot \mathrm{T}$ I 8

פ"ג Hier ist geborgen

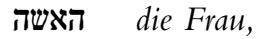

חשובה מרת die angesehene, Frau

Esther, Tochter des e. H(errn)

5 Meir s.G. Sie verschie(d)

am 26. Siwan

ל בשנת תקנא

n.kl.Z.

ת'ניפקיב'ה' I.S.E.B.L.

א' 10 A(men) S(ela) 
Buna bat Menachem Mosche

I6. IO.I 792

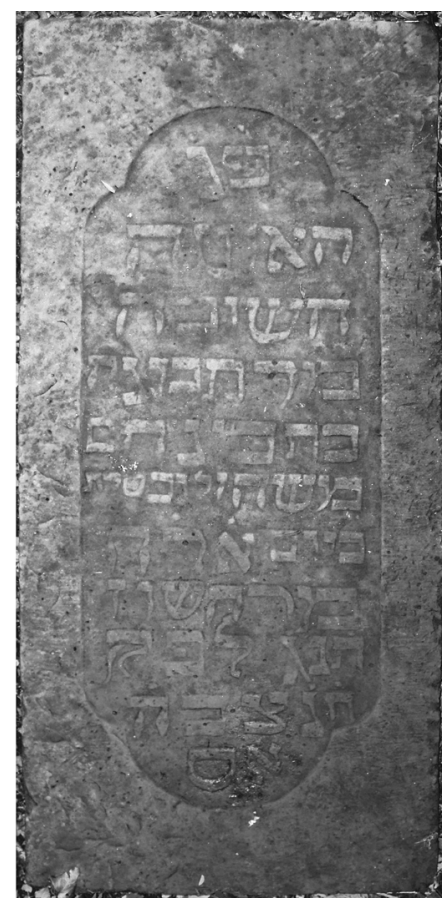

H I8I - B $78 \cdot \mathrm{T}$ I 8

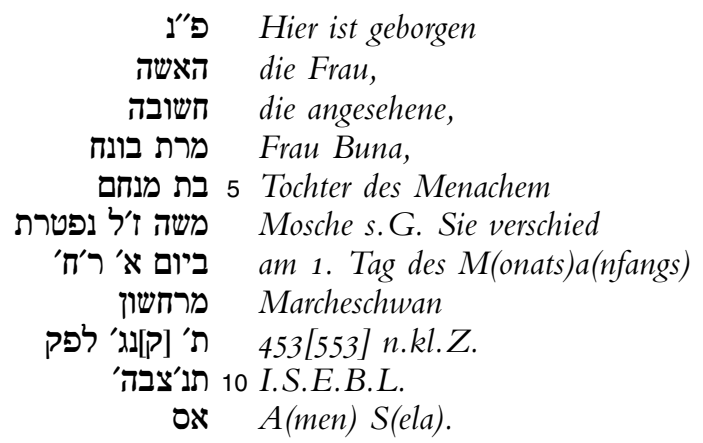

4 בונח, fehlerhafte Schreibung für בונה. 8 Nach der auf dem Grabstein vorhandenen Datumsangabe I I.IO.I692. Dagegen spricht jedoch, dass die benachbarten und stilistisch ähnlich gestalteten Grabsteine I I 8 I is I Io I 22 I I9 alle aus der 2. Hälfte des I 8. Jahrhunderts stammen. Offenbar wurde bei der Angabe der Jahreszahl nach $\Omega(=400)$ das $P$ (= IOO) vergessen: 553 $=\mathrm{I} 792 / 3$. 


$$
\begin{gathered}
\text { Levi Moses Ilten } \\
\text { um I737/38 - I6.IO.I } 807
\end{gathered}
$$

Seit 1777 Schutzjude in Adelebsen · Eltern: Moses Ilten I 9 - Gelle Meyer

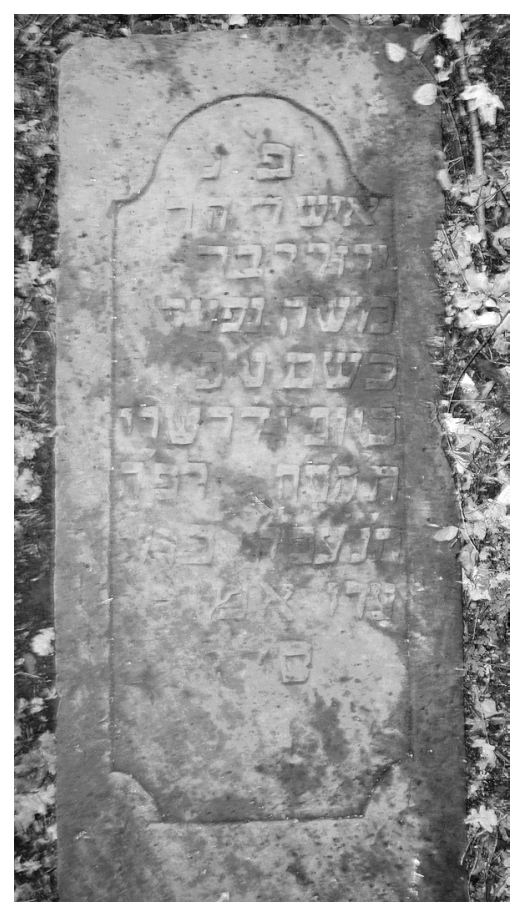

\begin{tabular}{|c|c|}
\hline & \\
\hline פּ"נ & Hier ist geborgen \\
\hline איש היקר & der geachtete Mann \\
\hline יהודה בר & Jehuda, Sohn des \\
\hline משה נפטר & Mosche. Er verschied \\
\hline 5 בשם טוב & in gutem Namen \\
\hline ביום ג ד' דע & am $\operatorname{Tag} 3$, 4. [T]ischri \\
\hline תקסח לפק & 568 n.kl.Z. \\
\hline תנצבה בגן & S.S.E.B.L. im Garten \\
\hline עדן אמן & Eden. Amen \\
\hline & \\
\hline
\end{tabular}

$\mathrm{H}{ }_{76} \cdot \mathrm{B} 74 \cdot \mathrm{T} 20$

6 תשרי (Tischri). · Quelle: L I762 (Geburtsjahr nach Altersangabe) 


\section{Jehuda Leib ben Schimon}

$$
\text { I } 735 / 36-3 . \text { I I.I } 809
$$

Eltern: Simon Meyer - Röschen Simcha - Ehefrau: Friederike - Kinder: Friederike (I773-I849, Duderstadt); Rahel (I774-I852, Mollenfelde); Simon Rosenberg (I780I865, Burgdorf: Grab 4I); Lucas Stehberg III 79; Betty (I796)

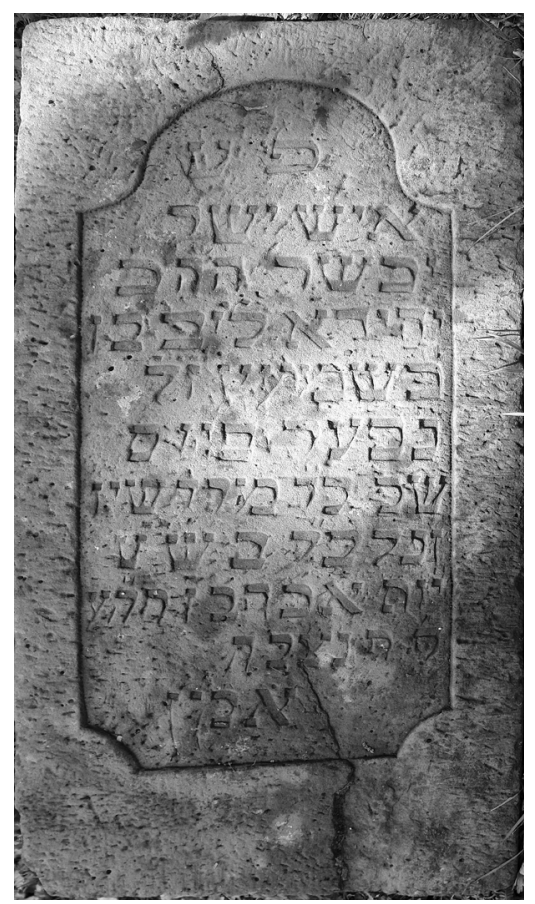

$\mathrm{H} \mathrm{I}_{70} \cdot \mathrm{B} 79 \cdot \mathrm{T} 2 \mathrm{I}$

$$
\begin{aligned}
& \text { פ'ט Hier ist geborgen } \\
& \text { איש ישר } \\
& \text { und geschickt. Dies ist der e. } \\
& \text { יהודא ליב בן Jehuda Leib, Sohn des }
\end{aligned}
$$

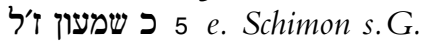

$$
\begin{aligned}
& \text { Er verschied am Tag des } \\
& \text { Sב' Sד Sch(abbat), 24. Marcheschwan, } \\
& \text { ונקבר בש'ט מר מרו } \\
& \text { am } \operatorname{Tag} 1 \text { 1, 25. i(m) s(elben Monat) } 570 \\
& \text { } 10 \text { n.kl.Z. S.S.E.B.L. }
\end{aligned}
$$

נפער Fehlschreibung für נפטר: • 6 s. babylonischer Talmud Berakhot I7a - Quellen: L I762 (Geburtsjahr: Rückrechnung nach Altersangabe) 
Eltern: Joel D. Rothschild II I 8 - Hindel II is

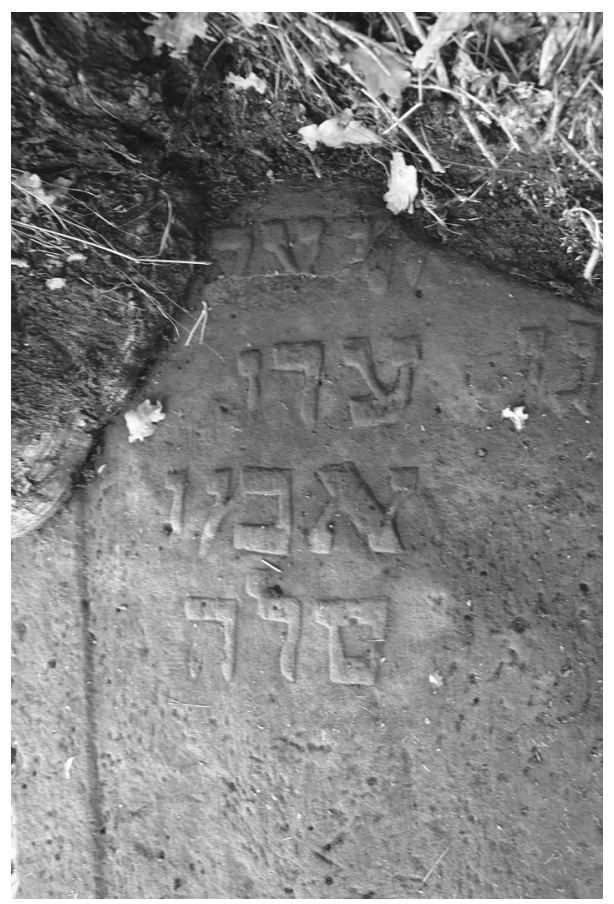

$\mathrm{H} \mathrm{I} 75 \cdot \mathrm{B} 70 \cdot \mathrm{T}$ i6

Zerbrochener Stein, von Baumwurzeln umwachsen. Bei der Textaufnahme I989 noch in beiden Teilen erhalten, inzwischen nur der untere Teil vorhanden

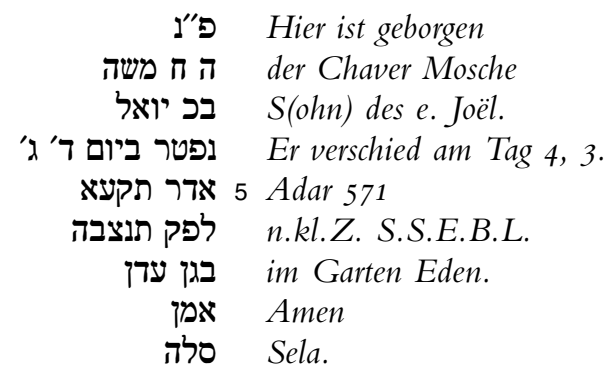

2 Chaver $=$ Genosse; vermutlich Kennzeichnung als Mitglied der örtlichen Beerdigungsgenossenschaft (Chevra Kaddischa), möglich aber auch Hinweis auf das Ansehen als torakundiges Gemeindeglied. - 4 Gegen das Datum des Sterbetags spricht ein amtliches Schreiben vom 20.2.I I I I in dem berichtet wird: "Es ist ferner Moses Joel Rothschild vor einigen Wochen ohne einiges Vermögen zu hinterlassen verstorben ...« (HStAH, Hann. 74 Uslar Nr. 2067) 
Hindel bat David

I $743 / 44-29.8$. I 8 I I

Ehemann: Joel D. Rothschild II I 8 - Kinder: Moses II ıо; Amalia II I2; Salomon III 4O; Johanne III 87

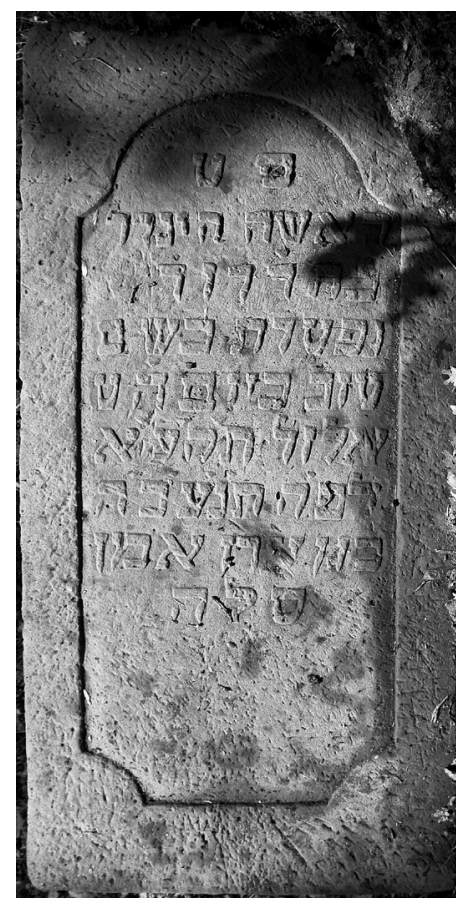

H I70 - B $77 \cdot$ T I6

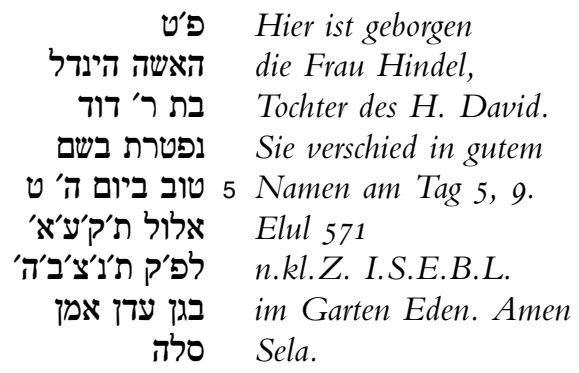

Quelle: HStaH, Hann. 74 Uslar Nr. I058 
Gidel Backstein, geb. Rosenberg 26.9. I 8 I I

Geb. vermutl. in Dankelshausen - Vater: Mendel Rosenberg/Esberg, Dankelshausen · Ehemann: Abraham Backstein II 27 · Kinder: Herz (I800-I877, Dransfeld: Grab 64), Mendel (I802), Malchen (I804), Henriette III 69, Telzchen (I8IO)

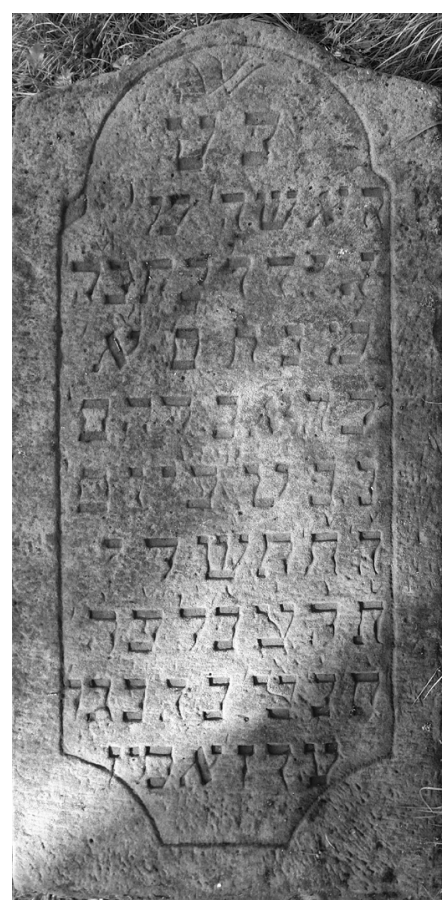

$\mathrm{H}{ }_{\mathrm{I}} 64 \cdot \mathrm{B} 72 \cdot \mathrm{T}$ I 5

פטier ist geborgen

['] die Frau, Fr[au]

גידל בת כה Gidel, Tochter des e.H.

['] Menachem, E[hefrau]

des e.H. Avraham.

Sie verschied am

Tag 5, 8. Tischri

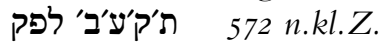

ת'ת'ניצ'בה בגן לפקי

10 Eden. Amen. 
Schafti Ilten

I $2.7 .18 \mathrm{I} 2$

Eltern: Moses Meyer Ilten I 9 - Gelle Meyer - Ehefrau: Edel II I9

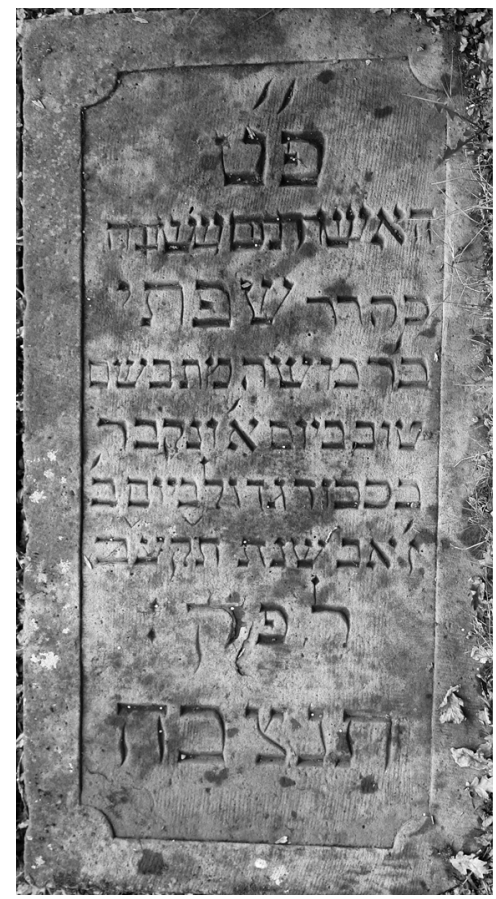

H I6I - B 8 I $\cdot$ T I 8

Ursprünglich für ein Frauengrab vorgesehener Stein, s. zu Z. 2

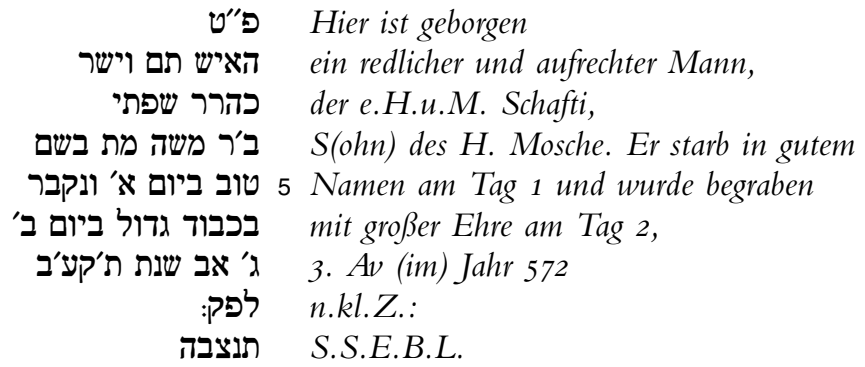

2 Unter dem Text sind Teile einer weiteren Inschrift erkennbar: die , האישה החשובה angesehene Frau“. · 3 Schafti bzw. Schafte, jiddische Kurzform von Sabbatai · 5f s. babylonischer Talmud Berakhot I7a 
Mosche bar Pinchas

22.3 .18 I 3

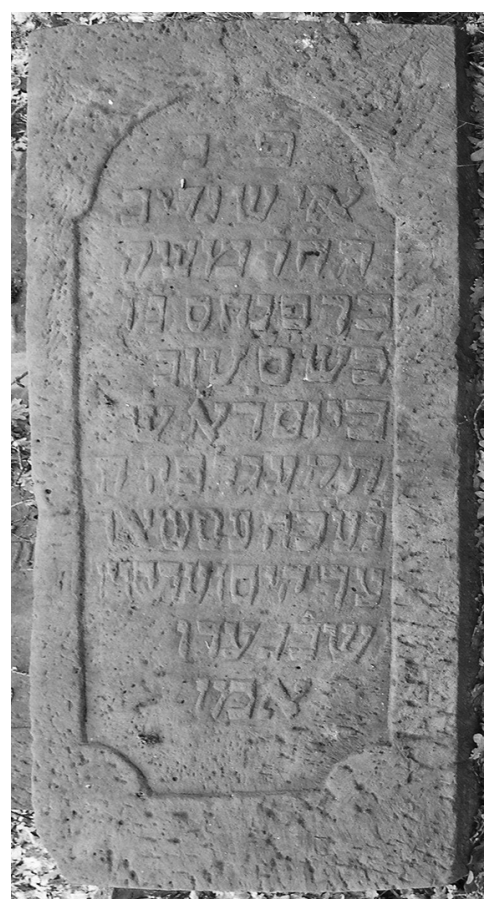

H I74 $\cdot$ B $73 \cdot$ T I 5

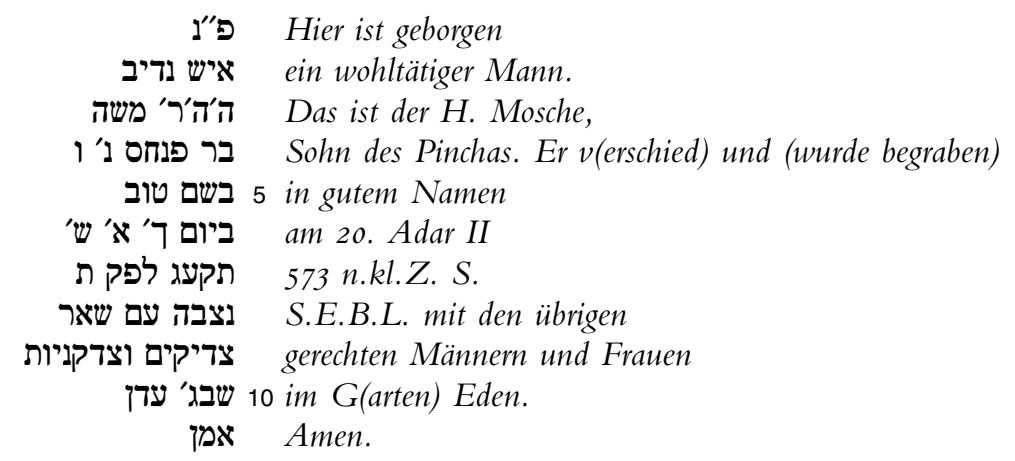

5 s. babylonischer Talmud Berakhot I7a 
Joel D. Rothschild

$$
\text { I739/40 - 30.8. I } 8 \text { I } 4
$$

Vater: David Joel · Ehefrau: Hindel II is · Kinder: s. ebd. · Bruder: Levi David Löwenthal II 3 I

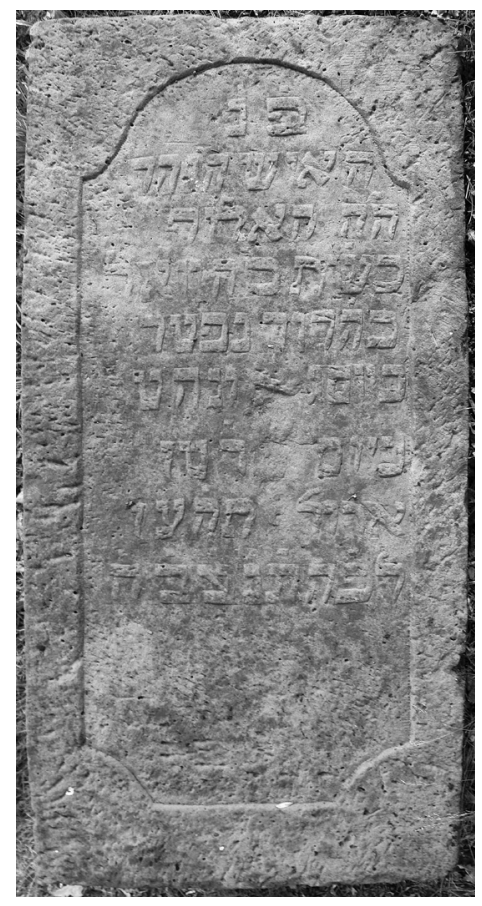

$\mathrm{H} \mathrm{I75} \cdot \mathrm{B} 75 \cdot \mathrm{T}$ I6

פעינ Hier ist geborgen

האיש היקר der geachtete Mann,

d(as) i(st) der Vorsteher

e(hrenvollem) N(amens), der e.H. Joël,

5 S(ohn) des H. David. Er verschied

am Tag 3 und wurde beg[raben]

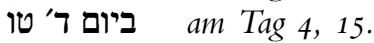

Elul 574.

n.kl.Z. S.S.E.B.L.

Quelle: HStaH, Hann. 74 Uslar Nr. I058 


\section{Levi Daniel Rosenthal}

$$
6.3 .18 \text { I } 5
$$

Um I 790 »aus der Gegend von Preußisch Münden [= Minden/Westfalen] als Lehrer nach Adelebsen gekommen und sich daselbst ohne Schutz verheirathet" (HStAH, Hann. 74 Uslar Nr. 2065) · Ehefrau: Miene Rothstein II 9 - Sohn: s. ebd.

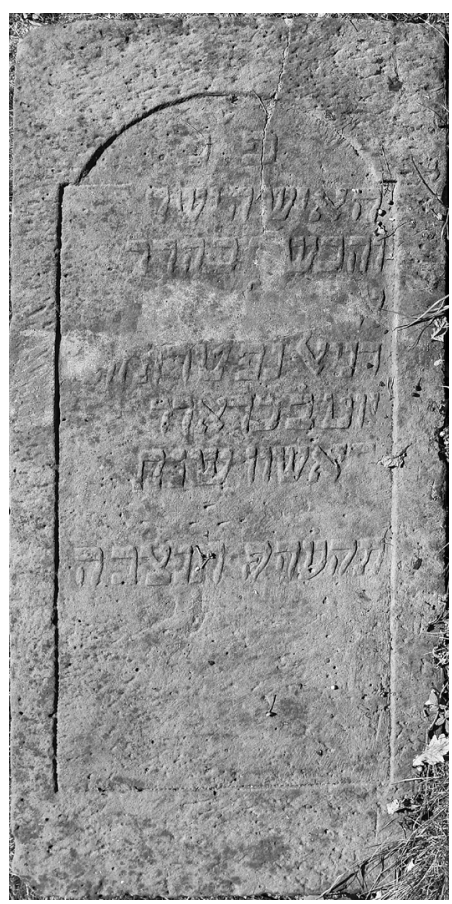

$\mathrm{H}$ I $80 \cdot \mathrm{B} 78 \cdot \mathrm{T}$ i 8

פ"נ Hier ist geborgen

der Mann, aufrecht

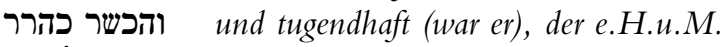

Jehuda Leib, Sohn des

5 Daniel. Er verschied und wurde begraben

יום ב' כד אדר

I (im) Jahr

575 n.kl.Z. S.S.E.B.L. 


\section{Rachel Ilten}

I $746-3$ I.3.I 8 I 5

Eltern (?): Moses Meyer Ilten I 9 - Gelle Meyer

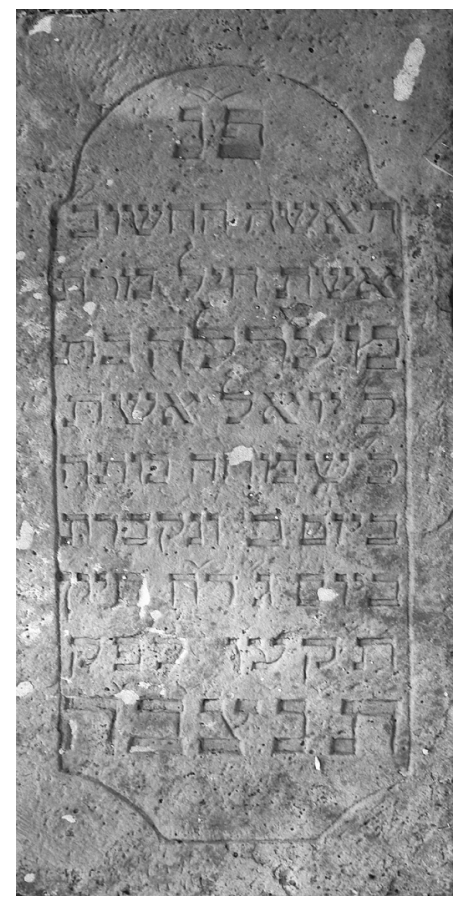

H I64 $\cdot$ B $75 \cdot$ T I9

פ'ט Hier ist geborgen

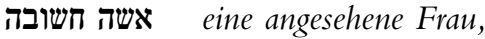

die bescheidene Frau

Rachel, Tochter des e. Mosche.

5 Sie verschied am Tag 1

und wurde begraben am

ב' ג' ג'יסן

576 n.kl.Z.

I.S.E.B.L. 
Abraham Moses Edelstein

$$
\text { I } 743 / 44-4.4 .18 \text { I } 6
$$

Eltern: Moses Meyer Ilten I 9 - Gelle Meyer - Ehefrau: Edel Friedheim II $25 \cdot$ Kinder: ebd.

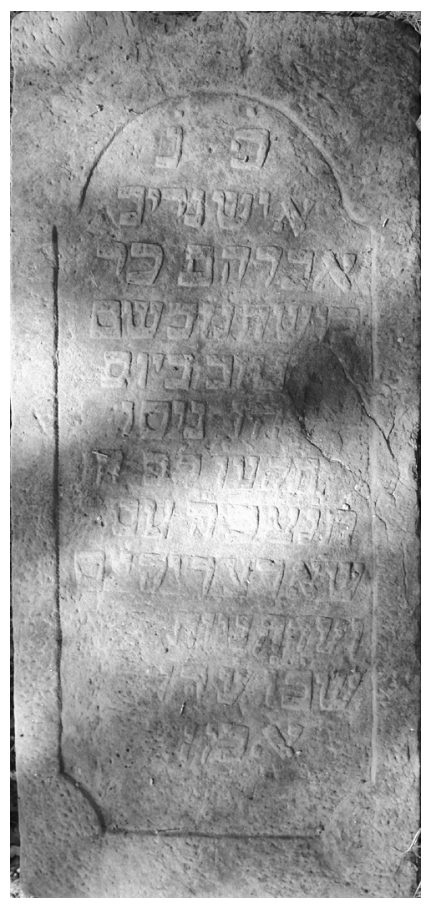

H I68 - B $68 \cdot$ T I6

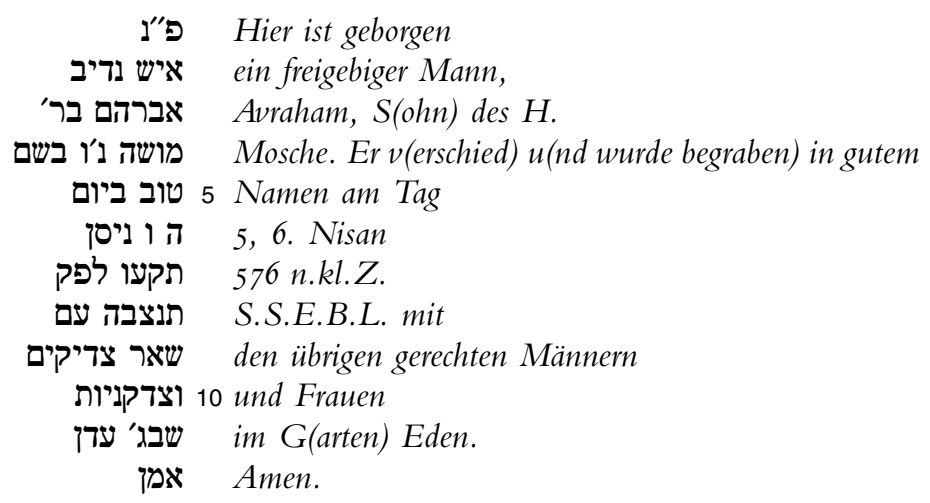


Amalie Eichenberg, geb. Rothschild I 78 I $/ 82-27.5$. I 8 I 6

Eltern: Joel D. Rothschild II 18 - Hindel bat David II I5 - Ehemann: Simon Meyer Eichenberg II $35^{\circ}$ Kinder: Simon III 83; David IV 6; Meyer (I8I3)

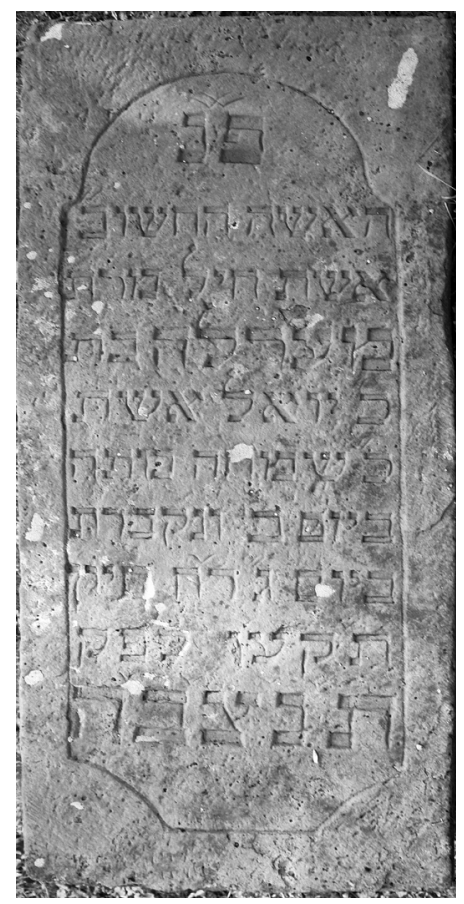

$\mathrm{H} \mathrm{I72} \cdot \mathrm{B} 7 \mathrm{I} \cdot \mathrm{T}$ I 8

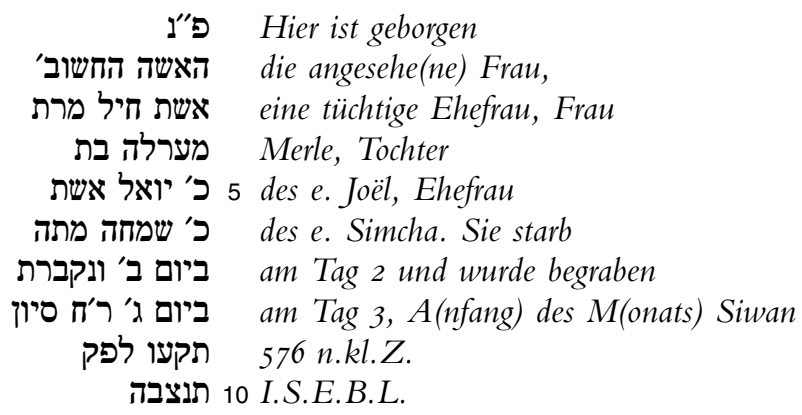

3 s. Prov 3 I, Io · Quelle: HStaH, Hann. 74 Uslar Nr. I058 
Kalonymus ben Mosche

$$
\text { 6.2. I } 8 \text { I9 }
$$

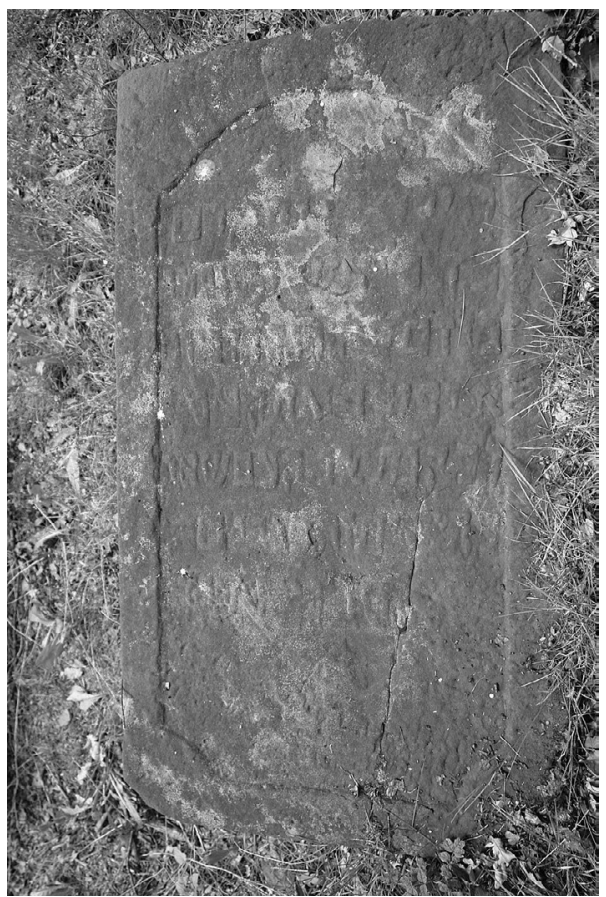

$\mathrm{H}$ I I3 $\cdot \mathrm{B} 64 \cdot \mathrm{T}$ I 3

Erhabene Inschrift, verwittert

פיל

הילד קלונמוס der Knabe Kalonymus,

Sohn des e.H. Mosche. Er verschied

am Tag des hl. Sch(abbat) und wurde begraben am Tag 1, 12. Schevat 579

n.kl.Z. S.S.E.B.L. mit den übrigen

Gerechten und Frommen

שבג'עי im Gar(ten) E(den). 
Nathan ben Baruch

3.7.I 820

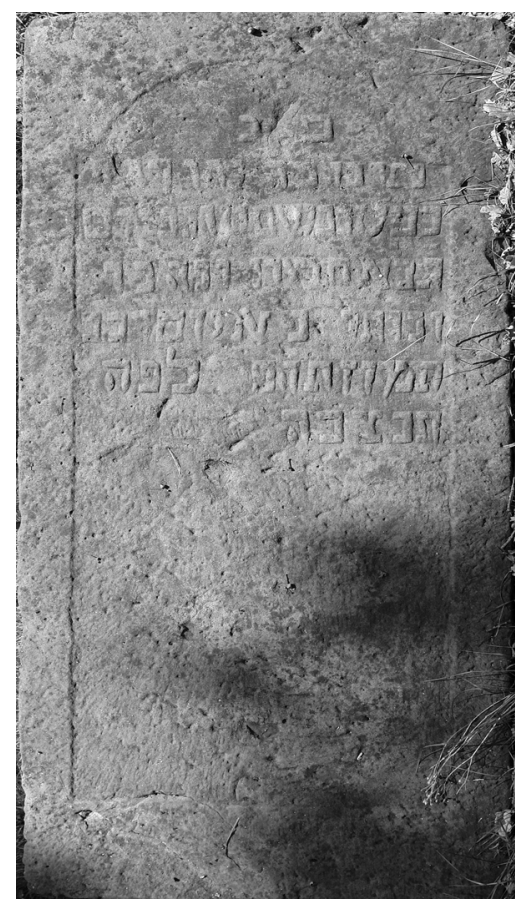

$\mathrm{H} \mathrm{I75} \cdot \mathrm{B} 76 \cdot \mathrm{T}$ I 8

פמינ Hier ist geborgen

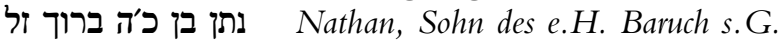

Er verschied in gutem Namen am Tag

3, 21. Tammuz, und wurde begraben

5 [...] am Tag 4, 22.

Tammuz 580 n.kl.Z.

S.S.E.B.L.

3 s. babylonischer Talmud Berakhot I7a - 5 פ ונותר כא / läßt sich nicht übersetzen, vermutlich Abschreibfehler, Verlesung und Aufnahme vorhergehender Textteile. 
Abraham Backstein

$$
\text { 24.6. I } 82 \text { I }
$$

Viehhändler in Güntersen · Ehefrauen: I. Gidel Rosenberg II 32; 2. N.N. (gest. I 832) · Kinder: I: s. zu II 32

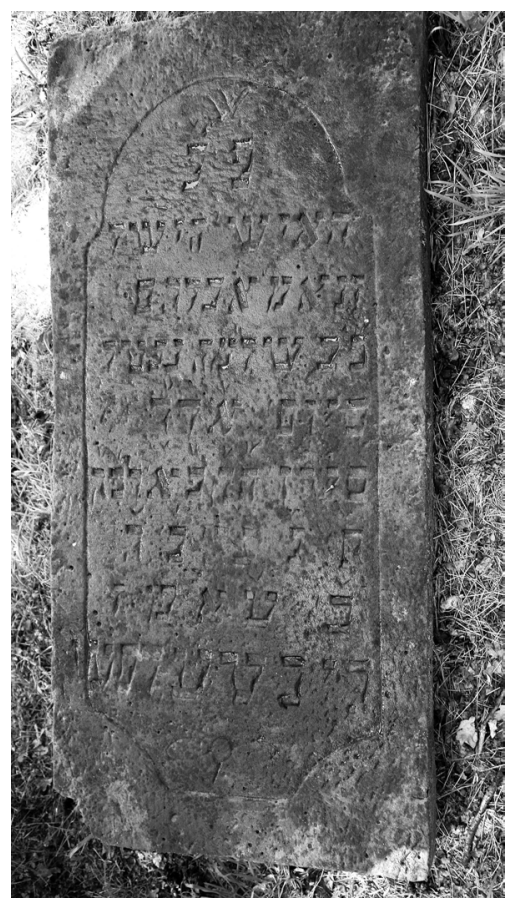

$\mathrm{H} \mathrm{I6I} \cdot \mathrm{B} 74 \cdot \mathrm{T}$ I4

פַינ Hier ist geborgen

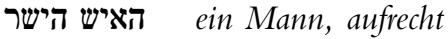

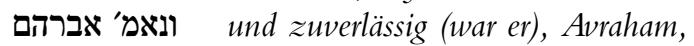

Sohn des e. Schlomo. Er verschied

5 am Tag 1, 24.

סיון ת'ק'פ'א' לפ'ק' Siwan 581 n.kl.Z.

ת.S.E.B.L.

ב'ע' אמן

Güntersen 
Edel Ilten

27.I2.I 82 I

Ehemann: Schafti Ilten II I6

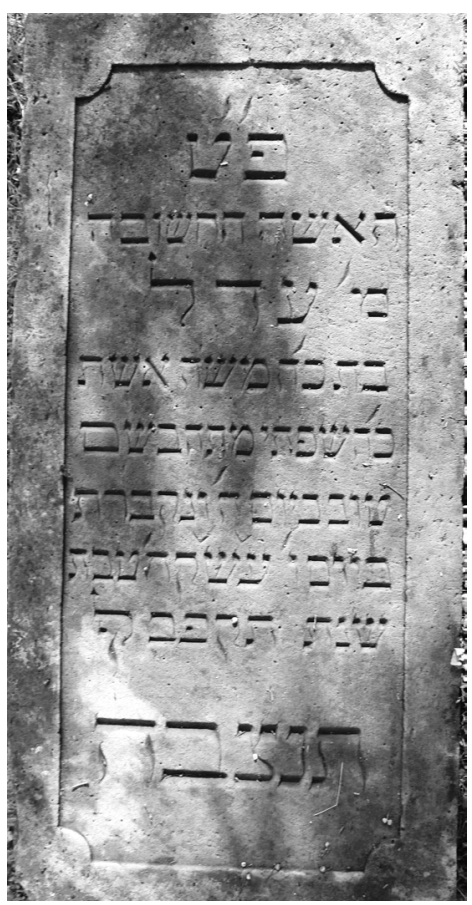

$\mathrm{H} \mathrm{I60} \cdot \mathrm{B} 78 \cdot \mathrm{T}$ I 8

פ'

האשה החשובה פ' die angesehene Frau,

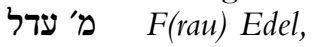

Tochter des e.H. Mosche, Ehefrau des

5 e.H. Schafti. Sie starb in gutem

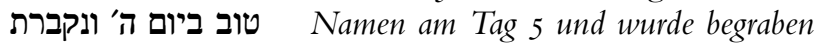

am Tag 6, am V(orabend) des hl. Sch(abbat), 4. Tevet

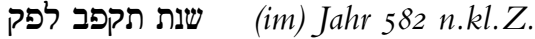

I.S.E.B.L.

5 s. baylonischer Talmud Berakhot I7a 


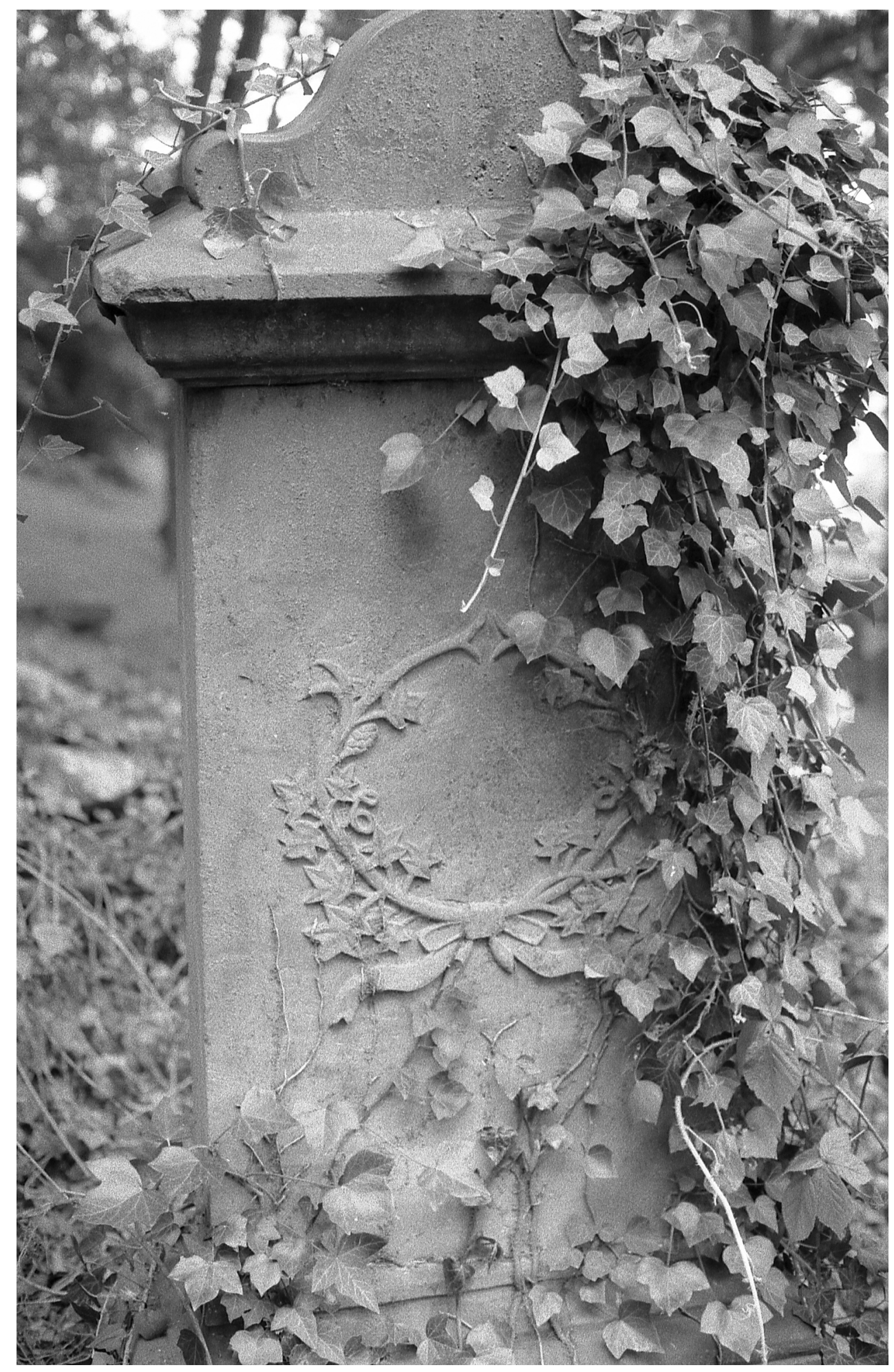




\section{Meyer Philipp Freudenstein}

$$
\text { I6.9.I } 739-3 \text { I.I2.I } 82 \text { I }
$$

Vater: Philipp Jacob (?) · Ehefrauen: I. Name unbekannt; 2. Golde / Julchen; 3. Name unbekannt (Witwe) · Kinder: zu I): Philipp Rosenstein (I769-I848); Marcus Löwenstern II 29; zu 2): Sara (I780-I835, Dransfeld: Grab 34); Rosette (I782-I86I, Burgdorf); Jacob Meyer (I786-I 858, Dransfeld: Grab I06); Samuel Freudenstein III 68; Moses Freudenstein II 38

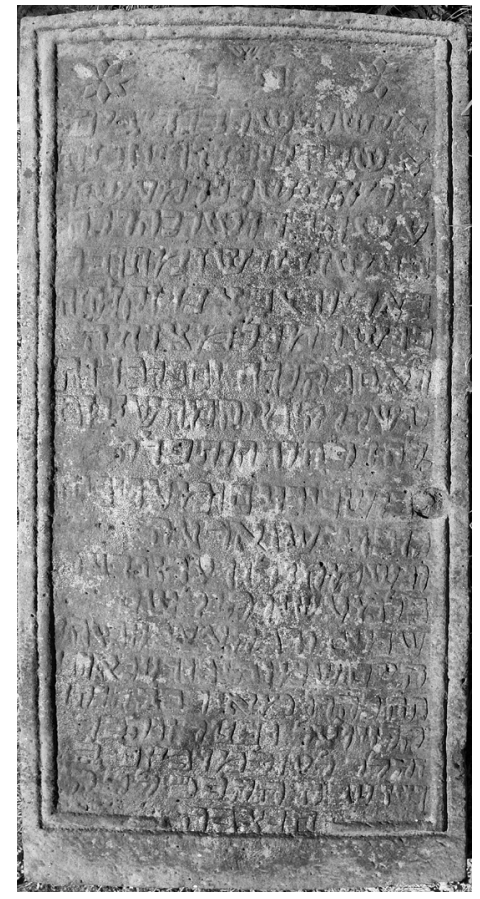

$\mathrm{H} \mathrm{I} 83 \cdot \mathrm{B} 78 \cdot \mathrm{T} \mathrm{I} 7$ 


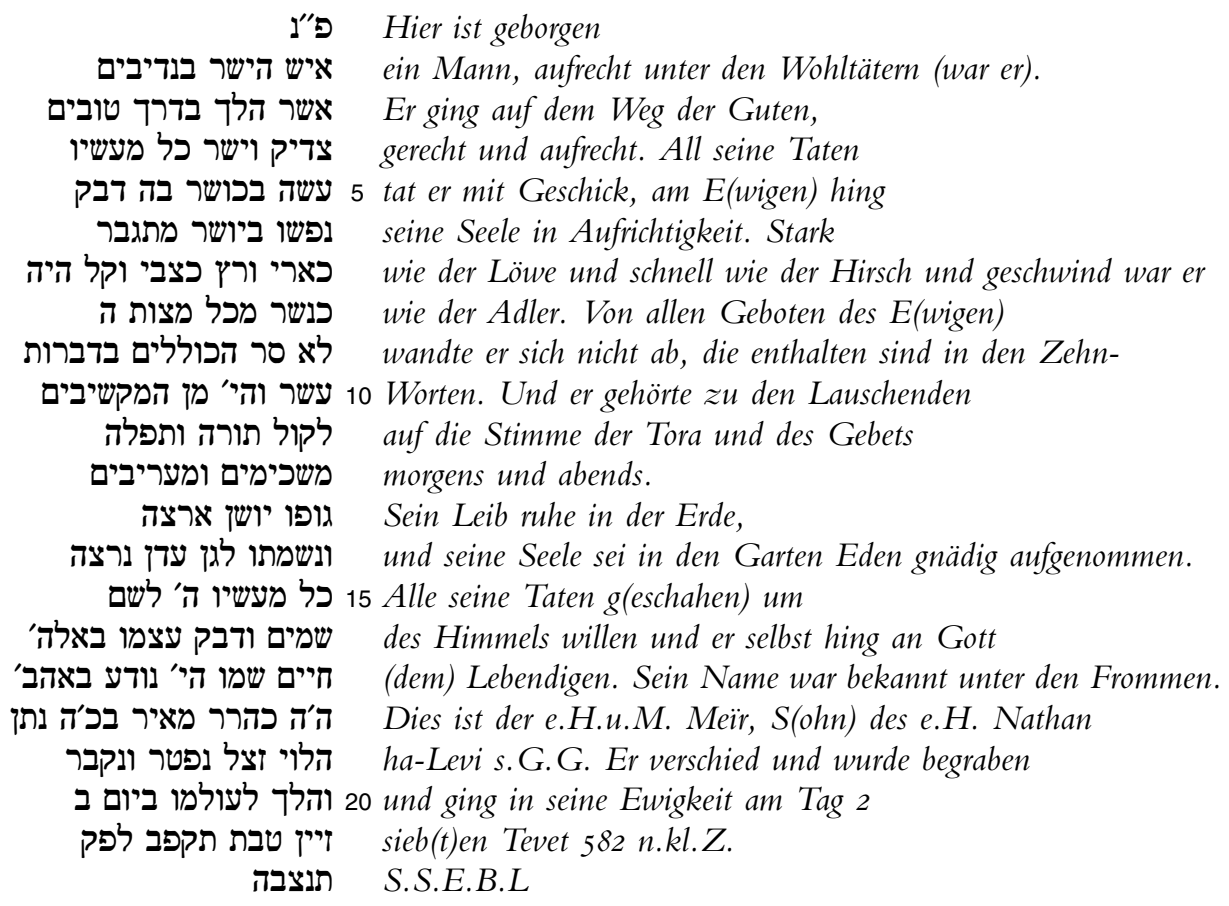

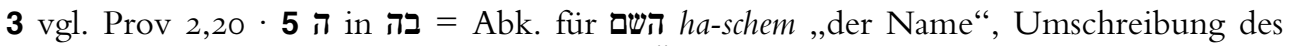
Tetragramms, des biblischen Gottesnamens. Übersetzung „der Ewige“ von Moses Mendelssohn eingeführt. - 6-8 Zitat Mischna Avot 5,20 • 9 דברות עשר dibb'rot asar, Worte der zehn (Gebote), Kurzbezeichnung des Dekalog · 15f "Himmel", seit alters verwendet als Ersatzbezeichnung für Gott. · 17 באהב'[ים] wörtlich: (Gott-)Liebenden oder Geliebten • Quelle: Mappa Nr. 7 (Geburtstag) 
Wolf Meyenberg

25.2.I 822

Eltern: Alexander Meyenberg - Bertha Wolfsohn

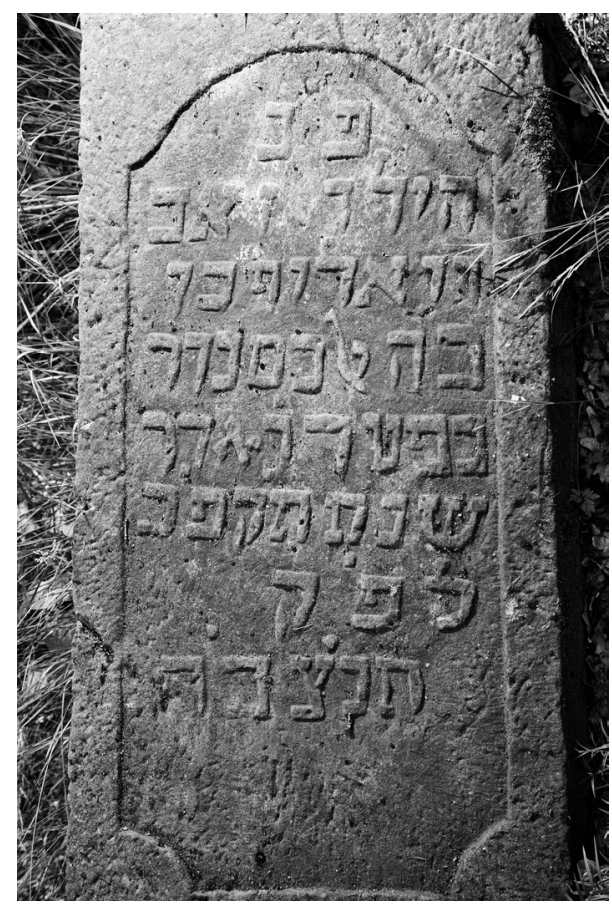

H II5 $\cdot$ B $63 \cdot \mathrm{T}$ I5

פעינ Hier ist geborgen

der Knabe Seev

[Wolf], Sohn des

e.H. Alexander.

5 Er verschied am 4. Adar

(im) Jahr 582

לפ'.kl.Z.

ת.S.E.B.L.

3 וואלף Wolof, verschrieben für וואלוף Wolf 
Eva Rosenbaum

2I.6.I 822

Ehemann: Samuel Levi Rosenbaum II $36 \cdot$ Kinder: Meier III 8I; Henriette III 90

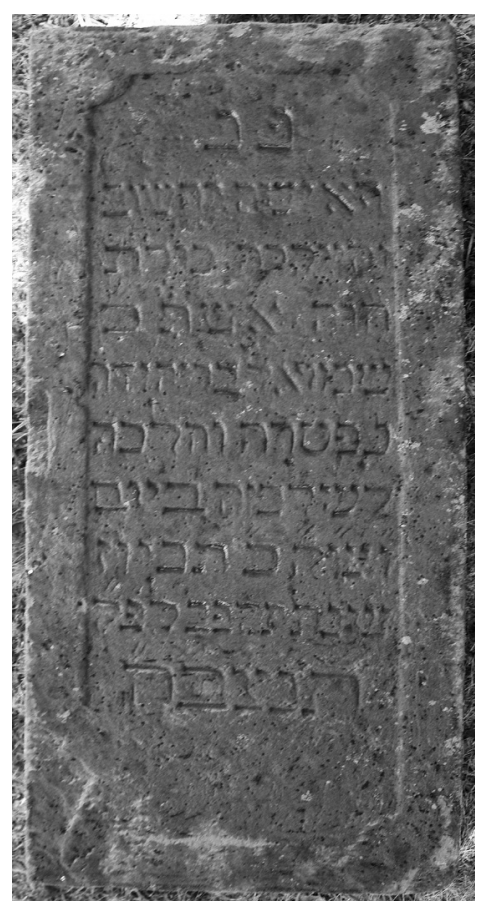

H $167 \cdot \mathrm{B} 6 \cdot \mathrm{T}$ I9

פ"ג Hier ist geborgen

die Frau, angesehen

und geachtet (war sie), Frau

Chava, Ehefrau des e.

5 Schmuel, Sohn des Jehuda.

Sie verschied und ging

לעולמה ביום וn in ihre Ewigkeit am

Tag 6, [dem Abend des] hl. S(chabbat), 2. Tammuz

(im) Jahr 582 n.kl.Z.

10 I.S.E.B.L.

8 Der 2. Tammuz fällt auf einen Freitag, d.h. den Vorabend des Schabbat. Auf der Inschrift ist das nicht, wie sonst üblich (ע: Abk. für ערב 'Vorabend' vor 'ש'ק), vermerkt. 
Nathan bar Nathan Segal

6.I2.I 822

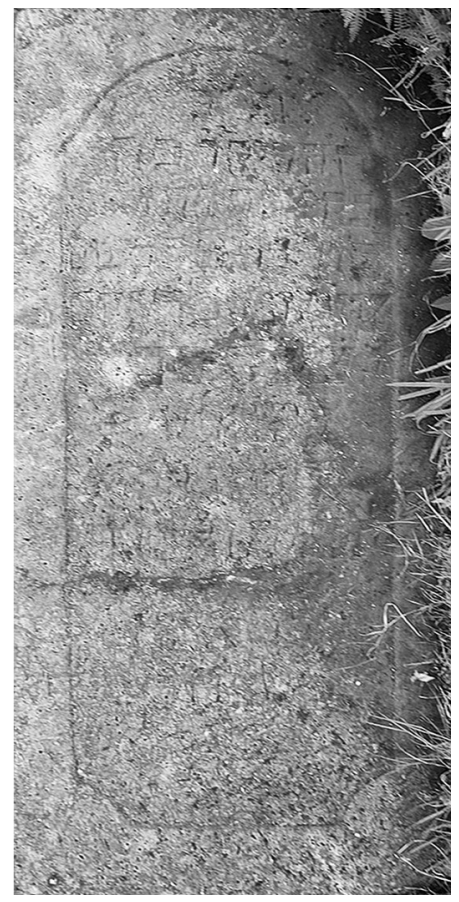

$\mathrm{H} \mathrm{I} 8 \mathrm{O} \cdot \mathrm{B} 78 \cdot \mathrm{T} 2 \mathrm{O}$

Inschrift durch Flechten verkrustet

פַ"ג Hier ist geborgen

dies ist der geachtete e.H.

נתן בר נתן Nathan, Sohn des Nathan

Segal. Er verschied in gutem

5 Namen und wurde begraben am

ו' ו'ש'ק' כב

Koslew

583 n.kl.Z.

S.S.E.B.L. im Garten

10 Eden. Amen

סלה Sela.

3 Gleicher Name für Sohn und Vater. Im Allgemeinen unüblich; könnte darauf beruhen, dass der Vater starb, ehe der Sohn einen Namen erhielt. 


\section{Jente Gräfenberg}

I4. bzw. I 8.2. I 823

aus Netra/Hessen - Ehemann: Selig Nathan Gräfenberg II 20 - Kinder: Nathan (I802I 874, Göttingen: Grab 76), Friederike (I805-I873, Bremke: Grab 42)

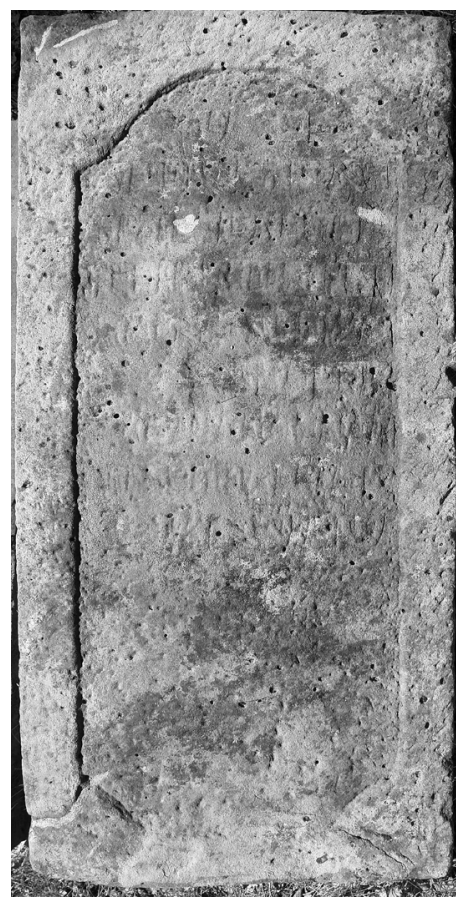

$\mathrm{H} \mathrm{I} 72 \cdot \mathrm{B} 75 \cdot \mathrm{T} 2 \mathrm{I}$

Inschrift durch Flechten verkrustet

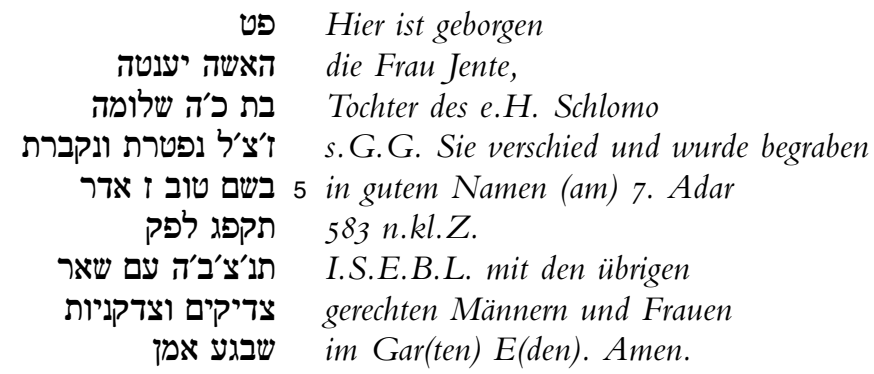

5 s. babylonischer Talmud Berakhot I 7a - Die Lesung des Sterbetags ist unsicher; möglich $\lambda(=3)$ statt $i(=7): 3$. Adar $583=$ I 4.2.1823. 
Bertha Müller, geb. Bacharach

IO.3.I 823

Ehemann: Aron Isaak Müller III 23 - Kinder: Herz III 2I; Isaak III 46; Zeline/Cäcilie (I 822-I 888, Göttingen: Grab 376)

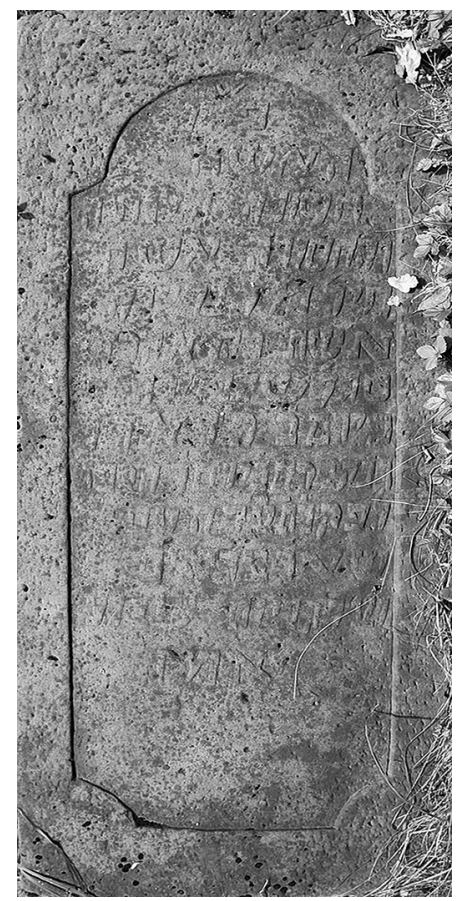

$\mathrm{H} \mathrm{I}_{7} \cdot \mathrm{B} 74 \cdot \mathrm{T}$ I9

פע"נ Hier ist geborgen

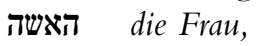

angesehen, bescheiden (war sie)

und gütig, eine tüchtige

5 Ehefrau, Fr(au) Breine

Ehefrau des e.H. Aharon

Segal. Sie verschied

am Tag 2, 27. Adar

und wurde begraben am Tag 4583

10 n.kl.Z. I.S.E.B.L. mit

den übrigen gerechten Männern

und Frauen im Gar(ten) E(den).

אמן Amen.

4f. $s$ Prov 3 I, IO 
Miene Rosenthal, geb. Rothstein

IO.6.I 823

Vater: Samuel Rothstein - Ehemann: Levi Daniel Rosenthal II 4 - Sohn: David Levi Rosenthal III 56

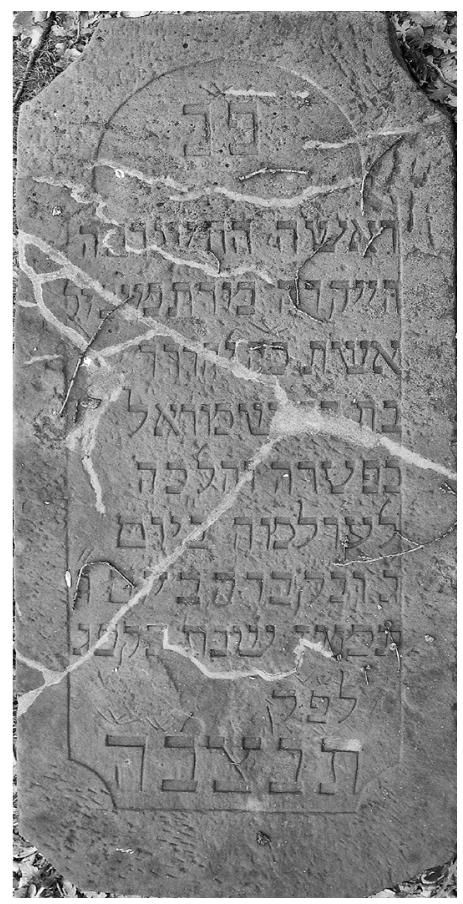

$\mathrm{H} \mathrm{I76} \cdot \mathrm{B} 75 \cdot \mathrm{T} \mathrm{I} 4$

\begin{tabular}{|c|c|}
\hline & \\
\hline האשה החשובה & esehen. \\
\hline הייקרה מרת מינדל & geachtet (war sie), Frau Mindel, \\
\hline אשת כ'ה יהודה & Ehefrau des e.H. Jehuda, \\
\hline בת כ'ה שמואל & Tochter des e.H. Schmuel. \\
\hline נפטרה והלכה & Sie verschied und ging \\
\hline לעולמה ביום & in ihre Ewigkeit am Tag \\
\hline ג' ונקברה ביום ג' & 3 und wurde begraben am 3. \\
\hline תמוז שנת תק'פג & Tammuz (im) Jahr 583 \\
\hline ג'צ'ב'ה' & $\begin{array}{l}\text { n.kl.Z. } \\
\text { I.S.E.B.L. }\end{array}$ \\
\hline
\end{tabular}

3 Doppelschreibung des, 
Salomon Simon Meyenberg

$$
\text { I } 740 \text { - I.I2.I } 823
$$

Eltern: Simon Meyer - Röschen Simcha - Ehefrau: Marline Kaufmann II 6 - Kinder: s. ebd.

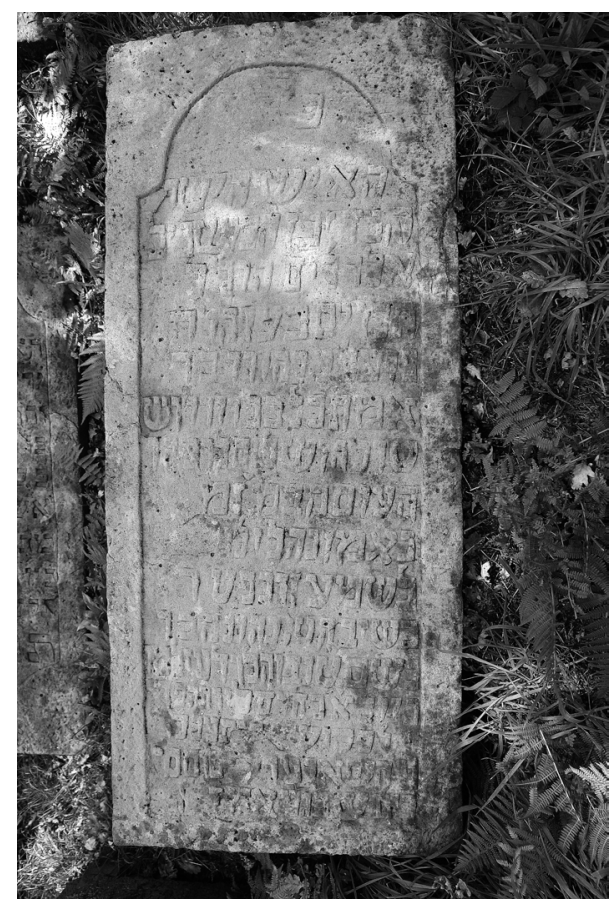

$\mathrm{H}$ I $85 \cdot \mathrm{B} 78 \cdot \mathrm{T} 20$ 


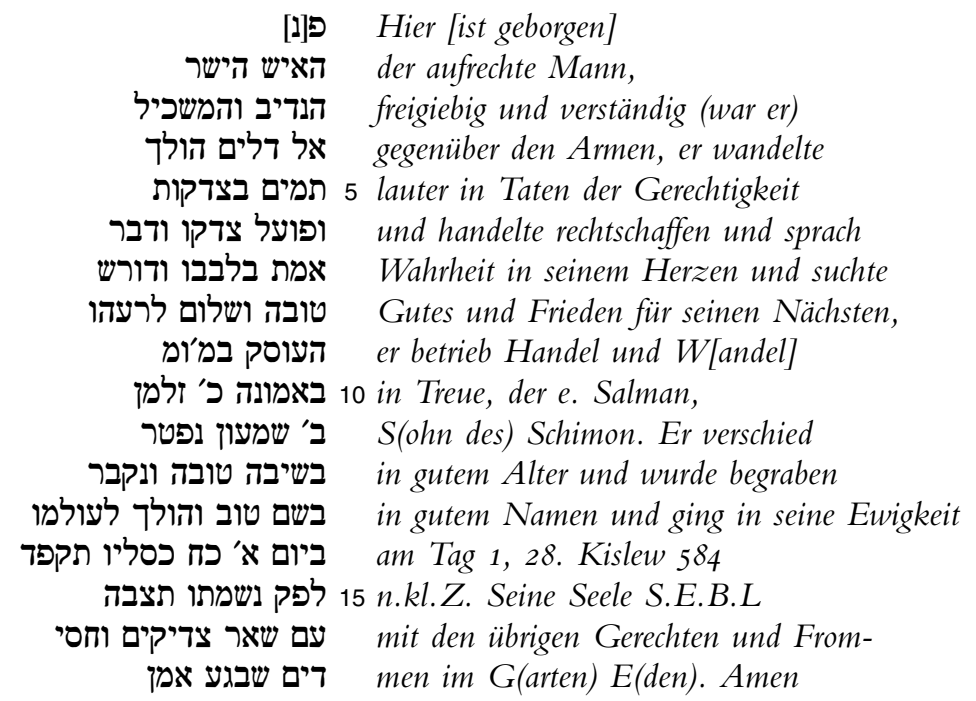

5 צדקו 6 - Taten der Gerechtigkeit: insbesondere soziale Hilfe, "Almosen" צutlich Doppelschreibung des folgenden ו, möglich auch ת ausgelassen = בדקות 


\section{Beila bat Schimon}

28.6. 1824

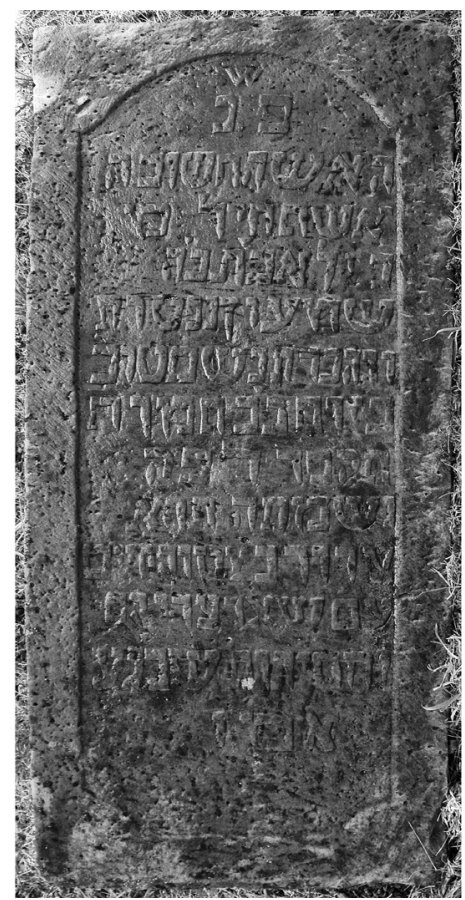

$\mathrm{H}$ I $87 \cdot \mathrm{B} 78 \cdot \mathrm{T} 2 \mathrm{O}$

פעינ Hier ist geborgen

האשה חשובה

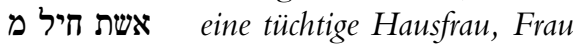

Beila, Tochter des e.H.

5 Schimon. Sie verschied

und wurde begraben in gutem Namen

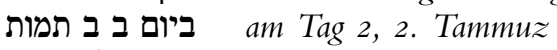

584 n.kl.Z.

Ihre Seele sei

10 eingebunden ins Bündel des Lebens

mit den übrigen gerechten Männern

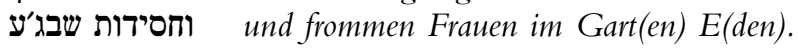

אמן Amen

3 s. Prov 3 I, Iо 6 s. babylonischer Talmud Berakhot I7a 7 Verschreibung תמות in; beruht auf der stimmhaften aschkenazischen Aussprache des $\boldsymbol{\Omega}$ und ist zugleich ein Wortspiel »Du wirst sterben«. 
Schlomo ben Mosche

28. I. I 826

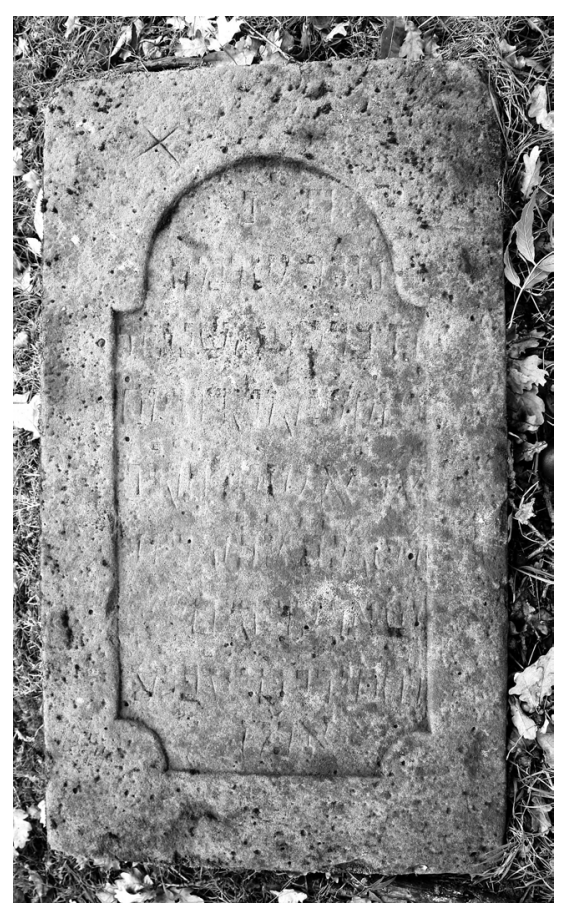

$\mathrm{H} 99 \cdot \mathrm{B} 57^{\cdot} \mathrm{T}$ I3

\section{פעינ Hier ist geborgen \\ der Knabe Schlomo,}

Sohn des e. H. Mosche. Er verschied

am Tag des hl. Sch(abbat) und wurde begraben am Tag 1, 21. Schevat 586

n.kl.Z. S.S.E.B.L. mit

שאר צדיקים den übrigen Gerechten

וחסידים שב'ג'עי ומים

אמן Amen. 
Selig Moses Oppenheim

um I742-29.IO.I 826

Eltern: ? Moses Meyer Ilten I 9 - Gelle Meyer · Sohn: Moses Selig (I 809-I8 I2 erwähnt)

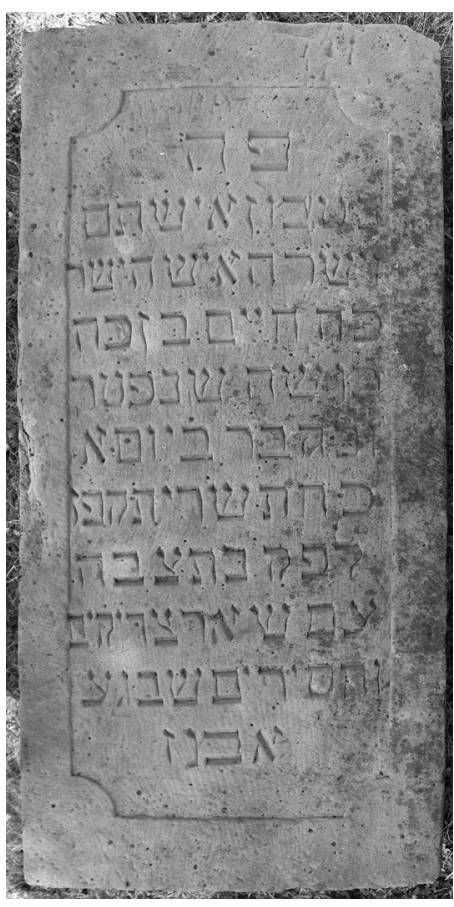

$\mathrm{H} \mathrm{I} 74 \cdot \mathrm{B} 76 \cdot \mathrm{T}$ I4

פה Hier

ist geborgen ein Mann, redlich

und aufrecht (war er), der geachtete Mann,

der e.H. Chajjim, Sohn des e.H.

5 Mosche. Er verschied

ונקבר ביום א

28. Tischri 587

n.kl.Z. S.S.E.B.L.

mit den übrigen Gerechten

אמה עם שבידים שבגע. 10 und Frommen im Gar(ten) E(den).

אמן Amen.

2f s. Hi I, 8 
Anonymus

I 830

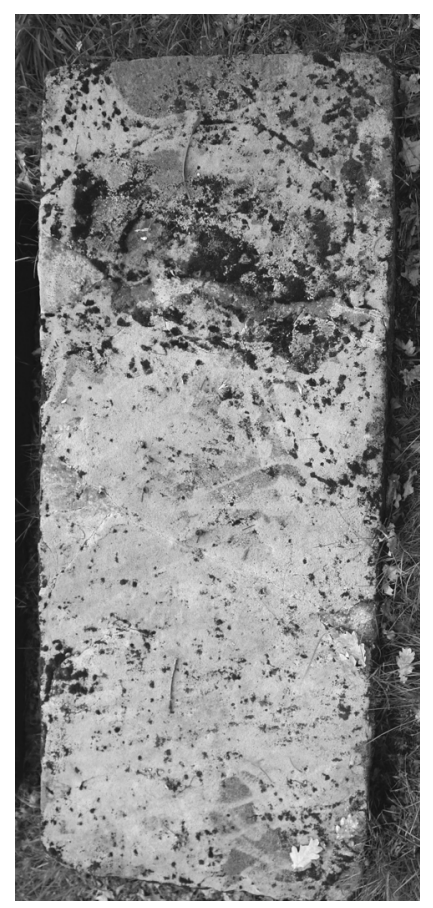

H I8I $\cdot$ B $77 \cdot$ T I 8

Inschrift nicht mehr erkennbar

Datierung nach der Ortslage 


\section{Mendel Herz Bähre}

$$
\text { I737/38 - I8.I.I } 830
$$

Pferdehaarverarbeiter und Fellhändler in Barterode - Vater: Herz Mendel I I 8 - Ehefrau: Name nicht bekannt. - Kinder: Samuel Weinstein (I772-I838); Relchen (um I780); unbekannter Name (um I780 / Mutter von Hirsch Bähr, III 57)

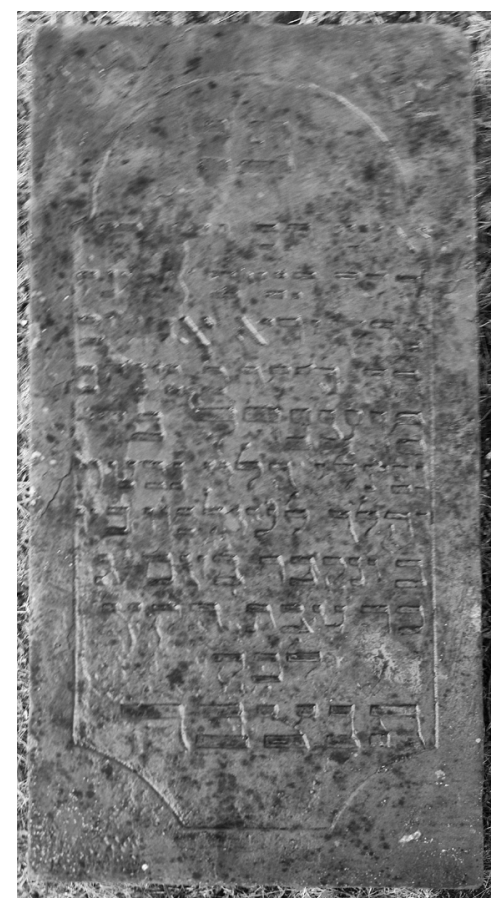

$\mathrm{H} \mathrm{I67} \cdot \mathrm{B} 73 \cdot \mathrm{T} \mathrm{I6}$

\begin{tabular}{|c|c|}
\hline & \\
\hline אישו תמ וישר & 1iler \\
\hline הלד תמים ון ופרן. & ein redicher und aufrechter Mann, \\
\hline צדק ירא אלהים & rechtschaffen, fürchtete Gott. \\
\hline הה היקר כ מנח & $D$ (as) i(st) der geachtete e. Menachem \\
\hline מענדל בר & Mendel, Sohn des \\
\hline נפתלי הלוי נפטר & Naphtali ha-Levi. Er verschied \\
\hline והלך לעולמו ביו & und ging in seine Ewigkeit am Tag \\
\hline ב ונקבר ביום ג & 2 und wurde begraben am Tag 3, \\
\hline טבת ת'ק'ץ' & 24. Tevet 590 \\
\hline 'ואיגו' & \\
\hline א'נ'צ'ב'ה & S.S.E.B.L. \\
\hline
\end{tabular}

2-4 Zitat aus Ps I5,2, in das Zitat aus Hi I,8 eingeschoben, vgl. IV 6. - 7 Phonetische Schreibung נפטר - Quelle: HStAH, Hann. 52 Nr.I866 (Geburtsjahr) 


\section{Nathan Calman Hammerschlag}

um I759/60 - 28.IO.I 83 I

Metzger in Güntersen · Eltern: Calman Hammerschlag - Gela · Ehefrau: Jette Marcus aus Witzenhausen · Kinder: Calman (I 800, vgl. II 42); Caroline (I 806-I 839)

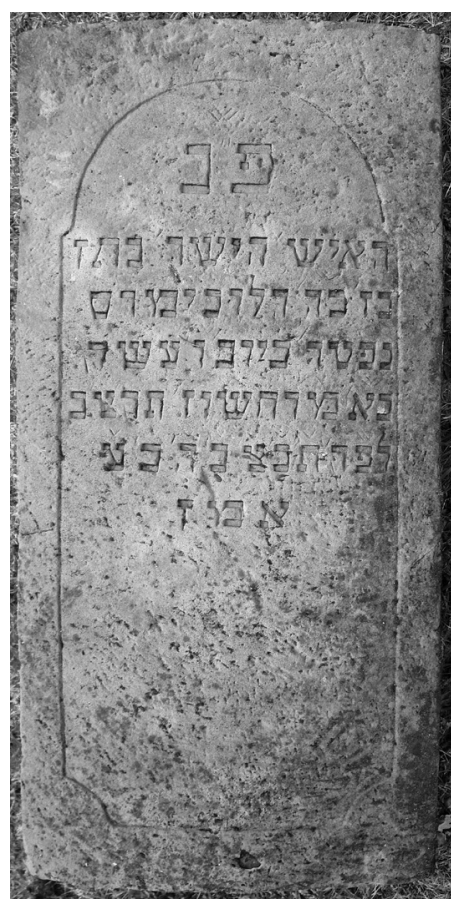

$\mathrm{H} \mathrm{I76} \cdot \mathrm{B} 83 \cdot \mathrm{T}$ I6

פ'ד Her ist geborgen

der aufrechte Mann, Nathan,

בן כohn des e.H. Kalonymus.

Er verschied am Tag 6, dem V(orabend) des) hl. Sch(abbat),

5 21. Marcheschwan 592

רפק ת'ג'צ'ב'ה' ב'ע'

אמן Amen.

Quelle: L I762 (Geburtsjahr nach Altersangabe) 
Bertha Löwenstern, geb. Dahl

$$
\text { 22.6. } 1776-22.6 .1832
$$

Geb. in Karlshafen/Hessen - Vater: Jacob Dahl - Ehemann: Marcus Meyer Löwenstern II 29· Kinder: Philipp (I 804); Simon III 36; Samuel III 48; Jacob (I8 I I-I 893); Bertha (I8 I 4)

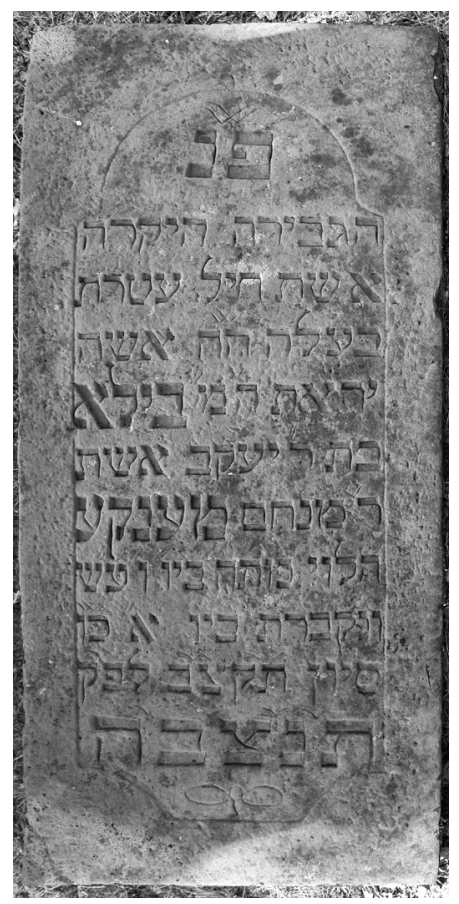

$\mathrm{H}{ }_{\mathrm{I}} 77 \cdot \mathrm{B} 74 \cdot \mathrm{T}$ I9

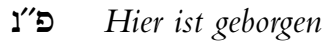

die geachtete Herrin,

השת חיל עטרת tüchtige Ehefrau, die Krone

ihres Ehemannes. Dies ist eine Frau,

5 die G[ott] fürchtete, F[rau] Beila,

Tochter des H. Jaakov, Ehefrau des

H. Menachem Menke

ha-Levi. Sie starb am Tag 6, am V(orabend) des Sch(abbat)

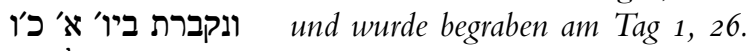

10 Siwan 592 n.kl.Z.

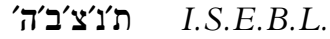

3a s. Prov 30, Io · 3bf. s. Prov I2,4 - Quelle: FamB (Geburtstag) 
Marline Meyenberg

$$
25 \cdot 7.1832
$$

Ehemann: Salomon Simon Meyenberg II 2 - Kinder: Meyer II 34; Simon (I783-I849); Alexander/Süßkind (I785-I87I); Simon/Simcha III 6I; Rosette III 3; Friederike (I798); Clara III 66

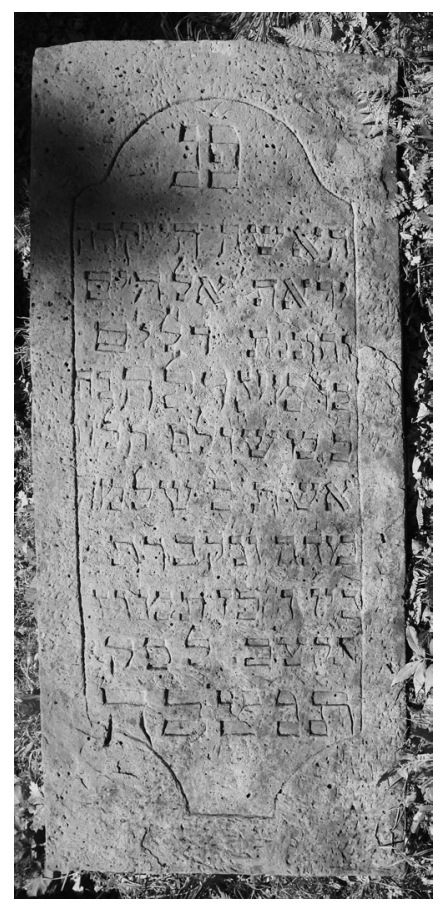

H $178 \cdot \mathrm{B} 77 \cdot$ T I 8

פצ'נ Hier ist geborgen

$$
\begin{aligned}
& \text { die geachtete Frau, } \\
& \text { יראת אלהים gottesfürchtig (war sie) } \\
& \text { und gütig zu den Armen, } \\
& \text { F(rau) Merle, Tochter } \\
& \text { des e. Meschullam ha-Levi, } \\
& \text { Ehefrau des e. Schlomo. } \\
& \text { Sie starb und wurde begraben } \\
& \text { a a a (m) Tag 4, 27. Tammuz } \\
& 10592 \text { n.kl.Z. } \\
& \text { I.S.E.B.L. }
\end{aligned}
$$

3 s.Prov 3 I, Io -4 s. Prov I9, I7 
Henriette Müller

9.4.I 8 I $3-30.9 .1833$

Geb. in Barterode · Eltern: Simon Isaak Müller II 39 - Hannchen Levi II 46

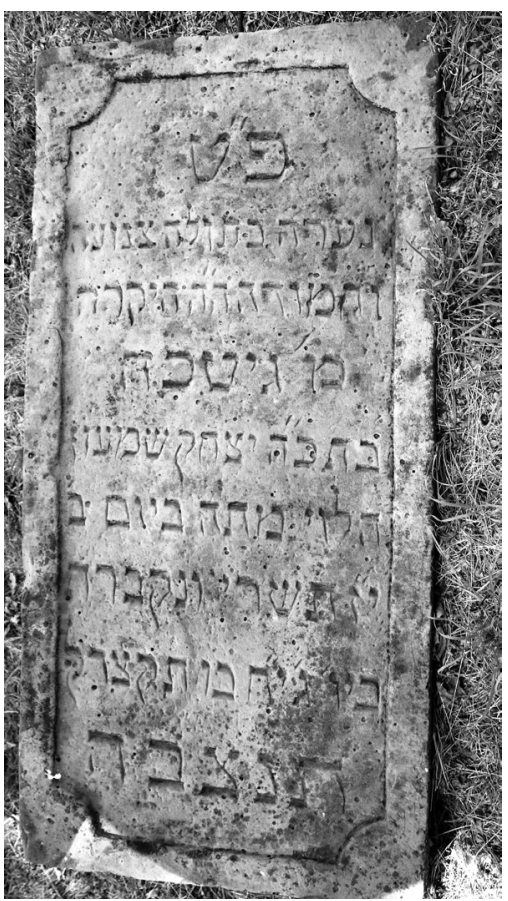

$\mathrm{H} \mathrm{I75} \cdot \mathrm{B} 86 \cdot \mathrm{T}$ I 5

פער Hier ist geborgen

eine junge unverheiratete Frau, bescheiden

und gütig (war sie). Dies ist die geachtete

F(rau) Gitche,

5 Tochter des e.H. Jizchak Schimon

ha-Levi. Sie starb am Tag 2,

17. Tischri und wurde begraben

a(m) Tag 3, 18. i(m) s(elben Monat) 593 n.kl.Z.

תנצבה I.S.E.B.L.

Quelle: FamB (Geburtstag) 


\section{Rivka bat Eljakim}

$$
\text { 2O.II.I } 833
$$

Weder in der Sterbeliste noch im Familienbuch verzeichnet. - Der Name Eljakim kommt in den Familien Müller, Stehberg und Eichenberg vor.

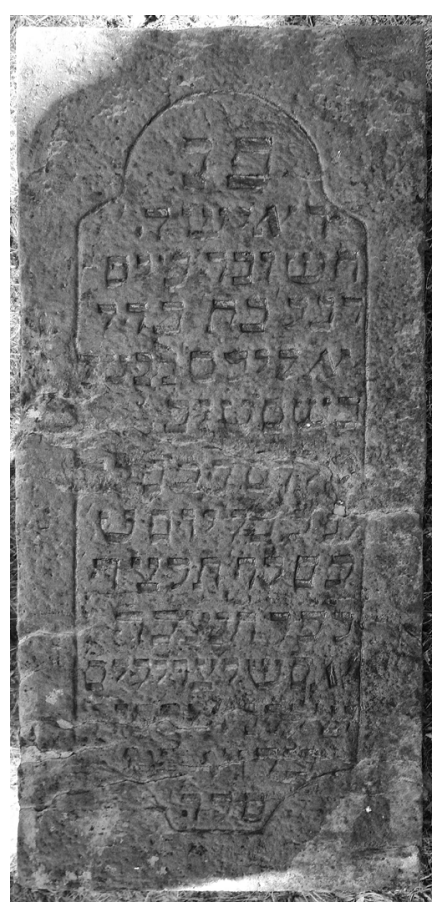

$\mathrm{H}$ I77 $\cdot \mathrm{B} 75 \cdot \mathrm{T}$ I 5

$$
\begin{aligned}
& \text { פ"נ Hier ist geborgen } \\
& \text { האישה פ"פ die Frau, } \\
& \text { angesehen (war sie), Fr[au] } \\
& \text { רבק' בת כהר Rivk(a), Tochter des e.H. } \\
& \text { (2) } 5 \text { Eljakim. Sie versch(ied) } \\
& \text { בשם טוב } \\
& \text { am 8. Kislew } \\
& \text { und wurde begra(ben) am } 9 . \\
& \text { Kislew } 594 \\
& 10 \text { n.kl.Z. I.S.E.B.L. } \\
& \text { mit den übrigen gerechten Männen } \\
& \text { und Frau(en) im Garten } \\
& \text { Eden. Amen } \\
& \text { סלה Sela. }
\end{aligned}
$$

3 Ungefüge Buchstaben; vermutliche Lesung מרת. • 6 s. babylonischer Talmud Berakhot I7a 11 Fehlerhafte Schreibung statt עם שאר. 


\section{Levi David Löwenthal}

$$
\text { 28.II.I753 - IO.9.I } 834
$$

Metzger - Eltern: David Joel - Golde - Ehefrau: I. Jette 2. Rahel Gerson (I759-I 834) aus Bückeburg · Kinder: Joel (I790-I868, Lödingsen); Moses (I796-I858, Moringen); Ruben (I 797-I 866, Wöllmarshausen); Elias (I 799-I 880, Bovenden: Grab 54[55]); Salomon III 99 - Bruder: Joel David Rothschild II I 8

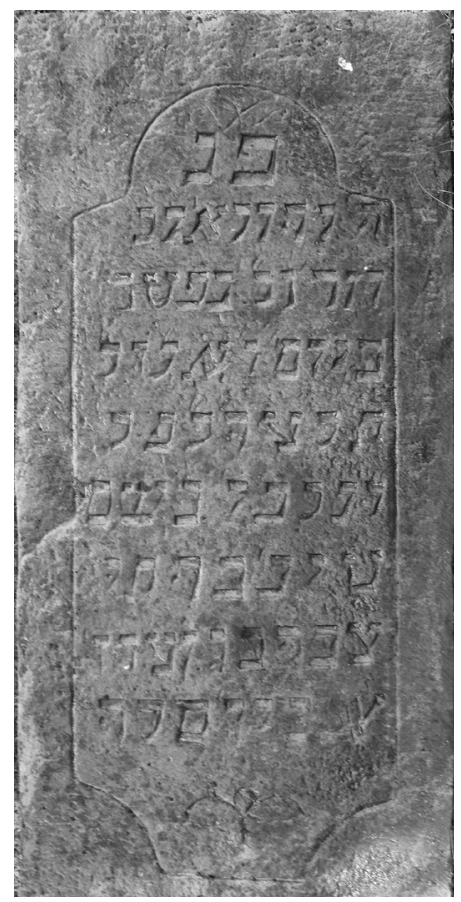

$\mathrm{H} \mathrm{I}_{75} \cdot \mathrm{B} 76 \cdot \mathrm{T}$ I9

פ"

d(er Mann) Jehuda, [Sohn des]

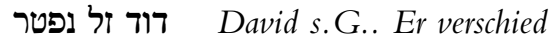

am 6. Elul

ונקצר 5594 n.kl.Z.

ונקבר בשם

Namen i(m Licht des) L(ebens). S.S.

E.B.L. im Garten Eden.

אמן סלה Amen Sela.

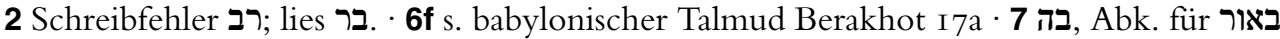
החיים (bor ha-chajjim) ,im Licht des Lebens“; s. Hüttenmeister, AHebG, 22. · Quelle: FamB (Geburtstag) 


\section{Selig Nathan Gräfenberg}

$$
\text { 28.7.1752- 20.2.1 } 836
$$

Urspr. Gräfenburg bzw. Grebenborg · Kaufmann (Manufakturwaren) - Eltern: Nathan Meyer - Perle Michel (aus Hersfeld/Hessen) · Ehefrau: Jentchen II I7 - Kinder: s. ebd.

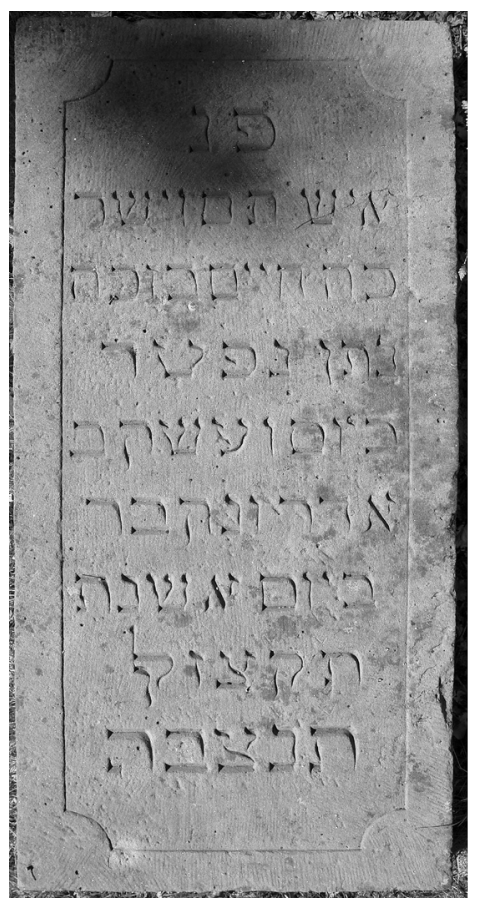

$\mathrm{H} \mathrm{I} 73 \cdot \mathrm{B} 76 \cdot \mathrm{T} 22$

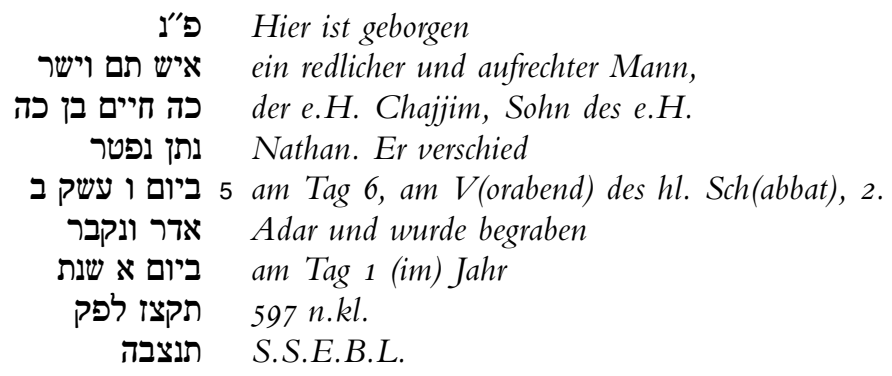

2 s. Hi I,8 - 8 Die Jahresangabe תקצז 597 stimmt nicht mit der Tagesangabe überein; Verwechslung von I (6) und i (7), s. StbL: I836. Q Quelle: FamB (Geburtstag) 
Abraham M. Edelstein

$$
\text { I2.5.I } 834-9.4 .1836
$$

Eltern: Moses Abr. Edelstein III I - Rosette Eichenberg III 2 (?)

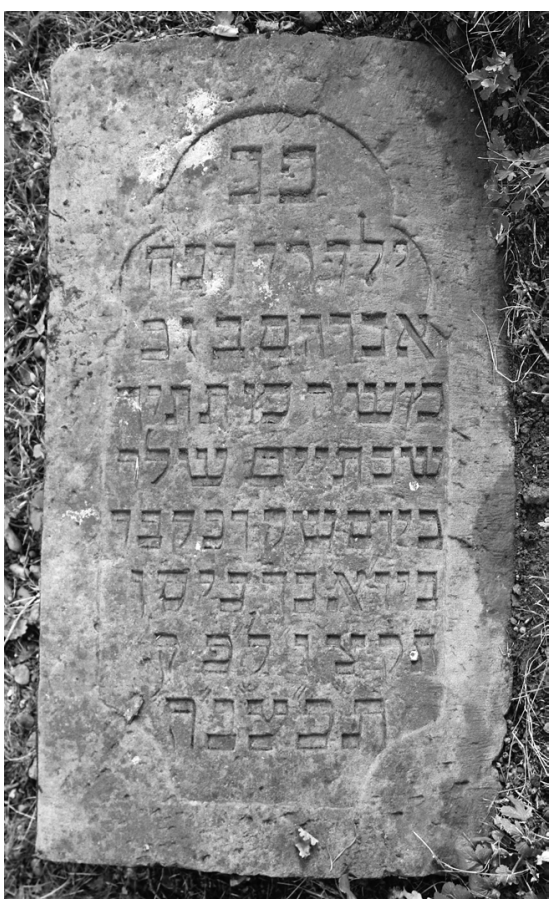

H IOI $\cdot$ B $58 \cdot$ T I2

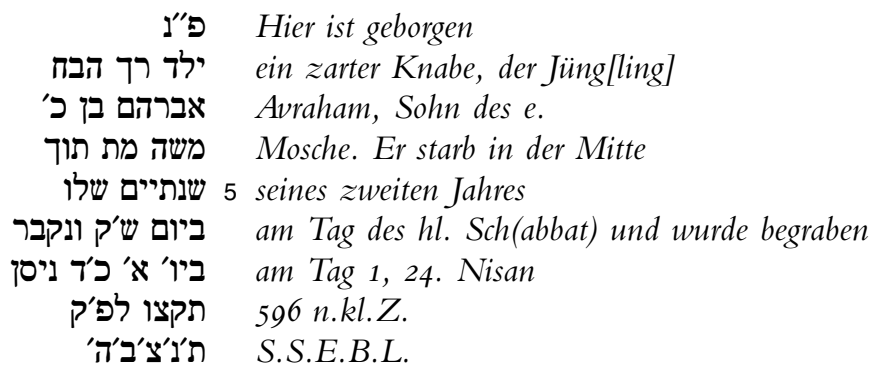

7 Die StL verzeichnet als Sterbetag 20.6. I836 (Montag 5. Tammuz) - Quelle: GbL (Geburtstag) 


\section{Samuel Rosenbaum}

$$
\text { I7.7.I779 - I9.5.I } 838
$$

Altwarenhändler · Vater: Levi Moses Ilten · Ehefrauen: I. Röschen Liebenfeld; 2. Eva II 37; 3. Henriette Levy - Kinder: zu I): Levi (I808); Friederike (I8 Io-I833), Moses III i6; $\mathrm{zu} \mathrm{2):} \mathrm{s.} \mathrm{II} \mathrm{37;} \mathrm{zu}$ 3): Bienchen verh. Neuhaus (I 826-I906, Göttingen Grab 236), Goldchen (I 828), Clärchen (I83 I), Karoline/Goldchen (I834)

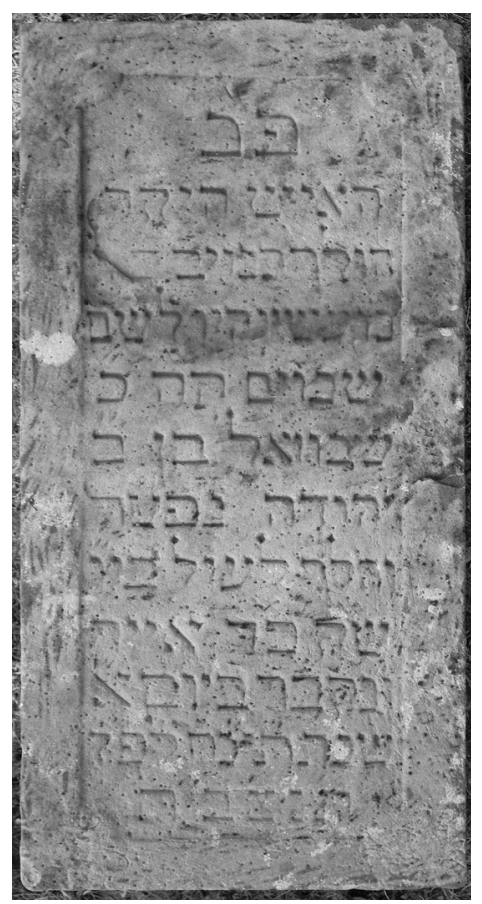

$\mathrm{H} \mathrm{I63} \cdot \mathrm{B} 7 \mathrm{I} \cdot \mathrm{T} 20$

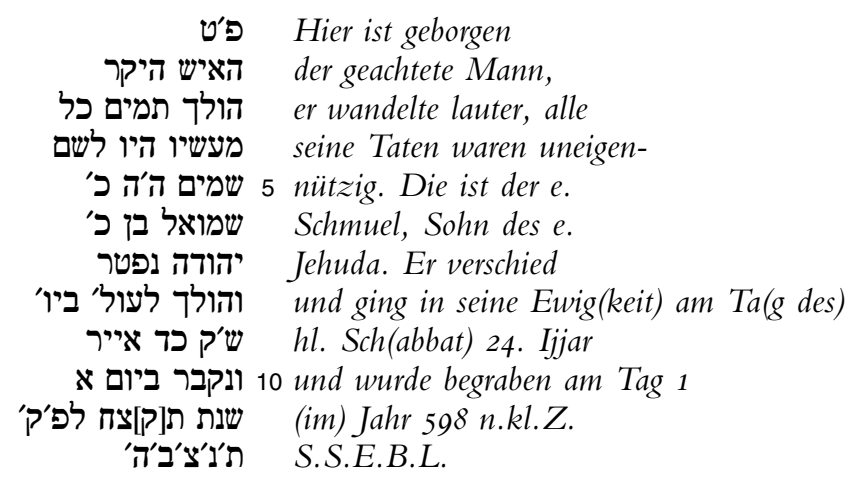

3-5 Mischna Avot 2,I2. - לשם שמים (leschem schmajiim) wörtlich: ,um des Himmels [Gottes] willen“. · 9 StL nennt Sonntag 20.5.I838 $11 \boldsymbol{\Omega}$ ist ausgefallen, vermutlich Abschreibefehler - Quelle: FamB (Geburtstag) 
Betty Müller

I 3.8.I $832-25.5$. I 839

Eltern: Aron Isaak Müller III 23 - Rieke Bacharach

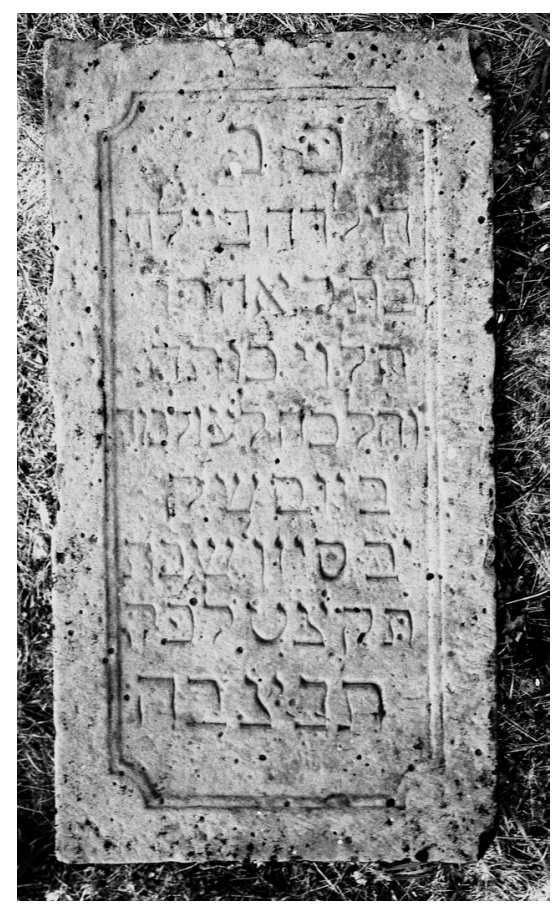

$\mathrm{H} \mathrm{I0} 8 \cdot \mathrm{B} 58 \cdot \mathrm{T}$ I5

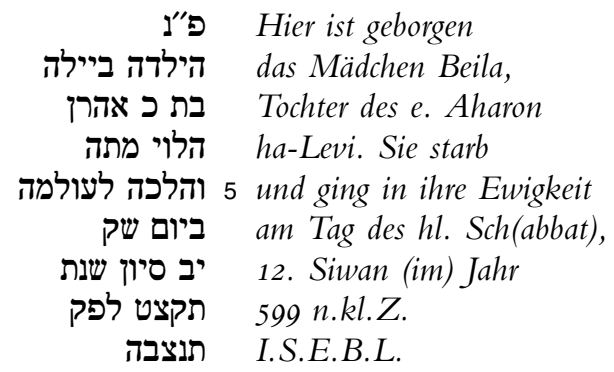

6f. StbL/FamB verzeichnen als Sterbetag 20.5 (Montag, 7. Siwan) · Quelle: GbL/FamB (Geburtstag) 


\section{Marcus Löwenstern}

$$
\text { I6.8.I } 774-23.6 .1840
$$

Lotteriecollecteur - I8Io/I I und I832 als Vorsteher der Synagogengemeinde erwähnt · Vater: Meyer Philipp Freudenstein II 7 · Ehefrau: Bertha Dahl II $28 \cdot$ Kinder: s. ebd.

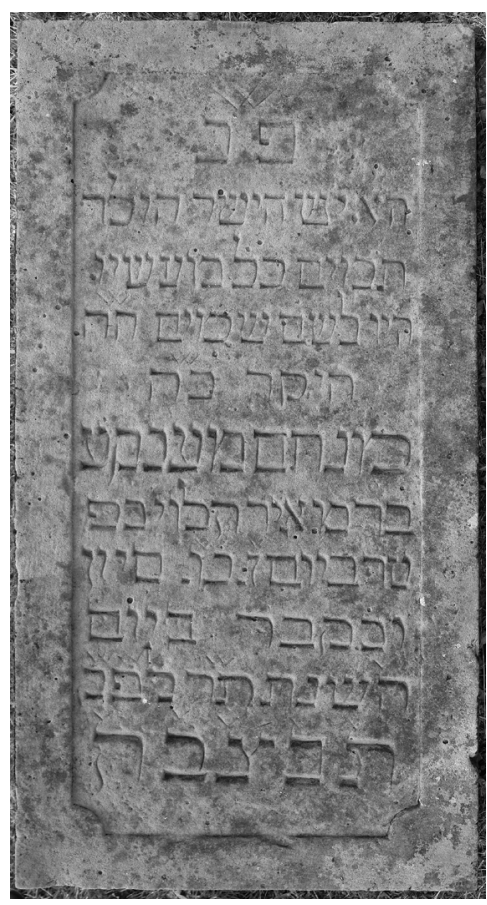

$\mathrm{H} \mathrm{I} 65 \cdot \mathrm{B} 8 \mathrm{I} \cdot \mathrm{T} 22$

פע"ג Hier ist geborgen

der aufrechte Mann, er wandelte

lauter, all seine Taten

geschahen uneigennützig. Dies ist der

5 geachtete e.H.

Menachem Menke,

Sohn des Meir ha-Levi. Er ver-

טר ביום ג כג סיון schied am Tag 3, 23. Siwan,

und wurde begraben am

10 Tag 5 (im) Jahr 600 n.kl.Z.

תנצבה S.S.E.B.L.

3-5 Mischna Avot 2, I2 s.o. II $39 \cdot \mathbf{4}$ s. zu II $7 \cdot 10$ Die Tagesangabe „Tag 3“ verweist auf Abendstunden des 23. Siwan $=23.6$. - Die StbL verzeichnet als Sterbetag den Io.6.I840 $(=9$. Siwan $) \cdot$ Quellen: FamB/Mappa (Geburtstag) 


\section{Simon Meier Eichenberg}

$$
\text { 20.6. } 1780-20.2 .1843
$$

Pferdehändler · Eltern: Meyer S. Eichenberg - Mariana · Geschwister: Baruch (I778I850), Lucas (I790-I859), Levi III 74, Leiser III 79, Rosette III 2? · Ehefrau: I. Amalie Rothschild II I2; 2. Edel Kopperschlag II $45 \cdot$ Kinder: zu I) s. II I2; zu 2) s. II 45.

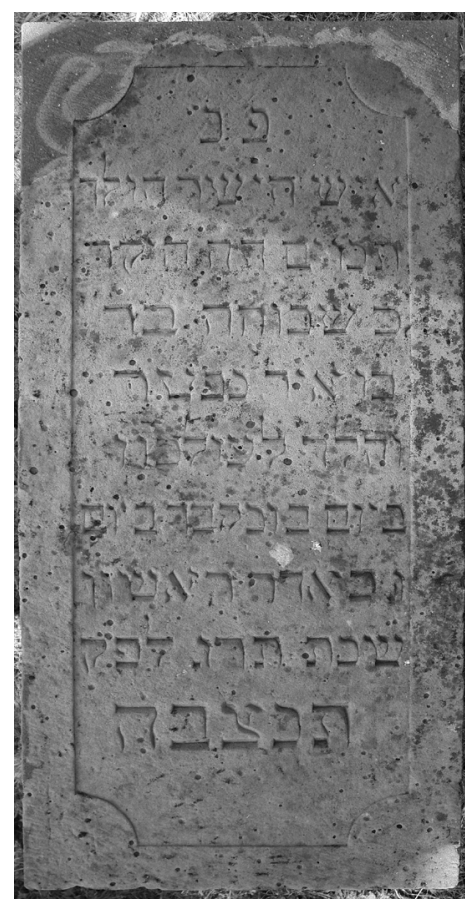

$\mathrm{H} \mathrm{I}_{62} \cdot \mathrm{B} 7 \mathrm{O} \cdot \mathrm{T}$ I 8

$$
\begin{aligned}
& \text { פ"נ Hier ist geborgen } \\
& \text { איש הישר הולך ein aufrechter Mann, er wandelte } \\
& \text { lauter. Die ist der geachtete } \\
& \text { e. Simcha, Sohn des } \\
& 5 \text { Meir. Er verschied } \\
& \text { und ging in seine Ewigkeit } \\
& \text { am Tag } 2 \text { und wurde begraben am } \\
& \text { Tag 3, 20. Adar I } \\
& \text { (im) Jahr } 603 \text { n.kl.Z. } \\
& 10 \text { S.S.E.B.L. }
\end{aligned}
$$

2f s. Ps I 5,2 7 Datums- und Tagesangaben stimmen nicht überein: i9. Adar (5)603 fiel auf einen Sonntag, nicht Montag · Quelle: FamB (Geburtstag) 


\section{Meyer Salomon Meyenberg}

$$
\text { 23.I I.I78 I - I2.9.I } 844
$$

Pferdehändler - Eltern: Salomon Simon Meyenberg II 2 - Marline Kaufmann II 6 . Ehefrau: Brunette Wolfsohn aus Sudheim (I79I) - Kinder: Röschen (I8I5); Goldchen (I8I7); Kaufmann (I8I9); Bertha (I821); Simon (I823); Salomon (I827); Wolf (I828); Amalie (I83 I); Pauline (I832)

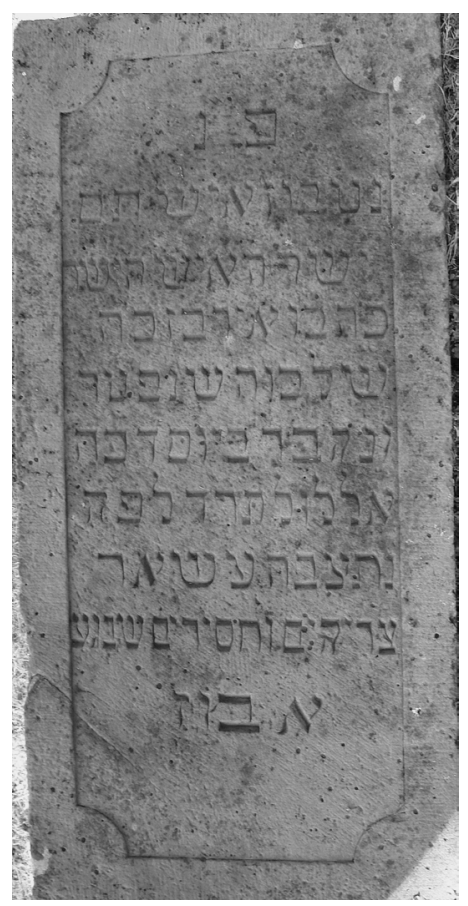

$\mathrm{H}$ I60 $\cdot$ B $76 \cdot$ T I 7

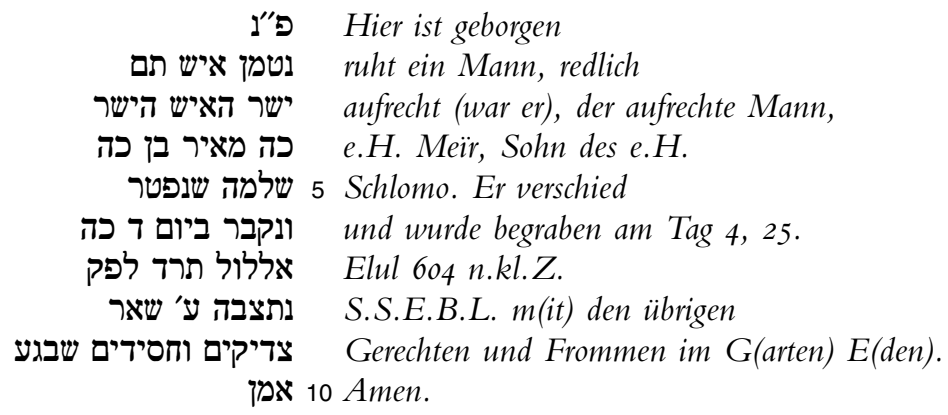

2f s. Hi I,8 - 6 Die Angaben zum Sterbetag, „Tag 4-25. Elul“ stimmen nicht überein. StbL verzeichnet den I0.9.I844 (=26. Elul), aber auch dieser Termin paßt nicht zum angegebenen Wochentag 7 Schreibfehler: Verdoppelung des (Geburtstag) 
Hannchen Müller

3.2.I 770 - 3O.I.I 846

Geb. in Eschershausen / Kr. Holzminden - Vater: Aron Levi - Ehemann: Simon Isaak Müller II 39 • Kinder: Herz III 50; Moses (I805-I885, Göttingen: Grab I I 5); Henriette II

24

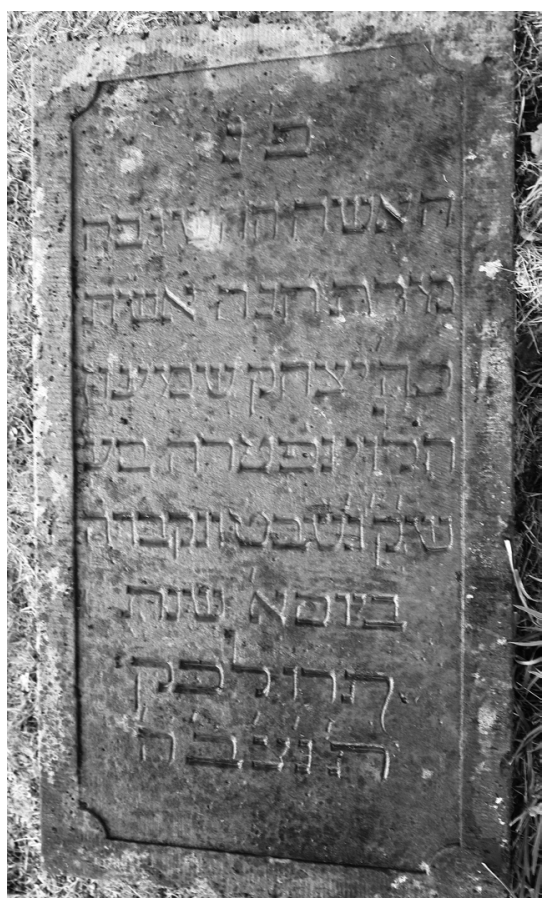

$\mathrm{H} \mathrm{I} 40 \cdot \mathrm{B} 77 \cdot \mathrm{T}$ i9

פ"נ Hier ist geborgen

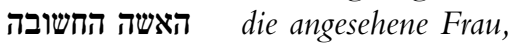

Frau Channa, Ehefrau des

e.H. Jizchak Schimon

5 ha-Levi. Sie verschied am V(orabend des)

ש' ש'ק' ג' שבט ונקברה בער

ביום א׳ שנת am Tag 1 (im) Jahr

606 n.kl.Z.

I.S.E.B.L.

Quelle: FamB (Geburtstag) 
Moses Meyer Freudenstein

$$
\text { I6.8. I790 - I8.4.I } 847
$$

Lotteriecollecteur, später Hokenhändler in Güntersen - Eltern: Meyer Philipp Freudenstein II 7 - Julchen · Ehefrau: Betty Rosengarten aus Röhrenfurth/Hessen (I802 - I865, Dransfeld: Grab 60)

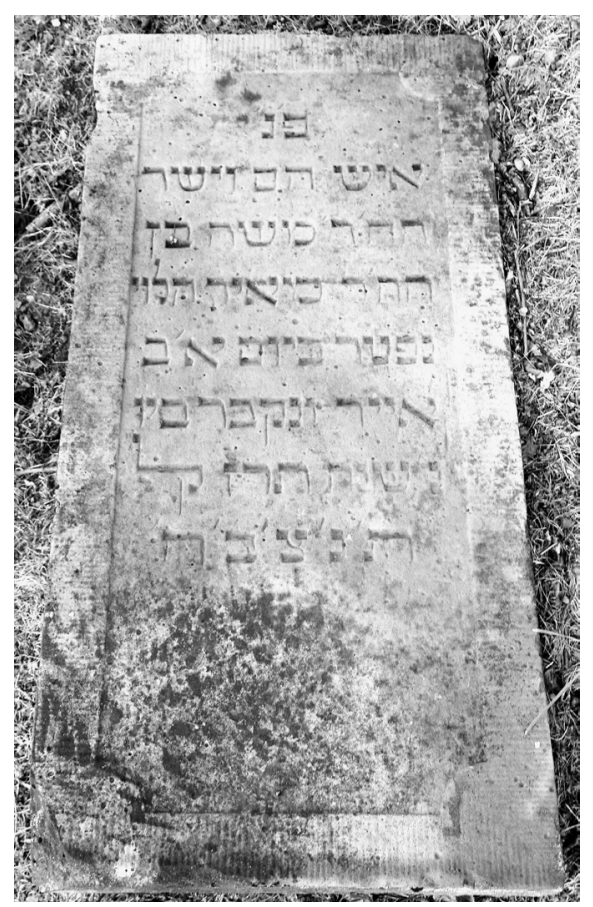

$\mathrm{H} \mathrm{I} 66 \cdot \mathrm{B} 80 \cdot \mathrm{T}$ I2

פ"ג Hier ist geborgen

איש תם וישר

ה'ח'ר' משה בן Dies ist der w(eise) Herr Mosche, Sohn

desw(eisen) Herrn Meir ha-Levi.

5 Er verschied am Tag 1, 2.

Ijjar, und wurde begraben am

Tag 3 (im) Jahr 607 n.kl.Z.

S.S.E.B.L.

2 s. Hi I,8 - 4 Ausdruck für einen Toragelehrten - Quelle: FamB (Geburtstag) 
Goldchen Jacobsohn

9.2. 1848

Ehemann: Abraham Jacobsohn (aus Sudheim) - Tochter: Henriette III 75

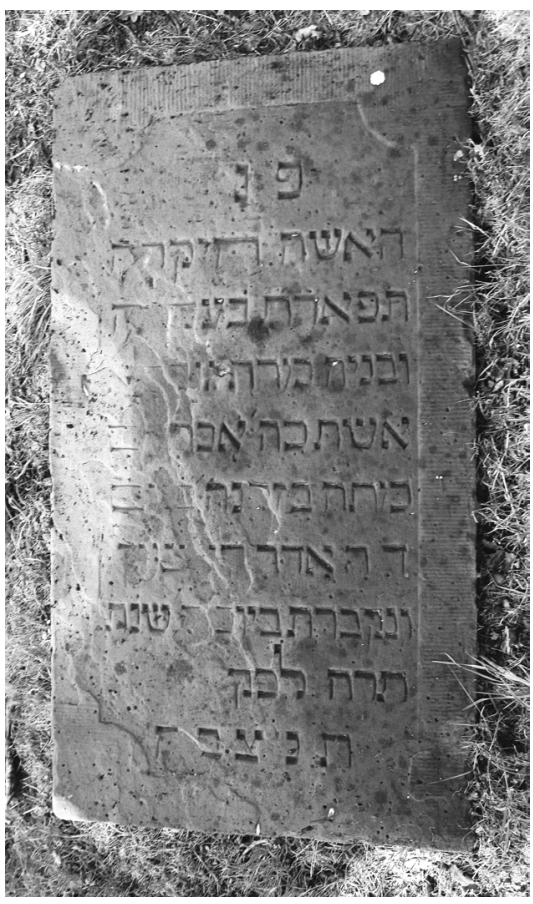

H I60 $\cdot$ B $87 \cdot$ T го

פע"ג Hier ist geborgen

die geachtete Frau,

die Zierde ihres Ehemannes

und ihrer Kinder, Frau Golda,

5 Ehefrau des e.H. Avraham.

Sie starb im hohen Alter am

ו ד' דיברת אדר ראשון

und wurde begraben am Tag 5 (im) Jahr

608 n.kl.Z.

10 I.S.E.B.L. 
Goldchen Hammerschlag, geb. Wolfsohn

$$
\text { 22.I.I } 80 \text { I - 20.9.I } 848
$$

Geb. in Sudheim; seit I 808 wohnhaft in Northeim, gest. in Güntersen - Eltern: Selig Wolfsohn - Perle Katzenstein - Ehemann: Calman Hammerschlag, Metzger in Güntersen, I 842-I 844 Vorsteher der Synagogengemeinde Barterode-Güntersen; später wohnhaft in Dransfeld, danach ausgewandert mit 3 Kindern in die USA. · Kinder: Pauline (I83 I); Nathan (I 832); Wolf (I 835), Jette (I 837); Selig (I 839); Moses (I844)

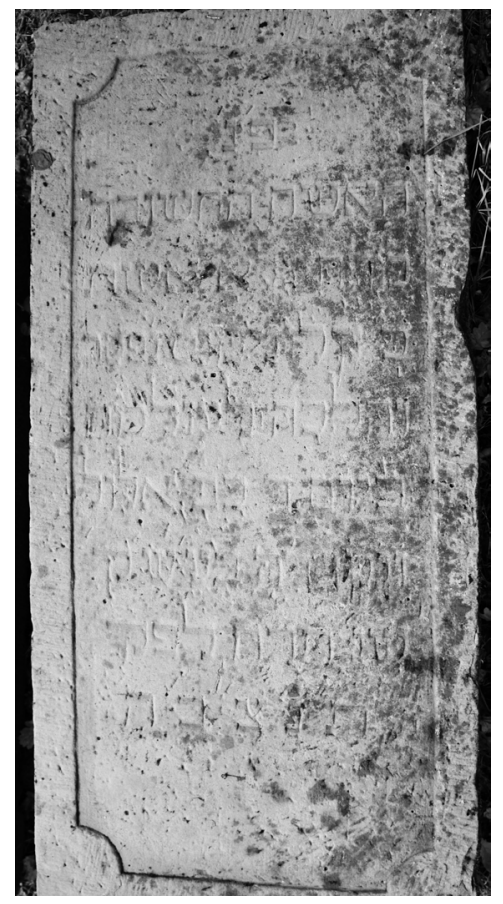

$\mathrm{H} \mathrm{I} 70 \cdot \mathrm{B} 8 \mathrm{I} \cdot \mathrm{T}$ I 4

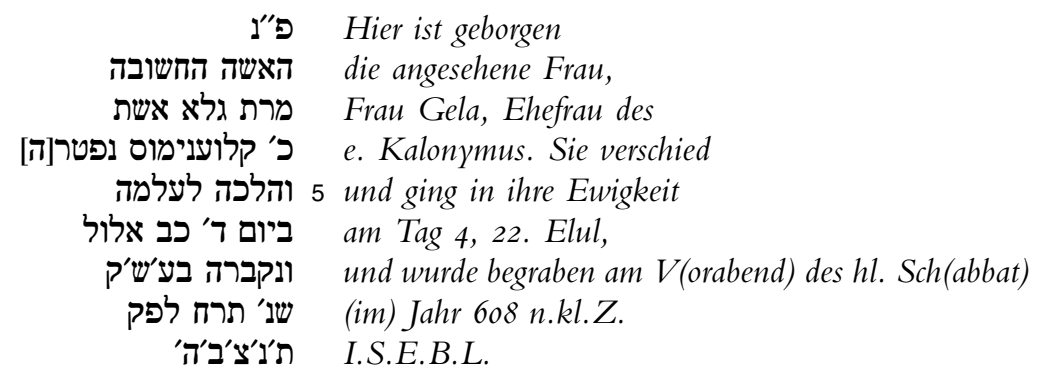

Quelle: FamB (Geburtstag) 
Edel Eichenberg, geb. Kopperschlag

$$
\text { 24.I 2.I793-24.I I.I } 848
$$

Geb. in Herlingshausen/Westfalen - Ehemann: Simon M. Eichenberg II 35 - Kinder: Baruch (I8 I 8-I895 Köln); Levi IV I4; Lucas (I825-I852); Jacob (I827); Marianne (I830I834); Zerline (I832-I858); Henriette (I834-I858); Röschen (I836-I852); Johanne (I837)

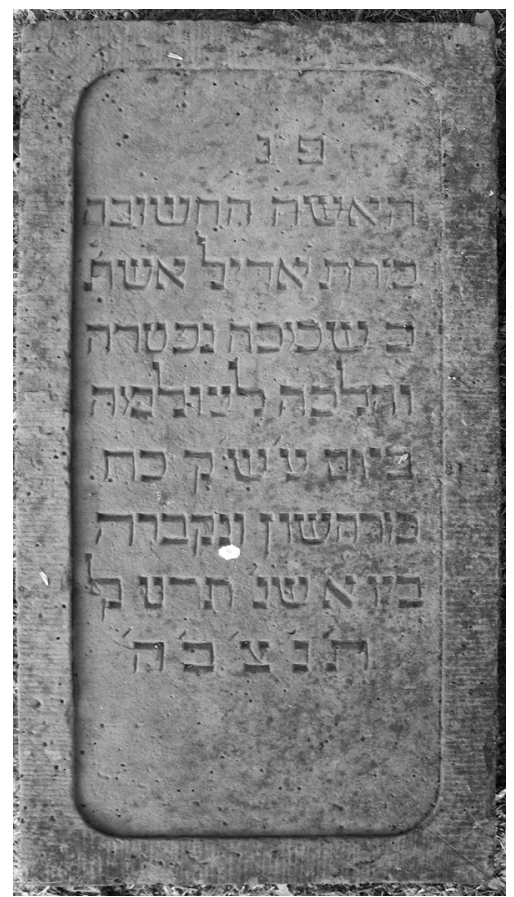

$\mathrm{H} \mathrm{I73} \cdot \mathrm{B} 85 \cdot \mathrm{T}$ I5

פעינ Hier ist geborgen

die angesehene Frau,

Frau Adil, Ehefrau des

e. Simcha. Sie verschied

5 und ging in ihre Ewigkeit

ביום ע'ש'ק כח am Tag des V(orabends des) hl. Sch(abbat), 28.

Marcheschwan, und wurde begraben

a am Tag 1 (im) Jahr 609 n.kl.Z.

תנצבה I.S.E.B.L.

4 שמכה - Quelle: FamB Geburtstag) 
Moses Abraham Edelstein

$$
\text { 8.7.I } 794 \text { - 20. I.I } 849
$$

Metzger - Eltern: Abraham Moses Edelstein II 22 - Edel Friedheim II 25 - Ehefrau: Rosette Eichenberg III $2 \cdot$ Kinder: ebd.

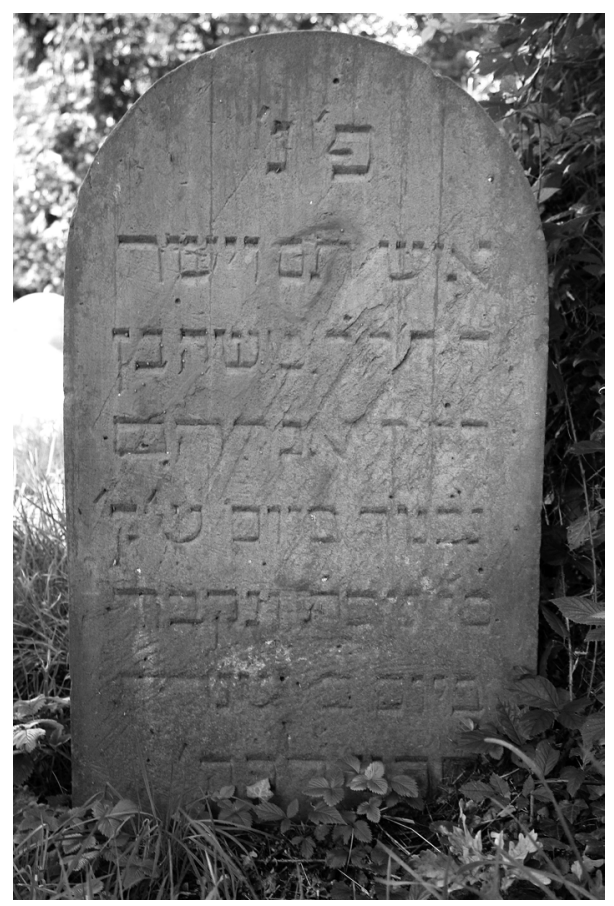

$\mathrm{H} \mathrm{I} 2 \mathrm{O} \cdot \mathrm{B} 7 \mathrm{O} \cdot \mathrm{T}$ I9

\begin{tabular}{|c|c|}
\hline פ״"נ & Hier ist geborgen \\
\hline איש תם וישר - - - 1 & ein redlicher und aufrechter Mann. \\
\hline הח'ה'חר משה בן אברהם & $\begin{array}{l}\text { Das ist der C(haver) H. Mosche, Sohn des } \\
\text { e. C(haver) H. Avraham. }\end{array}$ \\
\hline 5 נפטר ביום ש'ק & Er verschied am Tag des hl. Sch(abbat), \\
\hline כו טבת ונקבר & 26. Tevet, und wurde begraben \\
\hline ביום ב שנת & am Tag 2 (im) Jahr \\
\hline 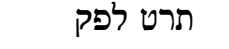 & 609 n.kl.Z. \\
\hline $\begin{array}{l}\text { Rücks } \\
\text { צ'ב'ה'ה }\end{array}$ & $S$ \\
\hline
\end{tabular}

2 s. Hi I,8 - Quelle: FamB (Geburtstag) 


\section{Aron Isaak Müller}

I 4.9.I 779 - I4.3.I 849

Kaufmann · Eltern: Isaak Müller - Betty · Geschwister: Simon II 39; Gitel III 76; Abraham (I784-I834); David III 87 Ehefrauen: I) Bertha Gottschalk; 2) Bertha Bacharach II 5I; 3) Rieke Bacharach · Kinder: zu I): Gottschalk (I8I4-I899, Göttingen: Grab I67); zu 2): s. zu II 5I; zu 3): Betty II 30; Moses (I 834)

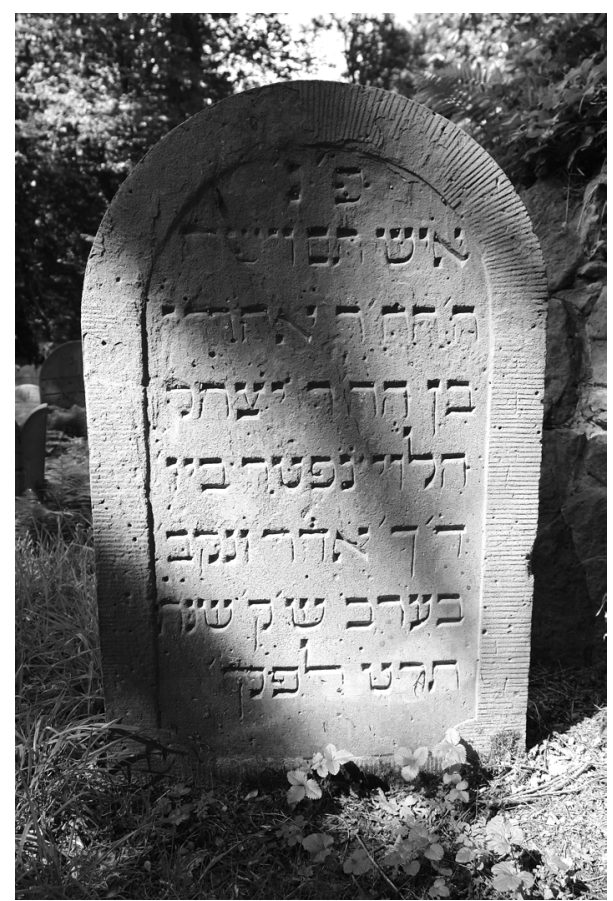

H II $8 \cdot \mathrm{B} 78 \cdot$ T I3

פ"ג Hier ist geborgen

איש תם וישר

Dies ist der C(haver) H. Aharon,

Sohn des H.u.M. Jizchak

5 ha-Levi. Er starb am Tag

4, 20. Adar, und wurde begraben

am Vorabend des hl. Sch(abbat) (im) Jahr

609 n.kl.Z.

ת.S.E.B.L.

2 s. Hi I,8 · Quelle: FamB (Geburtstag) 


\author{
Hendel Hess \\ um I764/65 - I6.3.I 849
}

Ehemann: Moses Hess - Tochter: Fanny III 4I

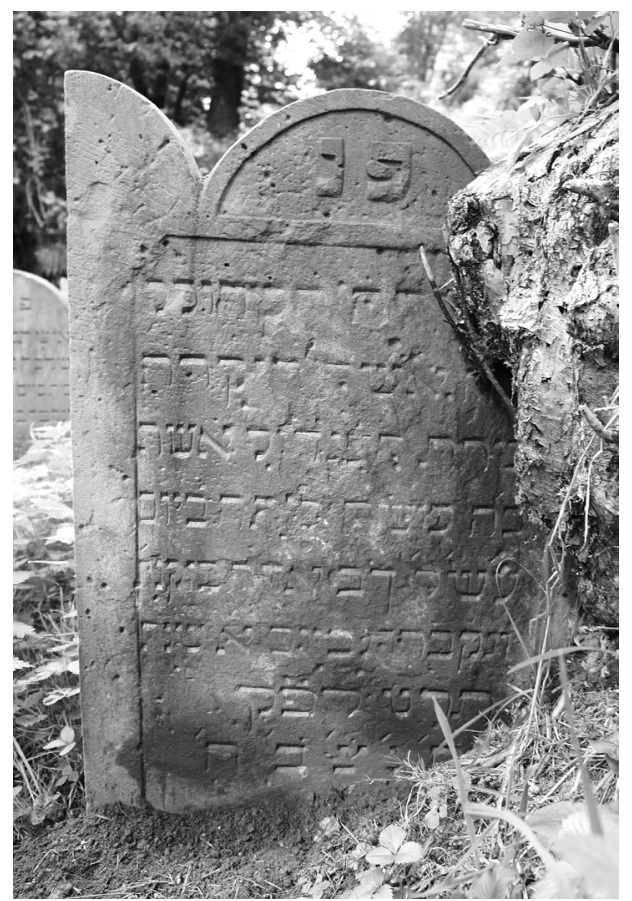

$\mathrm{H} \mathrm{IOO} \cdot \mathrm{B} 72 \cdot \mathrm{T} \mathrm{I} 4$

פ Hier ist geborgen

[שש]"ה המהולל' eine [Fra]u, die gepriesene.

Dies ist die geachtete Frau,

Frau Hendil, Ehefrau

5 des e.H. Mosche. Sie starb am Tag des

V(orabends des) hl. Sch(abbat), 22. Adar, in ihrem (hohen) Alter

und wurde begraben am Tag 1 (im) Jahr

609 n.kl.Z.

I.S.E.B.L.

Quelle: StL (Geburtsjahr nach Altersangabe) 


\section{Rösche Dannenberg, geb. Meyenberg}

$$
\text { 5.I.I } 792-20.7 .1849
$$

Eltern: Salomon Simon Meyenberg II 2 - Marline Kaufmann II $6 \cdot$ Ehemann: Moses Selig Dannenberg III 3a Kinder: Calman II 8 (?); Betti IV I 5 ; Meyer III 7; Simon IV 2 I; Jonas (I 824); Amalie (I 826); Johanne III I 5; Minna (I 830-I900, Bodenfelde); Goldchen (I 832I834)

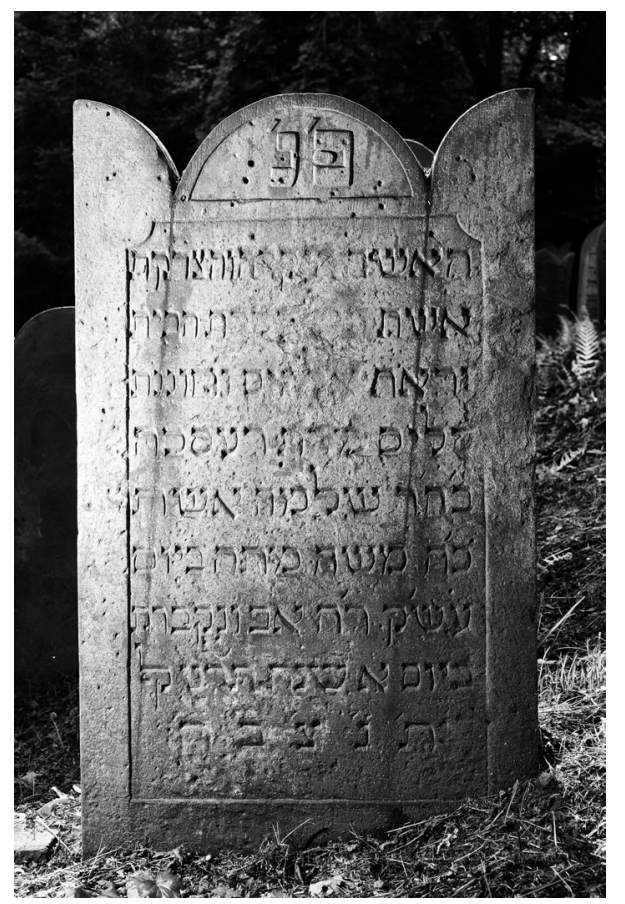

$\mathrm{H} \mathrm{I24} \cdot \mathrm{B} 70 \cdot \mathrm{T}$ I9

פעינ Hier ist geborgen

die geachtete und wohltätige Frau,

אשת חיל ועקרת הבית

gottesfürchtig (war sie) und barmherzig den

5 Armen, Frau Rösche,

T' T'ochter) des Ch(aver) H. Schlomo, Ehefrau

des e.H. Mosche. Sie starb am Tag des

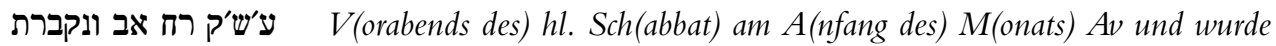
begraben

am Tag 1 (im) Jahr 609 n.kl.Z.

10 I.S.E.B.L.

3a s. Prov 3 I, IO · 3b s. Ps I I 3,9 4 s. Prov 3 I,30 - 8 StbL: 2 I.7. · Quelle: GbL (Geburtstag) 


\section{Anonymus}

I 850

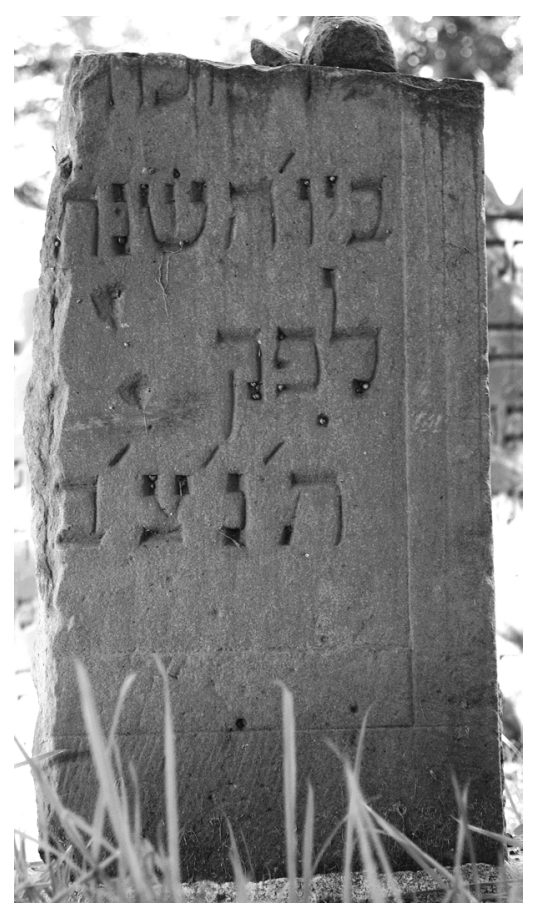

Fragment $\mathrm{H}_{74} \cdot \mathrm{B}_{4} \mathrm{I} \cdot \mathrm{T}$ I4

Datierung um i 850 nach Lage

\begin{tabular}{|c|c|}
\hline & \\
\hline בין' & $n$ Ta \\
\hline לפק ... & n.kl.Z. \\
\hline יצ'צ'בה.]. & S.S.E.B.[L. ... \\
\hline
\end{tabular}


Edel Edelstein, geb. Friedheim

$$
\text { 2.2.1 } 768-\mathrm{I} 3.2 .1850
$$

Vater: Menachem Friedheim in Gifhorn - Ehemann: Abraham Moses Edelstein II 22 . Kinder: Moses III I; Alexander III 63; Friederike III 98; Jonas (I804); Meyer (I 806)

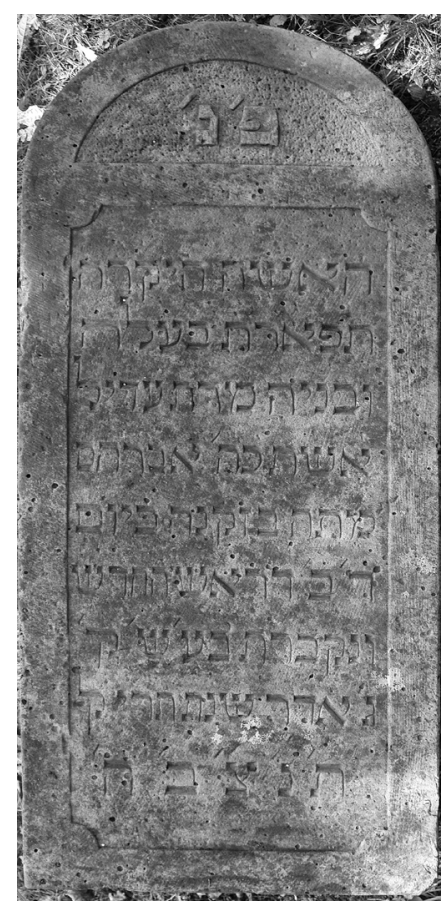

$\mathrm{H} \mathrm{I} 8 \mathrm{I} \cdot \mathrm{B} 72 \cdot \mathrm{T}$ I6

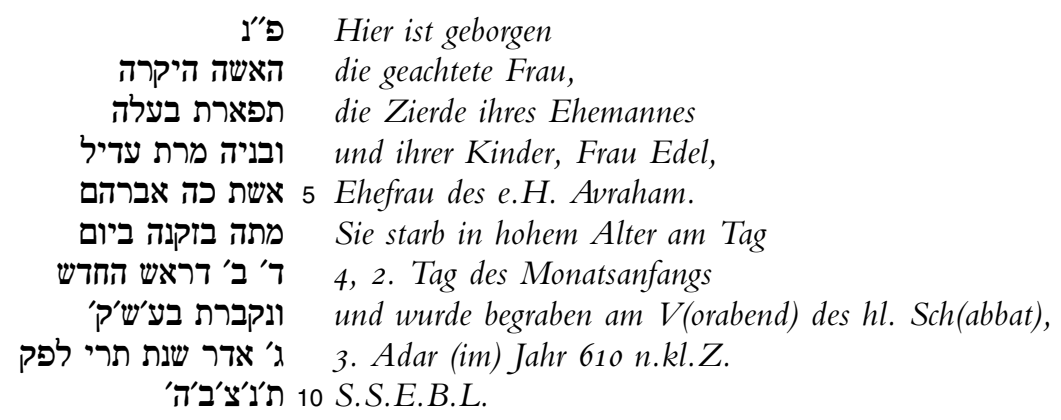

3 s. Prov 3 I, Iо · 7 4. Tag (Mittwoch) abends (I3.2.I850), Beginn des 2. Adar - Quelle: FamB (Geburtstag) 
Moses Sachs

$$
\text { I796/97 - 24.2.I } 850
$$

Geb. in Radegau, Prov. Posen: heute Radojewo, Polen · Seit I 827/28 Lehrer, Vorsänger und Schächter in Adelebsen; I 836 aus seinen Gemeindeämtern entlassen, danach zeitweise Vorsänger in Barterode; ferner als Buchbinder tätig. · Vater: Jechiel · Ehefrau: Henriette/Jette Samuel (I797) - Kinder: Friederike (I8I9); Johanna (I82 I); Jeanette/Hannchen (I 823); Rosalia (I 825); Marlien (I826); Meyer (I827); Samuel III 39; Michel III 54; Lisette/Lea (I834); Marianne (I839-I844); Joseph (I84I)

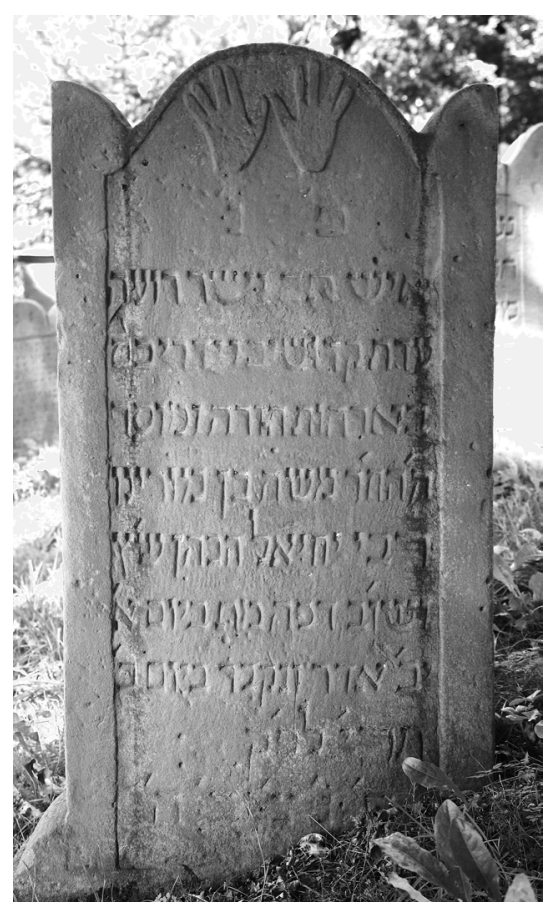

$\mathrm{H}$ I $35 \cdot \mathrm{B} 63 \cdot \mathrm{T}$ I 5

פ"פ Hier ist geborgen

פיש תם וישר רועה

die Gemeinde der Heiligen und führte sie

בארחות תורה ומוסר

5 Dies ist der C(haver) H. Mosche, Sohn unseres Lehrers

Herrn Jechiël ha-Kohen, V(or)b(eter)

ושו'ב דפה מת ביום א' und Sch(ächter) und F(leischbeschauer) von hier. Er starb am Tag 1,

12. Adar, und wurde begraben am Tag 2

610 n.kl.Z.

10 S.S.E.B.L.

2 s. Hi I , 8 - 3 ,Gemeinde der Heiligen“, traditionelle Bezeichnung in Anlehnung an Lev I9,2 4 Tora - Mussar: biblisch-rabbinische Weisungen und die daran anknüpfende Ethik.

5 Die Bezeichung „,unser Lehrer« ist vermutlich Ehrentitel. - Quelle: StL (Altersangabe) 
Samuel Sachs

$$
\text { I6.8. I } 828 \text { - I I.5. I } 85 \text { I }
$$

Eltern: Moses Sachs III 5 - Henriette Samuel

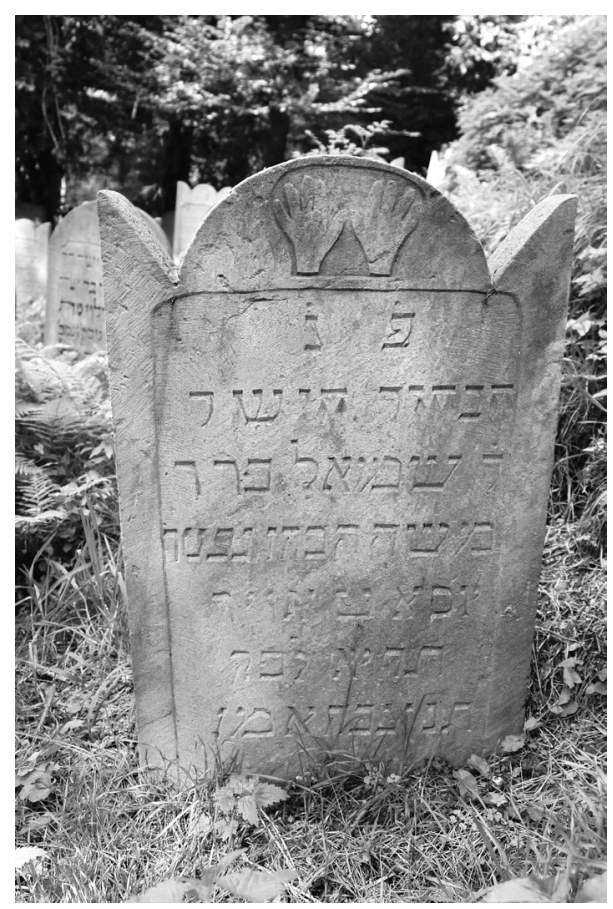

$\mathrm{H} 99 \cdot \mathrm{B} 63 \cdot \mathrm{T}$ I2

פע"ג Hier ist geborgen

der aufrechte Junggeselle

H. Schmuel, Sohn des H.

Mosche ha-Kohen. Er verschied

5 am Tag 1, 9. Ijjar

611 n.kl.Z.

ת.S.E.B.L. Amen.

5 StbL: 12.5 . 


\section{Samuel Simon Oppenheim(er)}

$$
\text { 8.I2.I } 783-\mathrm{I} 3.5 . \mathrm{I} 85 \mathrm{I}
$$

Kaufmann - Vater: Schmeiche Moses I i9 · Ehefrau: Jeanette Plaut III I3 - Kinder: s. ebd.

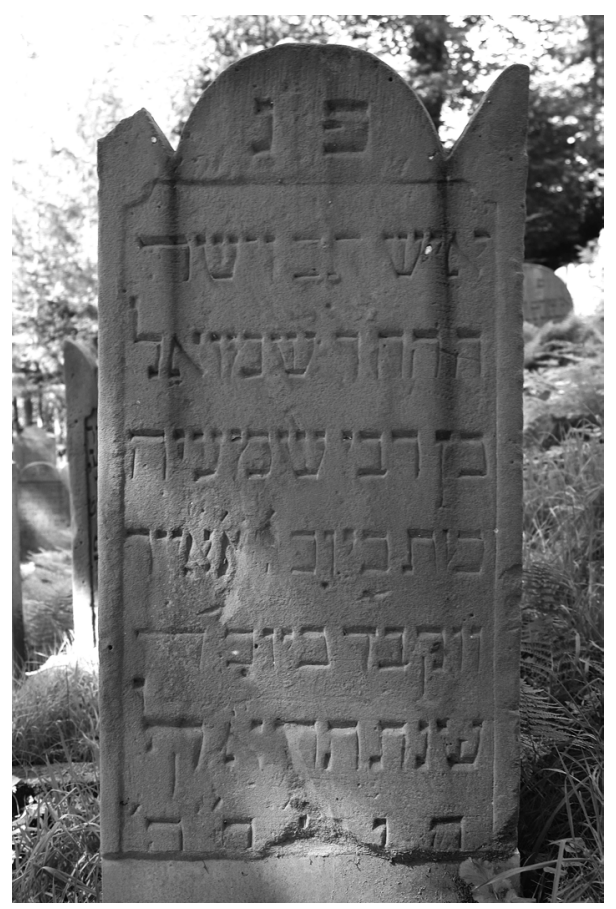

$\mathrm{H} 97 \cdot \mathrm{B} 54 \cdot \mathrm{T}$ I 5

Grabstein nachträglich wieder aufgestellt, unterer Teil beschädigt

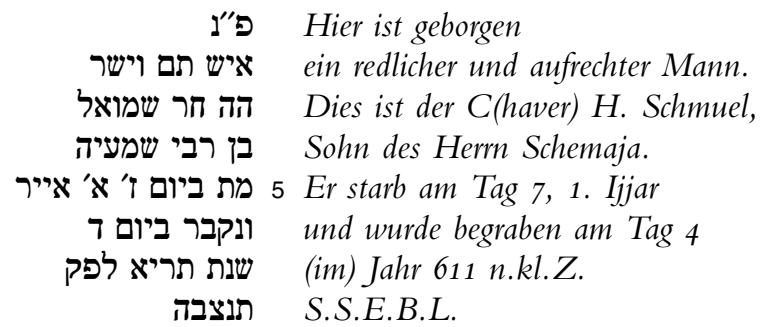

2 s. Hi I,8 - 6 Auffällig langer Zeitraum zwischen Tod (Samstag) und Begräbnis (Mittwoch) 7 Ungewöhnliche Angabe des Wochentags Schabbat nur durch die Zahl 7 . Quelle: FamB (Geburtstag) 

Bertha Müller
Salomon Müller
6.IO.I $849-20 . I 2 . I 85$ I
I.4.I $848-$ I $8 . \mathrm{I} 2 . \mathrm{I} 85 \mathrm{I}$

Eltern: Gottschalk Aron Müller (vgl. III 23) - Rosette Meyenberg

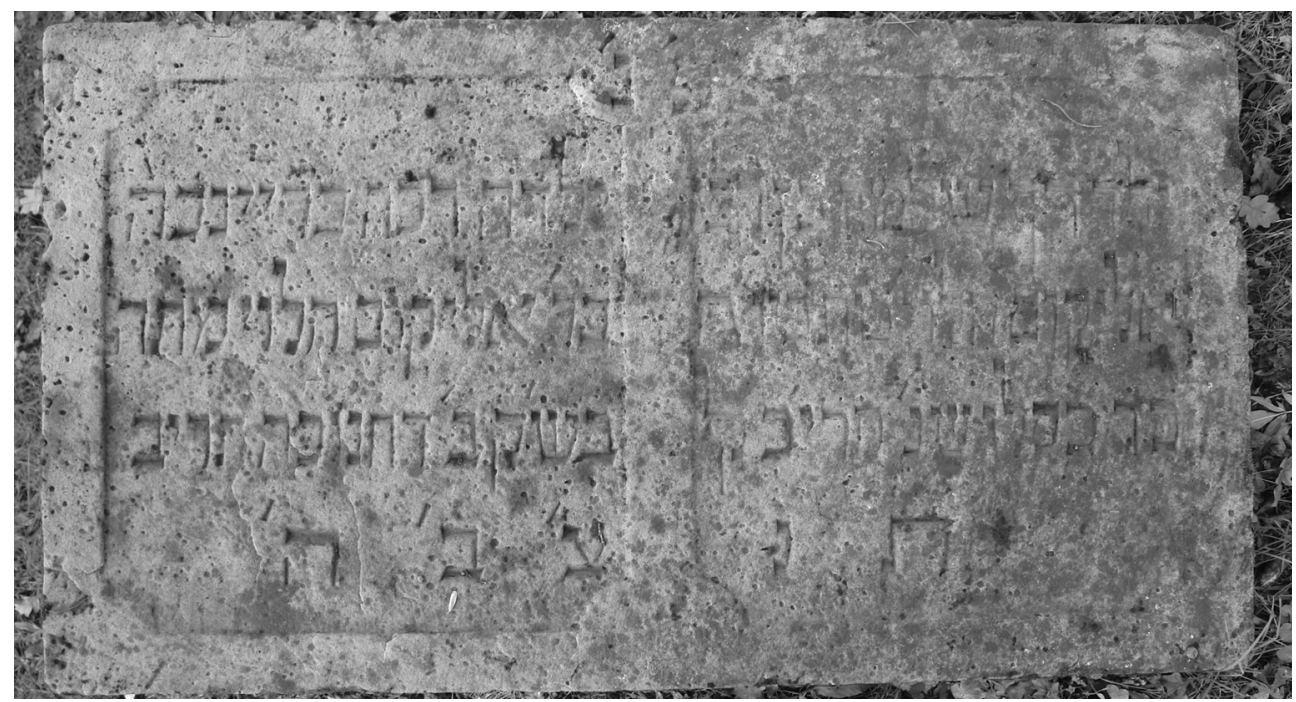

$\mathrm{H}$ I $54 \cdot \mathrm{B} 84 \cdot \mathrm{T}$ I5

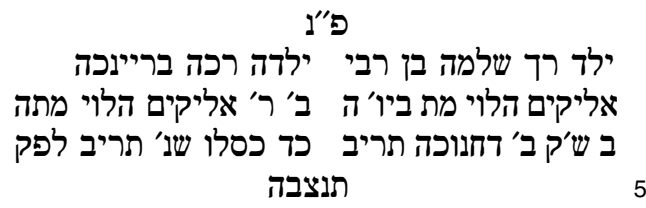

Hier sind geborgen

ein zarter Knabe, Schlomo, Sohn des Herrn ein zartes Mädchen, Breinche

Eljakim ha-Levi. Er starb am Tag 5

T(ochter) des H. Eljakim ha-Levi. Sie starb

24. Kislew (im) Ja(hr) 612 n.kl.Z.

am hl. Sch(abbat), dem 2. (Tag) von Chanukka 612

Quelle: GbL (Geburtstag) 
Isaak Müller

I.2.I $847-8$. I.I 852

Eltern: Gottschalk Aron Müller (vgl. III 23) - Rosette Meyenberg

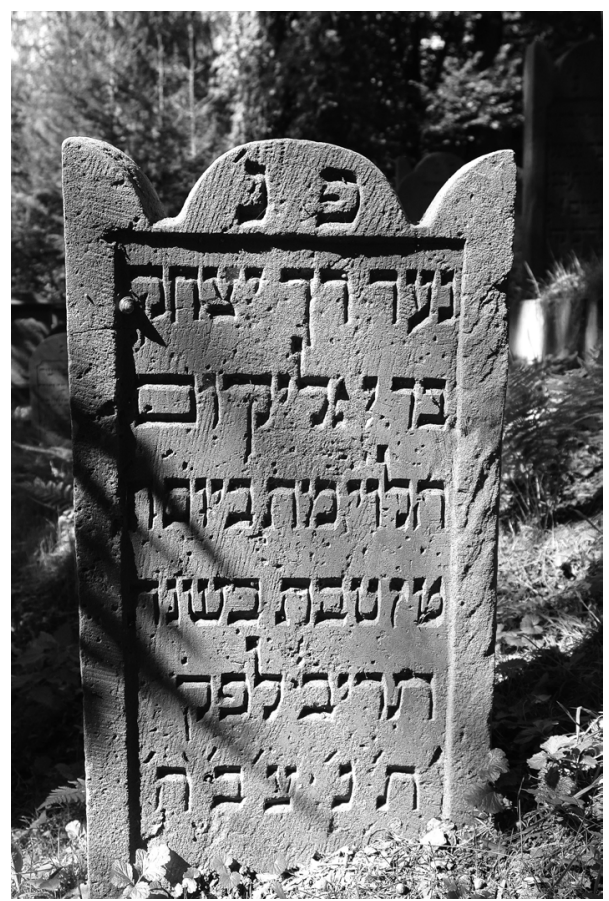

$\mathrm{H} \mathrm{IIO} \cdot \mathrm{B} 56 \cdot \mathrm{T}$ I2

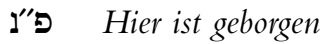

נער רך יצחק ein zarter Knabe, Jizchak,

S(ohn) des Eljakim

ha-Levi. Er starb am Tag 5,

5 16. Tevet im Jahr

612 n.kl.Z.

ת.S.E.B.L.

Quelle: GbL (Geburtstag) 
Johanne Dannenberg

6.I2.I 828 - I6.I.I 852

Eltern: Moses Selig Dannenberg III $3 \mathrm{a}$ - Rosette Meyenberg III 3

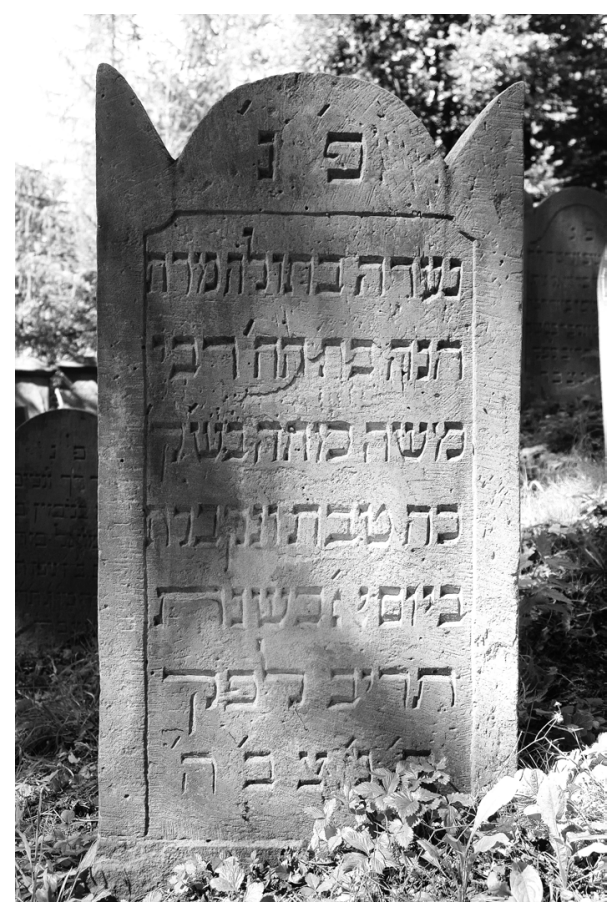

$\mathrm{H}$ II $3 \cdot \mathrm{B} 66 \cdot \mathrm{T}$ I5

פע"נ Hier ist geborgen

eine junge unverheiratete Frau,

ח Channa, Tochter des e. Herrn

Mosche. Sie starb am hl. Sch(abbat),

25. Tevet, und wurde begraben

ביום א' בשנת

612 n.kl.Z.

I.S.E.B.L.

6f. StbL verzeichnet I6.I. = Sabbatbeginn in den Abendstunden - Quelle: FamB (Geburtstag) 
Levi L. Eichenberg 25.6.I $837-2$ I.I.I 852

Eltern: Leiser M. Eichenberg III 79 - Friederike Stehberg III 78

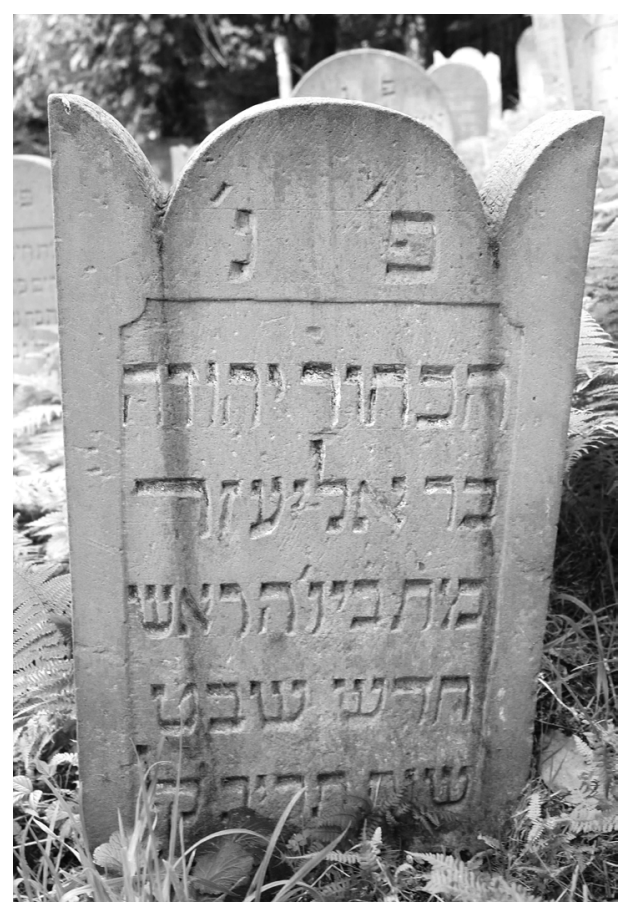

H II9 $\cdot$ B $55 \cdot$ T I4

\author{
פעינ Hier ist geborgen \\ הבחור יהודה der Jüngling Jehuda, \\ Sohn des Elieser. \\ Er starb am Tag 5 am Anfang \\ 5 des Monats Schevat \\ (im) Jahr 612 n.kl.Z. \\ S'ת.S.B.L.L.
}

4 Inschrift und StL weisen auf Mittwochabend 2I.I. als Sterbedatum. - Quelle: GbL (Geburtstag) 
Rösche Rosenbaum

I9.4.I 848 - 22.I.I 852

Eltern: Moses Rosenbaum III I6 - Emilie Stern III I7

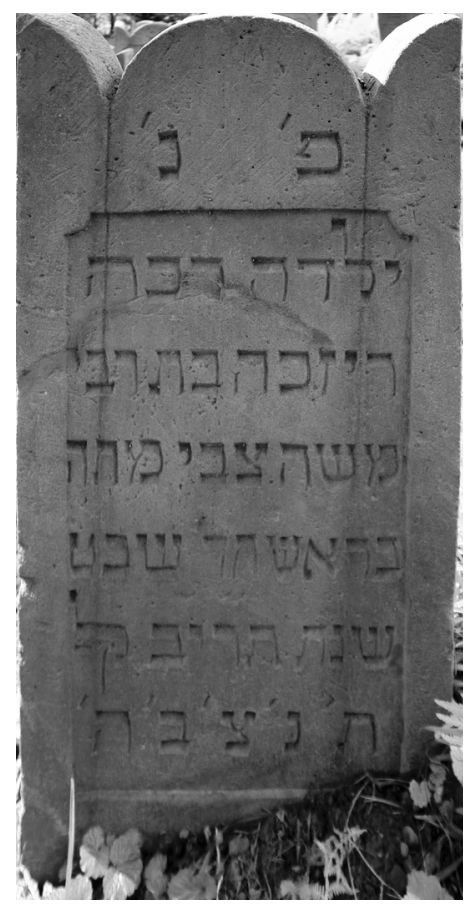

$\mathrm{H} \mathrm{I22} \cdot \mathrm{B} 52 \cdot \mathrm{T}$ I 2

פ"ג Hier ist geborgen

ילדה רכה פ"פ ein zartes Mädchen,

Rösche, Tochter des Herrn

Mosche Zvi. Sie starb

5 am Anfang des Mo(nats) Schevat

שנת תריב לפק (im) Jahr 612 n.kl.Z.

ת'ת'צ'ב'ת'ת' I.S.E.B.L. 
Louis Herz Stehberg 29.IO.I $850-29$. I.I 852

Eltern: Herz Stehberg IV I6 - Betti Dannenberg IV I5

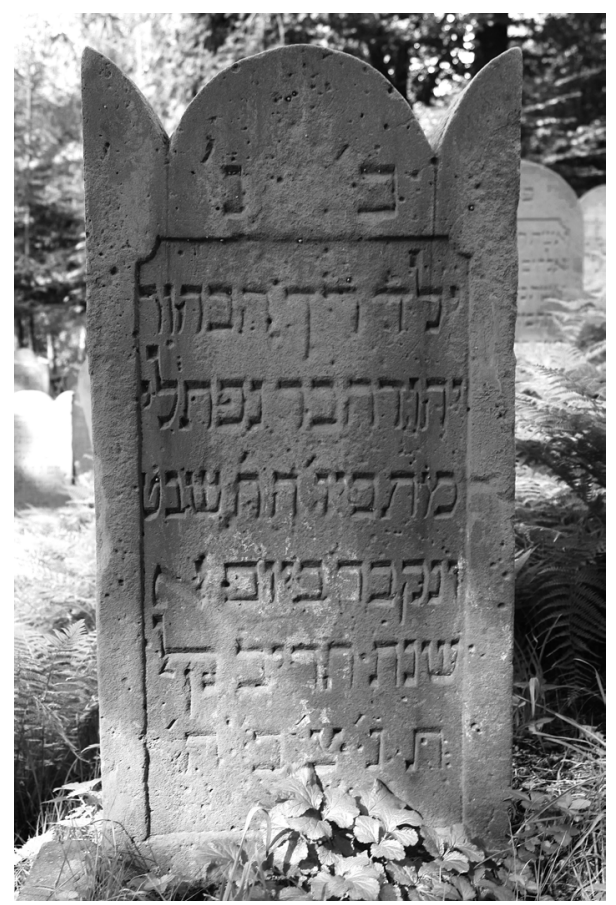

H II9 - B $58 \cdot$ T I4

פ"ג Hier ist geborgen

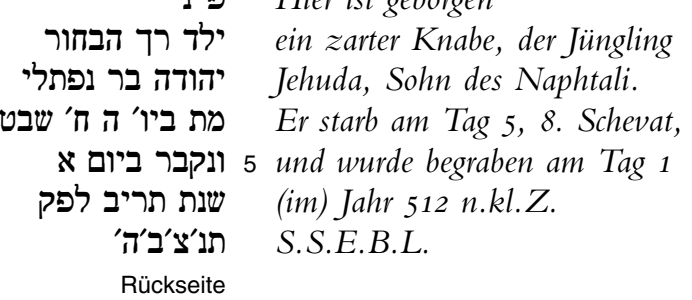

Louis Herz Stehberg

Quelle: GbL (Geburtstag) 


\section{Marcus Löwenstern}

I I.8.I $847-5.2 .1852$

Eltern: Jacob Marcus Löwenstern III 9 - Johanne Dahl III Io

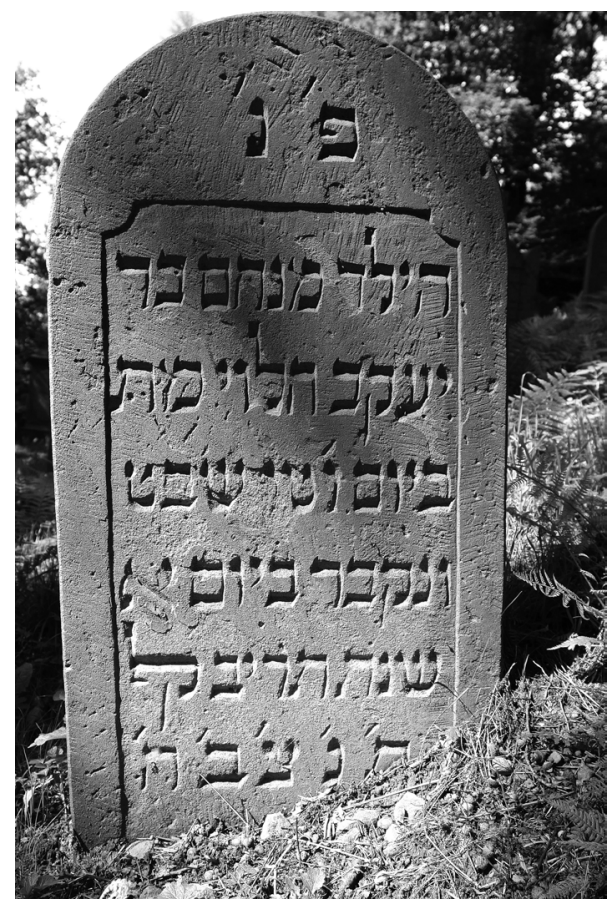

$\mathrm{H} \mathrm{IO}_{4} \cdot \mathrm{B} 54 \cdot \mathrm{T}$ I I

פיד

der Knabe Menachem, Sohn des

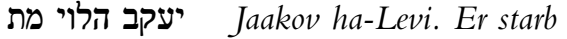

am Tag 6, 16. Schevat

5 und wurde begraben am Tag 1

(im) Jahr 612 n.kl.Z.

S'ת'נ'צ'ב'ה' S.E.B.L.

4 Sterbetag I6. Schevat nach StL 5.2., d.h Donnerstagabend - Quelle: GbL (Geburtstag) 
Levi Löwenthal

I 4.3.I $84 \mathrm{I}-\mathrm{I} 8.2 . \mathrm{I} 852$

Eltern: Joel Löwenthal - Marianne Rosenberg

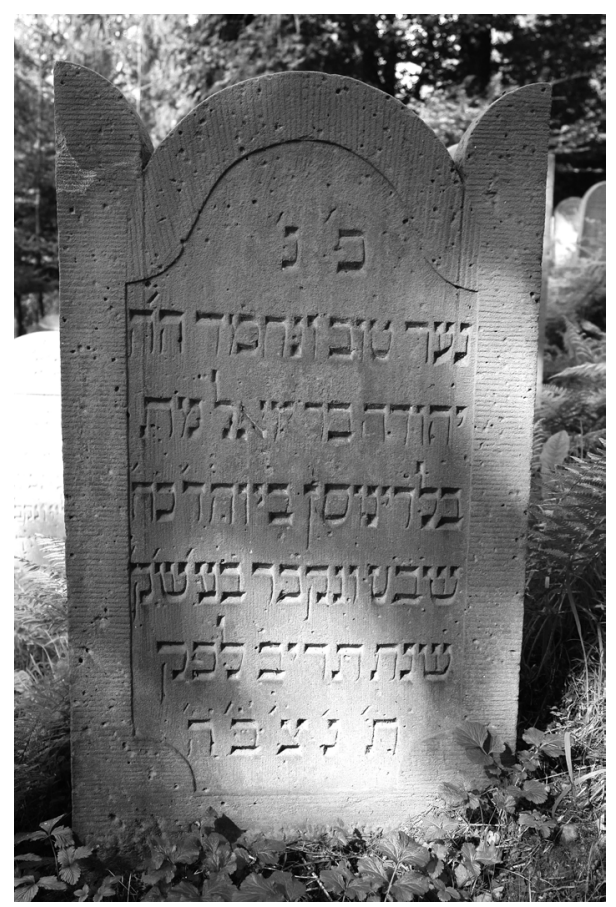

H I I7 $\cdot$ B 7I $\cdot$ T I2

פע"נ Hier ist geborgen

ein guter und liebenswerter Junge. Dies ist

יהודה בר יואל מת נתוח Jehuda, Sohn des Joël. Er starb

in Lödingsen am Tag 4, 28.

5 Schevat, und wurde begraben am V(orabend des) hl. Sch(abbat)

(im) Jahr 612 n.kl.Z.

S.S.E.B.L.

Quelle: GbL (Geburtstag) 
Pauline Edelstein

I.7.I 846 - I 5.IO.I 852

Eltern: Alexander Abr. Edelstein III 63 - Minna Grunsfeld

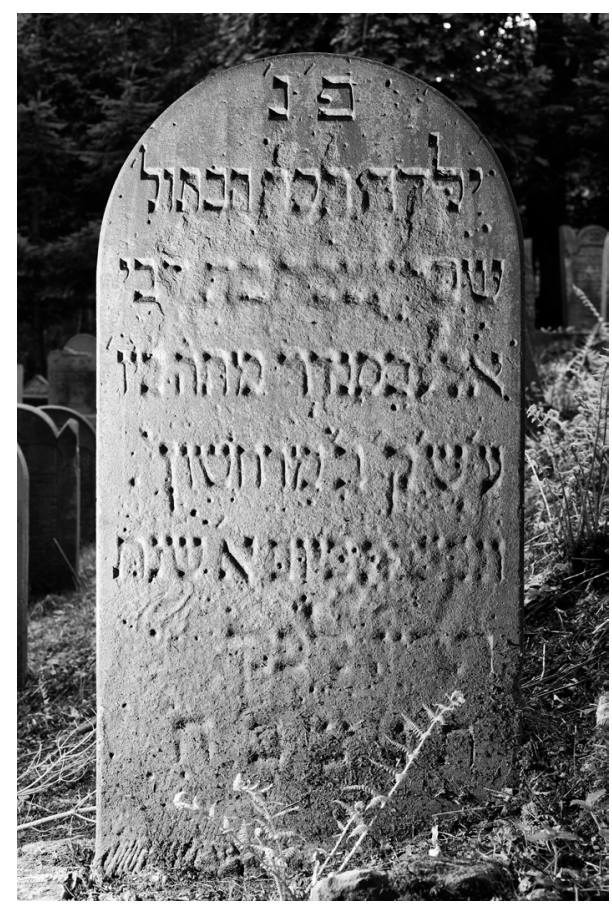

$\mathrm{H} \mathrm{IO7} \cdot \mathrm{B}$ 6I $\cdot \mathrm{T} \mathrm{I4}$

פ"ג Hier ist geborgen

ילדה רכה הבתול' ein zartes Mädchen, die Jungfr(au)

Sprinzche, Tochter des Herrn

Alexander. Sie starb am Ta(g) des

5 V(orabends des) hlg. Sch(abbat), 2. Marcheschwan, ונקבר ביום א' שנת משת

613 n.kl.Z.

I.S.E.B.L.

Quelle: GbL (Geburtstag) 
Salomon Joel Rothschild 20.8.I 790 - 24.II.I 852

Kaufmann - I848 - I850 Rechnungsführer der Synagogengemeinde - Eltern: Joel D. Rothschild II I 8 - Hindel David II I5 - Ehefrau: Fanni Hess III 4I - Kinder: s. ebd.

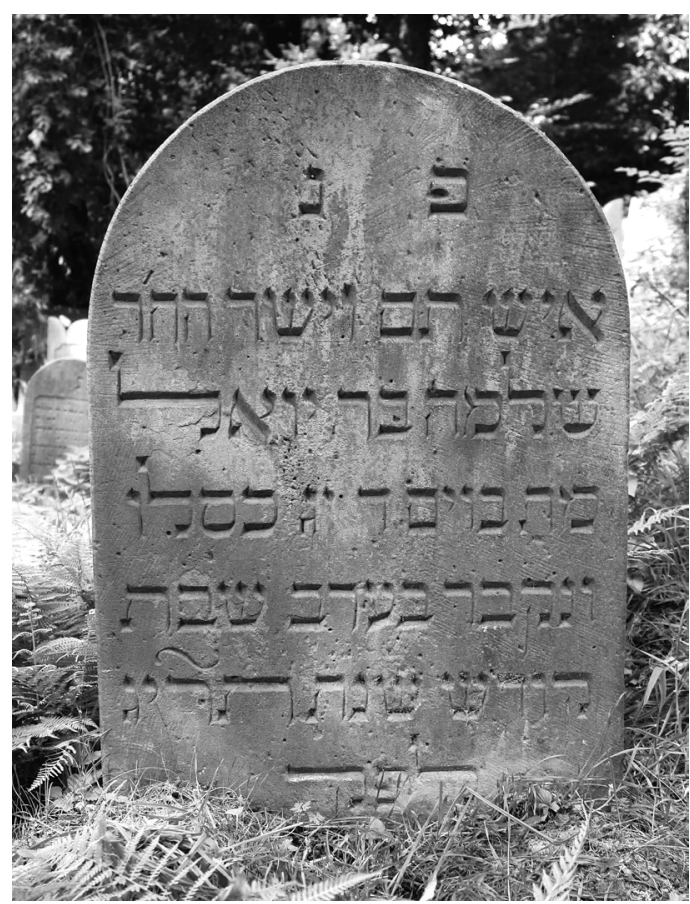

$\mathrm{H}$ II5 $\cdot \mathrm{B} 69 \cdot \mathrm{T}$ I3

פ Hier ist geborgen

איש תם וישר הח'ר ein redlicher und aufrechter Mann, der C(haver) $H$.

Schlomo, Sohn des Joël.

Er starb am Tag 4, 13. Kislew,

5 und wurde begraben am Vorabend des heiligen

Schabbat (im) Jahr 613

לפ.kl.Z.

S.S.E.B.L.

2 s. Hi I,8 · Quelle: FamB (Geburtstag) 
Rösche Rosenstein, geb. Oppenheim

$$
\text { I4.9.I } 776-8.5 .1853
$$

Geb. in Helmarshausen/Hessen • Ehemann: Philipp Meyer Rosenstein (I769-I848)

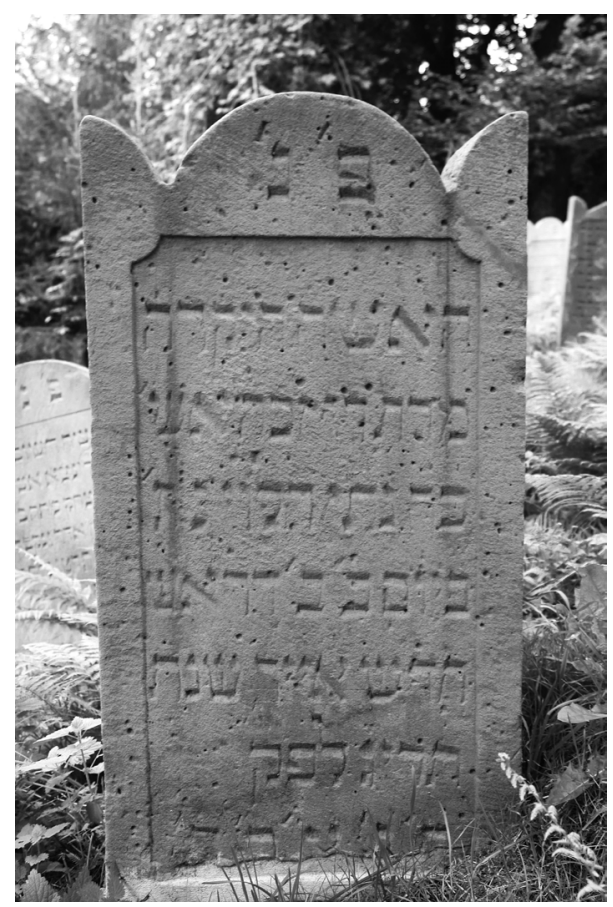

H IIo $\cdot$ B $69 \cdot$ T I2

פ"ג Hier ist geborgen

die geachtete Frau,

Frau Rösche, Ehef[rau]

des e.H. Nathan ha-Levi. Sie sta(rb)

5 am Tag 2, dem 2. des Monats-

Anfangs des Ijjar (im) Jahr

613 n.kl.Z.

I.S.S.B.L.

Quelle: FamB (Geburtstag) 


\section{Hanna Rothschild}

I6.I I.I $837-2$. IO.I 853

Eltern: Salomon Joel Rothschild III 40 - Fanny Hess III 4I

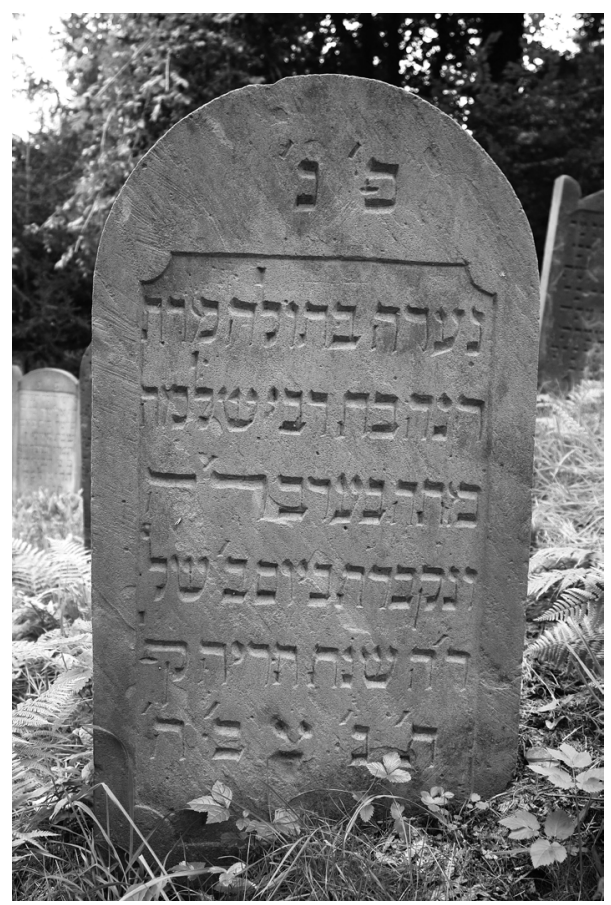

H II $8 \cdot \mathrm{B} 6 \mathrm{I} \cdot \mathrm{T} 9,5$

פע"ג Hier ist geborgen

ein junges Mädchen, Frau

ח Channa, Tochter des Herrn Schlomo.

Sie starb am Vorabend des n(euen) J(ahres)

5 und wurde begraben am 2. Tag des

N(euen) J(ahres) (im) Jahr 614 n.kl.Z.

I.S.E.B.L.

Quelle: GbL (Geburtstag) 


\section{Simon Isaak Müller}

$$
\text { 24.I.I } 766-7 . \text { II.I } 853
$$

Lotterie-Collecteur in Barterode · I83 I als „Ältester“, I 832 als Repräsentant der Judenschaft zu Barterode erwähnt (HStAH, Hann.74 Uslar Nr. 2046) · Eltern: Isaak Müller Betty - Geschwister: Gitel III 76; Aron III 23; Abraham (I784-I834); David III 87 • Ehefrau: Hannchen, Tochter des Aron Levi II $46 \cdot$ Kinder: ebd.

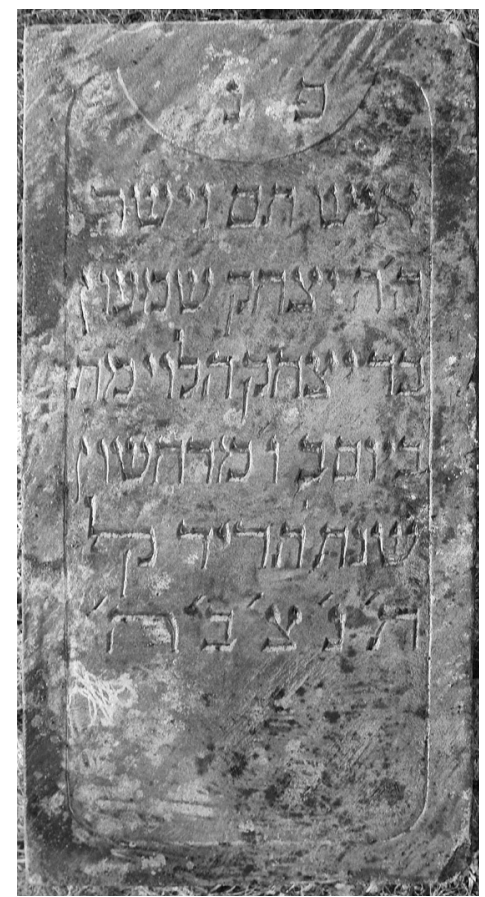

$\mathrm{H} \mathrm{I} 38 \cdot \mathrm{B} 65 \cdot \mathrm{T} \mathrm{I2}$

פ"ג Hier ist geborgen

היש תם וישר

Dies ist Jizchak Schimon, Sohn des Jizchak ha-Levi. Er starb 5 am Tag 2, 6. Marcheschwan

～(im) Jahr 614 n.kl.Z.

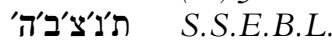

2 s. Hi I,8 - Quelle: FamB (Geburtstag) 
Isaac Moses Freudenthal I 4.4. I $780-6 . \mathrm{I} 2 . \mathrm{I} 853$

Metzger - Eltern: Moses Isaac - Jette · Ehefrau: Sophie Heilbrunn, verw. Grunsfeld III 52

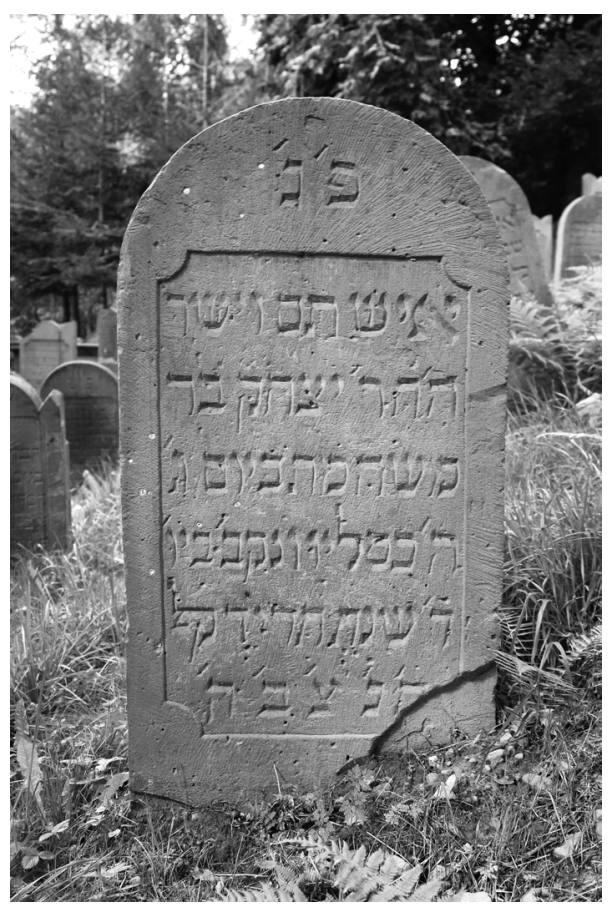

$\mathrm{H} \mathrm{I} 22 \cdot \mathrm{B} 62 \cdot \mathrm{T}$ I I

פיש

איש תם וישר der C(haver) H. Jizchak, Sohn des

Mosche. Er starb am Tag 3,

5 5islew, und wurde begraben am Tag 4 (im) Jahr 614 n.kl.Z.

S.S.E.B.L.

2 s. Hi I,8 - Quelle: FamB (Geburtstag) 


$$
\begin{gathered}
\text { Philipp Bähr(e) } \\
\text { I2.5.I792 - 5.I.I } 854
\end{gathered}
$$

Pferdehaarverarbeiter und -händler in Barterode - zeitweise Vorbeter im dortigen Gemeindegottesdienst · Eltern: Levi Bähr(e) (Sohn von Herz Mendel, I I 8) - Fanni · Ehefrau: Mathilde Kahlberg III $45 \cdot$ Kinder: s. ebd.

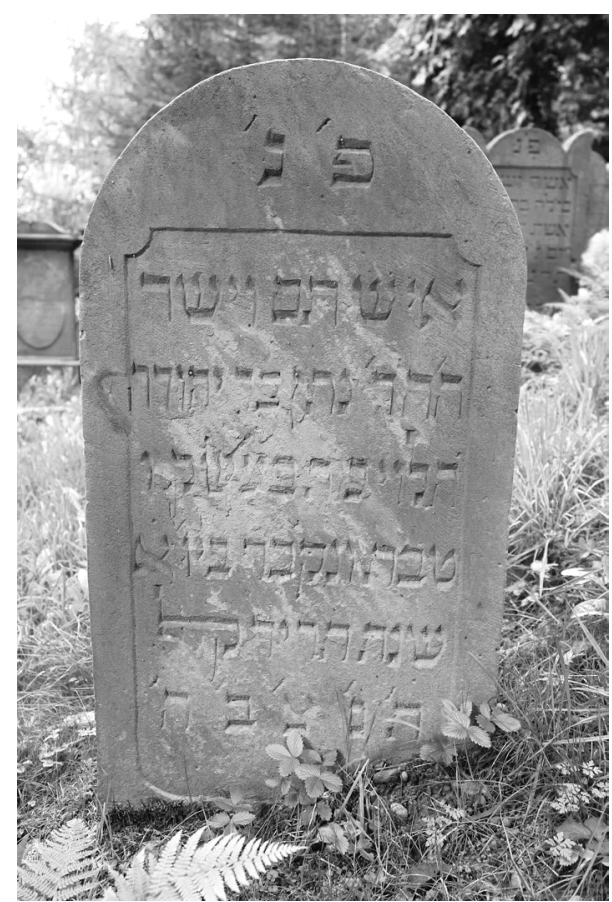

H IOI $\cdot$ B $59 \cdot$ T IO

פ"ג Hier ist geborgen

איש תם וישר

Dies ist der H. Nathan, Sohn des Jehuda

ha-Levi. Er starb am V(orabend) des hl. Sch(abbat), 6.

5 Tevet und wurde begraben am Tag 1

(im) Jahr 614 n.kl.Z.

S.S.E.B.L.

2 s. Hi I,8 4 StL: 5.I.I $854=$ Donnerstag, Abendstunden des Sabbatvortags $\cdot$ Quellen: FamB /StL (letztere datiert Geburtstag auf 9.5.) 
Fanni Rothschild, geb. Hess

8.5.I 80 I - 3I.I.I 854

Geb. in Merzhausen Hessen - Eltern: Moses Hess - Hendel III $27 \cdot$ Ehemann: Salomon Joel Rothschild III 40 - Kinder: Joel IV I7; Amalie/Merline (I82 I-I900, Uslar); Moses (I823); Lina (I 826); David (I 827); Jacob (I 829); Levi (I836-I853, Rodenberg); Hanna III 5I; Henriette (I844)

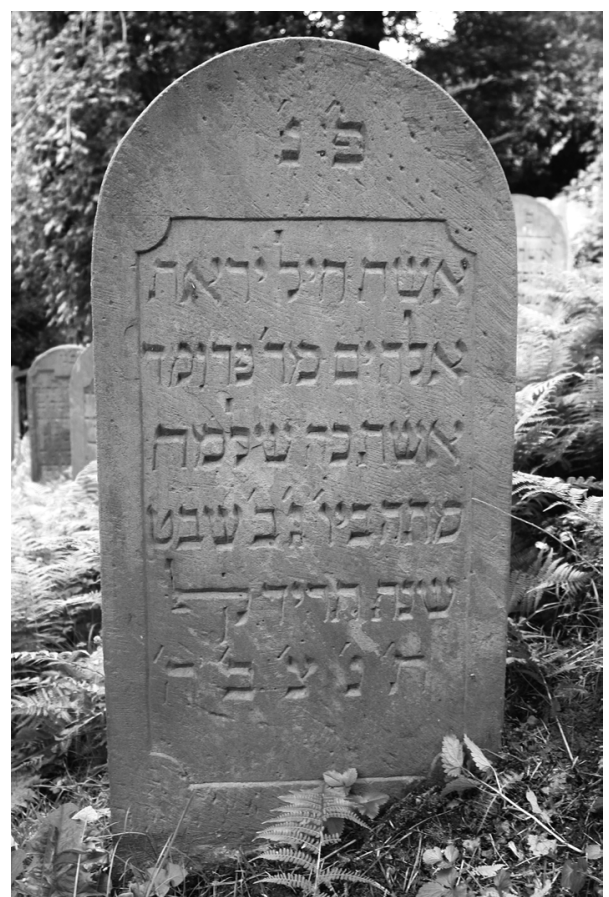

$\mathrm{H} \mathrm{I} 20 \cdot \mathrm{B} 6 \mathrm{I} \cdot \mathrm{T} \mathrm{I} 2$

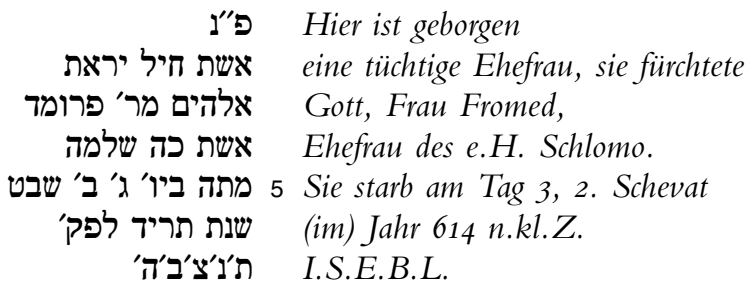

2 s. Prov 3 I, I0.30 - Quelle: FamB (Geburtstag) 


\section{Herz Simon Müller}

$$
\text { 20.8. } 1803-4.4 .1854
$$

Handelsmann (Pferdehändler) und Metzger in Barterode · I836-I842; I844-I846 Vorsteher der Synagogengemeinde Barterode-Güntersen · Eltern: Simon Isaak Müller II 39 Hannchen II 46 · Ehefrau: Rieke Norden (geb. I8 I2, Moringen) · Kinder: Selig (I840I920, Göttingen: Grab 20I); Julie (I842-I936, Barsinghausen); Isaac (I844-I9I 8, Göttingen: Grab I80); Hanne (I846); Adolph (I849-I935, Northeim); Jacob (I85 I-I 899, Heiligenstadt), Abraham (I853-I896, Göttingen)

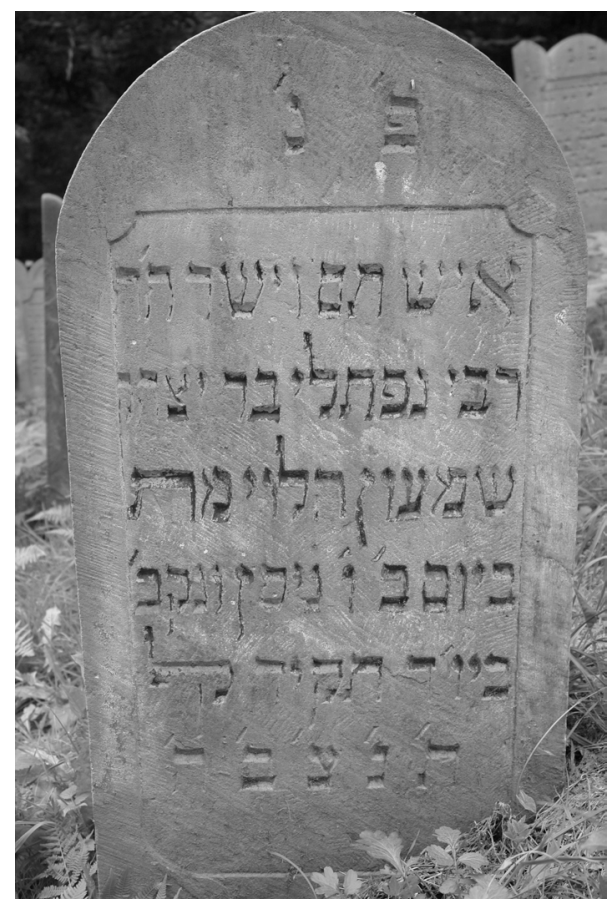

Rückseite

Herz Simon Müller

Barterode

gest. 4. April I 854

$\mathrm{H}$ I IO $\cdot \mathrm{B} 60 \cdot \mathrm{T}$ Iо

פַיש Hier ist geborgen

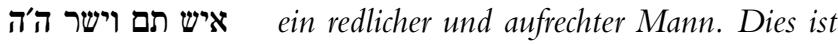

Herr Naphtali, Sohn des Jizchak

Schimon ha-Levi. Er starb

ביום ב' ו' ניסן ונקב' 5 am Tag 2, 6. Nisan, und wurde begra(ben)

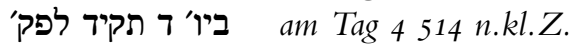

S.S.E.B.L.

2 s. Hi I,8 - 6 Die Angabe des Sterbejahres in der hebr. Inschrift תקיד (5I4= I754) beruht auf einem Schreibfehler. Zutreffend ist die Datierung der dt. Inschrift: I854 תריד = (6I4). Quelle FamB (Geburtstag) 
Salomon J. Rothschild

$$
\text { 6.8.I } 854 \text { - I5.9.1 } 854
$$

Eltern: Joel S. Rothschild IV I7 - Betty Davison II 53

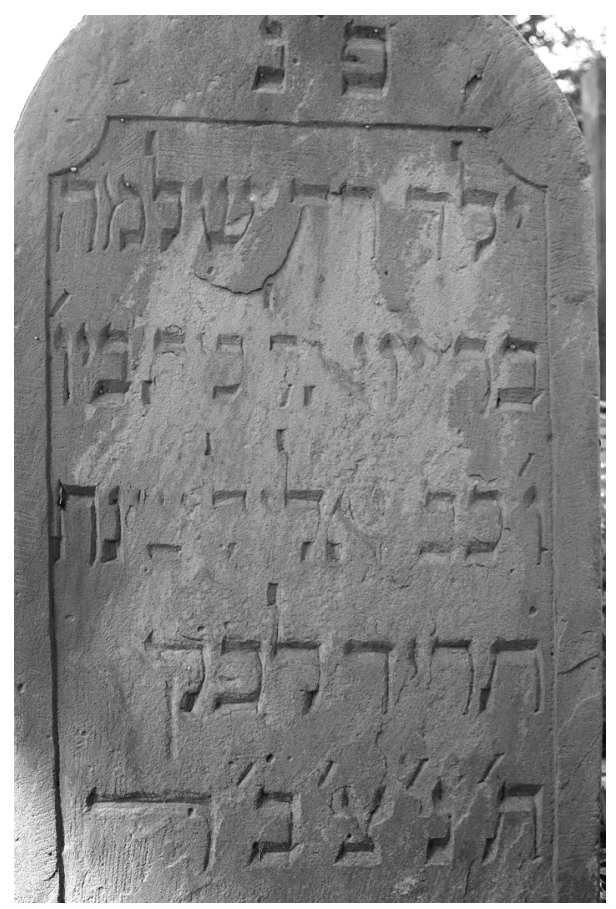

H II3 B 52 T Io

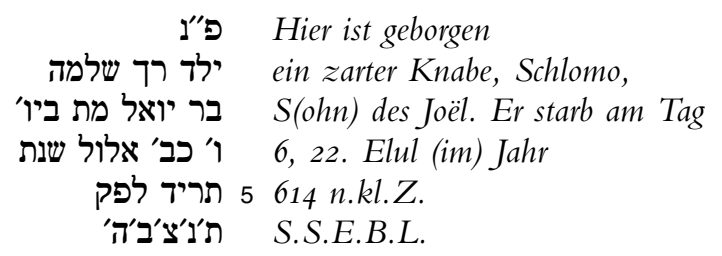

Quelle: GbL (Geburtstag) 
Michel Sachs

$$
\text { I 7.2.I } 834 \text { - I2.I I.I } 854
$$

Eltern: Moses Sachs III 5 - Henriette Samuel

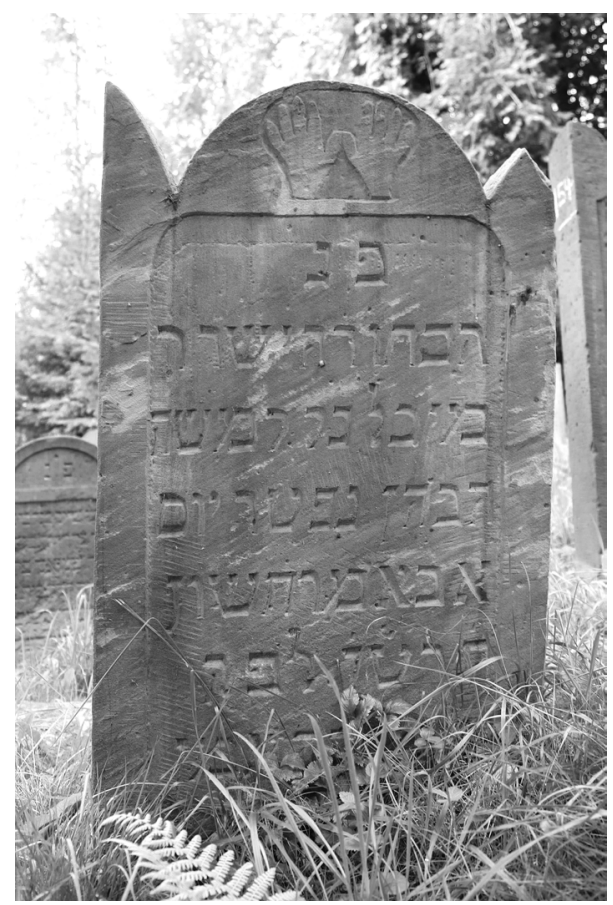

H I09 $\cdot$ B 6I $\cdot$ T I3

פע"ג Hier ist geborgen

der aufrechte Junggeselle $H$.

מיכל בר ר משה Michel, Sohn des H. Mosche

ha-Kohen. Er verschied am Tag

א 5 1, 21. Marcheschwan

615 n.kl.Z.

ת.S.E.B.L. Amen.

Quelle: GbL (Geburtstag) 
Rosette Edelstein, geb. Eichenberg

$$
\text { 20.5.I797-2I.I.I } 855
$$

Eltern: Meyer S. Eichenberg - Mariana - Geschwister: Baruch (I778-I850), Simon II 35 , Lucas (I790-I 859), Levi III 74, Leiser III 79 - Ehemann: Moses A. Edelstein III I · Kinder: Merline/Lina IV I 3; Goldchen (I 829; Sudheim), Susanne (I83 I); Rieke (I 833); Abraham II 2I; Meier (I 837); Ester (I837); Henriette (I839)

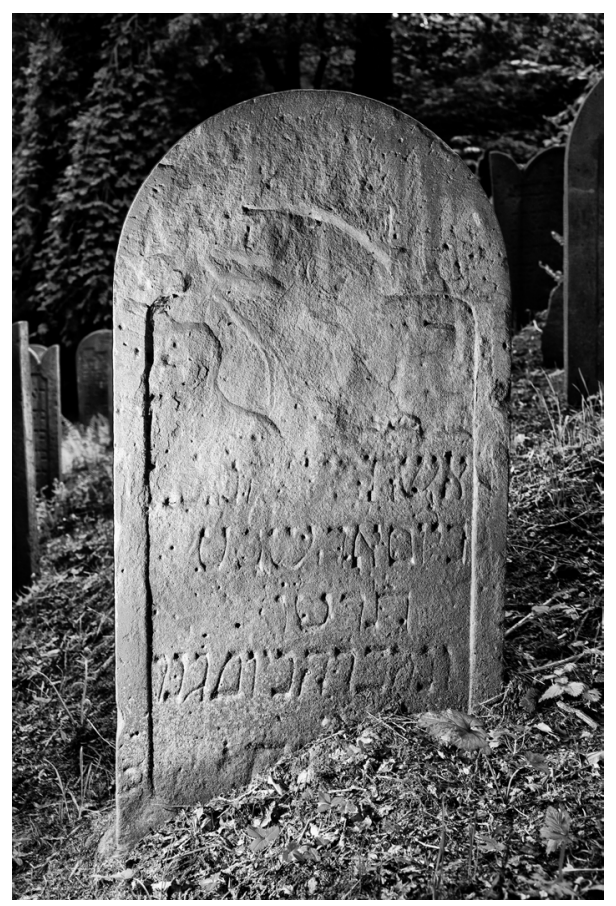

H I20 - B 6I $\cdot$ T I2,5

Inschrift im oberen Teil nur teilweise lesbar

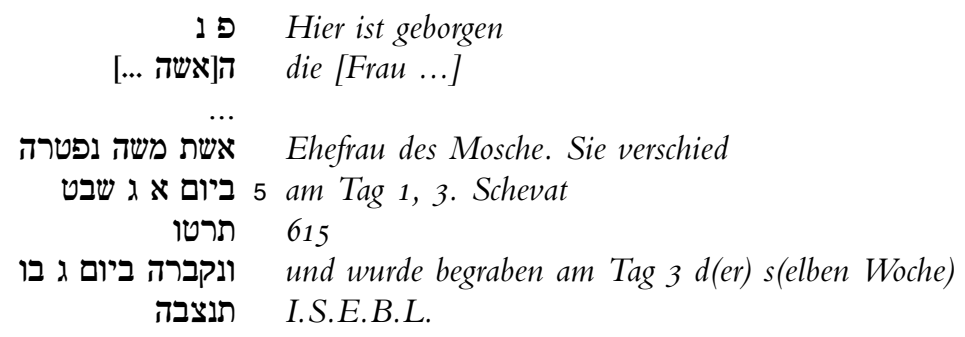

5 StL verzeichnet als Sterbetag den I9.5.1855 (= Samstag, 2. Sivan) - Quelle: FamB (Geburtstag) 
Sophie Freudenthal, geb. Heilbrunn IO.IO.I770 - I7.3.I 855

Geb. in Abterode bei Eschwege - Vater: Moses Heilbrunn · Ehemann: I. Joel Grunsfeld, Gelliehausen; 2. Isaac Moses Freudenthal III 43 · Tochter: zu I) Fanny III 47

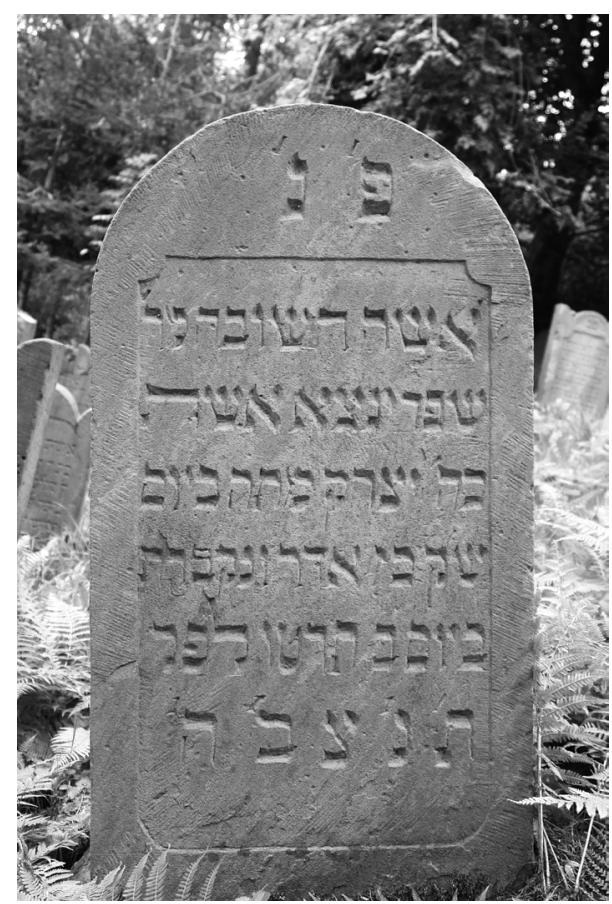

$\mathrm{H} \mathrm{IO7 \cdot B} 52 \cdot \mathrm{T} \mathrm{I} 4$

\author{
פע"ג Hier ist geborgen

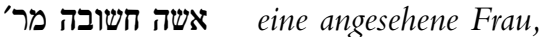 \\ Sprinze, Ehefrau des \\ e.H. Jizchak. Sie starb am Tag des \\ 5 hl. Sch(abbat), 27. Adar, und wurde begraben \\ am $\operatorname{Tag} 2615$ n.kl.Z. \\ I.S.E.B.L.
}

Quelle: FamB (Geburtstag) 
Betty Rothschild, geb. Davison

I 5.I 2.I $829-2$ I.8.I 855

Geb. in Rodenberg/Deister - Eltern: Abraham Davison - Jette Meyer - Ehemann: Joel S. Rothschild IV I7 · Sohn: Salomon III 26

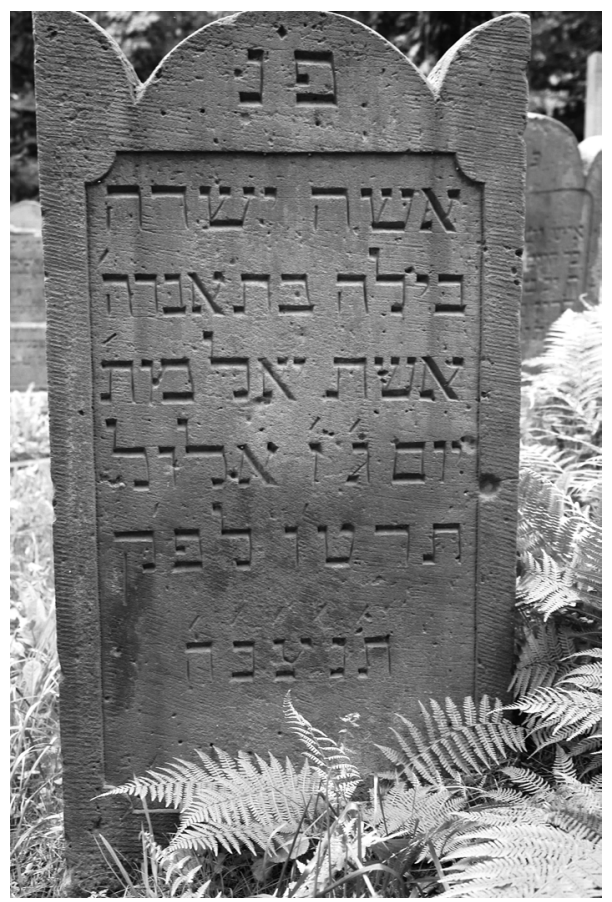

$\mathrm{H}$ I I9 $\cdot \mathrm{B} 64 \cdot \mathrm{T}$ I4

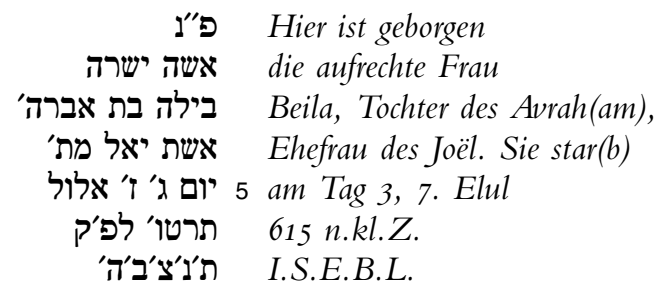

Quelle: Geburtsdatum berechnet nach der Altersangabe in StL. 
Simon/Simcha Meyenberg

$$
\text { 2I.I.I } 787-2 \text { I.I.I } 856
$$

Handelsmann, Altwarenhändler · Eltern: Salomon Simon Meyenberg II 2 - Marline Kaufmann II 6 - Ehefrau: Minna Hirsch III $62 \cdot$ Kinder: s. ebd.

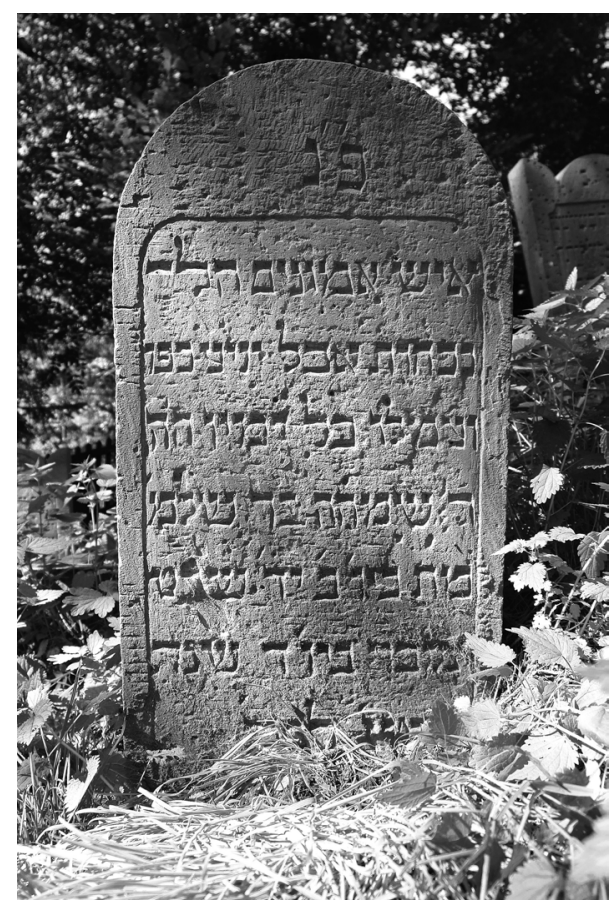

$\mathrm{H} \mathrm{II} 3 \cdot \mathrm{B} 56 \cdot \mathrm{T}$ I I

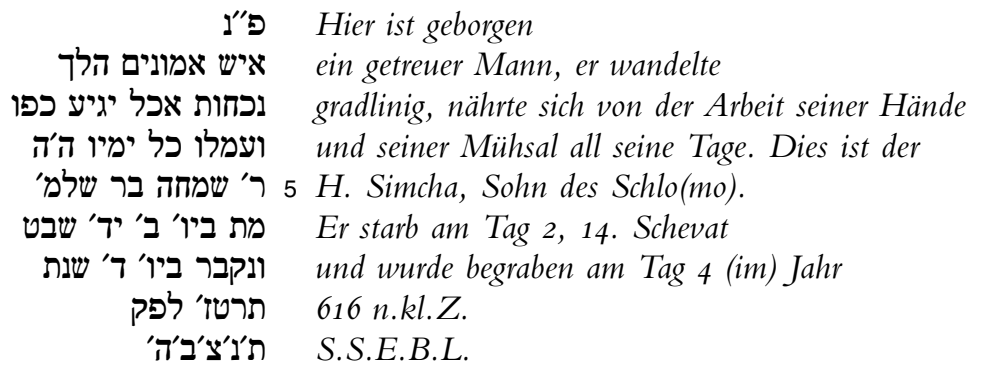

2/3 s. Jes $57,2 \cdot 3$ s. Ps I 28,2 $\mathbf{2 - 4}$ vgl. Dankelshausen: Grab I $\cdot$ Quelle: FamB (Geburtstag) 


\section{Alexander Abraham Edelstein}

$$
\text { 4.6.I } 799-3.2 .1856
$$

Metzger · i 828 Schutzbrief an Stelle seiner Mutter - Eltern: Abraham Moses Edelstein II 22 - Edel Friedheim II 25 Ehefrauen: I. Henriette Abraham (I797, Wanfried/Hessen I832, Adelebsen); 2. Minna Grunsfeld (I805, Bremke) - Kinder: Line/Gelle (I834); Emilie/Ester IV 23; Susanne/Sara (I 839); Amalia (I843); Rosalie IV I9; Pauline III 3 I

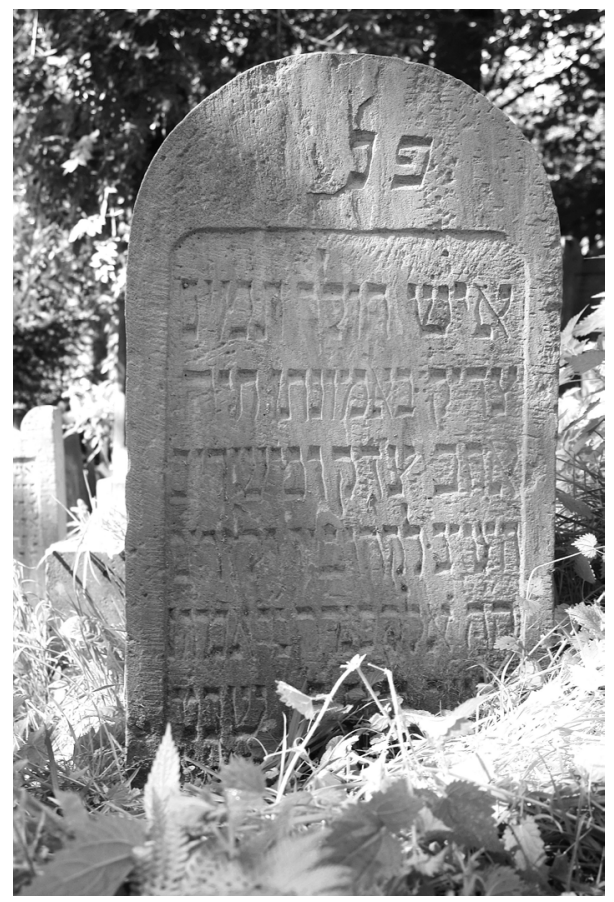

$\mathrm{H} \mathrm{I02} \cdot \mathrm{B} 56 \cdot \mathrm{T}$ I0

】 Hier ist geborgen

ein Mann, er wandelte lauter,

- der Gerechte lebt in seinem Glauben -

אהב צדק ומשרים er liebte Gerechtigkeit und Aufrichtigkeit,

er wandte sich seinen Nächsten und den Fremden zu.

Dies ist Alexander, S(ohn) des H. Avraham.

Er verschied am 27. Schevat

und wurde begraben am 28.d(es) s(elben Monats) 616

2 s. Ps I 5,2 3 Zitat Hab 2,4 
Lea Freudenstein, geb. Katz

$$
\text { I 7.5.I } 834-6.6 .1856
$$

Geb. in Mollenfelde - Eltern: Hirsch Katz - Betty Friedmann - Ehemann: Meyer Moses Freudenstein (I822 Güntersen - I902 Northeim, begr. in Sudheim), Viehhändler in Güntersen, Dransfeld und Northeim · Sohn: Moses (I 854)

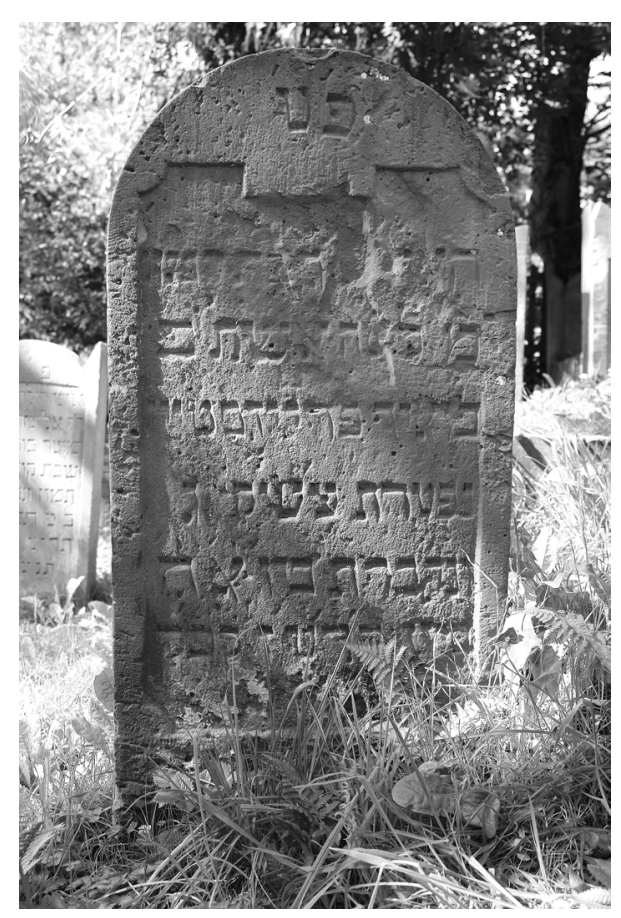

H гіо $\cdot$ В $59 \cdot$ T I 3

\begin{tabular}{|c|c|}
\hline 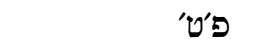 & Hier ist geborgen \\
\hline האשה רבת המעל" & eine Frau, reich an guten Eigenschaften, \\
\hline מ' לטה אשת כ & $F$ (rau) Lea, Ehefrau des e. \\
\hline מאיר פריידסטיין & Meï Freudstein. \\
\hline 5 & Sie verschied am A(bend des) hl. Sch(abbat), 3. \\
\hline סיון תברת מב'יז' לפ'ק & $\begin{array}{l}\text { und wurde begraben am Iag 1, } 5 . \\
\text { Siwan } 616 \text { n.kl.Z. }\end{array}$ \\
\hline ת'ג'צ'ב'ה' & I.S.E.B.L. \\
\hline
\end{tabular}

3 Leta, Verschreibung für לאה = Lea · Quelle: FamB LR Mollenfelde (Geburtstag) 


\section{Calman Selig Dannenberg}

$$
\text { 24.I.I } 789-8 . \text { I.I } 857
$$

Kaufmann (Altwarenhändler) · Eltern: Selig Simon Dannenberg - Amalia Simon · Ehefrau: Clara Meyenberg III $66 \cdot$ Kinder: s. ebd.

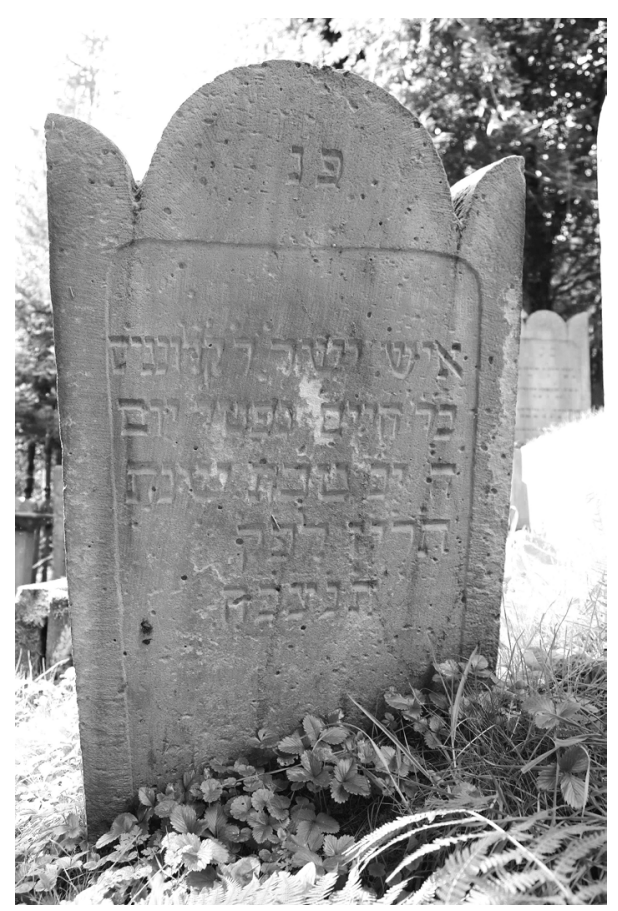

$\mathrm{H}$ IOI $\cdot \mathrm{B} 63 \cdot \mathrm{T}$ I2

\begin{tabular}{|c|c|}
\hline פנ נ & Hier ist oehoroen \\
\hline איש ישר ר קלונמס & ein aufrechter Mann, H. Kalonymus, \\
\hline בר חיים נפטר יום & Sohn des Chajjim. Er verschied am Tag \\
\hline 5 ה ת'ר'יב טבת שני' ל'פ' & $\begin{array}{l}\text { 5, 12. Tevet (im) Jahr } \\
617 \text { n.kl.Z. }\end{array}$ \\
\hline ת'נ'צ'ב'ה' & S.S.E.B.L. \\
\hline
\end{tabular}




\section{Caroline Freudenstein}

$$
\text { 5.4.I } 790-\text { I0.5.I } 857
$$

Geb. in Peine - Vater: Salomon Traube - Ehemann: Samuel Meyer Freudenstein III 68 • Kinder: Julie III 84; Henriette (I 82 I); Selina/Sabine (I 823); Johanne (I825-I 858); Meyer (I 827-I 858); Auguste IV I I; Rosalie (I829-I 858); Salomon (I832-I858); Bertha IV 40

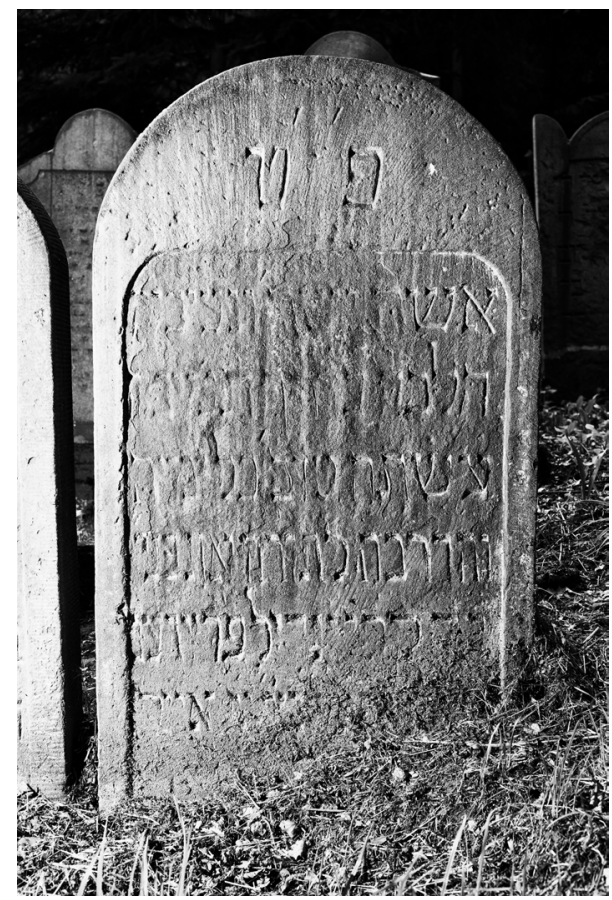

$\mathrm{H}$ II5 $\cdot \mathrm{B} 64 \cdot \mathrm{T}$ I 3

פ Hier ist geborgen

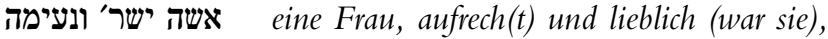

sie wandelte redlich,

tat Gutes all ihre Tage

5 und wandte zur Tora ihr Angesicht.

Dies ist Kreindel Freuden-

stein. Sie versch(ied) am 17. Ijjar

617 n.kl.Z.

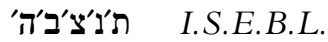

Caroline Freudenstein 10

geb. Traube

Gest. am Io. Mai I 857

5 Statt פני gönnte es auch בני gelesen werden "führte zur Tora ihre Kinder/Söhne» • Quellen: FamB (Geburtstag); StbL 
Clara Dannenberg, geb. Meyenberg

$$
\text { 8.5.I } 800-22.6 .1857
$$

Eltern: Salomon Simon Meyenberg II 2 - Marline Kaufmann II 6 - Ehemann: Calman Selig Dannenberg III 65 - Kinder: Amalie (I832); Mine (I833); Selig IV 27; Salomon (I837); Golde (I837); Betty (I839); Esther III 20; Rosette (I843-I844)

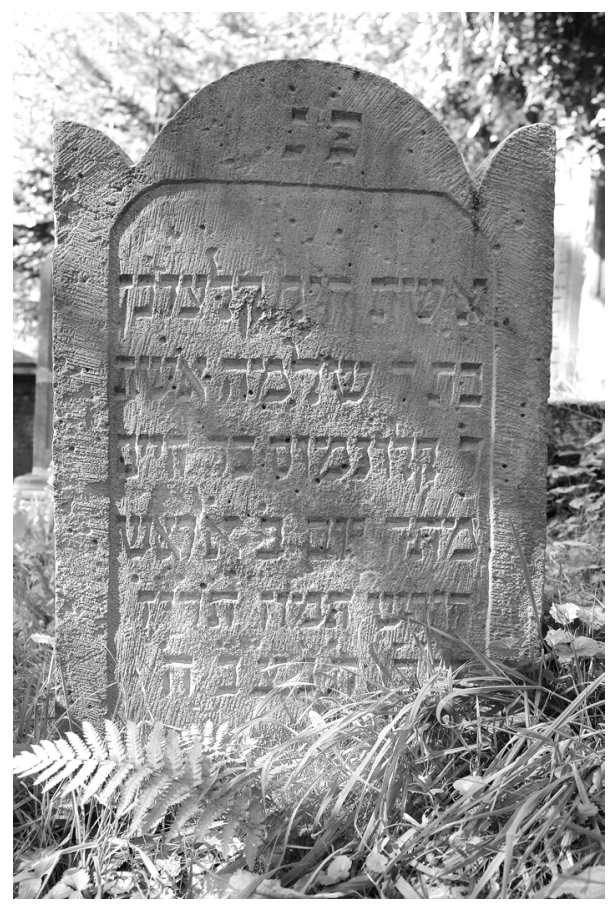

H $106 \cdot$ B $63 \cdot$ T I2

פע"נ Hier ist geborgen

אשת חיל קלערכן

Tochter des H. Schlomo, Ehefrau des

H. Kalonymus, Sohn des Chajjim.

5 Sie starb am Tag 2, dem 1. (Tag) des Monats-

חודש תמוז ת'ר'י'ז' Anfangs des Tammuz 617

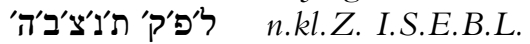

2 s. Prov 3 I, IO 
Henriette Eichenberg, geb. Jacobsohn

$$
\text { 8.3.I } 8 \text { OI - 4.I.I } 858
$$

Geb. in Sudheim - Eltern: Abraham Jacobsohn - Golda II 43 - Ehemann: Levi M. Eichenberg III 74 - Kinder: Marianne (I6.2.I823-6. IO.I892, Göttingen: Grab I02); Meier Levi IV 38; Abraham IV Io; Simon (I829); Betty (I83 I-I 832); Roselle (I833-I834); Feis (I 837-I 838); Bernhard (I839); Immanuel (I84I-I 842); Friederike III 33

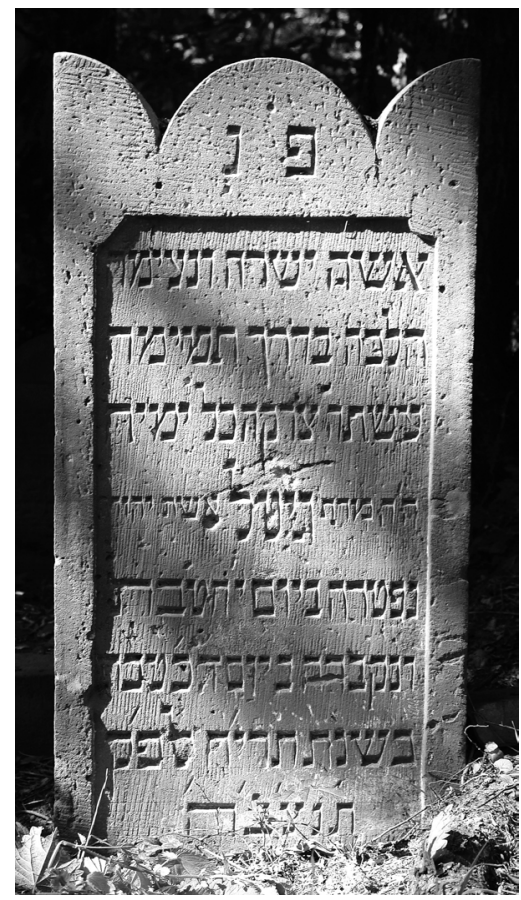

$\mathrm{H} \mathrm{I} 2 \mathrm{O} \cdot \mathrm{B} 60 \cdot \mathrm{T} \mathrm{I} 4$

פּ

השה ישרה ונעימה sie wandelte auf rechtem Weg,

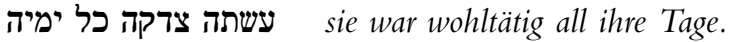
מפר מרת גיטל אשת יהודה 5 Dies ist Frau Gitel, Ehefrau des Jehuda.

Sie verschied am 18. Tevet

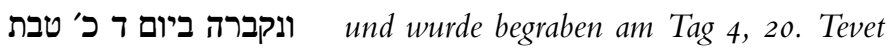

Im Jahr 618 n.kl.Z.

ת'ת'נצ'ב'ה ת.S.E.B.L.

Quelle: FamB (Geburtstag) 


\section{Lucas Stehberg}

$$
\text { I.7.I } 78 \text { I }-23 . \text { I.I } 858
$$

Kaufmann (Manufakturwaren - Vieh), Erbauer des Hinterhauses Lange Straße 27 (s.o. S. 24 Inschrift über dem Türsturz) - I 834 Vorsteher der Synagogengemeinde - Eltern: Levi Simon Rosenberg II 5 - Friederike · Ehefrau: Gitel Müller III 76 • Kinder: s. ebd.

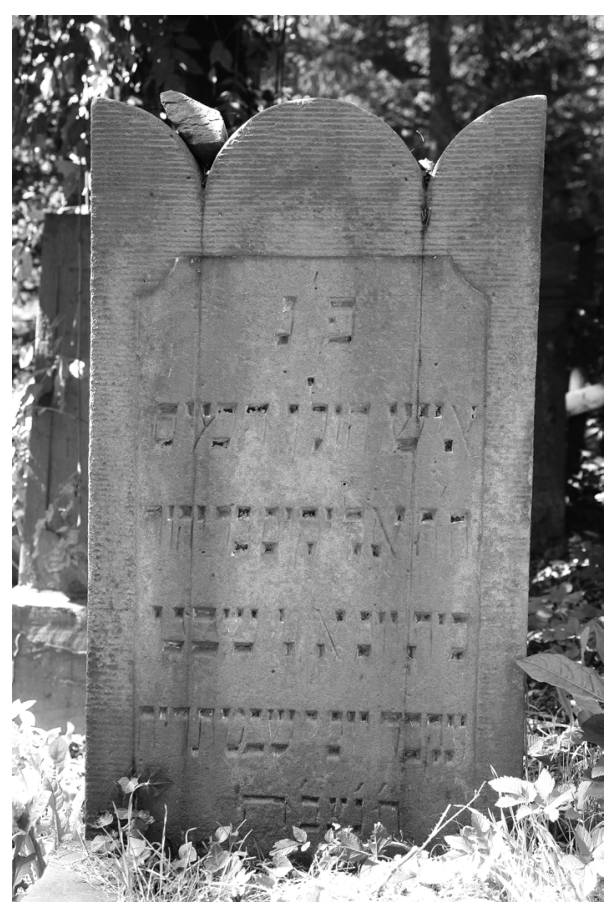

$\mathrm{H} \mathrm{IO}_{4} \cdot \mathrm{B} 58 \cdot \mathrm{T} \mathrm{I} 2$

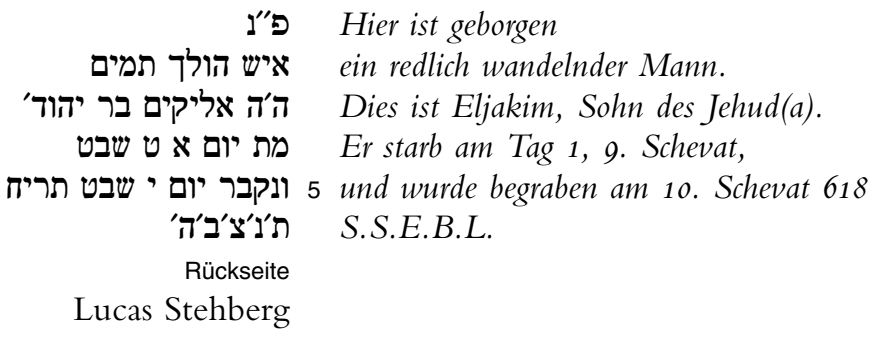

2 s. Ps I $5,2 \cdot$ Quelle: FamB (Geburtstag) 
Bertha Müller

$$
\text { 26.6. I } 857-6.7 .1858
$$

Eltern: Isaac Aron Müller III 46 - Henriette Schloss

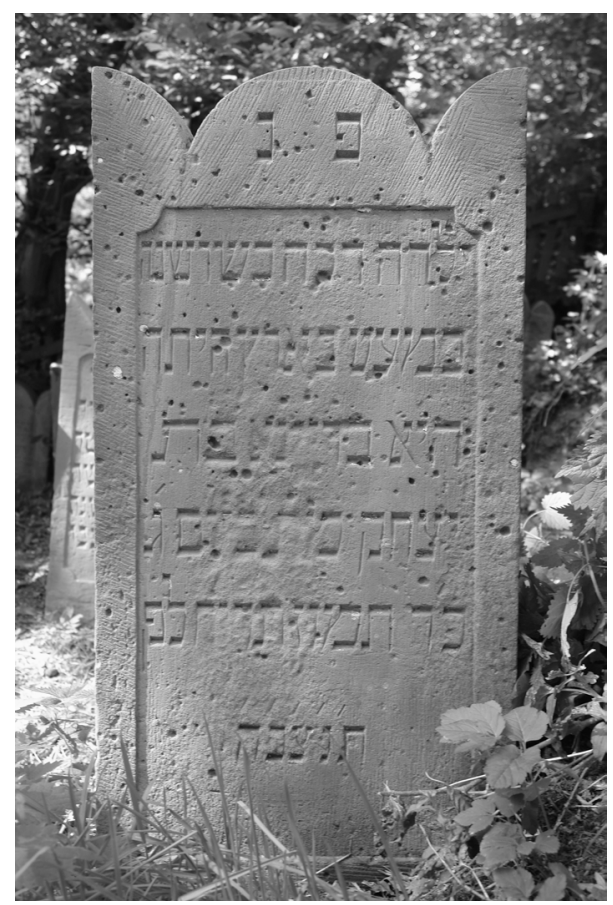

$\mathrm{H} \mathrm{II} 2 \cdot \mathrm{B} 56 \cdot \mathrm{T}$ I2

פ"ג Hier ist geborgen

ein Mädchen zart wie eine Lilie,

kurze Zeit auf der Erde nur war sie,

es ist Breine Tochter des

, 5 Jizchak. Sie starb am Tag 3,

24. Tammuz 618 n.kl.Z.

תנצבה I.S.E.B.L.

Quelle: GbL (Geburtstag) 


\section{Samuel Meyer Freudenstein}

$$
\text { I7.4.1789-20.9. I } 858
$$

Lotteriecollecteur - I82 I und I844 Vorsteher der Synagogengemeinde - Eltern: Meyer Philipp Freudenstein II 7 - Golde $\cdot$ Ehefrau: Caroline/Kreindel Traube III $67 \cdot$ Kinder: s. ebd.

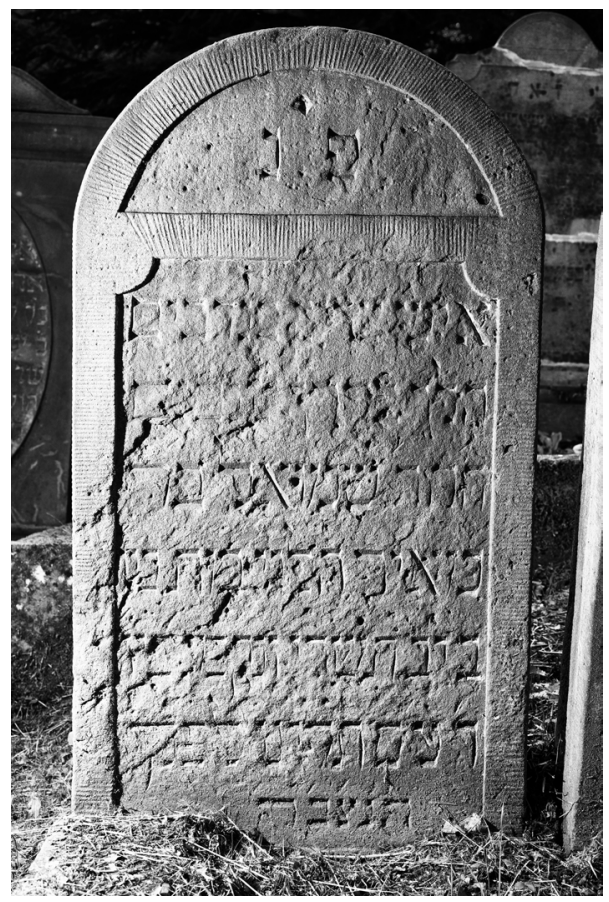

$\mathrm{H} \mathrm{I06} \cdot \mathrm{B} \mathrm{6I} \cdot \mathrm{T}$ I4

I Hier ist geborgen

איש צדיק בנדבים er wandelte auf dem Weg der Guten.

Dies ist der H. Schmuel, Sohn des

5 Meir ha-Levi. Er starb am Tag

2, 12. Tischri, und wurde begraben am Tag

4, am V(orabend) von Sukkot 619 n.kl.Z.

S.S.E.B.L.

Samuel Freudenstein

gest. am 20. September I 85810

Quelle: FamB (Geburtstag) 
Albert Eichenberg

I6.8.I $858-29.1 . I 859$

Eltern: David S. Eichenberg IV 6 - Sophie Grunsfeld IV 5

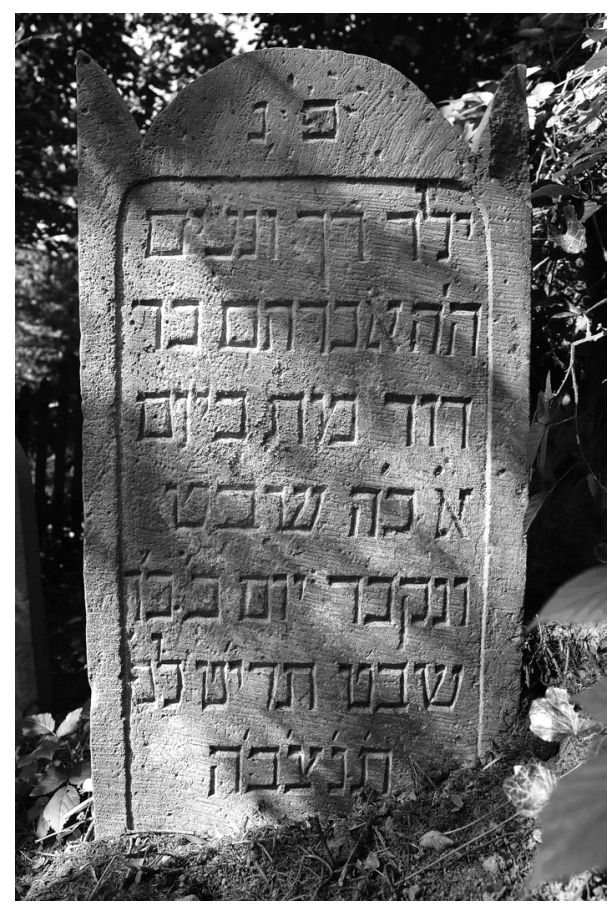

$\mathrm{H} \mathrm{I02} \cdot \mathrm{B} 57^{\cdot}$ T I I

פ"ג Hier ist geborgen

ילד רך ונעים ein zarter und lieblicher Knabe, dies ist Avraham, Sohn des

David. Er starb am

5 Sonntag, den 25. Schevat

und wurde begraben am Tag 2, den 26.

Schevat 619 n.kl.(Z.)

ת'ת'צ'ב'ביה ת.S.E.L.

Rückseite

Albert Eichenberg

gb: I6. Au: I858. 10

gst: 29. Ja: I 859

11 StbL 29.I.I 859 
Bernhart Löwenstern

24.7.I $848-$ I0.4.I 859

Eltern: Samuel Löwenstern III 48 - Fanni Grunsfeld III 47

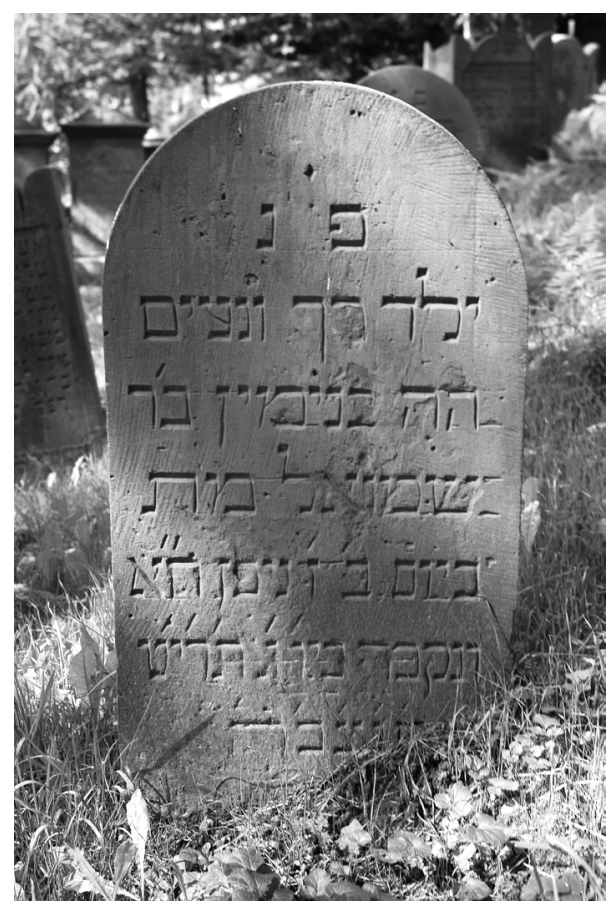

$\mathrm{H} 92 \cdot \mathrm{B} 53 \cdot \mathrm{T}$ Iо

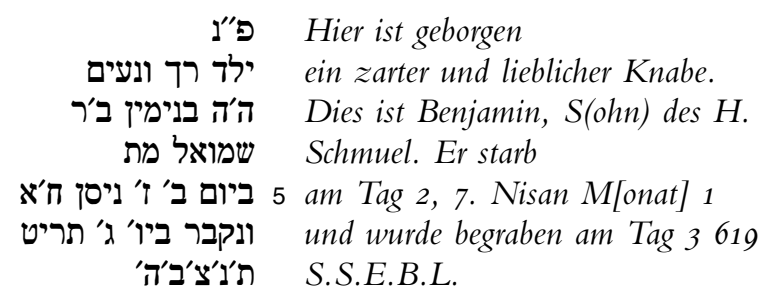

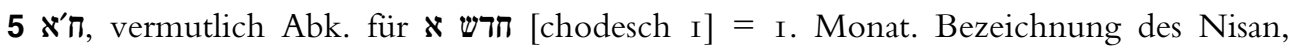
entsprechend altbiblischer Zählung; vgl. Esther 3,7; s. ferner Ex I2, I 8; 4O, I7; Lev 23,5; Num 20,I; 33, 3; Jos 4, I9; Esther 3, I2; I Chr 27,2, dazu Mahler, Handbuch der jüdischen Chronologie, I99-207. · 6 Der Vergleich von Inschrift und StL weist auf Sonntagabend Io.4. als Sterbedatum. · Quelle: GbL (Geburtstag) 


\section{Leiser Eichenberg}

$$
\text { 29.I.I795/4.6.I796 - I I.7.I } 859
$$

Pferdehändler · Eltern: Meier S. Eichenberg - Mariana Baruch · Geschwister: Baruch (I778-I850), Simon II 35, Lucas (I790-I859), Levi III 74, Rosette III 2 (?) - Ehefrau: Friederike Stehberg III 78 - Kinder: s. ebd.

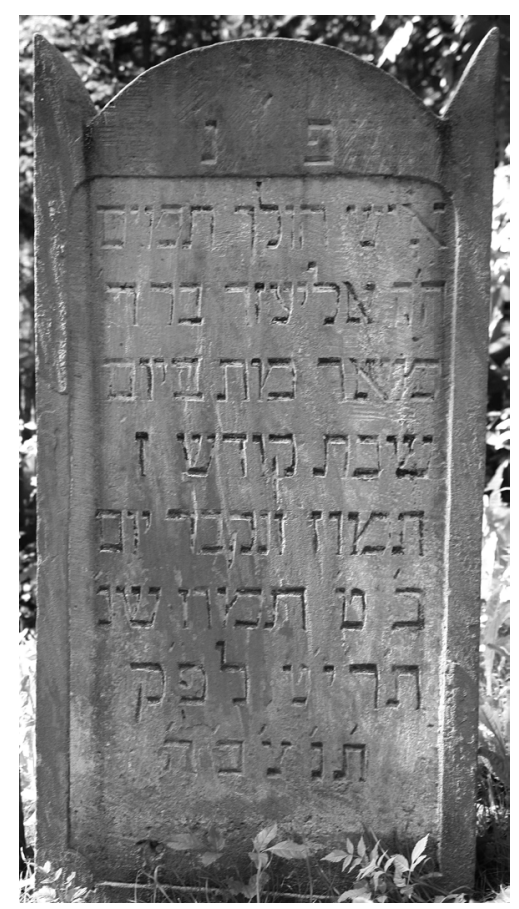

H I2O - B $64 \cdot$ T I2

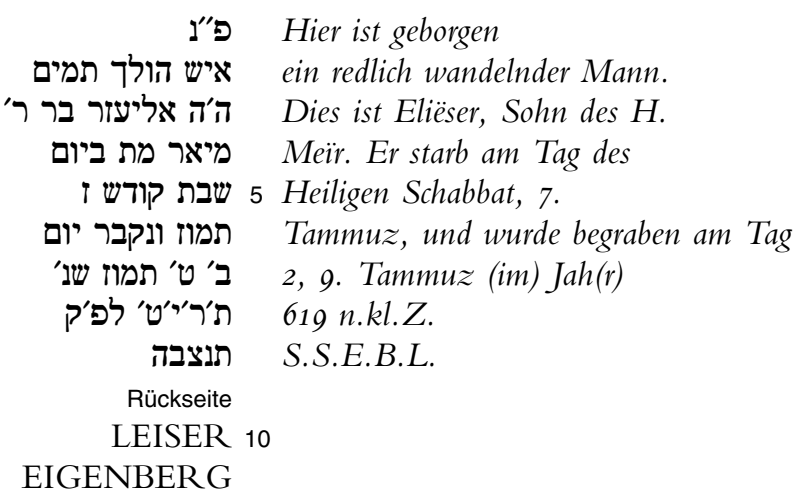

4 מיאר 7 StL 9.7. • 11 Schreibweise „Eigenberg“ nach örtlicher Mundart (anlautendes G weich gesprochen) - Quelle: FamB (Geburtstag: beide Angaben nebeneinander) 
Lucas Meyer Eichenberg

$$
\text { I4.6.I790 - 4.IO.I } 859
$$

Pferdehändler · Eltern: Meyer S. Eichenberg - Mariana Baruch

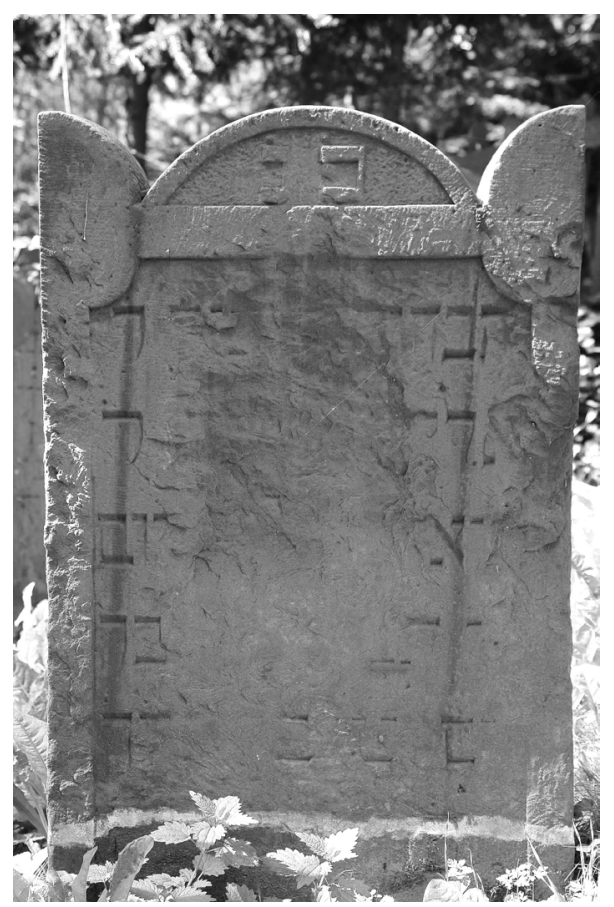

$\mathrm{H}_{107} \cdot \mathrm{B} 63 \cdot \mathrm{T} 9$

Text im Mittelteil nur noch begrenzt entzifferbar. Verlust der letzten 2 Zeilen durch Neuaufstellung

\begin{tabular}{|c|c|}
\hline & \\
\hline & Hier lst gevorgen \\
\hline הבחור [הי[שר & der aufrechte Jüngling $H$. \\
\hline אליריקים] ב'רים & Elj[akim, Sohn] des $H$. \\
\hline מאיר [מת] ביום & Meir. [Er starb] am \\
\hline [ז תשרי ... ונק]בר & 5 [7. Tischri ...und wurde beg]raben \\
\hline ליו[ם ט ביוו ת[רך & a[m] 9. in [ihm 6]20 \\
\hline 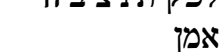 & Amen. \\
\hline
\end{tabular}

5-6 Die Rekonstruktion des hebr. Textes folgt den Angaben der StL. - Quelle: FamB (Geburtstag) 
Meyer Rosenbaum

20.3.I8I 7 - 6.2.I 860

Kaufmann - Eltern: Samuel Levi Rosenbaum II 36 und Eva II 37 - Ehefrau: Sara Blumenberg III $82 \cdot$ Kinder: s. ebd.

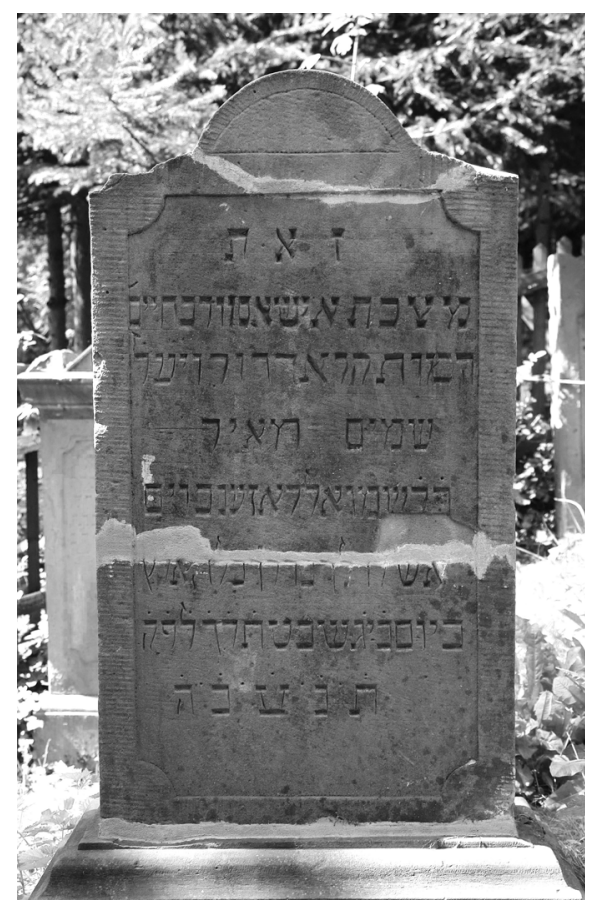

$\mathrm{H} \mathrm{II} 3 \cdot \mathrm{B} 63 \cdot \mathrm{T}$ is

zerbrochener Stein neu aufgestellt 


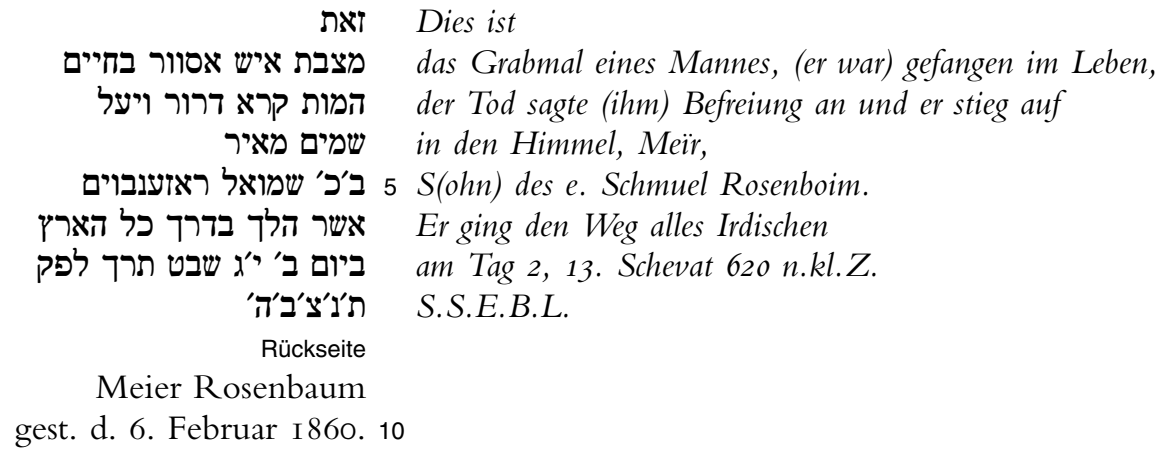

1-3 Die Gegenüberstellung von Leben und Tod unter dem Vorzeichen von Gefängnis und Freiheit greift stoisches Gedankengut auf (s. auch bei Josephus, Jüdischer Krieg VII,344). Sie findet sich in gleicher Weise auf Grabsteinen der benachbarten Friedhöfe in Dankelshausen (Grabstein 20) und Dransfeld (Grabsteine 23. 75). Vermutlich wurde sie auch aber auch sonst verwendet; bislang konnte indes nur für die (sprachlich biblisch geprägte, s. Lev. 25, I0; Jes 60, I; Jer 34,8.15.I7) Wendung המות קרא דרור ha-mawet kara dror „,Der Tod sagte Befreiung an“ ein weiterer Beleg gefunden werden auf dem Friedhof Liten bei Prag, Inschrift 5 (I832) (s. http://www.etf.cuni.cz/ prudky/morina/DushiMatzevot3.rtf). 6 Zitat Jos 23, I4 - Quelle: FamB (Geburtstag) 


\section{Julius Stehberg \\ I2.6.I 857 - I 5.6.I 860}

Eltern: Herz Stehberg IV I6 - Betti Dannenberg IV is
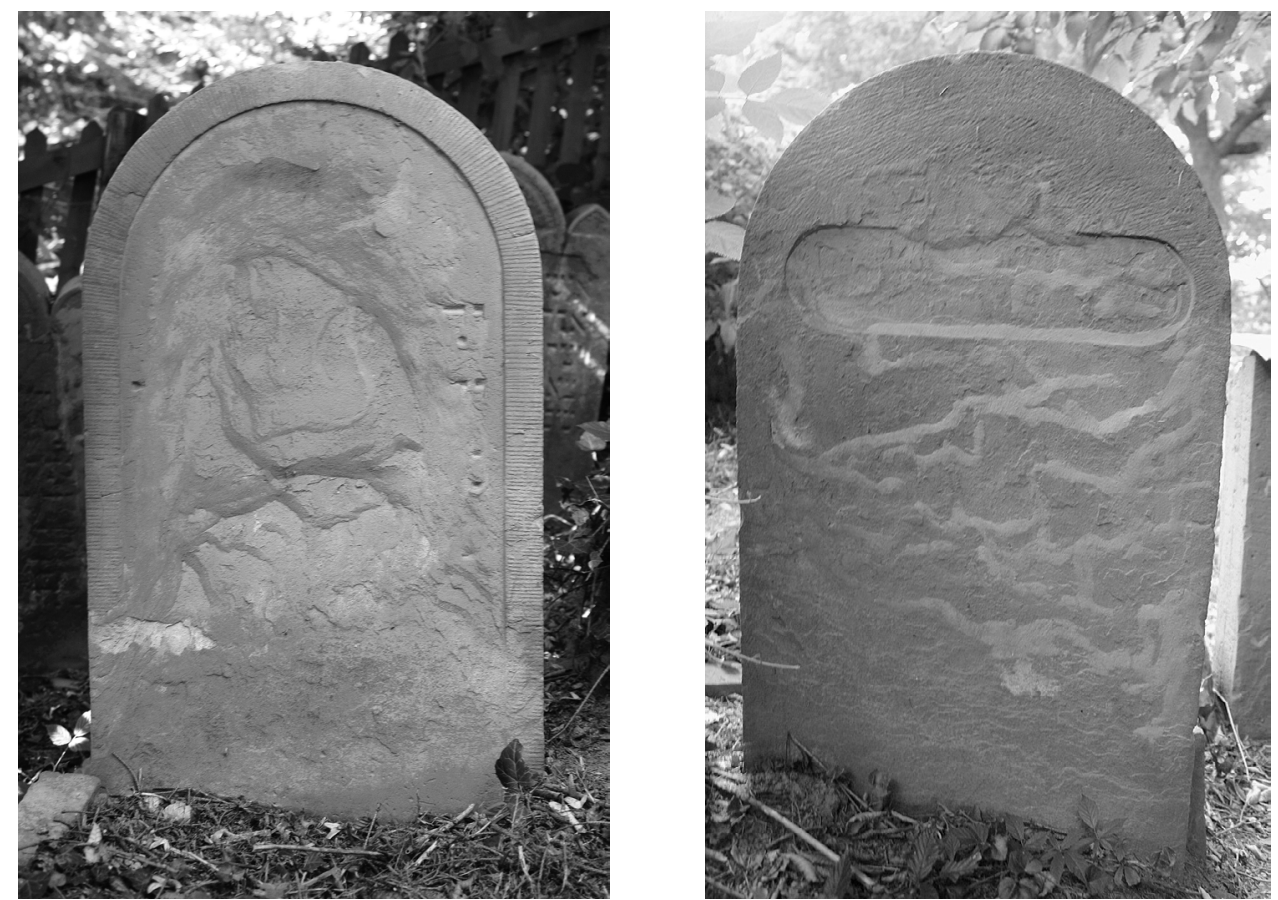

$\mathrm{H} 88 \cdot \mathrm{B} 57 \cdot \mathrm{T}$ IO

Kindergrab. Vorder- und Rückseite nur noch Buchstabenreste

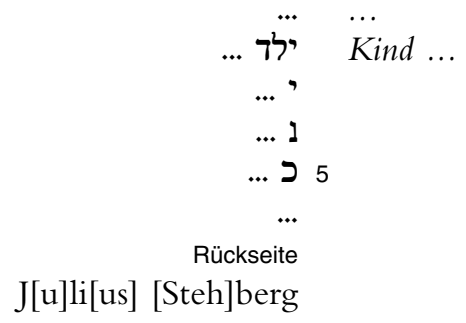

Identifizierung an Hand der Inschriftreste auf der Rückseite 
Johanna Müller, geb. Rothschild

$$
\text { I2.5.I } 798-29.7 .1860
$$

Eltern: Joel Rothschild II I 8 - Henriette/Hindel II I 5 - Ehemann: David Isaak Müller III 87 - Kinder: Henriette IV 28; Isaak (I820); Betti (I 827)

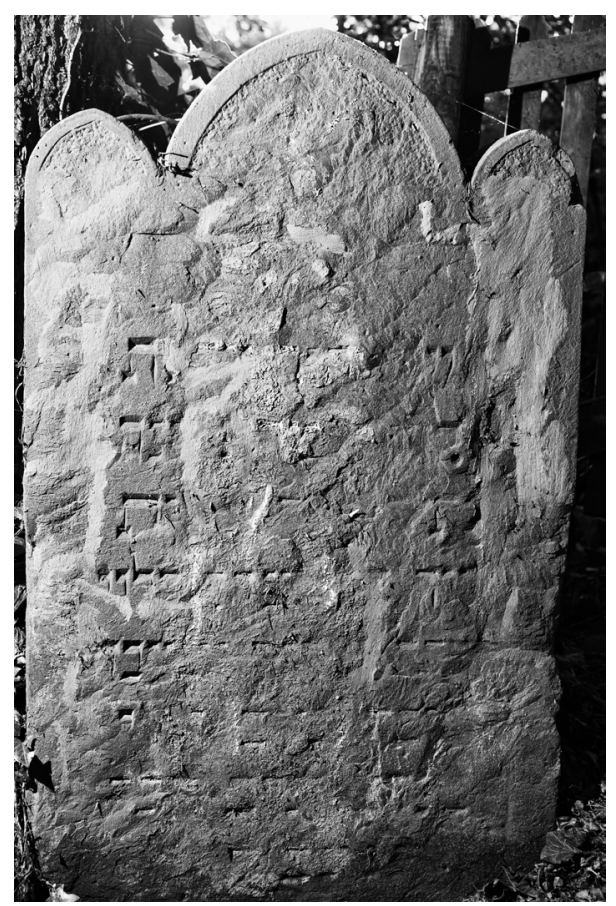

$\mathrm{H}$ IO5 $\cdot$ B $62 \cdot$ T I I

Inschrift stark verwittert, nur noch partiell entzifferbar

】 Hier ist geborgen

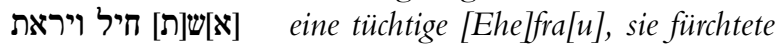

[א][לה[ים] מרת חנה

Tochter des H. Meïr, Ehefrau des

5 David, [Sohn des] Jizchak ha-Levi.

[Sie st]arb ....

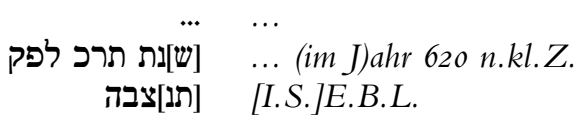

2 s. Prov 3 I, Io - Quellen: FamB (Geburtstag); StbL (Sterbetag) 
Henriette Katzenstein, geb. Rosenbaum

$$
\text { I7.6.I } 820-26 . \text { I 2.I } 860
$$

Eltern: Samuel Levi Rosenbaum II 36 - Eva II 37 - Ehemann: Julius Katzenstein III 89 • Kinder: Helene IV 47; Bertha (I850); Jeanette (I853); Fanni (I856); Wolf (I859)

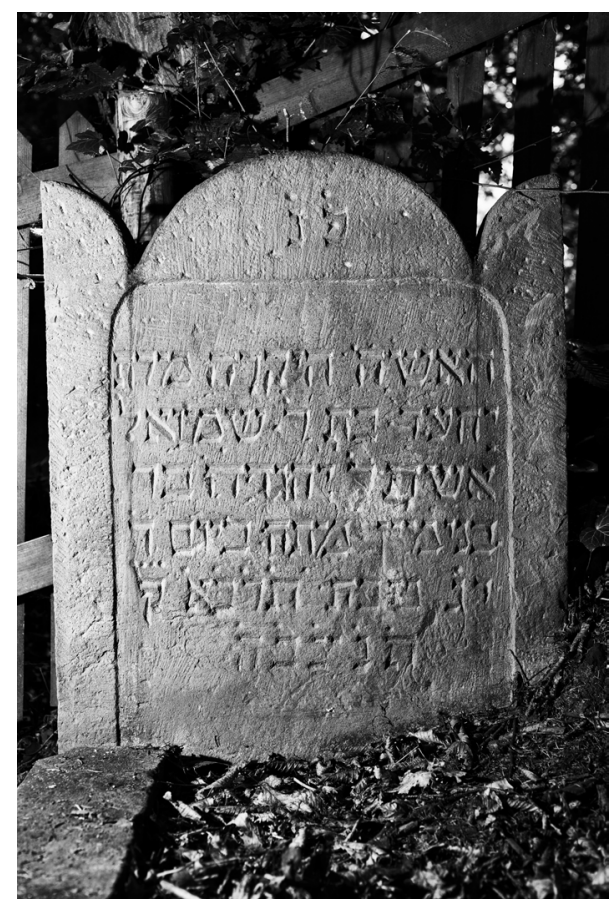

$\mathrm{H} 7 \mathrm{I} \cdot \mathrm{B} 65 \cdot \mathrm{T}$ I I

פ"פ Hier ist geborgen

die geachtete Frau, Frau

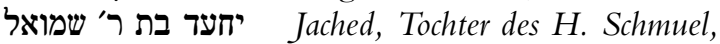

Ehefrau des H. Jehuda Sohn des

5 Benjamin. Sie starb am Tag 4, 13. Tevet 621 n.kl.Z.

I.S.E.B.L.

$6 \mathrm{StL}$ 25.I2.I860 - Quelle: FamB 
Gitel Stehberg, geb. Müller

$$
\text { I6.8.I } 777 \text { - I2.8.I862 }
$$

Eltern: Isaac Simon - Betty - Geschwister: Simon II 39; Aron III 23; Abraham (I784I 834); David III 87 - Ehemann: Lucas Levi Stehberg III $77 \cdot$ Kinder: Friederike III 78; Levi III 6; Herz IV I6; Esther III 22; Lina (I8I8-I856, Mollenfelde)

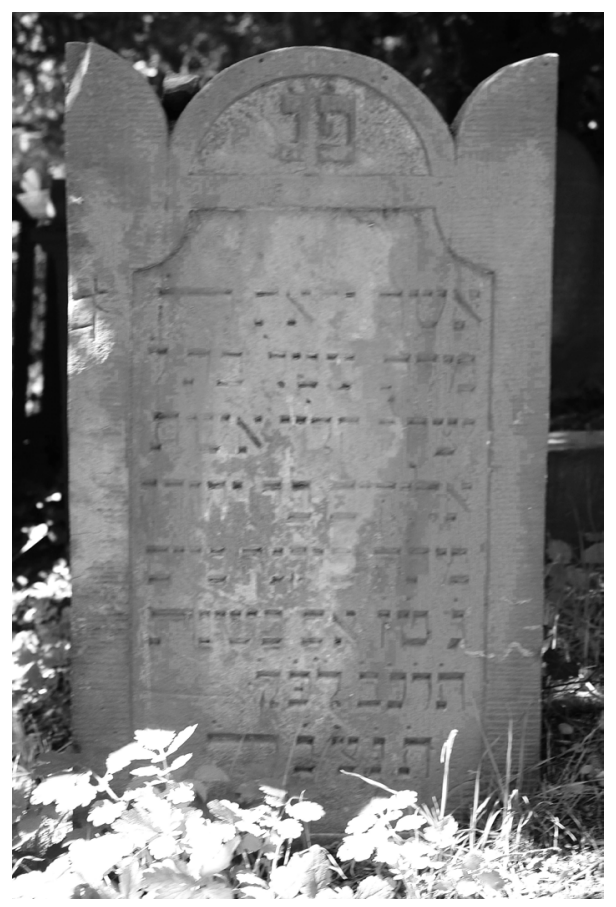

$\mathrm{H} 99 \cdot \mathrm{B} 60 \cdot \mathrm{T} \mathrm{I} 2$

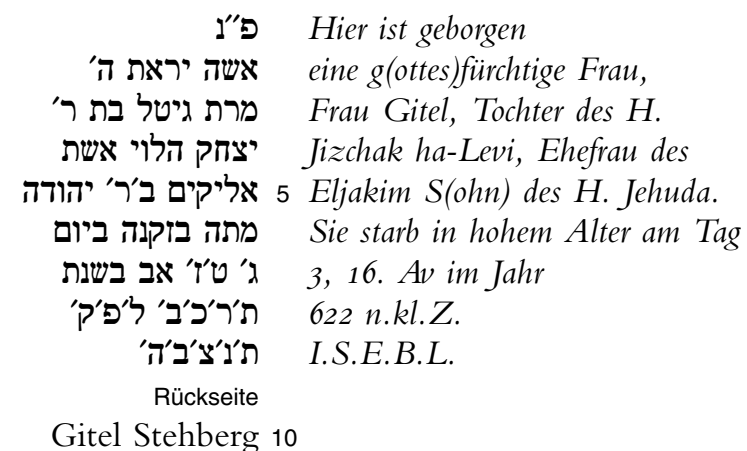

Quelle: FamB (Geburtstag) 
David Levi Rosenthal

I6.2.I $802-26.2 .1863$

Altwarenhändler · Eltern: Levi Rosenthal II 4 - Miene Rothstein II $9 \cdot$ Ehefrau: Henriette Rothstein III $55^{\circ}$ Sohn: s. ebd.

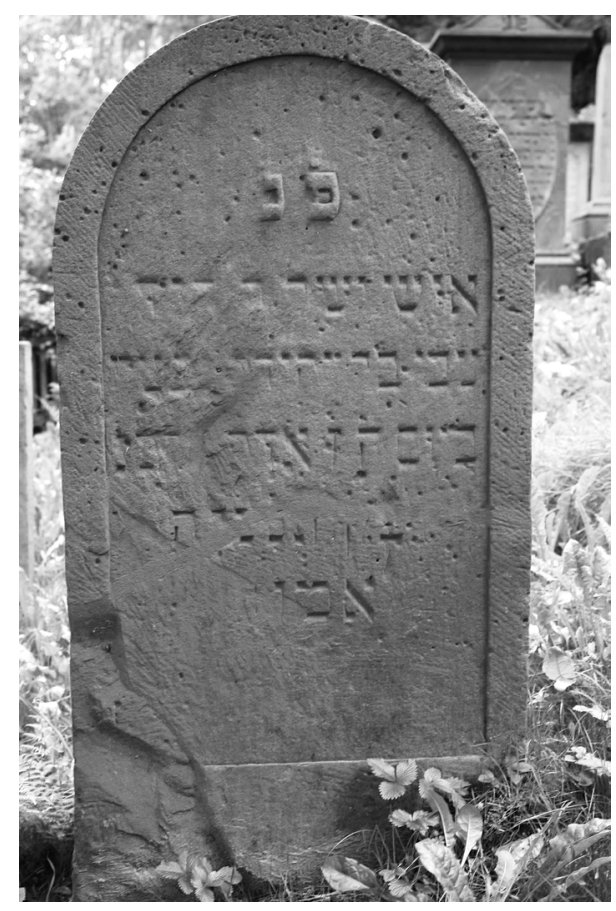

$\mathrm{H} \mathrm{II7} \cdot \mathrm{B} 65 \cdot \mathrm{T}$ II

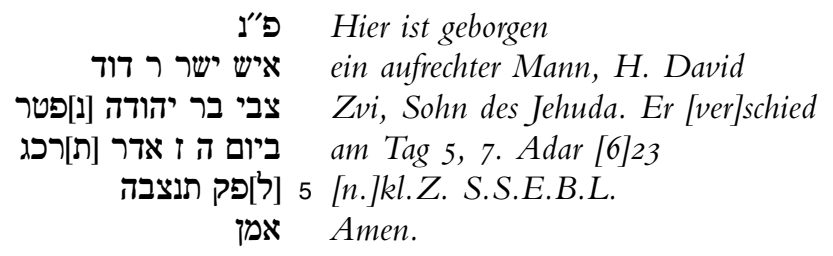

Quelle: FamB (Geburtstag) 


\section{Moses Selig Dannenberg}

$$
25.10 .1785-4.2 .1864
$$

Kaufmann · I836-I 838 Rechnungsführer der Synagogengemeinde · Eltern: Selig Simon Dannenberg - Amalia Simon · Ehefrau: Rosette Meyenberg III 3 - Kinder: s. ebd.

Stein fehlt III 3; Quellen: FamB (Geburtstag), StbL (Sterbetag)

III 9I

$$
\begin{gathered}
\text { Jacob Stehberg } \\
\text { IO.I.I853-9.9.I } 864
\end{gathered}
$$

Eltern: Levi Stehberg III 6 rechts - Julie Dahlberg III 6 links

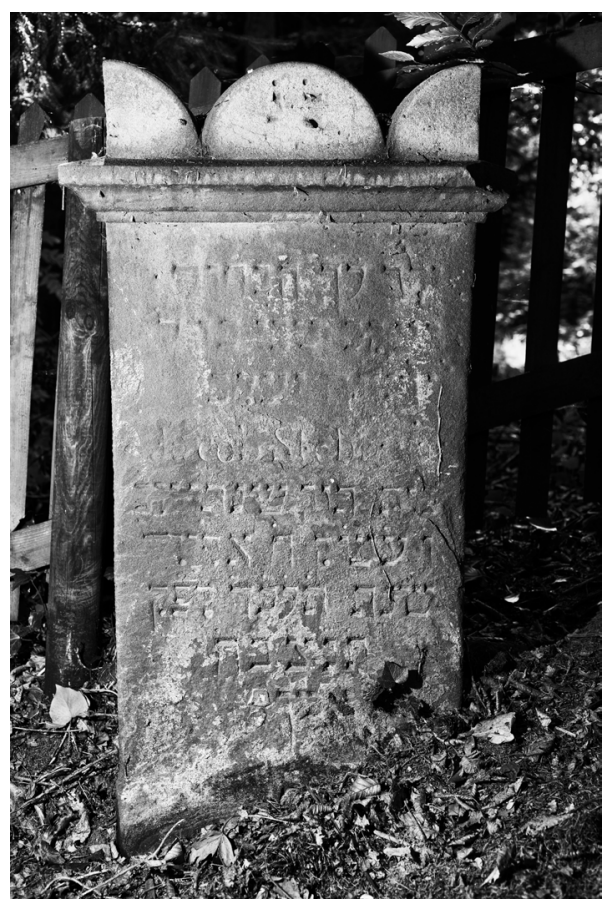

$\mathrm{H} \mathrm{I06} \cdot \mathrm{B} 52 \cdot \mathrm{T} \mathrm{I} 3$

פינ Hier ist geborgen

ילד רך הבחור

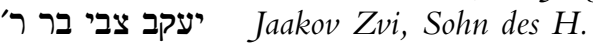

יהודה יעקב Jehuda Jaakov.

Jacob Stehberg 5

Er starb mitten im Schlaf am

T Tag 6, V(orabend) des hl. Sch(abbat), 8. Elul

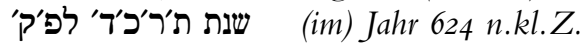

S.S.E.B.L.

10 Amen.

6 Alternative Übersetzung: ,in der Mitte seines Jahres“: s. IV 4 · 7 StbL datiert einen Tag später: Sonntag I0.9. I 864 


\section{Simon Eichenberg}

4.II.I 808 - 9.IO.I 865

Lotteriecollecteur und Großhändler (Getreide, Branntwein) · I845-I847, I857-I 862 Vorsteher der Synagogengemeinde · Eltern: Simon M. Eichenberg II 35 - Amalie Rothschild II I 2 Ehefrau: Julie Freudenstein III $84 \cdot$ Kinder: s. III 84

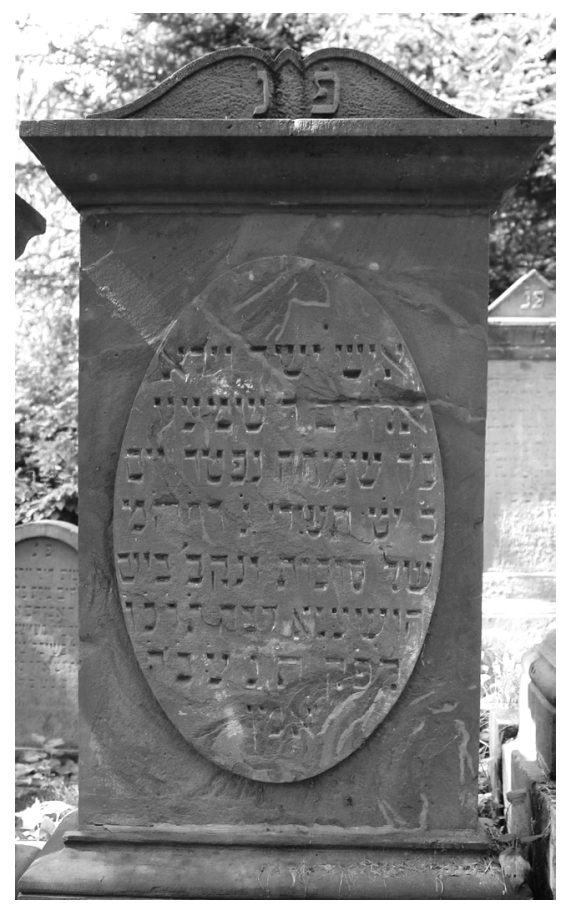

$\mathrm{H}$ II $5 \cdot \mathrm{B} 75 \cdot \mathrm{T}$ I 8

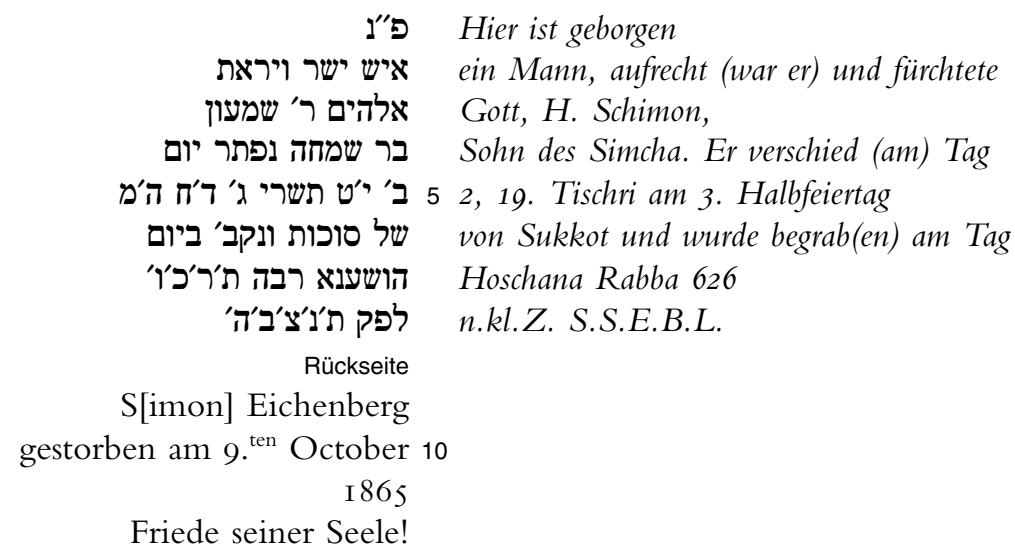

7 Hoschana Rabba, 7. und letzter Tag des Sukkot-Fests · Quelle: FamB (Geburtstag) 
Eva Eichenberg

6. I I.I 850 - 24. IO.I 865

Eltern: Simon S. Eichenberg III 83 - Julie Freudenstein III 84

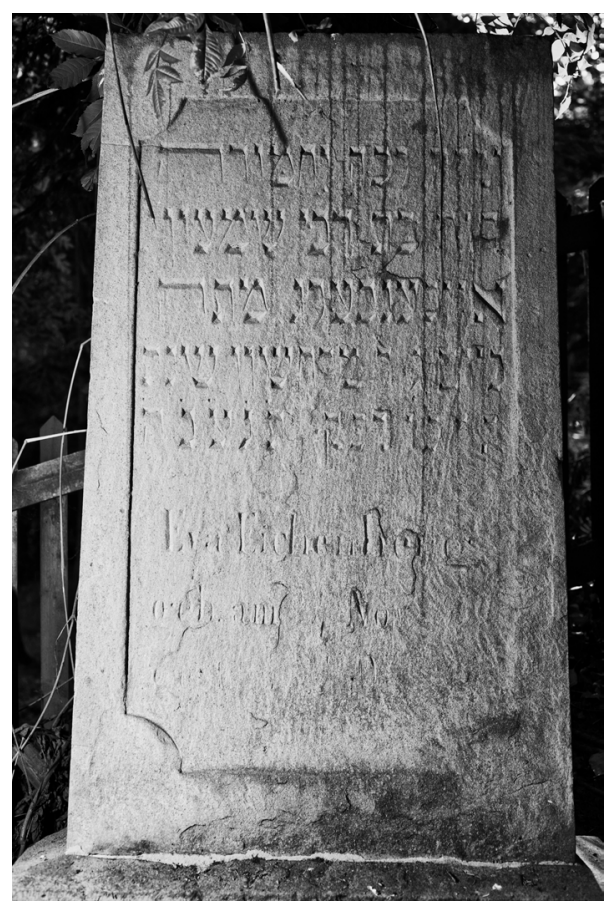

H II2 $\cdot$ B $66 \cdot$ T I7

Aufsatz mit $\perp$ fehlt

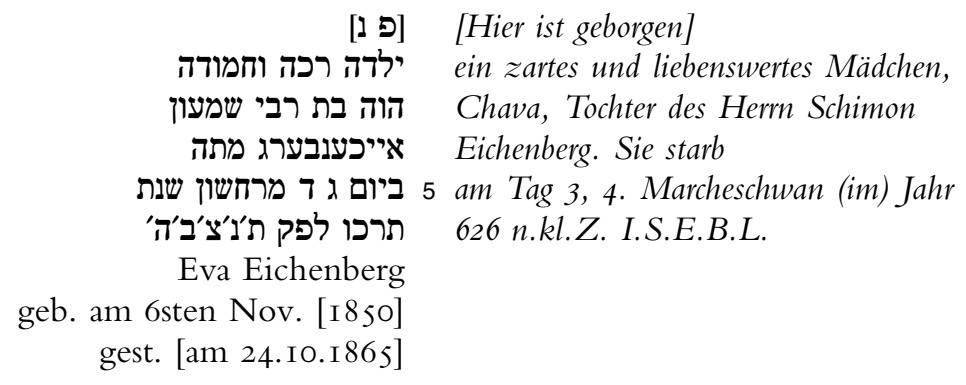

7f. Daten ergänzt nach GbL bzw. hebr. Inschrift. · Quelle: GbL (Geburtstag: 24.I I.I850) 
Rike Dahl, geb. Hellenstein

I $777 / 78-26.4$. I 866

Geb. in Beverungen/Westfalen - Ehemann (?): Heinemann Jacob Dahl, Karlshafen · Tochter (?): Johanne III Io

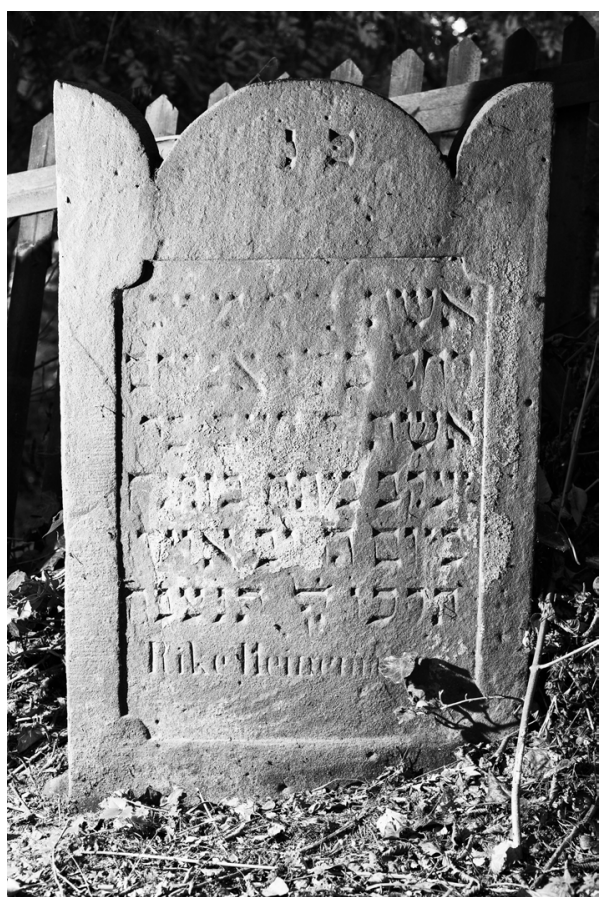

$\mathrm{H} 98 \cdot \mathrm{B} 65 \cdot \mathrm{T}$ I I

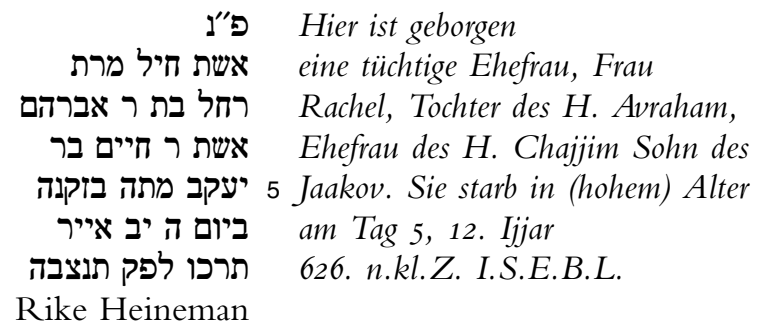

2 s. Prov 3 I, Io 6 Donnerstagabend, Beginn des I2. Ijjar · Quelle: StL (Geburtsjahr nach Altersangabe) 
Bertha Rothschild

8.I $2.1858-2.6 .1866$

Eltern: Joel S. Rothschild IV I7 - Amalie Rosenbaum

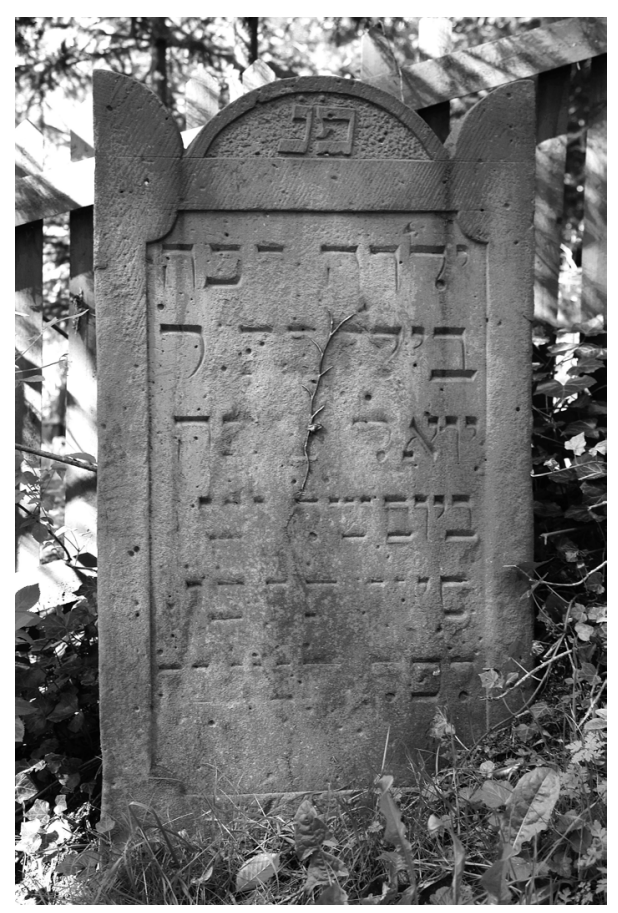

$\mathrm{H} \mathrm{II} 4 \cdot \mathrm{B} 65^{\circ} \mathrm{T}$ I2

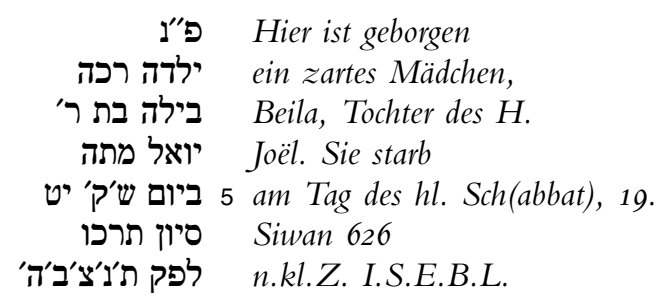

Quelle: GbL (Geburtstag) 
Emilie Müller

I.IO.I 859 - IO.7.I 866

Eltern: Isaac Aron Müller III 46 - Henriette Schloss

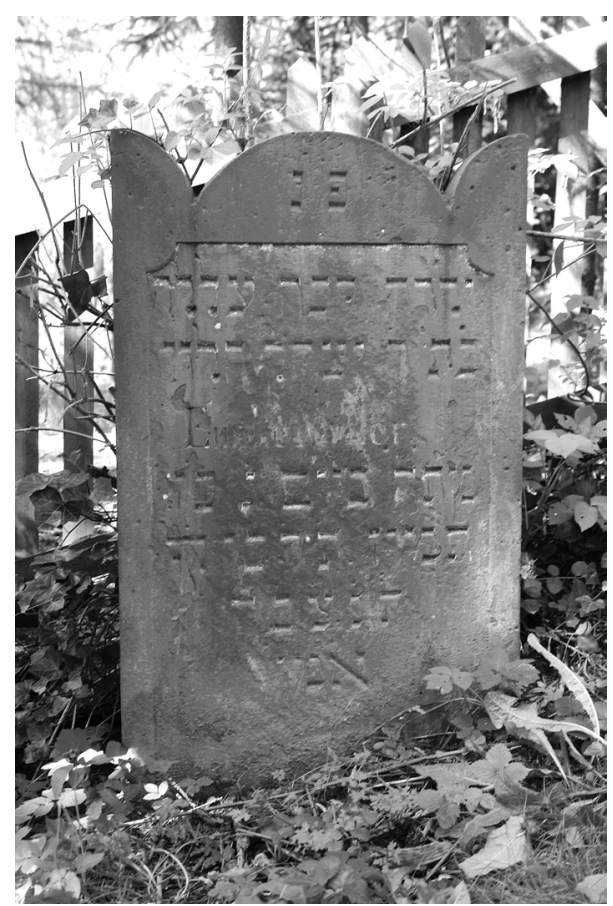

H III $\cdot \mathrm{B} 66 \cdot \mathrm{T}$ I I

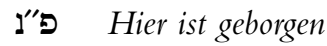

ילדה רכה עללה = ein zartes Mädchen, Ella,

Tochter des H. Jizchak ha-Levi.

Emilie Müller

5 Sie starb am Tag 3, 27.

Tammuz 626 n.kl.Z.

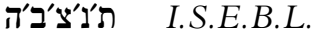

אמן Amen.

Quelle: GbL (Geburtstag) 


\section{Lehmann Unger}

I6.I I.I 7997 - 29.7.I 866

Buchbinder und Kurzwarenhändler · Eltern: Philipp Unger (= Feidel Leifmann) - Betti Ehefrau: Friederike Empsberg III $96 \cdot$ Kinder: s. ebd.

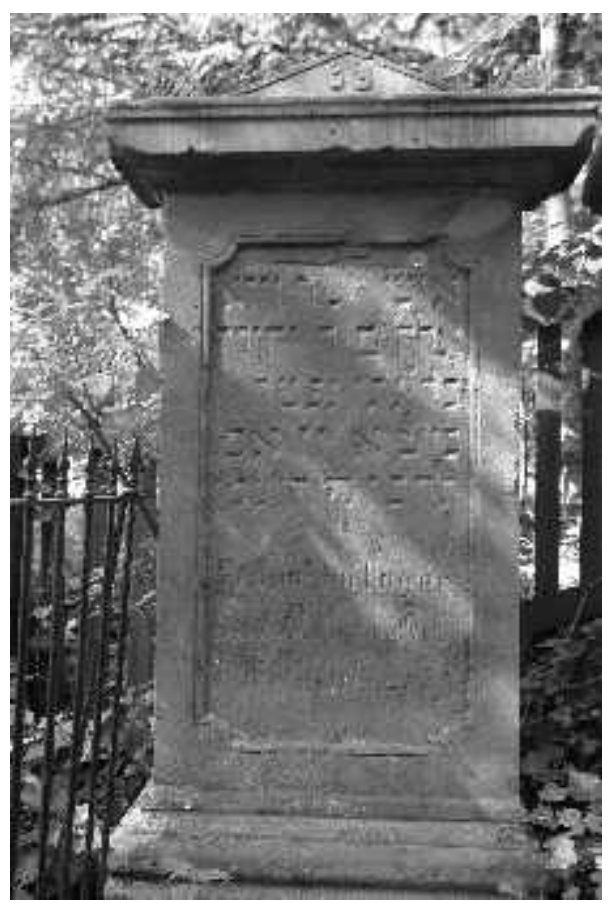

$\mathrm{H}$ I I $7 \cdot \mathrm{B} 68 \cdot \mathrm{T}$ I 8

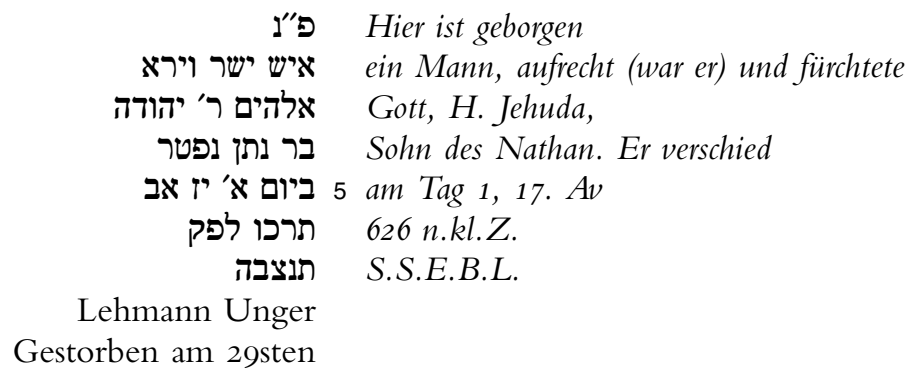

Lehmann Unger

Gestorben am 29sten Juli I 866 Friede [ihm!] 10

Quellen: FamB/Mappa Nr. 2i (Geburtstag I6.I I.I797 / I I.I I.I796) 
Mathilde Bähr, geb. Kahlberg 20.7/I4.IO.I789- I.3.I 867

Mathilde Bähr(e), geb. Kahlberg · geb. in Bodenfelde · Vater: Simon Kahlberg · Ehemann: Philipp Bähr(e) III $44 \cdot$ Kinder: Hermann (I $823-1892$, Dransfeld: Grab III); Fanny (I 824); Simon (I825); Rieke (I828); Mendel (I829-I838); Mendel (I830); Simon (I83 II839); Levi (I834)

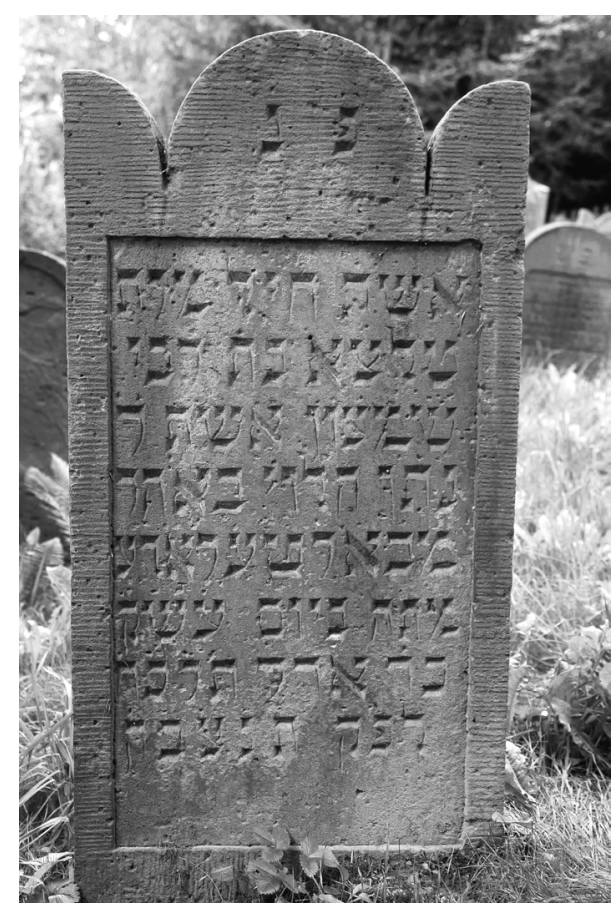

H II7 $\cdot$ B $59 \cdot$ T I 3

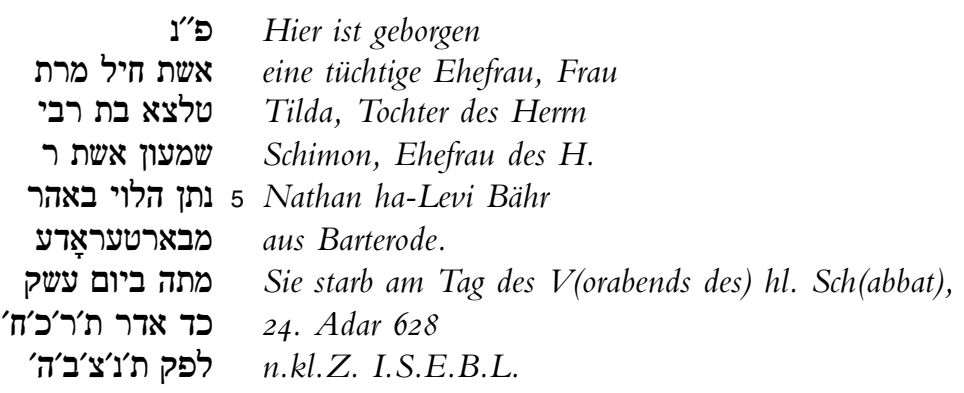

2 s. Prov 3 I, IO · טלצא / Tלדא / Tilza verschrieben statta. 8 Nach der StL 627 (ein Schaltjahr mit 2 Adar benannten Monaten), nicht 628. Dem enstspricht die Angabe über den Todestag: Freitag 24. Adar = I.3.I 867. · Quellen: FamB / StL (Geburtstag; Rückrechnung jeweils aus Altersangaben) 
Minna Meyenberg, geb. Hirsch

$$
\text { 26.9.I } 793-22.10 .1867
$$

Geb. in Nörten · Vater: Samuel Hirsch - Ehemann: Simon Meyenberg III 6I - Kinder: Röschen IV 22; Isaac (I 822-I 842); Wolf II 48; Kaufmann IV 9; Samuel (I 832; vgl. IV 34)

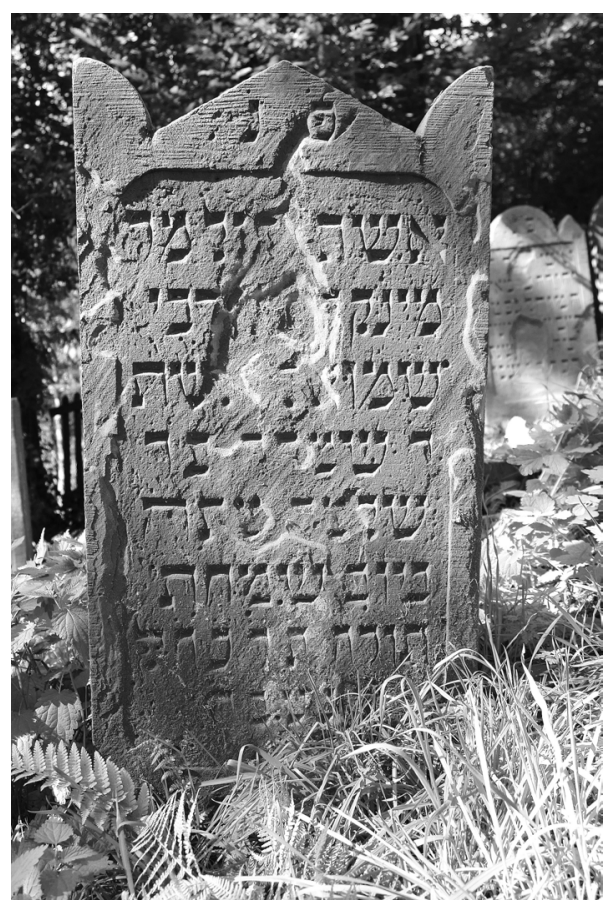

H III $\cdot$ B $58 \cdot$ T II

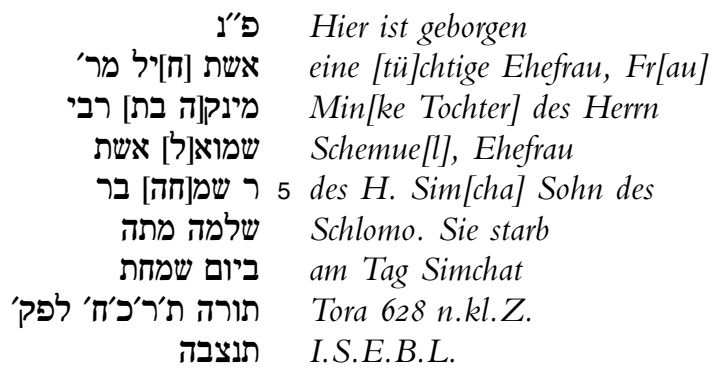

2 s. Prov 3 I, Io 7 Simchat Tora, s.u. S. $332 \cdot$ Quelle: FamB (Geburtstag) 
Henriette Rosenthal, geb. Rothstein

$$
\text { 20.4. I } 800 \text { - I3.I 2.I } 867
$$

aus Sudheim · Vater: Isaac Rothstein · Ehemann: David Rosenthal III $56 \cdot$ Sohn: Levi III 58

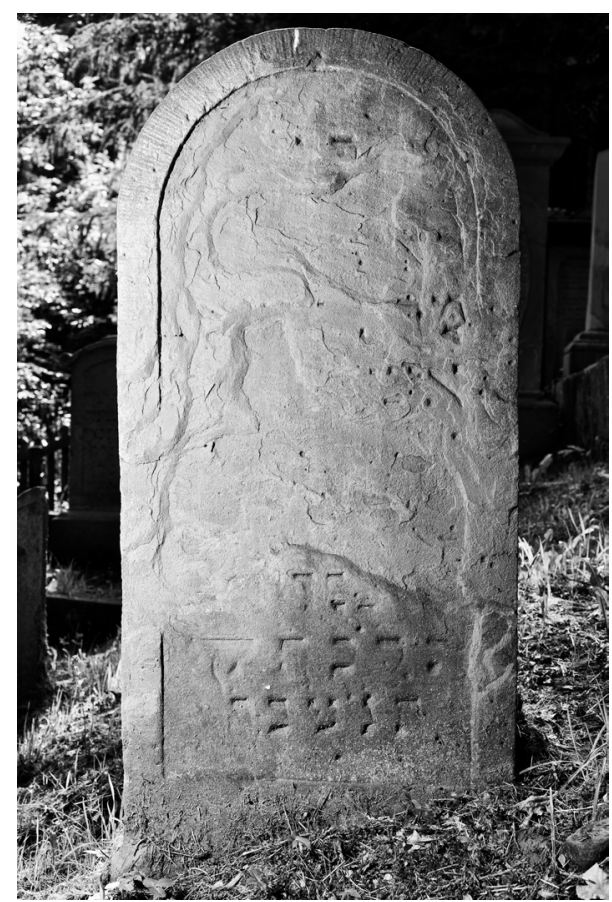

H I27 - B $58 \cdot$ T I7

Stein neu aufgestellt. Inschrift bereits I 984 stark verwittert

$$
\begin{aligned}
& \text { פַ" Hier ist geborgen } \\
& \text { [... die Fr[au ...] } \\
& \text { [... Fr[au ...] } \\
& \text {... איצ[י] } \\
& \text {... } 5 \\
& \text {... } \\
& \text { ת תרכח לפק } 628 \text { n.kl.Z. } \\
& 10 \text { I.S.E.B.L. }
\end{aligned}
$$

Quellen: FamB (Geburtstag); StB (Sterbetag) 


\section{Levi Meyer Eichenberg}

$$
\text { I2.3.I } 793 \text { - IO.I.I } 868
$$

Handelsmann (Pferdehändler), zuletzt auch Pfandleiher; übernahm I 855 die Fortführung der von Alexander Meyenberg begründeten Pfandleihe unter der Bezeichnung „Adelebsensche Leih-Kammer" . Auch als Beschneider (Mohel) in Adelebsen und Umgebung tätig (HStAH, Hann. 74 Uslar Nr. 2045) - Eltern: Meyer Simon Eichenberg - Mariana Baruch - Geschwister: Baruch (I778-I850), Simon II 35, Lucas (I790-I 859), Leiser III 79, Rosette III 2?) · Ehefrau: Henriette geb. Jacobsohn III $75 \cdot$ Kinder: s. ebd.

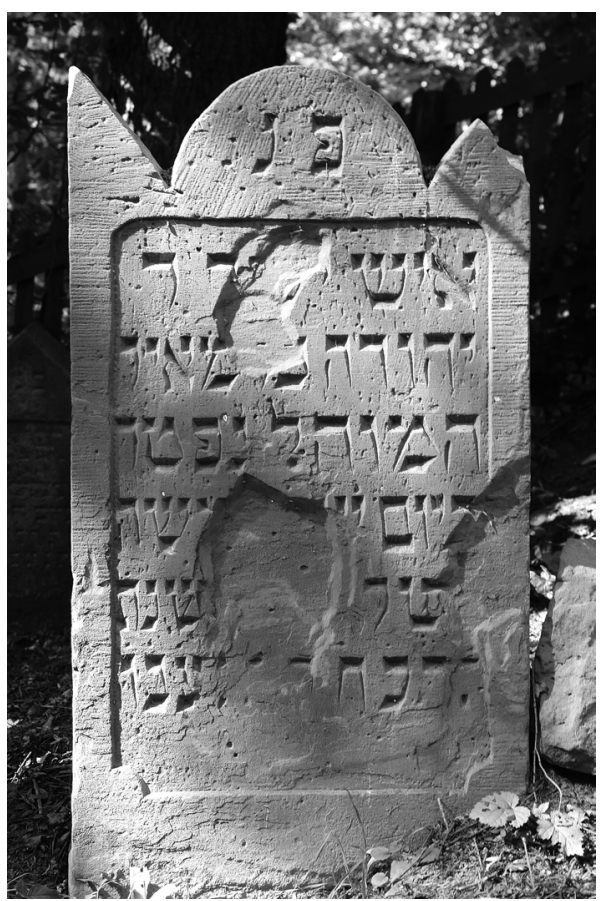

$\mathrm{H} \mathrm{IOI} \cdot \mathrm{B} 64 \cdot \mathrm{T} \mathrm{I} 4$

\begin{tabular}{|c|c|}
\hline \\
\hline פ"נ & Hier ist geborgen \\
\hline איש [יש]ר ר' & ein aufrechter Mann, $H$. \\
\hline יהודה [בר] מאיר & Jehuda, Sohn des Meir, \\
\hline המוהל נפטר & der Beschneider. Er starb \\
\hline ביום [עשק חמ]שה & 5 am Abend des hl. Sch(abbat) den fü \\
\hline עשר ט[בת] שנת & zehnten Te[vet] (im) Jahr \\
\hline תרכח לפק תנצבה & 628 n.kl.Z. S.S.E.B.L. \\
\hline
\end{tabular}

Quelle: FamB (Geburtstag) 


\section{Salomon Löwenthal}

$$
\text { 20.3.I } 802-\text { IO.8.I } 868
$$

Metzger, später Handelsmann - Von I844 bis zu seinem Tode verantwortlich für die Geburts-, Trauungs- und Sterbelisten der Gemeinde. · Eltern: Levi David Löwenthal II 3I - Rahel Gerson · Ehefrau: Friederike Edelstein III $98 \cdot$ Kinder: s. ebd.

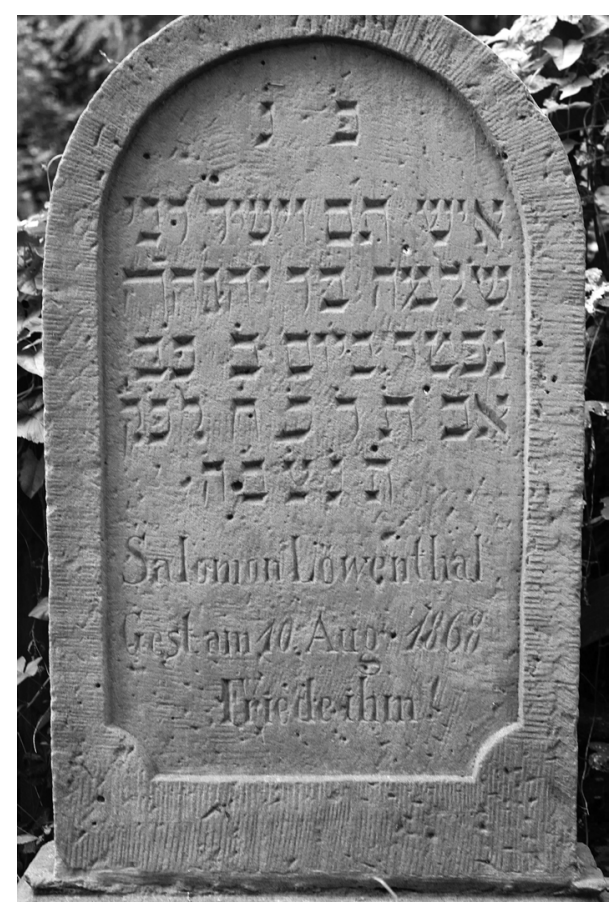

$\mathrm{H} 99 \cdot \mathrm{B} 60 \cdot \mathrm{T} \mathrm{I} 6$

פ"נ Hier ist geborgen

איש תם וישר רבי פיש

שלמה בר יהודה Schlomo, Sohn des Jehuda.

Er verschied am Tag 2, 22.

' 5 Av 628 n.kl.Z. S.S.E.B.L.

Salomon Löwenthal

Gest. am Io. Aug. I 869

Friede ihm!

2 s. Hi I,8 - Quelle: FamB (Geburtstag) 


\section{Schilein Eisig}

$$
\text { I6.2.I794 - I9.I2.I } 868
$$

Geb. in Sommerach/Unterfranken, gest. in Güntersen · I 8 I9 Lehrer in Güntersen, später "Knecht und Gehülfe» der Witwe Backstein, seit I 829 Lotterie-Collecteur ebd. · Ehefrau: Henriette Backstein III 69 · Tochter: s. ebd.

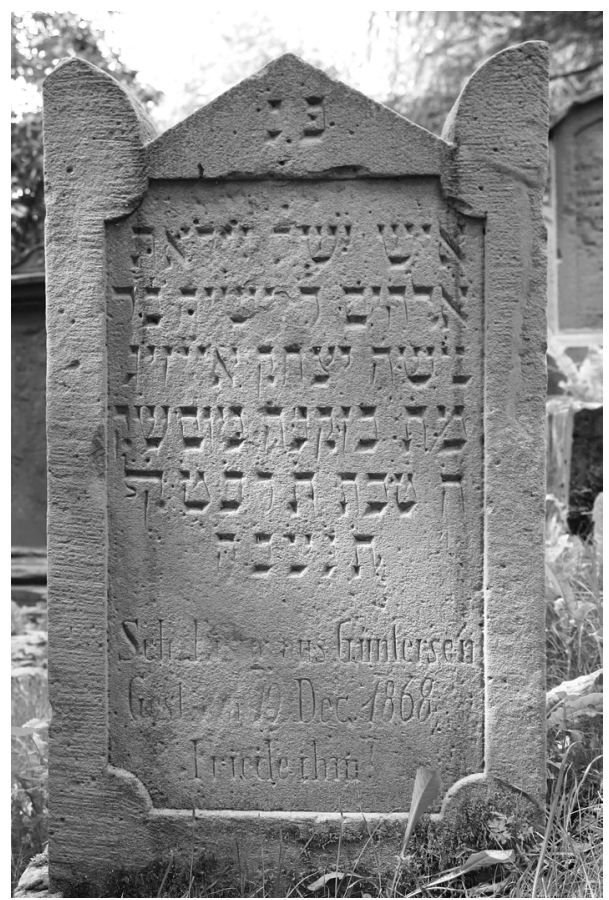

$\mathrm{H}_{9 \mathrm{I}} \cdot \mathrm{B} 63 \cdot \mathrm{T}$ I 5

פ

איש ישר ויראת ein Mann, aufrecht (war er) und fürchtete

Gott, H. Jeschaje, Sohn des

משה יצחק אייזיג

5 Er starb in hohem Alter am Tag des hl. Sch(abbat), 5. Tevet 629 n.kl.Z.

S.S.E.B.L.

Sch. Eisig aus Güntersen

Gest. am I9. Dec i 868

Friede ihm! 10

Quelle: FamB (Geburtstag) 
Friederike Gräfenberg, geb. Eichenberg

$$
\text { I 5.I I.I } 843-25.2 .1869
$$

Eltern: Levi Meyer Eichenberg III 74 - Henriette Jacobsohn III 75 - Ehemann: Salomon Gräfenberg (I834-I9I8, Göttingen: Grab 333) · Kinder: Selly (I863-I92 I Frankfurt/M.), Max (I864), Adolf (I866-I929 Berlin), Ida (I868-I933, Berlin)

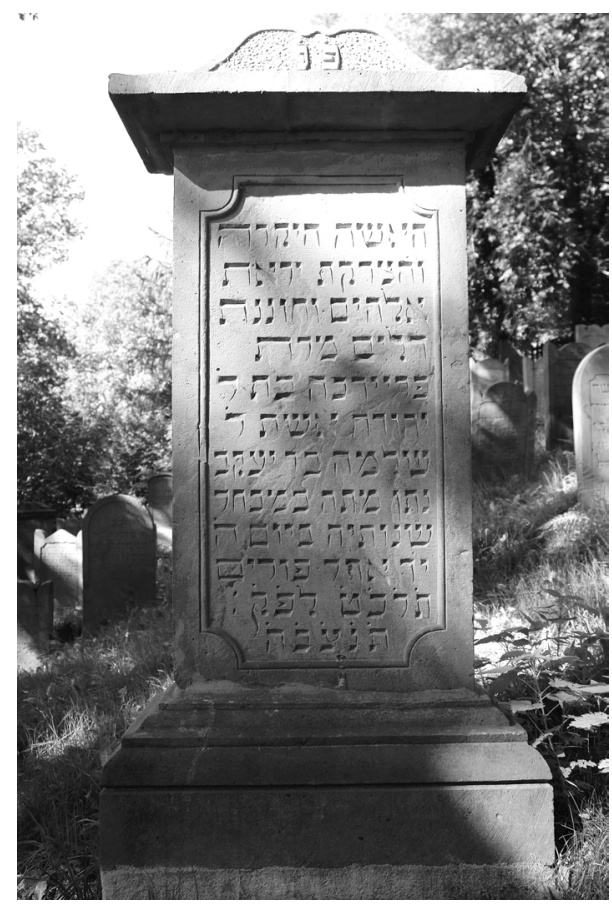

Rückseite

Friederike Gräfe[nber]g geb. Eichenberg Geb. am I 5. No[ve]mb. I 843 Gest. am 25. Febr. I869 Friede ihrer Seele!

$\mathrm{H} \mathrm{II9} \cdot \mathrm{B} 63 \cdot \mathrm{T}$ I4

\begin{tabular}{|c|c|}
\hline פ״"נ & Hier ist geborgen \\
\hline האישה היקרה & die geachtete \\
\hline והצדקת יראת & und wohltätige Frau, gottes- \\
\hline אלהים וחוננת & fürchtig (war sie) und barmherzig \\
\hline דלים מרת & den Armen, Frau \\
\hline פריידכה בת ר & Freidche, Tochter des $H$. \\
\hline יהודה אשת ר' & Jehuda, Ehefrau des $H$. \\
\hline שלמה בר יעקב & Schlomo Sohn des Jaakov \\
\hline נתן מתה במבחר & Nathan. Sie starb in ihren besten \\
\hline שנותיה ביום ה & Jahren am Tag 5, \\
\hline יד אדר פורים & 14. Adar, Purim \\
\hline ת'ר'כ'ט ל'פ'ק' & 629 n.kl.Z. \\
\hline ג'ו'טיר' & I.S.I \\
\hline
\end{tabular}


Jeanette Oppenheim, geb. Plaut

$$
\text { I4.5.I79I - 22.3.I } 869
$$

Geb. zu Frankershausen/Hessen - Vater: Marcus Plaut - Ehemann: Samuel Simon Oppenheim[er] III I2 - Kinder: Caroline (I82 I); Marcus (I 823); Simon III I9; Mine (= Maria Schönfeld geb. Oppenheim, I 828-I877, Sondershausen, Grab Nr. 0077); Auguste (I83 I)

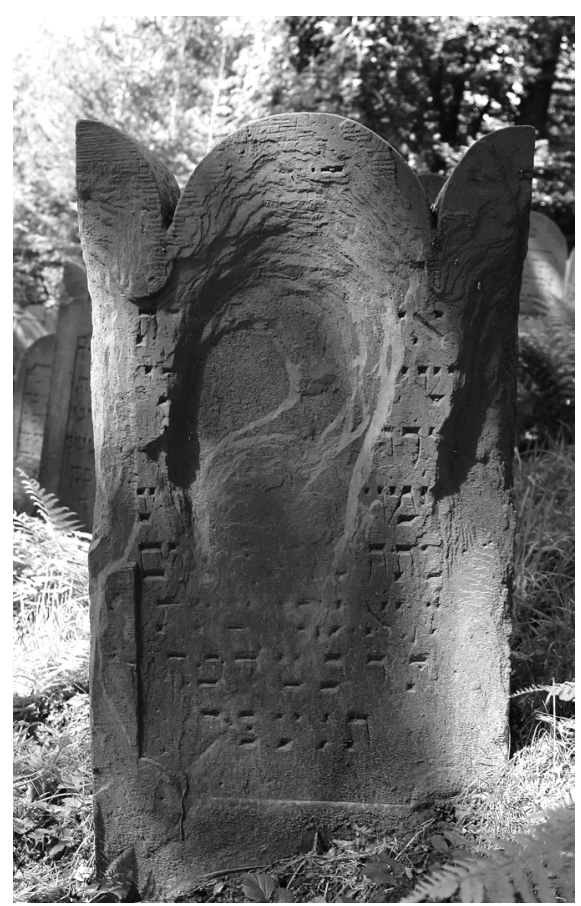

H I I6 $\cdot$ B $64 \cdot$ T I7

Stark abgeblätterte Inschrift

[נ] [Hier ist geborgen]

[eine tüchtige] [E]hefrau, [F]rau

שיי[נכה בת ר]בי מרת מרין Schei[nche, Tochter des H]errn

Morde[chai, Frau des]

ש.... . 5 Schmu[el] ...

Sie starb ... [am] Tag

3, 11. Nisan (im) Jahr

629 n.kl.Z.

I.S.E.B.L.

7 Nach StL in den Abendstunden des Vortags 22.3.I869 - Quelle: FamB (Geburtstag) 
Jette Isaac, geb. Meyer

I0.9. I 8 IO - 29.7.I 869

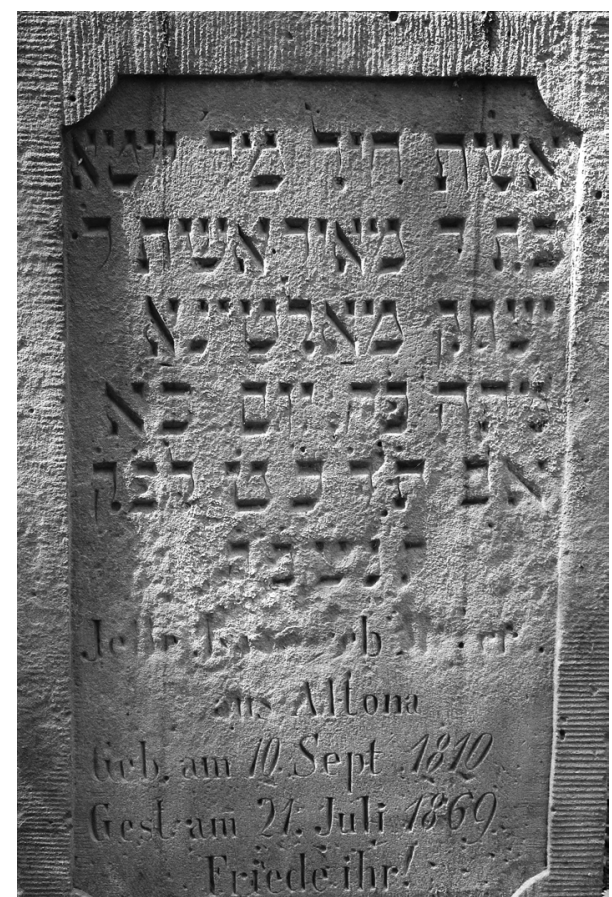

H IIO $\cdot$ B $58 \cdot$ T Is

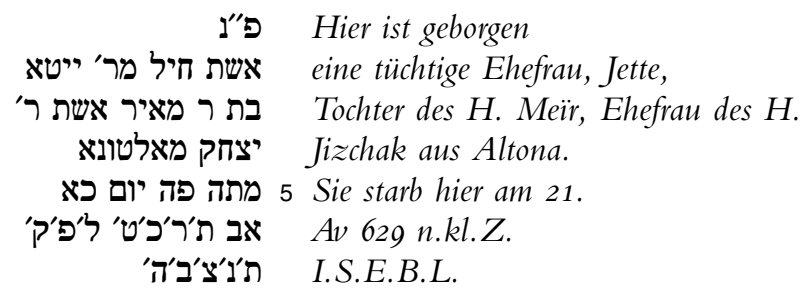

Jette Isa[ac] geb. Meier

aus Altona

Geb. am Io. Sept. I 8 Iо 10

Gest. am 2I. Juli I 869

Friede ihr!

2 s. Prov 3 I, IO - 11 Das Tagesdatum der deutschen Inschrift 2I. ist fälschlich dem der hebräischen Inschrift entnommen, richtig ist 29.7 . 
Dora Rosenbaum

27.5.I 853 - IO.IO.I 869

Eltern: Moses Rosenbaum III I6 - Emilie Stern III I7

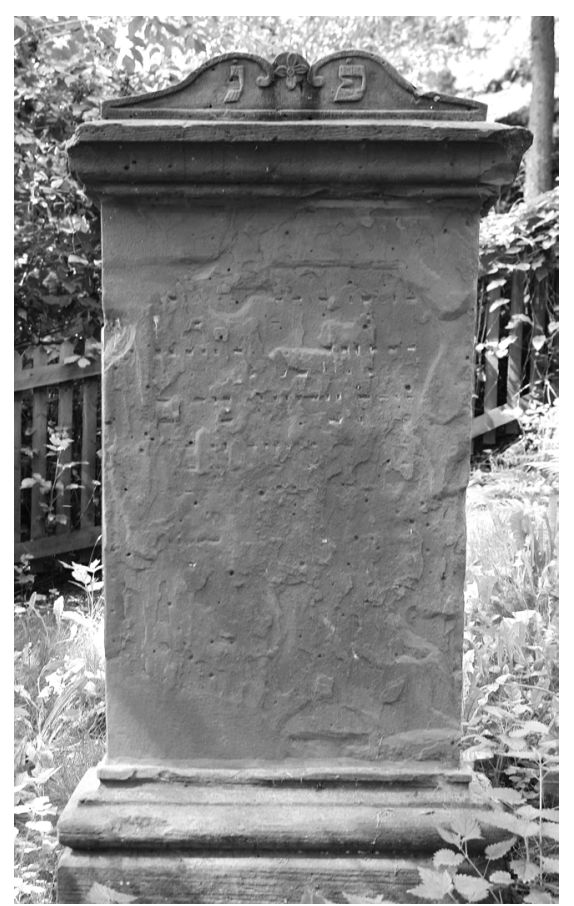

$\mathrm{H} \mathrm{I00} \cdot \mathrm{B} 67 \cdot \mathrm{T} \mathrm{I} 4$

Dt. Text der Rückseite bei der Aufnahme i 988 noch lesbar, inzwischen aber gleichfalls verwittert

פ"נ
$\ldots$
Rückseite

Dora Rosenbaum

Geb am 27 Mai I 853

Gest am io Oct i 8695

Friede ihr!

3 StbL: i I.Io. I 869 


\section{Moses Löwenstern}

9.I.I $840-$ I 2.8.I 870

Kaufmann · Eltern: Samuel Löwenstern III 48 - Fanni Grunsfeld III 47

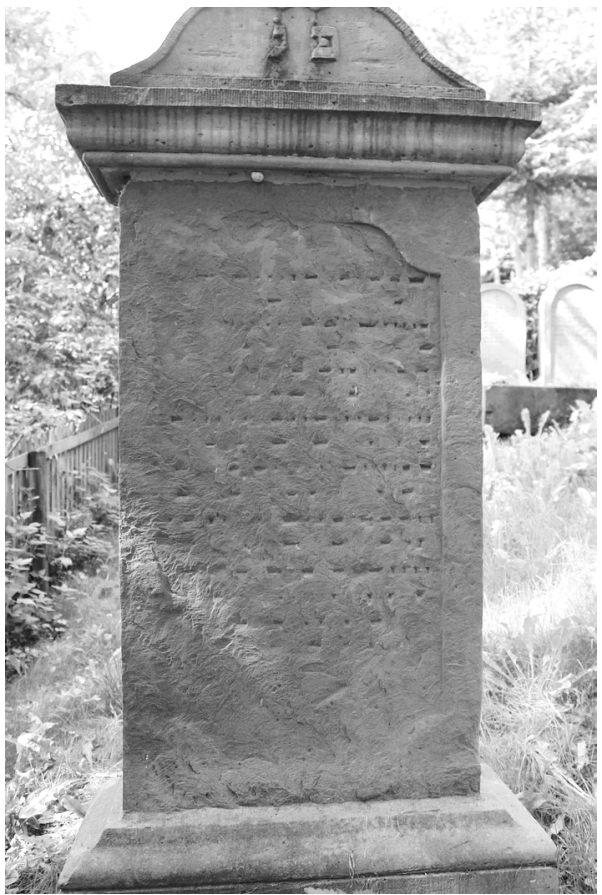

H II2 $\cdot$ B $63 \cdot$ T I6

Vorderseite: Inschrift nur beschränkt lesbar, Rückseite (s.S. 47): Inschrift von einem Kranz aus Eichenlaub umfasst

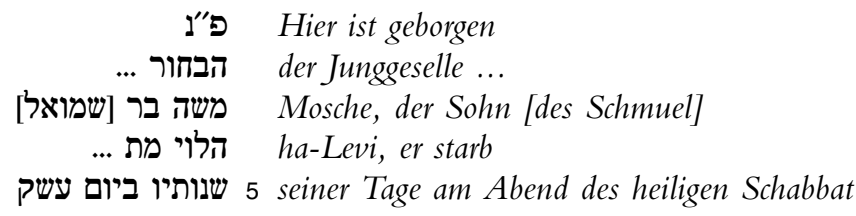

er wurde begraben am Tag ...Av

(im) Jahr 630 n.kl.Z.

10 S.S.E.B.L.

Rückseite

Hier ruhet

Moses Löwenstern

Geb. am 9. Jan I 840

Gest. am I2. Aug I 870

Friede ihm! 15 
Hirsch Bähr

I7.I 2.I $799-22.2 .187 \mathrm{I}$

Handelsmann in Barterode - Eltern: Abraham (weiterer Name unbekannt) - Tochter von Mendel Bähr, II 49 • Ehefrau: Rieke Lehmann-Gottschalk aus Sievershausen/Solling · Söhne: Gottschalk (I827), Levi IV 7

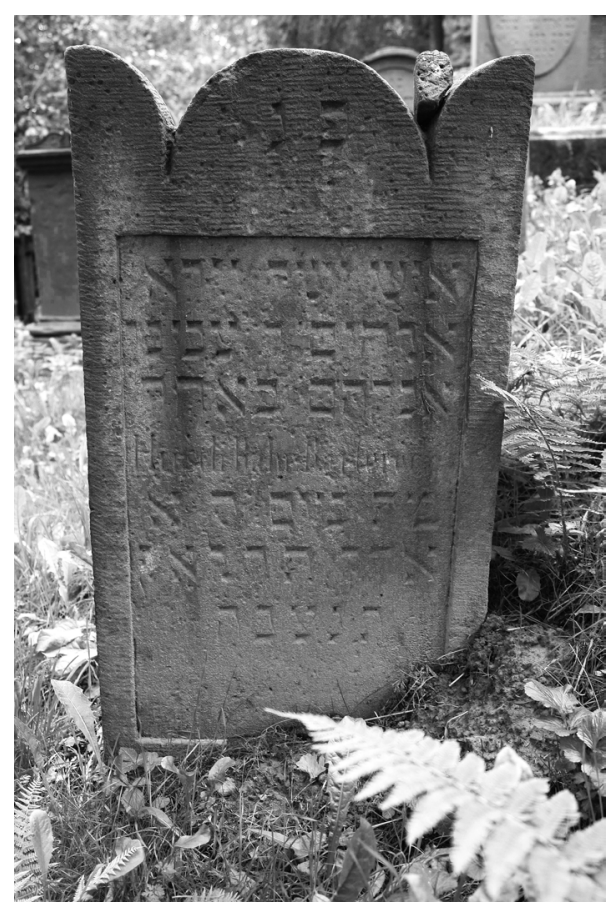

$\mathrm{H} 99 \cdot \mathrm{B} 58 \cdot \mathrm{T}$ I 2

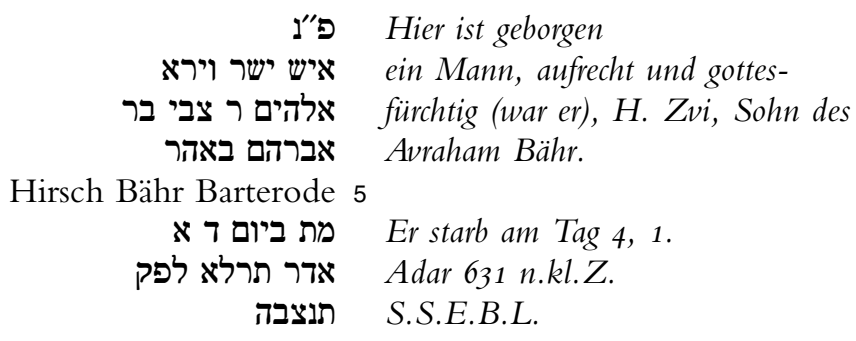

3 Hirsch, dt. Übersetzung des hebr. Zvi (צבי). · Quelle: FamB (Geburtstag) 
Isaac Aron Müller

I8.8.I 8 I9 - 8.3.I 872

Eltern: Aron Isaak Müller III 23 - Bertha Bacharach II $5 \mathrm{I} \cdot$ Ehefrau: Henriette Schloss (aus Witzenhausen; geb. I4.6.I 824 in Hebenshausen/Hessen) - Kinder: Bertha (I855); Bertha III 60; Emilie III 95; Pauline, verh. Heymann (I86I-I942, Treblinka); Rahel (I863-I943); Adolph (I 864); Ida, verh. Lamm (I 866-I944, Theresienstadt)

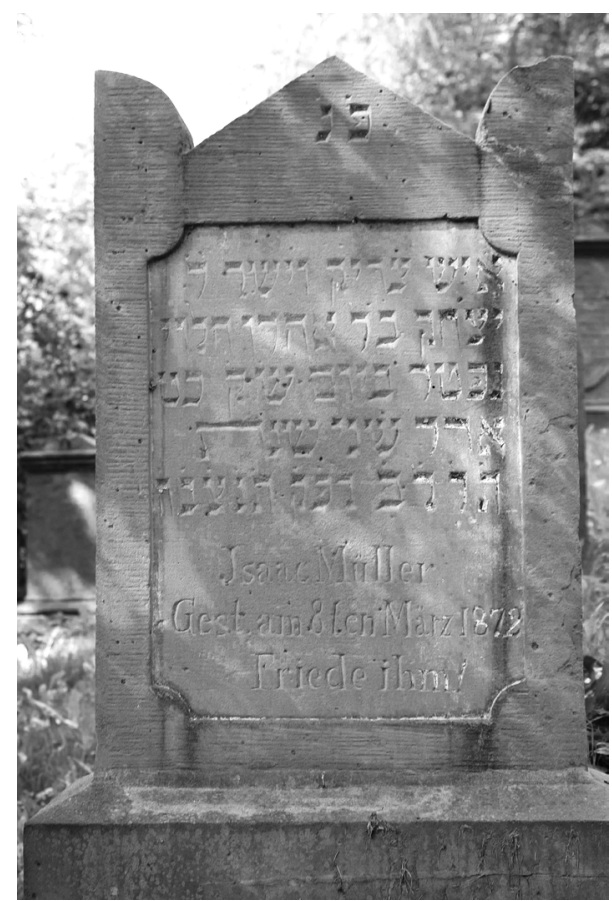

$\mathrm{H} \mathrm{IOO} \cdot \mathrm{B} 66 \cdot \mathrm{T} \mathrm{I} 3$

פיפ $\quad$ Hier ist geborgen

איש צדיק וישר ר'

ניצחק בר אהרן הלוי Jizchak, Sohn des Aharon ha-Levi.

Er verschied am Tag des hl. Sch(abbat), 29.

5 Adar II (im) Jahr

632 n.kl.Z. S.S.E.B.L.

Isaac Müller

Gest. am 8ten März I 872

Friede ihm!

5 Schreibfehler: Adar II. Der 8.3.I 872 ist der 29. Adar I. · Quelle: FamB (Geburtstag) 


\section{Julius Katzenstein}

2.I.I 8 I I - I9.2.I 873

Kleinhändler (Hausierer) · Eltern: Wolf Katzenstein (I 8 I I / I 8 I6 in Adelebsen erwähnt) Jeanette - Ehefrau: Henriette Rosenbaum III 90 - Kinder: Helene IV 47; Bertha (I850); Jeanette (I 853); Fanni (I 856); Wolf (I 859)

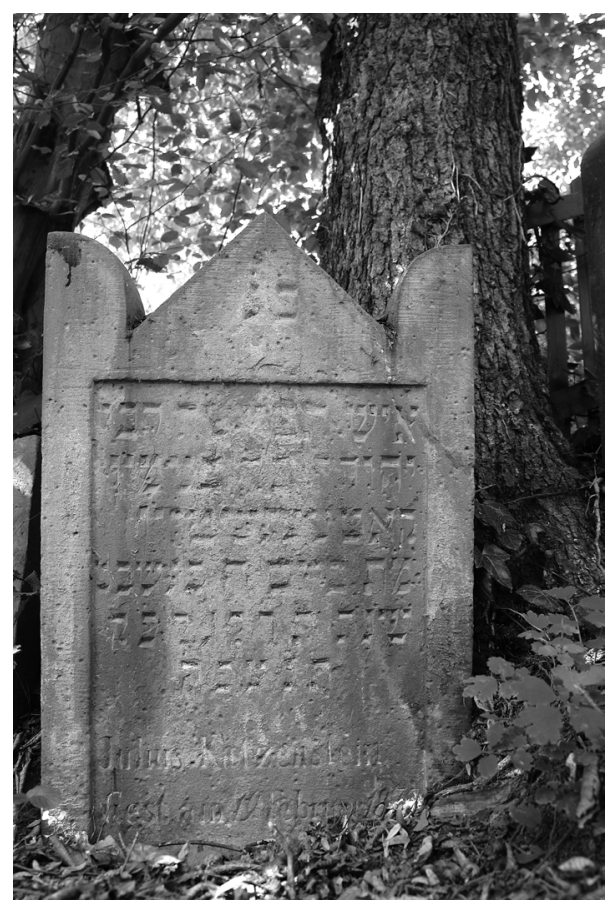

$\mathrm{H} 107 \cdot \mathrm{B} 65 \cdot \mathrm{T}$ I5

פ"ג Hier ist geborgen

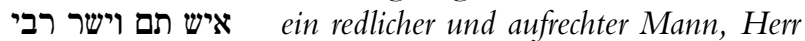

Jehuda, S(ohn) des H. Benjamin

קatzenstein.

5 Er starb am Tag 5, 23. Schevat

(im) Jahr 633 n.kl.Z.

S.S.E.B.L.

Julius Katzenstein

Gest. am I9 Februar I 873

Friede ihm! 10

2 s. Hi I,8 - Quelle: FamB (Geburtstag) 
Friederike Eichenberg, geb. Stehberg

$$
\text { I6.8. I } 8 \text { IO - 3.7.I } 873
$$

Eltern: Lucas Stehberg III 77 - Gitel Müller III 76 - Ehemann: Leiser Meier Eichenberg III 79 - Kinder: Meier IV I8; Levi III 28; Mathilde (I847); Bertha/Betti (I 852)

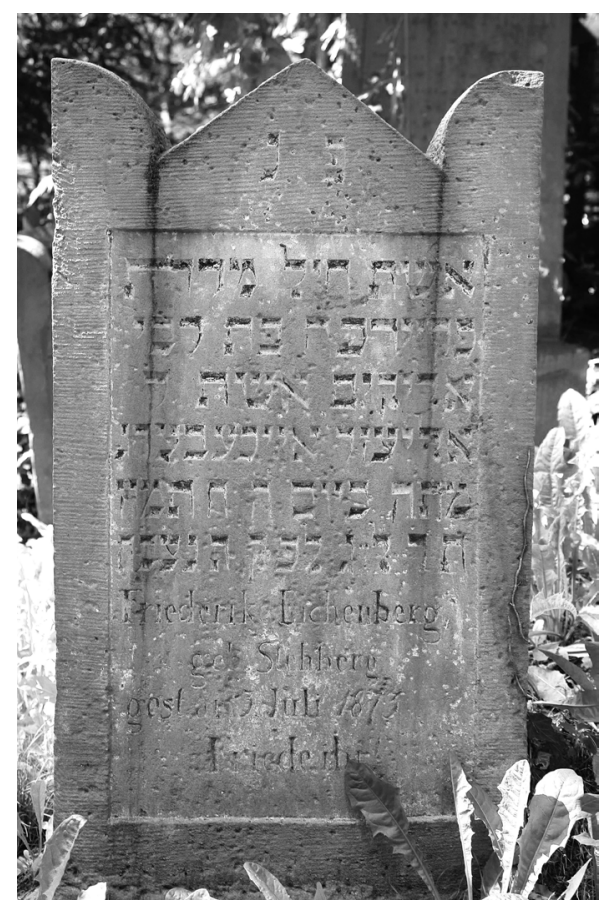

$\mathrm{H} 105 \cdot \mathrm{B} 60 \cdot \mathrm{T}$ I5

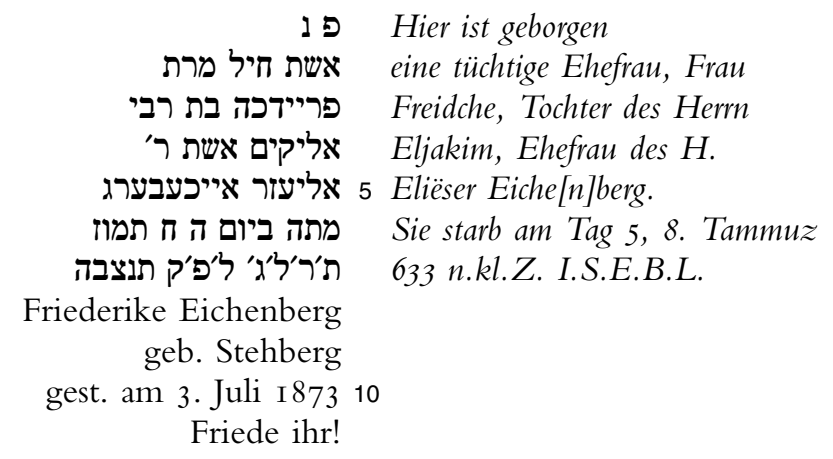

2 s. Prov 3I,Io · Quelle: FamB (Geburtstag) 
Levi Rosenthal

28.3.I $833-24.9 .1873$

Eltern: David Rosenthal III 56 - Henriette Rothstein III 55

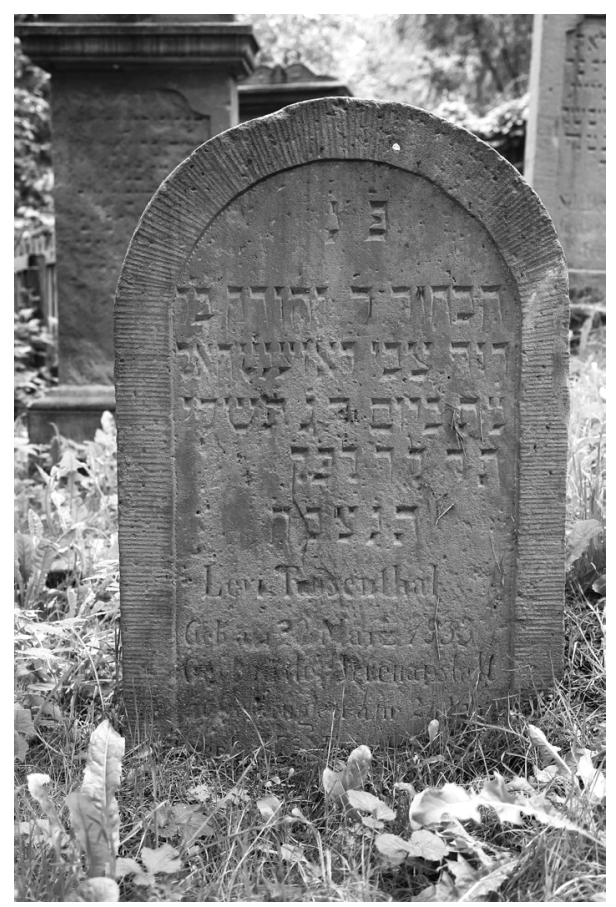

H $109 \cdot \mathrm{B} 62 \cdot \mathrm{T}$ I5

פע"ג Hier ist geborgen

der Junggeselle H. Jehuda, Sohn des דוד צבי ראזענטהאל ברור ריור

Er starb am Tag 4, 3. Tischri

5634 n.kl.Z.

S.S.E.B.L.

Levi Rosenthal

Geb. am 28. März I 833

Gest. in der Irrenanstalt

zu Göttingen am 24ten 10

Sept. I 873 Friede ihm! 


\section{Joseph Arensberg}

29.5.I $840-20$. I.I 874

Kaufmann, geb. in Dransfeld, seit ca. I870 in Adelebsen - Eltern: David Arensberg Caroline Ballin · Ehefrau: Berta Löwenstern III $34 \cdot$ Kinder: s. ebd.

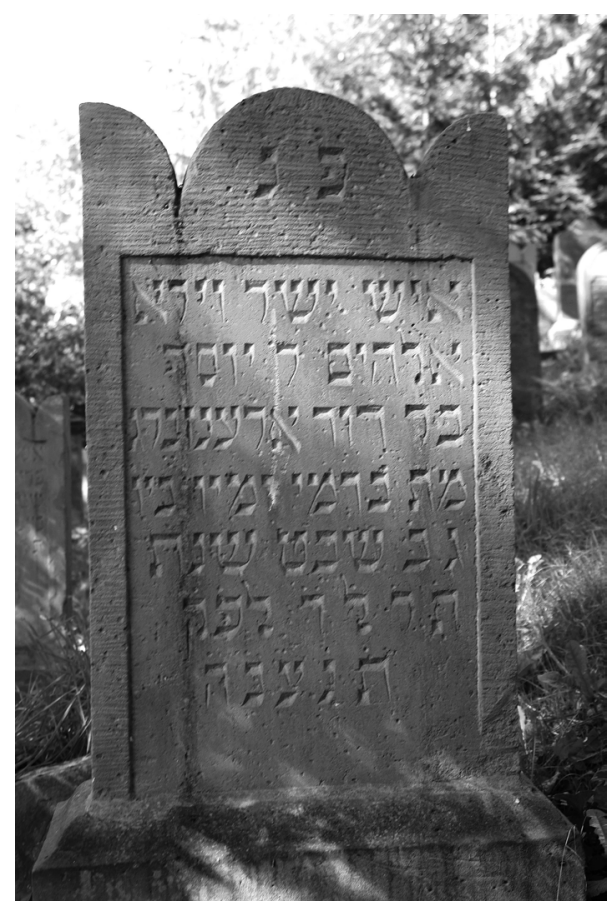

$\mathrm{H} 97 \cdot \mathrm{B} 59 \cdot \mathrm{T} \mathrm{I} 4$

\ Hier ist geborgen

איש ישר וירא

fürchtig (war er), H. Joseph,

Sohn des David Arensberg.

שת Er starb in der Mitte seiner Tage am Tag

3, 2. Schevat (im) Jahr

ת'ת' 634 n.kl.Z.

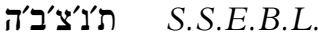

Rückseite

Joseph Arensberg

gest. am 20. Januar 10

I 874

Friede ihm!

5 vgl. Jes 38, Io - Quelle: FamB Dransfeld (Geburtstag) 
Carl Oppenheim

$24.5 .1872-26.3$. I 874
Saly Oppenheim

2.I I.I $870-28.3 .1874$

Eltern: Simon Oppenheim III I9 - Esther Dannenberg III 20

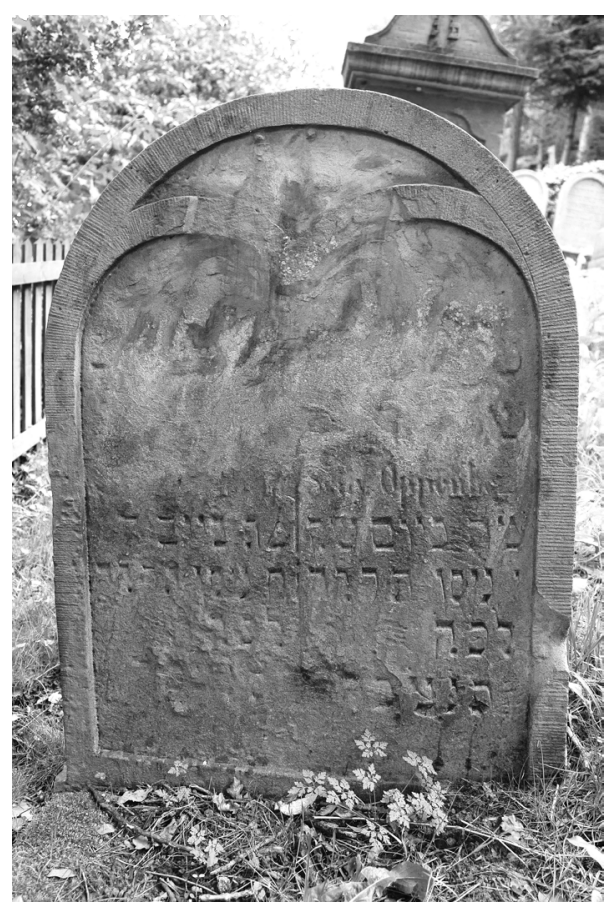

H I I $8 \cdot \mathrm{B} 82 \cdot \mathrm{T}$ I6

Inschrift im oberen Teil inzwischen nicht mehr lesbar

[1"פ]

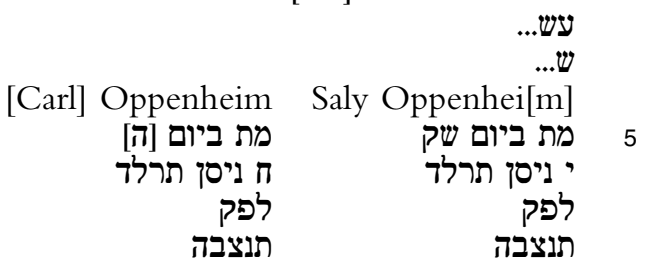

[H(ier) (sind geborgen)]

5 Er starb am Tag [5],

Er starb am Tag des hl. Sch(abbat),

8. Nisan 634

n.kl.Z.

10. Nisan 634

S.S.E.B.L.

n.kl.Z.

S.S.E.B.L.

Quellen: GbL (Geburtstage) 
Moses Rosenbaum

I9.I.I 8 I $2-23 \cdot 3 \cdot I 876$

Kaufmann · Eltern: Samuel Levi Rosenbaum II 36 - Röschen Liebenfeld · Ehefrau: Emilie Stern III $17 \cdot$ Kinder: s. ebd.

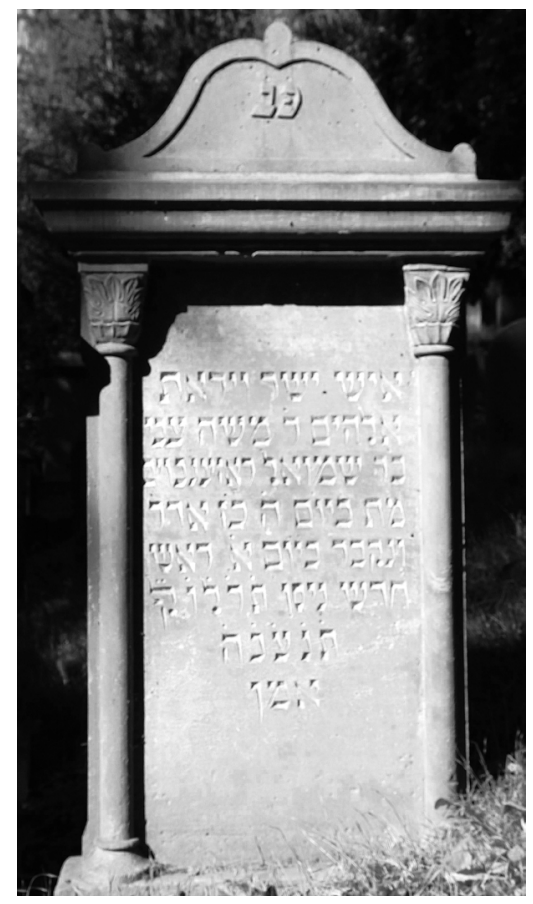

$\mathrm{H} \mathrm{I75} \cdot \mathrm{B} 778 \cdot \mathrm{T} \mathrm{I} 4$

פ Hier ist geborgen

איש ישר ויראת ein Mann, aufrecht (war er) und gottes-

fürchtig, H. Mosche Zvi,

S'S(ohn) des H. Schmuel Rosenboim.

5 Er starb am Tag 5, 27. Adar

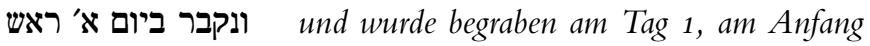

des Monats Nisan 636 n.kl.Z.

S'ת.S.E.B.L.

Rückseite

אמן Amen.

Moses Rosenbaum 10

Geb. am I9. Januar I8 22

Gest. am 23. März I 876

Friede ihm!

11 FamB: I4. Io.; StB: I2.Io. 
Röschen Dannenberg

$$
\text { 5.7.I } 86 \text { I - 22.I.I } 877
$$

Eltern: Jonas Dannenberg - Marianna Heilbrun(n)

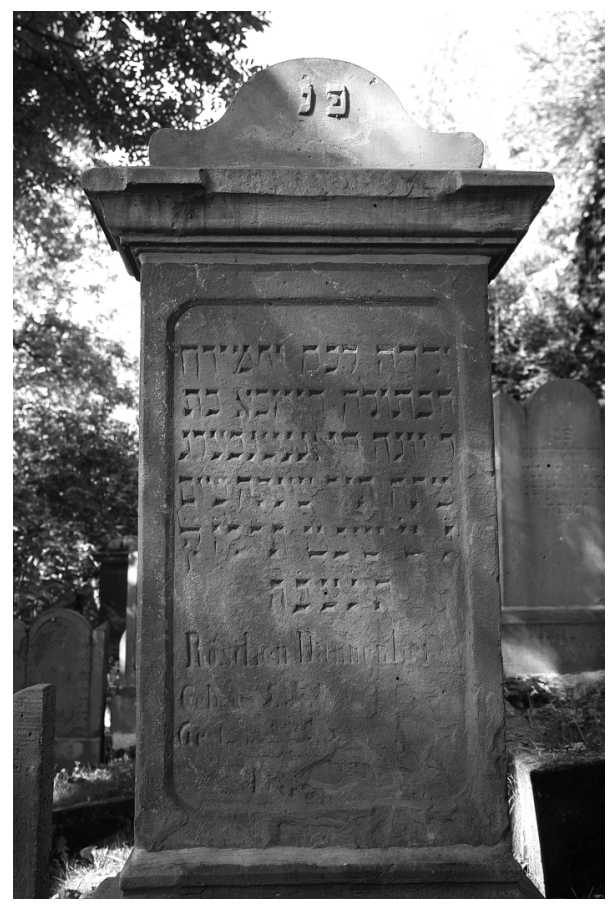

$\mathrm{H} \mathrm{I} 53 \cdot \mathrm{B} 63 \cdot \mathrm{T}$ I6

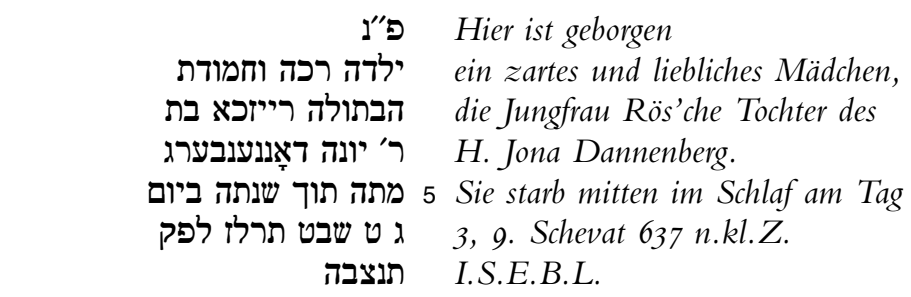

Röschen Dannenberg

Geb. am 5. Juli I[I86I]

Gest. am 22. Januar [I 877] 10

Friede [ihr!]

9 Geburtsjahr ergänzt nach GbL 10 Sterbejahr ergänzt nach hebr. Inschrift und StbL (dort 23.I.). 
Friederike Unger, geb. Empsberg 22.I.I 8 IO - I I.7.I 877

Geb. in Salzkotten Westfalen · Ehemann: Lehmann Unger III $97 \cdot$ Kinder: Philipp (I 836); Meyer (I 837); Samuel (I 838); Susmann (I 840); Bertha (I 844)

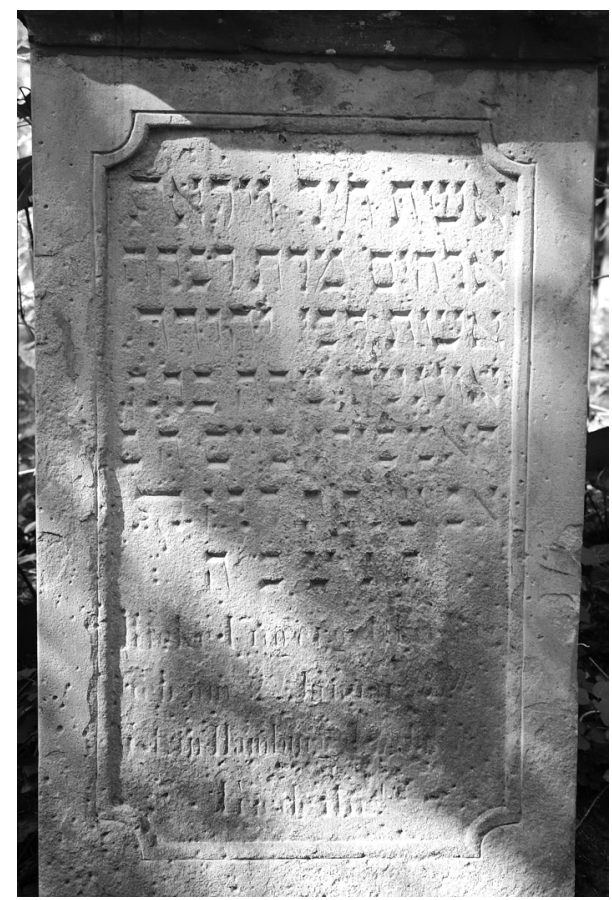

H IIO $\cdot$ B $68 \cdot$ T I9

\begin{tabular}{|c|c|}
\hline פ״ג & Hier ist geborgen \\
\hline אשת חיל ויראת & eine Ehefrau, tüchtig (war sie) und fürchtete \\
\hline אלהים מרת רבקה & Gott, Frau Rivka, \\
\hline אשת רבי יהודה ' & Ehefrau des Herrn Jehuda \\
\hline 5 אונגער מתה ב ק׳ק' & Unger. Sie starb in der hl. G(emeinde) \\
\hline האמבורג ביום ה' ב' & Hamburg am Tag 5, 2. \\
\hline$-3 L^{2}=-$ & Av (im) Jahr 637 n.kl.Z. \\
\hline תנצבד & I.S.E.B.L. \\
\hline
\end{tabular}

Rieke Unger geb. E[mps]berg

Geb. am 22. Januar I 8 IO 10

Gest. in Hamburg d. [I I. Juli I 877]

Friede ihr!

2 s. Prov 3 I, IO 


\section{Samuel Löwenstern}

$$
\text { 22.7.I } 809 \text { - I 5.IO.I } 877
$$

Metzger, erhielt I 834/35 Schutzbrief an Stelle von Isaac M. Freudenthal - Eltern: Marcus Meyer Löwenstern II 29 - Bertha Dahl II 28 - Ehefrau: Fanny Grunsfeld III 47 - Kinder: ebd.

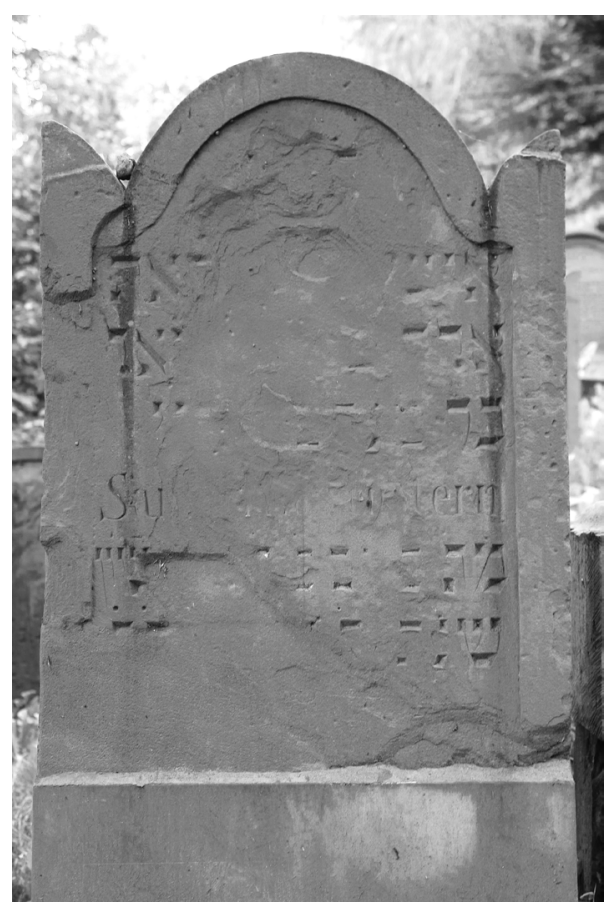

$\mathrm{H} 74 \cdot \mathrm{B} 62 \cdot \mathrm{T} \mathrm{I} 3$

Stein, neu aufgestellt $\cdot$ unterer Teil fehlt

$$
\begin{aligned}
& \text { [פ'] Hier ist geborgen } \\
& \text { איש ein Mann ... gottes- } \\
& \text { fürchtig... [Schm]uël, } \\
& \text { Sohn des e. M[enachem ha-Le]vi } \\
& \text { Sa[muel] [Löwe]nstern } 5 \\
& \text { Er starb am Tag 2, 8. Marcheschwan } \\
& \text { (im) Jahr 6[38] .... }
\end{aligned}
$$

Quellen: FamB (Geburtstag); StbL/SHR (Sterbetag) 


\section{Simon Löwenstern}

$$
\text { 6.IO.I } 806 \text { - I8.I.I } 878
$$

Lotteriecollecteur - I842 bis I 844 und I 85 I bis I 856 Vorsteher der Synagogengemeinde · Eltern: Marcus Meyer Löwenstern II 29 - Bertha Dahl II 28 - Ehefrau: Adelheide Meyersberg aus Einbeck (I 820) - Kinder: Marcus (I 844-I907, Hamburg); Bertha (I846I847); Hermann (I848); Berthilde (I85I-I854); Eduard (I853); Mylius (I855); Adolf (I 858 -I943, Theresienstadt)
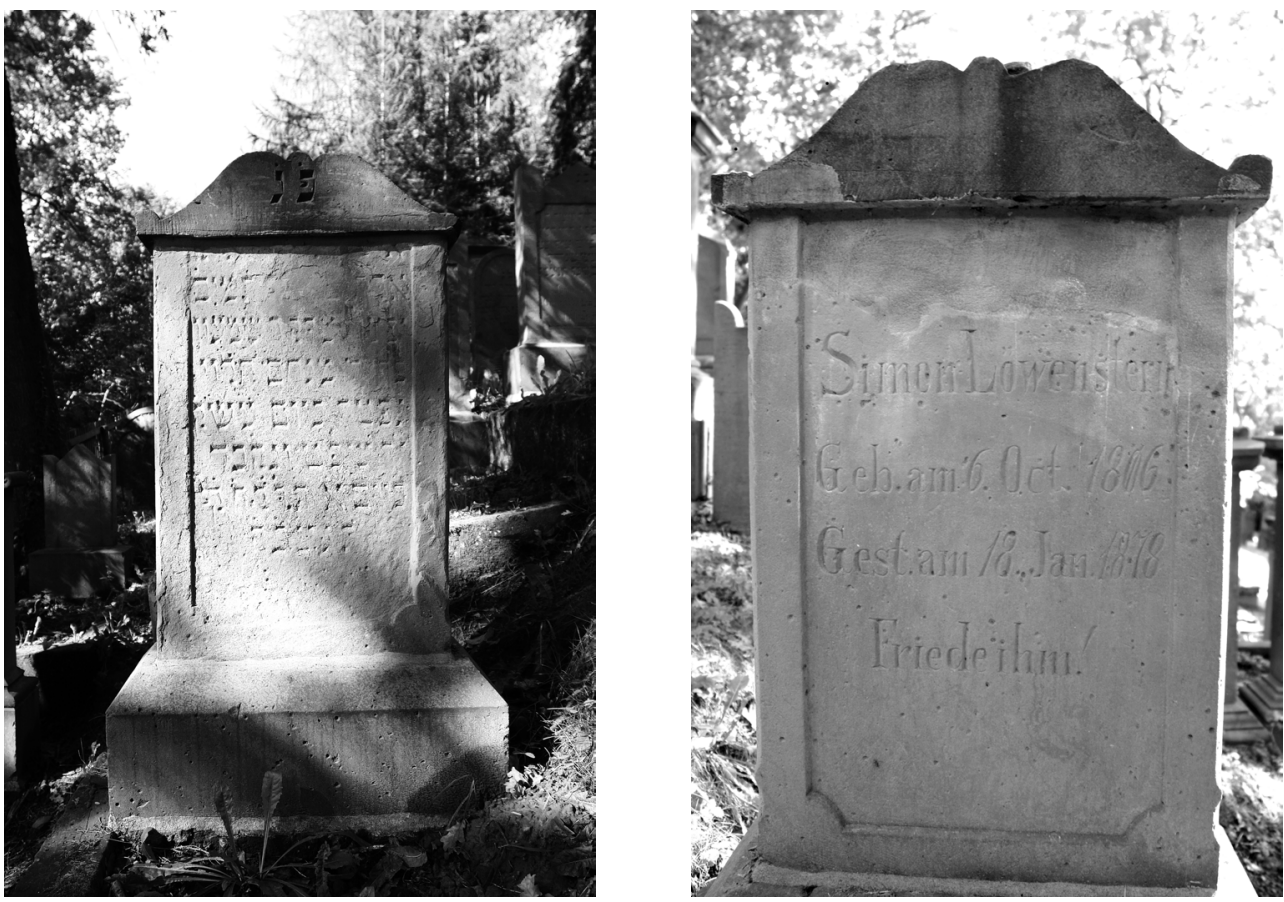

$\mathrm{H} 88 \cdot \mathrm{B} 60 \cdot \mathrm{T} \mathrm{I} 3$ 


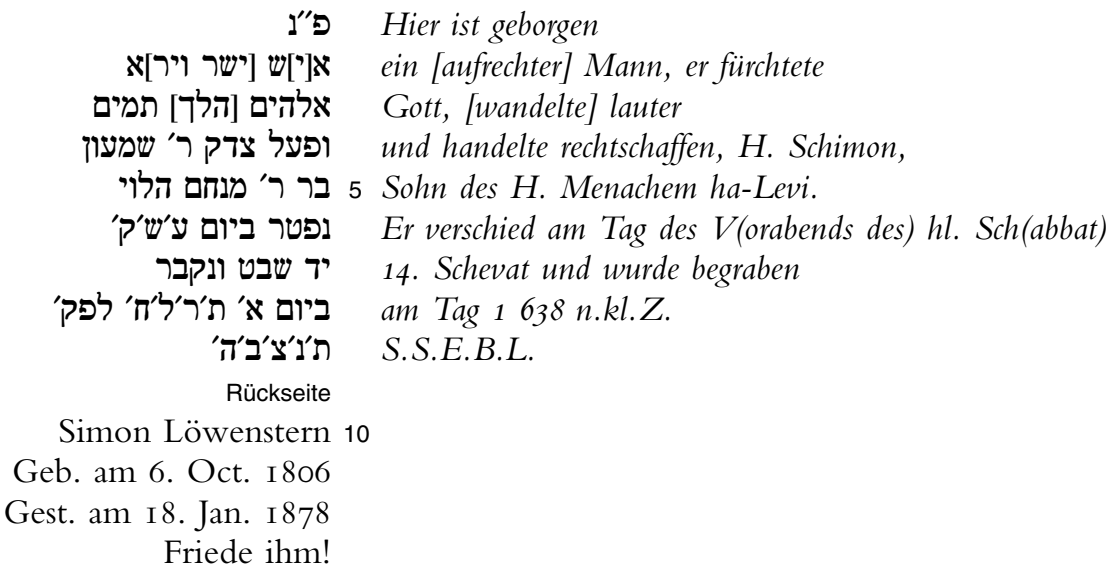

3f s. Ps I 5,2

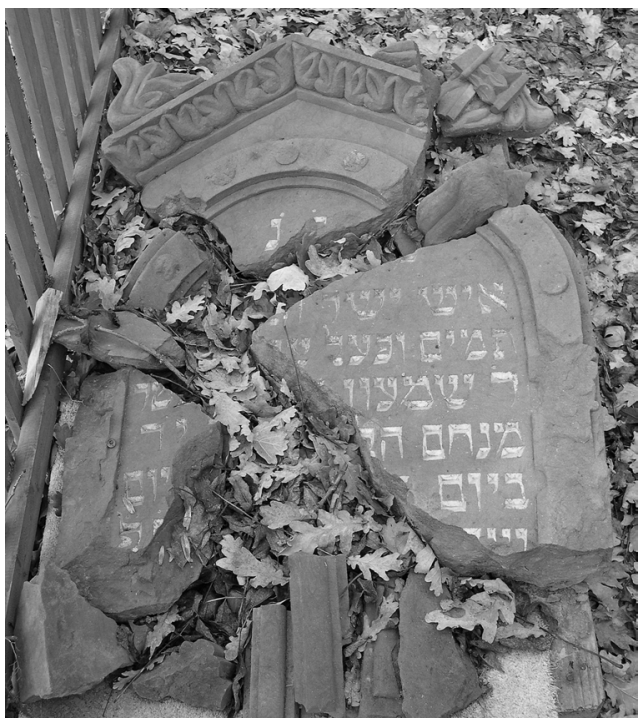

Bei den Arbeiten zur Restaurierung des Friedhofs 2004 wurden Fragmente eines Vorgängersteins gefunden, der abgesehen von der Zeilenführung eine nahezu identische Inschrift wie der vorhandene Grabstein bietet, aber eine erheblich aufwendigere künstlerische Gestaltung aufweist. Was sich dahinter genauer verbirgt, warum und wann der Ersatzstein aufgestellt wurde, läßt sich nicht mehr klären. Ein Zusammenhang mit der I929 erfolgten Schändung des Friedhofs kann angesichts des darüber vorhandenen Berichts (s. S. 33) ausgeschlossen werden 


\section{Paul Gräfenberg}

I I.IO.I 873 - I2.6.I 878

Eltern: Salomon Gräfenberg (I834-I9I8, Göttingen Grab 333) - Minna Eichenberg (I845-I9Io, Göttingen: Grab 333)

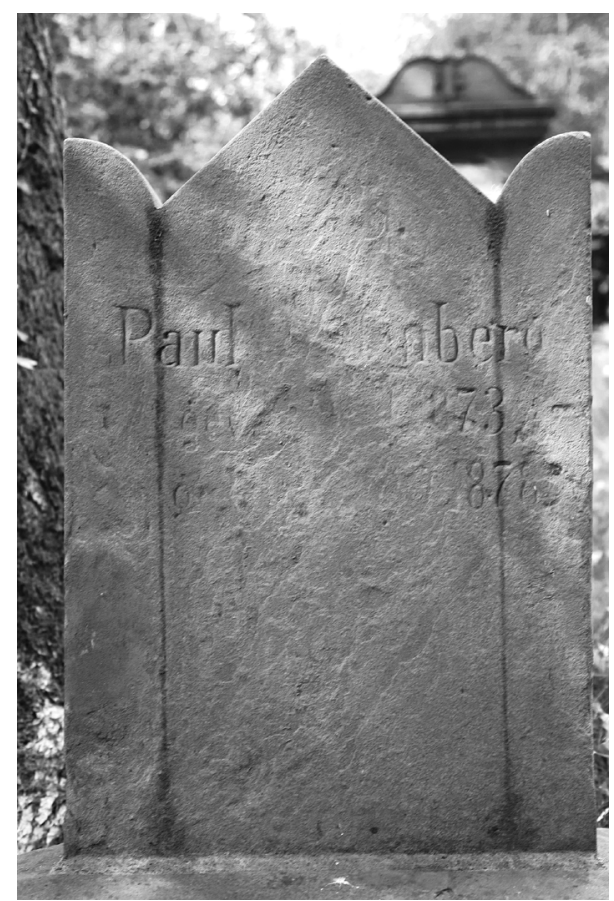

$\mathrm{H} 66 \cdot \mathrm{B} 43 \cdot \mathrm{T} \mathrm{I} 3$

Inschrift überwiegend abgeblättert

Paul [Gräfe]nberg

geb. [I I.IO.] I 873

gest. [I2.6.] I 878

2 Datierung ergänzt nach GbL · 3 Datierung ergänzt nach StbL/SHR 


\section{David Isaak Müller}

$$
\text { 4.4.1785 - I9.2.1 } 879
$$

Eltern: Isaak Müller - Betty · Geschwister: Simon II 39; Gitel III 76; Aron III 23; Abraham (I784-I834) · Ehefrau: Johanna Rothschild III 88 - Kinder: s. ebd.

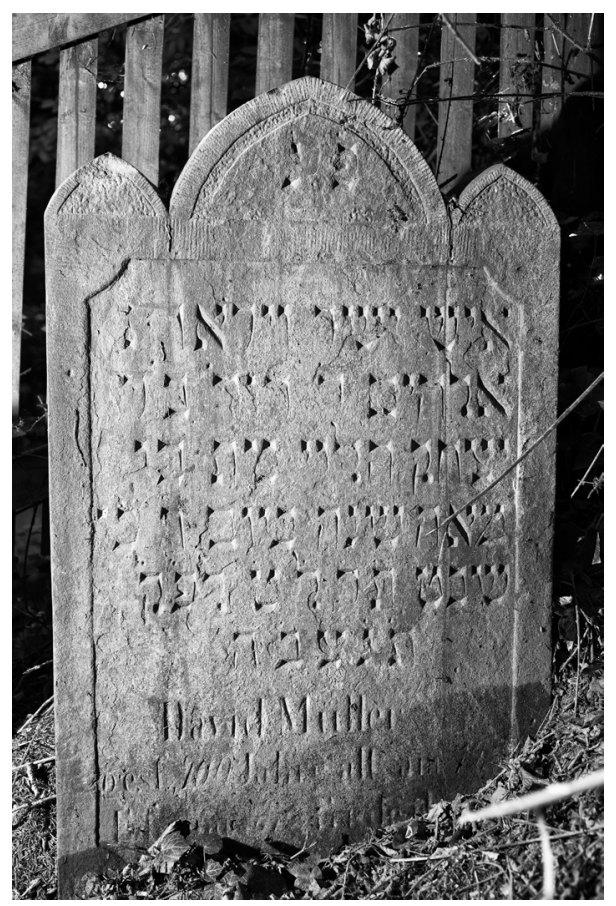

$\mathrm{H} \mathrm{IO}_{2} \cdot \mathrm{B} 63 \cdot \mathrm{T}$ I

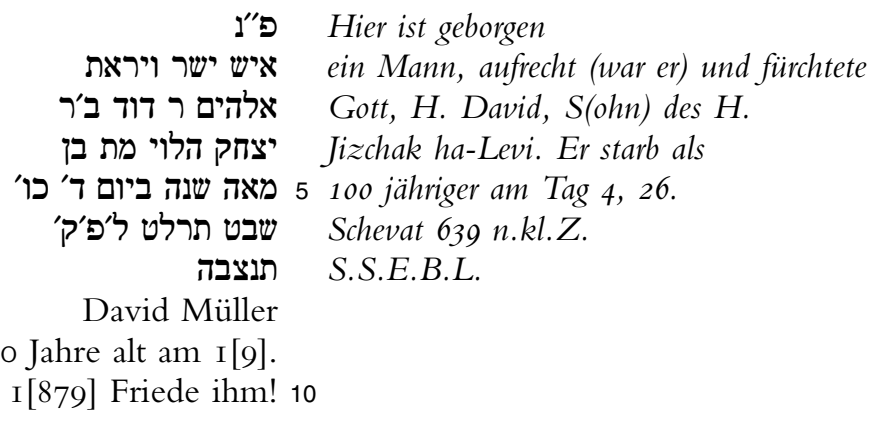

2f $\mathrm{s}$. Hi I , $8 \cdot \mathbf{5 . 9}$ Die Altersangabe ist aufgerundet; in der StbL steht zutreffend (vgl. FamB) "94 J.«・Quelle: FamB (Geburtstag) 
Julie Stehberg, geb. Dahlberg

$$
\text { I.5.I } 82 \text { I - 26.5.I } 879
$$

Levi Stehberg

I2.I2.I 8 I I - 30.8.I 879

Julie · geb. in Marsberg/Westfalen · Eltern: Abraham Dahlberg - Sara Rutenburg · Levi · Kaufmann - Eltern: Lucas Levi Stehberg III 77 - Gitel, geb. Müller III $76 \cdot$ Kinder: Sara (I850-I85I); Albert IV 30; Isidor (I85I-I852); Jacob III 9I; Moritz (I855); Bernhard (I 856 ); Hermann (I 857 )
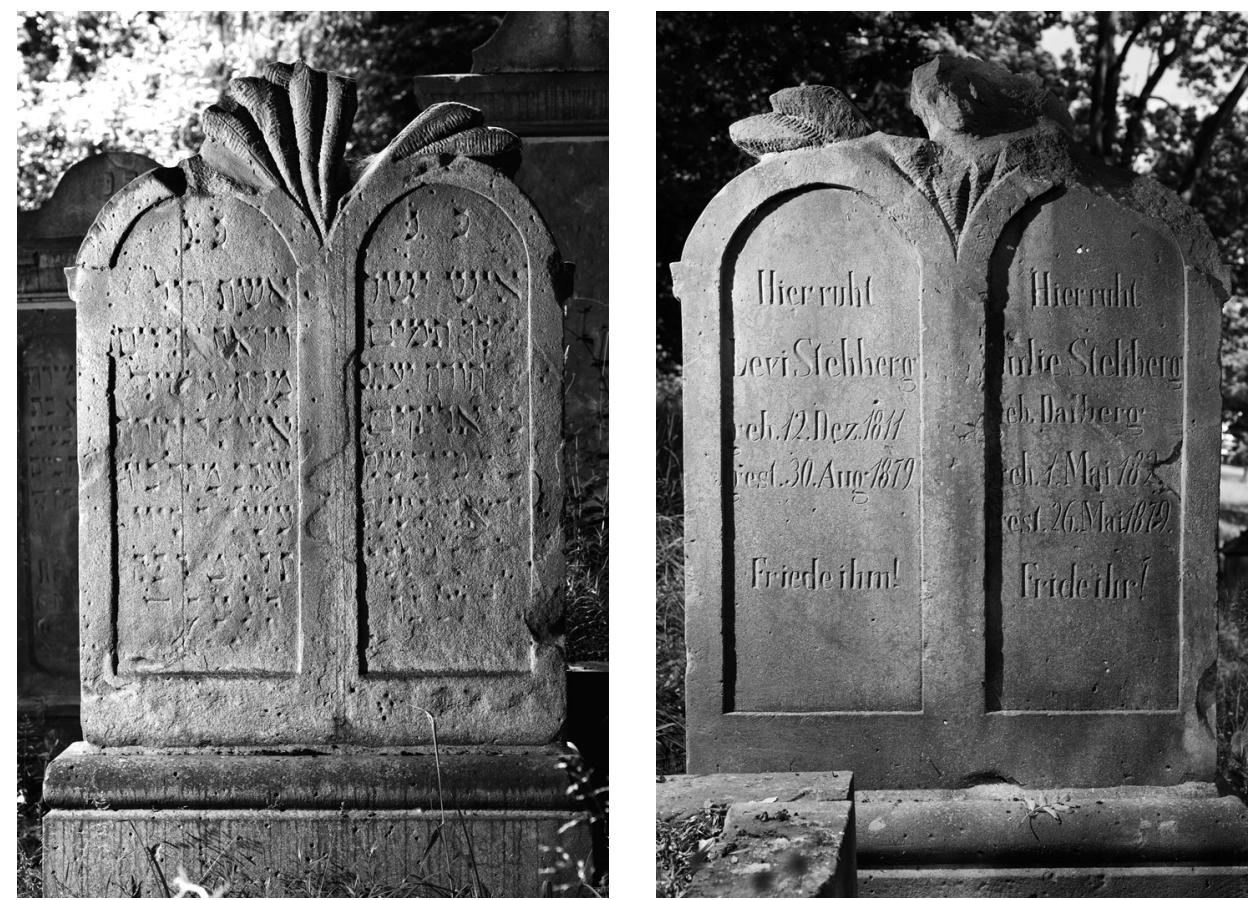

$\mathrm{H}$ IO5 $\cdot \mathrm{B} 86 \cdot \mathrm{T}$ is 


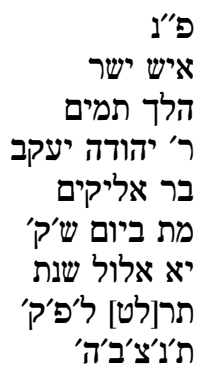

Rückseite

Hier ruht Levi Stehberg geb. I2. Dez. I8 I I gest. 30. Aug. I 879

Friede ihm!

Hier ist geborgen ein aufrechter Mann.

Er wandelte lauter, H. Jehuda Jaakov,

5 Sohn des Eljakim.

Er starb am Tag des hl. Sch(abbat), 11. Elul (im) Jahr 6[79] n.kl.Z. S.S.E.B.L.

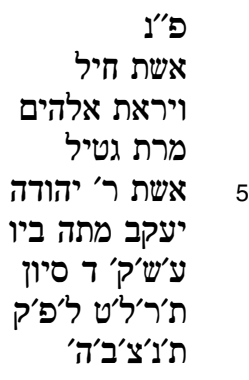

Hier ruht 10 Julie Stehberg geb. Dalberg geb. I. Mai I 82 I gest. 26. Mai I 879

Fride (sic!) ihr!

2 (RS) s. Prov 3 I, Io 3 (RS) s. Prov 3 I,30 3 (LS) s. Ps I 5,2 · 12 (LS) FamB: 6.I.I 8 I 2 - 13 (RS) FamB: 24.4.I82I

Hier ist geborgen eine Ehefrau, tüchtig und gottesfürchtig, Frau Gitel, Ehefrau des H. Jehuda Jaakov. Sie starb am $\mathrm{Ta}(g)$ des V(orabends des) hl. Sch(abbat), 4. Siwan 679 n.kl.Z. I.S.E.B.L. 


$$
\begin{gathered}
\text { Agnes Speyer } \\
\text { 5.I2.I } 880-29.5 .188 \mathrm{I}
\end{gathered}
$$

Selka Speyer

$$
\text { 4.6.I } 877-3 \text { I.IO.I } 880
$$

Eltern: Aron Speyer IV 33 - Therese Heilbrunn III 38

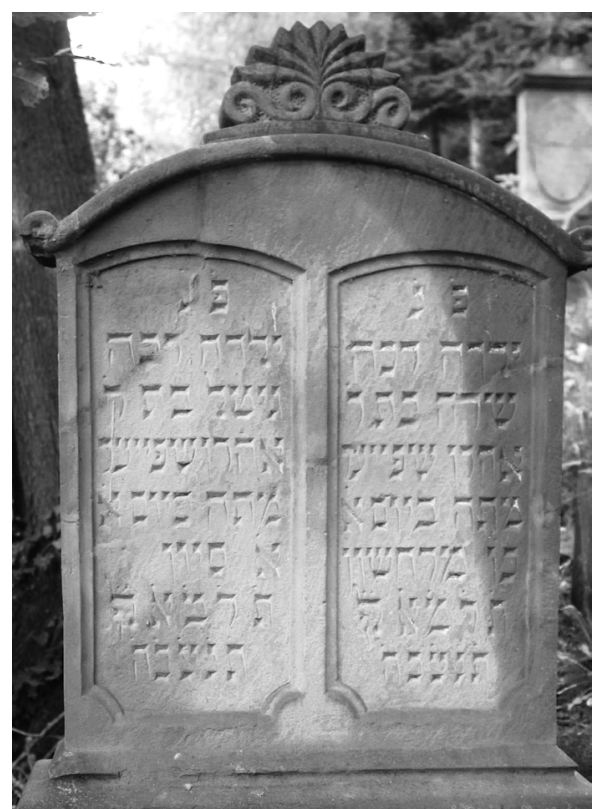

$\mathrm{H} \mathrm{I}_{42} \cdot \mathrm{B}_{7 \mathrm{I}} \cdot \mathrm{T}$ I2

\section{Rückseite}

Agnes Speyer Selka Speyer

Geb. 5. Dez. I88o. Geb. d. 4. Juni I 877.

Gest. 29. Mai I88I. Gest. d. 31. Oct. I880.
Hier ist geborgen

ein zartes Mädchen

Sara, Tochter des $H$.

Aharon Speyer.

5 Sie starb am Tag 1,

26. Marcheschwan

641 n.kl.Z.

I.S.E.B.L.
פ"ג ילדה רכה פ"ני

שרה בת ר' רכור

אהרן שפייער בת ריע

מתה ביום א' מרופר

כ'ו' מרחשון

ת'ר'מ'א' מרח' לפק'

ת'נ'צ'ב'ה'

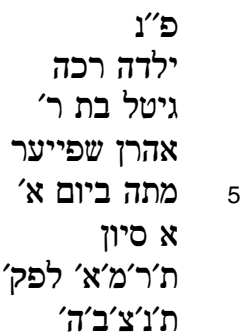

Hier ist geborgen

ein zartes Mädchen

Gitel, Tochter des H.

Aharon Speyer.

Sie starb am Tag 1,

1. Siwan

641 n.kl.Z.

I.S.E.B.L. 


\section{Simon Oppenheim}

I 2.I I.I 825 - I 7.2.I 882

Handelsmann (Productenhändler) · Eltern: Samuel Simon Oppenheim[er] III I2 - Jeanette Plaut III I3 - Ehefrau: Esther Dannenberg III 20 - Kinder: s. ebd.

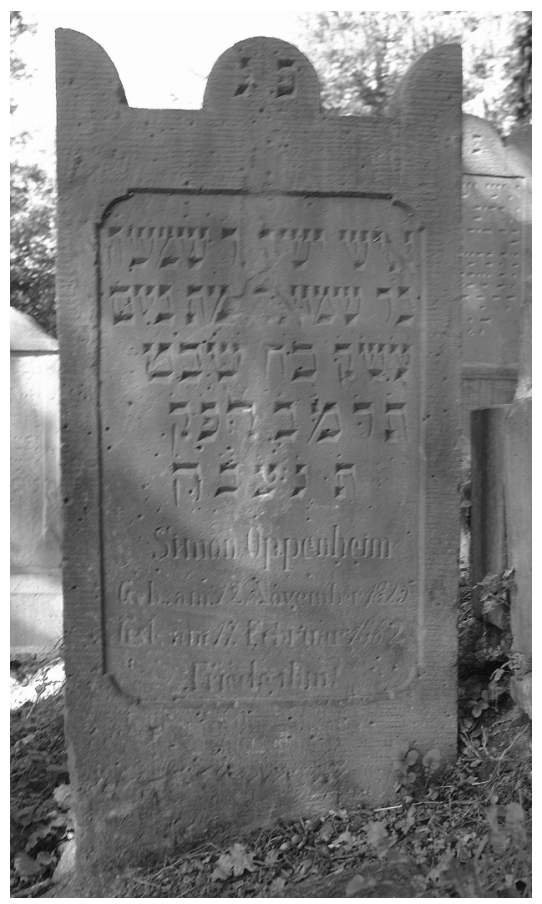

H I 2 I $\cdot$ B 64

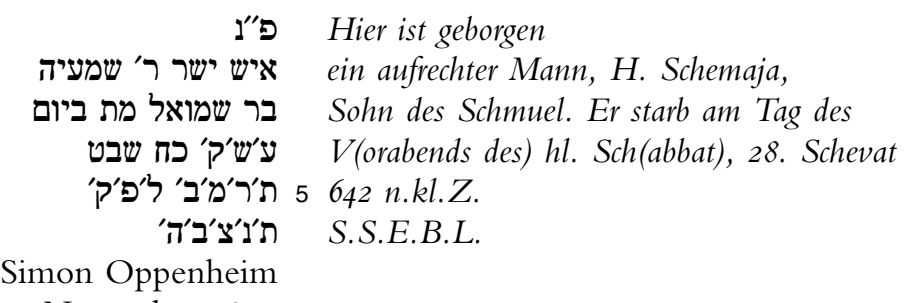

Geb. am I2. November I 825

Gst. am I7. Februar I 882

Friede ihm! 10 
Friederike Löwenthal, geb. Edelstein

$$
\text { I9.3.I } 802-9 \cdot 3 \cdot 1882
$$

Eltern: Abraham Edelstein II 22 - Edel Friedheim II 25 - Ehemann: Salomon Löwenthal III 99 - Kinder: Line (I829); Susanne/Sophie (I83 I); Adolph (I833); Rahel (I835); Levi (I 838); Moses (I 840); Hannchen (I 843)

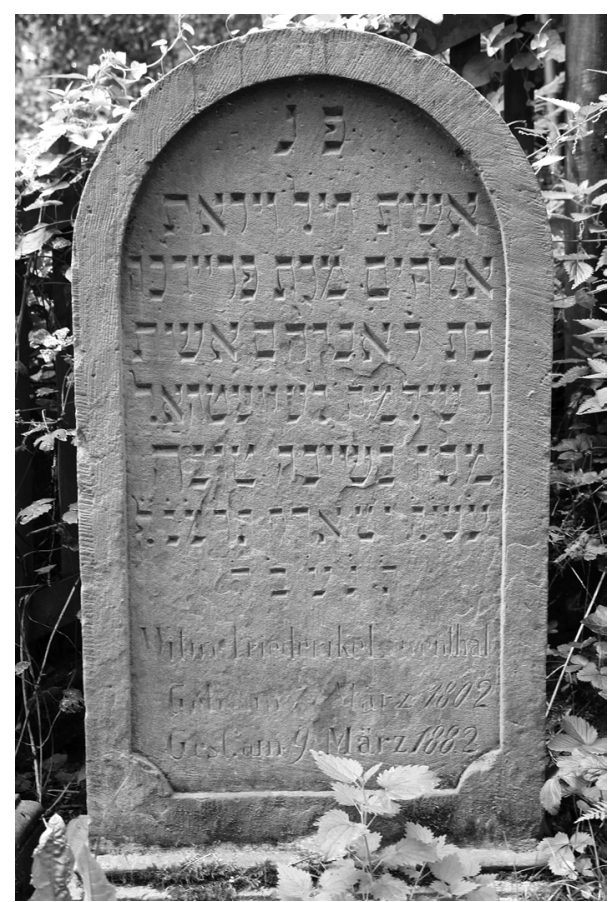

$\mathrm{H} \mathrm{II}_{4} \cdot \mathrm{B} 66 \cdot \mathrm{T} \mathrm{I} 3$

פ Hier ist geborgen

eine Ehefrau, tüchtig (war sie) und fürchtete

Gott, Frau Freidche,

Tochter des H. Avraham, Ehefrau des

5 H. Schlomo Löwenthal.

Sie starb in gutem Alter

am V(orabend des) hl. Sch(abbat), 19. Adar 642 n.kl.Z.

ת'ת'צ'S.E.L.L.

Witwe Friederike Löwenthal

Geb. am [I9.] März I802 10

Gest. am 9. März I 882

2 s. Prov 3 I,IO.30 - 10 Ergänzung der Datierung nach FamB: I9.3. 
Bertha Dannenberg, geb. Buchthal

$$
\text { I 4.8.I } 836-8 . \mathrm{I} 2 . \mathrm{I} 882
$$

Geb. in Hohen-Wepel bei Warburg, Westfalen - Eltern: Pinchas/Berthold Buchthal Rebekka Rothstein · Ehemann: Meyer Dannenberg III $7 \cdot$ Kinder: Bernhard (I 862-I930, Göttingen - begr. Seesen); Rosa III I I; Rebekka (I865-I935, Göttingen: Grab 387); Moritz (I866); Albert (I868-I920, Duisburg); Meta (I870-I950, Buenos Aires); Emil (I872-I940, London); Selly (I874-I943, Theresienstadt); Julius (I877-I933, Wuppertal)

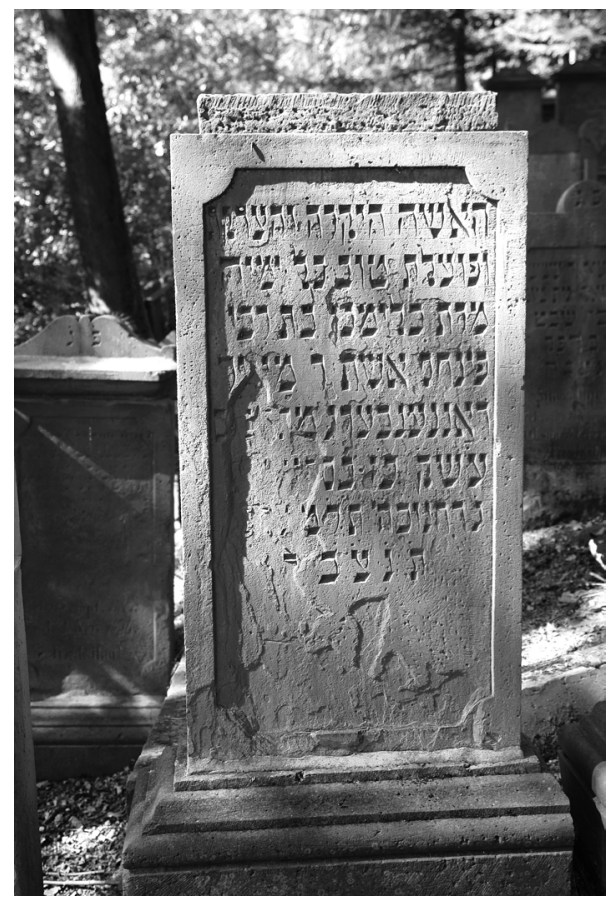

Rückseite

Bertha Dannenberg geb. Buchthal

Geb. am I4. August I 836

Gest. am 8. December I 882

Friede ihr!

H IOI $\cdot \mathrm{B} 64 \cdot \mathrm{T}$ I5

[פ] [Hier ist geborgen]

האשה היקרה והצדקה die geachtete und wohltätige Frau,

sie tat Gutes all ihre Tage,

Frau Blimchen, Tochter des Herrn

5 Pinchas, Ehefrau des H. Meir

דאנגנענבערג מתה [ביום כannenberg. Sie starb am (Ta)g des

V(orabends des) hl. Sch(abbat), dem 27. Kislew

3. Tag von Chanukka 643 n.kl.Z.

I.S.E.B.L. 
Esther Müller, geb. Stehberg I8.I.I 8 I 5 - II.I $2 . I 883$

Eltern: Lucas Stehberg III 77 - Gitel Müller III 76 - Ehemann: Herz Aron Müller III 2 I · Kinder: Isidor IV 49; Adolph (I850-I851); Louis (I853); Gustav (I854); Leopold (I858); Simon (I860)

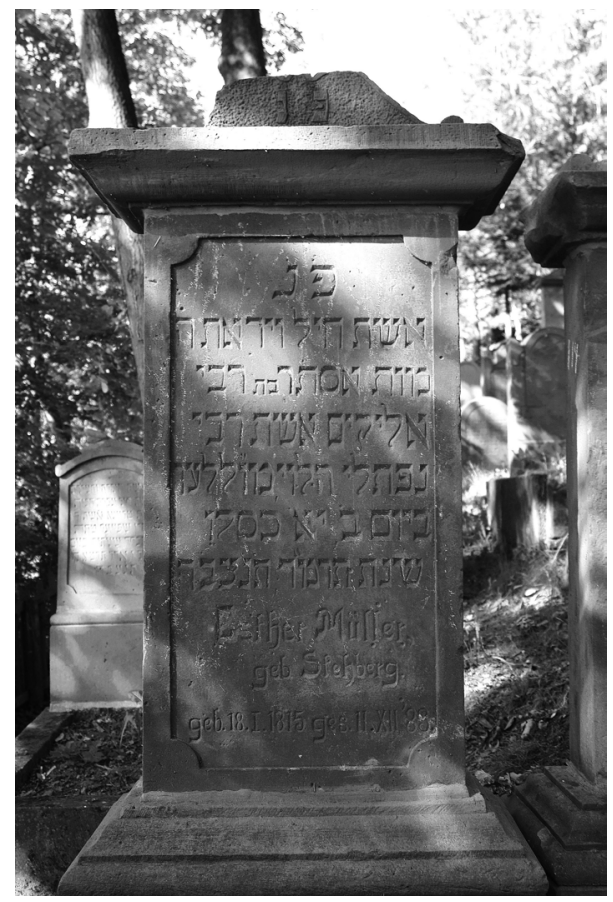

$\mathrm{H} \mathrm{IO} 4 \cdot \mathrm{B} 64 \cdot \mathrm{T} \mathrm{I7}$

Aufsatz mit פַ פ" gehört ursprünglich nicht zu diesem Stein

פע"נ Hier ist geborgen

אשת חיל ויראת ה'

Frau Esther, Tochter des Herrn

Eljakim, Ehefrau des Herrn

5 Naphtali ha-Levi Müller.

[Verstorben] am Tag 2, 11. Kislew

(im) Jahr 644 I.S.E.B.L.

Esther Müller

geb. Stehberg

geb. I8. I. I 8 I 5 gest. I I. XII. ' 8310

2 s. Prov $3 \mathrm{I}, \mathrm{IO} .3 \mathrm{O} \cdot \mathbf{5}$ Umlautzeichen über dem $\mathrm{l}=$ ü. $\cdot \mathbf{1 0}$ Geburtsdatum im FamB: 4.2.I8I6; StB: 22.I.I8I6; Sterbedatum im StB: IO.I2.I883 
Johanne Löwenstern, geb. Dahl

$$
\text { 2.2. oder IO.6.I } 8 \text { I } 2 \text { - I4.2.I } 884
$$

Geb. in Karlshafen - Eltern: Heinemann Dahl - Rike Hellenstein - Ehemann: Jacob Marcus Löwenstern III 9 - Kinder: Heinemann (I834-I838); Meyer (I837-I840); Betti (I839-I9I7); Julchen (I840-I842); Betti; Marcus III 25

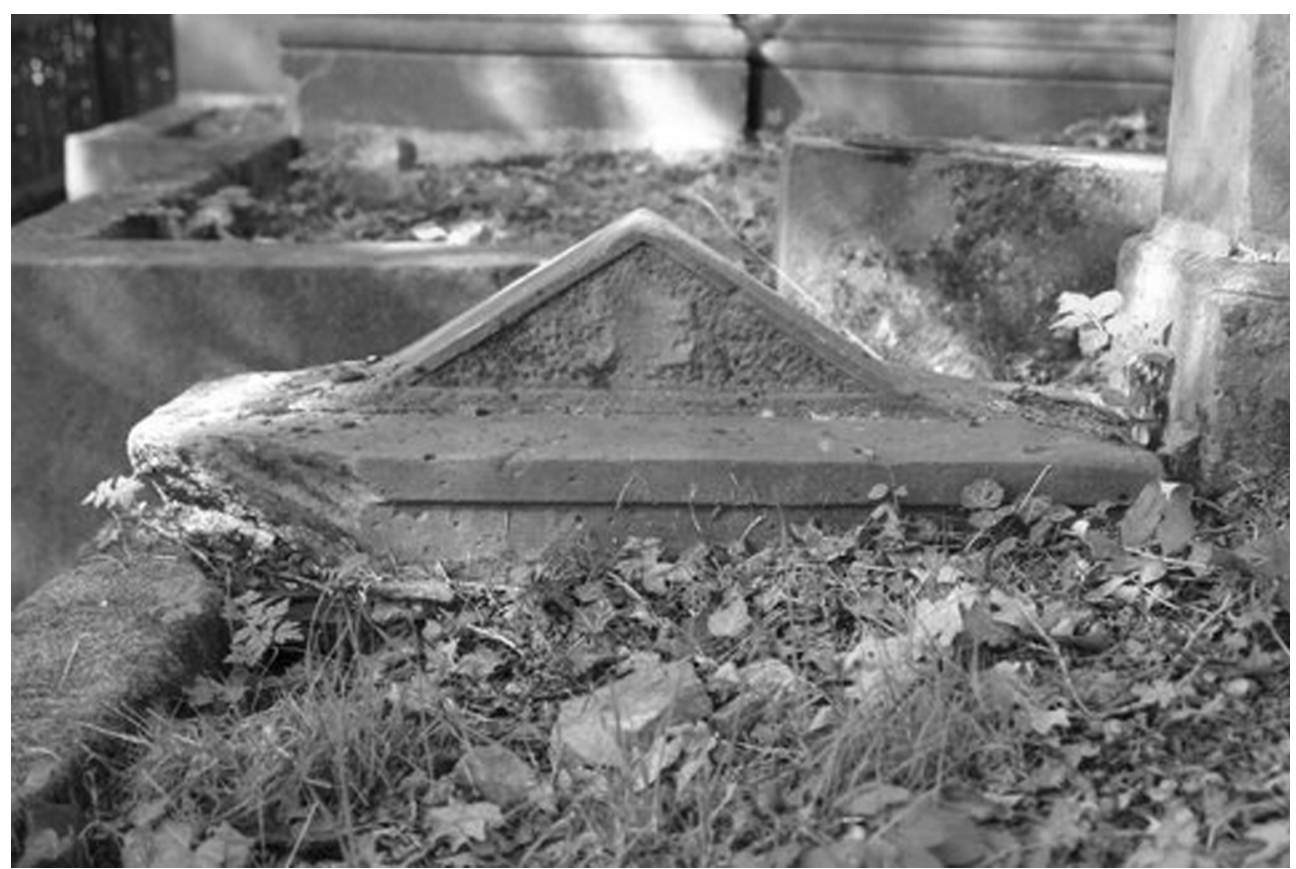

$\mathrm{H} \mathrm{I} 45 \cdot \mathrm{B} 66 \cdot \mathrm{T}$ i 5

Vom Grabstein ist nur noch der Giebel vorhanden. Die mit Grab III 9 gemeinsame Steinumfassung erweist die Anlage als Doppelgrab und ermöglicht die Identifizierung der Bestatteten als Ehepaar. Datierung nach FamB bzw. Stb 
Rosa Dannenberg

4.4. I 863 - 20.9. I 884

Eltern: Meyer Dannenberg III 8 - Bertha Buchthal III 7

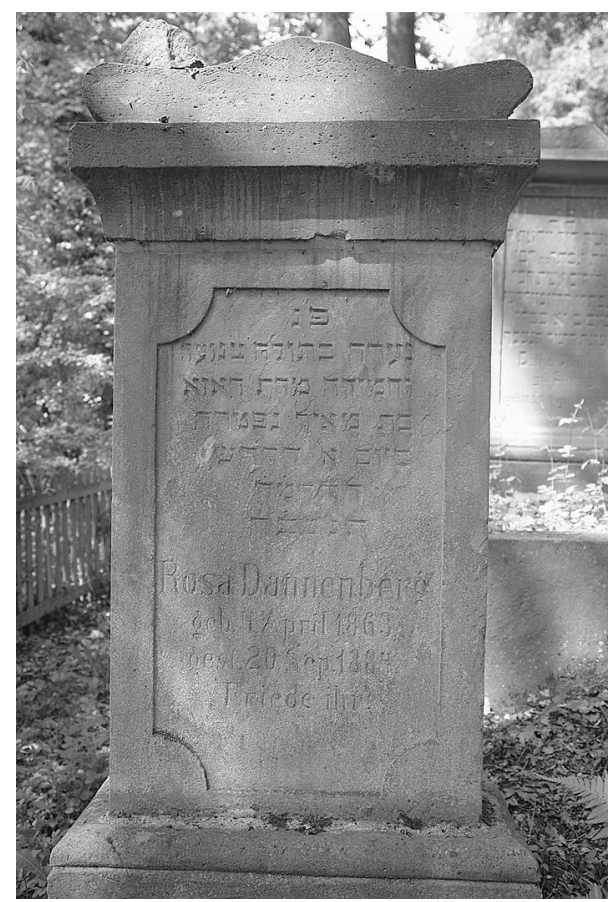

$\mathrm{H}$ I $52 \cdot \mathrm{B} 72 \cdot \mathrm{T} 26$

פ"ג Hier ist geborgen

eine unverheiratete junge Frau, bescheiden

und lieblich (war sie), Frau Rosa,

Tochter des Meir. Sie verschied

5 am 1. Tag von R(osch) ha-Sch(anah)

5645

I.S.E.B.L.

Rosa Dannenberg

geb. 4. April I 863

gest. 20. Sept. I 88410

Friede ihr! 
Therese Speyer, geb. Heilbrunn

$$
\text { IO.I.I } 849-2 \text { I.2.I } 885
$$

Geb. Immenrode bei Sondershausen/Thüringen - Eltern: Mendel Heilbrunn - Minna Stern - Ehemann: Aron Speyer IV 33 - Kinder: Selka III 37; Louis IV 25; Agnes III 37; Paula, verh. Dannenberg (I882-I942, Treblinka); Heinz IV 3

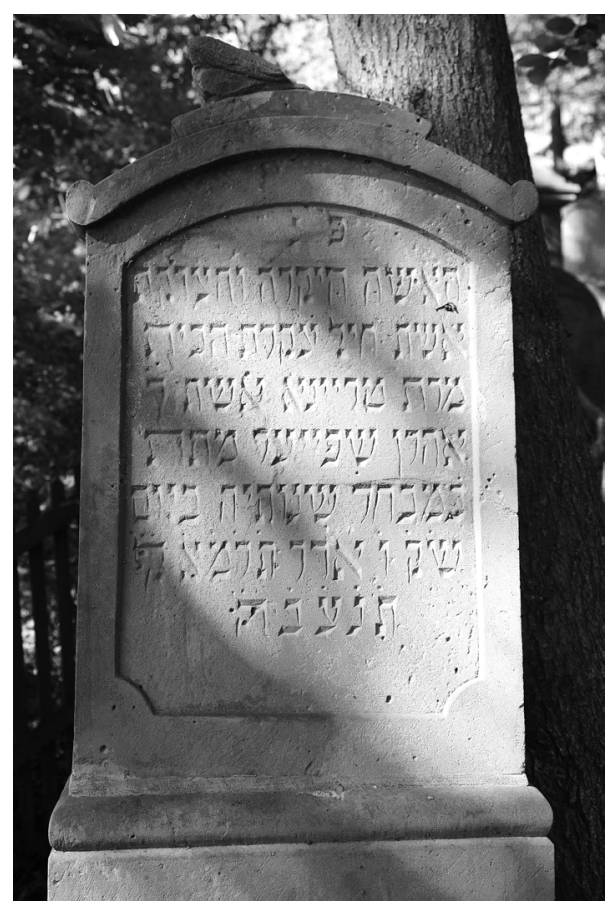

Rückseite

Hier ruhet

Therese Speyer

geb. Heilbrunn

Geb. am Io. Jan. I 849 .

Gest. am 2I. Feb. I 885 .

Friede ihr!

$\mathrm{H} 73 \cdot \mathrm{B} 57 \cdot \mathrm{T} \mathrm{I} 4$

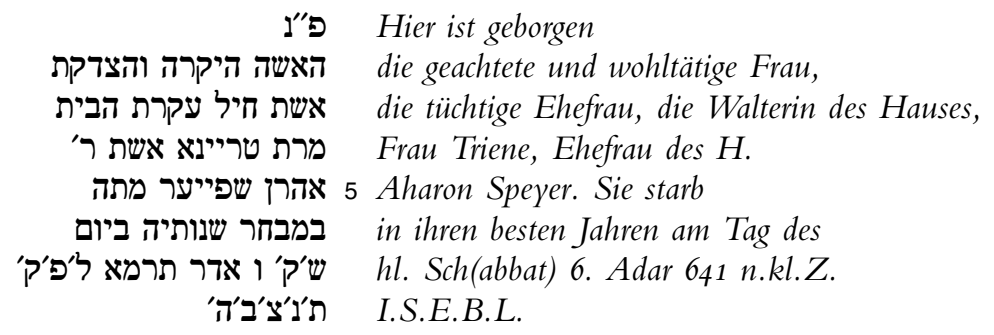

7 Die hebräische Inschrift datiert das Sterbejahr auf (5)64I = I88 I, die deutsche auf I885; so auch $\mathrm{StB}$ 
Esther Oppenheim, geb. Dannenberg

$$
\text { 8.I.I } 84 \text { I - I8.7.I } 885
$$

Eltern: Calman Selig Dannenberg III 65 - Clara Meyenberg III 66 - Ehemann: Simon Oppenheim III I9 · Kinder: Selly III 59; Carl III 59; Max (I874); Siegfried (I875); Moritz (I877-I942, Piaski [s.S. 3 Io $\left.43^{\star}\right]$ )

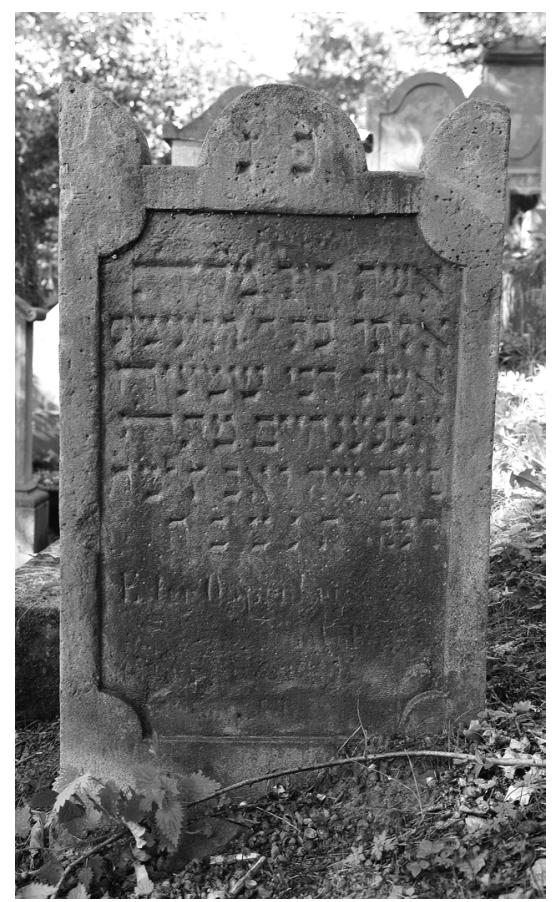

H $107 \cdot \mathrm{B} 63 \cdot \mathrm{T}$ го

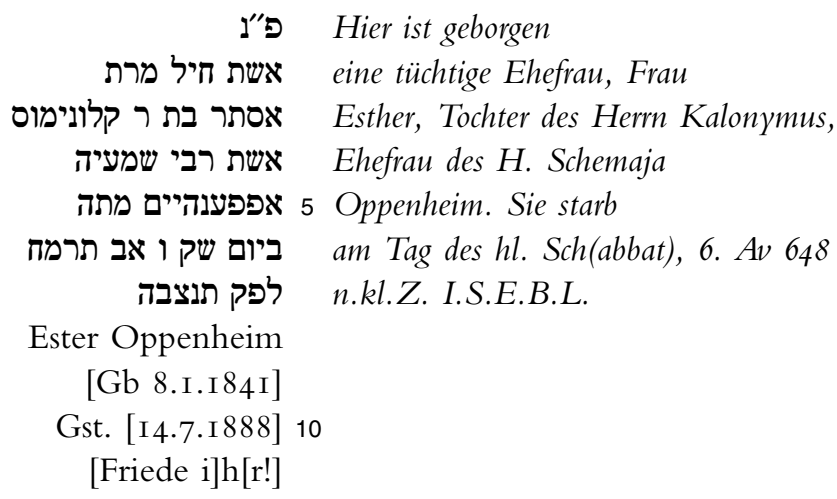

2 s. Prov 3 I, Io · 9 Datum ergänzt nach FamB; anders SHR: Io. I. I840) - 10 Datum ergänzt nach hebr. Inschrift (= SHR) 


\section{Wolf Meyenberg}

5.7.I 824 - I7.IO.I 885

Eltern: Simon Meyenberg III 6I - Minna Hirsch III 62

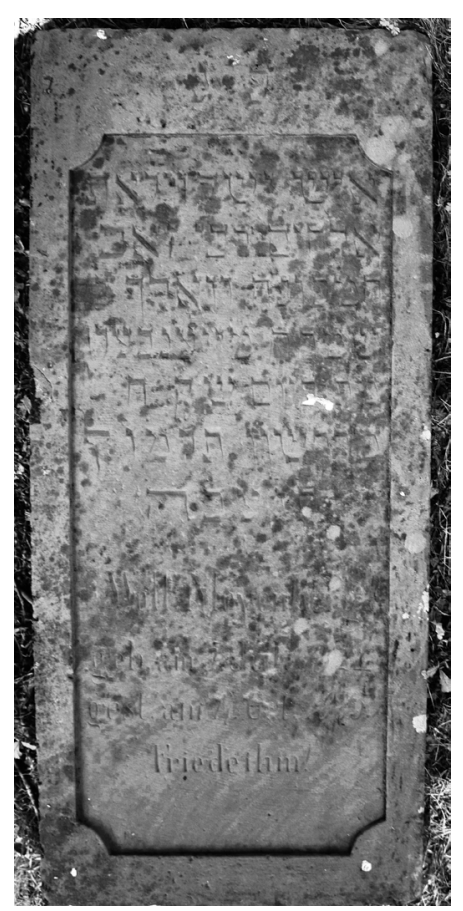

H I65 $\cdot$ B $72 \cdot$ T I 8

Inschrift durch Flechten verkrustet

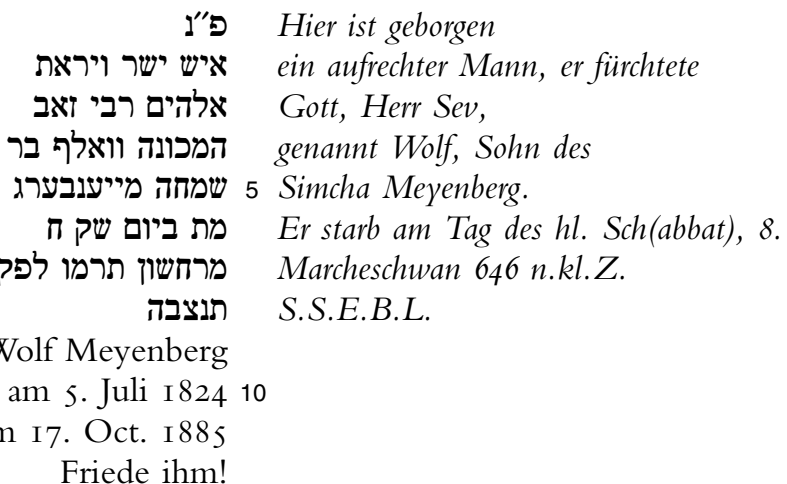


Herz Stehberg

25.I2.I 8 I 3 - I8.9.I 886

Kaufmann (Manufakturwaren) · I 863-I868 Vorsteher der Synagogengemeinde - Eltern: Lucas Stehberg III 77 - Gitel Müller III 76 • Ehefrau: Betti Dannenberg IV I5 · Kinder: s. ebd.
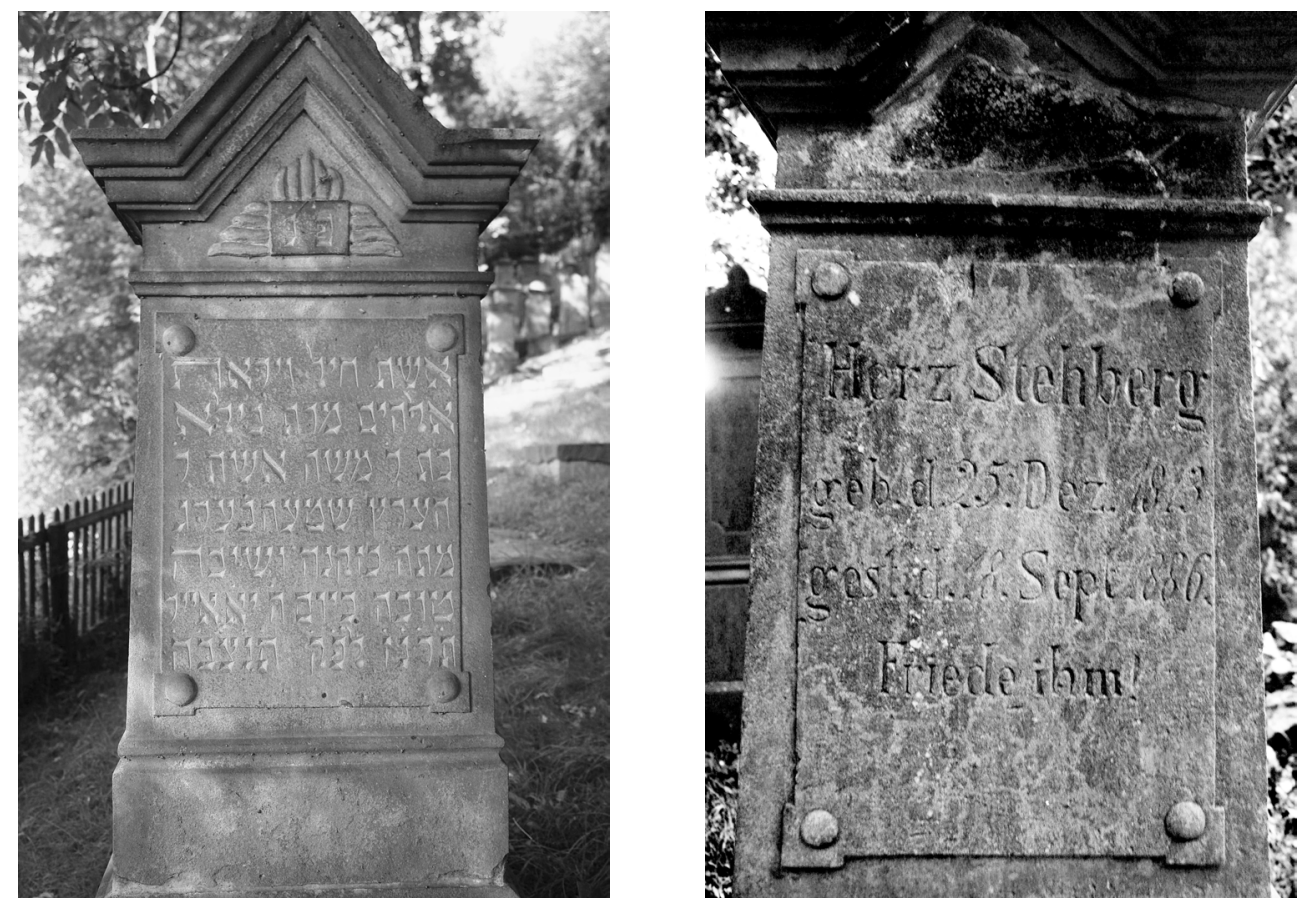

$\mathrm{H} \mathrm{I00} \cdot \mathrm{B} 60 \cdot \mathrm{T} 26$

פ"ג Her ist geborgen

איש ישר וירא אלהים ein aufrechter und gottesfürchtiger Mann,

und rechtschaffen handelnd alle seine Tage,

H. Naphtali, Sohn des Eljakim.

Er starb in gutem Alter

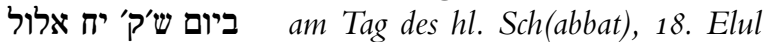

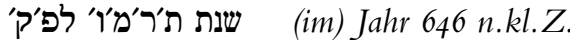

S.S.E.B.L.

Rückseite

Herz Stehberg

geb. d. 25. Dez. I 8 I 310

gest. d. I 8 . Sept. I 886

Friede ihm!

2 s. Hi I,8 3 s. Ps I 5,2 - 10 FamB: I2.I.I8I4 / StB: I4.I.I8I4 
Henriette Eisig, geb. Backstein

$$
\text { I.I.I } 806-8.2 .1888
$$

Eltern: Abraham Backstein II 27 - Gidel Rosenberg II 32 - Ehemann: Schilein Eisig III 70 - Tochter: (unehelich) Jeanette/Hannchen (I827-I898, Dransfeld: Grab 52b)

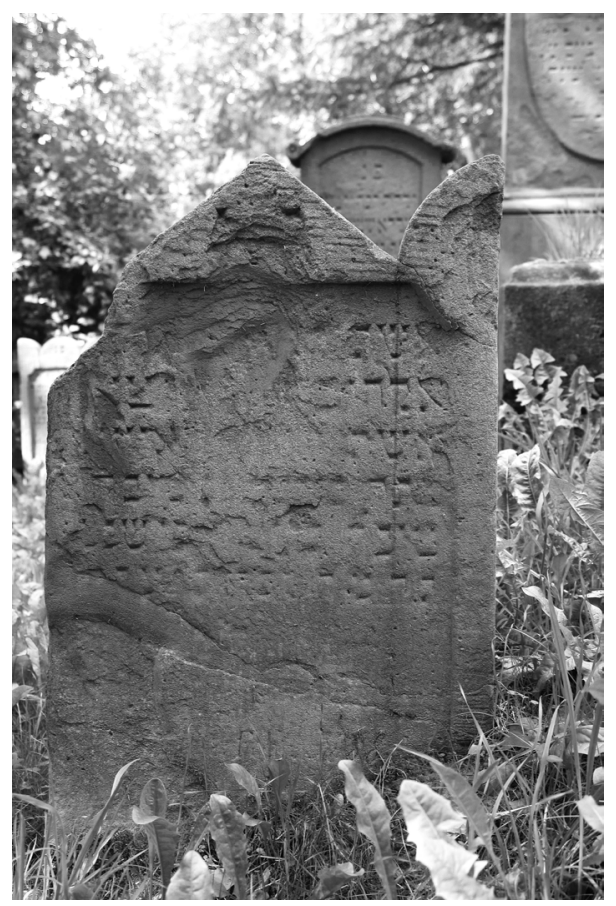

$\mathrm{H} 70 \cdot \mathrm{B} 6 \mathrm{I} \cdot \mathrm{T} \mathrm{I} 3$

Stark beschädtigter Stein, wieder aufgerichtet

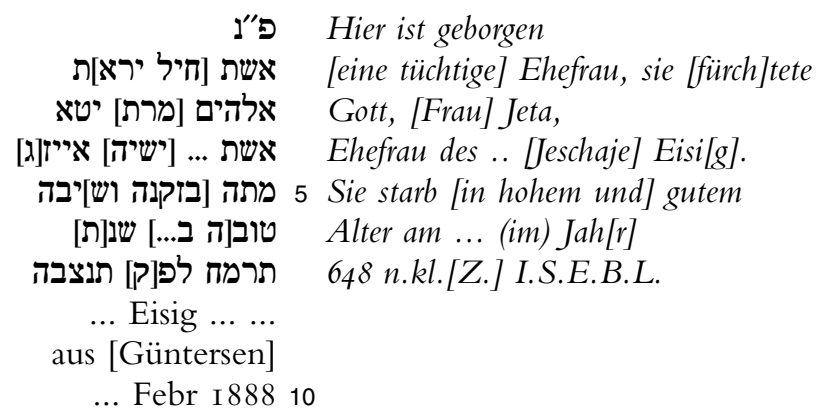

Quelle: FamB (Geburtstag), StB (Sterbetag) 


\section{Hilda Stehberg}

I5.6.I $885-$ I6.4.I 888

Eltern: Albert Stehberg IV 30 - Rosa Stehberg IV 32

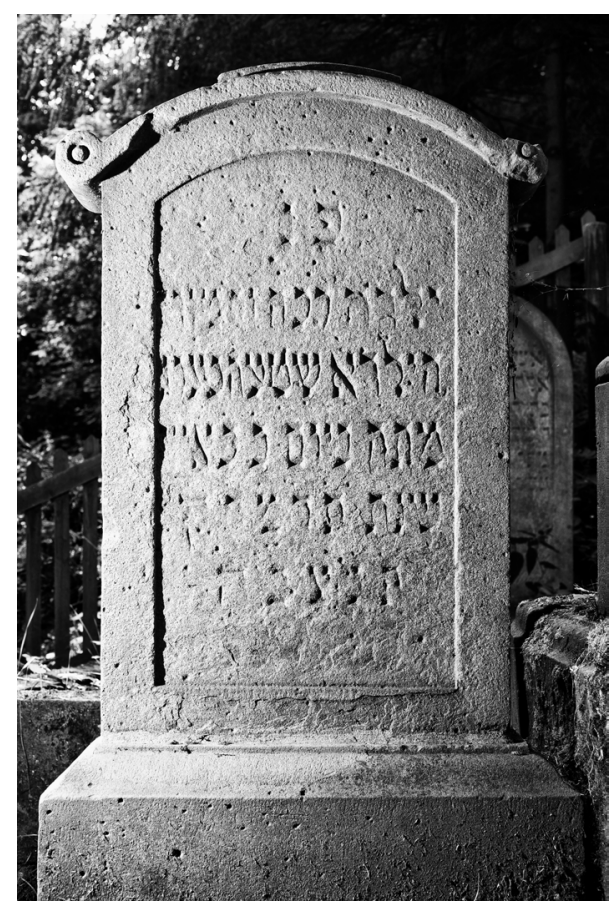

H 90/37 B 56/69 - T г3/I 8

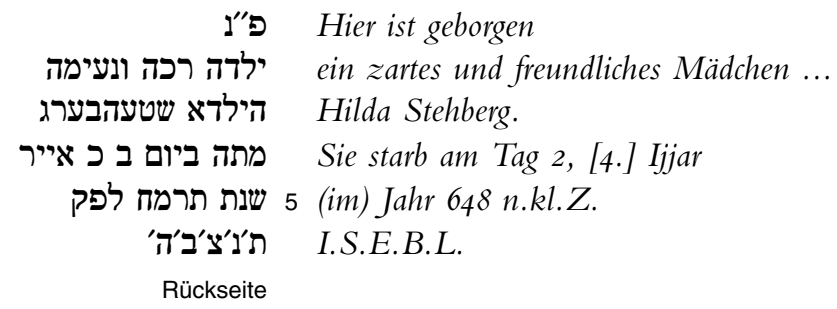

Hier ruht

Hilda Stehberg

Geb. am I5. Juni I 883

Gest. am i6. April i 88810

4 Die Datierung des Sterbetags auf den 20. Ijjar in der hebräischen Inschrift (= I. Mai I 888, Dienstag) passt weder zur Angabe in der deutschen Inschrift (I6. April i 888) noch zum Vermerk über den Wochentag (Tag $2=$ Montag). Sie beruht vermutlich auf einer Fehlschreibung: כ (20) statt 7 (4). 
Emilie Rosenbaum, geb. Stern

$$
\text { 8.I I.I } 8 \text { I } 2-28 \text {.I } 2 . \mathrm{I} 888
$$

Geb. in Förste bei Osterode a.H. · Eltern: Levi Stern - Dorette - Ehemann: Moses Rosenbaum III I6 - Kinder: Rosette III 24, Louis (I850-I9I5, Berlin), Dora III 86

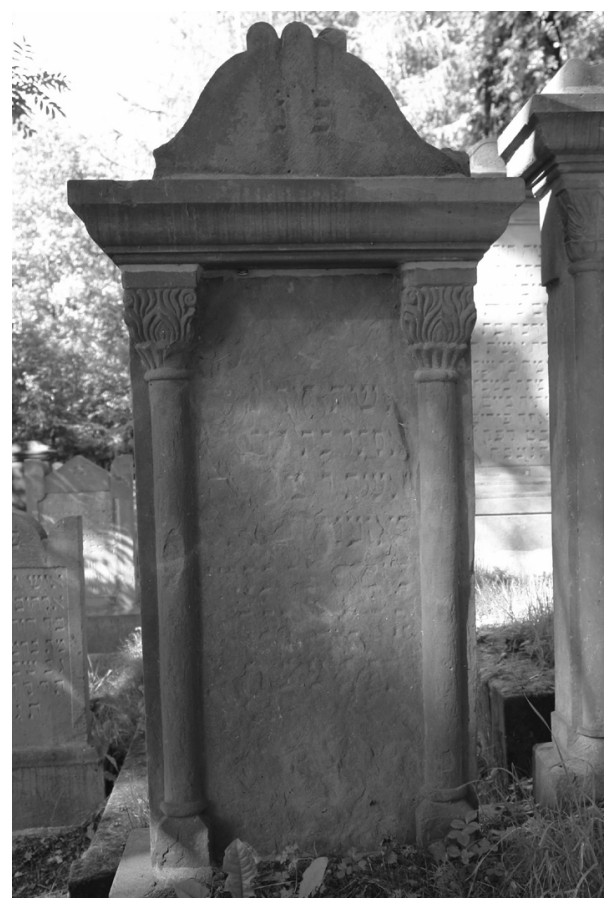

$\mathrm{H} \mathrm{I} 70 \cdot \mathrm{B} 70 \cdot \mathrm{T} \mathrm{I} 3$

Inschrift seit Textaufnahme im Mitteilteil abgeblättert

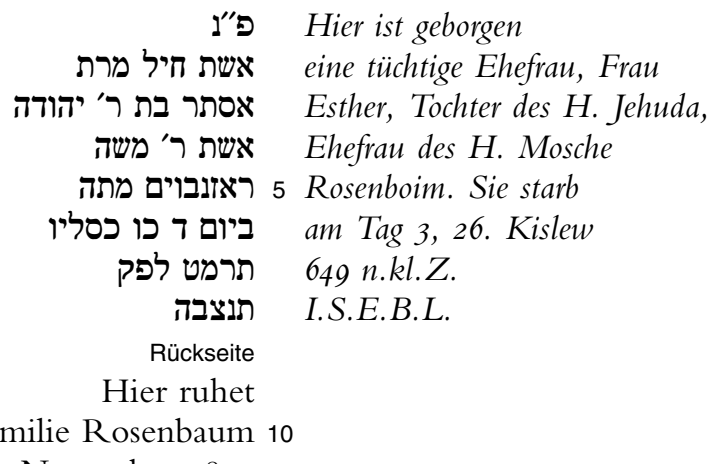

Geb. am 8. November I8I2

Gest. am 28. Dezember I 888

Friede ihr!

2 s. Prov 3I, IO 


\section{Meyer Dannenberg}

I2. I I.I 82 I - 3 I.I2.I 888

Kaufmann (Manufakturwaren) - Eltern: Moses Dannenberg III 3a - Rosette Meyenberg III 3 - Ehefrau: Bertha Buchthal III $8 \cdot$ Kinder: ebd.

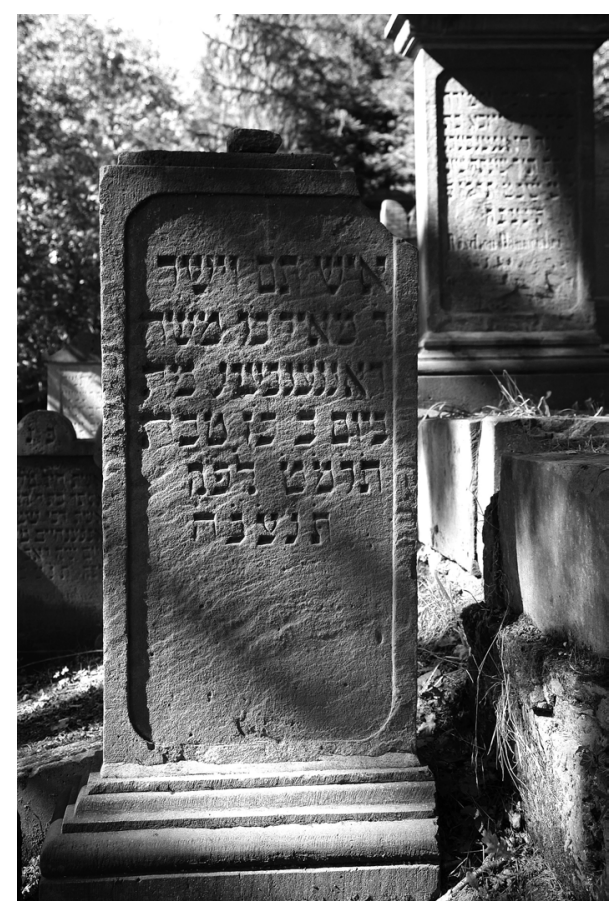

H IOI $\cdot$ B 6 I $\cdot$ T I6

פ"ג Hier ist geborgen

איש תם וישר H. Meir, Sohn des Mosche

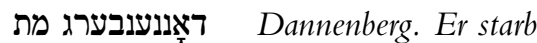

5 am Tag 2, 27. Tevet

תרמט לפק 649 n.kl.Z.

ת.S.E.B.L.

Rückseite

Hier ruhet

Meÿer Dannenberg

Geb. am I2. November I82 I 10

Gest. am 3I. Dezember I 888

Friede ihm!

1 s. Hi I,8 - Quelle: StB (Geburtsdatum, FamB: I820) 
Levi Eichenberg

I3.IO.I 82 I - 8.3.I 889

Metzger - Eltern: Simon M. Eichenberg II 35 - Edel Kopperschlag II $45 \cdot$ Ehefrau: Lina Edelstein IV I3 - Kinder: s. ebd.

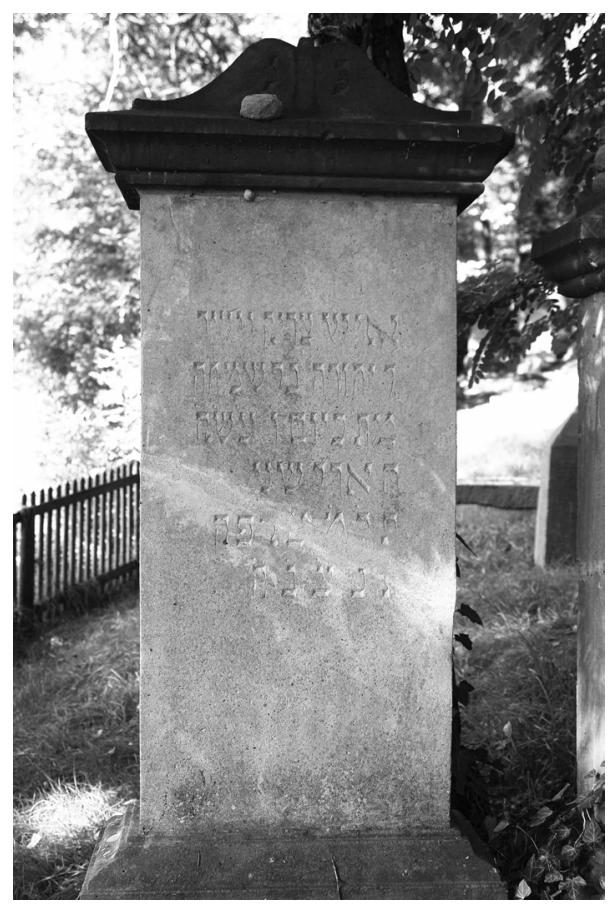

$\mathrm{H}$ I76 $\cdot$ B $57 \cdot$ T I 8

פע"נ Hier ist geborgen

איש צדיק וישר

H. Jehuda, Sohn des Simcha.

Er starb am Tag 6, dem V(orabend) des hl. Sch(abbat),

5 5. Adar II

64[9] n.kl.Z.

[S.S.]E.B.L.

Rückseite

Levi Eichenberg

geb. I3. Okt. I 82 I

gest. 8. März I889 10

5 Adar II s. zu IV 42 


\section{Bertha Dannenberg}

$$
\text { 20.4.I } 868-4 \cdot 3.1890
$$

Eltern: Jonas Dannenberg - Marianna Heilbrunn

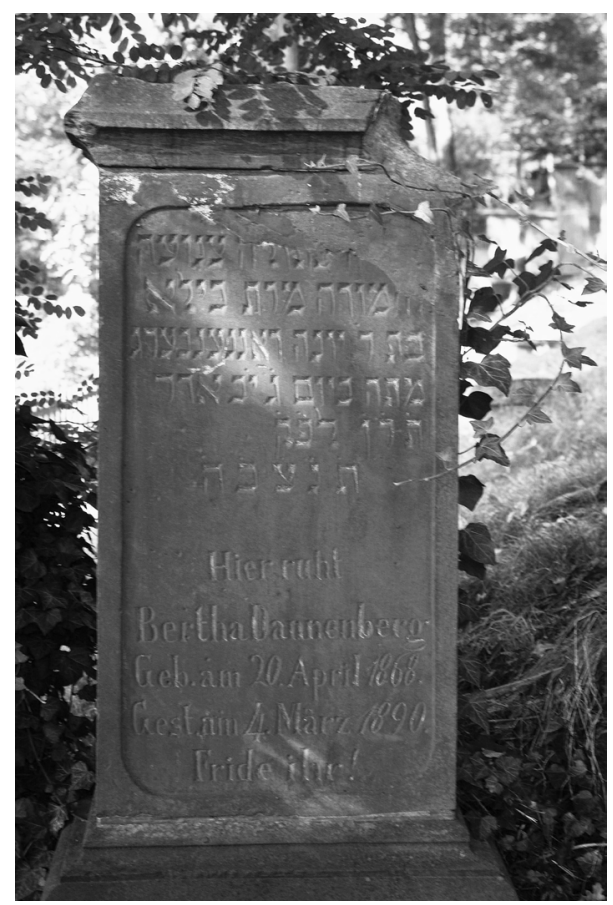

H $109 \cdot$ B $59 \cdot$ T г6

Giebelaufsatz beschädigt

[פ] [Hier ist geborgen]

eine junge unverheiratete Frau, bescheiden

und lieblich (war sie), Frau Beila,

Tochter des H. Jona Dannenberg.

5 Sie starb am Tag 3, 12. Adar 650 n.kl.Z.

I.S.E.B.L.

Hier ruht

Bertha Dannenberg

Geb. am 20. April I 86810

Gest. am 4. März I 890

Fride ihr! 
Auguste Eichenberg, geb. Freudenstein

$$
\text { I 3. I I.I } 828 \text { - 26.9. I } 890
$$

Eltern: Samuel Meyer Freudenstein III 68 - Caroline Traube III $67 \cdot$ Ehemann: Abraham Eichenberg IV Io - Kinder: Max (I856); Karoline (I857-I926, Nürnberg); Paul (I859I927, Groß Flottbek bei Hamburg), Adele/Ida (I86I); Siegmund/Selli (I862); Salomon/Carl (I864-I93I, Galveston); Otto (I867)
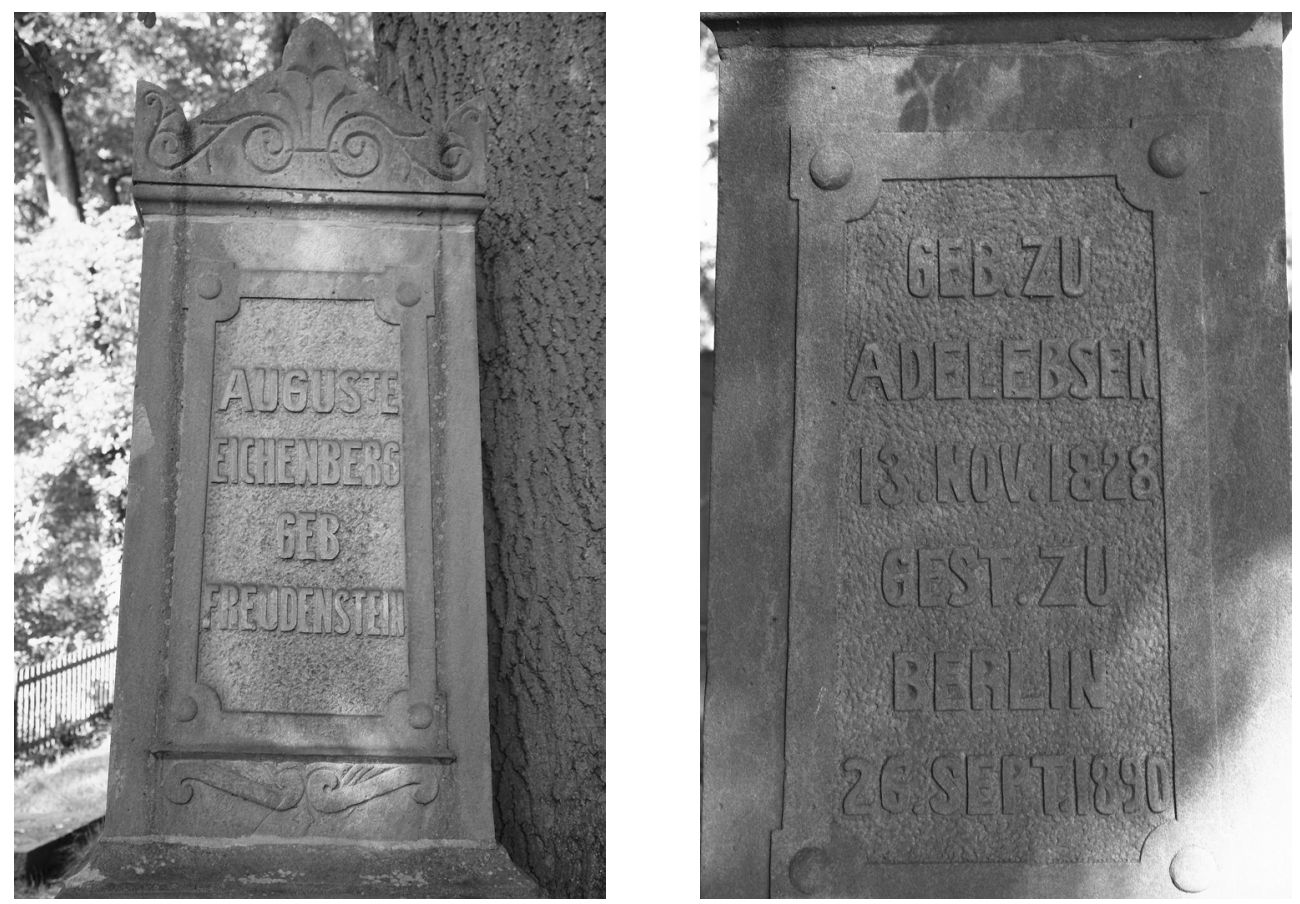

H $108 \cdot$ B 6I $\cdot$ T 25

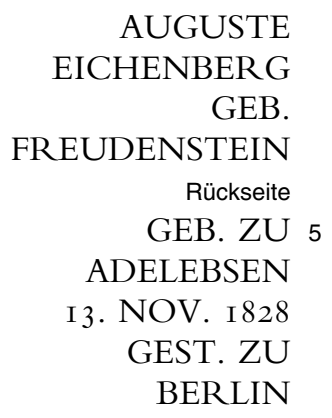

26. SEPT. I 89010 
Georg Müller

29.9. I $879-20.4$. I 89 I
Robert Müller

26. 9.I 883 - II.4.I 89 I

Eltern: Isidor Müller IV 49 - Goldine Eichenberg IV 48

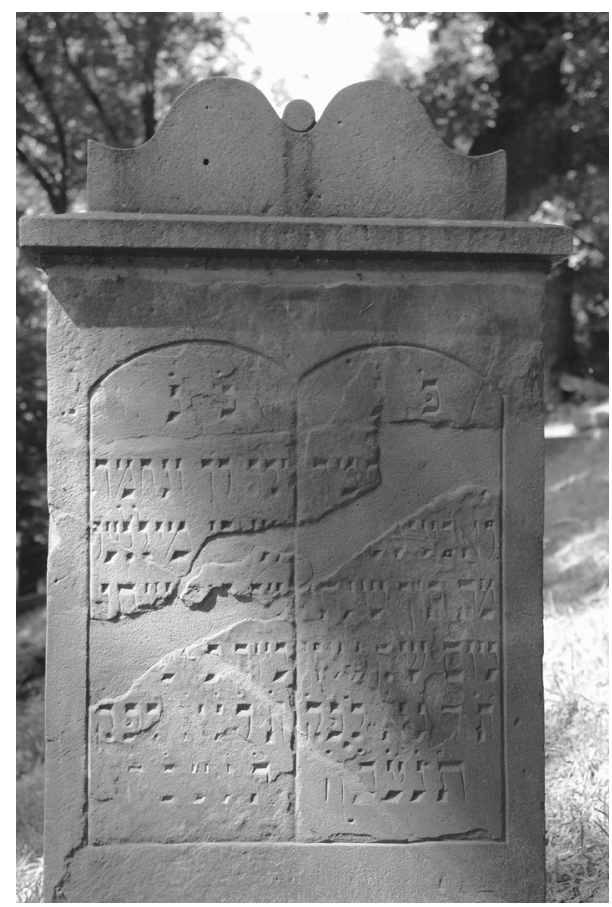

$\mathrm{H} 90 \cdot \mathrm{B} 70 \cdot \mathrm{T}$ I6

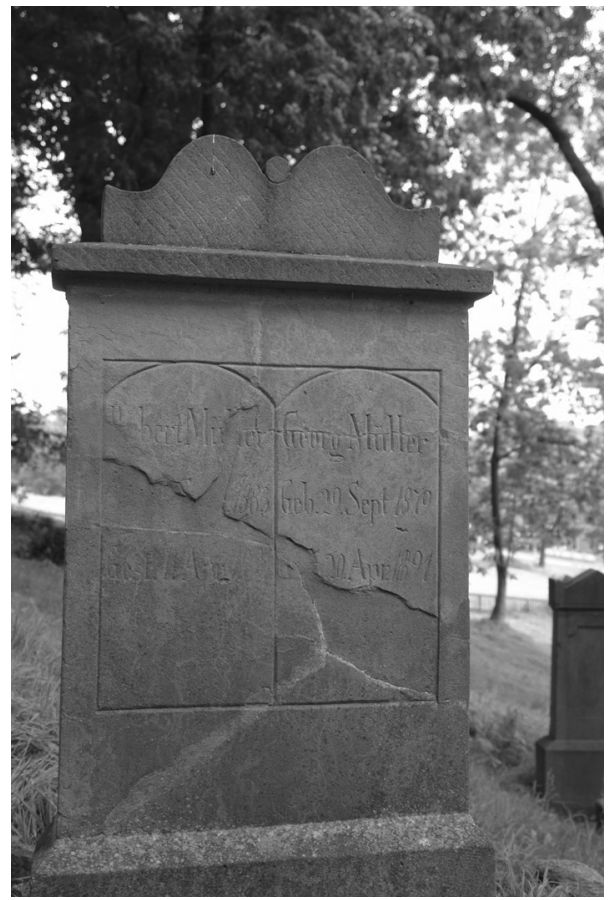

Stark beschädigter Stein, wieder zusammengesetzt und aufgerichtet 


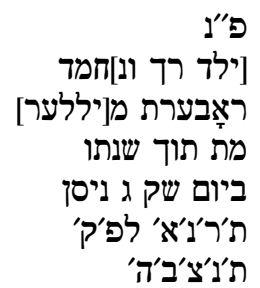

ת'נ'צ'ב'ה'

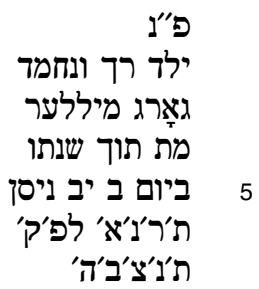

Rückseite

Robert Müller [Geb. 26.] Sept. I 883

Georg Müller Geb. 29. Sept. I 879 [Gest.] 20.Apr. I89I 10
Hier ist geborgen

[ein zarter und lie]benswerter [Knabe], Robert M[üller].

Er starb mitten im Schlaf

5 am Tag des hl. Sch(abbat) 3. Nisan 651 n.kl.Z.

S.S.E.B.L.
Hier ist geborgen

ein zarter und liebenswerter Knabe, Georg Müller.

Er starb mitten im Schlaf

am $\operatorname{Tag} 2$ 2, 12. Nisan

651 n.kl.Z.

S.S.E.B.L.

4.14 Möglich auch „,mitten seines Jahres“, Ausdruck vorzeitigen Todes. · 19 Angabe ergänzt nach GbL 


$$
\begin{gathered}
\text { Max Speyer } \\
\text { 27.I.I890 - 24.4.I89I }
\end{gathered}
$$

Heinz Speyer

6.2. I $884-$ I 8.4.I $89 \mathrm{I}$

Eltern: Aron Speyer IV 33 - [Max] Bertha Heilbrunn IV 35 [Heinz] Therese Heilbrunn III 38
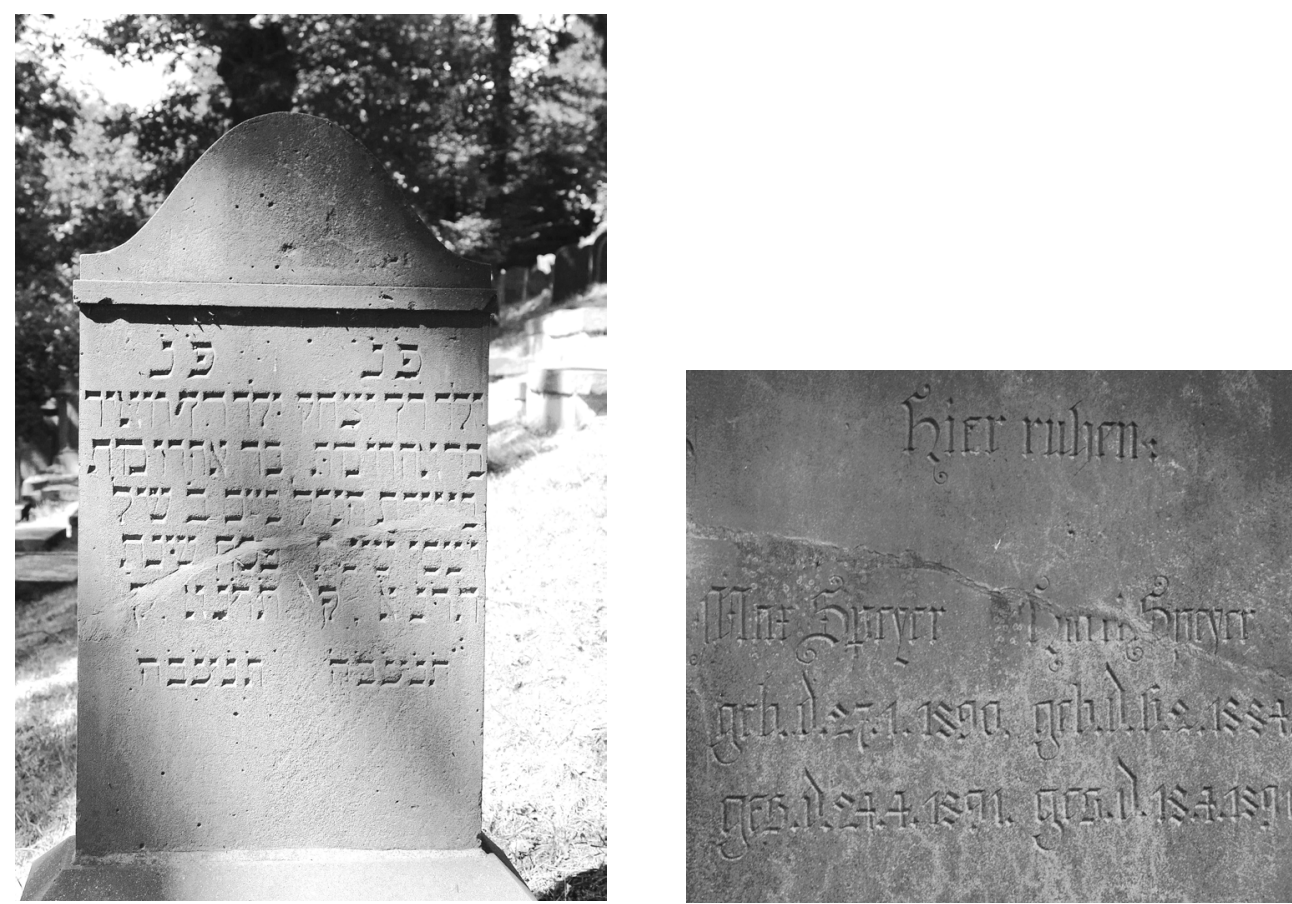

H I27/I68 - B 70/90 - T I3/40

Zerbrochener Stein, wieder zusammengesetzt und aufgerichtet 

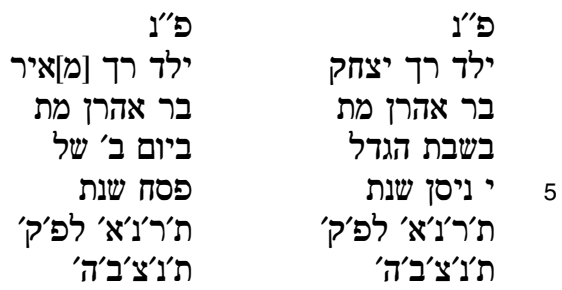

Rückseite

Hier ruhen

Max Speyer

Heinz Speyer

geb. d. 27.I.I 890 geb. d. 6.2.I 884

Hier ist geborgen

ein zarter Knabe, Meir,

Sohn des Aharon. Er starb

am 2. Tag des

5 Pessach (im) Jahr

651 n.kl.Z.

S.S.E.B.L.
Hier ist geborgen

ein zarter Knabe, Jizchak, Sohn des Aharon. Er starb am großen Schabbat, 10. Nisan (im) Jahr 651 n.kl.Z.

S.S.E.B.L.

2 Statt מ steht als Anfangsbuchstabe des Namens וl, offenkundig Schreibfehler · 4 "Großer Schabbat«: Bezeichnung des Schabbat vor oder am I. Tag des Pessachfestes. 

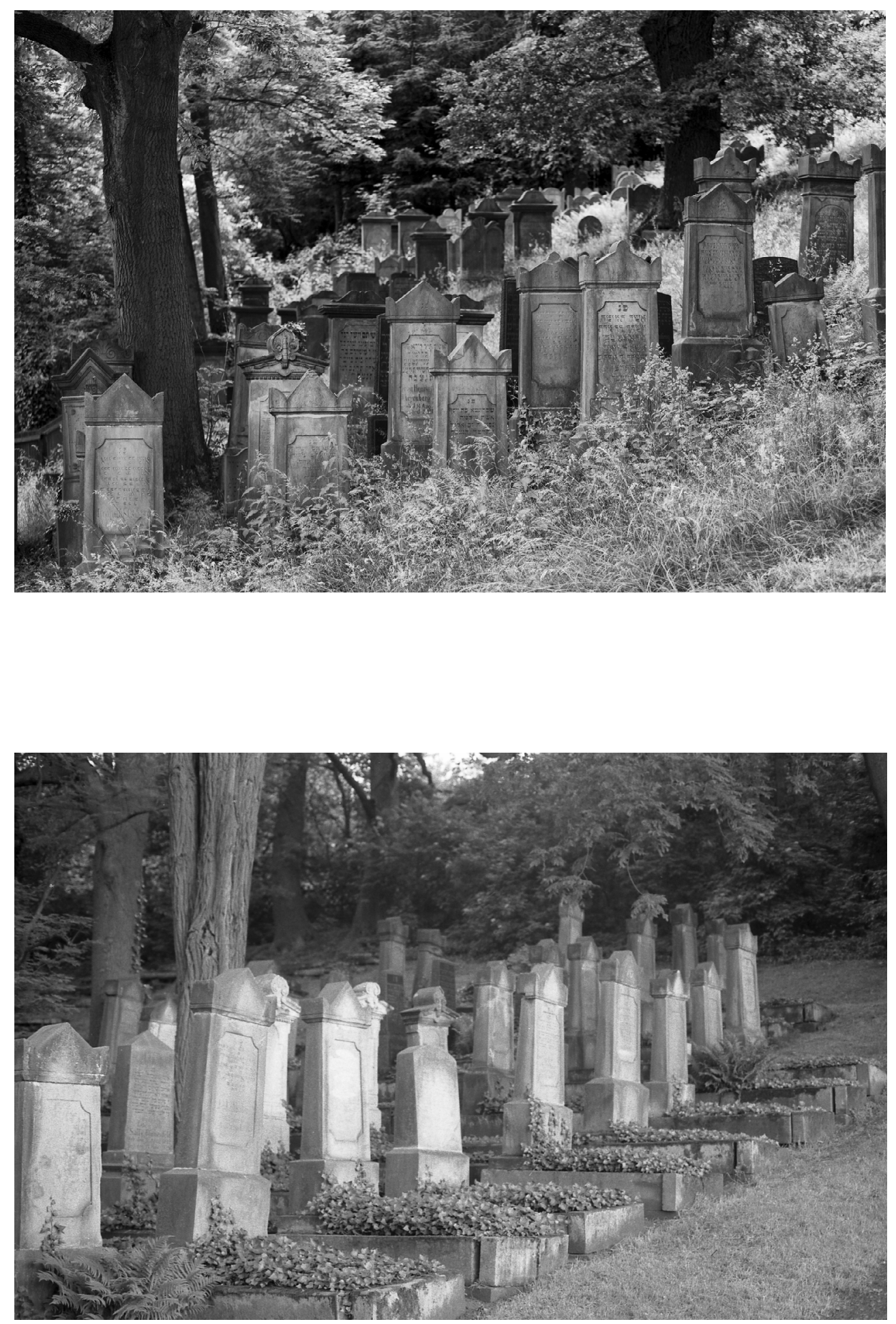
Henriette Gräfenberg

$$
\text { 8.8.I } 890-2 \text { I.2.I } 892
$$

Eltern: Salomon Gräfenberg (I834-I9I8, Göttingen: Grab 333) - Minna Eichenberg (I845-I9Io, Göttingen: Grab 333)

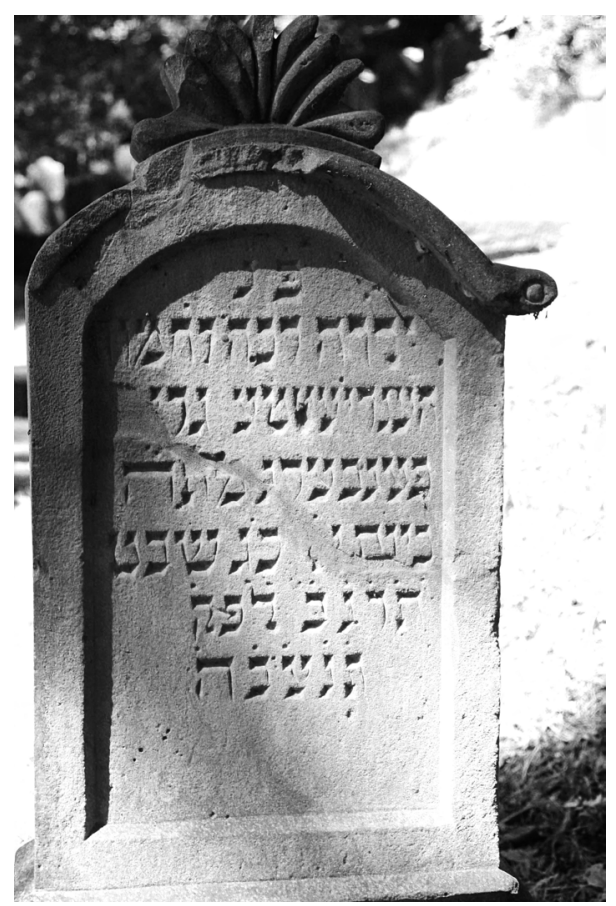

$\mathrm{H} 93 \cdot \mathrm{B} 48 \cdot \mathrm{T}$ I6

Umgestürzter Stein, wieder zusammengesetzt und aufgerichtet

\begin{tabular}{|c|c|}
\hline \multicolumn{2}{|r|}{ Hier ist geborgen } \\
\hline & ein zartes und liebliches Mädchen, \\
\hline הענריעטטע גרי. & Henriette Gr[ä]- \\
\hline פענבערג מתה & fenberg. Sie starb \\
\hline ביום א' כ'ג שבט & 5 am $\operatorname{Tag} 1,23$. Schevat \\
\hline ת'ר'נ'ב' לפ'ק & 652 n.kl.Z. \\
\hline ת'ג'צ'ב'ה' & I.S.E.B.L. \\
\hline Rückseite & \\
\hline Hier ruhet & \\
\hline Henriette & \\
\hline Gräfenberg & \\
\hline b. 8. Aug: I 890 & \\
\hline 2I. Febr: I 8 & \\
\hline
\end{tabular}


Kaufmann Meyenberg

$27.5 .1829-3 \cdot 3.1892$

Kürschnermeister (Mützenmacher) · Eltern: Simon Meyenberg III 6I Minna Hirsch III 62 - Ehefrau: Mathilde Wollberg IV 8 - Kinder: ebd.
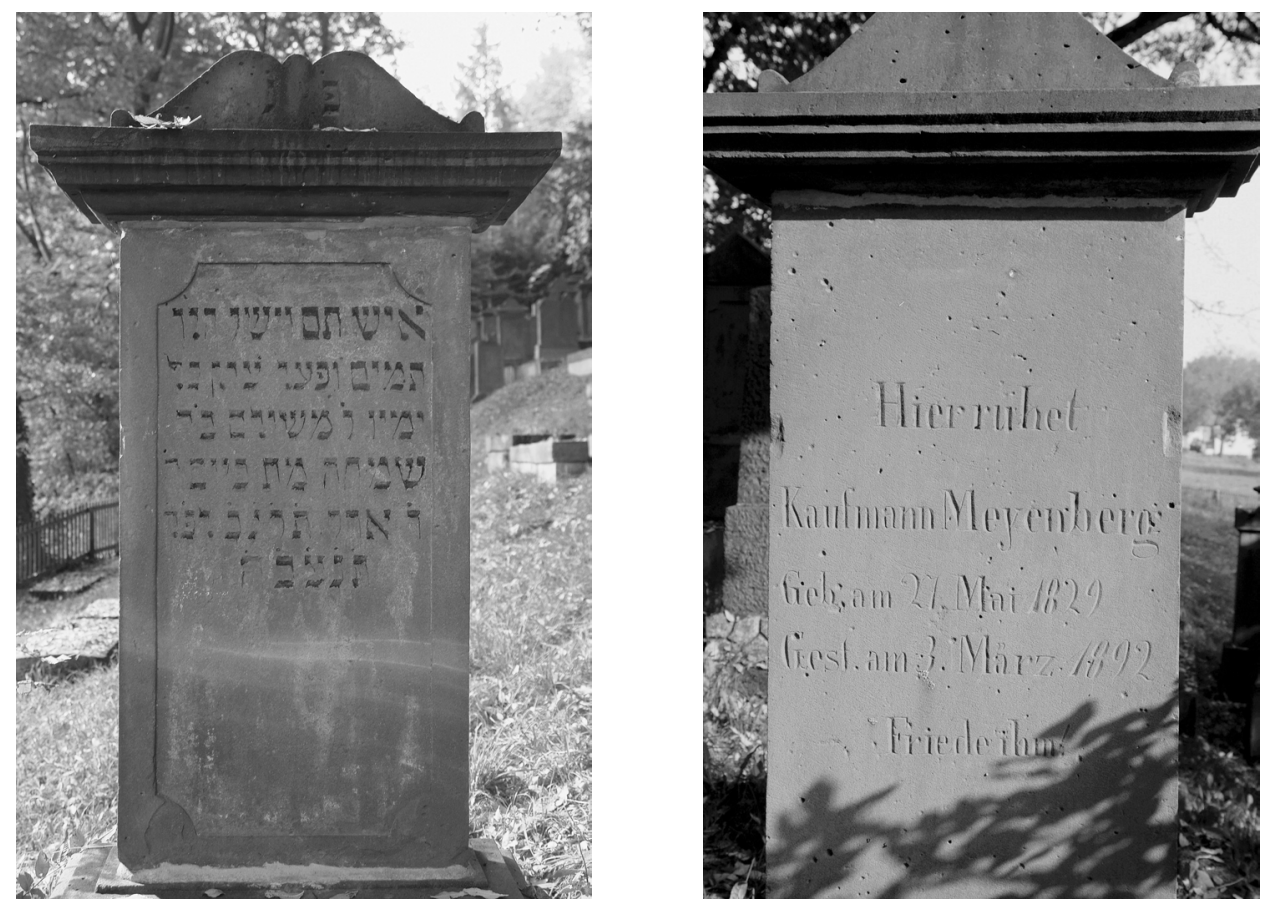

$\mathrm{H} \mathrm{I} 46 \cdot \mathrm{B} 62 \cdot \mathrm{T} \mathrm{I6}$

פ"ג Hier ist geborgen

איש תם וישר הלך lauter und handelte rechtschaffen all

ימיו ר' משולם ב'ר ת' seine Tage, H. Meschullam, S(ohn) des H.

5 Simcha. Er starb am Tag 5, 4. Adar 652 n.kl.Z.

S.S.E.B.L.

Rückseite

Hier ruhet

Kaufmann Meyenberg Geb. am 27. Mai I 82910

Gest. am 3. März I 892

Friede ihm!

2a s. Hi I, $8 \cdot \mathbf{2 b f}$ s. Ps I 5,2 


\section{David Eichenberg \\ I.8.I 8 I I - I 5.5.I 893}

Kaufmann - Eltern: Simon M. Eichenberg II 35 - Amalie Rothschild II I2 - Ehefrau: Sophie Grunsfeld IV $5 \cdot$ Kinder: s. ebd.

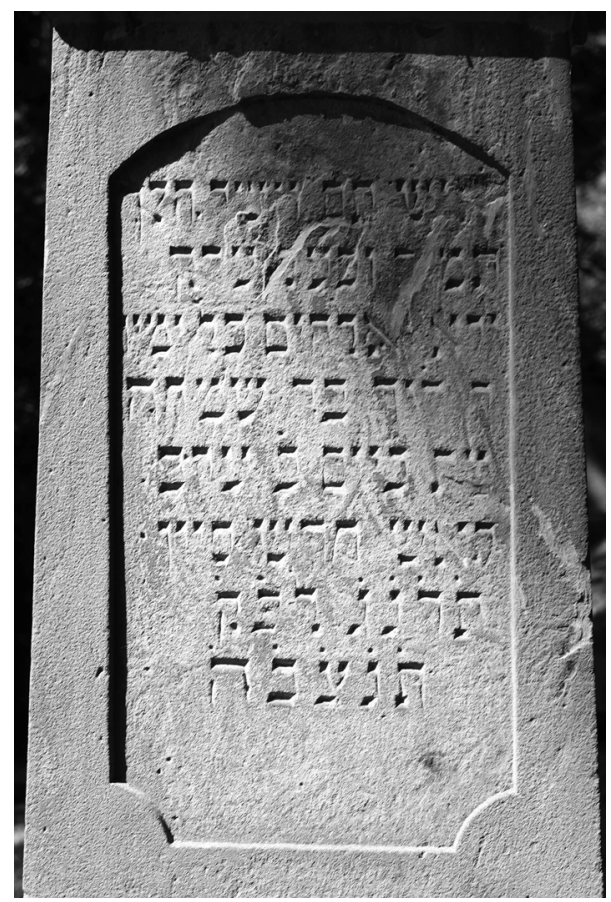

$\mathrm{H}$ I $5 \mathrm{I} \cdot \mathrm{B} 55^{\cdot} \mathrm{T} 24$

פע"נ Hier ist geborgen

איש תם וישר הלך

lauter und handelte rechtschaffen,

ירא אלהים כל ימיו

5 H. David, Sohn des Simcha.

Er starb am Tag 2, am Vorabend des

Anfang des Monats Siwan

653 n.kl.Z.

ת.S.E.B.L.

Rückseite

Hier ruhet 10

David Eichenberg

Geb. am I. Aug. I8I I

Gest. am I 5. Mai I 893

Friede ihm!

2-4 Vermengung von Ps I 5,2 und Hi I,8. 


\section{Jacob Marcus Löwenstern}

$$
\text { 29.I.I8II - I2.I2.I } 893
$$

Lotterie-Collecteur in Adelebsen - Eltern: Marcus Meyer Löwenstern II 29 - Bertha/Betty geb. Dahl II 28 - Ehefrau: Johanne Dahl III Io - Kinder: ebd.

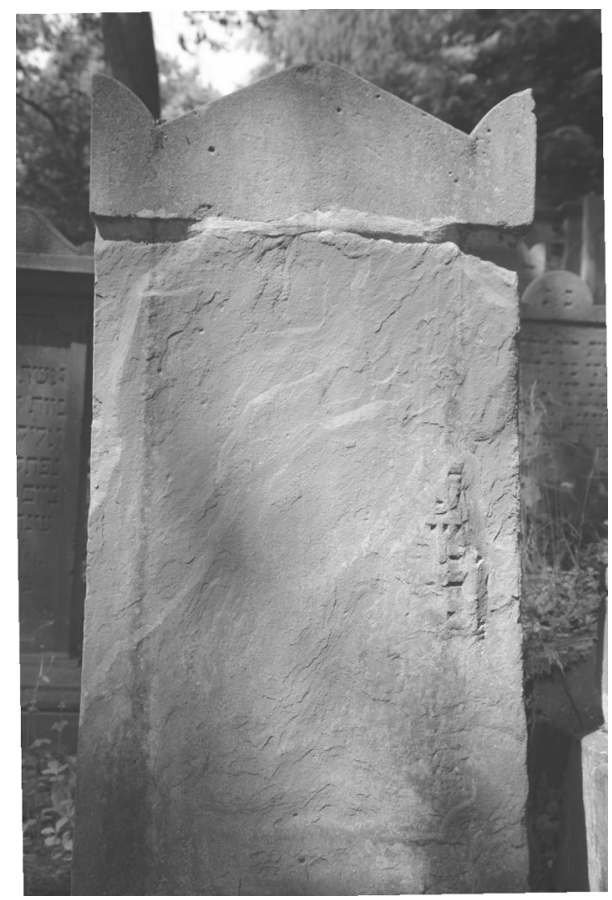

$\mathrm{H} \mathrm{I}, 44 \cdot \mathrm{B}$ o,6I $\cdot$ T I $8 / 22$

Zerbrochener Stein, wieder zusammengesetzt und aufgerichtet. Inschrift nahezu völlig verwittert

[Löwens]tern

[Friede] ihm! 5

Quelle: FamB/StB (Geburtstag) 


\section{Henriette Müller}

24.8.I 8 I 8 - I8.I2.I 893

Eltern: David Isaak Müller III 87 - Johanna Rothschild III 88

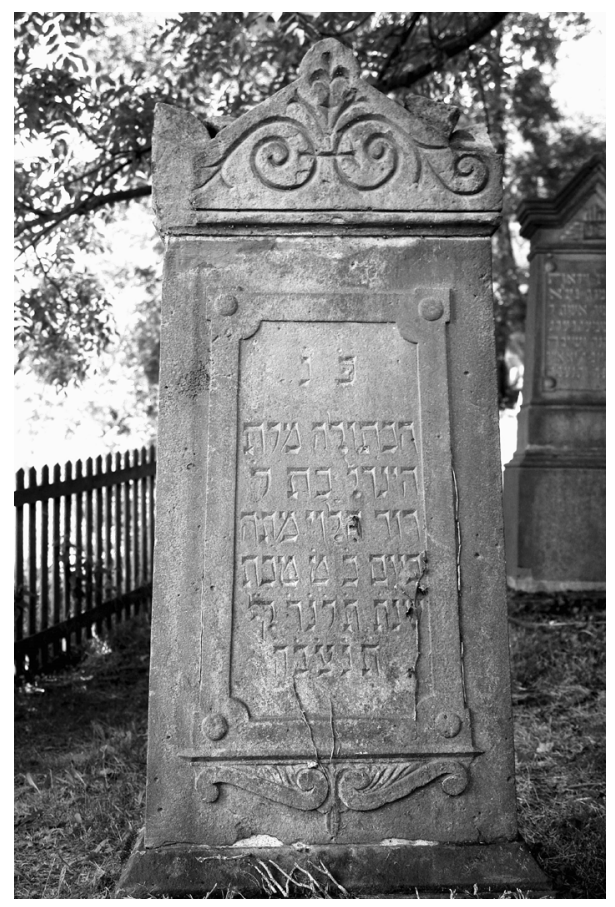

H $107 \cdot \mathrm{B} 65 \cdot \mathrm{T} 23$

\begin{tabular}{|c|c|}
\hline & \\
\hline & \\
\hline & \\
\hline & \\
\hline & \\
\hline שנת ת'ר'נ'ד' ל' & \\
\hline & \\
\hline & \\
\hline פ"ג & Hier ist geborgen \\
\hline הבתולה מרת & \\
\hline הינדל בת ר' & Hendl, Tochter des $H$. \\
\hline דוד הלוי מתה & David ha-Levi. Sie starb \\
\hline ביום ב' ט' טבר & am $\operatorname{Tag} 2$, 9. Tevet \\
\hline ב'ה' & I.S.E.B.L. \\
\hline
\end{tabular}

Hier ruhet

Henriette Müller

Geb. 24. Aug. I 8 I 810

Gest. I8. Dez. I 893 .

Fiede ihr! 
Levi Bähr

$20.5 .1829-25.3 .1893$
Minna Bähr, geb. Henneberg

6.I.I $832-28.4 .1895$

Levi Bähr · Geb. in Barterode · Althändler in Barterode, seit I 88 I wohnhaft in Adelebsen · Eltern: Hirsch Bähr III 57 - Rieke Lehmann-Gottschalk ·

Minna Bähr geb. Henneberg · Geb. in Geismar bei Göttingen · Eltern: Simon Henneberg - Jette Rosenthal

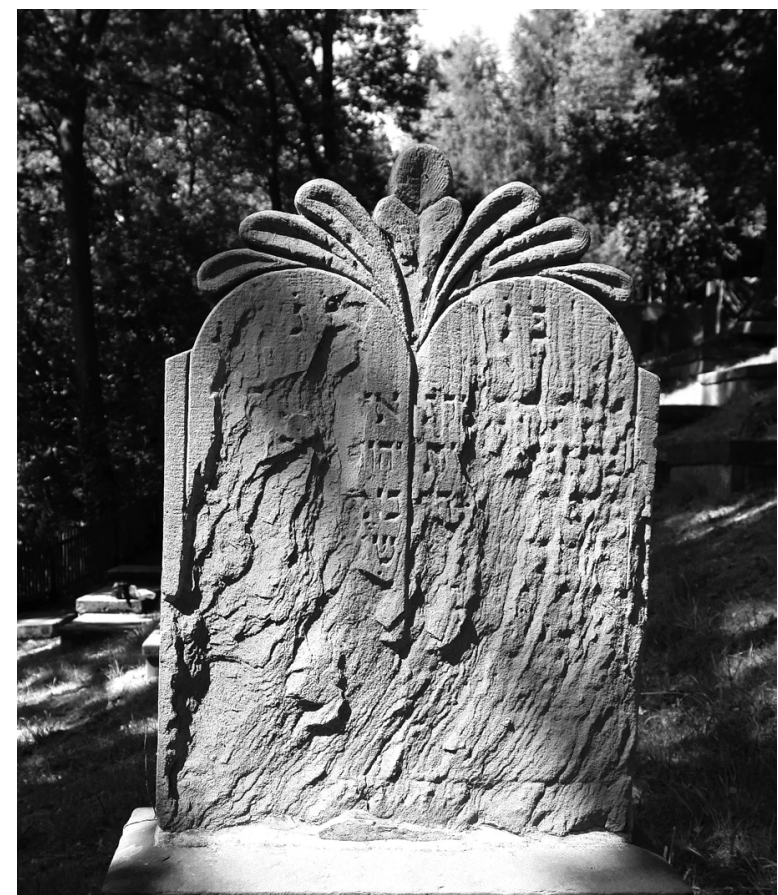

$\mathrm{H}$ I 7 - B $83 \cdot$ T I 3

Inschrift fortschreitend stark verwittert 


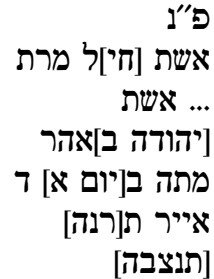

Minna Bähr geb. Henneberg Geb. 6. Jan. I 832 Gest. 28. Apr. I895 Friede ihr!

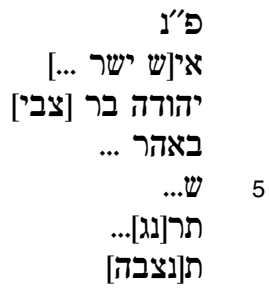

Rückseite

Levi Bähr

Geb. 20. Mai I 829

Gest. 25. März I $893 \quad 10$

Friede ihm!
Hier ist geborgen

eine [tüch]tige Ehefrau, Frau

..., Ehefrau des

[Jehuda] Bähr.

5 Sie starb am [Tag 1,] 4.

Ijjar [655]

I.S.E.B.L.
Hier ist geborgen

ein aufrechter Mann,

Jehuda, Sohn des [Zvi]

Bähr

...

6[53]

S.[S.E.B.L.]

2 s. Prov 3 I, IO

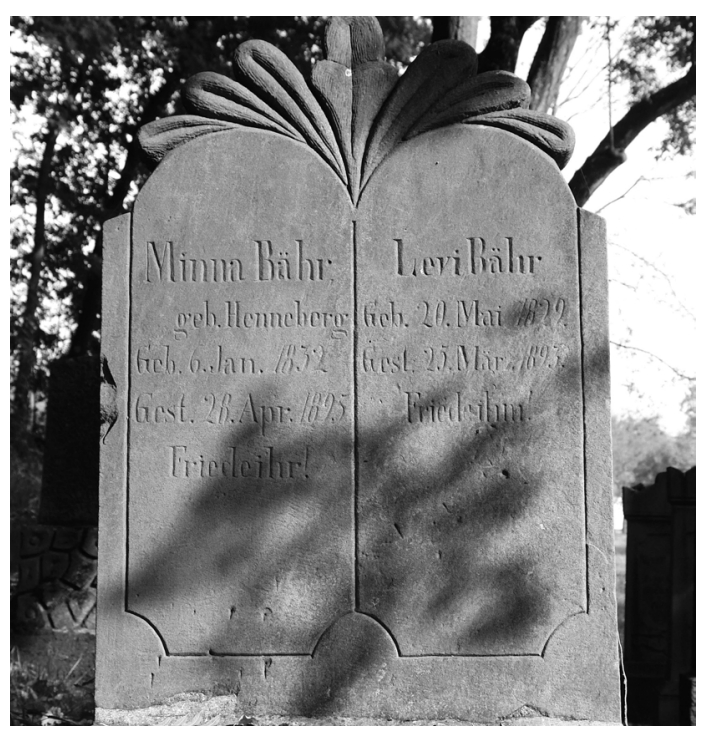



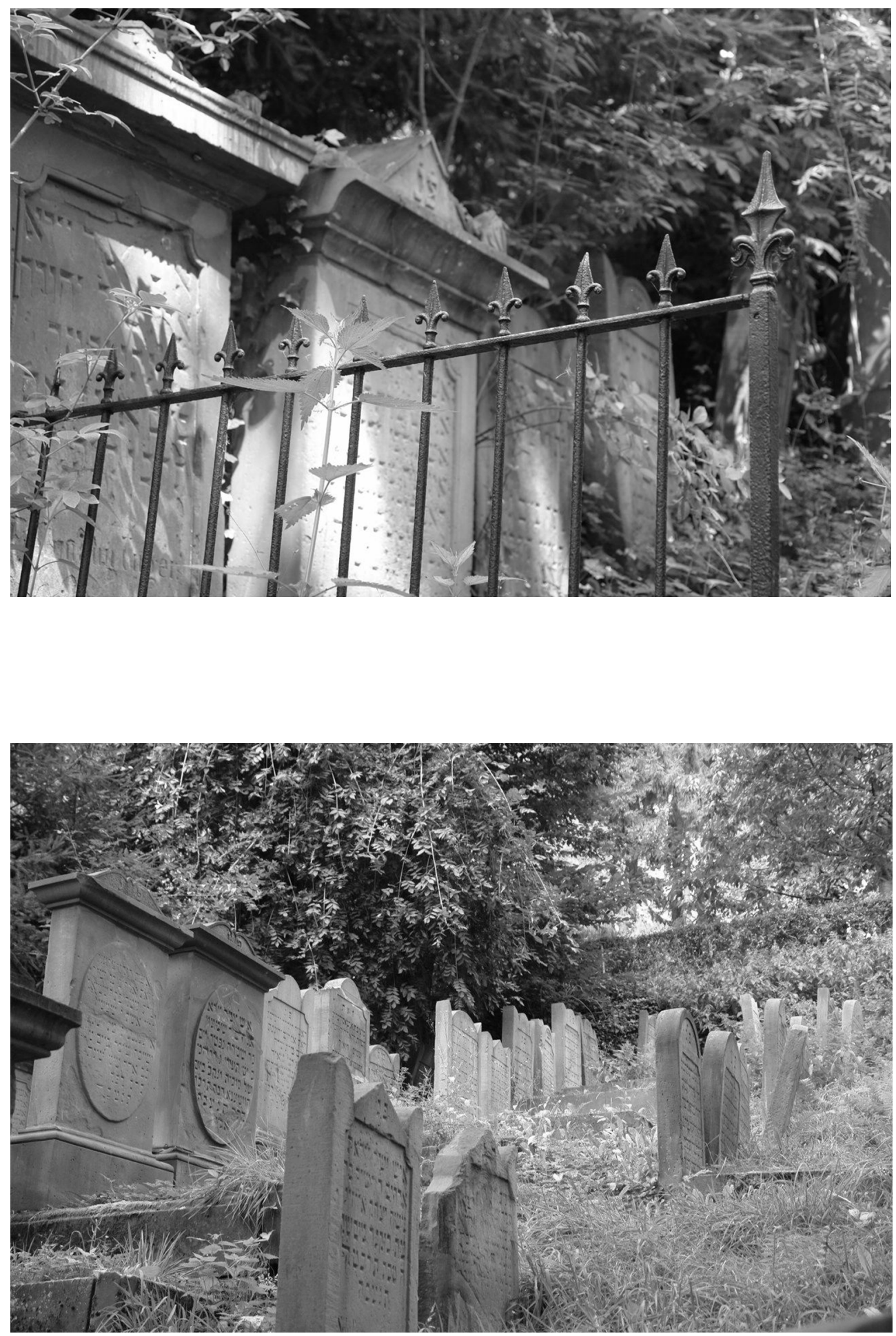
Abraham Eichenberg

3 I.I2.I 828 - I 5.I.I 894

Tierarzt in Adelebsen, I880-I89 in Gronau/Leine · Eltern: Levi M. Eichenberg III 74 Henriette Jacobsohn III $75^{\cdot}$ Ehefrau: Auguste Freudenstein IV I I Kinder: s. ebd.
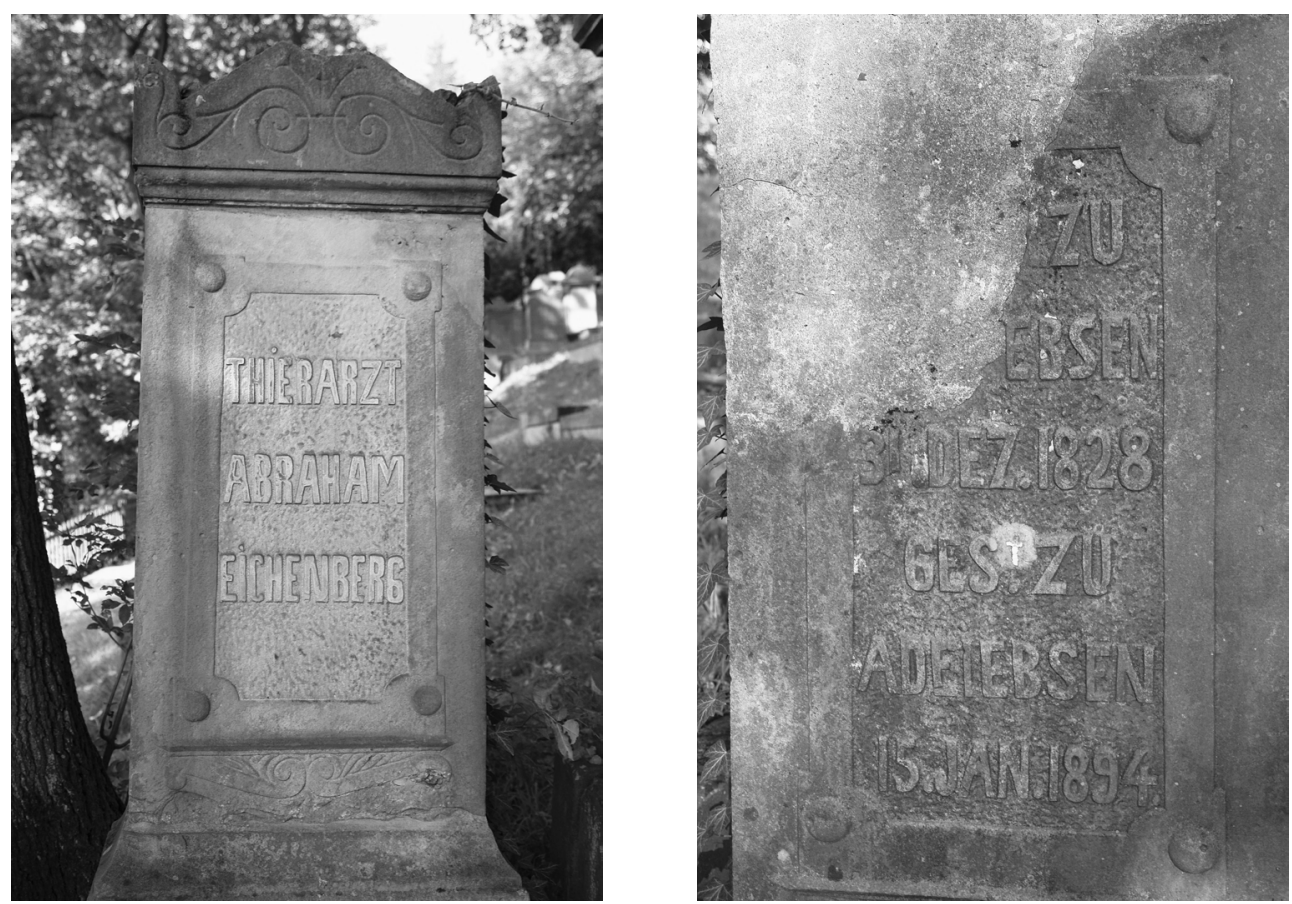

$\mathrm{H} \mathrm{I09} \cdot \mathrm{B} 6 \mathrm{I} \cdot \mathrm{T} 23$

\section{THIERARZT \\ ABRAHAM \\ EICHENBERG}

Rückseite

[GEB.] ZU

[ADEL]EBSEN 5

3I. DEZ. I 828

GEST ZU ADELEBSEN

I 5. JAN. I 894

5 25.I.I828 nach StB 
Herz Aron Müller

I 5.9.I 8 I 7 - 2.II.I 894

Färbermeister und Fabrikant · Eltern: Aron Isaak Müller III 23 - Bertha Bacharach II 5 I Ehefrau: Esther Stehberg III $22 \cdot$ Kinder: s. ebd.

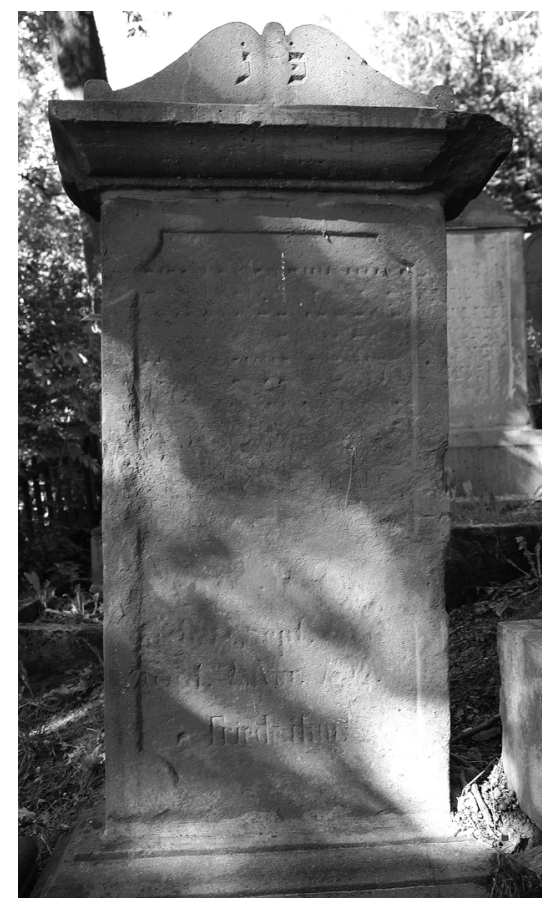

H I5I $\cdot$ B $88 \cdot$ T I6

Inschrift stark verwittert

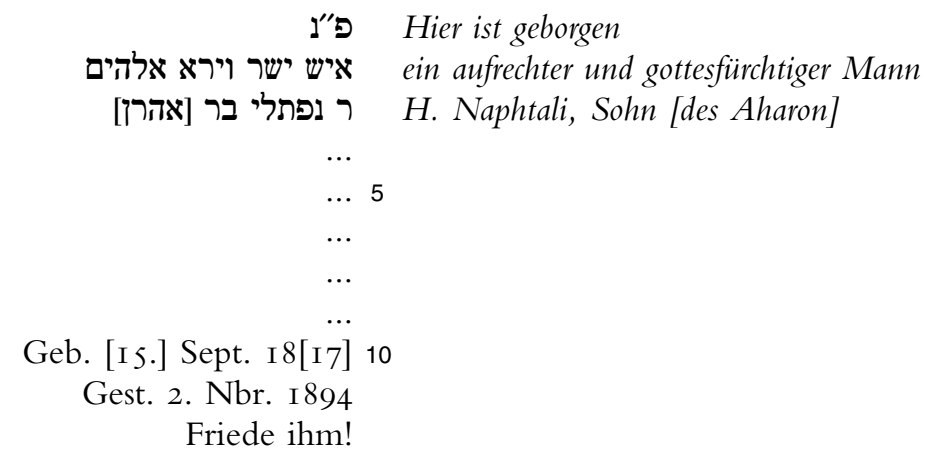

7 Geburtsdatum ergänzt nach FamB/StB 


\section{Selig Dannenberg}

6.IO.I $834-23.2 .1896$

Kaufmann (Manufakturwaren) • I895/96 stellvertretender Vorsitzender der Synagogengemeinde - Eltern: Calman Selig Dannenberg III 65 - Clara Meyenberg III 66 - Ehefrau: Amalie König IV 26 · Kinder: s. ebd.

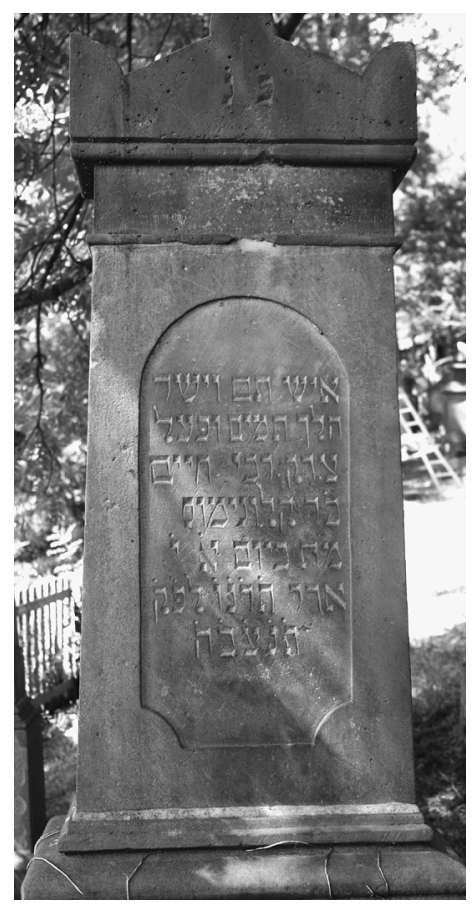

H IOI $\cdot$ B $59^{\circ}$ T 23

\begin{tabular}{|c|c|}
\hline 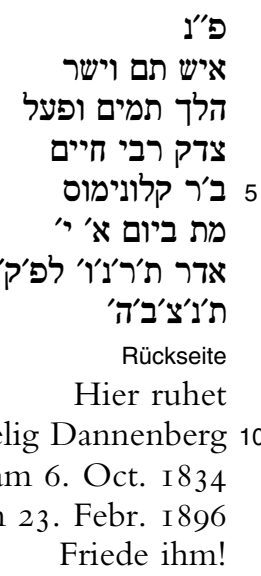 & $\begin{array}{l}\text { Hier ist geborgen } \\
\text { ein redlicher und aufrechter Mann, } \\
\text { er wandelte lauter und handelte } \\
\text { rechtschaffen, Herr Chajjim, } \\
\text { S(ohn) des H. Kalonymus. } \\
\text { Er starb am Tag 1, } 10 . \\
\text { Adar } 656 \text { n.kl.Z. } \\
\text { S.S.E.B.L. }\end{array}$ \\
\hline
\end{tabular}

2 s. Hi I,8 3 s. Ps I 5,2 
Sophie Eichenberg, geb. Grunsfeld

$$
\text { I0.9. I } 8 \text { I } 8 \text { - 21.6. I } 896
$$

Geb. in Bremke · Eltern: Abraham Grunsfeld - Hannchen Löwenstein · Ehemann: David S. Eichenberg IV 6 - Kinder: Mathilde (I849-I942, Theresienstadt); Johanna (I85I); Simon/Siegfried (I853-I9I7, Göttingen: Grab I76); Abraham/Albert III 72

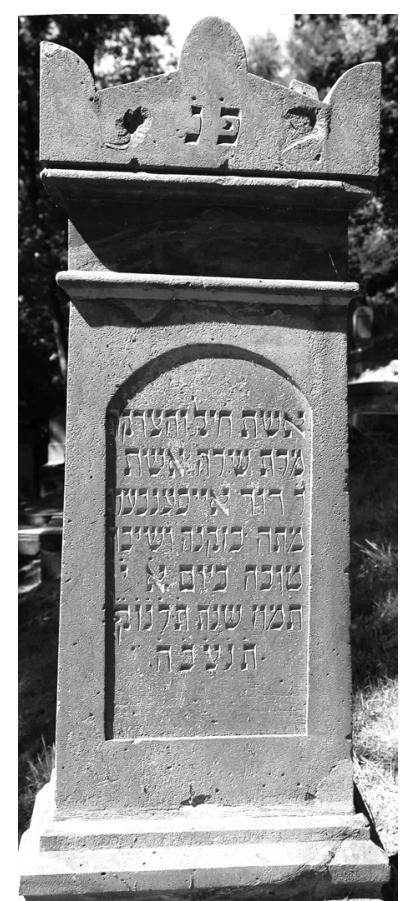

$\mathrm{H} \mathrm{I} 50 \cdot \mathrm{B} 59 \cdot \mathrm{T} 25$

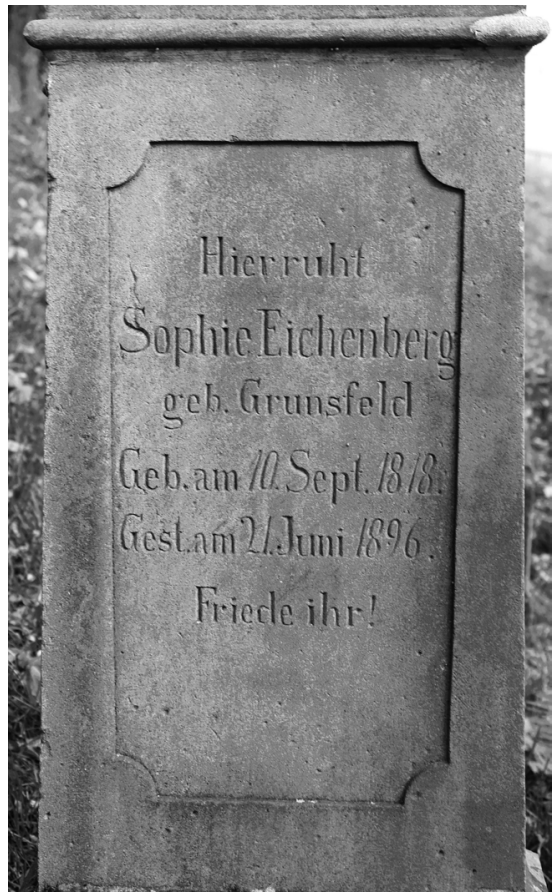

פעינ $\quad$ Hier ist geborgen

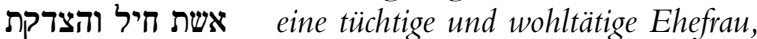

Frau Sara, Ehefrau

des H. David Eichenberg.

5 Sie starb in hohem und gutem

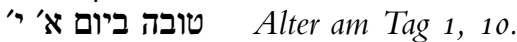

Tammuz (im) Jahr 656 n.kl.Z.

ת'ת'נ'צ'ב'ה' I.S.E.B.L.

Rückseite

Hier ruht

Sophie Eichenberg 10

geb. Grunsfeld

Geb. am Io. Sept. I8I 8

Gest. am 2I. Juni I 896

Friede ihr!

2 s. Prov 3 I, IO 
Betti Stehberg, geb. Dannenberg

$$
\text { 2.II.I } 8 \text { I } 8-\text { I3.5.I } 897
$$

Eltern: Moses Dannenberg III 3a - Rosette Meyenberg III 3 - Ehemann: Herz Lucas Stehberg IV I6 - Kinder: Louis III 29; Rosa IV 32; Julius III 73; Leopold IV 45
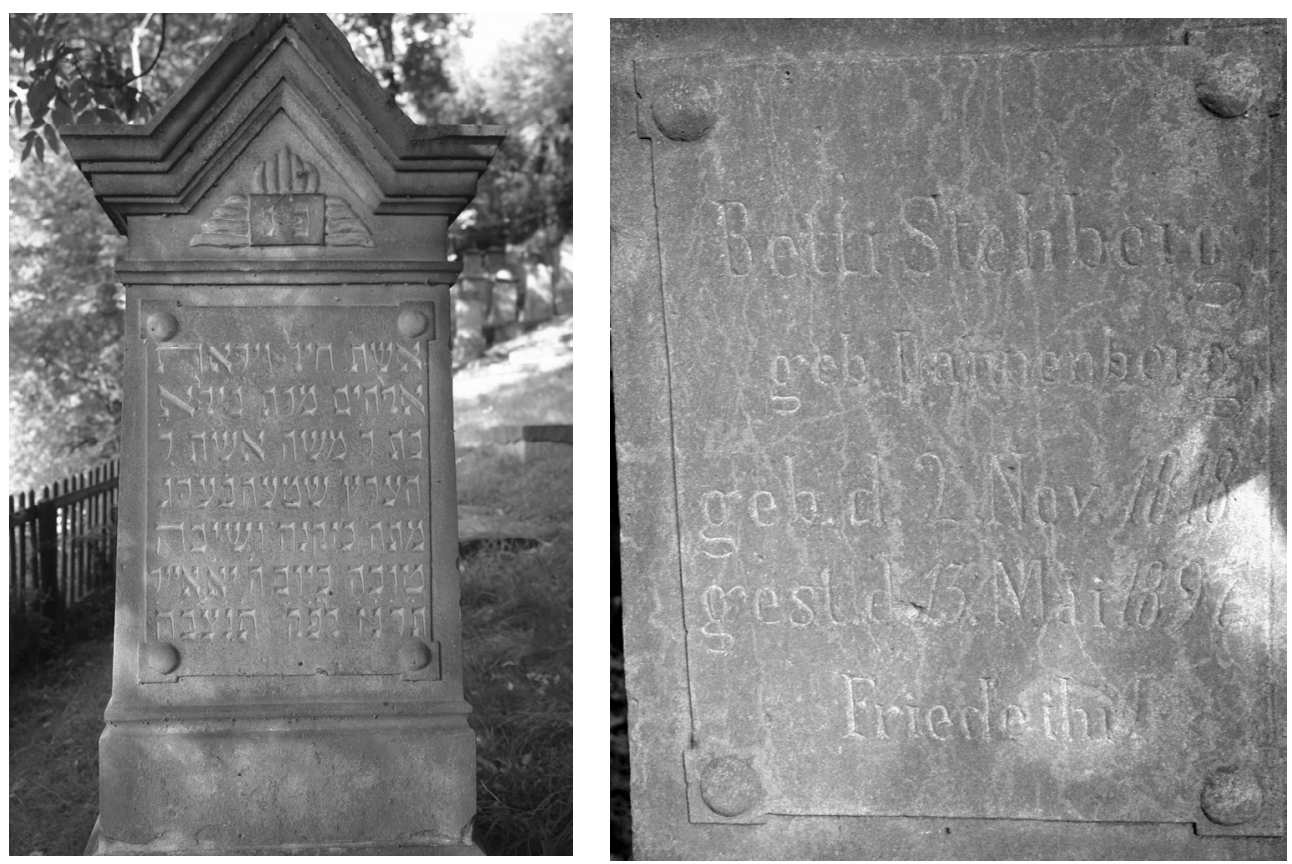

$\mathrm{H} 95 \cdot \mathrm{B} 60 \cdot \mathrm{T} 26$

פ"ג Hier ist geborgen

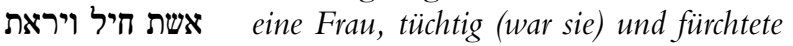

Gott, Frau Beila,

Tochter des H. Mosche, Ehefrau des H.

5 Herz Stehberg.

Sie starb in hohem und guten

Alter am Tag 5, 11. Ijjar

ת'ר'ניז' לפ'ק' תנצבה 657 n.kl.Z. I.S.E.B.L.

Rückseite

Betti Stehberg

geb. Dannenberg 10

geb. d. 2. Nov. I 8 I 8

gest. d. I 3. Mai I 897

Friede ihr!

2 s. Prov 3 I, IO 


\section{Louis Speyer}

3I.3.I $879-$ I3.I2.I 897

Eltern: Aron Speyer IV 33 - Therese Heilbrunn III 38

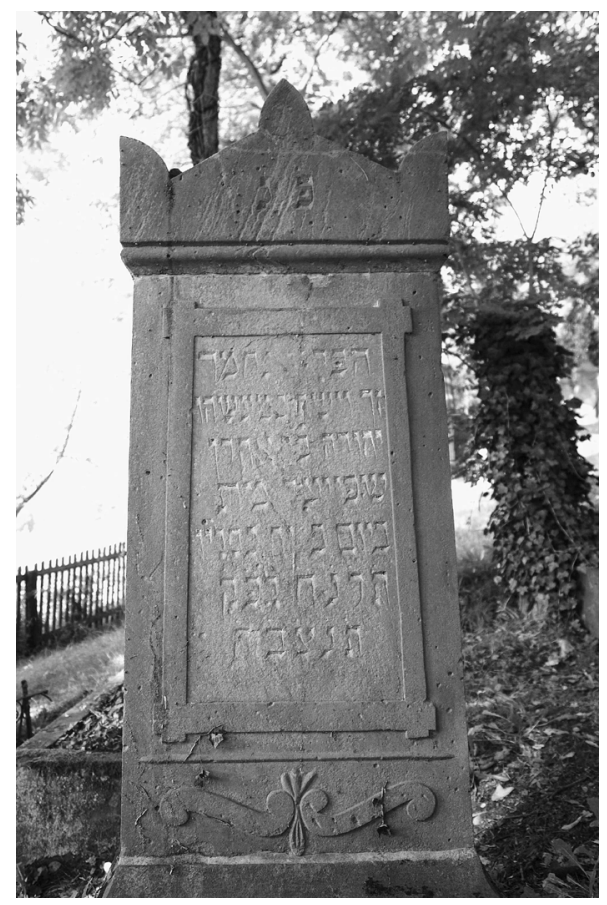

H 105 B 56/62 T I9/22

פע"ג Hier ist geborgen

der Junggeselle, liebenswert,

זך וישר במעשהו

Jehuda, Sohn des Aharon

5 Speyer. Er starb

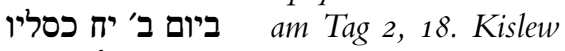

ת'ת'ר.k.Z.Z.

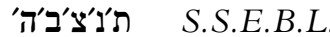

Rückseite

Hier ruht

Louis Speyer 10

Geb. d. 3I. März

I 879

Gest. d. I3. Dez.

I 897

Friede ihm! 15 


\title{
Louis Rothschild
}

5.I2.I 87 I - 25.I.I 898

Eltern: Joel S. Rothschild IV I7 - Bertha Gans IV 42

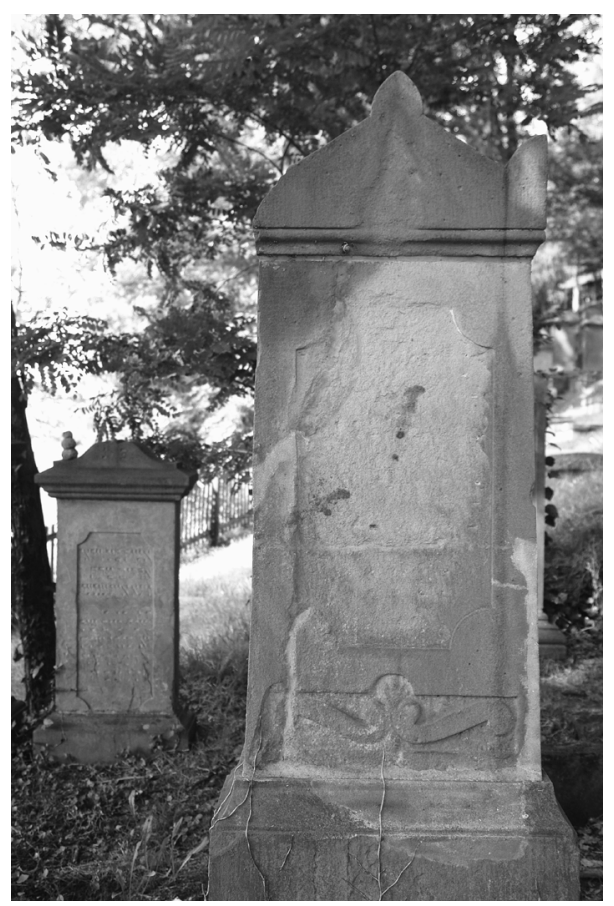

$\mathrm{H}$ I05 $\cdot \mathrm{B} 60 \cdot \mathrm{T} 24$

Inschrift der Vorderseite vollständig verwittert

\author{
$[\ldots]$ \\ Rückseite \\ Hier ruht \\ Louis Rothschild \\ geb. d. 5. Dez. I87I. \\ gest. d. 25. Jan I89[8] 5 \\ Friede ihm!
}

Quelle: GbL (mit Randnotiz zu Sterbedatum). Sterbefall, beim Standesamt Adelebsen nicht verzeichnet 
Fanny Fromet Löwenstern, geb. Grunsfeld I7.3.I 8 I I - 4.IO.I 898

Geb. in Gelliehausen - Eltern: Joel Grunsfeld - Sophie Heilbrunn (später verh. mit Isaac M. Freudenthal, Adelebsen) · Ehemann: Samuel Löwenstern III $48 \cdot$ Kinder: Joel (I837I858); Meyer (I838-I839); Moses III 7I; Bertha III 34; Bernhart III 32
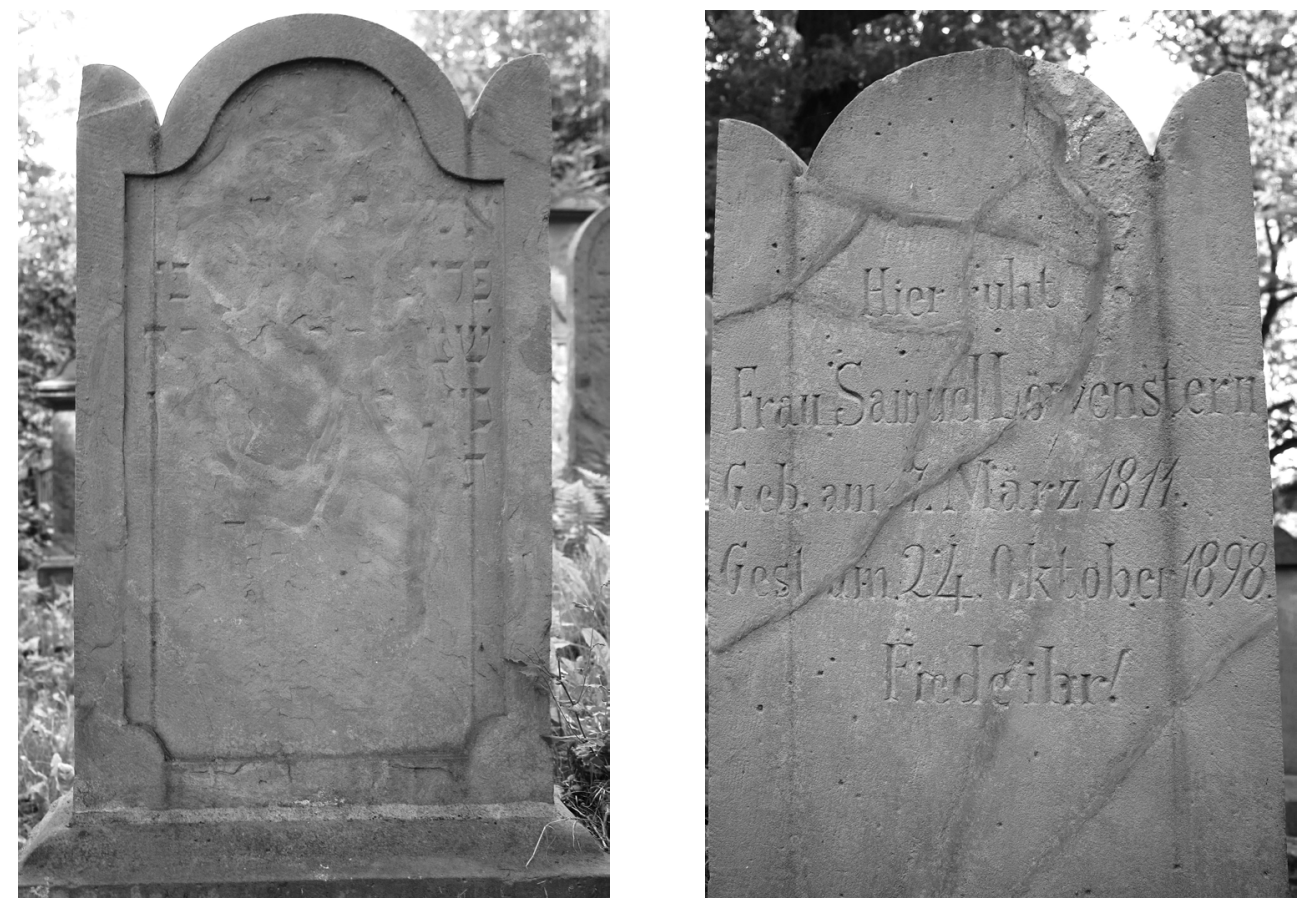

$\mathrm{H} \mathrm{IO}_{4} \cdot \mathrm{B} 62 \cdot \mathrm{T} \mathrm{I} 4$

Inschrift nach Aufnahme I984, seither stark verwittert

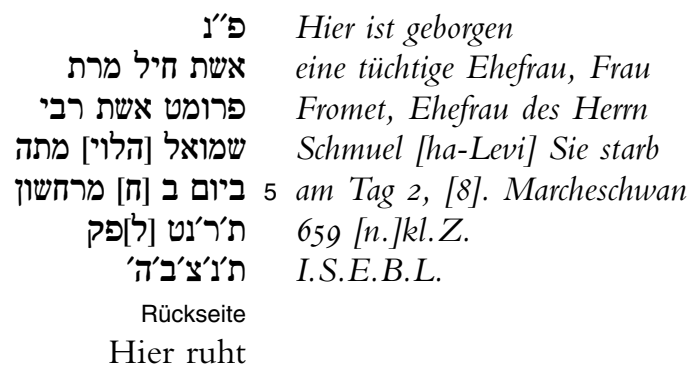

Frau Samuel Löwenstern

Geb. am I7. März I8I I. 10

Gest. am 24. Oktober I 898.

Friede ihr!

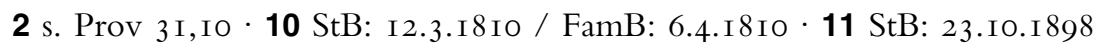




\title{
Emilie Edelstein
}

$$
\text { 3 I.I2.I } 856 \text { - I6.6.I } 899
$$

Haushälterin, zuletzt wohnhaft in Berlin; gest. in Adelebsen im Haus der Schwester Rosalie IV I9 und deren Ehemann Meyer Leiser Eichenberg IV I8 - Eltern: Alexander Abr. Edelstein III 63 - Minna Grunsfeld

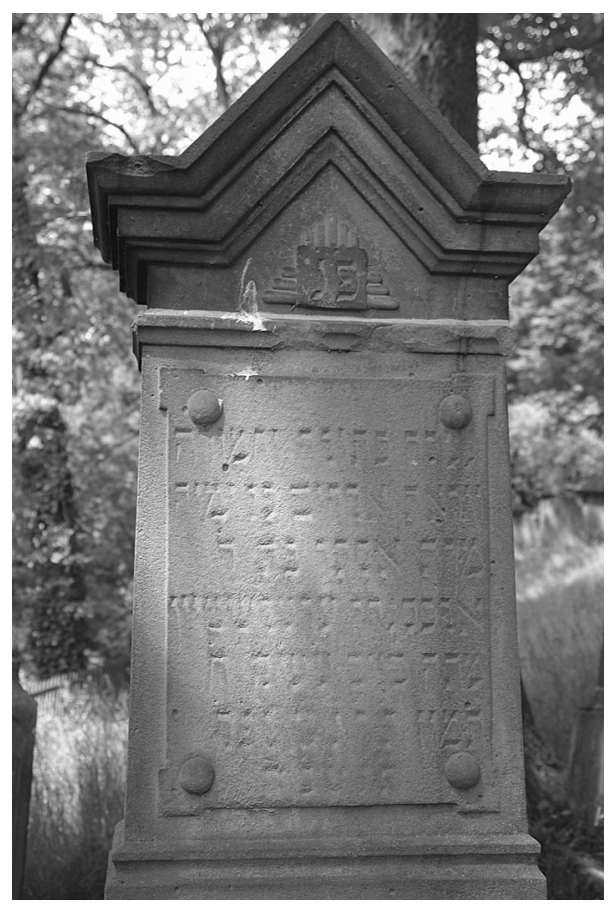

\author{
Rückseite \\ Hier ruht \\ Emilie Edelstein \\ geb. am I. Jan. I 836 \\ gest. am I6. Juni I 899 \\ Friede ihr!
}

H 95 B 34/60 T 23/30

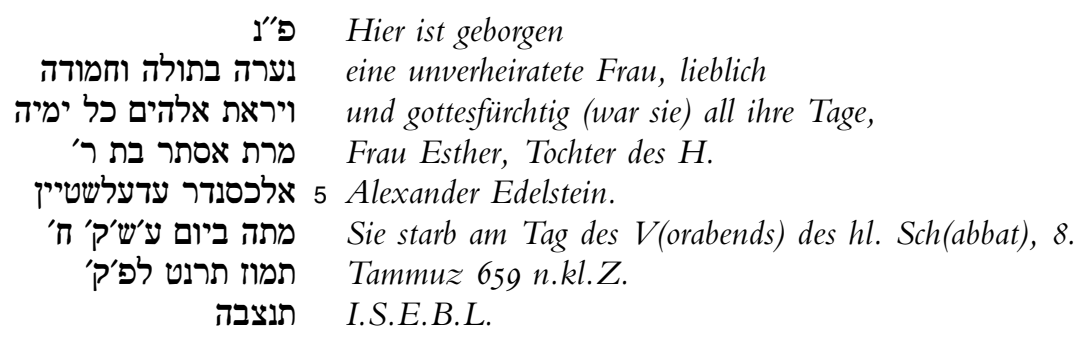

3 s. Prov 3 I,30 - 11 3I.I2.I 836 nach GbL. Anders die Angabe auf der deutschen Inschrift I.I.I 836; vermutlich verursacht durch Verwechslung der Jahreszahl: I837. 


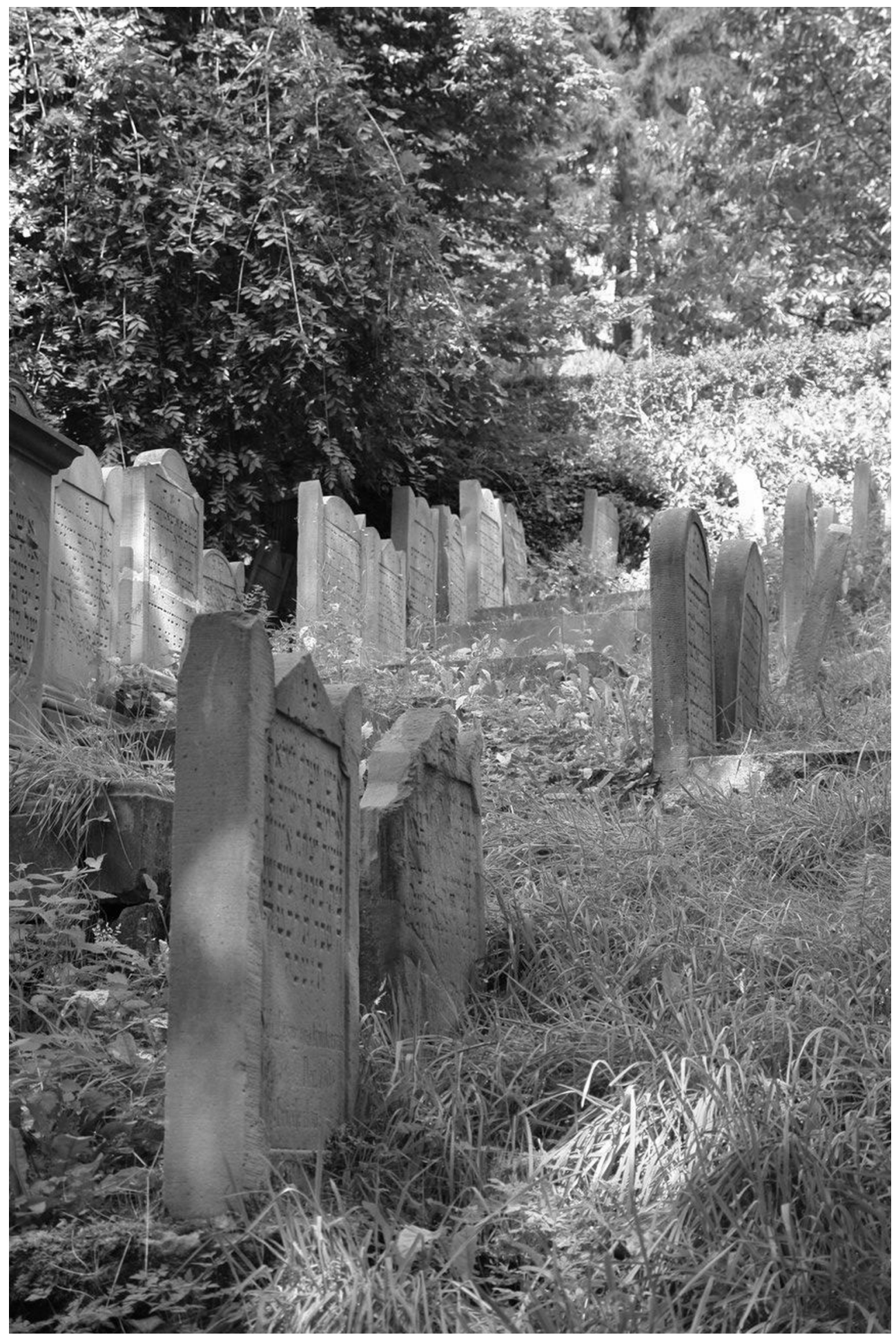


Julie Eichenberg, geb. Freudenstein

$$
\text { 28.6.I } 8 \text { I9 - 23.3.1900 }
$$

Eltern: Samuel M. Freudenstein III 68 - Caroline Traube III $67 \cdot$ Ehemann: Simon S. Eichenberg III 83 - Kinder: Meyer (I839); Mathilde (Grab IV.37); Salomon (I 842-I89I, Göttingen: Grab 344); Ida (I844-I9I3, Göttingen: Grab 334); Minna (I845-I9Io, Göttingen: Grab 333); Siegfried (I 847-I905, Göttingen: Grab 257); Bertha (I849-I912, Warburg); Eva III 92; Helene (I852); Feodor/Philipp (I854); Emma (I 856); Auguste (I 856 I935 Bielefeld); Karoline (I 858-I926, Göttingen); Selly (I862-I930, Hannover)

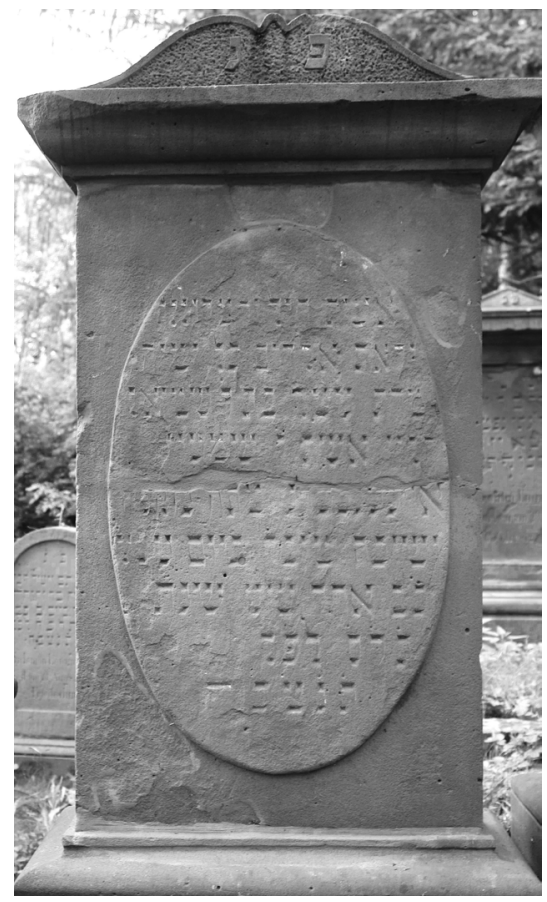

Rückseite

Julie Eichenberg

Geb. Freudenstein

geb. d. 28. Juni I 8 I9

gest. d. 23. März I900

Friede ihr!

H II6 $\cdot \mathrm{B} 72 \cdot \mathrm{T}$ I 8

\section{פ Hier ist geborgen}

אשת חיל והמהוללה eine tüchtige Ehefrau, gepriesen, gottesfürchtig all ihre Tage, Frau Gitel, Tochter des H. Schmuel

5 ha-Levi, Ehefrau des H. Schimon

\section{Eichenberg. Sie starb in hohem}

und gutem Alter am Tag des V(orabends des) hl. Sch(abbat),

22. Adar II (im) Jahr

660 n.kl.Z.

10 I.S.E.B.L.

2 s. Prov $3 \mathrm{I}, \mathrm{IO} \cdot 3$ s.Prov. $3 \mathrm{I}, 3 \mathrm{O}$ 
Röschen Meyenberg

I 8.8. I 8 I 8 - I.I.I9O2

Eltern: Simon Meyenberg III 6I - Minna Hirsch III 62

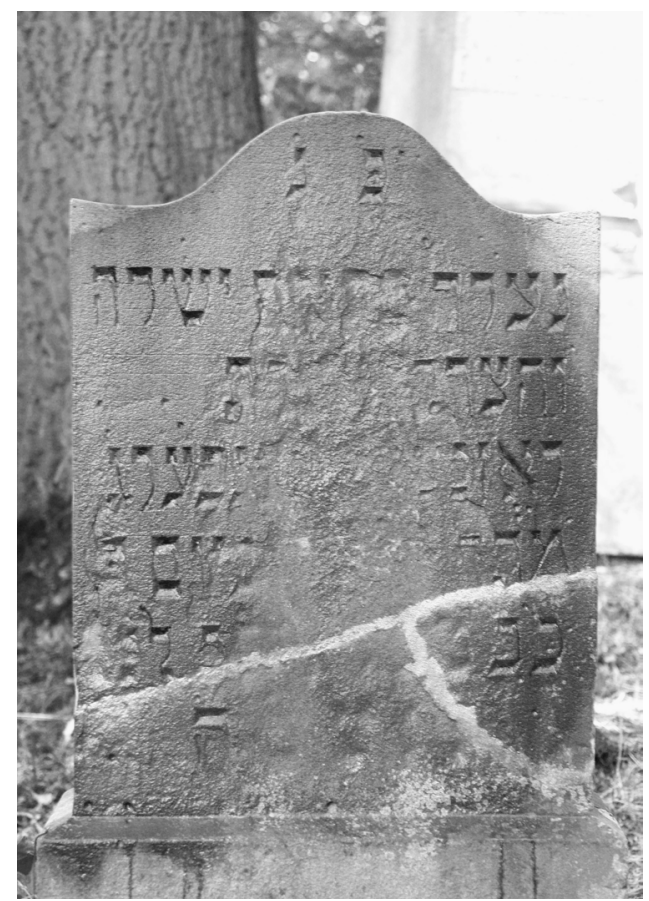

H 63 B 47 T I7

פע"ג Hier ist geborgen

eine unverheiratete Frau, aufrecht

und wohltätig (war sie), Frau

Röschen Meyenberg.

5 Sie starb im [Alter] am Tag 4, 22. [Tevet] [66]2 n.kl.Z.

ת'ת'נב'ב'ה'ת.S.E.B.L.

Rückseite

Röschen

Meyenberg

geb. I 8. Aug. I 8 I 8, 10

gest. I. Januar 1902

$10 \mathrm{FamB}$ I7.8. I8 8 
Hedwig Blumenfeld

I6.3.I $868-3$ I.7.1902

Eltern: Sally Blumenfeld IV 39 - Bertha Freudenstein IV 40

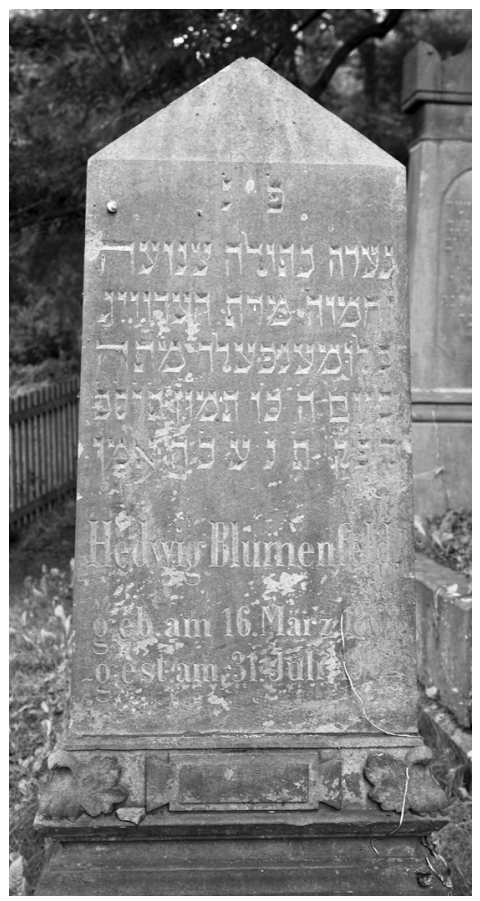

$\mathrm{H}_{9 \mathrm{I}} \cdot \mathrm{B} 56 \cdot \mathrm{T} 27$

פע"ג Hier ist geborgen

נערה בתולה צנועה פ"נ eine unverheiratete Frau, bescheiden und lieblich (war sie), Frau Hedwig

Blumenfeld. Sie starb

5 am Tag 5, 26. Tammuz 662

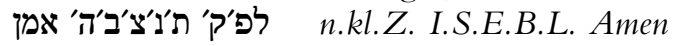

Hedwig Blumenfeld geb. am i6. März I 868

gest. am 3 I. Juli I9O2

Rückseite

Die Liebe verbindet 10

die Lebenden

mit den Toten

3 Lies חמודה. 
Amalie Dannenberg, geb. König

$$
\text { 6.7.I } 845-4.1 .1903
$$

Geb. in Felsberg/Hessen - Eltern: Sußmann König - Fratche Speyer - Ehemann: Selig Dannenberg IV 27 • Kinder: Karl (I870-I942); Clara, verh. de Groot (I872-I943, Sobibor); Albert (I875-I944, Theresienstadt); Sally (I878-I94I, Riga); Franziska (I882I940, Göttingen: Grab 4I 8)

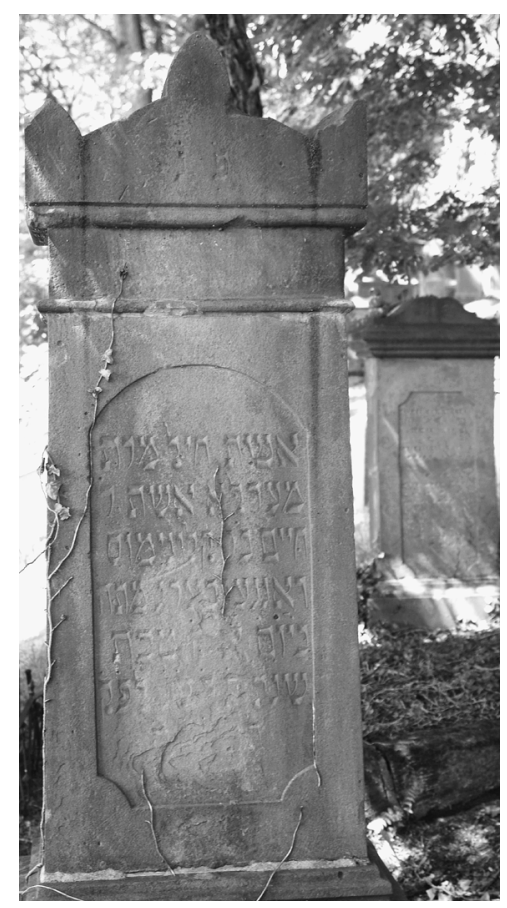

H IOI $\cdot$ B $59 \cdot \mathrm{T} 23$

פע"נ Hier ist geborgen

אשת חיל מרת פ" eine tüchtige Ehefrau, Frau

Merle, Ehefrau des $H$.

חיים בר קלונימוס Chajjim Sohn des Kalonymus

5 Dannenberg. Sie starb

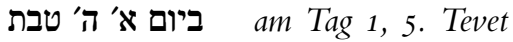

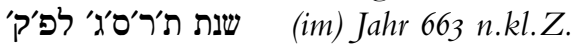

ת.S.E.B.L.

Rückseite

Hier ruht

Amalie Dannenberg 10

geb. König

geb. d. 6. Juli I 845

gest. d. 4. Jan. I9O3

Friede ihr! 
Mathilde Meyenberg, geb. Wollberg

I9.I2.I 84 I - I6.8.I9O3

Ehemann: Kaufmann Meyenberg IV 9 - Kinder: Minna (I872-1938, Frankfurt a. M.); Rosa (I876); Regina, verh. Polak (I88I-I943, Sobibor)

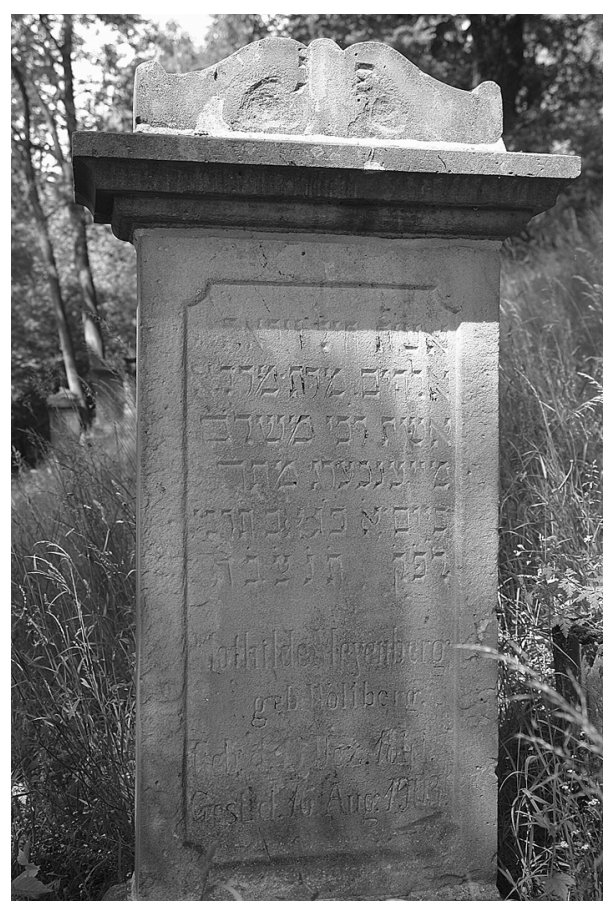

$\mathrm{H} \mathrm{I} 48 \cdot \mathrm{B} 64 \cdot \mathrm{T}$ I7

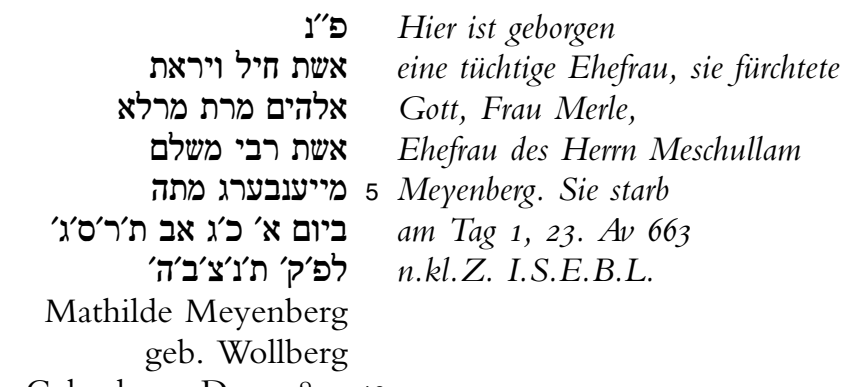

Geb. d. I9. Dez. I84I 10

Gest. d. I6. Aug. 1903

2f s. Prov 3 I, IO.3O 


$$
\begin{aligned}
& \text { Simon Dannenberg } \\
& \text { I4.9.I } 822-27 . \text { I I.I903 }
\end{aligned}
$$

Handelsmann - Eltern: Moses Selig Dannenberg III 3a - Rosette Meyenberg III 3 . Ehefrau: Henriette Brandes IV 20 - Kinder: s. ebd.

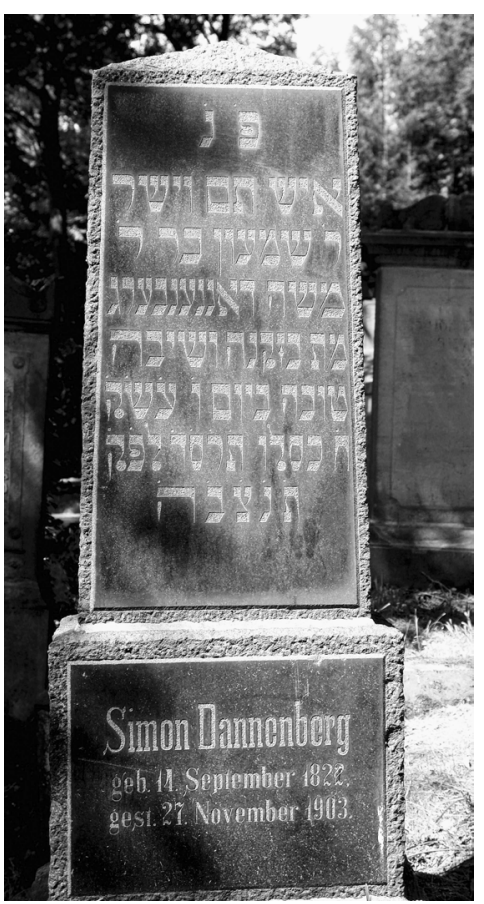

$\mathrm{H} \mathrm{IOO} \cdot \mathrm{B} 50 \cdot \mathrm{T}$ I8

פיפ $\quad$ Hier ist geborgen

איש תם וישר

H. Schimon, Sohn des H.

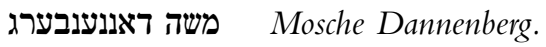

5 Er starb in hohem und gutem

טובה ביום ו' ע'ש'ק' Alter am Tag 6, am V(orabend des) hl. Sch(abbat),

8. Kislew 664 n.kl.Z.

S'ת.S.E.B.L.

Simon Dannenberg

geb. I 4. September I 82210

gest. 27. November 1903

2 s. Hi I, 8 
Rosalie Eichenberg, geb. Edelstein

I.7.I $846-$ I7.2.1904

Eltern: Alexander A. Edelstein III 63 - Minna Grunsfeld - Ehemann: Meier Leiser Eichenberg IV I8 · Kinder: Frieda, verh. Jakobi (1873-I942, Theresienstadt); Alexander (I 877-I943, Auschwitz)

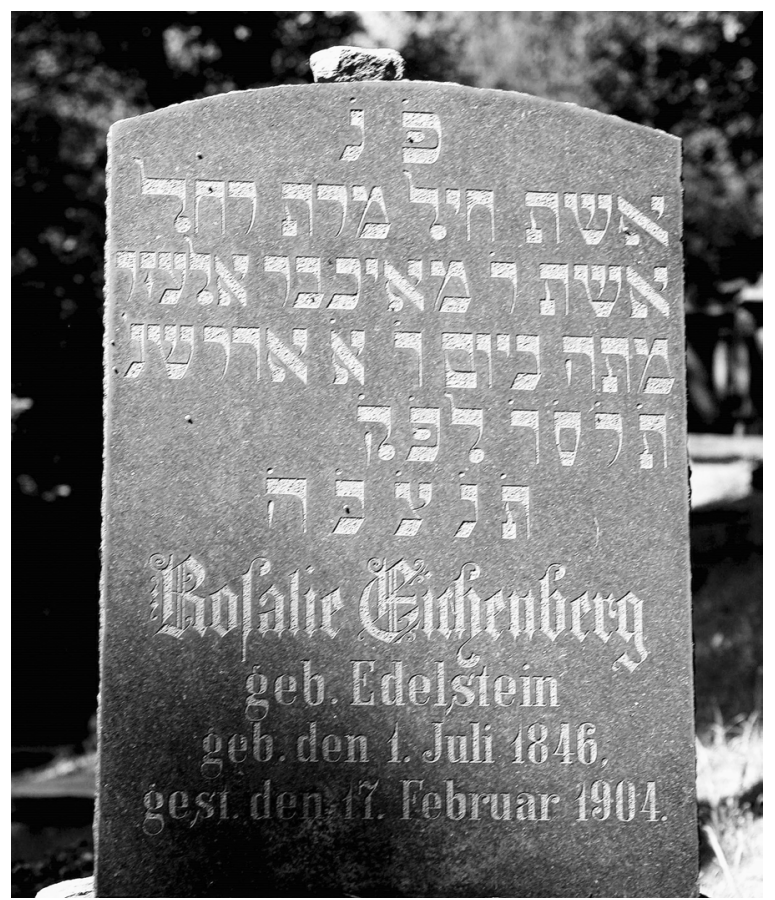

$\mathrm{H} 69 \cdot \mathrm{B} 50 \cdot \mathrm{T} 24$

פ"נ Hier ist geborgen

אשת חיל מרת רחל משל

Ehefrau des H. Meir Sohn des Elazar.

Sie starb am Tag 4, 1. Adar (im) Jah(r)

'ת'ת 5664 n.kl.Z.

I.S.E.B.L.

Rosalie Eichenberg

geb. Edelstein

geb. den I. Juli I 846

gest. den I7. Februar I904 10

2 s. Hiob I,8 - מאיכ verschrieben für מאיר 


\section{Meier Levi Eichenberg}

$$
\text { 27.3.I } 824-26 . \text { I I.I9O4 }
$$

Vieh- bzw. Pferdehändler · I883-I895 Bürgervorsteher · Eltern: Levi M. Eichenberg III 74 - Henriette Jacobsohn III $75^{\cdot}$ Ehefrau: Mathilde Eichenberg IV $37 \cdot$ Kinder: s. ebd.

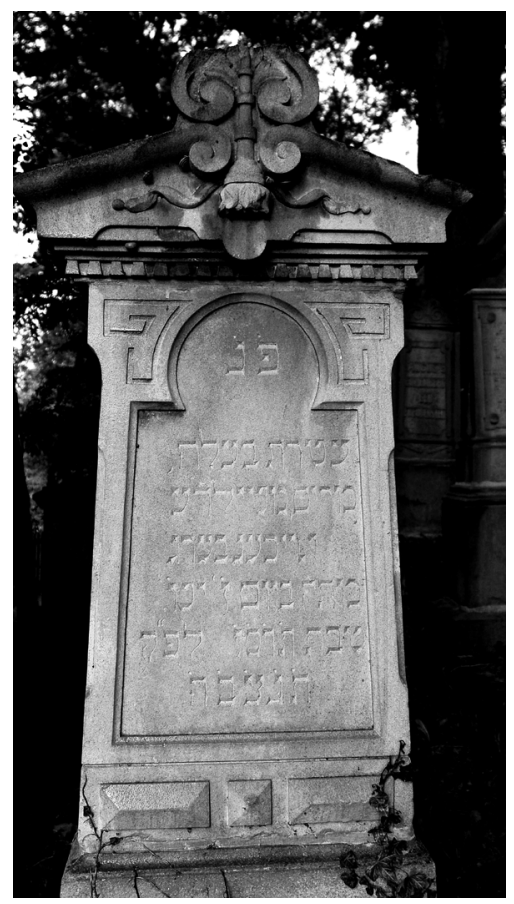

$\mathrm{H} 95 \cdot \mathrm{B} 57 \cdot \mathrm{T}$ I9

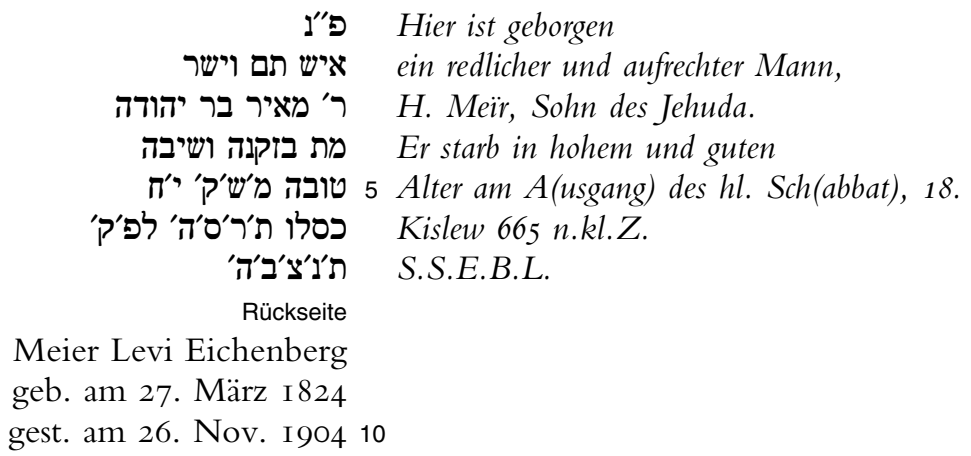

$4 f$ vgl. Gen 25,8 - 9 Auf der Mappa Nr. 24 (s. Dokument Nr. $3^{\star}$ ) ist als Geburtstag der 27. Nisan $(5) 584=25$. April I 824 genannt. 
Lina Eichenberg, geb. Edelstein

I I.I2.I $826-9.12 .1905$

Eltern: Moses A. Edelstein III I - Rosette Eichenberg III 2?) · Ehemann: Levi Eichenberg IV I4 · Kinder: Emma (I853-I94I); Röschen (I856); Johanne V I
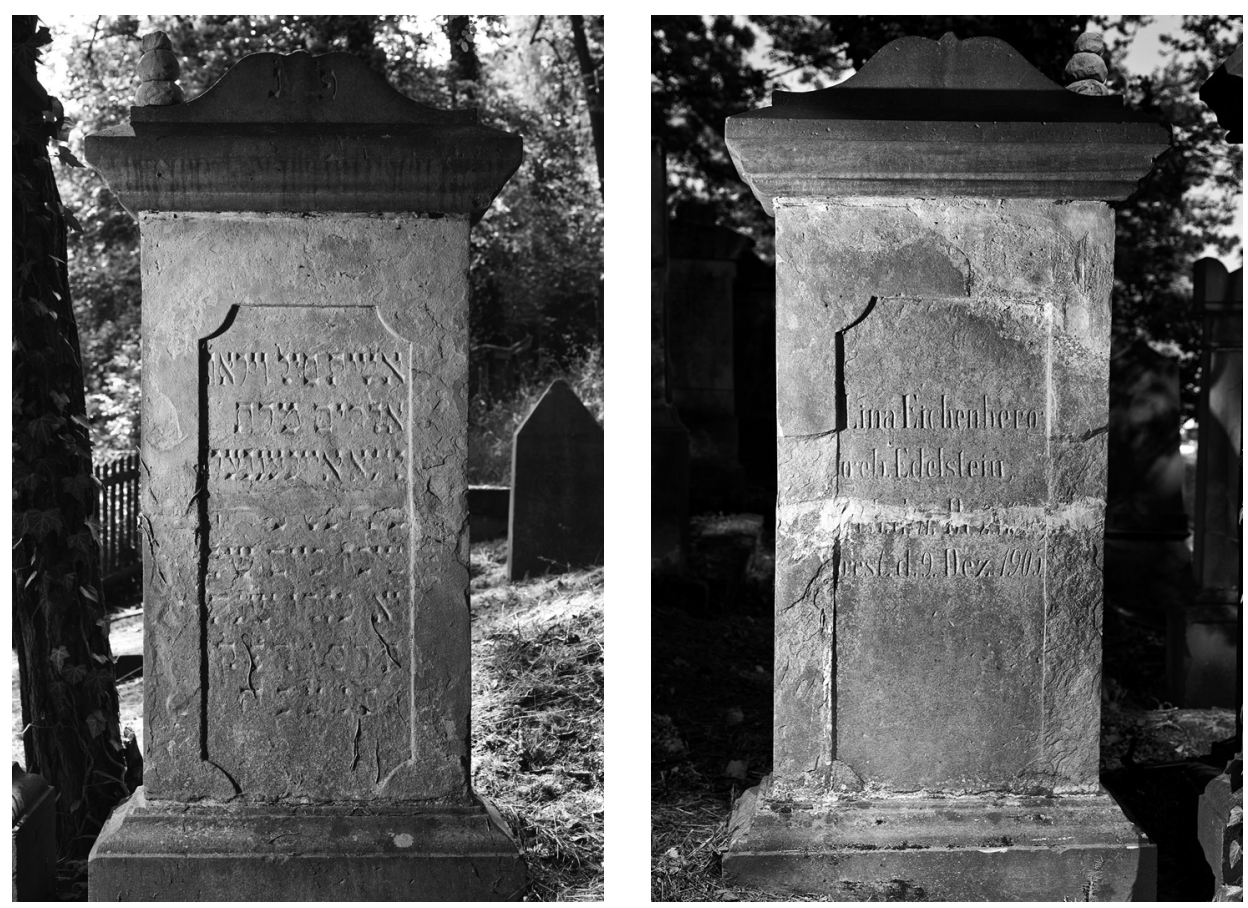

$\mathrm{H}$ I05 $\cdot$ B $58 \cdot \mathrm{T}$ i9

Stein wieder zusammengesetzt

פ"ג Hier ist geborgen

אשת חיל ויראת eine Frau, tüchtig (war sie) und fürchtete

Gott, Frau

Lina Eichenberg.

5 Sie starb in gutem

טובה ביום ש'ק' Alter am Tag des hl. Sch(abbat),

11. Kislew (im) Jahr

ת'ת'ת.kl.Z.

I.S.E.B.L.

Rückseite

Lina Eichenberg 10

geb. Edelstein

geb. d. I I. Dez. I 826

gest. d. 9. Dez. I905

2 s. Prov 3 I, IO 
Hugo Polak

$$
\text { I I.4.1906 - 8.8.1906 }
$$

Eltern: Israel/Julius Polak - Regine Meyenberg

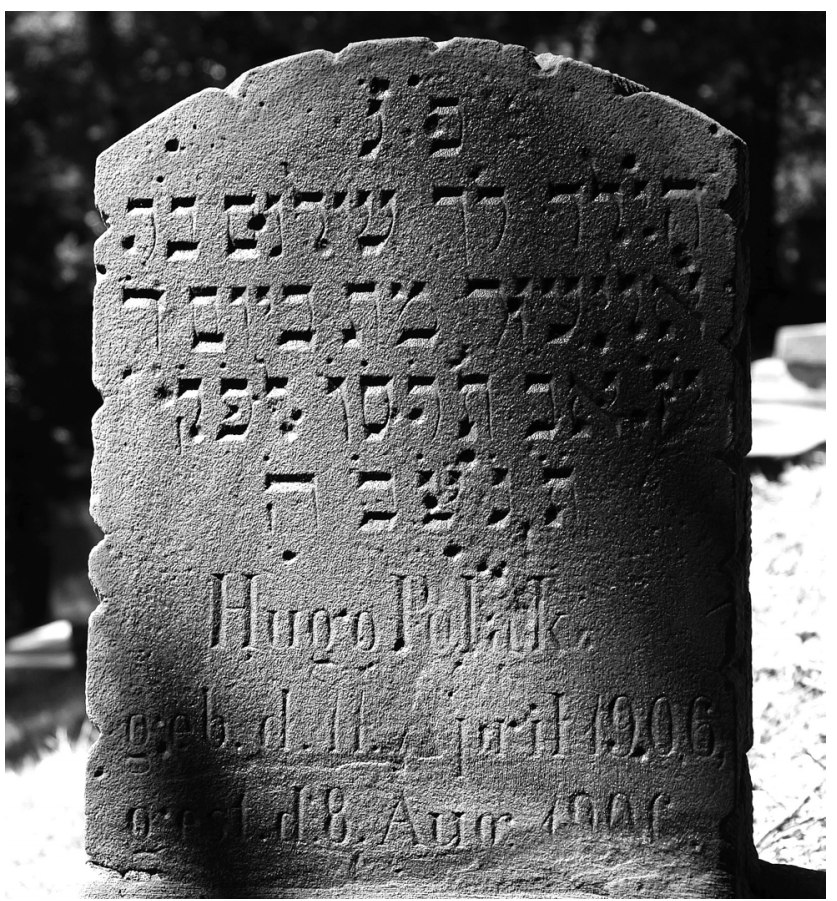

$\mathrm{H} 50 \cdot \mathrm{B} 37 \cdot \mathrm{T}$ Iо

\section{פ"פ Hier ist geborgen}

der zarte Knabe Schalom, Sohn

des Eliëser. Er starb am Tag 4,

17. Av 666 n.kl.Z.

5 S.S.E.B.L.

Hugo Polak

geb. d. I I. April I906

gest. d. 8. Aug. 1906

2 zum Namen „Schalom“ s. IV 39 
Sara Rosenbaum, geb. Blumenberg 26.IO.I 826 - I.I2.I906

Geb. in Sudheim - Eltern: Meier Blumenberg (Sudheim) - Betti/Perle Stehberg - Ehemann: Meyer Rosenbaum III 8I - Kinder: Johanna IV 50; Salomon IV 44; Rosalia (I 858-I86I, Sudheim); Mathilde IV 46

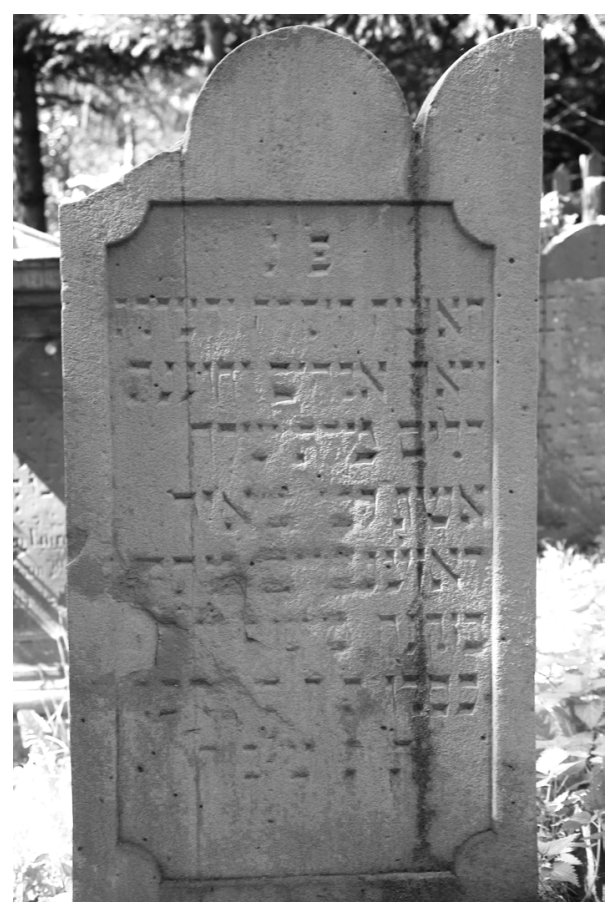

$\mathrm{H}$ I $15 \cdot \mathrm{B} 60 \cdot \mathrm{T}$ I5

פ"ג Hier ist geborgen

האשה היקרה והצדקת die geachtete und wohltätige Frau,

יראת אלהים וחוננת

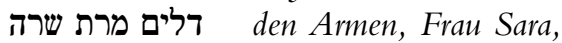

5 Ehefrau des Herrn Meir

Rosenboim. Sie starb

im Alter [(am) A(usgang des) heiligen Sch(abbat) 15.]

Kislew 667 n.kl.Z.

I.S.E.B.L.

Rückseite

Frau Sara Rosenbaum, 10

geb. Blumenberg.

geb. d. 26. Oktober I 826 ,

gest. d. I. Dezember I906.

3 s. Prov 3 I,3O $12 \mathrm{StB}$ I6.Io.I825 $1 \mathbf{1 3}=\mathrm{StB}$ 
Mirjam Mathilde Eichenberg, geb. Eichenberg

$$
\text { 3.2.I } 84 \mathrm{I}-\text { 5.I.I9O7 }
$$

Eltern: Simon S. Eichenberg III I6 - Julie Freudenstein III $84 \cdot$ Ehemann: Meyer Levi Eichenberg IV $38 \cdot$ Kinder: Albert (I 86I-I922, Düsseldorf); Siegfried (I 862-I953, Buenos Aires); Selly (I864-I865); Minna (I865-I909, Gailingen); Clara (I867-I954, Sao Paulo); Olga (I869-I943/44, Treblinka); Louis (I87I-I92I, Krefeld); Ida, verh. Lamm (I873I944, Theresienstadt); Oscar (I875-I936, Buenos Aires); Willi IV 36; Richard (I879I945, Buenos Aires); Harry (I88I-I943, Sobibor); Grete, verh. Blank (I883-I944, Theresienstadt); Fritz (I889-I943 Majdanek)

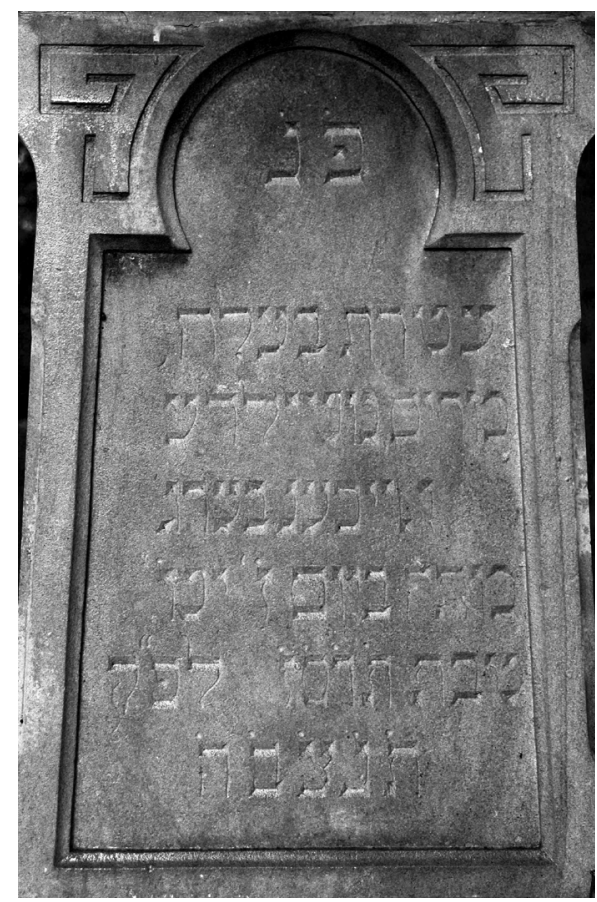

Rückseite

Mathilde Eichenberg geb. Eichenberg geb. d. 3. Februar I84I gest. d. 5. Januar 1907

$\mathrm{H} 93 \cdot \mathrm{B} 55 \cdot \mathrm{T}$ I9

פע"נ Hier ist geborgen

die Krone ihres Ehemannes,

Mirjam, Mathilde

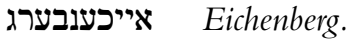

5 Sie starb am Tag 7, 19.

Tevet 667 n.kl.Z.

I.S.E.B.L.

2 Zitat Prov I $2,4 \cdot 5$ Keine Erwähnung des Schabbat als Todestag, anders z.B. IV 38 
Joel S. Rothschild

I 8.2.I8I9 - I 5.3.I9O9

Kaufmann - Eltern: Salomon Rothschild III 40 - Fanny Hess III 4I - Ehefrauen: I. Betty Davison II 53; 2. Amalie Rosenbaum (I833-I865); 3. Bertha Gans IV 42 - Kinder: zu I) s. II 53; zu 2) Fanny (I 856-I939, Hannover); Berta III 94; Johanne (I863-I 864); zu 3) s. IV 42

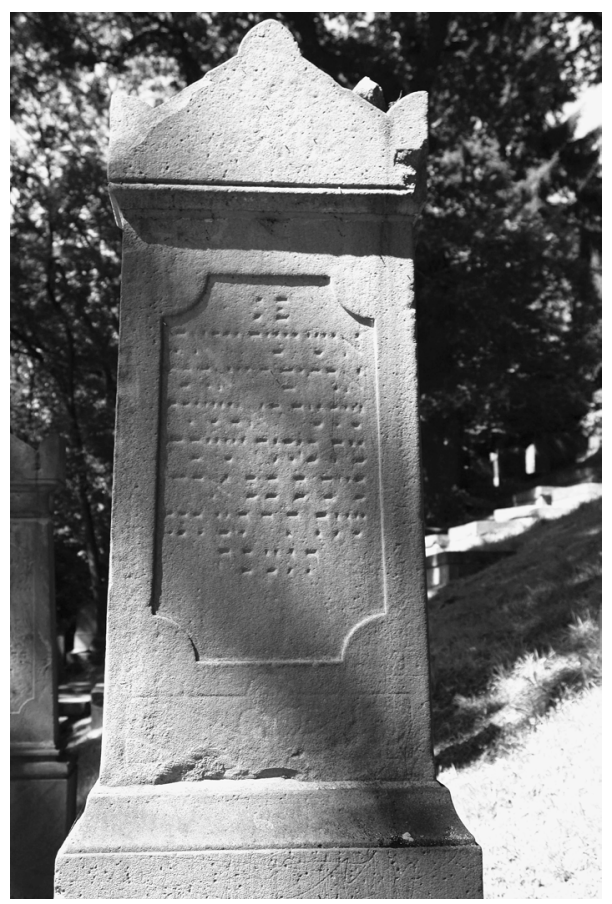

$\mathrm{H} 105 \cdot \mathrm{B} 60 \cdot \mathrm{T} 23$

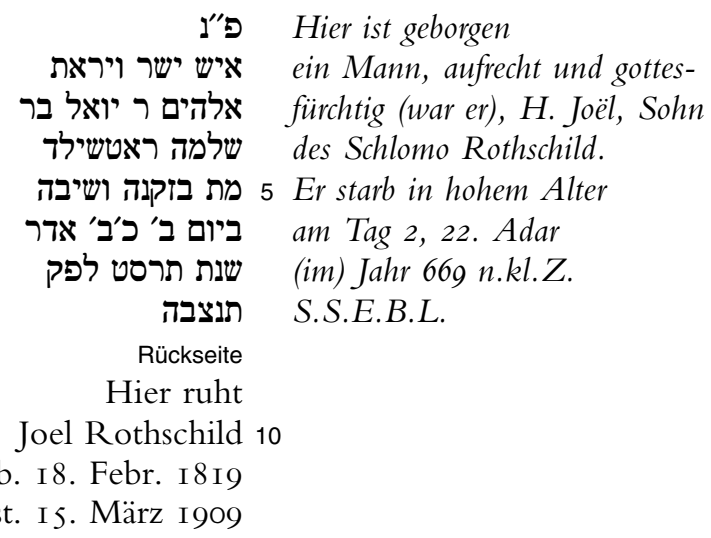

2 s. Hi I, 8 
Willi Eichenberg

I.I I. I $876-2.9 .1909$

Eltern: Meyer Levi Eichenberg IV 38 - Mathilde Eichenberg IV 37

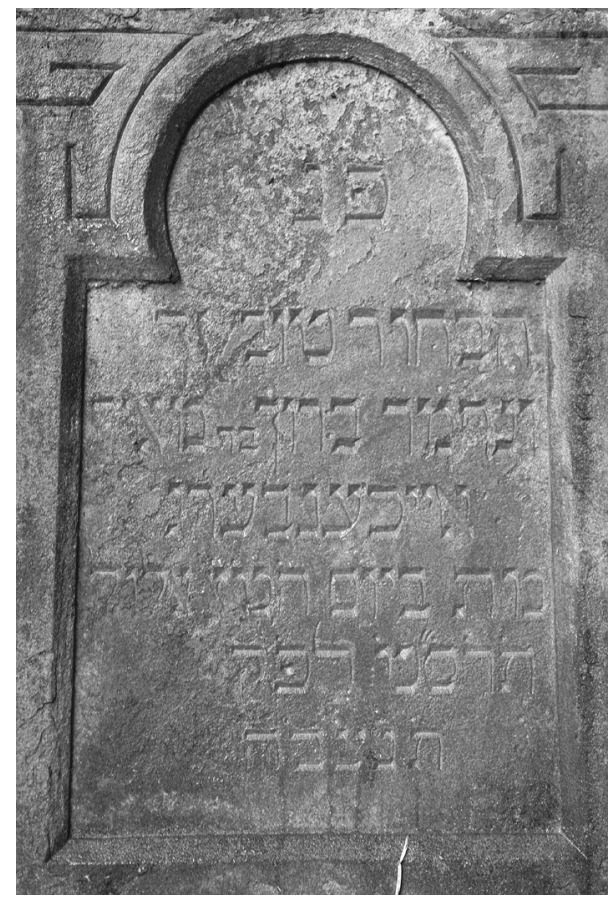

$\mathrm{H} 94 \cdot \mathrm{B} 54 \cdot \mathrm{T}$ I9

פע"ג Hier ist geborgen

der gute, lautere und liebenswerte

Junggeselle Baruch, Sohn des Meir

Eichenberg.

5 Er starb am Tag 5, 16. Elul

ת'ת.S.B.B.L.

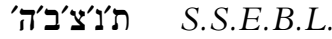

Rückseite

Willi Eichenberg

geb. d. I. Nov. I 876

gest. d. 2. Sept. I909 10 
Berta Blumenfeld, geb. Freudenstein

$$
\text { 5.7.I } 833-2 \text { I.7.I9I } 2
$$

Gest. in Göttingen · Eltern: Samuel Meyer Freudenstein III 68 - Caroline Traube III 67 . Ehemann: Sally Blumenfeld IV $39 \cdot$ Kinder: Lina (I 866-I943, Theresienstadt), Hedwig IV 4I, Karl (I869-I940, Brandenburg a. d. Havel [Opfer der „Euthanasie“]), Johanna (I87II944, Theresienstadt), Hugo (I873-I942, Treblinka)

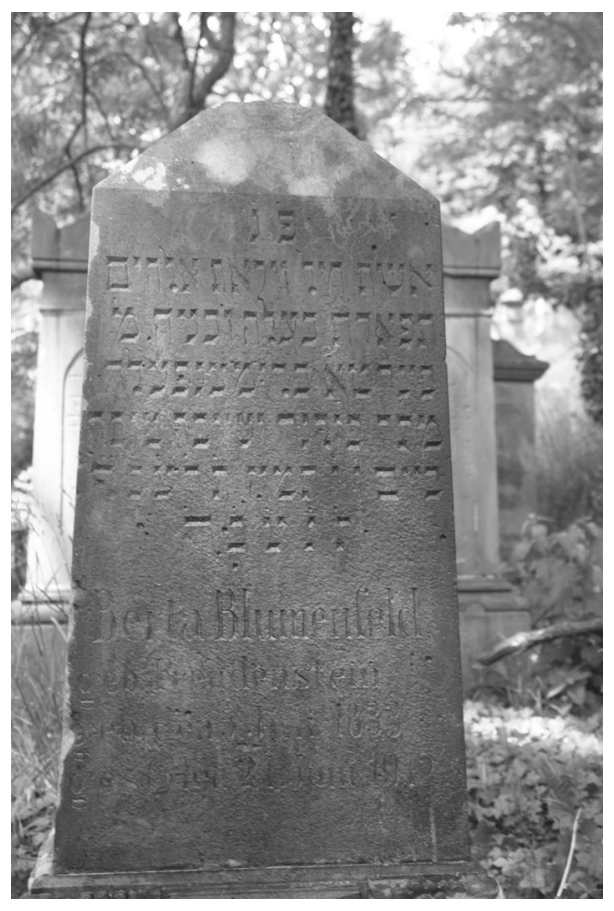

Rückseite

Was Liebe vereint, kann der Tod nicht trennen

$\mathrm{H} \mathrm{III} \cdot \mathrm{B} 55^{\cdot} \mathrm{T} 27$

פע"נ Hier ist geborgen

תשת חיל ויראת אלהים

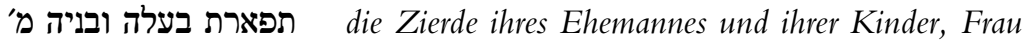

Berta Blumenfeld.

5 Sie starb in hohem und guten Alter

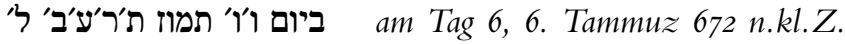

I.S.E.B.L.

Berta Blumenfeld

geb. Freudenstein

geb. den 5. Juli I 83310

gest. den 2 I. Juni I9I 2

2 s. Prov $3 \mathrm{I}, \mathrm{IO} .30 \cdot 5$ vgl. Gen 25,8 
Bertha Speyer, geb. Heilbrunn

23.7.I $855-21.7 .1912$

Geb. in Immenrode bei Sondershausen/Thüringen - Eltern: Mendel Heilbrunn - Minna Stern · Ehemann: Aron Speyer IV 33 · Kinder: Toni (I 886-I 888); Meyer (I 888); Max IV 3

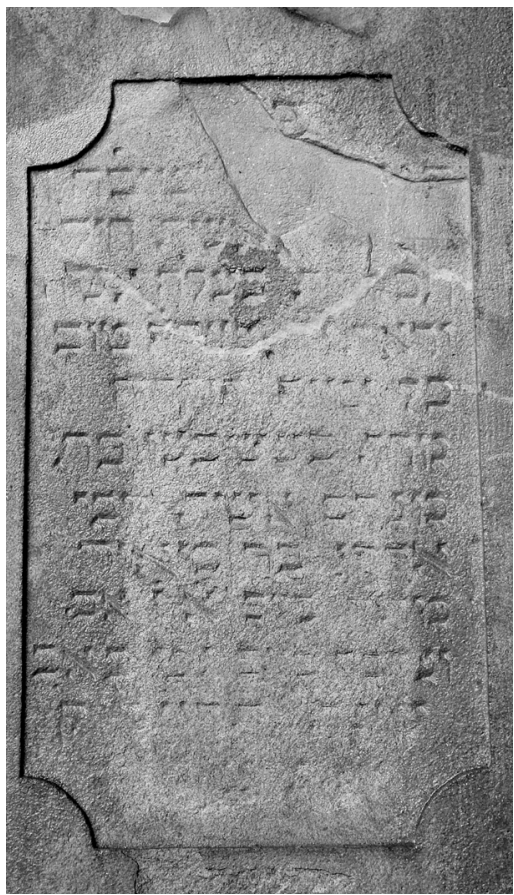

Rückseite

Ein Vorbild edlen Sinns

[und reiner] Sitte, stand waltend sie in ihres Hauses Mitte. Bertha Speyer, geb. Heilbrun, geb. am 23. Juli I 855 gest. am 2 I. Juli I9I 2

H г39 $\cdot$ B $60 \cdot$ T $24 \cdot$ Stark beschädigt

פע"נ Hier ist geborgen

(אשה] החשובה

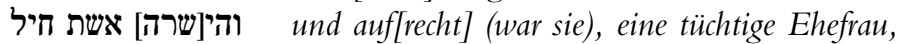

die Zierde ihres Ehemannes, eine Frau,

5 G(ott) fürchtend, Gutes schaffend

all ihre Tage, die geachtete

Frau Besschen, Tochter

des Menachem, Ehefrau des Herrn

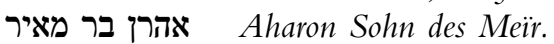

10 Sie starb am Tag 1, 7. Av

ונקבר]ה] ביום ג' ט' באב

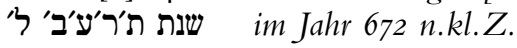

תנצבה I.S.E.B.L.

3-5 vgl. Prov 3 I, Io - 11 Der 9. Av (Tischa b'av) wird als Trauer- und Fasttag begangen im Gedenken an die Zerstörung des Jerusalemer Tempels durch die Römer im Jahr 70 chr. Z. - $20 \mathrm{StB} 23 \cdot 7.1856$ 


\section{Meier Eichenberg}

$$
\text { 5.4.I } 835 \text { - II.I.I9I } 4
$$

Pferdehändler · Eltern: Leiser M. Eichenberg III 79 - Friederike Stehberg III 78 • Ehefrau: Rosalie Edelstein IV I9 · Kinder: s. ebd.

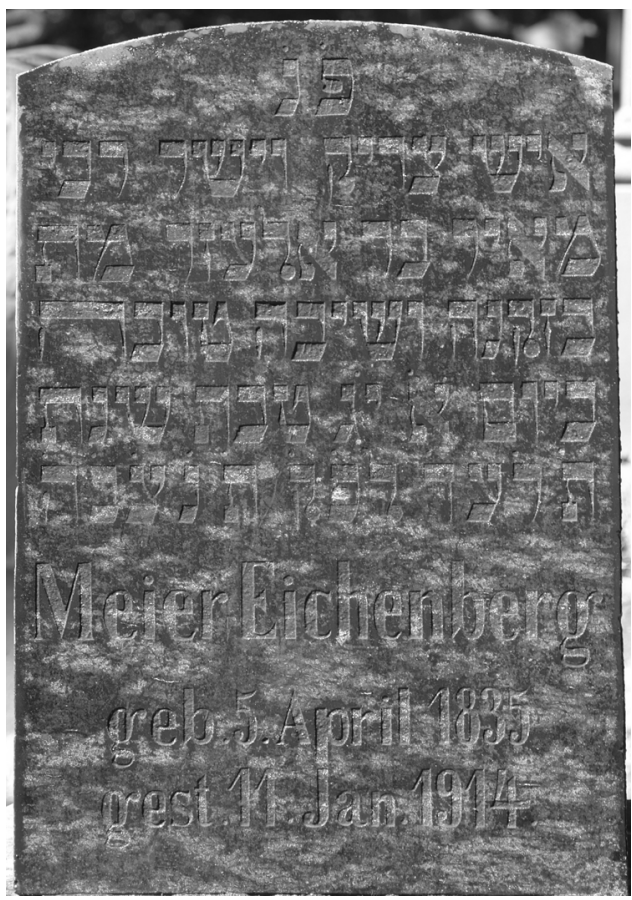

$\mathrm{H} 67 \cdot \mathrm{B} 43 \cdot \mathrm{T} 24$

\section{פעינ Hier ist geborgen}

איש צדיק וישר רבי פיש

Meir, Sohn des Elazar. Er starb

in hohem und gutem Alter

5 am Tag 1, 13. Tevet (im) Jahr

ת'ת 674 n.kl.Z. S.S.E.B.L.

Meier Eichenberg

geb. 5. April I 835

gest. I I. Jan. I9I 4 


$$
\begin{gathered}
\text { Aron Speyer } \\
\text { 26.9.I843-28.2.I9I5 }
\end{gathered}
$$

Geb. in Röhrenfurth bei Melsungen/Hessen - Kaufmann, in Adelebsen seit ca. I875 . I 899-I905 sowie seit I9 I s stellv. Vorsitzender der Synagogengemeinde, daneben seit I 899 2. und seit I9I I I. Vorsitzender der Chewra Kaddischah - Eltern: Meyer Speyer - Sara Speyer - Ehefrauen: I. Therese Heilbrunn III 38, 2. Bertha Heilbrunn IV 35 - Kinder: s. III 38 und IV 35 .

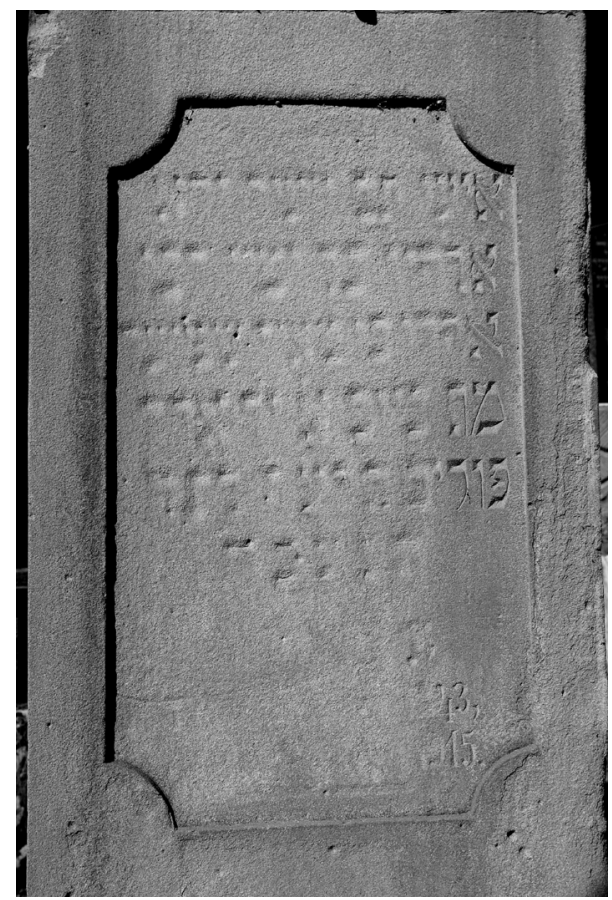

$\mathrm{H} 99 \cdot \mathrm{B} 59 \cdot \mathrm{T} 23$

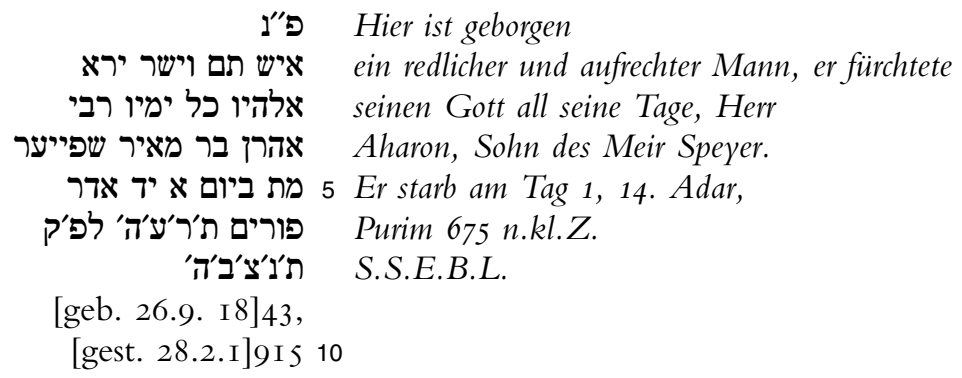

9-10 Angaben ergänzt nach der StB 


\section{Ludwig Stehberg \\ $29.3 .1889-6.5 .1915$}

Handlungsgehilfe $\cdot$ Reservist im Preußischen Infanterieregiment Nr. I64, gestorben im Feldlazarett von Viéville-sous-les-Côtes (Dép. Meuse) »in Folge der Verwundung im Gefecht auf den Combreshöhen" (StB); s. auch Ehrenmal neben und Gedenkfenster in der St. Martini-Kirche - Eltern: Albert Stehberg IV 30 - Rosa Stehberg IV 32

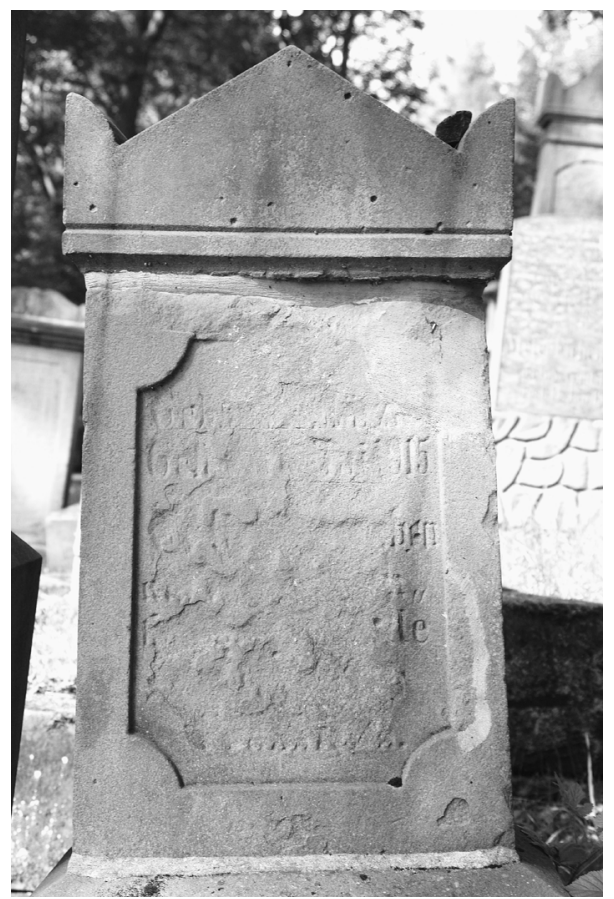

Rückseite

Den Heldentod

starb beim Sturm auf

Les Eparges unser

lieber Sohn u. Bruder

Ludwig Stehberg

I.R. I64. Iо. Komp.

Jehuda ben Abrohom

$\mathrm{H} 64 \cdot \mathrm{B} 49 \cdot \mathrm{T}$ I 8

Gedenkstein, Vorderseite inzwischen stark abgeblättert

Geb. am 29.

März I 88[9]

Gest. am 6. Mai I9I5

Er liegt begraben

auf dem Ehren 5

friedhof in Vieville

sous les côtes

Frankreich

15 Schreibung "Abrohom» entspricht aschkenasischer Aussprache. - Quelle: GbL 


\section{Rosa Stehberg}

2I.II.I854-26.II.I9I6

Ehemann: Albert Stehberg IV 30 - Kinder: Ida V 3; Martha, verh. Lippers (I883-I944 Auschwitz); Hilda III 85; Sophie (I887-I934, Vechta: Grab 3 ; Ludwig IV 3I; Hugo (I89I-I965, Santiago de Chile); Margarete V 2; Erich (I898-I94I, Minsk)

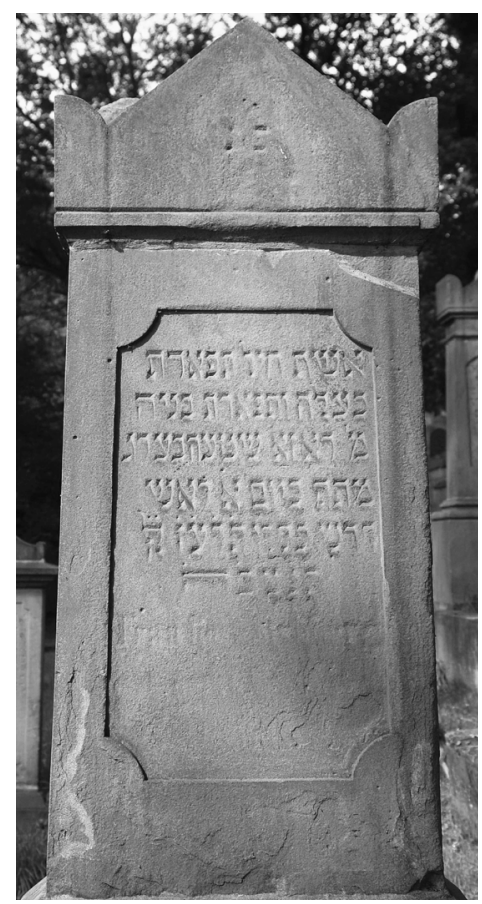

$\mathrm{H} \mathrm{I00} \cdot \mathrm{B} 60 \cdot \mathrm{T} 23$

\section{פ"ג Hier ist geborgen}

אשת חיל תפארת פ" eine tüchtige Ehefrau, die Zierde

בעלה ותפארת בניה

F(rau) Rosa Stehberg.

5 Sie starb am Tag 1, am Anfang

des Monats Kislew 677 n.kl.Z.

תנצב'ה' I.S.E.B.L.

Frau Rosa [Stehberg]

Rückseite

Wer Liebe sät,

wird Liebe ernten. 10

2f s. Prov 3 I, IO 


\section{Betti Löwenstern}

$$
\text { 3.4.I } 839-23.2 \text {.I9I } 7
$$

Eltern: Jacob Marcus Löwenstern III 9 (?) - Johanne Dahl III Io (?)

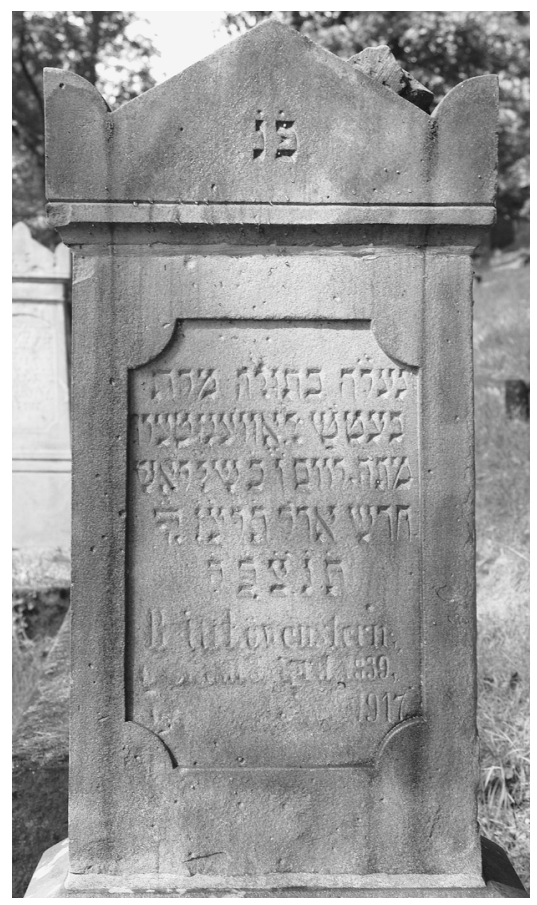

$\mathrm{H} 93 \cdot \mathrm{B} 60 \cdot \mathrm{T}$ I 8

פע"ג Hier ist geborgen

eine unverheiratete Frau, Frau

Betti Löwenstern.

Sie starb am Tag 6, 2. des Anfangs

5 des Monats Adar 677 n.kl.Z.

ת'ת'ניצ'ית' I.S.E.B.L.

Betti Löwenstern

ge[bore]n 3. April I 839

g[estorben 23. Febr.]I9I7

2 נערה בתולה, wörtl.: jungfräuliches Mädchen = Jungfer; oft aber auch allgemein für eine unverheiratete Frau verwendet. Q Quelle: GbL (Geburtstag) 
Johanna Rosenbaum

2.9.I 856 - IO.I.I9I 8

Eltern: Meyer Rosenbaum III 8I - Sara Blumenberg III 82

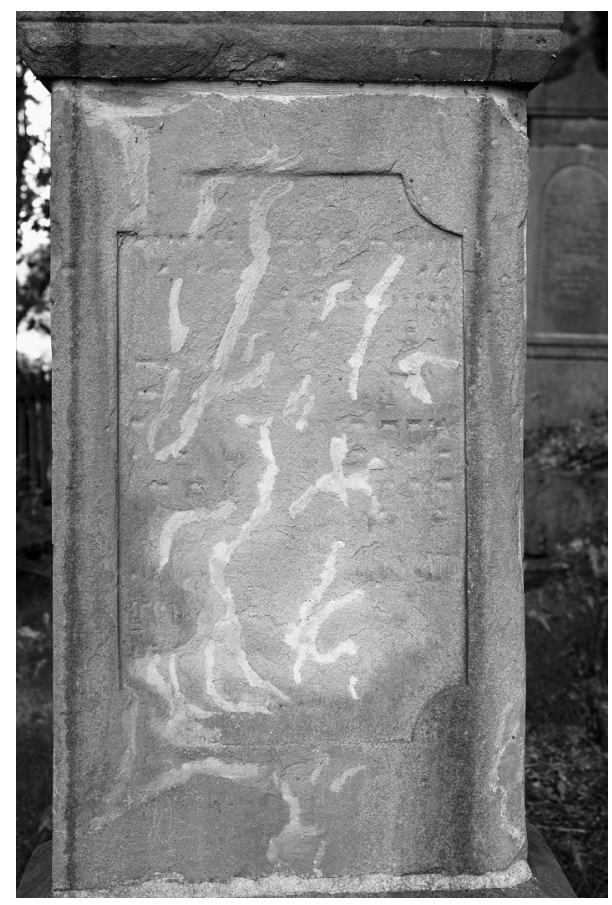

H I78/I $35 \cdot$ B 58/74 $\cdot$ T 20/33

Inschrift stark verwittert

פער Hier ist geborgen

eine unverheiratete Frau, bescheiden

und aufrecht (war sie). G[erechtigkeit ...]

[... Joha[nna Rosenbaum.]

5 Sie starb am Tag $[5,26$. Tevet $]$

67[8] n.kl.Z. I.S.E.B.L.

Jo[hanna Rosenba]um

geb [2.9.1 856$]$

ges[t IO.I.I9I8]

3 Gerechtigkeit im Sinn von Wohltätigkeit · 6 Datierung ergänzt nach StB - Quellen: $\mathrm{GbL} ; \mathrm{StB}$ 


\section{Albert Stehberg}

I2.I2.I $850-29.3 .19$ I 8

Kaufmann (Eisenwaren) · I883-I888 Vorsteher der Synagogen-Gemeinde, I899-I903 und I909 stellvertretender Vorsteher und Rechnungsführer, I895-I897 und I9II-I9I3 stellvertretender Vorsteher der Chewra Kaddischa. - Schiedsmann des Fleckens Adelebsen - Erbauer des Vorderhauses Lange Straße 27 • Eltern: Levi Stehberg III 6 - Julie Dahlberg ebd. - Ehefrau: Rosa Stehberg IV $32 \cdot$ Kinder: s. ebd.

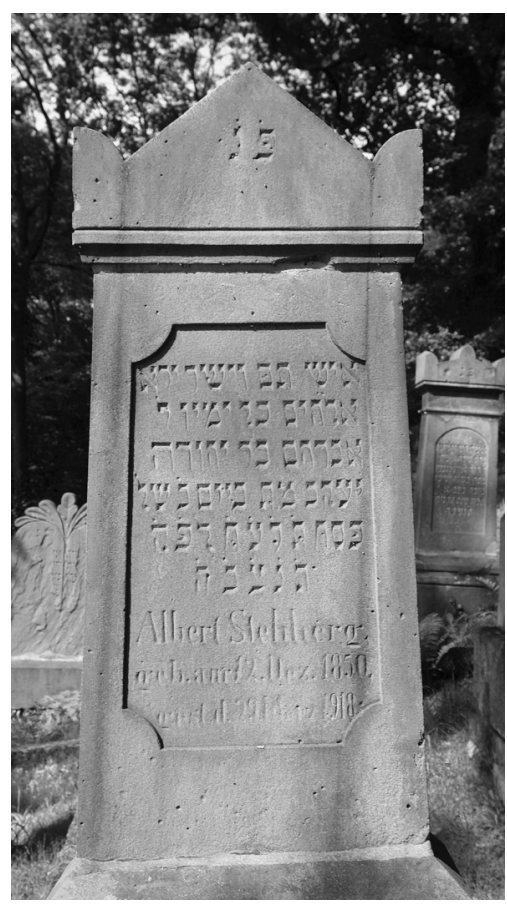

$\mathrm{H}$ IO2 $\cdot$ B $59 \cdot$ T 23

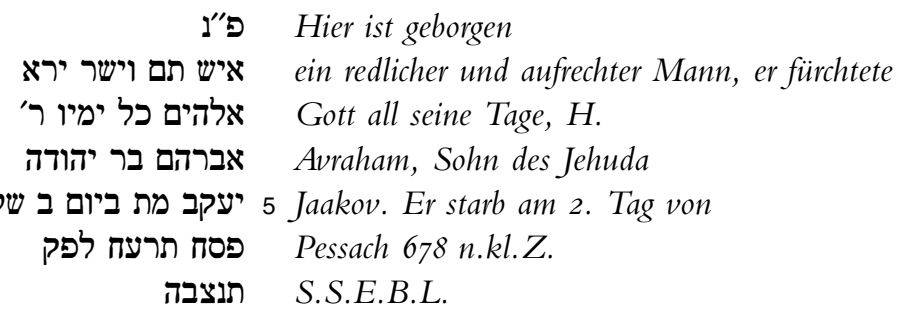

Albert Stehberg

geb. am I2. Dez. I 850

gest. d. 29. März I9I 810

2f s. Hi I, 8 
Henriette Meyenberg, geb. van Campen

$$
\text { I4.8. I } 836 \text { - I 5.IO.I9I } 8
$$

Geb. in Emden. I9I5 als Witwe aus Esens nach Adelebsen gezogen zu ihrer Nichte Regina und deren Ehemann Julius Polak. Eltern: Moses van Campen - Sara van Zanten • Ehemann: Samuel Meyenberg (Lohgerber, geb. I832 in Adelebsen)

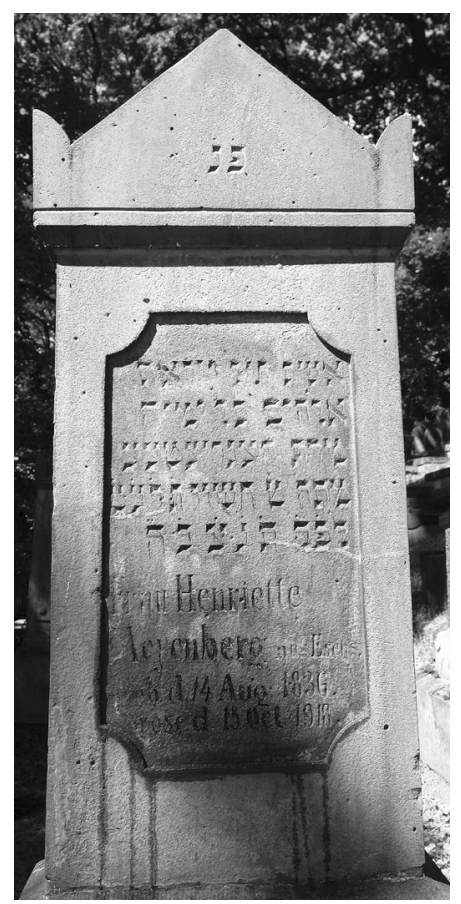

H $100 \cdot$ B $59 \cdot$ T 2 I

פמינ $\quad$ Hier ist geborgen

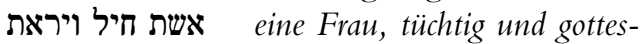

fürchtig (war sie) all ihre Tage,

Frau Henriette.

5 Sie starb am 9. Cheschwan 679

n.kl.Z. I.S.E.B.L.

Frau Henriette

Meyenberg aus Esens

geb. d. I4. Aug. I 836

gest. d. I5. Oct. I9I 810

2f. s. Prov 3 I, IO.3O 4 Die Doppelung des $\boldsymbol{y}$ anstelle des $\boldsymbol{U}$ geht vermutlich auf eine Verwechslung der Buchstaben durch den Steinmetzen zurück. 
Isidor Müller

$$
\text { 3I.I2.I } 848 \text { - 30.4.I9I9 }
$$

Kaufmann, zunächst in Adelebsen, seit I9I I in Wibbecke, Bahnhofstraße (heute Wibbecker Straße 8) - Eltern: Herz Aron Müller III 2 I - Esther Stehberg III 22 - Ehefrau: Goldine. Eichenberg IV 48 - Kinder: s. ebd.

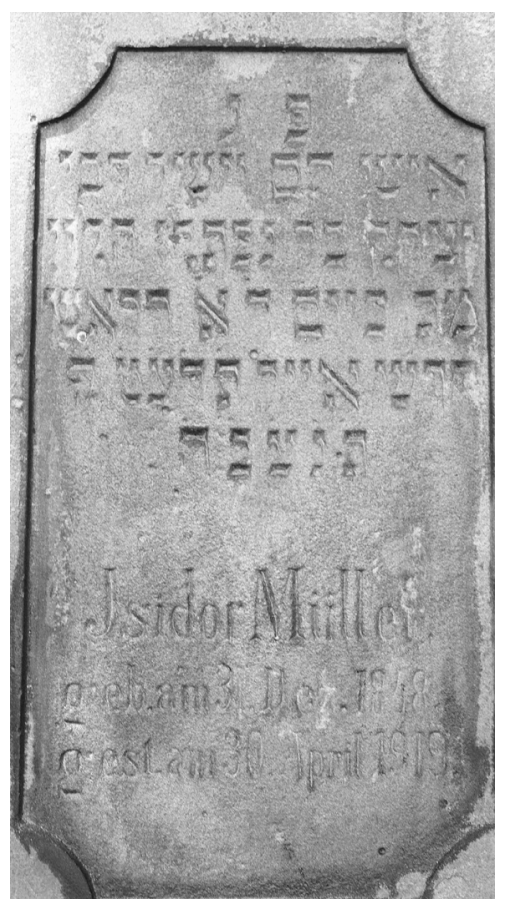

$\mathrm{H} \mathrm{IO} \cdot \mathrm{B} 60 \cdot \mathrm{T} 22$

פ"ג Hier ist geborgen

איש תם וישר רבי

יצחק בר נפתלי הלוי Jizchak, Sohn des Naphtali ha-Levi.

Er starb am Tag 4, dem 1. (Tag) des Anfangs des Monats Ijjar 679 n.kl.Z.

S.S.E.B.L.

Isidor Müller

geb. am 3I. Dez. I 848

gest. am 30. April I9I9

2 s. Hi I, $8 \cdot 8$ 30.I2.I 848 nach GbL 
Helene Katzenstein

$$
\text { 9.6.I } 848-26.7 .192 \mathrm{I}
$$

Eltern: Julius Katzenstein III 90 - Henriette Rosenbaum III 89

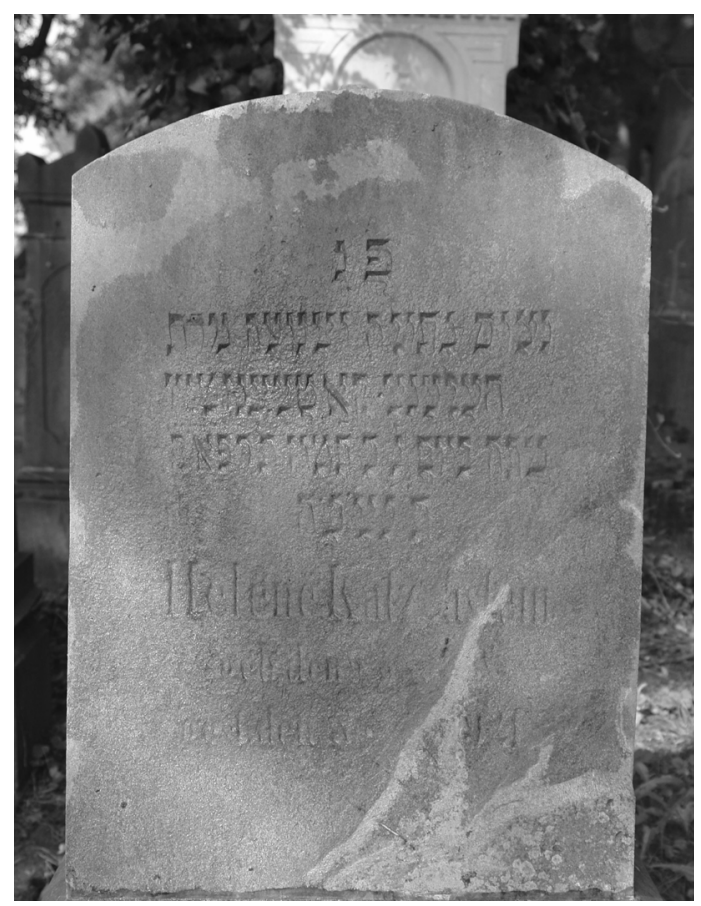

$\mathrm{H} 90 \cdot \mathrm{B} 65 \cdot \mathrm{T}$ I7

פעים Hier ist geborgen

eine freundliche und bescheidene, unverheiratete Frau, Helene Katzenstein.

Sie starb am Tag 3, 20. Tammuz 681 n.kl.Z. 5 I.S.E.B.L.

Helene Katzenstein geb. den 9. Juni 1848 gest. den 26. Juli I92 I 


\section{Leopold Stehberg}

I 8.8. I $860-28.8 .1922$

Kaufmann, Erbauer des Hauses Lange Straße $22 \cdot$ I 889-I92I/22 Vorsteher der Synagogengemeinde - Eltern: Herz Stehberg IV I6 - Betti Dannenberg IV i 5 - Ehefrau: Mathilde Rosenbaum IV $46 \cdot$ Kinder: s. ebd.

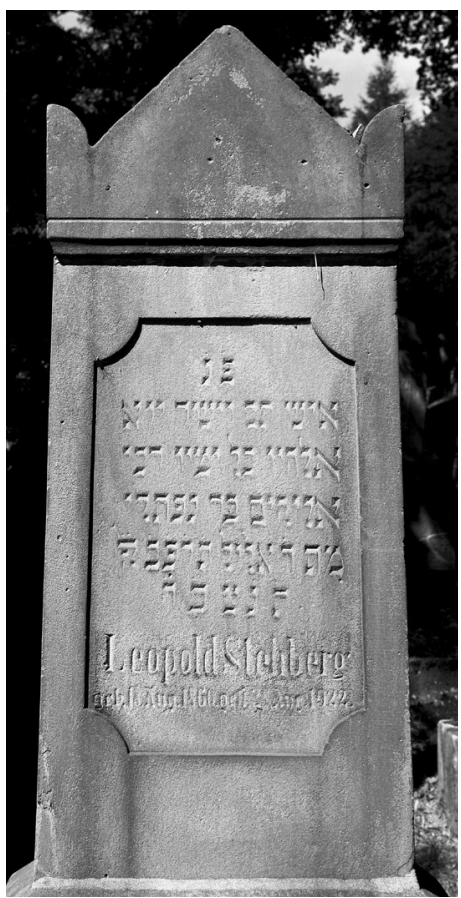

$\mathrm{H} \mathrm{IOO} \cdot \mathrm{B} 60 \cdot \mathrm{T} 22$

פ"ג $\quad$ Hier ist geborgen

איש תם וישר ירא פלי כיש

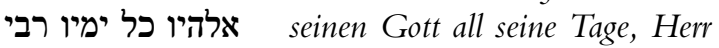

Eljakim, Sohn des Naphtali.

. 5 Er starb am 4. Elul 682 n.kl.Z.

S.S.E.B.L.

Leopold Stehberg

geb. I 8. Aug. I 860, gest. 28. Aug. I922

2f s. Hi I, 8 
Berta Arensberg, geb. Löwenstern

$$
\text { 8.4.I } 843 \text { - I 3.7.I } 923
$$

Eltern: Samuel Löwenstern III 48 - Fanni Grunsfeld III 47 • Ehemann: Joseph Arensberg III 35 - Kinder: Rosa (I868-I942, Hannover), Selma IV 43; Louis (I87I-I944, Berlin); $\operatorname{Max}(\mathrm{I} 873)$

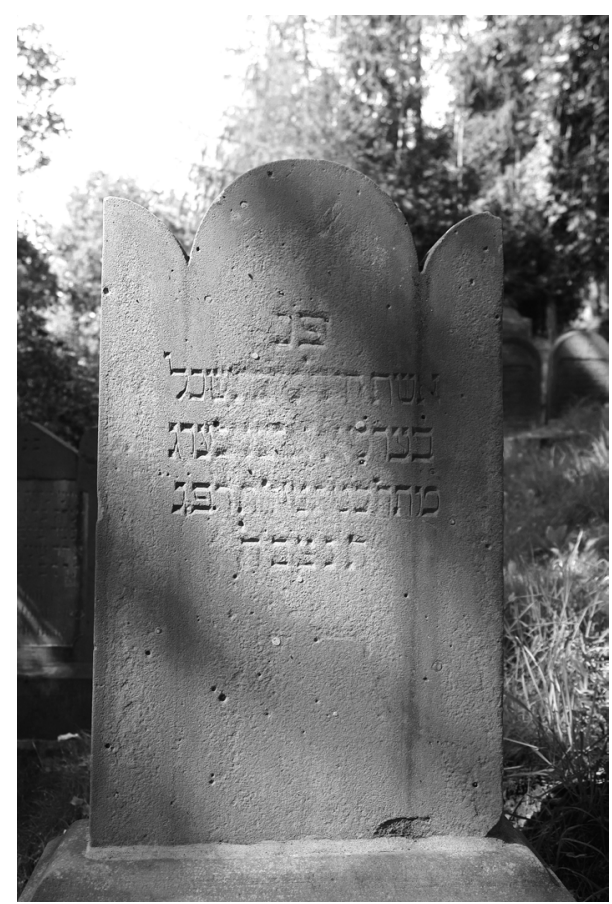

$\mathrm{H} 98 \cdot \mathrm{B} 57 \cdot \mathrm{T} \mathrm{I} 3$

פמינ Hier ist geborgen

אשת חיל טובת שכל פ"נ

Berta Arensberg.

Sie starb am 29. Tammuz 683

'ת'נ'צ'ב'ה 5 I.S.E.B.L.

Rückseite

Hier ruht

Berta Arensberg

geb. 8. April I 843

gest. I3. Juli I 923

2a s. Prov I2,4; 3 I, IO; Ruth 3, I I (Ruth) · 2b s. I. Sam 25,3 (Abigail) $\cdot \mathbf{8}=$ GbL 
Henriette Dannenberg, geb. Brandes

$$
\text { I I.I.I839 - I4.I.I924 }
$$

Geb. in Mansbach bei Hersfeld/Hessen - Eltern (?): Gerson Brandes - Adelheide Bodenheim - Ehemann: Simon Dannenberg IV 2 I - Kinder: Gerson (I 862), Rosa verh. Jankau (i 864-i942, Champs de Noë bei Drancy/Frankreich), Emma (i 867), Moses (I870), Joseph (I 872), Meta (I875-I942), Jenni, verh. Peters (I877-I944, Auschwitz)

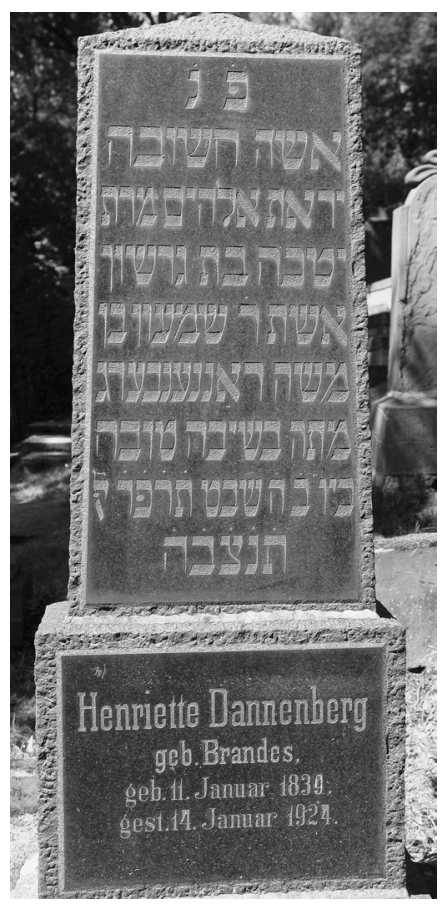

H $100 \cdot$ B 5 I $\cdot$ T I9

\author{
פדינ Hier ist geborgen \\ eine Frau, angesehen, \\ gottesfürchtig (war sie), Frau \\ יטכה בת גרשון Jettche, Tochter des Gerson, \\ 5 Ehefrau des H. Schimon, Sohn

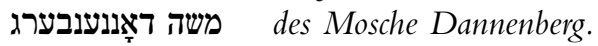 \\ Sie starb in gutem Alter \\ ביו' ב' ח' שבט ת'ר'פ'ד' ל' \\ I.S.E.B.L. \\ Henriette Dannenberg 10 \\ geb. Brandes \\ geb. I I. Januar I839, \\ gest. I4. Januar I924
}

3 s. Prov 3I,30 
Goldine Müller, geb. Eichenberg

$$
\text { I4. 9.I } 849 \text { - 30.6.I } 924
$$

Geb. in Reichensachsen bei Eschwege/Hessen - Vater: Moses Eichenberg - Ehemann: Isidor Müller IV 49 ' Kinder: Alfred (I 878-I943, Sobibor); Georg IV 4; Else, verh. Höxter (I88I-I843, Auschwitz); Robert IV 4; Otto (I884)

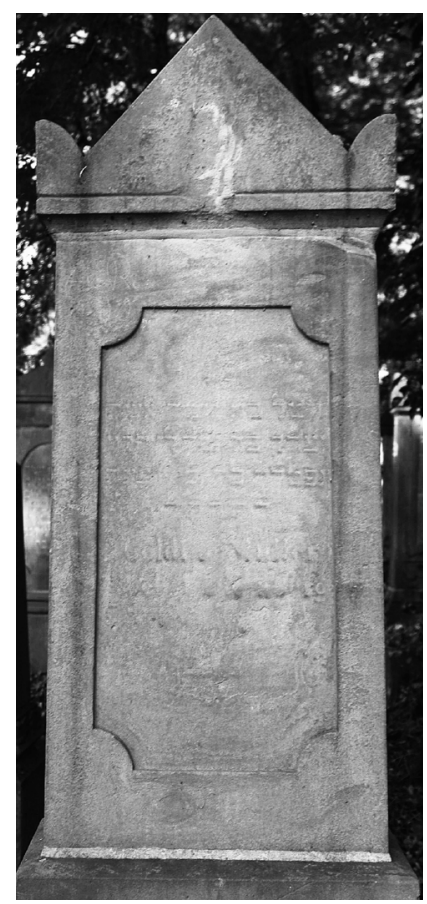

$\mathrm{H} \mathrm{IO}_{4} \cdot \mathrm{B} 54 \cdot \mathrm{T} 22$

Inschrift nur noch schwach erkennbar

\section{פ"נ Hier ist geborgen}

Gitel, Tochter des Mosche, Ehefrau

ניצחק בר נפתלי הלוי des Jizchak, Sohn des Naphtali ha-Levi.

Sie verschied am 28. Siwan (im) Jahr

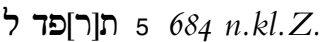

Gold[ine] Müller

Geb. ...

Quelle: StB (Geburtstag) 
Salomon Rosenbaum

8.II.I $857-28.2 .1925$

Eltern: Meyer Rosenbaum III 8I - Sara Blumenberg III 82 - Ehefrau: Selma Arensberg IV 43

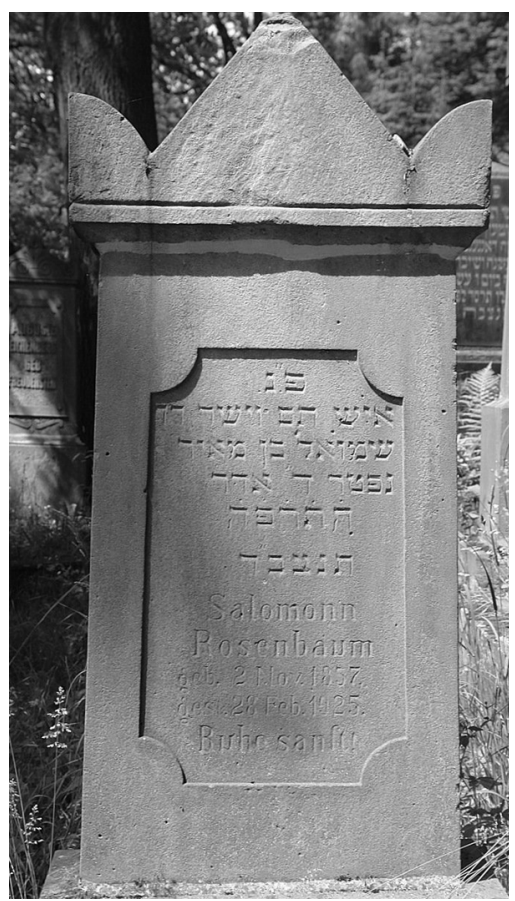

$\mathrm{H} 96 \cdot \mathrm{B} 57 \cdot \mathrm{T} 2 \mathrm{I}$

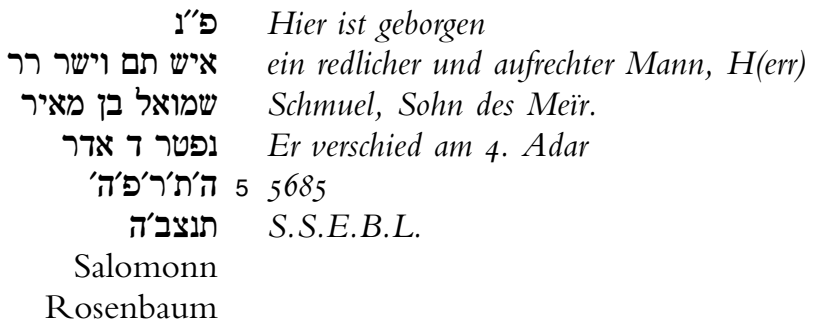

geb. 8. Nov. I 857 , gest. 28. Feb. I925. 10

Ruhe Sanft!

2 s. Hi I,8 - 3.7 Die Verwendung von Schmuel als hebräisch innerjüdisch verwendeten und Salomon als deutschen standesamtlichen Vornamen ist verbreitet. 9 2.I I.I857 GbL 
Sallÿ Blumenfeld

$$
\text { 5.4.I } 842 \text { - I4.II.I925 }
$$

Geb. in Momberg/Hessen, gest. in Göttingen · I86I-I9Io Lehrer, Vorsänger und Schächter. Vorsteher der Beerdigungsbruderschaft sowie des Israelitischen Lesevereins. I9IO Ehrenmitglied der Jüdischen Gemeinde Adelebsen, Ruhestand in Göttingen · I. Vorsitzender (I 888) und Ehrenvorsitzender (I909) des Vereins jüdischer Lehrer in der Provinz Hannover; Mitbegründer, 2. Vorsitzender (I895) und I. Vorsitzender (I90I) des Verbandes jüdischer Lehrervereine im Deutschen Reich - Eltern: Jacob Blumenfeld - Fromet Isenberg · Ehefrau: Bertha Freudenstein IV $40 \cdot$ Kinder: s. ebd.

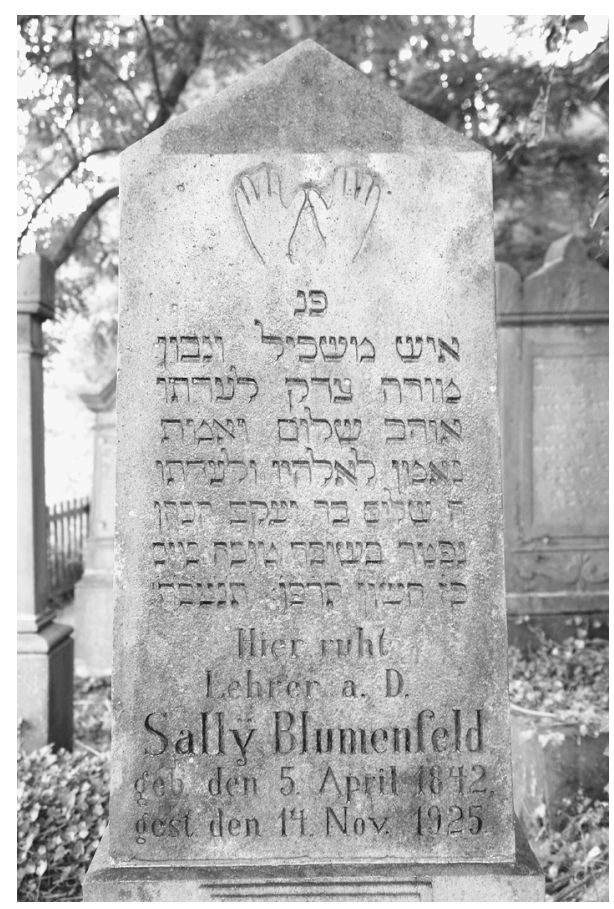

H III $\cdot$ B $54 \cdot$ T 25 


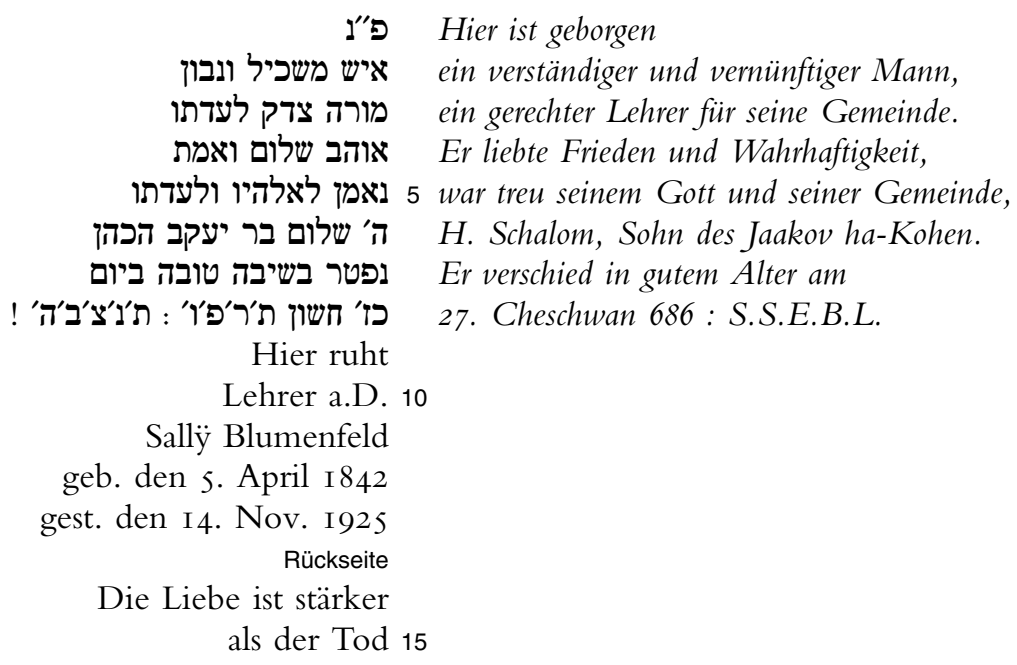

4 Das Wortpaar שלום ואמת schalom we-emet, ,Friede und Wahrhaftigkeit“ (biblisch s. Jer 33,6; 2 Kön 20,I9) ist schwerlich bloß als Gemeinplatz gewählt. Es dürfte den Titel der ersten, grundlegenden Programmschrift jüdischer Reformpädagogik ,sifrei schalom weemet" (I782. I785) von Naphtali Herz Wessely (I725-I805) aufgreifen und die Leistung des Verstorbenen als Pädagogen würdigen. · 6a Aussprache des Namens שלום = ,Schalom“, daneben auch „Schalum“ bzw. „Schlum“, in deutschsprachigen Quellen z.T. „Salem“: Variante zu Schlomo/Salomo · 7 vgl. Gen 25,8 


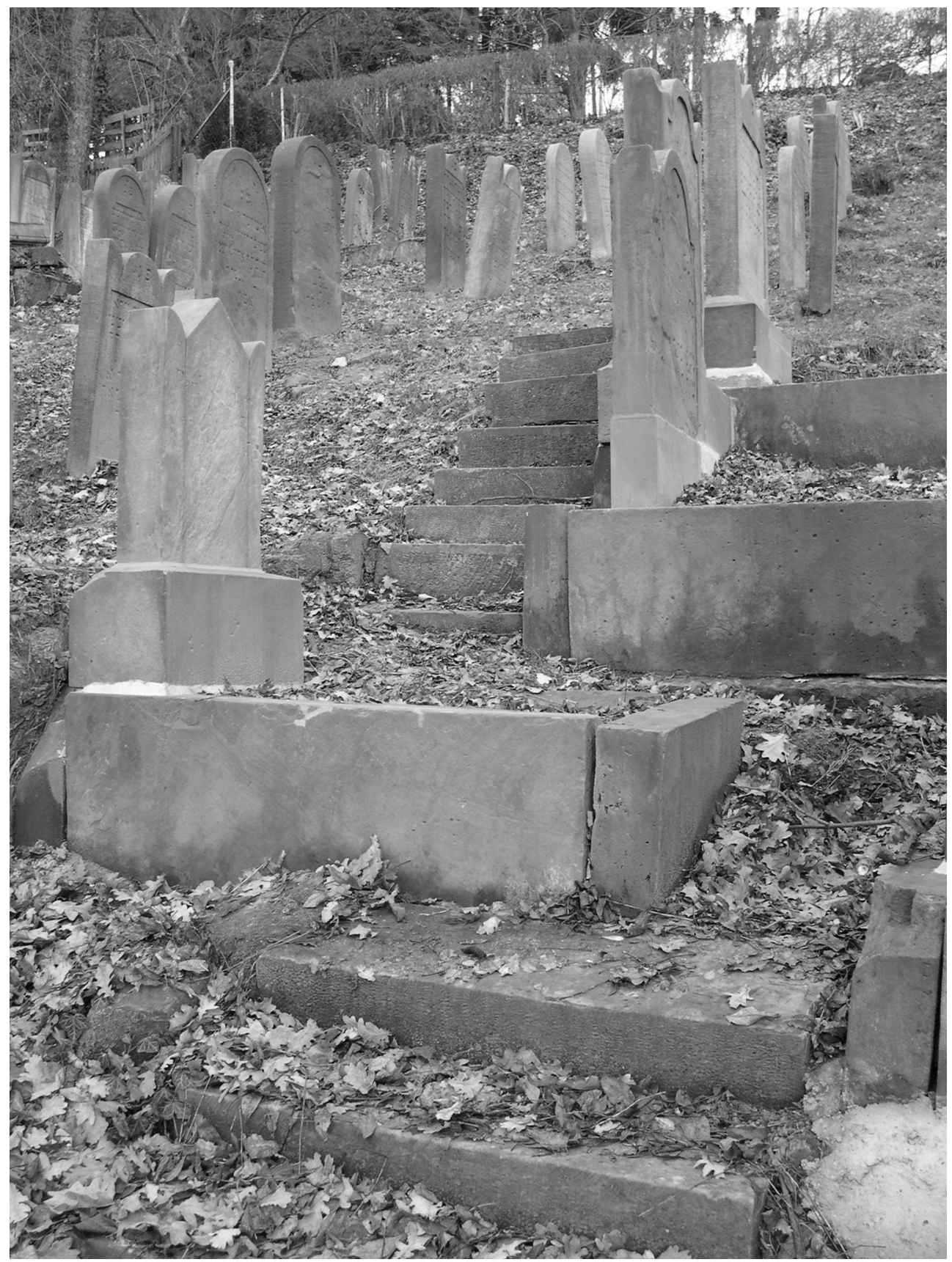




\section{Bertha Rothschild, geb. Gans}

$28.3 .1837-8.3 .1927$

Geb. in Witzenhausen - Eltern: Hirsch Gans - Friederike Katz · Ehemann: Joel S. Rothschild IV I7 · Kinder: Max (I868-I942, Treblinka); Noa V 4; Louis IV 24

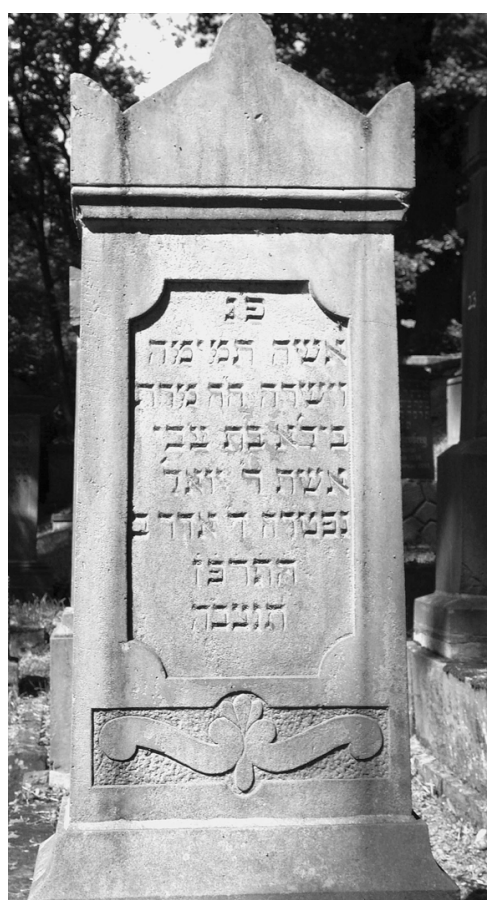

H $106 \cdot$ B $58 \cdot$ T 23

פע"נ Hier ist geborgen

eine lautere und aufrechte

Frau. Dies ist Frau

Beila, Tochter des Zvi,

5 Ehefrau des H. Joël.

Sie verschied am 4. Adar II

5687

תנצב'ה I.S.E.B.L.

Rückseite

Bertha Rothschild

geb. 28. März I 83710

geztr. 8. März I927

Friede ihr

2f s. Hi I, 8 
Selma Rosenbaum, geb. Arensberg I6.8. I $869-28.8 .1928$

Geb. in Dransfeld · Eltern: Joseph Arensberg III 35 - Bertha Löwenstern III 34 - Ehemann: Salomon Rosenbaum IV 44

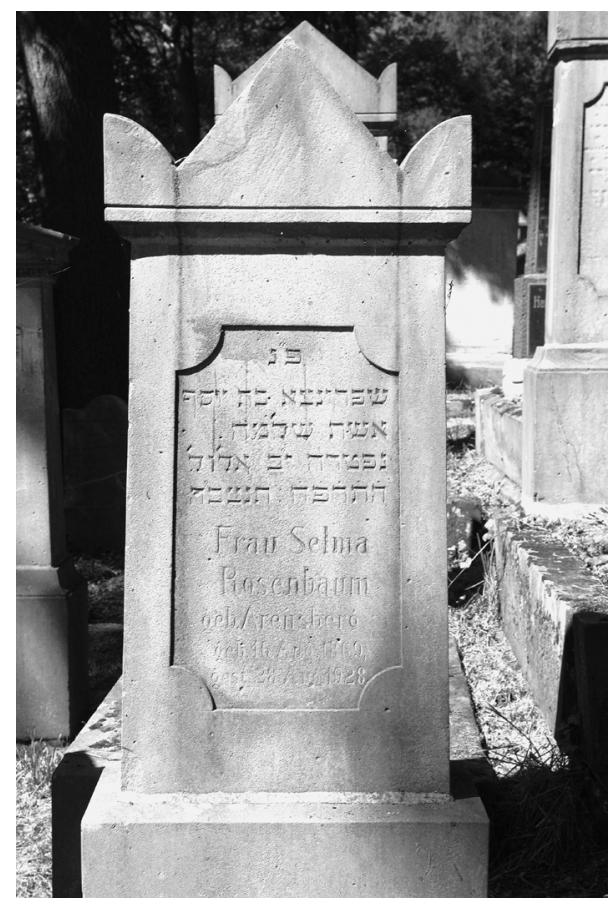

$\mathrm{H} 95 \cdot \mathrm{B} 57 \cdot \mathrm{T} 20$

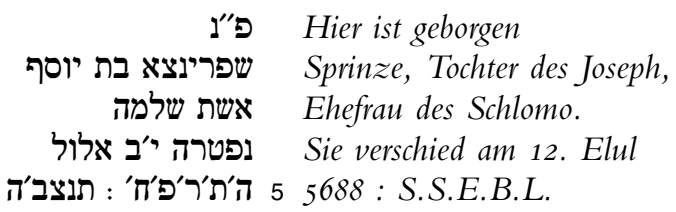

Frau Selma

Rosenbaum

geb. Arensberg

geb. I6 Aug. I869, gest. 28 Aug. I928 10 
Mathilde Stehberg, geb. Rosenbaum

$$
6.5 .1860-22.7 .1929
$$

Eltern: Meier Rosenbaum III 8 I - Sara Blumenberg III $82 \cdot$ Ehemann: Leopold Stehberg IV 45 - Kinder: Gertrud, verh. Seligmann (I895-I94I, Minsk); Herbert (I896-I980 Dallas/Texas); Otto (I900-, Rio de Janeiro)

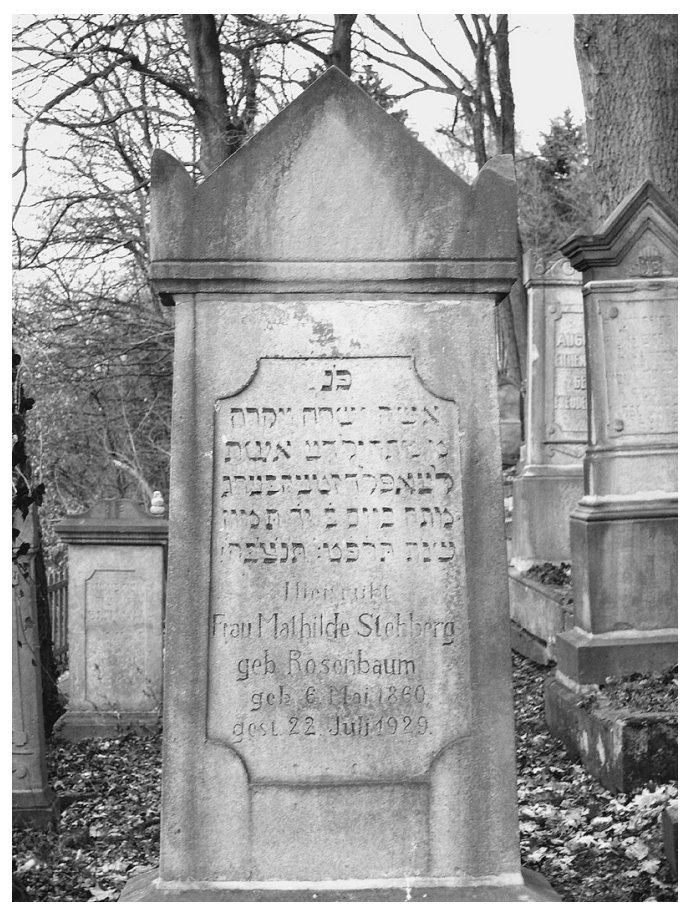

$\mathrm{H} \mathrm{I} 34 \cdot \mathrm{B} 56 \cdot \mathrm{T} 9$

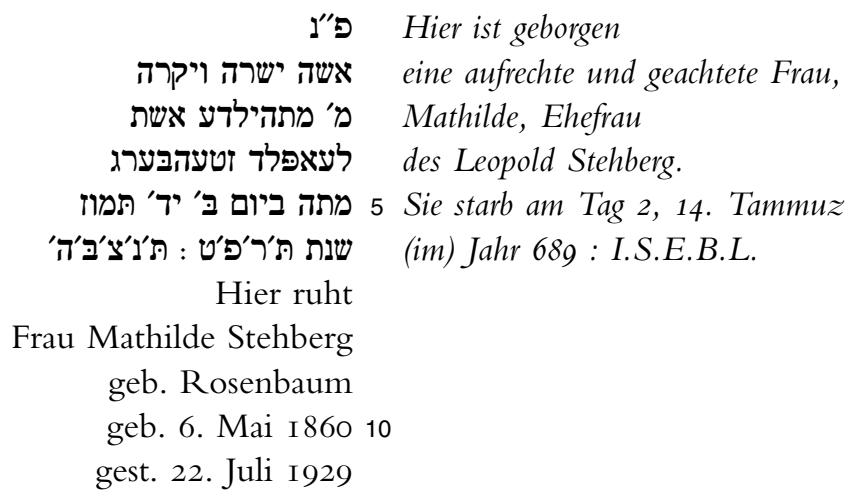

4 Die Schreibung des Namens Stehberg mit I (statt wie sonst üblich mit $\boldsymbol{E}$ ) weist auf die in der norddeutschen Aussprache verbreitete Trennung von s und t. 10 5.5.I860 nach GbL 


\section{Johanne Eichenberg}

23.I.I859 - I7.I I.I935

Wollwarenhändlerin · Eltern: Levi Simon Eichenberg IV I4 - Lina Edelstein IV I 3

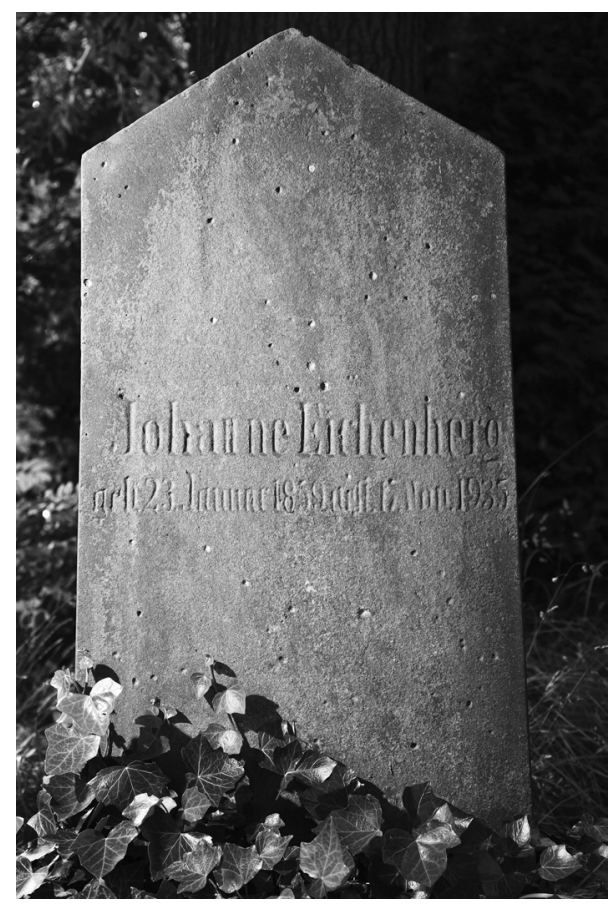

$\mathrm{H} \mathrm{IO} 3 \cdot \mathrm{B} 60 \cdot \mathrm{T}$ is

Johanne Eichenberg

geb. 23. Januar I 859 , gest. I7. Nov. I935

Lit.: Gedenkbuch Gö, 57f. 


\section{Margarete Gerson, geb. Stehberg}

$$
\text { I0.7.I } 892-\text { I } 3.5 \cdot 1936
$$

Verkäuferin, Haushälterin, Handarbeitslehrerin - Eltern: Albert Stehberg IV 30 - Rosa Stehberg IV $32 \cdot$ Ehemann: Philipp Gerson, Viehhändler aus Bunde/Ostfriesland · Sohn: Arno/Avraham (I923, Hannover; ausgewandert I939 nach Israel)

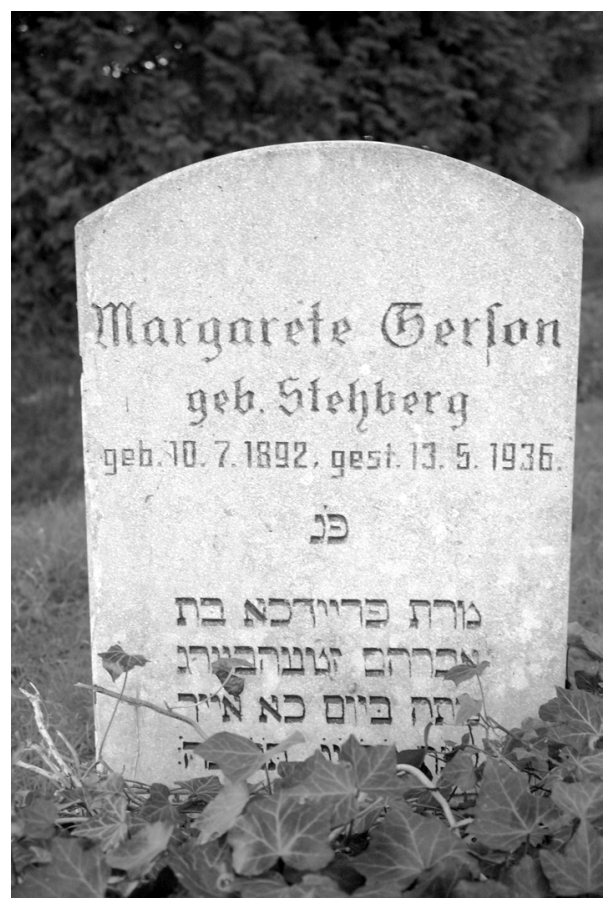

$\mathrm{H} 85 \cdot \mathrm{B} 55 \cdot \mathrm{T}$ I 5

Margarete Gerson geb. Stehberg geb. I0.7.I 892 , gest. I3.5.1936

פ"ג Hier ist geborgen

5 Frau Freidche, Tochter אברהם זטעהבערג מרת פירת Des Avraham Stehberg.

Sie starb am 21. Ijjar

שנת ת'ר'צו : ת'נ'צ'ב'ה

Lit.: Gedenkbuch Gö, 74 
Ida Katzenstein, geb. Stehberg

$$
\text { I4.IO.I } 88 \text { I - I8.2.I938 }
$$

Eltern: Albert Stehberg IV 30 - Rosa Stehberg IV $32 \cdot$ Ehemann: Adolf Katzenstein aus Heinebach bei Melsungen, Kaufmann in Rotenburg a.d. Fulda, später in Adelebsen . Kinder: Bernhardine (I906); Manfred (I9I0)

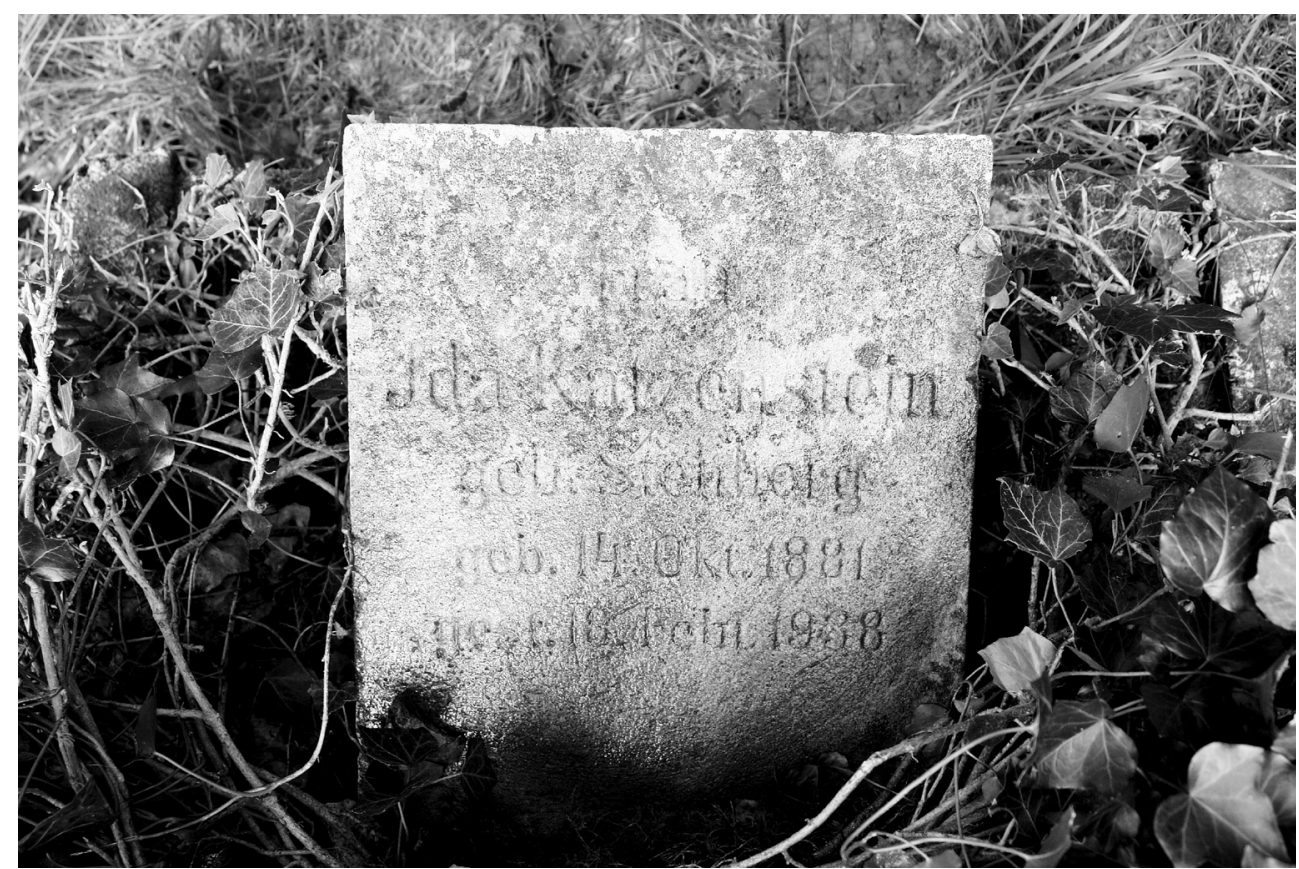

$\mathrm{H}_{50} \cdot \mathrm{B}_{4 \mathrm{I}} \cdot \mathrm{T} 24$

Frau

Ida Katzenstein geb. Stehberg geb. I4. Okt. I 88 I gest. I 8. Febr. I938 5

Lit.: Gedenkbuch Gö, I22 


\section{Noa Rothschild}

$$
\text { 4.9. I } 869-24 \cdot 5 \cdot 1948
$$

Kaufmann (Textilhandel), Versicherungsagent · I907 - I9I 3 erwähnt als stellvertretender Vorsitzender der Synagogengemeinde - 2 I.7 I942 deportiert nach Theresienstadt. Eltern: Joel S. Rothschild IV I7 - Bertha Gans IV 42 - Ehefrauen: I) Franziska Dannenberg (I882-I940, Göttingen: Grab o4I8); 2) Rosa Rülf, verw. Schaumberg (I878-I943, Theresienstadt)

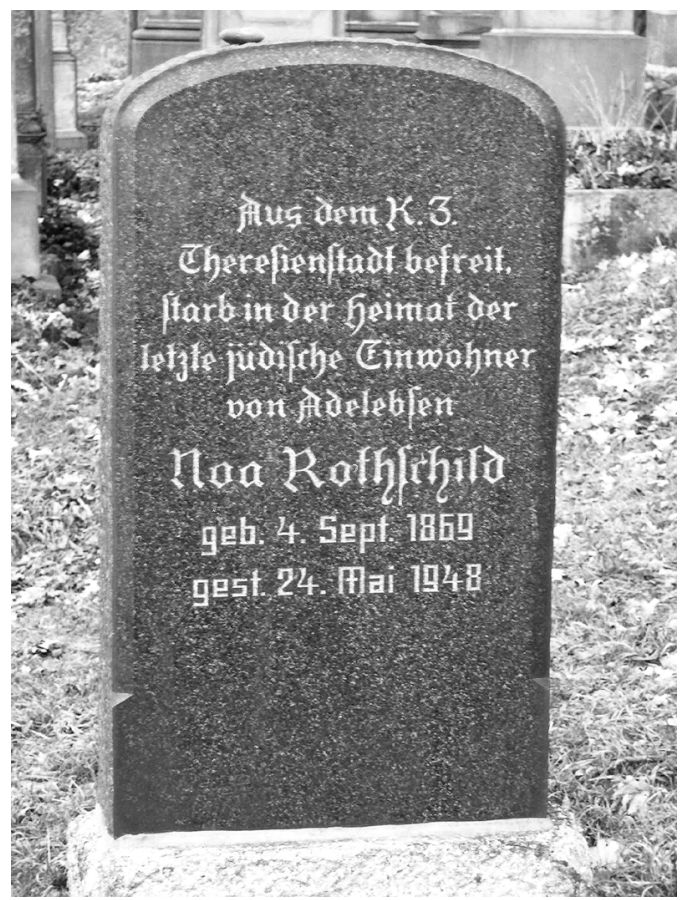

$\mathrm{H} 89 \cdot \mathrm{B} 5 \mathrm{I} \cdot \mathrm{T}$ I5

Aus dem K.Z.

Theresienstadt befreit, starb in der Heimat der letzte jüdische Einwohner

von Adelebsen 5

Noa Rothschild

geb. 4. Sept. I 869

gest. 24. Mai I948

Lit.: Gedenkbuch Gö, 237 


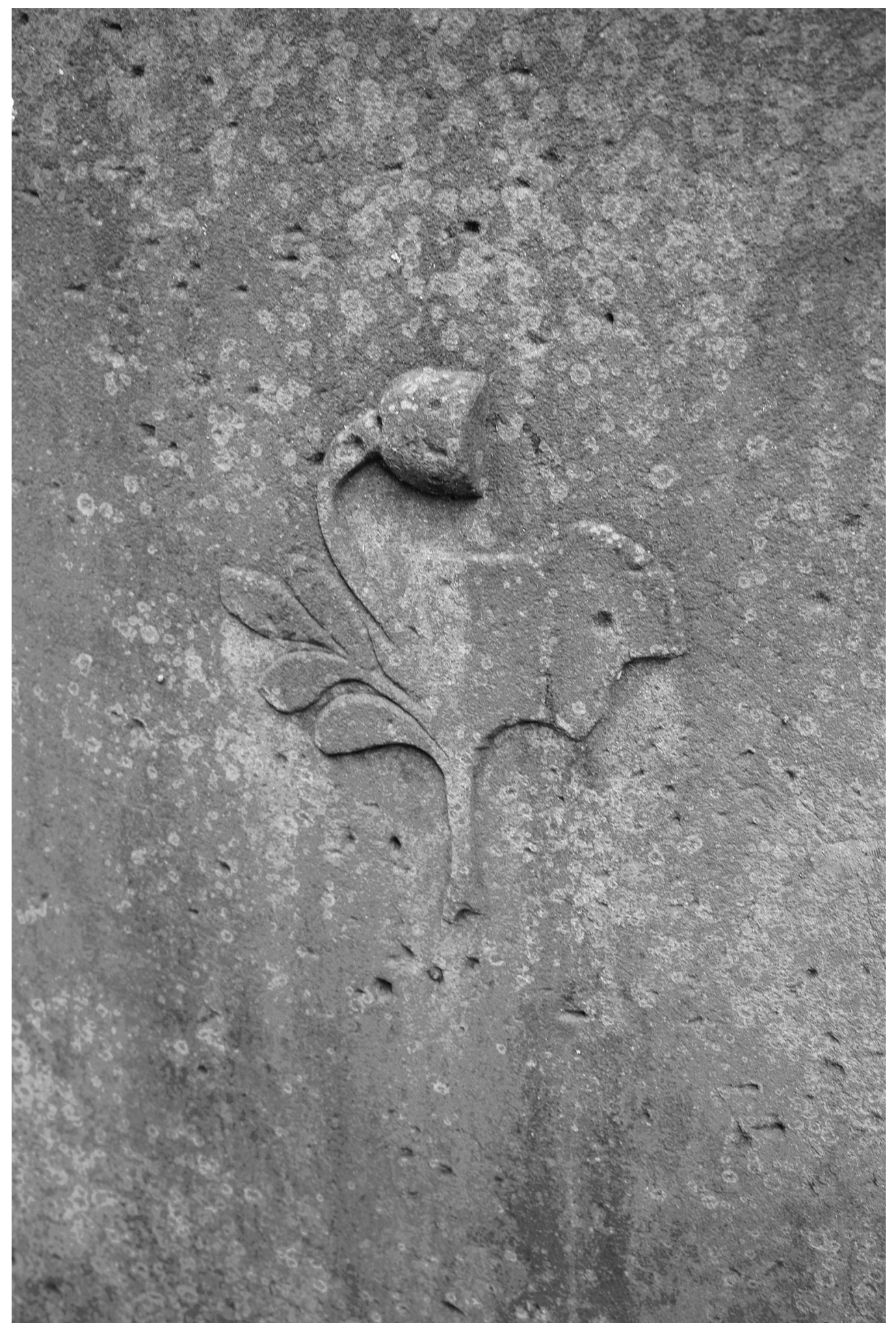




\section{Memorbuch für die Opfer der Schoa \\ זכור \\ Zum Gedenken \\ an die Kinder, Frauen, Männer \\ der jüdischen Gemeinde zu Adelebsen \\ Opfer der Schoa \\ ohne Ort und Stein verschollen}

\section{$I^{\star}$ Bachmann, Mathilde}

Eltern: David Eichenberg, IV 6 - Sophie Grunsfeld, IV 5

Ehemann: Joseph Bachmann, geb. 2I. Mai I 842 in Körbecke/Kreis Höxter

geb. 25. Oktober 1879 in Adelebsen · wohnhaft zuletzt in Gera · deportiert 20. September I942 nach Theresienstadt · gest. 26. Dezember 1942 im Ghetto Theresienstadt

\section{$2^{\star}$ Barnass, Dina}

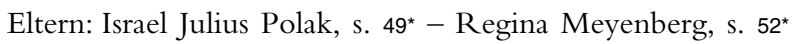

Ehemann: Hans Daniel Barnass, geb. 3. März 1907 in Pfungstadt bei Darmstadt, gest. vermutlich im Ghetto Warschau

geb. 29. September 1907 in Adelebsen · wohnhaft zuletzt in Göttingen · deportiert 26. März I942 nach Warschau · gest. vermutlich im Ghetto Warschau (Gedenkbuch Gö 32)

\section{$3^{\star}$ Blank, Grete}

Eltern: Meyer Levi Eichenberg, IV 38 - Mathilde Eichenberg, IV 37

Ehemann: Salomon Blank, geb. I9. September I 873 in Horn/Lippe, gest. Io. September 1942 im Ghetto Theresienstadt

geb. 22. Oktober I883 in Adelebsen · wohnhaft zuletzt in Bielefeld · deportiert 3I. Juli I942 nach Theresienstadt $\cdot$ gest. 20. April I944 im Ghetto Theresienstadt

\section{$4^{\star}$ Blumenfeld, Hugo}

Eltern: Sally Blumenfeld, IV 39 - Bertha Freudenstein, IV 40

geb. 6. November I 873 in Adelebsen · wohnhaft zuletzt in Berlin · deportiert I7. Juli I 942 nach Theresienstadt, I9. September I942 nach Treblinka, ' gest. im Vernichtungslager Treblinka 


\section{$5^{\star}$ Blumenfeld, Johanna}

Eltern: Sally Blumenfeld, IV 39 - Bertha Freudenstein, IV 40

geb. 6. Dezember I87I in Adelebsen - wohnhaft zuletzt Hannover · deportiert 23. Juli I942 nach Theresienstadt · gest. 3. März I944 im Ghetto Theresienstadt

(Gedenkbuch Gö 43)

\section{6* Blumenfeld, Karl}

Eltern: Sally Blumenfeld, IV 39 - Bertha Freudenstein, IV 40

geb. I. Dezember I869 in Adelebsen - wohnhaft zuletzt in der Heil- und Pflegeanstalt Ilten bei Hannover · verschickt 27. September 1940 nach Brandenburg a. d. Havel · gest. 27. September I940, Opfer der „Euthanasie“ in der „Heilanstalt Brandenburg“

\section{$7^{\star}$ Blumenfeld, Lina}

Eltern: Sally Blumenfeld, IV 39 - Bertha Freudenstein, IV 40

geb. 9. Mai I 866 in Adelebsen · wohnhaft zuletzt in Hannover · deportiert 23. Juli I942 nach Theresienstadt $\cdot$ gest. 28. Februar I943 im Ghetto Theresienstadt

(Gedenkbuch Gö 43)

\section{8^ Dannenberg, Albert}

Eltern: Selig Dannenberg, IV 27 - Amalie König, IV 26

geb. 3 I. März I875 in Adelebsen · wohnhaft zuletzt in Würzburg · deportiert 23. September 1942 nach Theresienstadt · gest. I7. Februar I944 im Ghetto Theresienstadt

\section{9^ Dannenberg, Harry}

Eltern: Karl Dannenberg, s. $10^{*}-$ Paula Speyer, s. $11^{\star}$

geb. 5. Februar I905 in Adelebsen · wohnhaft zuletzt in Berlin · deportiert 6. März I943 nach Auschwitz $\cdot$ gest. im Vernichtungslager Auschwitz

(Gedenkbuch Gö 53)

IO* Dannenberg, Karl

Eltern: Selig Dannenberg, IV 27 - Amalie König, IV 26

Ehefrau: Paula Speyer. s. $11^{*}$

geb. I6. Juli I 870 in Adelebsen · wohnhaft zuletzt in Adelebsen · deportiert 2 I. Juli I942 nach Theresienstadt, 26. September 1942 nach Treblinka $\cdot$ gest. im Vernichtungslager Treblinka

(Gedenkbuch Gö 53) 
I I ${ }^{\star}$ Dannenberg, Paula

Eltern: Aron Speyer, IV 33 - Therese Heilbrunn, III 38

Ehemann: Karl Dannenberg, s. 10*

geb. 26. März I 882 in Adelebsen · wohnhaft zuletzt in Adelebsen · deportiert 2 I. Juli I942 nach Theresienstadt, 26. September I942 nach Treblinka, ' gest. im Vernichtungslager Treblinka

(Gedenkbuch Gö 54)

\section{I2* Dannenberg, Sally}

Eltern: Meyer Dannenberg, III 7 - Bertha Buchthal, III 8

geb. 2. Mai I 874 in Adelebsen · wohnhaft zuletzt in Dortmund · deportiert 29. Juli I942 nach Theresienstadt $\cdot$ gest. I3. Februar I943 im Ghetto Theresienstadt

\section{I3* Dannenberg, Sally}

Eltern: Selig Dannenberg, IV 27 - Amalie König, IV 26

geb. Iо. März I 878 in Adelebsen · wohnhaft zuletzt in Nürnberg · deportiert 29. November I94I nach Riga · gest. in Riga

\section{I ${ }^{\star}$ Eichenberg, Alexander}

Eltern: Leiser Eichenberg, IV I8- Rosalie Edelstein, IV I9

geb. I. September I877 in Adelebsen · wohnhaft zuletzt in Berlin · deportiert 2. März I943 nach Auschwitz · gest. im Vernichtungslager Auschwitz

\section{5 * Eichenberg, Fritz}

Eltern: Meyer Levi Eichenberg, IV 38 - Mathilde Eichenberg, IV 37

geb. 6. Dezember I 889 in Adelebsen - wohnhaft zuletzt in Düsseldorf, danach in Frankreich · deportiert 4. März I943 von Drancy (Champ de Noë) nach Majdanek · gest. im Vernichtungslager Majdanek

\section{I6* Eichenberg, Harry}

Eltern: Meyer Levi Eichenberg, IV 38 - Mathilde Eichenberg, IV 37

geb. 2I. Januar I88I in Adelebsen - wohnhaft zuletzt in Düsseldorf, danach in den Niederlanden · deportiert I I. Mai I943 von Westerbork nach Sobibor · gest. I4. Mai I943 im Vernichtungslager Sobibor 


\section{I $7^{\star}$ Eichenberg, Olga}

Eltern: Meyer Levi Eichenberg, IV 38 - Mathilde Eichenberg, IV 37

geb. 2. Mai I 869 in Adelebsen · wohnhaft zuletzt in Adelebsen · deportiert 2 I. Juli I942 nach Theresienstadt, 23. September 1942 nach Treblinka gest. vermutlich im Vernichtungslager Treblinka

(Gedenkbuch Gö 59)

\section{8* Eichenberg, Rolf}

Eltern: Siegfried Eichenberg - Helene Philippsborn

Großeltern: Meyer Levi Eichenberg, IV 38 - Mathilde Eichenberg, IV 37

geb. 6. August I9I3 in Adelebsen · wohnhaft zuletzt in den Niederlanden - deportiert 23. Februar I943 von Westerbork nach Auschwitz · gest. 28. Februar I943 im Vernichtungslager Auschwitz

(Gedenkbuch Gö 60)

\section{I9 $9^{\star}$ Fischendler, Edith}

Eltern: Israel Jakobi, s. $30^{\star}$ - Frieda Eichenberg, s. $27^{\star}$

Ehemann: Adolf Fischendler, geb. 22. September I9Io in Hannover, gest. vermutlich im Ghetto Warschau

geb. I9. Juli I9I5 in Adelebsen ' wohnhaft zuletzt in Hannover - abgeschoben 28. Oktober I938 nach Bentschen (Zbąszyn)/Polen · gest. vermutlich im Ghetto Warschau

(Gedenkbuch Gö I03)

$20 \star$ Groot, Clara de

Eltern: Selig Dannenberg, IV 27 - Amalie König, IV 26

Ehemann: David de Groot, geb. 3. August I863 in Steenwijk/Niederlande

geb. Io. Juni 1872 in Adelebsen · wohnhaft zuletzt in Zwolle/Niederlande · deportiert 27. April I943 von Westerbork nach Sobibor - gest. 30. April I943 im Vernichtungslager Sobibor

\section{$2 I^{\star}$ Herold, Dina}

Eltern: Levi Polak, s. 50* - Berta Lichtenstein, s. $47^{\star}$

Ehemann: Arthur Herold, geb. 26. Dezember 1907 in Schopfloch/Württemberg, gest. 2. Juli I943 im Vernichtungslager Sobibor

geb. 3 I. Oktober I9I2 in Adelebsen · wohnhaft zuletzt in Amsterdam · deportiert 29. Juni I943 von Westerbork nach Sobibor · gest. 2. Juli I943 im Vernichtungslager Sobibor

(Gedenkbuch Gö 203) 


\section{2* Heymann, Pauline}

Eltern: Isaak A. Müller, III 46 - Henriette Schloss

Ehemann: Leopold Heymann, gest. I 886 in Osnabrück

geb. Io. Mai I 86I in Adelebsen · wohnhaft zuletzt in Osnabrück · deportiert 3I. Juli 1942 nach Theresienstadt, 23. September 1942 nach Treblinka $\cdot$ gest. vermutlich im Vernichtungslager Treblinka

\section{3* Hoexter, Berthold/Benedikt}

Eltern: Moses Hoexter - Giedel Baum

Ehefrau: Else Müller, s. 24*

geb. 4. November I883 in Zimmersrode bei Fritzlar/Hessen · wohnhaft zuletzt in Amsterdam · deportiert 23. Februar I943 von Westerbork nach Auschwitz - gest. 26. Februar I943 im Vernichtungslager Auschwitz

(Gedenkbuch Gö 97)

$24^{\star}$ Hoexter, Else

Eltern: Isidor Müller, IV 49 - Goldine Eichenberg, IV 48

Ehemann: Berthold Hoexter, s. $23^{*}$

geb. 7. September I88I in Adelebsen · wohnhaft zuletzt in Amsterdam - deportiert 23. Februar I 943 von Westerbork nach Auschwitz gest. 26. Februar 1943 im Vernichtungslager Auschwitz

(Gedenkbuch Gö 97)

$25^{\star}$ Jakobi, Alfred

Eltern: Israel Jakobi, s. $30^{\star}-$ Frieda Eichenberg, s. $27^{*}$

Ehefrau: Edith Meyer, s. 26*

geb. I8. Dezember I9I2 in Adelebsen · wohnhaft zuletzt in Adelebsen - deportiert 26. März I942 nach Warschau · gest. vermutlich im Ghetto Warschau (Gedenkbuch Gö I03)

\section{$26^{\star}$ Jakobi, Edith}

Eltern: Siegfried Meyer - Rosa Lachmann

Ehemann: Alfred Jakobi, s. 25*

geb. 4. März I922 in Bentheim · wohnhaft zuletzt in Sögel/Emsland · deportiert I3. Dezember I94I nach Riga · gest. vermutlich I94I/42 in Riga

\section{$27^{\star}$ Jakobi, Frieda}

Eltern: Meyer Leiser Eichenberg, IV I8 - Rosalie Edelstein, IV I9

Ehemann: Israel Jakobi, s. 30*

geb. I I. September I 873 in Adelebsen · wohnhaft zuletzt in Adelebsen · deportiert 2 I. Juli I942 nach Theresienstadt · gest. 27. Dezember 1942 im Ghetto Theresienstadt

(Gedenkbuch Gö Io3f.) 


\section{$28^{\star}$ Jakobi, Hugo}

Eltern: Israel Jakobi, s. $29^{\star}$ - Frieda Eichenberg, s. $27^{\star}$

geb. I7. September 1909 in Adelebsen · wohnhaft zuletzt in Den Haag · deportiert 29. Januar I943 von Westerbork nach Auschwitz - gest. 3 I. Januar I943 im Vernichtungslager Auschwitz

(Gedenkbuch Gö I04)

\section{9^ Jakobi, Israel}

Eltern: Jakob Jakobi - Hannchen Eichholz

Ehefrau: Frieda Eichenberg, s. 27*

geb. 25. Juni I 879 in Fürstenau/Kreis Höxter · wohnhaft zuletzt in Adelebsen · deportiert 2 I. Juli I 943 nach Theresienstadt · gest. I I. Juli I944 im Ghetto Theresienstadt

(Gedenkbuch Gö Io4f.)

\section{$30^{\star}$ Jakobi, Kurt}

Eltern: Israel Jakobi, s. 29* - Frieda Eichenberg, s. 27*

geb. 22. Februar I9I4 in Adelebsen · wohnhaft zuletzt in Adelebsen · deportiert 26. März I942 nach Warschau · gest. vermutlich Ghetto Warschau

(Gedenkbuch Gö I04)

\section{$3 I^{\star}$ Jankau, Rosa}

Eltern: Simon Dannenberg, IV 2 I - Henriette Brandes, IV 20

geb. Io. Januar I 864 in Adelebsen · wohnhaft zuletzt in Hemsbach/Baden · deportiert 22. Oktober I940 nach Gurs/Frankreich · gest. 26. Januar I942 im Internierungslager Champs de Noë bei Drancy/Frankreich

\section{$32^{\star}$ Katzenstein, Adolf}

Eltern: Meyer Katzenstein - Fanni Marx

Ehefrau: Ida Stehberg, V 3

geb. 24. Oktober I 874 in Heinebach bei Melsungen/Hessen - wohnhaft zuletzt in Amsterdam $\cdot$ gest. unbekannt

(Gedenkbuch Gö I2 If.)

\section{$33^{\star}$ Katzenstein, Manfred}

Eltern: Adolf Katzenstein, s. $32^{\star}$ - Ida Stehberg, V 3

geb. I 5. März I9Io in Rotenburg/Fulda · wohnhaft zuletzt Bendorf-Sayn · deportiert 29. November I942 von Berlin nach Auschwitz · gest. vermutlich im Vernichtungslager Auschwitz

(Gedenkbuch Gö I23) 
$34^{\star}$ Lamm, Ida

Eltern: Isaak A. Müller, III 46 - Henriette Schloss

Ehemann: Otto Lamm

geb. 30. Oktober I 866 in Adelebsen · wohnhaft zuletzt in Hannover · deportiert 23. Juli I942 nach Theresienstadt · gest. 22. Februar I944 im Ghetto Theresienstadt

\section{$35^{\star}$ Langstein, Mathilde}

Eltern: Mendel Bähr - Marianne Jacobsohn

geb. 26. August I867 ' wohnhaft zuletzt in Dresden ' gest. 29. Juli I94I Ort und Umstände unbekannt

\section{$36^{\star}$ Lippers, Martha}

Eltern: Albert Stehberg, IV 30 - Rosa Stehberg, IV 32

Ehemann: Isidor Lippers, geb. 24. Dezember I873 in Nottuln/Westfalen, gest. 6. September I944 im Vernichtungslager Auschwitz

geb. I4. Juli I883 in Adelebsen ' wohnhaft zuletzt in Zwolle/Niederlande - deportiert 3. September I944 von Westerbork nach Auschwitz; · gest. 6. September I944 im Vernichtungslager Auschwitz

\section{$37^{\star}$ Löwenstern, Adolf}

Eltern: Simon M. Löwenstern, III 36 - Adelheide Meyersberg

geb. I. Februar I 858 in Adelebsen · wohnhaft zuletzt in Berlin · deportiert I4. September I942 nach Theresienstadt · gest. I6. Februar I943 im Ghetto Theresienstadt

\section{$3^{\star}$ Löwenthal, Louis}

Eltern: Salomon Löwenthal - Henriette Löwenstern

Urgroßvater: Levi David Löwenthal, II 3 I

geb. I 4. September I 863 in Lödingsen · wohnhaft zuletzt in Dortmund · deportiert 29. Juli I942 nach Theresienstadt, 23. September 1942 nach Treblinka $\cdot$ gest. vermutlich im Vernichtungslager Treblinka

\section{9^ Löwenthal, Siegfried}

Eltern: Salomon Löwenthal - Henriette Löwenstern

Urgroßvater: Levi David Löwenthal, II 3 I

geb. I 4. September I 867 in Lödingsen · wohnhaft zuletzt in Hannover · deportiert 23. Juli I942 nach Theresienstadt · gest. I6. August I942 im Ghetto Theresienstadt 
40* Müller, Alfred

Eltern: Isidor Müller, IV 49 - Goldine Eichenberg, IV 48

geb. I2. März I878 in Adelebsen · wohnhaft zuletzt in Amsterdam · deportiert 23. März I943 von Westerbork nach Sobibor · gest. 26. März I943 im Vernichtungslager Sobibor

$4^{\star}{ }^{\star}$ Müller, Rachel

Eltern: Isaak A. Müller, III 46 - Henriette Schloss

geb. 25. Januar I863 in Adelebsen · wohnhaft zuletzt in Hannover · deportiert 23. Juli I942 nach Theresienstadt · gest. I6. April I943 im Ghetto Theresienstadt

$4^{\star}{ }^{\star}$ Münden, Martha

Eltern: Salomon Gräfenberg, Grab Göttingen 333 - Minna Eichenberg, Grab ebd.

Ehemann: Max Münden, geb. 25. Februar I 862 in Hamburg gest. 24. September 1936 in Hamburg (Gefängnis)

geb. Io. Juli I 876 in Adelebsen · wohnhaft zuletzt in Hamburg · deportiert 6. Dezember I94I nach Riga · gest. vermutlich Riga

$43^{\star}$ Oppenheim, Moritz

Eltern: Simon Oppenheim, III I9 - Esther Dannenberg, III 20

geb. 6. April I 877 in Adelebsen · wohnhaft zuletzt in Mainz · deportiert 25. März I942 in das Ghetto Piaski / Polen · gest. unbekannt

\section{$44^{\star}$ Peters, Jenni}

Eltern: Simon Dannenberg, IV 2I - Henriette Brandes, IV 20

Ehemann: Rudolf Peters, geb. 22. November I 878 in Wolfenbüttel, gest. November I94I in Liebenau bei Nienburg/Weser

geb. I7. September I877 in Adelebsen · wohnhaft zuletzt in Petershagen · deportiert 3 I. Juli 1942 nach Theresienstadt, I5. Mai I944 nach Auschwitz · gest. vermutlich im Vernichtungslager Auschwitz

\section{$45^{\star}$ Polak, Bernhardine}

Eltern: Adolf Katzenstein, s. $32^{\star}$. - Ida Stehberg, V 3

Ehemann: Friedrich Karl Polak, s. $47^{\star}$

geb. 24. November 1906 in Rotenburg/Fulda · wohnhaft zuletzt in Amsterdam · gest. I I. Februar I944 im Vernichtungslager Auschwitz

(Gedenkbuch Gö I22) 
$46^{\star}$ Polak, Bertha

geb. Lichtenstein

Ehemann: Levi Polak s. 49*

geb. 2. Februar I 888 in Rhoden/Waldeck - wohnhaft zuletzt in Amsterdam - deportiert 29. Juni I943 von Westerbork nach Sobibor - gest. 2. Juli I943 im Vernichtungslager Sobibor

(Gedenkbuch Gö 203)

\section{7* Polak, Friedrich Karl}

Eltern: Israel Julius Polak, s. $48^{\star}-$ Regina Meyenberg, s. 51*

geb. 24. August I9O4 in Adelebsen · wohnhaft zuletzt in Amsterdam · deportiert I 943 von Westerbork nach Auschwitz, - gest. 30. Juni I944 im Vernichtungslager Auschwitz

(Gedenkbuch Gö 203f)

\section{$48^{\star}$ Polak, Israel Julius}

Eltern: Hartog Polak - Dina Engers

Ehefrau: Regina Meyenberg, s. 51*

geb. 4. November I 879 in Goor/Niederlande - wohnhaft zuletzt in Amsterdam - deportiert 20. Juli I943 nach Sobibor · gest. 23. Juli I943 im Vernichtungslager Sobibor

(Gedenkbuch Gö 204)

\section{9^ Polak, Levi}

Eltern: Eltern: Hartog Polak - Dina Engers

Ehefrau: Bertha Lichtenstein, s. $46^{*}$

geb. I3. November I883 in Goor/Niederlande - wohnhaft zuletzt in Amsterdam · deportiert 29. Juni I943 von Westerbork nach Sobibor - gest. 2. Juli I943 im Vernichtungslager Sobibor

(Gedenkbuch Gö 204)

\section{$50^{\star}$ Polak, Mathilde}

Eltern: Israel Julius Polak, s. $48^{\star}-$ Regina Meyenberg, s. 51*

geb. I. März I9 8 in Adelebsen · wohnhaft zuletzt in Amsterdam · deportiert 20. Juli I943

von Westerbork nach Sobibor · gest. 23. Juli 1943 im Vernichtungslager Sobibor

(Gedenkbuch Gö 204f.)

\section{$5 \mathrm{I}^{\star}$ Polak, Regina}

Eltern: Kaufmann Meyenberg, IV 9 - Mathilde Wollberg, IV 8

Ehemann: Israel Julius Polak, s. $48^{*}$

geb. I9. April I88 I in Adelebsen ' wohnhaft zuletzt in Amsterdam · deportiert 20. Juli I943 von Westerbork nach Sobibor - gest. 23. Juli I943 im Vernichtungslager Sobibor

(Gedenkbuch Gö 205) 
$52^{\star}$ Poli, Meta

Eltern: Simon Dannenberg, IV 2 I - Henriette Brandes, IV 20

Ehemann: Samuel Poli, geb. 29. Mai I 858 in Petershagen

geb. 6. Juli 1875 in Adelebsen · wohnhaft zuletzt in Petershagen bei Minden/Westfalen - deportiert 3I. Juli I942 nach Theresienstadt, 23. September I942 nach Treblinka $\cdot$ gest. vermutlich im Vernichtungslager Treblinka

\section{3 * Rapp, Lucie Ilse}

Eltern: Siegfried Eichenberg - Helene Philippsborn

Großeltern: Meyer Levi Eichenberg, IV 38 - Mathilde Eichenberg, IV 37

Ehemann: Carl Rapp, 20.I2.I873 in Frankfurt/Main gest. 29.6.I943 im KZ Westerbork - gest. 29.6.I943 im KZ Westerbork

geb. I I. August i9 Io in Adelebsen · wohnhaft zuletzt in Den Haag · deportiert 1942 nach Auschwitz $\cdot$ gest. 22. Oktober I943 im Vernichtungslager Auschwitz

(Gedenkbuch Gö 58f.)

\section{$54^{\star}$ Rothschild, Max}

Eltern: Joel S. Rotschild, IV I7 - Betty Davidson, III 53

geb. 5. April I 868 in Adelebsen · wohnhaft zuletzt in Berlin · deportiert 3. September I942 nach Theresienstadt, 29. September 1942 nach Treblinka gest. vermutlich im Vernichtungslager Treblinka

\section{$55^{\star}$ Rothschild, Rosa}

Eltern: Seligmann Rülf - Vanny Stiefel

I. Ehemann: N.N. Schaumberg

2. Ehemann: Noa Rotschild, V 4

geb. 3. Juli I 878 in Wittelsberg / Hessen · wohnhaft zuletzt in Adelebsen · deportiert 2 I. Juli I942 nach Theresienstadt · gest. 4. Juni I943 im Ghetto Theresienstadt

(Gedenkbuch Gö 237)

\section{$56^{\star}$ Schaumberg, Gustav}

Eltern: N.N. Schaumberg - Rosa Rülf, s. 55*

Ehefrau: Toni Dannenberg, s. 59*

geb. I8. Dezember 1904 in Schweinsberg / Hessen - wohnhaft zuletzt in Adelebsen - deportiert 26. März I942 nach Warschau · gest. vermutlich im Ghetto Warschau

(Gedenkbuch Gö 240) 


\section{$57^{\star}$ Schaumberg, Hans}

Eltern: Gustav Schaumberg, s. 56* - Toni Dannenberg, s. 59*

geb. 30. Juni I938 in Adelebsen · wohnhaft in Adelebsen · deportiert 26. März I 942 nach Warschau $\cdot$ gest. vermutlich im Ghetto Warschau

(Gedenkbuch Gö 240)

\section{$58^{\star}$ Schaumberg, Joachim}

Eltern: Gustav Schaumberg, s. 56* - Toni Dannenberg, s. 59*

geb. 4. April 1932 in Adelebsen · wohnhaft zuletzt in den Niederlanden - deportiert 2. März I943 von Westerbork nach Sobibor · gest. 5. März I943 im Vernichtungslager Sobibor

(Gedenkbuch Gö 24I)

\section{$59^{\star}$ Schaumberg, Toni}

Eltern: Karl Dannenberg, s. $10^{\star}-$ Paula Speyer, s. $11^{\star}$

Ehemann: Gustav Schaumberg, s. 56*

geb. I4. Mai I909 in Adelebsen · wohnhaft zuletzt in Adelebsen · deportiert 26. März I942 nach Warschau $\cdot$ gest. vermutlich im Ghetto Warschau

\section{$60^{\star}$ Schulhöfer, Ida}

Eltern: Meyer Levi Eichenberg, IV 38 - Mathilde Eichenberg, IV 37

Ehemann: Salomon Schulhöfer, geb. 26. September I865 in Bibergau/Unterfranken, gest. 26. September 1939 in Würzburg

geb. I4. Mai I 873 in Adelebsen · wohnhaft zuletzt in Würzburg · deportiert 23. September I942 nach Theresienstadt · gest. I4. März I944 im Ghetto Theresienstadt

\section{I ${ }^{\star}$ Segal, Anne}

Eltern: Karl Dannenberg, s. $10^{\star}-$ Paula Speyer, s. $11^{\star}$

Ehemann: Mayer Jacob Segal, geb. 8. September 1904 in Radymno/Polen; deportiert zusammen mit seiner Frau, gest. vermutlich ebenfalls im Vernichtungslager Auschwitz

geb. 25. Mai I9I2 in Adelebsen · wohnhaft zuletzt in Frankreich · deportiert 28.8.1942 von Drancy (Champ de Noë) nach Auschwitz · gest. vermutlich im Vernichtungslager Auschwitz

(Gedenkbuch Gö 53)

\section{2* Seidl, Gertrud}

Eltern: Salomon Gräfenberg, Grab Göttingen 333 - Minna Eichenberg, Grab ebd.

Ehemann: Paul Seidl, gest. I4. September 1929 in Hamburg

geb. I 8. Juni I 883 in Adelebsen · wohnhaft zuletzt in Groningen/Niederlande · deportiert 25. Mai I943 von Westerbork nach Sobibor - gest. 28. Mai I943 im Vernichtungslager Sobibor 


\section{$63 \star$ Seligmann, Gertrud}

Eltern: Leopold Stehberg, IV 45 - Mathilde Rosenbaum, IV 46

Ehemann: Ferdinand Seligmann, geb. Io. Juni I 883 in Voerde/Westfalen, gest. vermutlich in oder bei Minsk

geb. I5. Februar I895 in Adelebsen · wohnhaft zuletzt in Düsseldorf - deportiert io. November I94I nach Minsk · gest. vermutlich in oder bei Minsk

$64^{\star}$ Stehberg, Erich

Eltern: Albert Stehberg, IV 30 - Rosa Stehberg, IV 32

geb. I 5. Juli I 898 in Adelebsen · wohnhaft zuletzt in Hamburg · deportiert 8. November I94I nach Minsk · gest. vermutlich in oder bei Minsk

\section{Quellen}

I Gedenkbuch - Opfer der Verfolgung der Juden unter der nationalsozialistischen Gewaltherrschaft in Deutschland I933 - I945, Bundesarchiv 2007. http://www.bundesarchiv.de/gedenkbuch/

2 The Central Database of Shoah Victims' Names, Yad Vashem, Jerusalem. http://www.yadvashem.org/

3 Oorlogsgravenstichting, Den Haag. http://www.ogs.nl

4 Digitaal Monument Joodse Gemeenschap in Nederland, Joods Historisch Museum, Amsterdam. http://www.joodsmonument.nl/

5 Memorial de la Shoah. Centre de documentation juive contemporaine, Paris. http://www.memorialdelashoah.org/

6 Schäfer-Richter, Uta - Klein Jörg: Die jüdischen Bürger im Kreis Göttingen I933I945. Ein Gedenkbuch, Göttingen I992 (= Gedenkbuch Gö) 


\section{אֵל מָלִא בַחְמִים

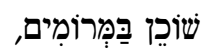

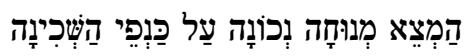

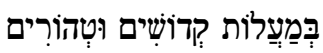

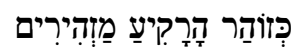

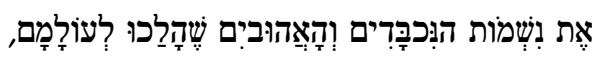

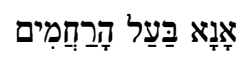

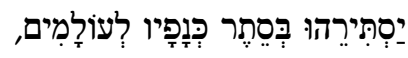

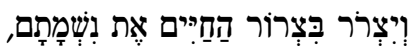

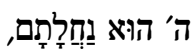

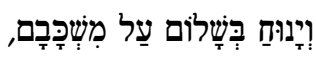 \\ וְניאמַר אָמֵן:}

Gott voller Erbarmen

der wohnt in den Höhen !

Lass wahre Ruhe finden unter den Flügeln der Schechina,

wenn sie hinaufsteigen, die Heiligen und Reinen,

die wie der Glanz des Himmelgewölbes glänzen,

die Seelen der Verehren und Geliebten, die in ihre Ewigkeit eingingen.

Ach, Herr des Erbarmens,

berge sie in der Geborgenheit deiner Flügel in Ewigkeit

und bündele in das Bündel des Lebens ihre Seelen.

Der Ewige, ER ist ihr Erbteil.

Und sie mögen ruhen in Frieden auf ihrem Lager.

Amen 


\section{Anhänge}

\section{Register der Namen und der Grabstellen}

\section{Namen}

Anonymus [1830]

II 23

Anonymus [i 850$]$

III 4

Arensberg, Berta, geb. Löwenstern [8.4.I843 - I3.7.I923]

III 34

Arensberg, Joseph [29.5.I840 - 20.I.I874]

III 35

Backstein, Abraham [24.6.I82I]

II 27

Backstein, Gidel, geb. Rosenberg [26.9.I8I I]

II 32

Bähr(e), Philipp [I2.5.I792 - 5.I.I 854]

III 44

Bähr, Hirsch [I7.12.1799-22.2.I87I]

III 57

Bähr, Levi [20.5.I829 - 25.3.I893]

IV 7

Bähr, Mathilde, geb. Kahlberg [20.7/I4.I0.I789 - I.3.I867] III 45

Bähr, Minna, geb. Henneberg [6.I.I 832 - 28.4.I895]

IV 7

Bähre, Mendel Herz [I737/38 - I8.I.I830]

Beila bat Benjamin [29.I.I773]

II 49

Beila bat Schimon [28.6.I824]

I I6

Blumenfeld, Berta, geb. Freudenstein [5.7.I833-2I.7.I9I2]

II 44

Blumenfeld, Hedwig [I6.3.I868 - 31.7.1902]

IV 40

Blumenfeld, Sallÿ [5.4.I 842 - I4.I I.I925]

Breine bat Meïr [1 3.3.I770]

Buna bat Menachem Mosche [i6.Io.I792]

Dahl, Rike, geb. Hellenstein [I777/78 - 26.4.I866]

IV $4 \mathrm{I}$

IV 39

I 20

I 23

Dannenberg, Amalie, geb. König [6.7.I845 - 4.I.I903]

III 93

Dannenberg, Bertha [20.4.I 868 - 4.3.I890]

IV 26

Dannenberg, Bertha, geb. Buchthal [I 4.8.I 836 - 8.I2.I 882]

IV I2

Dannenberg, Calman Selig [24.I.I789-8.I.I 857]

III 8

Dannenberg, Clara, geb. Meyenberg [8.5.I 800 - 22.6.I 857 ]

III 65

Dannenberg, Henriette, geb. Brandes [I I.I.I839 - I4.I.I924]

III 66

Dannenberg, Johanne [6.I2.I828 - I6.I.I852]

IV 20

Dannenberg, Meyer [I2.I I.I82 I - 3I.I2.I888]

Dannenberg, Moses Selig [25.IO.I785 - 4.2.I 864]

III I 5

Dannenberg, Rosa [4.4.I863 - 20.9.I884]

III 7

III $3 \mathrm{a}$

Dannenberg, Rösche, geb. Meyenberg [5.I.I792 - 20.7.I 849]

III II

Dannenberg, Röschen [5.7.I86I - 22.I.I877]

III 3

Dannenberg, Selig [6.IO.I834 - 23.2.1896]

III I 8

Dannenberg, Simon [I 4.9.I 822 - 27.I I.I903]

David Arend [23.2.1773]

David, Levi [10.4.1756]

Edelstein, Abraham M. [I2.5.I834 - 9.4.I836]

IV 27

IV 2 I

I 22

I I 3

II 2 I

Edelstein, Abraham Moses [I743/44 - 4.4.I8I6]

II 22

Edelstein, Alexander Abraham [4.6.I799 - 3.2.I 856]

III 63

Edelstein, Edel, geb. Friedheim [2.2.1768 - I3.2.I850]

II 25

Edelstein, Emilie [3 I.I2.I856 - I6.6.I899]

IV 23

Edelstein, Moses Abraham [8.7.I794 - 20.I.I849]

III I 
Edelstein, Pauline [I.7.I 846 - I 5.IO.I 852 ]

Edelstein, Rosette, geb. Eichenberg [20.5.I797 - 2I.I.I855]

III 3 I

Eichenberg, Abraham [3 I.I2.I828 - I 5.I.I894]

III 2

Eichenberg, Albert [I6.8.1858 - 29.I.I 859]

IV IO

III 72

Eichenberg, Amalie, geb. Rothschild [I78 I/82 - 27.5.I 8 I6]

II I2

Eichenberg, Auguste, geb. Freudenstein [I 3. I I.I 828 - 26.9. I 890]

Eichenberg, David [I.8.I8I I - I5.5.I893]

Eichenberg, Edel, geb. Kopperschlag [24.I2.I793 - 24.I I.I 848]

IV II

IV 6

Eichenberg, Eva [6.I I.I 850 - 24.I0.I865]

II 45

III 92

Eichenberg, Friederike, geb. Stehberg [I6.8.I8Io - 3.7.I873]

III 78

Eichenberg, Henriette, geb. Jacobsohn [8.3.I80I - 4.I.I858]

Eichenberg, Johanne [23.I.I859 - I7.I I.I935]

III 75

Eichenberg, Julie, geb. Freudenstein [28.6.I 8 I9 - 23.3.I900]

V I

Eichenberg, Leiser [29.I.I795/4.6.I796 - I I.7.I859]

III 84

Eichenberg, Levi [I3.Io.I82 I - 8.3.I889]

III 79

Eichenberg, Levi L. [25.6.I 837 - 2I.I.I852]

IV I4

III 28

Eichenberg, Levi Meyer [I2.3.I793 - IO.I.I 868]

Eichenberg, Lina, geb. Edelstein [I I.I2.I826 - 9.I2.I905]

III 74

Eichenberg, Lucas Meyer [I4.6.I790 - 4.IO.I 859]

IV I 3

III 80

Eichenberg, Meier [5.4.I835 - I I.I.I9I4]

IV I8

Eichenberg, Meier Levi [27.3.I824 - 26.I I.I904]

Eichenberg, Mirjam Mathilde, geb. Eichenberg [3.2.I84 I - 5.I.I907]

IV 38

Eichenberg, Rosalie, geb. Edelstein [I.7.I846 - I7.2.1904]

IV 37

IV I9

Eichenberg, Simon [4.I I.I 808 - 9.IO.I865]

Eichenberg, Simon Meier [20.6.I780 - 20.2.I843]

Eichenberg, Sophie, geb. Grunsfeld [Io.9.18 88 - 21.6.1896]

III 83

II 35

IV 5

Eichenberg, Willi [I.I I.I876 - 2.9.1909]

IV 36

Eisig, Henriette, geb. Backstein [I.I.I806 - 8.2.I888]

III 69

Eisig, Schilein [I6.2.I794 - I9.I2.I868]

Elkele eschet Jaakov [I3.IO.I749]

Esther bat Herz Kaz [I743/44]

Esther bat Meïr [28.6.I79I]

Freidche eschet Meir [5.5.1755]

Freudenstein, Caroline [5.4.I790 - I0.5.I 857]

Freudenstein, Lea, geb. Katz [I7.5.I834-6.6.I856]

III 70

I 5

I I

I 24

I 6

III 67

III 64

Freudenstein, Meyer Philipp [I6.9.I739 - 3I.I2.I82I]

II 7

II 38

Freudenstein, Moses Meyer [I6.8.I790 - I 8.4.I 847 ]

III 68

Freudenthal, Isaac Moses [14.4.I780 - 6.I2.1853]

III 43

III 52

Freudenthal, Sophie, geb. Heilbrunn [IO.IO.I770 - I7.3.I855]

Fromet [3.5.I733]

Gerson, Margarete, geb. Stehberg [10.7.I 892 - I3.5.1936]

Gitel bat Naphtali ha-Kohen [20.9.1735]

Gräfenberg, Friederike, geb. Eichenberg [I 5.I I.I $843-25.2 .1869]$

Gräfenberg, Henriette [8.8.I890 - 21.2.I892]

Gräfenberg, Jente [I4. bzw. I 8.2.1823]

I 3

V 2

I 2

III 33

IV 2

II $\quad$ I7

Gräfenberg, Paul [II.IO.I873 - I2.6.I878]

III 49 
Gräfenberg, Selig Nathan [28.7.I752 - 20.2.I836]

II 20

Hammerschlag, Goldchen, geb. Wolfsohn [22.I.I80I - 20.9.I 848]

II 42

Hammerschlag, Nathan Calman [um I759/60 - 28.Io.I83 I]

II 47

Hess, Hendel [um I764/65 - I6.3.I 849]

III 27

Hindel bat David [I743/44 - 29.8.I8I I]

II IS

Ilten, Edel [27.I2.I82I]

Ilten, Levi Moses [um I737/38 - I6.Io.I807]

II I9

Ilten, Moses [I 7.IO.I775 - 29.3.I778]

Ilten, Moses Meyer [25.4.I753]

Ilten, Rachel [I746 - 3I.3.I8I 5]

I 25

I 2 I

I 9

Ilten, Schafti [12.7.I 8 I 2 ]

II I I

Isaac, Jette, geb. Meyer [Io.9.I 8 Io - 29.7.I 869]

II I6

Itzig, Joseph [28.I.I76I]

Jacob Nathan [3.7.1742]

Jacobsohn, Goldchen [9.2.I848]

Jehuda Leib ben Schimon [I735/36 - 3.I I.I809]

Kalonymus ben Mosche [6.2.18 I9]

III IOO

Katzenstein, Helene [9.6.I848 - 26.7.I92I]

Katzenstein, Henriette, geb. Rosenbaum [I 7.6.I 820 - 26.I2.I860]

Katzenstein, Ida, geb. Stehberg [I4.IO.I88I - I 8.2.I938]

I $\quad$ I 7

I 7

II 43

II 5

II 8

Katzenstein, Julius [2.I.I8 I I - I9.2.I873]

Levi, Meyer [25.6.I737]

Löwenstern, Bernhart [24.7.I848 - I0.4.I 859 ]

Löwenstern, Bertha, geb. Dahl [22.6.1776 - 22.6.I 832]

IV 47

III 90

V 3

III 89

I 4

III 32

Löwenstern, Betti [3.4.I839 - 23.2.19I7]

II 28

Löwenstern, Fanny Fromet, geb. Grunsfeld [I7.3.I8I I - 4.Io.I898]

IV 29

Löwenstern, Jacob Marcus [29.I.I 8 I I - I2.I2.I893]

III 47

Löwenstern, Johanne, geb. Dahl [2.2. oder Io.6.I8I 2 - I4.2.I 884]

III 9

Löwenstern, Marcus [I I.8.I 847 - 5.2.I 852 ]

III IO

Löwenstern, Marcus [I6.8.1774 - 23.6.I840]

III 25

Löwenstern, Moses [9.I.I 840 - I2.8.I 870$]$

Löwenstern, Samuel [22.7.I809 - I 5.I0.1877]

II 29

III 7 I

Löwenstern, Simon [6.I0.I806 - I8.I.I878]

III 48

Löwenthal, Friederike, geb. Edelstein [I9.3.I802 - 9.3.I882]

III 36

Löwenthal, Levi [I4.3.I84I - I8.2.I852]

III 98

Löwenthal, Levi David [28.I I.I753 - Io.9.I834]

III 30

Löwenthal, Salomon [20.3.I802 - I0.8.I868]

Meier, Joseph [10.5.1758]

Mendel, Herz [3.I0.1760]

Merle bat Jaakov [12.5.1775]

Meyenberg, Henriette, geb. van Campen [I4.8.I836 - I5.IO.I9I8]

Meyenberg, Kaufmann [27.5.I829 - 3.3.I892]

Meyenberg, Marline [25.7.1832]

Meyenberg, Mathilde, geb. Wollberg [I9.I2.I84I - I6.8.I903]

II 3 I

III 99

I $\quad$ I2

I 18

I $\quad$ I4

IV 34

IV 9

II 6

Meyenberg, Meyer Salomon [23.I I.I78I - I2.9.I844]

IV 8

Meyenberg, Minna, geb. Hirsch [26.9.1793 - 22.I0.I867]

II 34

Meyenberg, Röschen [I 8.8.I8I8 - I.I.I902]

III 62

IV 22 
Meyenberg, Salomon Simon [I740 - I.I2.I 823]

II 2

Meyenberg, Simon/Simcha [2I.I.I787-2I.I.I856]

III 6I

Meyenberg, Wolf [25.2.I 822]

II I 3

Meyenberg, Wolf [5.7.I824 - I7.IO.I885]

Meyer, Abraham [9.3.I749]

Mosche bar Pinchas [22.3.I8I3]

Moses, Schmeiche [I739/40 - I6.7.I785]

II 48

I I I

II I

Müller, Aron Isaak [I 4.9.I779 - I4.3.I 849]

I 19

Müller, Bertha [26.6.I 857 - 6.7.I 858 ]

III 23

Müller, Bertha [6.Io.I849 - 20.I2.I85I]

III 60

Müller, Bertha, geb. Bacharach [Io.3.I 823]

II $4 \mathrm{I}$

II 5 I

Müller, Betty [I3.8.I832- 25.5.I839]

II 30

Müller, David Isaak [4.4.I785 - I9.2.I879]

III 87

Müller, Emilie [I.Io.I859 - I0.7.I 866]

Müller, Esther, geb. Stehberg [I8.I.I8I5 - I I.I2.I883]

III 95

Müller, Georg [29.9.I879 - 20.4.I89I]

III 22

Müller, Goldine, geb. Eichenberg [I4. 9.I 849 - 30.6.I924]

IV 4

IV 48

Müller, Hannchen [3.2.I770 - 30.I.I 846]

II 46

Müller, Henriette [24.8.I8I 8 - I8.I2.I893]

IV 28

Müller, Henriette [9.4.I 8 I 3 - 30.9.1833]

II 24

Müller, Herz Aron [I 5.9.I8I 7 - 2.I I.I 894]

III 2 I

Müller, Herz Simon [20.8.I803 - 4.4.I854]

III 50

Müller, Isaac Aron [i 8.8.I8I9 - 8.3.I872]

III 46

Müller, Isaak [I.2.I $847-8$.I.I 852 ]

III I4

Müller, Isidor [3 I.I2.I 848 - 30.4.I9I9]

IV 49

Müller, Johanna, geb. Rothschild [I2.5.I 798 - 29.7.I860]

III 88

Müller, Robert [26. 9.I 883 - I I.4.I89I]

Müller, Salomon [I.4.I848 - I8.I2.I85I]

IV 4

II 4 I

Müller, Simon Isaak [24.I.I766 - 7.I I.I853]

II 39

Nathan bar Nathan Segal [6.I2.I822]

II 3

Nathan ben Baruch [3.7.I 820]

Oppenheim(er), Samuel Simon [8.I2.I783 - I3.5.I85I]

II I 4

III I 2

Oppenheim, Carl [24.5.I872 - 26.3.I874]

III 59

Oppenheim, Esther, geb. Dannenberg [8.I.I84I - I8.7.I885]

III 20

Oppenheim, Jeanette, geb. Plaut [I4.5.I79I - 22.3.I 869]

III I3

Oppenheim, Saly [2.I I.I870 - 28.3.I874]

III 59

Oppenheim, Selig Moses [um I742 - 29.IO. I826]

II 26

Oppenheim, Simon [I2.I I.I825 - I7.2.I882]

Peier eschet Avraham [I 4.6.I74I]

Polak, Hugo [I I.4.1906 - 8.8.1906]

Rieke eschet Masus [I4.II.I756]

III I9

I 8

IV I

I IO

Rivka bat Eljakim [20.1 I.I833]

II 33

Rosenbaum, Dora [27.5.1853 - IO.IO.I869]

III 86

Rosenbaum, Emilie, geb. Stern [8.I I.I8I2 - 28.I2.I888]

III I7

Rosenbaum, Eva [2 I.6.I 822]

II 37

Rosenbaum, Johanna [2.9.1856 - IO.I.I9I8]

IV 50

Rosenbaum, Meyer [20.3.I8I7-6.2.I860]

III 8 I 
Rosenbaum, Moses [I9.I.I8I2 - 23.3.I876]

III I6

Rosenbaum, Rösche [I9.4.I 848 - 22.I.I 852 ]

III 24

Rosenbaum, Salomon [8.II.I857-28.2.1925]

IV 44

Rosenbaum, Samuel [I7.7.I779 - I9.5.I838]

II 36

Rosenbaum, Sara, geb. Blumenberg [26.10.I826 - I.I2.I906] III 82

Rosenbaum, Selma, geb. Arensberg [I6.8.1869-28.8.1928] IV 43

Rosenstein, Rösche, geb. Oppenheim [I4.9.I776 - 8.5.I853] III 42

Rosenthal, David Levi [I6.2.I802 - 26.2.I863]

III 56

Rosenthal, Henriette, geb. Rothstein [20.4.I800 - I3.I2.I867] III 55

Rosenthal, Levi [28.3.I 833 - 24.9.I873]

Rosenthal, Levi Daniel [6.3.I8I5]

Rosenthal, Miene, geb. Rothstein [Io.6.I 823]

III 58

Rothschild, Bertha [8.I2.I 858 - 2.6.I866]

Rothschild, Bertha, geb. Gans [28.3.1837-8.3.1927]

Rothschild, Betty, geb. Davison [I 5.I2.I829-2I.8.I 855]

II 4

II 9

III 94

Rothschild, Fanni, geb. Hess [8.5.I80I - 3I.I.I 854]

IV 42

II 53

Rothschild, Hanna [I6.I I.I837 - 2.Io.I853]

Rothschild, Joel D. [I739/40 - 30.8.I8 I4]

III 4 I

III 5 I

Rothschild, Joel S. [I 8.2.I8I9 - I 5.3.I909]

II I 8

Rothschild, Louis [5.I2.I87I - 25.I.I898]

Rothschild, Moses Joel [27.2.I8I I]

Rothschild, Noa [4.9.1869-24.5.1948]

Rothschild, Salomon J. [6.8.I854 - I 5.9.I 854 ]

IV 17

IV 24

II IO

V 4

Rothschild, Salomon Joel [20.8.I790 - 24.I I. I 852 ]

III 26

Sachs, Michel [I7.2.I834 - I2.I I.I854]

III 40

Sachs, Moses [I796/97 - 24.2.1850]

III 54

Sachs, Samuel [I6.8.I828 - II.5.I85I]

III 5

Schlomo ben Mosche [28.I.I826]

Speyer, Agnes [5.I2.I $880-29.5 . \mathrm{I} 88 \mathrm{I}]$

III 39

II 40

Speyer, Aron [26.9.1843 - 28.2.1915]

III 37

Speyer, Bertha, geb. Heilbrunn [23.7.I855-2I.7.I9I2]

IV 33

Speyer, Heinz [6.2.I884 - I8.4.I89I]

IV 35

Speyer, Louis [3 I.3.I879- I3.I2.I 897]

IV 3

Speyer, Max [27.I.I $890-24.4 . I 89$ I]

IV 25

Speyer, Selka [4.6.I877 - 3I.Io.I880]

IV 3

III 37

Speyer, Therese, geb. Heilbrunn [IO.I.I849-2I.2.I 885]

III 38

Stehberg, Albert [I2.I2.I850 - 29.3.I9I8]

Stehberg, Betti, geb. Dannenberg [2.I I.I 8 I 8 - I3.5.I 897]

IV 30

IV IS

Stehberg, Gitel, geb. Müller [I6.8.I777 - I2.8.I 862]

III 76

Stehberg, Herz [25.I2.I8I 3 - I8.9.I886]

IV 16

Stehberg, Hilda [I 5.6.I 885 - I6.4.I888]

III 85

Stehberg, Jacob [IO.I.I 853 - 9.9.I 864 ]

III 9I

Stehberg, Julie, geb. Dahlberg [I.5.I 82 I - 26.5.I879]

III 6

Stehberg, Julius [I 2.6.I 857 - I 5.6.I 860]

III 73

Stehberg, Leopold [i 8.8.1860 - 28.8.1922]

IV 45

Stehberg, Levi [I2.I2.I8I I - 30.8.I879]

III 6

Stehberg, Louis Herz [29. IO.I 850 - 29.I.I 852]

III 29 
Stehberg, Lucas [I.7.I78I - 23.I.I858]

III 77

Stehberg, Ludwig [29.3.I889-6.5.I9I5]

IV 3 I

Stehberg, Mathilde, geb. Rosenbaum [6.5.I860 - 22.7.I929]

IV 46

Stehberg, Rosa [2I.II.I854-26.II.I9i6]

IV 32

Unger, Friederike, geb. Empsberg [22.I.I 8 Io - I I.7.I 877]

III 96

Unger, Lehmann [I6.I I.I797 - 29.7.I866]

III 97

Zerle bat Schlomo [8.3.I773]

I 15

\section{Grabstellen}

I I Esther bat Herz Kaz

I 2 Gitel bat Naphtali ha-Kohen

$\mathrm{I} 743 / 44$

I 3 Fromet

I 735

I 4 Levi, Meyer

I 733

I 5 Elkele eschet Jaakov

I 737

I 749

I 6 Freidche eschet Meir

I 755

I 7 Jacob Nathan

I 742

I 8 Peier eschet Avraham

I 74 I

I 9 Ilten, Moses Meyer

I 753

I 756

I IO Rieke eschet Masus

I 749

I I I Meyer, Abraham

I 758

I I2 Meier, Joseph

I 756

I 3 David, Levi

I 775

I I4 Merle bat Jaakov

I 773

I I6 Beila bat Benjamin

I 773

I 17 Itzig, Joseph

I76I

I I 8 Mendel, Herz

I 760

I I9 Moses, Schmeiche

1785

I 770

I 20 Breine bat Meïr

I 778

$2 \mathrm{I}$ Ilten, Moses

I 773

I 23 Buna bat Menachem Mosche

1792

I 24 Esther bat Meïr

I79 I

I 25 Ilten, Levi Moses

I 807

I 8 I 3

I 823

I 822

I 8 I 5

I 809

I 832

I 82 I

I 8 I 9

II 8 Kalonymus ben Mosche

I 823

II 9 Rosenthal, Miene, geb. Rothstein

I 8 I I

II Io Rothschild, Moses Joel

I 8 I 5

II I I Ilten, Rachel

I 8 I 6

II I2 Eichenberg, Amalie, geb. Rothschild 
$\begin{array}{llll}\text { II } & \text { I3 Meyenberg, Wolf } & \text { I822 }\end{array}$

II I4 Nathan ben Baruch $\quad$ I 820

II I5 Hindel bat David $\quad$ I 8 I I

II I6 Ilten, Schafti

I 8 I 2

II $\quad$ I Gräfenberg, Jente

I 823

II I8 Rothschild, Joel D. I $\quad$ I 4

II I9 Ilten, Edel I 82 I

$\begin{array}{lr}\text { II } 20 \text { Gräfenberg, Selig Nathan } & \text { I } 836\end{array}$

$\begin{array}{lll}\text { II } 2 \text { I Edelstein, Abraham M. } & \text { I } 836\end{array}$

II 22 Edelstein, Abraham Moses $\quad$ I8 I6

$\begin{array}{lll}\text { II } 23 \text { Anonymus } & \text { I830 }\end{array}$

$\begin{array}{llll}\text { II } & 24 & \text { Müller, Henriette } & \text { I833 }\end{array}$

$\begin{array}{lll}\text { II } 25 & \text { Edelstein, Edel, geb. Friedheim } & \text { I } 850\end{array}$

$\begin{array}{ll}\text { II } 26 \text { Oppenheim, Selig Moses } & \text { I } 826\end{array}$

II 27 Backstein, Abraham I82 I

$\begin{array}{lll}\text { II } 28 & \text { Löwenstern, Bertha, geb. Dahl } & \text { I832 }\end{array}$

$\begin{array}{ll}\text { II } 29 \text { Löwenstern, Marcus } & \text { I840 }\end{array}$

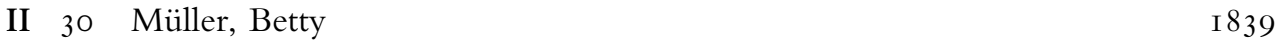

II 3 I Löwenthal, Levi David $\quad$ I834

II 32 Backstein, Gidel, geb. Rosenberg I 8 I I

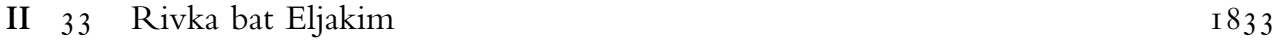

$\begin{array}{ll}\text { II } 34 \text { Meyenberg, Meyer Salomon } & \text { I844 }\end{array}$

$\begin{array}{ll}\text { II } 35 \text { Eichenberg, Simon Meier } & \text { I843 }\end{array}$

$\begin{array}{ll}\text { II } 36 & \text { Rosenbaum, Samuel } \\ & \text { I } 838\end{array}$

$\begin{array}{ll}\text { II } 37 \text { Rosenbaum, Eva } & \text { I } 822\end{array}$

$\begin{array}{lll}\text { II } 38 & \text { Freudenstein, Moses Meyer } & \text { I } 847\end{array}$

II 39 Müller, Simon Isaak $\quad$ I 853

II 40 Schlomo ben Mosche $\quad$ I826

II 4I Müller, Bertha $\quad$ I85I

II 4I Müller, Salomon $\quad$ I $85 \mathrm{I}$

II 42 Hammerschlag, Goldchen, geb. Wolfsohn I848

$\begin{array}{lll}\text { II } 43 \text { Jacobsohn, Goldchen } & \text { I } 848\end{array}$

$\begin{array}{ll}\text { II } 44 \text { Beila bat Schimon } & \text { I824 }\end{array}$

$\begin{array}{lll}\text { II } 45 & \text { Eichenberg, Edel, geb. Kopperschlag } & \text { I848 }\end{array}$

II 46 Müller, Hannchen $\quad$ I846

II 47 Hammerschlag, Nathan Calman $\quad$ I83 I

$\begin{array}{lll}\text { II } 48 \text { Meyenberg, Wolf } & \text { I } 885\end{array}$

II 49 Bähre, Mendel Herz $\quad$ I830

$\begin{array}{ll}\text { II } 5 \text { I Müller, Bertha, geb. Bacharach } & \text { I823 }\end{array}$

$\begin{array}{ll}\text { II } 53 \text { Rothschild, Betty, geb. Davison } & \text { I855 }\end{array}$

$\begin{array}{lr}\text { III I Edelstein, Moses Abraham } & \text { I849 }\end{array}$

$\begin{array}{lll}\text { III } 2 \text { Edelstein, Rosette, geb. Eichenberg } & \text { I855 }\end{array}$

III 3 Dannenberg, Rösche, geb. Meyenberg $\quad$ I849

III 3a Dannenberg, Moses Selig $\quad$ I 864

$\begin{array}{lll}\text { III } 4 \text { Anonymus } & \text { I } 850\end{array}$

$\begin{array}{ll}\text { III } 5 \text { Sachs, Moses } & \text { I } 850\end{array}$

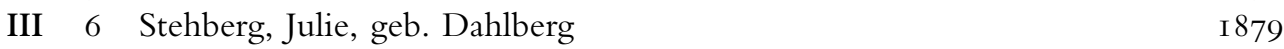




\begin{tabular}{|c|c|c|c|}
\hline III & 6 & Stehberg, Levi & I 879 \\
\hline III & 7 & Dannenberg, Meyer & I 888 \\
\hline III & 8 & Dannenberg, Bertha, geb. Buchthal & I 882 \\
\hline III & 9 & Löwenstern, Jacob Marcus & I 893 \\
\hline III & IO & Löwenstern, Johanne, geb. Dahl & I 884 \\
\hline III & I I & Dannenberg, Rosa & I 884 \\
\hline III & I 2 & Oppenheim(er), Samuel Simon & I $85 \mathrm{I}$ \\
\hline III & I3 & Oppenheim, Jeanette, geb. Plaut & I 869 \\
\hline III & I 4 & Müller, Isaak & I 852 \\
\hline III & I5 & Dannenberg, Johanne & I 852 \\
\hline III & I6 & Rosenbaum, Moses & I 876 \\
\hline III & I7 & Rosenbaum, Emilie, geb. Stern & I 888 \\
\hline III & I 8 & Dannenberg, Röschen & I 877 \\
\hline III & I9 & Oppenheim, Simon & I 882 \\
\hline III & 20 & Oppenheim, Esther, geb. Dannenberg & I 885 \\
\hline III & $2 \mathrm{I}$ & Müller, Herz Aron & I 894 \\
\hline III & 22 & Müller, Esther, geb. Stehberg & I 883 \\
\hline III & 23 & Müller, Aron Isaak & I 849 \\
\hline III & 24 & Rosenbaum, Rösche & I 852 \\
\hline III & 25 & Löwenstern, Marcus & I 852 \\
\hline III & 26 & Rothschild, Salomon J. & I 854 \\
\hline III & 27 & Hess, Hendel & I 849 \\
\hline III & 28 & Eichenberg, Levi L. & I 852 \\
\hline III & 29 & Stehberg, Louis Herz & I 852 \\
\hline III & 30 & Löwenthal, Levi & I 852 \\
\hline III & $3 \mathrm{I}$ & Edelstein, Pauline & I 852 \\
\hline III & 32 & Löwenstern, Bernhart & I 859 \\
\hline III & 33 & Gräfenberg, Friederike, geb. Eichenberg & I 869 \\
\hline III & 34 & Arensberg, Berta, geb. Löwenstern & I923 \\
\hline III & 35 & Arensberg, Joseph & I 874 \\
\hline III & 36 & Löwenstern, Simon & I 878 \\
\hline III & 37 & Speyer, Agnes & I 88 I \\
\hline III & 37 & Speyer, Selka & I 880 \\
\hline III & 38 & Speyer, Therese, geb. Heilbrunn & I 885 \\
\hline III & 39 & Sachs, Samuel & I $85 \mathrm{I}$ \\
\hline III & 40 & Rothschild, Salomon Joel & I 852 \\
\hline III & $4 \mathrm{I}$ & Rothschild, Fanni, geb. Hess & I 854 \\
\hline III & 42 & Rosenstein, Rösche, geb. Oppenheim & I 853 \\
\hline III & 43 & Freudenthal, Isaac Moses & I 853 \\
\hline III & 44 & Bähr(e), Philipp & I 854 \\
\hline III & 45 & Bähr, Mathilde, geb. Kahlberg & I 867 \\
\hline III & 46 & Müller, Isaac Aron & I 872 \\
\hline III & 47 & Löwenstern, Fanny Fromet, geb. Grunsfeld & I 898 \\
\hline III & 48 & Löwenstern, Samuel & I 877 \\
\hline III & 49 & Gräfenberg, Paul & I 878 \\
\hline III & 50 & Müller, Herz Simon & I 854 \\
\hline III & $5 \mathrm{I}$ & Rothschild, Hanna & I 853 \\
\hline
\end{tabular}


$\begin{array}{lll}\text { III } 52 & \text { Freudenthal, Sophie, geb. Heilbrunn } & \text { I } 855\end{array}$

III 54 Sachs, Michel I854

$\begin{array}{ll}\text { III } 55 \text { Rosenthal, Henriette, geb. Rothstein } & \text { I867 }\end{array}$

III 56 Rosenthal, David Levi $\quad$ I 863

$\begin{array}{ll}\text { III } 57 \text { Bähr, Hirsch } & \text { I87I }\end{array}$

$\begin{array}{lll}\text { III } 58 & \text { Rosenthal, Levi } & \text { I873 }\end{array}$

$\begin{array}{lll}\text { III } 59 & \text { Oppenheim, Carl } & \text { I874 }\end{array}$

$\begin{array}{ll}\text { III } 59 \text { Oppenheim, Saly } & \text { I } 874\end{array}$

$\begin{array}{lr}\text { III } 60 \text { Müller, Bertha } & \text { I } 858\end{array}$

III 6I Meyenberg, Simon/Simcha $\quad$ I856

III 62 Meyenberg, Minna, geb. Hirsch $\quad$ I867

$\begin{array}{llll}\text { III } 63 & \text { Edelstein, Alexander Abraham } & \text { I } 856\end{array}$

III 64 Freudenstein, Lea, geb. Katz $\quad$ I856

$\begin{array}{ll}\text { III } 65 \text { Dannenberg, Calman Selig } & \text { I857 }\end{array}$

III 66 Dannenberg, Clara, geb. Meyenberg $\quad$ I857

$\begin{array}{lll}\text { III } 67 & \text { Freudenstein, Caroline } & \text { I } 857\end{array}$

$\begin{array}{ll}\text { III } 68 \text { Freudenstein, Samuel Meyer } & \text { I } 858\end{array}$

$\begin{array}{ll}\text { III } 69 \text { Eisig, Henriette, geb. Backstein } & \text { I888 }\end{array}$

$\begin{array}{lll}\text { III } 70 & \text { Eisig, Schilein } & \text { I868 }\end{array}$

$\begin{array}{ll}\text { III 7I Löwenstern, Moses } & \text { I } 870\end{array}$

$\begin{array}{ll}\text { III } 72 \text { Eichenberg, Albert } & \text { I859 }\end{array}$

$\begin{array}{lll}\text { III } 73 \text { Stehberg, Julius } & \text { I } 860\end{array}$

$\begin{array}{ll}\text { III } 74 \text { Eichenberg, Levi Meyer } & \text { I } 868\end{array}$

III 75 Eichenberg, Henriette, geb. Jacobsohn $\quad$ I858

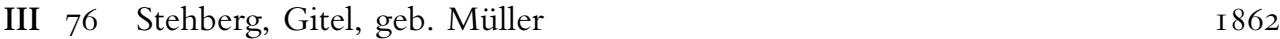

$\begin{array}{ll}\text { III } 77 \text { Stehberg, Lucas } & \text { I } 858\end{array}$

$\begin{array}{ll}\text { III } 78 & \text { Eichenberg, Friederike, geb. Stehberg }\end{array}$

$\begin{array}{ll}\text { III } 79 \text { Eichenberg, Leiser } & \text { I } 859\end{array}$

$\begin{array}{lr}\text { III } 80 \text { Eichenberg, Lucas Meyer } & \text { I859 }\end{array}$

$\begin{array}{ll}\text { III } 8 \text { I Rosenbaum, Meyer } & \text { I } 860\end{array}$

$\begin{array}{llll}\text { III } 82 & \text { Rosenbaum, Sara, geb. Blumenberg } & \text { I906 }\end{array}$

$\begin{array}{lll}\text { III } 83 \text { Eichenberg, Simon } & \text { I865 }\end{array}$

$\begin{array}{lll}\text { III } 84 \text { Eichenberg, Julie, geb. Freudenstein } & \text { I900 }\end{array}$

$\begin{array}{llll}\text { III } & 85 & \text { Stehberg, Hilda } & \text { I } 888\end{array}$

$\begin{array}{ll}\text { III } 86 & \text { Rosenbaum, Dora } \\ \text { I } 869\end{array}$

$\begin{array}{lll}\text { III } 87 \text { Müller, David Isaak } & \text { I } 879\end{array}$

III 88 Müller, Johanna, geb. Rothschild $\quad$ I860

$\begin{array}{ll}\text { III } 89 \text { Katzenstein, Julius } & \text { I873 }\end{array}$

III 90 Katzenstein, Henriette, geb. Rosenbaum I860

$\begin{array}{ll}\text { III 9I Stehberg, Jacob } & \text { I } 864\end{array}$

$\begin{array}{ll}\text { III } 92 \text { Eichenberg, Eva } & \text { I865 }\end{array}$

III 93 Dahl, Rike, geb. Hellenstein $\quad$ I866

$\begin{array}{ll}\text { III } 94 \text { Rothschild, Bertha } & \text { I } 866\end{array}$

$\begin{array}{ll}\text { III } 95 \text { Müller, Emilie } & \text { I } 866\end{array}$

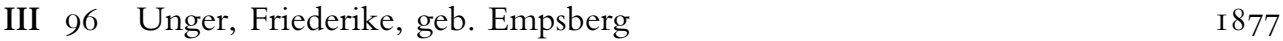

$\begin{array}{ll}\text { III } 97 \text { Unger, Lehmann } & \text { I866 }\end{array}$

$\begin{array}{ll}\text { III } 98 & \text { Löwenthal, Friederike, geb. Edelstein }\end{array}$ 
III 99 Löwenthal, Salomon $\quad$ I868

$\begin{array}{ll}\text { III Ioo Isaac, Jette, geb. Meyer } & \text { I869 }\end{array}$

IV I Polak, Hugo I906

IV 2 Gräfenberg, Henriette $\quad$ I892

IV 3 Speyer, Heinz I89I

IV 3 Speyer, Max I89I

IV 4 Müller, Georg I89I

IV 4 Müller, Robert I89I

IV 5 Eichenberg, Sophie, geb. Grunsfeld $\quad$ I896

$\begin{array}{lll}\text { IV } 6 & \text { Eichenberg, David } & \text { I893 }\end{array}$

$\begin{array}{lll}\text { IV } 7 & \text { Bähr, Levi } & \text { I893 }\end{array}$

IV 7 Bähr, Minna, geb. Henneberg $\quad$ I895

IV 8 Meyenberg, Mathilde, geb. Wollberg $\quad$ I903

$\begin{array}{lll}\text { IV } 9 & \text { Meyenberg, Kaufmann } & \text { I892 }\end{array}$

$\begin{array}{ll}\text { IV Io Eichenberg, Abraham } & \text { I894 }\end{array}$

IV I I Eichenberg, Auguste, geb. Freudenstein I890

$\begin{array}{lll}\text { IV I2 Dannenberg, Bertha } & \text { I } 890\end{array}$

IV I3 Eichenberg, Lina, geb. Edelstein $\quad$ I905

$\begin{array}{ll}\text { IV I4 Eichenberg, Levi } & \text { I889 }\end{array}$

$\begin{array}{llr}\text { IV } & \text { I5 Stehberg, Betti, geb. Dannenberg } & \text { I897 }\end{array}$

IV I6 Stehberg, Herz I886

IV $\quad$ I7 Rothschild, Joel S. $\quad$ I909

IV I8 Eichenberg, Meier $\quad$ I9I4

IV I9 Eichenberg, Rosalie, geb. Edelstein $\quad$ I904

IV 20 Dannenberg, Henriette, geb. Brandes $\quad$ I924

IV 2 I Dannenberg, Simon $\quad$ I903

$\begin{array}{ll}\text { IV } 22 \text { Meyenberg, Röschen } & \text { I9O2 }\end{array}$

$\begin{array}{llll}\text { IV } & 23 & \text { Edelstein, Emilie } & \text { I } 899\end{array}$

$\begin{array}{llr}\text { IV } 24 & \text { Rothschild, Louis } & \text { I898 }\end{array}$

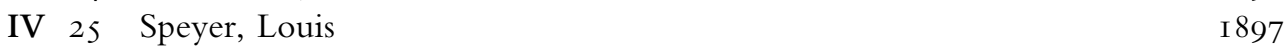

IV 26 Dannenberg, Amalie, geb. König $\quad$ I903

$\begin{array}{lll}\text { IV } 27 & \text { Dannenberg, Selig } & \text { I896 }\end{array}$

IV 28 Müller, Henriette $\quad$ I893

$\begin{array}{lll}\text { IV } 29 \text { Löwenstern, Betti } & \text { I9I7 }\end{array}$

IV 30 Stehberg, Albert $\quad$ I9I8

IV 3 I Stehberg, Ludwig $\quad$ I9I5

IV 32 Stehberg, Rosa $\quad$ I9I6

IV 33 Speyer, Aron I9I5

IV 34 Meyenberg, Henriette, geb. van Campen I9I8

$\begin{array}{lll}\text { IV } & 35 & \text { Speyer, Bertha, geb. Heilbrunn } \\ \text { I9I2 }\end{array}$

IV 36 Eichenberg, Willi $\quad$ I909

IV 37 Eichenberg, Mirjam Mathilde, geb. Eichenberg $\quad$ I907

$\begin{array}{ll}\text { IV } 38 \text { Eichenberg, Meier Levi } & \text { I904 }\end{array}$

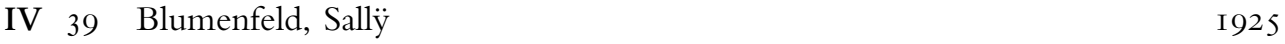

IV 40 Blumenfeld, Berta, geb. Freudenstein I9I2

$\begin{array}{ll}\text { IV 4I Blumenfeld, Hedwig } & \text { I9O2 }\end{array}$

$\begin{array}{ll}\text { IV } 42 \text { Rothschild, Bertha, geb. Gans } & \text { I927 }\end{array}$ 
IV 43 Rosenbaum, Selma, geb. Arensberg $\quad$ I928

IV 44 Rosenbaum, Salomon $\quad$ I925

IV 45 Stehberg, Leopold $\quad$ I922

IV 46 Stehberg, Mathilde, geb. Rosenbaum $\quad$ I929

IV 47 Katzenstein, Helene $\quad$ I92 I

IV 48 Müller, Goldine, geb. Eichenberg $\quad$ I924

IV 49 Müller, Isidor $\quad$ I9I9

IV 50 Rosenbaum, Johanna I9I 8

V I Eichenberg, Johanne $\quad$ I935

V 2 Gerson, Margarete, geb. Stehberg I936

V 3 Katzenstein, Ida, geb. Stehberg I938

$\begin{array}{lll}\text { V } 4 \text { Rothschild, Noa } & \text { I948 }\end{array}$

\section{Literatur}

\section{Allgemeines}

Ashkenazi, Shmuel - Jarden, Dov: Ozar Rashe Tevot - Thesaurus of Hebrew Abbreviations, Jerusalem I99I

Brocke, Michael: Bestattung III, Judentum, TRE 2, I980, 738-743

Brocke, Michael - Müller, Christiane E.: Haus des Lebens. Jüdische Friedhöfe in Deutschland, Leipzig 200 I

Diamant, Adolf: Jüdische Friedhöfe in Deutschland, Frankfurt/M. I982

Gal-Ed, Efrat: Das Buch der jüdischen Jahresfeste, Frankfurt/M. 200 I

Hüttenmeister, Frowald G.: Abkürzungsverzeichnis hebräischer Grabinschriften (AHebG), 2. erweiterte Auflage, Tübingen 2010

Kaplan, Marion (Hg.): Geschichte des jüdischen Alltags in Deutschland. Vom I7. Jahrhundert bis I945, München 2003

Schaller, Berndt: Von der Beredsamkeit jüdischer Friedhöfe, in: C. Dahling-Sander u.a. (Hg.), Herausgeforderte Kirche (Festgabe Eberhard Busch), Wuppertal I997, I33-I 39

Zobel, Moritz: Das Jahr der Juden in Brauch und Liturgie, Schocken, Berlin I936

\section{Regionales}

Alphei, Cord: Geschichte Adelebsens und Lödingsens, Göttingen I990 (= Geschichte)

Dietert, Eike: Geschichte der Juden in Bovenden, Plesse-Archiv 28, I992, 32 I-5 I 8

Dietert, Eike: Adelebsen, in: Obenaus, Handbuch I, 2005, 89-97

Dietert, Eike: Die Ansiedlung von Juden im Fürstentum Göttingen seit I670 und das Vorgehen der Landesregierung gegen eigenmächtige Judenaufnahmen durch die Inhaber der Adligen Gerichte, in: Landjuden in Nordwestdeutschland, Vorträge des Arbeitskreises Geschichte der Juden in der Historischen Kommission für Niedersachsen und Bremen (hrsg. v. Herbert Obenaus), Hannover 2005, I5-32 (= Ansiedlung)

Herbst, Detlev: Jüdisches Leben im Solling. Der Synagogenverband Bodenfelde - Uslar -Lippoldsberg und die Synagogengemeinde Lauenförde, Uslar I997

Marx, Albert, Geschichte der Juden in Niedersachsen, Hannover I995

Obenaus, Herbert ua. (Hg.): Historisches Handbuch der jüdischen Gemeinden in Niedersachsen und Bremen I-2, Göttingen 2005 (= Handbuch) 
Obenaus, Sibylle - Schucht, Gisela: Barterode, in: Obenaus, Handbuch I, 2005, I7I-I 78 Sabelleck, Rainer (Hg.): Juden in Südniedersachsen. Geschichte - Lebensverhältnisse Denkmäler, Schriften des Landesverbandes Südniedersachsen 2, Hannover I994

Schäfer-Richter, Uta - Klein Jörg: Die jüdischen Bürger im Kreis Göttingen I933-I945. Ein Gedenkbuch, Göttingen I992 (= Gedenkbuch Gö)

Wilhelm, Peter: Die jüdische Gemeinde in der Stadt Göttingen von den Anfängen bis zur Emanzipation, Studien zur Geschichte der Stadt Göttingen Io, Göttingen 1973

Ders.; Die Synagogengemeinde Göttingen, Rosdorf und Geismar I 850 - I942, Studien zur Geschichte der Stadt Göttingen I I, Göttingen I978

\section{Anspielungen und Zitate}

Bibel

Gen 25,8 IV 383940

Hab $2,4 \quad$ III 63

Hi I, 8 II 202634383949

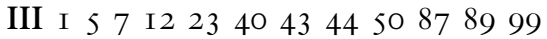

IV $69 \begin{array}{llllllll} & \text { I6 } & \text { I7 } & \text { I9 } & 2 \text { I } 27304244 & 45\end{array}$

Jer $33,6 \quad$ IV 39

Jes 38 , IO III 35

Jes $57,2 \quad$ III 6 I

Jos 23,I 4 III 8 I

Lev I9,2 III 5

Prov 2,20 II 7

Prov I $2,4 \quad$ II 28 III 34 IV 37

Prov I9, I7 II 6

Prov 3I,IO II 6 I2 2 I 252844 5I

III 36 I7 $20 \quad 22 \quad 344$ I 4562668488939698 IOO

IV $578 \quad$ I 3 I5 323435404778

Prov 3 I, 3O III 3622828498 IV $82023 \quad 3440$

Ps I $5,2 \quad$ II 3549 III 366377 IV $69 \begin{array}{lllll}\text { I } 6 & 27\end{array}$

Ps I 28,2 III 6I

Ruth 3,II III 34

I Sam 25,3 III 34

Rabbinische Literatur

mAvot 2,I2 II 2936

mAvot 5,20 II 7

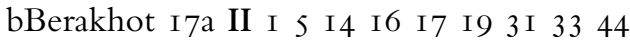


IV. Jüdischer Kalender: Monate und Festtage

\begin{tabular}{|c|c|c|c|}
\hline Monatsnamen & Tage & Jahreszeit & Festtage \\
\hline Tischri & 30 & September/Oktober & $\begin{array}{l}\text { I.2. Rosch ha-schana } \\
\text { Io. Jom Kippur } \\
\text { I 5.-23. Sukkot } \\
\text { 23. Simchat Tora }\end{array}$ \\
\hline (Mar-)Cheschwan & $29[30]$ & Oktober/November & \\
\hline Kislew & $30[29]$ & November/Dezember & 25. Channuka (8 Tage) \\
\hline Tevet & 29 & Dezember/Januar & \\
\hline Schewat & 30 & Januar/Februar & \\
\hline Adar $[\mathrm{I}]$ & 29 & Februar/März & $\begin{array}{l}\text { I3. Taanith Esther } \\
\text { I4. Purim }\end{array}$ \\
\hline Adar II & 29 & März/April & \\
\hline Nisan & 30 & März/April & I 5.-22. Pessach \\
\hline Ijjar & 29 & April/Mai & I 8. Lag ba-omer \\
\hline Siwan & 30 & Mai/Juni & 6.-7. Schavuot \\
\hline Tammuz & 29 & Juni/Juli & \\
\hline Av & 30 & Juli/August & 9. Tischa beAv \\
\hline Elul & 29 & August/September & \\
\hline
\end{tabular}

\section{Abkürzungen}

b.T. babylonischer Talmud

chr.Z. christliche Zeitrechnung

e.H. ehrenwerte Herr

H. Herr

HStAH Hauptstaatsarchiv Hannover

hl. heilig

H. u. M. Herr und Meister

I.S.E.B.L. Ihre Seele sei eingebunden in Bündel des Lebens

j.Z. jüdische Zeitrechnung

n.kl.Z. nach kleiner Zählung

s.G. seligen Gedenkens

s.G.G. seligen Gedenkens Gerechter

S.S.E.B.L Seine Seele sei eingebunden ins Bündel des Lebens 


\section{Kürzel für öfter verwendete Quellen}

FamB Familienbuch der Synagogengemeinde Adelebsen (einschließlich Barterode, Güntersen und Lödingsen) - Originaltitel: "Synagogenbuch der jüdischen Familien in dem Gerichte Adelebsen ...«, HStAH, Foto I Nr. 97 (s. S. 25 Dokument Nr. 6*)

FamB-LR Familienbücher des Landrabbinates Hannover, HStAH, Foto I Nr. 243-248

GbB Geburtenbuch des Standesamtes Adelebsen

GbL Geburtsliste der Synagogengemeinde Adelebsen (einschließlich Barterode und Güntersen), HStAH, Foto I Nr. 98

L I762 Liste der Schutzjuden im Gericht Adelebsen aus dem Jahre i762, HStAH, Hann. 74 Göttingen Nr. 42 I I

Mappa Mappot Adelebsen. Judaica Sammlung Städtisches Museum Göttingen, Inv. Nr. I9I7 / 24

StB Sterbebuch des Standesamtes Adelebsen (bzw. in Einzelfällen des ehem. Standesamtes Güntersen bzw. Wibbecke, jetzt ebenfalls im Standesamt Adelebsen)

StL Sterbeliste der Synagogengemeinde Adelebsen (einschließlich Barterode und Güntersen), HStAH, Foto I Nr. Ioo

\section{Erklärung von Fachbegriffen}

\section{Aschkenas/ Aschkenasim/ aschkenasisch}

Im Mittelalter aufgekommene hebräische Bezeichnung für Deutschland (und Mitteleuropa), heute gemeinhin verwendet zur Bezeichnung der von palästinischer, italienischer sowie mittel- und osteuropäischer Tradition geprägten Judenheit; Gegenüber zu $\rightarrow$ Sefardim / sefardisch.

\section{Begräbnisgenossenschaft $\rightarrow$ Chevra Kadischa}

\section{Beschneidung/B'rit Mila}

Beschneidung des männlichen Kindes, vollzogen von einem Beschneider (mohel), am 8 . Tag nach der Geburt als Zeichen der Zugehörigkeit zu dem zwischen Gott und dem Volk Israel geschlossenen Bund (b ${ }^{e}$ rit, s. Gen I 7, Iff.)

\section{Bima}

Lehnwort von griech. to bema [Neutrum, daher eigentlich das B., nicht die B.], Kernstück der Synagogeneinrichtung neben dem $\rightarrow$ Toraschrein, mit einem Pult versehenes Podium, von dem aus beim Gottesdienst die $\rightarrow$ Tora verlesen wird; traditionell in der Mitte des Raumes aufgestellt, in liberalen Gemeinden an die Wand vor den Toraschein gerückt, zum Auf- und Abgang mit seitlich angebrachten Stufen versehen.

\section{Birkat ha-Kohanim}

Nach Num 6,24-26 von den Priestern ( $\rightarrow$ Kohen) als Nachkommen Arons mit erhobenen Händen (vgl.Lev 9,22) erteilter Segen; im Kult am Tempel zu Jerusalem Teil des täglichen Rituals, danach auch im synagogalen Gottesdienst verwendet (dazu s. Elie Munk, Die Welt der Gebete, Frankfurt/M. 5698/I938: I, I96ff, II, I45-I 54); auf den Grabsteinen eines Kohen durch das Symbol der segnenden Hände wiedergegeben. 


\section{Chanukka}

Lichterfest, wird 8 Tage lang, beginnend mit dem 25. Kislew, gefeiert mit fortschreitendem Anzünden der 8 Lichter des Chanukka-Leuchters; gründet historisch in der Neuweihe des Jerusalemer Tempels im 2. Jh. v. chr. Z. und dient der Erinnerung an den siegreichen Aufstand der Makkabäer gegen die hellenistisch-syrische Staatsgewalt.

\section{Chaver}

Hebr.: Genosse, Bezeichnung der Mitglieder der $\rightarrow$ Chevra Kadischa oder Ehrentitel für torakundige Mitglieder der Gemeinde.

\section{Chevra Kadischa}

Begräbnisgenossenschaft, Gruppe in der jüdischen Gemeinde, die mit der Aufgabe der Fürsorge in Krankheits- und Todesfällen betraut ist, sorgt für Krankenpflege, Leichenbestattung, Gedächtnisgottesdienst und Unterstützung der Hinterbliebenen, ferner für die Erhaltung des Friedhofs.

\section{Chronogramm / Chronostichon}

Zeitinschrift; Angabe von Daten, insbesondere Jahreszahlen nicht durch Zahlziffern, sondern in Einzelworten oder Sätzen an Hand von besonders gekennzeichneten Buchstaben.

\section{Jom Kippur / Jom ha-Kippurim}

Versöhnungstag, der gewichtigste Tag des jüdischen Jahres, begangen mit ganztägigem Fasten am Io. Tischri, Höhepunkt der mit dem $\rightarrow$ Neujahrsfest beginnenden Io Bußtage; ursprünglich (biblische Grundlage Lev I6) zur Reinigung des Tempelheiligtums und zur Entsühnung des ganzen Volk vollzogen, inzwischen Tag der allgemeinen Selbstprüfung und Umkehr, in vielen Gemeinde vorbereitet u.a. durch Besuch des Friedhofs.

\section{Kohen / Kohanim}

Priester, Angehörige der Nachkommenschaft Arons; verloren mit der Zerstörung des Tempelheiligtums in Jerusalem $70 \mathrm{n}$. chr. Z. ihr Amt als Träger des Opferkults, behielten aber religiös eine herausgehobene Stellung in der jüdischen Gemeinde (z.B. Vorrecht der $\rightarrow$ Birkat ha-Kohanim sowie bei der $\rightarrow$ Toralesung).

\section{Laubhüttenfest $\rightarrow$ Sukkot}

\section{Levit / Leviten}

Nachkommen des Stammes Levi, unterstützten am Jerusalemer Tempel die dort amtierenden $\rightarrow$ Priester beim Opferdienst (u.a. Vollzug von Reinigungsriten), dienten aber auch als Torhüter, Sänger, Schatzmeister und behielten wie die Angehörigen der Priesterschaft religiöse Privilegien (z.B. bei der $\rightarrow$ Toralesung).

\section{Mappa / Mappot}

Lehnwort von lat. mappa, auch „Tora-Wimpel“ genannt, Tuchband aus weißem Leinen (Länge zwischen $2 \mathrm{~m}$ und $3,5 \mathrm{~m}$ ), das um die $\rightarrow$ Torarolle geschlungen wird, hergestellt aus der bei der Beschneidung benutzten Windel, die in Streifen geschnitten kunstvoll bestickt oder bemalt ist. Enthält Namen und Geburtsdatum des Kindes, dazu (meist in Abkürzungen) Segenswünsche und Bibelworte (alles hebräisch geschrieben), ferner Darstellungen der Torarolle und der Traubaldachins sowie Tier- und Blumenschmuck. 


\section{Memorbuch}

Gebetbuch, ursprünglich benutzt zum gemeindlichen Gebrauch bei Gedenkgottesdiensten; besteht neben einer Gebetssammlung aus einem Verzeichnis der verstorbenen Gemeindeglieder (teilweise auch sonst herausragender Personen jüdischen Lebens) und einer Zusammenstellung von Märtyrern und Martyriumsstätten. Über die ursprüngliche Funktion hinaus bilden die Memorbücher mit Nekrologium und Martyrologium eine herausragende historische Quelle für die Geschichte der einzelnen Gemeinden und auch für überregionale Ereignisse, z.B. Pogrome.

\section{Mischna}

Hebr.: Wiederholung, Lehre; älteste Sammlung rabbinischer Regelungen zu religions-, zivil- und strafrechtlich relevanten Fragen, zusammengestellt im 2./3. Jh. chr. Z., besteht aus 6 rechtsthematisch ausgerichteten Teilen (Sedarim, Ordnungen), bildet die Grundlage des $\rightarrow$ Talmud.

Morenu

Hebr.: unser Lehrer, Ehrentitel für einen $\rightarrow$ Tora- und $\rightarrow$ Talmud-Gelehrten.

Neujahrsfest $\rightarrow$ Rosch ha-schana

Pessach/Passa

Das erste der 3 Wallfahrtsfeste, 7 Tage lang begangen: beginnt am Abend des I 5. Nisan mit der Feier des Pessach-Mahls, endet am 22. Nisan: gefeiert im Andenken an die Befreiung des Volkes aus der ägyptischen Knechtschaft (vgl. Ex I2; 23, I5; 34, I 8; Lev 23,5-8; Num 9, I-I 4; 28, I6-25; Dtr I6, I-8) und in der Hoffnung auf die endzeitliche Erlösung; sachlich wie zeitlich bestimmend auch für das christliche Osterfest.

\section{Priester $\rightarrow$ Kohen}

\section{Priestersegen $\rightarrow$ Birkat ha-Kohanim}

\section{Purim}

Fest mit besonders ausgelassenem Charakter, gefeiert am I4./I5. Adar in Erinnerung an die im biblischen Estherbuch berichtete Bewahrung des jüdischen Volkes vor drohender Vernichtung im persischen Reich; in der Form in vielem ähnlich dem z.T. zeitgleichen christlichen Karneval/Fastnacht.

\section{Rabbiner}

Ordinierter Leiter einer Gemeinde (gewöhnlicher Titel Rabbi), tätig ursprünglich in erster Linie als Rechtskundiger und Lehrer, daneben als Prediger und neuerdings auch als Seelsorger.

Rosch Chodesch

Hebr.: Haupt/Anfang des Monats = Neumond, I. Tag des Monats, gilt als Halbfeiertag.

Rosch ha-schana

Hebr.: Haupt/Anfang des Jahres; Neujahrfest, begangen am I./2. Tischri, eröffnet die mit $\rightarrow$ Jom Kippur schließenden Io Bußtage, gilt als einer der höchsten Feiertage, ist geprägt vom Gedanken an das Gerichtshandeln und das Königtum Gottes. 
Schavuot / chag ha-schavuot

Hebr.: Wochenfest, gefeiert 50 Tage $=7$ Wochen nach $\rightarrow$ Pessach (vgl. Ex 34,22; Dtr I6, Io) am 6. (Israel) bzw. 6./7. (Diaspora) Siwan; das 2. der jüdischen Wallfahrtsfeste; ursprünglich Erntedankfest, später zusätzlich auch bezogen auf die Offenbarung der Tora am Sinai und die Erwählung Israels; Hintergrund des christlichen Pfingsfestes.

\section{Schechina}

Hebr.: Einwohnung; feminine Bezeichnung für die göttliche Gegenwart in der Welt, teilweise benutzt als Ersatz für den Gottesnamen, daneben aber auch eine Art Zwischenwesen zwischen Gott und Mensch.

\section{Schofar}

Rituelles Blasinstrument, gefertigt aus dem Horn eines Widders, kommt insbesondere an $\rightarrow$ Rosch ha-schana zur Verwendung, um mit seinem Klang an das göttliche Gericht und auch an die göttliche Erlösung zu erinnern.

\section{Sefardim / sefardisch}

Bezeichnung det ursprünglich in Spanien (hebr. Sefarad) und Portugal ansässigen Judenheit, die nach ihrer Vertreibung Ende des I5. Jh.s chr. Z. in Südosteuropa, Nordafrika, Vorderasien sowie in England, den Niederlanden und auch Nordwestdeutschland Zuflucht fand und kulturell wie religiös gegenüber dem $\rightarrow$ aschkenasischen Judentum eigenständige Profile aufweist.

\section{Sela}

Hebr. Wort unklarer Bedeutung; in den Psalmen als musikalisches Merkwort am Ende eines Sinnabschnitts verwendet, in der jüdischen Tradition (vgl. bErubin 54a) im Sinn von "für ewig« gedeutet (so auch im Schlussteil von Grabinschriften).

\section{Simchat Tora}

Hebr.: Freude an der $\rightarrow$ Tora; Fest am 23.(Diaspora) bzw. 22.(Israel) Tischri, letzter Tag von $\rightarrow$ Sukkkot; feiert die Gabe der Tora, findet seit dem 9. Jh. chr. Z. im Rahmen des einjährigen Zyklus der $\rightarrow$ Toralesung mit der Verlesung des letzten (Dtr 34) und des ersten (Gen I) Abschnitts statt.

\section{Sukkot}

Laubhüttenfest, nach $\rightarrow$ Pessach und $\rightarrow$ Schwavuoth das 3. Wallfahrtsfest, neuntägig vom I 5.-24. Tischri gefeiert in Erinnerung an die Wanderung Israels durch die Wüste und sein nichtsesshaftes Leben in Hütten (Sukkot) vor dem Einzug in das verheißene Land.

\section{Talmud / talmudisch}

Hebr.: Lernen, Lehre; umfangreichstes Sammelwerk der mündlichen $\rightarrow$ Tora, hervorgegangen aus den über die $\rightarrow$ Mischna in den rabbinischen Hochschulen Palästinas und Babyloniens geführten Lehrdebatten, enthält neben religiösen Vorschriften auch sonstiges Bildungsgut aller Art; hat in Gestalt des im 6./7. abgeschlossenen babylonischen Talmud im mittelalterlichen Judentum durchgehend kanonisches Ansehen erlangt und bildet bis heute die Grundlage der Lebens- und Glaubenswelt des orthopraxen Judentums. 
Tora

Hebr.: Weisung, Lehre (in der griechischen Bibelübersetzung und den darauf fußenden christlichen Bibeltexten verkürzt mit "Gesetz« wiedergegeben); in der jüdischen Tradition verwendet: a) speziell für das Schriftcorpus der 5 Bücher Mose, b) im weiteren Sinn für die gesamte hebräische Bibel sowie c) darüber hinaus für die als "mündliche Tora" eingestuften, nachbiblisch-rabbinischen Lehrtraditionen $(\rightarrow$ Mischna, $\rightarrow$ Talmud $)$.

\section{Torakrone / Keter Tora}

Aus Silber oder Gold gefertigte Krone, die als Symbol für den königlichen Rang der $\rightarrow$ Tora auf die oberen bei den Holzstäbe der $\rightarrow$ Torarolle gesetzt wird.

\section{Toralesung}

Fortlaufende Verlesung der $\rightarrow$ Tora ( 5 Bücher Mose) im synagogalen Gottesdienst, erfolgt nach einer Woche für Woche festgelegten Einteilung in einem einjährigen Zyklus, Kernstück des religiösen Lebens.

\section{Torarolle}

Pergamentrolle, von Hand mit dem Text der 5 Bücher Mose $(\rightarrow$ Tora $)$ beschrieben, an den Enden von zwei Holzstäben eingefasst, verwendet ausschließlich für den Gebrauch zur $\rightarrow$ Toralesung; wird kostbar geschmückt aufbewahrt in einem meist an der Ostwand der Synagoge befindlichen Schrein.

\section{Toraschrein}

Kernstück der Synagogeneinrichtung, Wandschrank (auch Aron ha-Kodesch genannt) an der Ostwand bzw. nach Jerusalem ausgerichteten Wand, erhöht aufgestellt, oft mit kunstvollem Schnitzwerk versehen, teils in der Wand eingelassen, gewöhnlich zusätzlich durch einen $\rightarrow$ Toravorhang verhüllt, dient zur Aufbewahrung der $\rightarrow$ Torarollen.

Toravorhang / Parochet

Vorhang vor dem Toraschrein, hergestellt aus kostbaren Stoffen, auf denen mit Gold- oder Silberfädenstickereien Darstellungen von Tempelgeräten, Tieren sowie vor allem von $\rightarrow$ Torakronen angebracht sind.

Versöhnungstag $\rightarrow$ Jom Kippur

\section{Bildnachweise}

Christoph Berner 2 I 5 und Rückseite Einband

Hauptstaatsarchiv Hannover 20, 2 I, 25, 26, 27, 36

Katasteramt GGL Göttingen 39

Ralf König I2, 58, 64, 68, 8 I, I36, I6I, I68, I70, I73, I82, I85, I88, I94, 2I7, 2 I 8 , $232,269,243$ (oben), 298, 334

Hartmud Plath 32

Städtisches Museum Göttingen 23, 30

Gottfried Wehr 42, 46

Alle übrigen: Berndt Schaller 


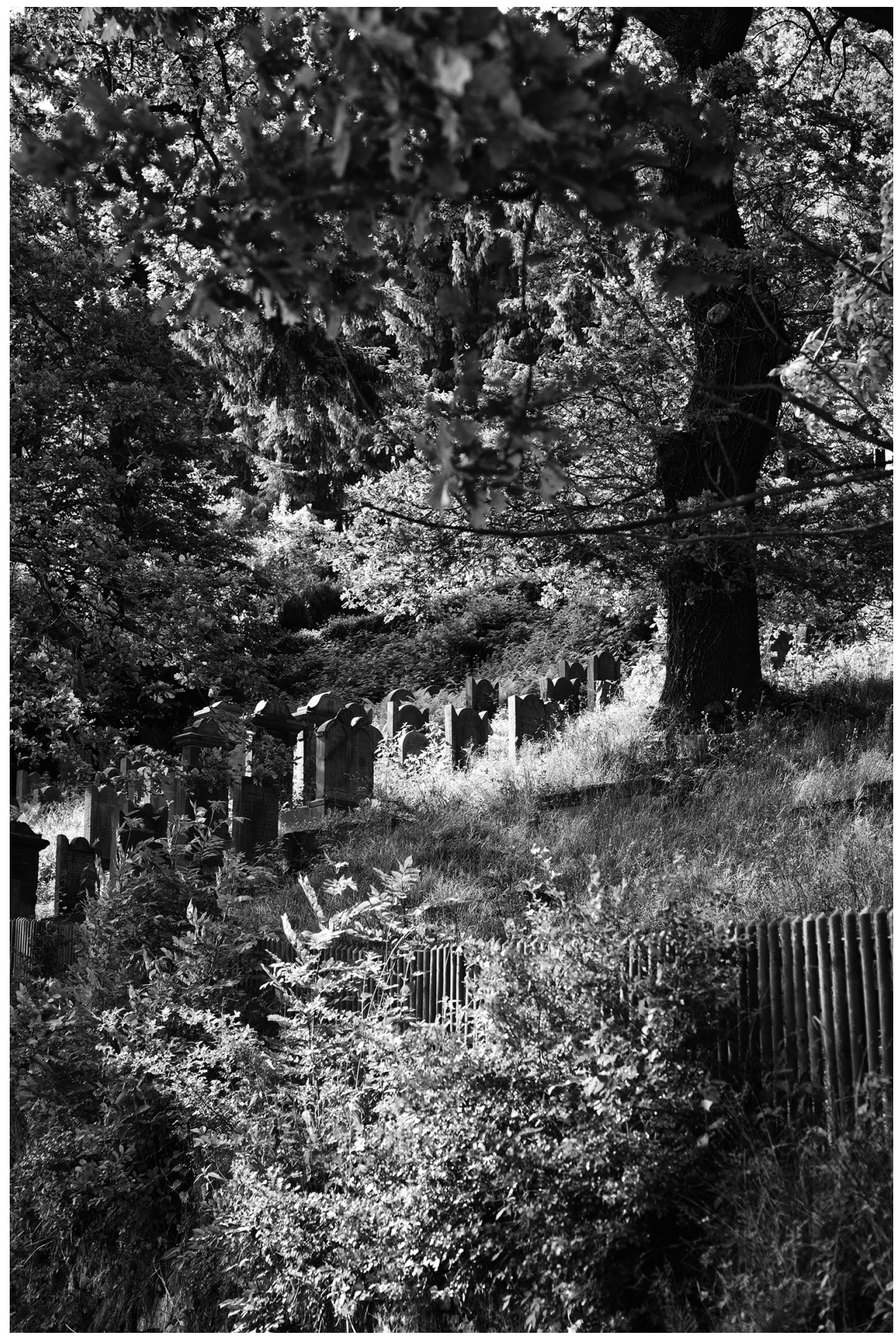


er Flecken Adelebsen - am Rande des Solling im südlichen Niedersachjüdischen Lebens zurückblicken. Im 19. Jahrhundert wurde er wegen des hohen Anteils jüdischer Einwohner sogar als „Klein Jerusalem“ bezeichnet. Heute erinnern daran im Ortsbild nur noch ganz wenige Spuren. Sichtbar „überlebt" hat wie die meisten Totenäcker der vernichteten jüdischen Gemeinden in Deutschland (230 allein in Niedersachsen) nur der Friedhof. Dieses nach jüdischem Brauch so genannte „Haus des Lebens" als historische Quelle zu erschließen und als Stätte der Erinnerung zugänglich zu machen, ist das Ziel der vorliegenden Dokumentation, ein Stück unerledigter und notwendiger Trauerarbeit.

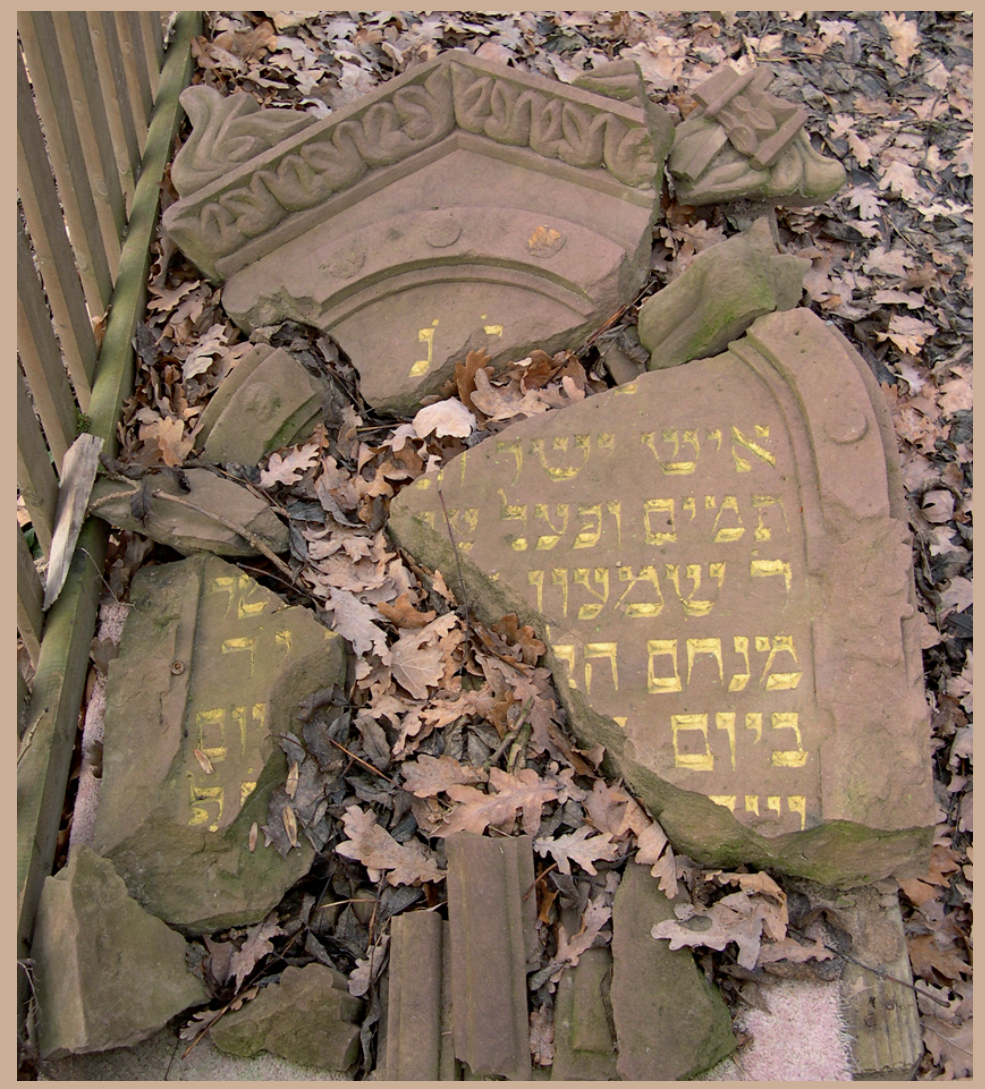

GEORG-AUGUST-UNIVERSITÄT
GÖTTINGEN 